\title{
The WTO Multilateral Trading System in a Globalizing World
}

Citation for published version (APA):

Smeets, M. (2017). The WTO Multilateral Trading System in a Globalizing World: Challenges and Opportunities. [Doctoral Thesis, Maastricht University]. Wolf Legal Publishers (WLP). https://doi.org/10.26481/dis.20170627ms

Document status and date:

Published: 01/01/2017

DOI:

10.26481/dis.20170627ms

Document Version:

Publisher's PDF, also known as Version of record

\section{Please check the document version of this publication:}

- A submitted manuscript is the version of the article upon submission and before peer-review. There can be important differences between the submitted version and the official published version of record.

People interested in the research are advised to contact the author for the final version of the publication, or visit the DOI to the publisher's website.

- The final author version and the galley proof are versions of the publication after peer review.

- The final published version features the final layout of the paper including the volume, issue and page numbers.

Link to publication

\footnotetext{
General rights rights.

- You may freely distribute the URL identifying the publication in the public portal. please follow below link for the End User Agreement:

www.umlib.nl/taverne-license

Take down policy

If you believe that this document breaches copyright please contact us at:

repository@maastrichtuniversity.nl

providing details and we will investigate your claim.
}

Copyright and moral rights for the publications made accessible in the public portal are retained by the authors and/or other copyright owners and it is a condition of accessing publications that users recognise and abide by the legal requirements associated with these

- Users may download and print one copy of any publication from the public portal for the purpose of private study or research.

- You may not further distribute the material or use it for any profit-making activity or commercial gain

If the publication is distributed under the terms of Article $25 \mathrm{fa}$ of the Dutch Copyright Act, indicated by the "Taverne" license above, 
THE WTO MULTILATERAL TRADING SYSTEM IN A GLOBALIZING WORLD:

\section{CHALLENGES AND OPPORTUNITIES}

MAARTEN SMEETS

ฟ 

THE WTO MULTILATERAL TRADING SYSTEM

IN A GLOBALIZING WORLD:

CHALLENGES AND OPPORTUNITIES

DISSERTATION

to obtain the degree of Doctor at Maastricht University, On the authority of the Rector Magnificus

Prof. Dr. Rianne M. Letschert

in accordance with the decision of the Board of Deans, to be defended in public

on Tuesday 27 June 2017, at 10.00 hours

By

Maarten Smeets 


\section{Supervisor:}

Prof. Dr. P. van den Bossche

Prof. Dr. Th. Conzelmann

\section{Assessment Committee}

Prof. Dr. M.G. Faure (Chairman)

Prof. Mag. M.A. PhD A. Dür (University of Salzburg, Austria)

Prof. Dr. S. Evenett (University of St Gallen, Switzerland)

Dr. D. Prevost

Dr. A.B. Spendzharova 
For Mina and Anahita 



\section{ACKNOWLEDGEMENTS}

This thesis would certainly not be what it is without the continued support and guidance provided by my PhD supervisors, Prof. Peter Van den Bossche and Prof. Thomas Conzelmann and to whom I would like to express my sincere gratitude and deep appreciation. The feedback that I received on earlier drafts as well as the discussions and interactions I had with both over the past three years have been very stimulating and rewarding. They have always encouraged and motivated me to dig deeper into complex multifaceted trade and globalization issues, to which there are no simple answers and solutions. Their comments and suggestions have contributed to strengthening the line of thought and sharpening the arguments presented in my thesis.

My $\mathrm{PhD}$ thesis is the result of many years of research, analysis and reflection on various academic and trade policy issues and which started even long before writing this $\mathrm{PhD}$ thesis ever crossed my mind. I had previously written on several topics included in the thesis, many of which have been published in peer reviewed journals and books. Also, some studies undertaken at the OECD and the WTO as well as papers presented at conferences provided for the back bone of the analysis. I would therefore like to extend my appreciation to all colleagues, academics and friends I have had the opportunity to interact and exchange views with on these topics privately and professionally, at work, during international meetings, conferences, courses and lectures that I have given at Universities. It is through the discussions and debates, especially with those holding different views and challenging ideas that the mind is stimulated.

My appreciation goes to the assessment committee, consisting of Prof. Dr. M.G. Faure, Dr. D. Prevost, Dr. A.B. Spendzharova, Prof. Dr. S. Evenett and Univ.-Prof. Mag. M.A. PhD A. Dür for taking the time to read the manuscript in their very busy schedules.

I would like to express my deepest gratitude and love to my wife Mina and daughter Anahita, who are my soul mates in life and have always encouraged and supported me in this rewarding journey. Our many conversations on trade, globalization and their impact on people's livelihood have helped me think through the issues from different perspectives. They have patiently accepted when I was undertaking research, reading and writing and thus was not available for family life.

Regrettably, my late parents, Jan and Catherine, who gave me life and created the opportunities for my personal and professional development and my late brother, Peter-Jan, who is closest to my heart and always on my mind, cannot witness this important moment in my life and my personal growth. I would also specifically like to thank my sisters in law Afsaneh Beschloss-Mashayekhi and Maryam Mashayekhi, who have often provided me with the perfect conditions and environment allowing me to fully focus on my PhD thesis without being distracted. Cookie, my dog, has enjoyed sitting by my side during the long hours of my work on my thesis, often wondering when we would go for a walk. 
'The Journey is the Reward' 


\section{FOREWORD}

It was three years ago that I decided to pursue one of my life time objectives to write a $\mathrm{PhD}$ thesis. I had wanted to do so for many years, but had never managed to find the time. I was strongly encouraged to embark on this important project by my wife and daughter, Mina and Anahita, who supported me at every step of my endeavours.

In many ways I consider the work that I undertook to be a natural consequence of the way my life has evolved. I obtained a Masters' degree in trade, banking and finance at Tilburg University in 1980. I was a teaching assistant prior to my graduation. I then pursued postgraduate studies at the Graduate Institute for International Studies in Geneva (IUHEI), and attained a diploma in 1981. I benefited from the knowledge and guidance of Mr Olivier Long, a former Director General of the General Agreement on Tariffs and Trade (GATT), Richard Blackhurst and Jan Tumlir, who were directors of the economic research department of the GATT, and later the World Trade Organization (WTO) and professors at the IUHEI. I developed a real passion for trade policy and wanted to work at the GATT. This was not possible given the then prevailing requirement of five years of national experience in a national administration. I did consider pursuing a $\mathrm{PhD}$ at the Graduate Institute, but instead accepted a job offer at the Ministry of Economic Affairs in Den Haag, where I started my professional life in 1981.

At the Ministry I learned how trade policies are designed and implemented. Policymaking is always challenging. It involves many different aspects, including innovative analysis, initiative, creativity and most importantly policy coordination between all stakeholders. Through the many internal coordination meetings at the Ministry, with European Union (EU) officials in Brussels, and from the GATT in Geneva, I learned how to design and defend national positions and came into close contact with the real economy and the actors who drive trade. Economic, trade and business interests can be very significant, as are the responsibilities for government defending those interests. Over a period of six years I represented the Netherlands at many GATT, United Nations Conference on Trade and Development (UNCTAD) and OECD meetings. The work was most relevant and exciting and exposed me to the real world, thus complementing the theories of trade policy that I had studied.

It quickly became apparent to me that linking the academic and policy worlds can be challenging, but that it is essential to formulate policy decisions. I soon felt that academic work should focus more on relevant policy issues, so as to guide policy decisions. In return, policy positions need to find their ground in economic analysis in order to provide a more robust, scientific and academic underpinning. Equally important are the outcomes of the consultations with the stakeholders, including the private sector, parliament and civil society. The role of the government is to facilitate the work of the economic actors. I participated and/or conducted many of these consultations, coordinated positions, and designed and 
explained policies. I often accompanied Ministers in Parliamentary debates and provided the necessary support during the question and answer periods.

The drive for communication and explaining policy led me to write, over the course of several years, monthly contributions on trade issues in economic journals, including in $\mathrm{Het}$ Financiele Dagblad. In addition I occasionally published in national newspapers, including Het NRC Handelsblad. I published several academic articles in the Economische Statistiche Berichten (ESB). I found writing most stimulating as it requires analysing an issue, thinking through the arguments and coming to a conclusion. The author needs to transmit his ideas to the reader. It is a powerful mental exercise that not only stimulates the mind, but involves your whole being. You need to identify yourself with the positions you develop and defend, you need to be ready to engage in a dialogue, listen to the other positions and appreciate them according to their intended meaning. It helps one understand that there is not one right answer, but there are many ways of looking at the same question from different angles and it is that challenge that is most exciting and rewarding. It opens the mind and leads to permanent questioning of the points one makes. The more you advance in life, the better you understand this and realize that there is not one single right answer. It also makes one realize that the position taken is mostly dictated by the environment in which one lives and the context in which one operates. The same truth and realities are viewed differently for those living under different social and economic conditions. Life is like a prism, and the angle from which the light shines on it provides you with a different perspective. I experienced this firsthand on many occasions in my life.

I had written my Masters' thesis on the theory and practice of economic sanctions and as a result I was invited to Conferences, participated in debates and realized again that the same facts can be viewed in different ways. I was threatened by those who disagreed with my academic position which questioned the effectiveness of sanctions as a policy instrument to end Apartheid in South Africa and cancelled my attendance to a panel debate on the issue. My position was completely unrelated to any views one may hold on Apartheid, which I strongly opposed, but that had not been understood. I published my ideas on sanctions in several articles and contributed to books on the topic and found it to be a most exciting area where theory and practice are confronted. It continues to be both a topical and challenging issue.

Having worked at the Ministry of Economic Affairs for six years, the Minister of Trade at the time, Mr Fritz Bolkestein, proposed that I attend the Ecole Nationale d'Administration (ENA). I moved to Paris in 1987 and completed the 18 month course successfully in 1989. It was a unique learning experience where my understanding of theory and practice was further enhanced. I first spent three months in the prefecture of the Haute Savoie (Chambery), working closely with the préfet and the then president of the Conseil Régional, Mr Michel Barnier, who later became Commissioner at the EU. In addition to dealing with local and regional issues, I was closely associated with the preparations of the Olympic Winter Games (Albertville) which were held in 1992. I prepared various studies and reports for the French government, one of which related to the policy aspects of the economic 
activities linked to the French coast and sea. Another project analysed the economic and employment implications of restructuring programmes conducted by the government for the coal and steel industry in France and more specifically in the Lorraine region. The layoffs generated much tension at the national level. Both projects once again required designing and translating policies into actions and looking at the same issues from different perspectives, namely from the perspectives of workers, employers and the government. Here again the theory and the practice needed to be matched. At the end of the ENA course, I spent three months at the Direction des Relations Extérieures of the Ministère des Finances, where I conducted research on policy issues, including on the second EU financial services Directive, studying its implications for France. During the ENA period, I occasionally represented France at international meetings, including at the GATT. In addition to the professional skills I developed at ENA I made many friends and built a network of professionals at the highest levels of policy-making, from which I still benefit today.

I expected to return to the Netherlands in early 1989, but I received an offer to work at the Organization for Economic Cooperation and Development (OECD), which I accepted with the agreement of the Ministry in the Netherlands. At the OECD, I mainly analysed trade policy issues and deepened my knowledge on specific trade topics. Again, the work combined academic thinking with policy analysis, as OECD studies need to be relevant for policy. I focused my analysis mostly on globalization of trade, which was a relatively new phenomenon at the time. Globalization was not well understood and the policy implications were unknown. As I argue in my thesis, globalization and its implications are not always well understood even today and remain topical and perhaps even controversial. Governments tended to be rather defensive towards globalization, both in developed and developing countries, driven by the economic realities on the ground, including high levels of job losses, mostly thought to be caused by globalization. The analysis showed however that the policy responses were in conflict with the economic theories, which called for openness and liberalization. This was a hard one to sell to the larger public. How could those two conflicting trends be reconciled? That was a most challenging issue and it is again today. Several sector studies were conducted, in which I took a lead role. These studies focused on measuring globalization with indicators and analysed how the automobiles and pharmaceutical industries were globalizing. The purpose of these studies was to better understand globalization, its policy implications and defining possible responses. I also won an OECD essay contest on the position of Japan in globalization, which resulted in an official two week visit to Japan and which included many discussions with high level government officials in various Ministries. Globalization is again at the heart of the policy debates today with many layers of society questioning whether globalization has gone too far and should be slowed down or even reversed.

It was also the time when the Uruguay Round negotiations of the GATT were completed (1994). I was closely linked with the preparation of an OECD Conference to analyse and discuss the outcome of the Marrakesh Agreement which had resulted in the creation of the 
WTO. The OECD Conference brought together leading academics, policy makers, think tanks, senior officials from the GATT as well as from other main international bodies, including the World Bank, and journalists, who debated the outcome of Marrakesh and the ways forward for the new multilateral trading system. The creation of the WTO was considered a milestone for the multilateral trading system and at long last completed the missing part of the Bretton Woods institutions. The Conference resulted in a book on the WTO and its main features. I was one of the organizers and coordinators of the Conference and the book. From there it was a logical step to join the WTO. I was one of the very first professionals recruited at the WTO in 1995 by the then Director General Peter Sutherland.

At the WTO I have contributed in fundamental ways to designing the trade capacity building programmes, both before and after the launch of the DDA in support of the Aid for Trade initiatives. Some of the main elements are discussed in an article published in the Journal of World Trade in 2013. In my current position, I coordinate trade capacity building programmes within the WTO and with other main international organizations and regional secretariats and hold joint responsibility for the WTO Chairs Programme (WCP). This programme, initiated in 2010 and expanded in 2014, is perhaps one of the best examples linking academic work with the policy world. Under the WCP academic work was pursued with initially 22 and now with 19 Universities around the world on trade policy questions. The work has resulted in two books with contributions from the WTO Chairs, of which I am one of the editors. I have obtained funding for the WCP from the Netherlands, with whom I have always continued to have excellent relations.

Over the past 30 years I have travelled around the world, visited all the continents many times, met people from different social and economic backgrounds, obtained exposure to different cultures, mind-sets and mentalities, which is enriching in many ways. It opens the mind and drives a person to do good for others, share knowledge and experience, while at the same time to learn from questions, views and economic realities on the ground. It is unique in itself and brings one to the essence of life. It provides one with a solid reality check in many ways. We tend to take our comfortable lives for granted too easily. It is a major challenge to find answers and provide solutions to issues that theoretically seem easy and straightforward, but are not necessarily so for those living in different economic conditions where there might not be access to the same information, knowledge and infrastructures. How can one cater for individual situations, keeping in mind the greater good, the international rules and principles and knowing that for some countries there is likely to be much pain before any gain? How can one convincingly explain that structural adjustment can lead to job losses for individuals, but that overall the country will be better off? There is no one size fits all solution. This continues to be a key challenge, which is very motivating and stimulating.

I have had the privilege of having been invited to many international conferences, to teach at universities, both in my professional and private capacities, to address Masters and $\mathrm{PhD}$ students, to give intellectual input and comment on their research and share knowledge 
and experience. This is most enriching and stimulating. I have attended and chaired various sessions at the Salzburg seminar, of which I am an alumnus, have taken part in the annual conference at St Petersburg University for more than 10 years and taught the students there. I regularly teach at Clingendael, of which I am a senior visiting fellow, have conducted trade negotiations courses at Maastricht University, provided a guest lecture at the Business School of Nyenrode, been part of the Evian Group in Switzerland, and continue to deliver courses at the Joint Vienna Institute (JVI) of which I am a board member. I am a regular visiting Professor at the University of International Business and Economics (UIBE) in China, where I deliver a two week summer course for graduate students. I am due to do so for the third time this summer. I taught at the Hunan Normal University in Shangsha (China), have provided various lectures at the Ecole Nationale D'Administration (ENA) and Sciences Po in Paris, given speeches at different societies in Geneva (including the Société de Lecture), contributed to a summer course at the Graduate Institute in Geneva, represented the WTO and made a speech at the annual Conference of the Global Trade Analysis Project (GTAP) in Sénégal (Dakar). I also participated at the Artnet debates of the United Nations Economic and Social Commission for Asia and the Pacific (UNESCAP) (Bangkok), was invited to speak before the Asian Development Bank (ADB) at a meeting in Korea, launched, jointly with WTO Deputy Directors-General the Chairs programme in South Africa and Brazil and took part in many other debates, including at the Ecole Polytechnique Fédérale de Lausanne (EPFL) in Lausanne. I was invited to deliver a key note speech for the celebration of the $25^{\text {th }}$ anniversary of the Central Bank of the Bahamas. For several years I have conducted training courses at the United Nations Institute for Training and Research (UNITAR) in New York and prepared UN diplomats on trade issues. I have organized and chaired many conferences and seminars for academics and diplomats in Geneva and around the world, including the WCP Advisory Board. I have attended most of the WTO's Ministerial Conferences and once represented the Director General at a heads of state meeting in Sudan. I have co-organized two Ministerial Conferences, one for Central Eastern European Countries and the Caucasus in Georgia and one for Balkan countries in Croatia. While working for the OECD, and at the invitation of the United States government, I undertook a five week study tour, which included debates with scholars and academics at various Universities. It is through the academic and policy discussions and debates that one learns and develops, refines and/or revisits one own thoughts and ideas about the topics. Learning is a never ending process in life and only gets better with time and experience.

These are some of the main explanations of why I felt it necessary to write a $\mathrm{PhD}$ thesis. I believe that the exposure I have had to the academic thinking, in combination with the policy work conducted allowed me to develop ideas and thoughts on many issues. It is the combination of the academic thinking and the policy relevance of the ideas that is enriching. The two go together and are in many ways inseparable. This is precisely what I try to underscore in this work - the policy relevance of the academic thinking and the relevance of policies for pursuing academic work and analysis. 
Writing is an important means of communication and transmitting ideas, but this requires time and availability. It was only recently that I managed to establish the right balance between my family life and professional work requirements and which allowed me to focus on this major academic challenge. The task was challenging, very interesting, gratifying and most exciting. One challenge was to develop a story line, a thread for the analysis, which would make for interesting reading. This was particularly challenging, as this study was meant to be a collection of readings, bringing together my various publications that cover a wide range of issues over a long period of time. Another directly related challenge was that several of the publications required some major updating, further analysis and rewriting, a task which I had seriously underestimated. This led me to review the literature on many topics and integrate the latest thought processes. A key objective is to provide insight into the topics from different angles, stimulate further ideas, and generate debates and reflection on the ways forward, bearing in mind that there is not one single right answer, but several ways of looking at the same issues. 


\section{CHAPTER 2 : FROM THE GENERAL AGREEMENT ON TARIFFS} AND TRADE TO THE WORLD TRADE ORGANIZATION:

\section{THE NEW MULTILATERAL TRADING SYSTEM}

2.0 Introduction

2.1 From GATT to WTO: History and Background

2.2 Main Features of the Multilateral Trading System of the WTO

2.2.1 Objectives

2.2.2 Structure and institutional set-up of the WTO

2.2.3 The key functions of the WTO

2.3 Expanding the WTO's Membership through Accession 64

2.4 Coalitions: how members defend common interests? 70

2.5 Moving from Traditional to 'new' Trade Issues in the WTO 82

2.5.1 Trade and labour standards 83

2.5.2 Trade and investment and trade and competition policy 85

2.5.3 Government Procurement Agreement 90

2.5.4 Trade Facilitation Agreement 92

2.5.5 Information Technology Agreement 92

$\begin{array}{lll}2.5 .6 & \text { Trade and environment } & 92\end{array}$

2.5.7 Electronic Commerce 94

2.5.8 Regional trade integration 95

$\begin{array}{lll}2.6 & \text { Conclusion } & 99\end{array}$ 


\section{CHAPTER 3 : GLOBALIZATION, GLOBAL VALUE CHAINS AND} THE RISE OF ASIA

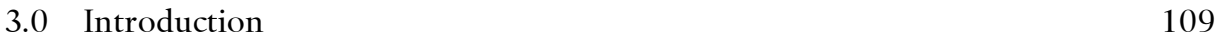

3.1 Understanding Globalization 110

3.2 Connecting to Markets through Global Value Chains 118

3.3 Changing Patterns of Trade and Investment 123

$\begin{array}{ll}\text { 3.3.1 New patterns of trade } & 123\end{array}$

3.3.2 Changing patterns of Foreign Direct Investment 133

3.4 The Shifting Economic Balance from the West to the East 135

3.5 Trade Policy Responses to Globalization 140

$\begin{array}{ll}3.5 .1 & \text { Defensive trade policies } \\ 3.5 .2 & 141\end{array}$

$\begin{array}{ll}\text { 3.5.2 Offensive trade policies: industrial targeting } & 145\end{array}$

3.5.3 A new look at the trade policy response to globalization,

$\begin{array}{ll}3.6 & \text { Conclusion } \\ & 157\end{array}$

CHAPTER 4 : MARKET ACCESS IN THE WORLD 161 TRADE ORGANIZATION

$\begin{array}{lll}4.0 \text { Introduction } & 161\end{array}$

4.1 Market access: Main features of tariffs 163

$\begin{array}{lll}4.1 .1 & \text { Introduction } & 163\end{array}$

$\begin{array}{ll}\text { 4.1.2 Characteristics of the tariff negotiations } & 164\end{array}$

$\begin{array}{ll}\text { 4.1.3 New tariff commitments } & 167\end{array}$

$\begin{array}{ll}\text { 4.1.4 Remaining high tariffs after the Uruguay Round } & 177\end{array}$

4.1.5 Tariffs vs non tariff measures in the Uruguay Round 181

$\begin{array}{lll}\text { 4.1.6 Conclusion } & 183\end{array}$

4.2 Example 1: The Integration of Textiles and Clothing in the Multilateral Trading System $\quad 184$

$\begin{array}{lll}4.2 .1 & \text { Introduction } & 184\end{array}$

4.2.2 Main elements of the Agreement on Textiles and Clothing 186

4.2.3 Trade and policy implications of the Agreement on Textiles
and Clothing

$\begin{array}{ll}\text { 4.2.4 Conclusions } & 199\end{array}$

4.3 Example 2: Tariffs on Leather and Leather Products 199

$\begin{array}{ll}\text { 4.3.1 Introduction } & 199\end{array}$

4.3.2 Main patterns of trade in leather and leather products 200

4.3.3 Tariffs and tariff escalation in leather and leather products 203

$\begin{array}{lll}\text { 4.3.4 Conclusions } & 207\end{array}$ 


\section{CONTENTS}

4.4 Market access in the WTO and the achievements in the Doha

Development Agenda 208

4.4.1 Multilateral negotiations on market access in agriculture 209

4.4.2 Multilateral negotiations on non-agricultural market access 220

4.5 Example 3: The Information Technology Agreement 226

4.6 Example 4: Trade in Services and the Trade in Services Agreement 229

4.6.1 GATS Protocol approach, on a MFN basis 232

4.6.2 Going it alone on an MFN basis 233

4.6.3 A plurilateral agreement within the WTO 234

4.6.4 A plurilateral agreement outside the WTO 234

$\begin{array}{lll}4.7 & \text { Conclusion } & 235\end{array}$

CHAPTER 5 : TRADE CAPACITY BUILDING FOR THE FULLER INTEGRATION OF DEVELOPING COUNTRIES INTO

THE WTO MULTILATERAL TRADING SYSTEM:

CHALLENGES AND OPPORTUNITIES 239

$\begin{array}{lll}5.0 & \text { Introduction } & 239\end{array}$

5.1 Developing Countries in the WTO 240

5.2 Trade Capacity Building in the WTO 249

$\begin{array}{lll}5.2 .1 & 249\end{array}$

5.2.2 How is trade capacity building addressed in the WTO? 251

5.2.3 Coordinating TRTA: a main challenge 258

5.2.4 How to build progressive and sustainable trade capacity 261

5.2.5 What are some of the specific achievements of the WTO's
trade capacity building?

5.2.6 Two key challenges: funding and coordination 275

$\begin{array}{lll}\text { 5.2.7 Conclusion } & 279\end{array}$

5.3 A fuller participation of developing countries in the

$\begin{array}{ll}\text { multilateral trading system } & 279\end{array}$

5.3.1 A quantitative assessment of developing countries' participation
in international trade

5.3.2 A qualitative assessment of the developing countries'
participation in the DDA

5.4 Case Study: Trade Capacity Building Provisions in the
Trade Facilitation Agreement

$\begin{array}{lll}5.5 \text { Conclusion } & 298\end{array}$ 


\section{CHAPTER 6 : THE FUTURE OF THE MULTILATERAL}

\section{TRADING SYSTEM: CHALLENGES AND OPPORTUNITIES}

6.1 Introduction

6.2 Trade liberalization accomplished in the WTO 303

6.3 The way forward 305

6.3.1 New approaches towards negotiations on trade liberalization 306

6.3.2 New rules required for trade, investment and competition policies 317

6.3.3 Regional trade integration as a vehicle for trade liberalization 318

6.3.4 Keep a focus on the development dimension in the negotiations 319

6.3.5 Is there a need for further institutional reforms in the WTO? 320

6.3.6 Is there a need to review the role of the Secretariat? 322

6.3.7 The future of the DDA: can it be concluded, and if so, how? 324

CHAPTER 7 : KEY FINDINGS, SUMMARY AND CONCLUSIONS 329

7.1 From the GATT to the WTO: a stronger multilateral trading system 330

7.2 Globalization, changing patterns of trade and the rise of Asia 335

7.3 Market access in the GATT and the WTO 339

7.4 The fuller integration of developing countries in $\begin{array}{ll}\text { the multilateral trading system } & 341\end{array}$

7.5 The future of the WTO multilateral trading system 344

7.6 Final conclusions and recommendations 345

$\begin{array}{ll}\text { BIBLIOGRAPHY } & 349\end{array}$

VALORIZATION ADDENDUM $\quad 367$

$\begin{array}{ll}\text { CURRICULUM VITAE } & 375\end{array}$ 


\section{ABBREVIATIONS}

ACP African, Caribbean and Pacific Island Countries

ACWL Advisory Centre on WTO Law

ADB Asian Development Bank

AfDB African Development Bank

ALADI Latin American Integration Association

AMF Arab Monetary Fund

AMS Aggregate Measurement of Support

APEC Asia-Pacific Economic Cooperation

ASEAN Association of Southeast Asian Nations

ATC Agreement on Textiles and Clothing

ATPC Advanced Trade Policy Course

BIT Bilateral Investment Treaty

BRICS Brazil, Russia, India, China, South Africa

CAP Common Agriculture Policy

CARICOM Caribbean Community Secretariat

CEB Chief Executive Board

CEECAC Central and Eastern Europe, Central Asia and the Caucasus

CEMAC Central African Economic and Monetary Cooperation

CGE computable general equilibrium

CIS Commonwealth of Independent States

CoCom Coordinating Committee for Multilateral Export Controls

COMESA Common Market for Eastern and Southern Africa

COP Conference of the Parties

CTD Committee on Trade and Development

DAC Development Assistance Committee

DDA Doha Development Agenda

DDAGTF Doha Development Agenda Global Trust Fund

DDG Deputy Director General

DFQF Duty Free Quota Free

DG Director General

DSU Dispute Settlement Understanding

EAC East African Community

EBRD European Bank for Reconstruction and Development

ECOWAS Economic Community of West African States

EIF Enhanced Integrated Framework

EPA Economic Partnership Arrangement

ERP Effective Rates of Protection

EU European Union

FDI Foreign Direct Investment

FIMIP French-Irish Mission Internship Programme 


\begin{tabular}{|c|c|}
\hline FLACSO & Latin American School of Social Sciences \\
\hline GATS & General Agreement on Trade in Services \\
\hline GATT & General Agreement on Tariffs and Trade \\
\hline GCC & Gulf Cooperation Council \\
\hline GDP & Gross Domestic Product \\
\hline GI & Geographical Indication \\
\hline GPA & Government Procurement Agreement \\
\hline GRULAC & Group of Latin America and Caribbean Countries \\
\hline GVC & Global Value Chain \\
\hline HS & Harmonized System \\
\hline IADB & Inter-American Development Bank \\
\hline IFA & Investment Framework Agreement \\
\hline IICA & Inter-American Institute for Cooperation on Agriculture \\
\hline IMF & International Monetary Fund \\
\hline INTAL & Institute for the Integration of Latin America and the Caribbean \\
\hline IsDB & Islamic Development Bank \\
\hline ISI & Import Substituting Industrialization \\
\hline ITA & Information Technology Agreement \\
\hline ITC & International Trade Centre \\
\hline ITO & International Trade Organization \\
\hline ITTC & Institute for Training and Technical Cooperation \\
\hline JVI & Joint Vienna Institute \\
\hline LDC & Least Developed Country \\
\hline LTA & Long Term Agreement on International Trade in Cotton and Textiles \\
\hline MDG & Millennium Development Goals \\
\hline MEAs & Multilateral Environmental Agreements \\
\hline MFA & Multi-Fibre Arrangement \\
\hline MFN & Most Favoured Nation \\
\hline MM & Monitoring Mechanism \\
\hline MNE & Multi National Enterprise \\
\hline NAMA & Non-Agricultural Market Access \\
\hline NIEs & Newly Industrialized Economies \\
\hline NTB & Non-Tariff Barriers \\
\hline NTP & Netherlands Trainees Programme \\
\hline OAS & Organization of American States \\
\hline OECD & Organisation for Economic Cooperation and Development \\
\hline OECS & Organization of Eastern Caribbean States \\
\hline OIF & Organisation Internationale de la Francophone \\
\hline OMA & Orderly Market Arrangement \\
\hline PIFS & Pacific Islands Forum Secretariat \\
\hline PLS & Progressive Learning Strategy \\
\hline PTA & Preferential Trade Areas \\
\hline R\&D & Research and Development \\
\hline
\end{tabular}




$\begin{array}{ll}\text { RAM } & \text { Recently Acceded Member } \\ \text { RBM } & \text { Results Based Management } \\ \text { RC } & \text { Reference Centre } \\ \text { RCEP } & \text { Regional Comprehensive Economic Partnership } \\ \text { RCI } & \text { Regional Coordinator Internship } \\ \text { RTA } & \text { Regional Trade Agreement } \\ \text { RTPC } & \text { Regional Trade Policy Course } \\ \text { RVC } & \text { Regional Value Chain } \\ \text { S\&D } & \text { Special and Differential (Treatment) } \\ \text { SAARC } & \text { South Asian Association for Regional Cooperation } \\ \text { SACU } & \text { Southern African Customs Union } \\ \text { SADC } & \text { South African Development Community } \\ \text { SDG } & \text { Sustainable Development Goals } \\ \text { SIECA } & \text { Secretariat for Centro-American Integration } \\ \text { SPS } & \text { Sanitary and Phytosanitary } \\ \text { SSM } & \text { Special Safeguard Mechanism } \\ \text { STDF } & \text { Standards and Trade Development Facility } \\ \text { SVEs } & \text { Small and Vulnerable Economies } \\ \text { TA Plan } & \text { Technical Assistance and Training Plan } \\ \text { Task Force } & \text { Technical Assistance Coordination Task Force } \\ \text { TBT } & \text { Technical Barriers to Trade } \\ \text { TFA } & \text { Trade Facilitation Agreement } \\ \text { TFS Program } & \text { Trade Facilitation Support Program } \\ \text { TISA } & \text { Trade in Services Agreement } \\ \text { TMB } & \text { Textiles Monitoring Body } \\ \text { TNC } & \text { Trade Negotiating Committee } \\ \text { TPP } & \text { Trans-Pacific Partnership } \\ \text { TPR } & \text { Trade Policy Review } \\ \text { TPRM } & \text { Trade Policy Review Mechanism } \\ \text { TRIMS } & \text { Trade Related Investment Measures } \\ \text { TRIPS } & \text { Trade Related Aspects of Intellectual Property Rights } \\ \text { TRPB } & \text { Trade Policy Review Body } \\ \text { TRTA } & \text { Trade Related Technical Assistance } \\ \text { TSB } & \text { Textiles Surveillance Body } \\ \text { TTIP } & \text { Transatlantic Trade and Investment Partnership } \\ \text { UN } & \text { United Nations } \\ \text { UNCTAD } & \text { United Nations Conference on Trade and Development } \\ \text { UNDP } & \text { United Nations Development Programme } \\ \text { UNECA } & \text { United Nations Economic Commission for Africa } \\ \text { UNESCAP } & \text { United Nations Economic Community for Asia and the Pacific } \\ \text { UNESCWA } & \text { United Nations Economic and Social Committee for West Asia } \\ \text { UR } & \text { Uruguay Round } \\ \text { VAR } & \text { Vector Auto Regressive } \\ & \end{array}$


THE WTO MULTILATERAL TRADING SYSTEM IN A GLOBALIZING WORLD

$\begin{array}{ll}\text { VAT } & \text { Value Added Tax } \\ \text { VER } & \text { Voluntary Export Restraint } \\ \text { VRAM } & \text { Very Recently Acceded Member } \\ \text { WAEMU } & \text { West African Economic Monetary Union } \\ \text { WCP } & \text { WTO's Chair Programme } \\ \text { WIPO } & \text { World Intellectual Property Organization } \\ \text { WIR } & \text { World Investment Report } \\ \text { WTO } & \text { World Trade Organization }\end{array}$




\section{LIST OF GRAPHS}

GRAPH 2.1: Structure of the WTO Secretariat 48

GRAPH 2.2: WTO structure 50

GRAPH 2.3: Groupings, coalitions and alliances. 102

GRAPH 3.1: Evolution of merchandise exports 1980-2015 150

GRAPH 3.2: Evolution of merchandise imports 1980-2015 150

GRAPH 3.3: Evolution of services exports 1980-2015 152

GRAPH 3.4: Evolution of services imports 1980-2015 153

GRAPH 3.5: Share of the global economy in purchasing power parity terms .161

GRAPH 3.6: Share of the global middle class in various regions in the world (\%). 162

GRAPH 5.1: Financial contributions and expenditures 281 


\section{LIST OF TABLES}

TABLE 2.1: Chairpersons of the General Council and bodies reporting to it (2016)...... 52

TABLE 2.2: Chairpersons of bodies established under the Trade Negotiations Committee (2016)

TABLE 2.3: Overall figures on disputes in the WTO (as of 1 December 2016) 62

TABLE 2.4: Most frequent complainants/respondents 77

TABLE 2.5: Trade policy reviews - WTO members reviewed, 1989-2016 81

TABLE 3.1 Developing economies' share in world trade by selected regions and countries, 1980-2015: merchandise exports (\%). 149

TABLE 3.2: Developing economies' share in world trade by selected regions and countries, 1980-2015: merchandise imports (\%). 149

TABLE 3.3: Developing economies' share in world trade by selected regions and countries, 1980-2015: commercial services exports (\%). 151

TABLE 3.4: Developing economies' share in world trade by selected regions and countries, 1980-2015: commercial services imports (\%) .

TABLE 3.5 : Evolution of ranking of the main traders (1980-2015). .154

TABLE 3.6: Importance of south - south trade in world merchandise trade, by product categories, 1995-2015 (\%).

TABLE 4.1: Binding of tariffs on industrial products 195

TABLE 4.2: Bindings with reductions for industrial products (\%)..... 196

TABLE 4.3: Developed country tariff and trade profiles by industrial product categories (excluding petroleum).

TABLE 4.4: Reductions in bound tariffs of developed countries by industrial product group

TABLE 4.5: Integration of textiles and clothing into WTO rules .214

TABLE 4.6: Tariff escalation in selected markets. 231 


\section{CHAPTER 1: INTRODUCTION}

The World Trade Organization (WTO) celebrated its 20th anniversary in 2015, thus providing for a timely opportunity to analyse its main achievements and address the key challenges that it is currently facing. The WTO succeeded the General Agreement on Tariffs and Trade (GATT), which had operated on a temporary basis for nearly half a century. The rules of this multilateral trading system were updated and expanded to capture the changing patterns in international trade, largely driven by globalization. While it is widely acknowledged that the WTO has provided a new basis for conducting international trade, strengthened and expanded the rules of the multilateral trading system, and accomplished many goals, it has been less successful in pursuing the key objectives of the Doha Development Agenda (DDA). The DDA was launched in 2001, is the longest negotiation round in the history of the GATT and the WTO and a conclusion is still not within sight. Despite the fact that the DDA was not formally concluded, considerable trade liberalization has been accomplished in areas of significant economic importance. Yet, more needs to be done to align policies and policy instruments to the new economic realities in a globalized world economy and regardless of whether the DDA can be concluded.

The research undertaken in the thesis focuses on how trade issues were addressed in the GATT and the WTO, and with a view to achieving higher levels of trade liberalization through negotiations. It does not provide for an analysis of the DDA per se, but refers to specific agreements illustrating the main obstacles encountered in the negotiations and which have prevented a successful conclusion of the DDA. It is argued that the changing trading environment requires further adjustments in the ways the trade negotiations are conducted and that the changes in the patterns of trade and investment witnessed over the last few decades require a fresh look at the trade agenda. WTO members should also better engage in a discussion of those trade issues that have become significant in international trade and for which presently there are no rules in the WTO. The thesis offers specific recommendations on how to further liberalize trade.

It will be argued that achieving progress in the trade negotiations is far more challenging in the WTO than it was in the GATT. While there are many factors that can explain these challenges, the main reasons can be found in the increasing complexity of the trade issues per se and the ways in which trade has evolved and is conducted. There has been a rapid breaking down of the production process due to globalization in a world where much of the trade liberalization at the borders has already been achieved. There are also a larger number of participants in the negotiations with many countries at widely divergent levels of economic development, each defending their national interests. Finally there is a growing interdependency between domestic and international policies. While trade liberalization in the GATT system was mainly pursued by addressing border issues in order to enhance market access for goods, the trade issues addressed in the WTO increasingly go beyond those traditional border policies and touch upon regulatory and domestic policy issues, 
particularly in the area of services.

In addition, some countries wish to move much faster in broadening the trade agenda in recognition of these new developments. They also want to include other trade related issues that have a direct effect on international trade, such as competition policies and foreign direct investment. Other, mostly developing countries, feel that the more traditional trade issues have not yet fully been addressed, nor in such ways as to provide them with better market opportunities in products of direct interest to them. The challenge thus consists of reconciling different ambitions and ensuring that all the WTO members are satisfied with the outcomes of the negotiations. It is therefore argued that new ways of enhancing trade liberalization should be explored, taking into account the ways in which trade has evolved over the last 20 years. In doing so, it reviews the traditional ways trade negotiations were pursued and analyses the more recent trends and approaches required to tackle the challenges posed for the multilateral trading system of the WTO.

Members of the WTO have had various opportunities to expand and update the trade agenda and include what were previously referred to as new trade issues, but to a large extent have chosen not to do so. Instead, the trade negotiations conducted under the umbrella of the DDA focus mostly on traditional trade policy issues, including agriculture, tariff negotiations for goods and expanding commitments in the services sector. The expected results were not obtained. Despite the apparent lack of progress in the DDA negotiations, liberalization was successfully achieved, including in areas that were not specifically part of the DDA. This includes the Trade Facilitation Agreement (TFA), which entered into force in February 2017 and the Information Technology Agreement (ITA). It is unclear at present if and in what manner the DDA will be concluded. The last Ministerial Conference (MC-X) held in Nairobi in December 2015 showed differences in views between the members on the way to move forward: some members wanted to conclude the DDA as set out by its original mandate and others wanted to test new approaches and broaden the agenda. The WTO is at a crossroads and it is of critical importance to decide how to progress.

What complicates matters further is the growing backlash against globalization, which is increasingly equated with trade liberalization, loss of jobs in the West, and stagnating economic growth. The arguments against globalization are mostly based on a lack of understanding of how the benefits of trade liberalization are transmitted to the consumers and how it generates economic welfare. The argument will be made that further efforts are required to better communicate and explain the mechanisms of how trade liberalization generates higher levels of welfare specifically for the consumer and more broadly for the world economy. It is also argued that governments can provide more support to those layers of the economy that stand to lose out due the effects of globalization.

On the methodology of the research conducted and before giving an explanation of the structure of this PhD thesis, it is worth nothing that the analysis in this thesis is largely based on research and studies that I have undertaken myself over the last 30 years on various 
aspects of the trading system. This has resulted in several publications, conference papers, articles in peer reviewed journals, chapters in books and two books, of which I am one of the editors. These studies cover a wide range of topics, most of which are also covered in this thesis and they are all interconnected in one way or another. Many of the studies were innovative at the time when the research was conducted, particularly on globalization and the trade policy response. Contrary to today, there was initially little literature available on globalization and its implications for trade. It had been established that the thesis would comprise a collection of readings and studies undertaken earlier. Efforts have been made to link the various issues covered in the thesis and connect the chapters. Several of the illustrations and examples used in the different chapters refer to specific sector studies that I had conducted and some of which were issued as policy papers and published. Most of these studies combine analysis with policy recommendations. The research presented in this thesis thus largely comprises a collection of readings, linking the various parts of research conducted on specific topics, which were revisited and updated with the most recent literature, rather than focusing on one specific issue per se. The analysis is therefore not exhaustive on each topic, as that is not its purpose, but rather attempts to provide a better and deeper understanding of the main developments that have occurred in the trading system over the last 20 years and how they affect the policies and the rules of the WTO. The thesis contributes to the literature by addressing trade issues from a theoretical and practitioner's perspective and offering practical results oriented recommendations on how to move the trade agenda forward.

As was noted by Winston Churchill, looking back into the past is a first step for a better understanding of the future. This study can hopefully and in a modest way contribute to a better understanding of the past, so as to provide insights for the future.

The structure of the thesis is as follows:

Chapter 2 discusses the main features of the multilateral trading system of the WTO and analyses how they differ from those of the GATT, which it replaced. It looks at the institutional aspects of the WTO, its main functions and how the rules have been extended and strengthened over the past 20 years. It argues that the WTO rules were created at a time when world trade became increasingly complex with a stronger interdependency between economies. Much of this process was triggered by globalization of international trade which had already started well before the creation of the WTO. The nature of trade also changed with the growing importance of services in international trade. The architecture of the WTO and its rules needed to be revised and the trade rules extended to include trade in services and trade related aspects of intellectual property rights. As the services sector is largely governed by domestic regulations, the distinction between border policies and domestic policies was increasingly blurred, adding to the complexity of rule-making. It addition, the WTO covers a far broader range of topics and issues that were not fully addressed under the GATT rules, including agriculture, thus making the new multilateral trading system increasingly complex. 
One of the significant differences between the GATT and the WTO is the way in which disputes are settled. It is argued that the shortcomings of the dispute settlement provisions of the GATT have led to the undermining of the trade rules and erosion of the multilateral trading system. In the absence of an effective enforcement mechanism there was no incentive to abide by the rules, which were gradually being ignored. Trade measures were increasingly made externally to the trading system, which undermined the trading system. With the creation of the WTO and the redesign of the dispute settlement provisions, the credibility of the multilateral trading system was restored. The WTO is a rules-based system and its provisions have proven to be most effective.

Another significant difference between the GATT and the WTO is the membership - it has expanded considerably following the creation of the WTO, and in this way has also become more diverse. The WTO has far more members than the GATT, with many of them at different levels of economic development and operating under different economic systems, which adds to the challenges of reaching common agreement. A range of countries joined the WTO after the collapse of the former Soviet Union and the end of the Cold War in the 1980s. These so-called 'transition economies' were required to undertake major domestic reforms and economic adjustments in order to obtain WTO membership and apply market-based policies. The extension of the rules to these countries has made the WTO multilateral trading system more universal. In addition, developing countries have gradually and steadily integrated more fully into the trading system with the aim of enhancing their levels of economic welfare. This is a relatively new and significant development, as developing countries previously showed little interest in the GATT. As a result the multilateral trading system of the WTO is more inclusive than that of the GATT.

The expanded membership and growing interest in active participation in the trading system also has important ramifications for the decision-making process. The consensus approach in the WTO unifies all the members by definition, and this is a core strength. At the same time decisions often reflect the lowest common denominator, which can be a weakness. The increasingly diverse range of members implies that there is more diversity in views and approaches, as some have greater ambitions and others are simply not prepared for the higher pace of liberalization and rule-making. Consensus means that decisions need to reflect the different levels of economic developments, ambitions and conflicting objectives that members may want to pursue. This adds to the complexity of decisionmaking and in part explains the lack of progress in the DDA negotiations.

In another development, there is an increasing number of coalitions by which WTO members align their position with other members that pursue similar objectives. These coalitions are far more numerous than in the GATT. Such coalitions are mostly based on common interests to secure outcomes that serve the broadest interests of all stakeholders. They cut across levels of development and include developed and developing countries alike, as well as Recently Acceded Members (RAMs). The coalitions are very diverse in composition and modus operandi. The positions and discussions are increasingly topic 
based, rather than focusing on developed vs developing country issues. Here again the nature of the discussions has significantly evolved.

One of the key functions of the WTO, conducting trade negotiations with a view to liberalizing trade, has not led to the expected results. The DDA was launched over 16 years ago and there is still no conclusion in sight. While the main obstacles in the progress have mostly been attributed to agriculture and non-agricultural market access (NAMA), there are various other explanations for the deadlock. One of them is the fact that all outcomes are interrelated and linked through the Single Undertaking principle, which means that nothing is agreed unless everything is agreed. It is argued that this approach certainly has many merits, but has had the opposite and undesired effect of delaying the outcome of the negotiations. Not only has there been no effort to exchange concessions between sectors and areas under negotiation, as was initially intended, negotiations progressed at different speeds. Some decisions were within reach and could not yet be taken, in the absence of progress in other areas, and the Single Undertaking principle stopped them from going ahead. Members finally decided to adopt the so-called early harvest approach and take decisions in deviation of the Single Undertaking concept. Abandoning this approach allowed progress in the negotiations and ensured the outcomes of discussions at MC-IX (Bali) and MC-X (Nairobi) in specific fields. Has the Single Undertaking approach therefore effectively ceased to be the guiding principle of negotiations?

With regard to the policy issues that are directly relevant for current trading patterns, members did recognize early on that there was a need to address the relationship between trade and investment, trade and competition policy and other issues, often referred to as the 'Singapore issues'. They had initially been put on the agenda during the first Ministerial Conference (MC-I) held at Singapore in 1996, prior to the DDA and less than 2 years after the WTO's creation. They were however removed at the Ministerial Conference at Cancún in 2003 (MC-IV). Explanations are provided on the key elements of those issues and about how they were addressed. It is argued that these areas require more specific attention, given their direct relationship with trade and the ways trade patterns have evolved. In addition to trade and investment and trade and competition policy, other issues include trade and labour standards, government procurement, trade facilitation, information technology, trade and environment, electronic commerce and regional trade integration. In some of these areas there has been progress and specific agreements. The discussions and negotiations on trade and environment seem to hold promising results. A revision and an extension of the Government Procurement Agreement (GPA) were accomplished with significant economic benefits. A brief overview is provided on the main issues and how the discussions evolve. Finally, a short discussion is provided on the new dimensions of various regional trade integration efforts pursued by some of the main economic actors in the world and how these initiatives relate to the multilateral trade negotiations. The discussion of these various points shows that even in the absence of a DDA outcome, trade continues to be liberalized, in economically significant and meaningful ways and that regional multilateral trade liberalization can be complementary in pursuing that objective 
Chapter 3 discusses the evolving nature of trade and the growing interdependence of markets that resulted from globalization. It is argued that globalization has led to more specialization and a further breaking up of the production process, thus driving trade and investment. In return, the new patterns of trade and investment drive globalization, thus generating a dynamic process. Globalization has triggered a deepening of the integration of economies and markets in the world economy which were largely facilitated by the emergence of new technology and innovations in production techniques. The geographical distances between markets of production and supply are of less important today than at any time before in history. Transaction costs have been reduced considerably and there is evidence that the new Trade Facilitation Agreement (TFA) will reduce these costs further in significant ways, making it even less of an issue about where to carry out the various parts of the production process and where to outsource.

Closely related to globalization are Global Value Chains (GVCs), which have become very topical and can be seen as a continuation and deepening of globalization. Connectivity through GVCs contributes to the rapid diversification of production of goods and services, with industries in many countries moving up the ladder of value adding. The basis for GVCs is increased specialization enhancing trade in parts and components which generates more revenue and higher levels of welfare. GVCs also lead to the creation of regional production networks, thus strengthening the regional dimension of trade integration. What GVCs actually are and how countries can connect to international markets through them is looked at in further detail. There is also consideration of what GVCs mean for international trade, what new opportunities they can offer, and what policies countries need to adopt with regard to GVCs that are conducive to achieving a better and fuller integration into the world economy and the global production process.

It is shown that some countries have connected to world markets more easily and have been faring very well as a result of globalization. The landscape for world trade and investment has evolved very rapidly since the creation of the WTO 20 years ago. This process was largely driven by a few countries, including China and India. While initially there were high expectations of the economic performance by other countries including Brazil, Russia, India, China and South Africa (BRICS), it was only China and India that became the main actors and fastest growing economies, with the other countries lagging behind. Since China has joined the WTO, it has rapidly grown into one of the leading nations for export and imports in goods and services. At the same time it has become the largest recipient of foreign direct investment (FDI) as well as the largest outside investor and provider of FDI. These developments have triggered a shifting of the balance for international trade and investment from the West to the East, with Asia now having moved from the periphery to the centre. At the same time the world is witnessing a rapid growth of the middle classes and their income in Asia and this is accelerating the shifting balance. These developments show a changing dynamic and balance in economic and trade relations.

With the changing landscape of trade and investment, the WTO also faced new 
challenges: the liberalization of trade accomplished under the GATT has led to better access to markets and generated higher levels of specialization and trade. However at the same time it has triggered new trends to protect domestic markets, hence the need for the WTO to resist protectionism. The trade policy responses offered to globalization have evolved considerably with a marked difference between the respective approaches of the GATT and the WTO. Due to the initial strong resistance to globalization, governments tended to adopt largely defensive policies, geared towards protecting domestic markets and industries, combined with more aggressive policies geared towards targeting winners and industrial leaders. These policies turned out to be largely ineffective and at the same time costly to both the governments and the consumers, and led governments to change their approach. The close interrelation between markets and their increasing interdependency meant that more emphasis was put on policies geared towards harmonization, coherence and policy coordination. Given the increasing interconnectivity of markets and interdependency of trade and investment, there is an increased need for governments to synchronize policies. Policy makers have less scope and leverage to act alone and take independent policy decisions without taking into account the policies conducted by their trading partners. This then leads to the question of the role of the state and global governance. There is a need for policy coherence and coordination between nations in order to avoid any negative repercussions from international policy actions on national economies. Policies are more geared towards creating new opportunities, innovation and research and development $(\mathrm{R} \& \mathrm{D})$ rather than protective policies. At the same time the world is witnessing yet again a fear that globalization is responsible for diminishing growth in the West and adding to unemployment, with new calls to shield domestic markets. The challenge for policy makers is to resist that temptation given the costs that protectionist policies imply. Despite an awareness of the economic costs, protectionism has been on the rise.

Given the centrality and significance of market access in the GATT and the WTO, Chapter 4 analyses how market access negotiations were addressed in the GATT and how they are presently negotiated in the WTO. It will be argued that the issues, priorities and approaches in the negotiations have evolved with time, largely driven by the ways in which international trade and trade policies have evolved. The discussion and analysis focuses particularly on tariffs as one of the most important trade policy instruments for liberalizing trade. It looks at the various negotiating approaches and techniques that have been considered and applied over time to reduce tariffs, and how they work in practice. It is argued that despite the significant tariff reductions performed under the GATT, tariffs continue to be of critical importance in international trade and need to be cut further. This explains the particular attention given to tariffs in the DDA negotiations, as they have the potential to provide much better access to markets and better market conditions for its members for goods and agricultural products. One of the key objectives is to reduce high tariffs and address the issue of tariff escalation. It appears increasingly difficult however to reach agreement on how to tackle tariff issues both in the areas of agriculture and goods. The negotiations have been in an impasse for nearly a decade and continue to be deadlocked without a solution in sight. This leads to the question whether the negotiating strategies and 
approaches that have guided the DDA market access discussions so far need to be pursued in the same way or abandoned and reconsidered. Some members are advocating a new approach, most recently at MC-X (Nairobi), in favour of new techniques and simpler approaches whereas other members continue to believe that an outcome is possible when following the old approach.

In order to better appreciate the evolving nature of negotiating approaches and understand tariff negotiations in the GATT, two example studies are presented. that serve to illustrate the broader topics discussed in chapter 4 . Both relate to what I refer to as the 'old economy', as they concern trade in traditional sectors of the economy. The first example examines how, through the elimination of quotas and non-tariff barriers in the textiles clothing sector, this sector became a 'tariffs only' regime. The challenge today mainly consists of reducing the high tariffs and tariff peaks in this sector. The second example discusses how tariff escalation has affected trade in leather and leather products, another sector with high and pervasive tariffs. There is scope for more diversification in both areas, the upgrading of production levels and an increase in value adding in the production process.

The second part of the chapter discusses the efforts undertaken in the DDA to reduce tariffs and the various approaches proposed to achieve further ambitious levels of trade liberalization, including through the formula approach. It focuses on the complexity of the market access negotiations in the field of agriculture and Non Agricultural Market Access (NAMA), which have been structured in such a way as to take into account specific concerns of individual countries as well as groups of countries. It is argued that the approaches followed in the DDA have substantially added to the complexities of the negotiations and contributed to their failure. While the efforts to reduce tariffs through a (simple) formula approach in the Uruguay Round yielded good results, the efforts made to take into account all the different positions of members in the draft agreements, especially in the market access negotiations for agriculture and NAMA have been counterproductive. Members' attempts to address individual country concerns (as well as those for groups of countries) in the draft agreement and in deviation from the formula have made the texts too complex, with the inclusion of too many exceptions. Transparency is effectively reduced and the overall negotiating objectives are undermined.

The question is raised whether an outcome is still feasible by sticking to the same approach with members making efforts to take into account all the exceptions and specific requests by countries and groups of countries. It is suggested that alternative approaches are likely to be more effective and yield economically meaningful outcomes. A plurilateral approach and/or the offer-request procedure could guide the trade negotiations, with members focusing on areas with high tariffs. Rather than aiming for liberalization to be achieved through the global formula approach, a strategy of incremental liberalization may prove to be more effective. This could include pursuing a sector approach, which has proven to yield tangible results. The argument is made that the outcomes of the negotiations should 
ideally receive multilateral application by virtue of the Most Favoured Nation (MFN) rulesbased system of the WTO in order to extend the benefits to the entire membership.

This discussion is followed by another two examples that relate to the modern economy, including one on the Information Technology Agreement (ITA) and one on the Trade in Services Agreement (TISA). Interestingly, both efforts were pursued largely outside the framework of the WTO. The outcomes for ITA were extended multilaterally and those for TISA are most likely to be confined only to its signatories. It is argued that the ITA negotiations resulted in zero-for-zero duties in a sector that is not only characteristic for the current modern economy, but economically very significant too. The liberalization of trade in technological goods is likely to contribute to a further reduction in cost for goods that incorporate IT components and thus come to the benefit of the consumer and the world economy at large. It is also significant for GVCs, as production processes increasingly use IT parts and components. Equally important is the fact that while the ITA was negotiated between 53 countries and largely outside the framework of the WTO, the benefits are extended by virtue of the MFN rules to the entire WTO membership.

The second example looks at efforts undertaken by some countries to advance the liberalization of services trade. Although the GATS specifically provided for negotiations to be conducted with the aim of achieving higher levels of liberalization, the TISA negotiations are conducted outside the framework of the WTO, in parallel to the DDA negotiations. It is unclear whether the eventual outcome would have the potential for multilateral application. One reason that could prevent members from doing so is that trade in services is governed mostly by domestic regulations and governments may not yet be ready to extend concessions to all the WTO members. The debate on market access has gradually shifted from a rather simple system of border measures to a more complex system of increasingly intertwined border and domestic policy issues. Market access concessions thus pose new policy challenges, and these are more sensitive than concessions in the goods area, which are more easily measurable and quantifiable in terms of economic impact. This is much harder when it comes to regulations, or rather, deregulation.

Chapter 5 takes a closer look at the status of developing countries in the WTO and more specifically at the development dimension of the negotiations in the DDA. Developing countries were barely integrated in the GATT system. The WTO, particularly through the DDA negotiations, meant to specifically address the concerns of developing countries in international trade. The fuller inclusion of developing countries in the multilateral trading system would seriously strengthen the credibility of the system per se. Here again, market access is a fundamental matter of critical importance for developing countries. Many developing countries state that they have made many commitments and obligations in the GATT period, but that the expected benefits from trade liberalization have not materialized. They have therefore built a case that developed countries need to make more effort in areas of specific interest to them, leading to better integration into the multilateral trading system. This partly explains the reluctance of some developing countries to accept proposals to 
further expand the trade agenda and include newer trade issues. The WTO can only pursue its liberalization efforts if it fully takes into account the developing country concerns.

Following a brief discussion of the place of developing countries in the WTO, it reviews the various approaches adopted with regard to trade capacity building in the WTO. This is followed by an analysis of the main achievements since the DDA began and a discussion of the key challenges. It is observed that as developing countries are not a homogeneous group, with many of them having different levels of economic development, their performance, interests, and challenges are not the same. Some are more economically advanced than others and depend less on preferences and special and differential treatment provisions. Others, mainly Least Developed Countries (LDCs) are highly dependent on preferences and are not in a position to make concessions in the negotiations. Accordingly, the priorities and economic interests of developing countries differ in the negotiations and a main challenge consists of reconciling all positions. The question is then addressed as to what policies allowed some of them to become active participants in international trade and integrate more fully into the trading system. It is argued that in these countries a gradual shift in domestic economic policies was witnessed since the creation of the WTO, and explanations are provided as to why that happened. Developing countries manifest much more interest in international trade and the DDA negotiations, based on the explicit recognition that trade is a vehicle generating economic benefits, stimulating growth and enhancing overall levels of welfare. Opening markets and liberalizing trade is essential to connect to international markets, deepen specialization and be part of GVCs. While the potential benefits of trade are increasingly recognized, the reality shows that the opening of the domestic markets in developing countries can pose major policy challenges, as trade liberalization implies adjustment costs. It is evident that not all countries benefit equally from the liberalization process, with the main differences being found in continents and among countries.

Developing country concerns are therefore central to the multilateral trading system and critical to the successful outcome of the DDA negotiations. It is argued that developing countries play an increasingly important role in the WTO negotiations, ensuring that the development dimension is effectively covered in the negotiations. The efforts undertaken by the WTO Secretariat in the area of trade capacity building aim precisely at facilitating the integration of developing countries in the trading system. Explanations are provided on the WTO's trade capacity building programmes, and on how they are implemented and support the development goals. Both quantitative and qualitative evidence is presented, which shows that developing countries are increasingly integrated in the multilateral trading system and are participating more fully in world trade. It is argued that the trade capacity building efforts in support of developing countries' integration into the multilateral trading system of the WTO have paid off. More specifically, it is argued that the trade capacity building efforts undertaken by the WTO over the last 20 years have contributed to the active role of developing countries in the negotiations, by allowing them to support their cases, defend their interests and take policy positions on complex issues based on analysis and a solid grasp of the issues. Developing countries are more actively engaged in the negotiations than ever 
before, either in their individual capacity or as part of a coalition, and influence the negotiation process in significant ways. Their engagement can be measured in many ways, including against the number of interventions and proposals submitted, often on complex issues. Their explicit inclusion in the debates and decision making process is of the essence for the system, and make the WTO truly universal.

The case study of the TFA illustrates how trade capacity building has gradually evolved, with innovative approaches and features. The TFA contains binding obligations for both developed and developing countries with regard to the delivery of trade capacity building. It can be considered to be a new model, thus gradually moving away from the best endeavour provisions that are characteristic of most of the current agreements. It shows another shift away from the GATT to the WTO and the continuation of a trend to make the trade capacity building efforts tangible and directly relevant for beneficiary countries.

Chapter 6 addresses the challenges and opportunities that the WTO multilateral trading system is currently facing and ways to address these. It starts by recalling the trade liberalization that was already accomplished during the twenty one years of existence of WTO and such despite the lack of progress in the DDA. The liberalization resulted from many factors and initiatives, including the increased membership of the WTO compared to that of the GATT, following the successful conclusion of many accessions. The accession process requires the opening of markets by acceding members, the reduction and/or elimination of barriers to trade, and domestic reforms, which all contribute to market efficiency and liberalization. It is argued that despite the slow progress in the multilateral trade negotiations of the DDA, it would be incorrect to suggest that it has not yielded significant results. Indeed, trade continues to be considerably liberalized, albeit in fragmented ways, with various agreements having been concluded in the WTO. These include the TFA which was negotiated at Bali (and is presently in the process of ratification by WTO members), the expanded GPA, and the ITA. These are tangible outcomes and have been calculated as generating significant economic benefits.

It then discusses issues that need to be addressed in order to move forward. Based on the analysis in the thesis it is observed that there is ample scope for further and deeper trade liberalization and enhancement of market access in the WTO, provided that the negotiating techniques and approaches take into account the ways in which trade and trade patterns have evolved. In terms of negotiating approaches, it is suggested to complement the multilateral approach with plurilateral negotiations. Not only has this already proven to work and yield specific outcomes, it allows to better and take more fully into account the different levels of economic development and members' ambitions. Suggestions and recommendations to that effect had already been made by independent experts prior to the launch of the DDA, shortly after the negotiations had started. Insufficient consideration has been given by members to apply these approaches. It is argued that the plurilateral approach should be complementary to the multilateral approach and would allow for more flexibility in the negotiations, as well as take into account the different levels of ambitions and economic development of the 
members. It is also argued that the 'single undertaking' approach that has guided the DDA negotiations is no longer justified. Similarly, it is argued that the closer and growing interdependency between economies, which has largely resulted from globalization, requires an explicit recognition of the significance of various other policies that directly affect trade and trade policies, including the relationship between trade and competition policy and trade and investment, which should be part of the negotiating agenda.

It is then argued that the multilateral trading system of the WTO is strengthened with a fuller participation and integration of developing countries in the multilateral trading system and that more efforts should be pursued in assisting them to achieve that objective. The development dimension is central in the DDA negotiations and the liberalization efforts undertaken should specifically take into account the economic interest of the developing country members. The ways in which developing countries have benefited from trade differs across and within regions and has not always been even between countries. Globalization has offered challenges and opportunities, but yet, many developing countries have not benefited from these opportunities and are not part of the GVCs. The reduction in transaction costs, especially in developing countries, would significantly help in the process of a fuller integration into the multilateral trading system. The negotiations should be conducted in ways which ensure that the DDA produces economically meaningful results for the developing countries.

It is shown in the literature that regional trade agreements (RTAs), many of which are currently being negotiated by large trading nations and fall outside the scope of the multilateral trading system of the WTO, can contribute to further liberalization. The longheld belief that RTAs are by definition incompatible with multilateral trade liberalization is revisited. While RTAs are generally considered to deviate from the multilateral trade principles, they do have the potential to generate significant positive multilateral spill-over effects to the benefit of the WTO membership. RTAs can contribute to enhancing overall levels of welfare and trade liberalization. In many ways RTAs may be complementary to the multilateral trade liberalization. The question today is to understand how that can be achieved given their selective nature. There are signs that members are getting ready to engage in analysis and discussions on how RTAs can interact with the multilateral trade rules.

The question is raised if there is a need for further institutional reforms in the WTO and if so what they would consist of. Explanations are provided on the reforms that had already been suggested and presented by independent experts and imminent persons at the time of the GATT as well as shortly after the launching of the DDA. It is pointed out that while several of the recommendations were implemented many remain valid today and need to be seriously considered and addressed. This includes various suggestions which resulted in a stronger role for the WTO Secretariat. 
In terms of the remaining challenges and the ways forward, the most important challenge consists of deciding on how to pursue the main objectives in the DDA negotiations and to bring its constituent elements to a conclusion. The question to address is what parts of the DDA negotiations will be pursued and which process will be followed, bearing in mind the conclusions arrived at by Ministers at the last Ministerial Conference (MC-X, Nairobi). MC$\mathrm{X}$ resulted in a split position between the WTO membership, with some reaffirming their full commitment to conclude the DDA, and others wishing to pursue new approaches to achieve meaningful outcomes in multilateral negotiations. It is argued that the discussions and the negotiations have remained centred on two key issues too long: agriculture and NAMA. This largely explains why there has been a lack of progress in other areas that have become important in international trade and more specifically the links between trade and investment and trade and competition policies. The Ministerial Declaration opened or perhaps reopened the door to address other issues affecting trade and the multilateral trading system. The question now is how these discussions can and will be initiated. It is argued that the developments in the international trading system mean it is important that the rules be expanded to cover trade and investment and trade and competition policy.

Chapter 7 provides an overview of the main findings and conclusions of this $\mathrm{PhD}$ thesis, and offers specific policy recommendations that result from this analysis. 


\section{CHAPTER 2: FROM THE GENERAL AGREEMENT ON TARIFFS AND TRADE TO THE WORLD TRADE ORGANIZATION: THE NEW MULTILATERAL TRADING SYSTEM}

\subsection{Introduction}

One of the common objectives of the GATT and WTO is to pursue trade liberalization with a view of generating economic growth and enhancing overall levels of welfare. This objective is traditionally pursued through rounds of trade negotiations, which were previously conducted under the aegis of the General Agreement on Tariffs and Trade (GATT) and more recently in the World Trade Organization.

The GATT has a priori a better track record in terms of trade liberalization than the WTO, with much uncertainty about the future and possible conclusion of the DDA.

In order to better appreciate the challenges for WTO members in the negotiations and the difficulties in achieving higher levels of liberalization this chapter analyses the main features of the multilateral trading system of the WTO and discusses how it differs from its predecessor, the GATT. It first examines how the rules-based system has evolved over the past 20 years, how it has been strengthened and how it functions. It provides a review of the origins of the WTO, followed by a discussion of the institutional set up, its key objectives and functions and how these are performed. In this framework an analysis of the main differences and improvements in comparison to the GATT system is set out. Amongst the large number of institutional changes introduced by the WTO in comparison to the GATT, it is argued that one of the most significant additions relate to the new and strengthened rules with regard to dispute settlement. The dispute settlement provisions have already proven to be one of the main successes of the WTO. The extensive use that the members make of the dispute settlement procedures is not only a sign of trust in the system but has also considerably enhanced the credibility of the rules-based multilateral trading system.

The WTO also goes much further and deeper in rule-making than the GATT did, covering a broader range of issues. The new multilateral trading system now explicitly covers agriculture, service and trade related aspects of intellectual property (TRIPs) and attempts have been made to extend the rules to other areas, including trade and investment and trade and competition policy. While the inclusion of the areas of agriculture, services and TRIPs in the rules-based system has been of critical importance for a strengthened multilateral trading system, the subsequent efforts to pursue liberalization in agriculture and services, as well as 
in the goods area have posed many challenges. The DDA negotiations have not yielded the expected results in the key areas, despite the efforts undertaken over many years.

It is argued that in the course of the DDA negotiations the WTO has shown considerable weaknesses. One of the weaknesses that have become apparent relates to the negotiating function of the WTO. It is widely agreed that while the WTO has delivered on some aspects of the negotiations and mostly so in the last 3 years, the DDA has not produced the expected outcomes. The negotiations have largely been stalled since 2008 and at the same time the world witnessed a financial crisis. Explanations are provided for the difficulties encountered and why this function has become a challenge. It is argued that in addition to the many technical aspects of the negotiations, the complexities in each of the specific areas, and the fundamental differences in positions the enlarged membership of the WTO also makes it harder to reach agreement. One significant difference between the GATT and the WTO is that not only has the number of WTO members significantly increased in the WTO compared to the GATT, but so has its diversity. In other words, any outcome needs to reflect the agreement between a larger and more diverse set of members. Whereas most of the decisions in the GATT were taken by a few and mostly large trading nations, this has fundamentally changed in the WTO with an active engagement by all stakeholders. The WTO thus is more inclusive than the GATT.

Consideration will be given to some of the systemic implications of the broader interest in the multilateral trading system and how the WTO addresses the challenges: this chapter explores the active participation of a larger number and more diverse range of WTO members as providing a fundamental contribution to the increasingly universal nature of the WTO and the multilateral trading system. At the same time because the members are committed to addressing all concerns and specific interests, it also means that the negotiations have become more complex and time consuming. It is shown that the creation of coalitions between WTO members play an important role in advancing negotiations. Increasingly, members of different levels of economic development align themselves and develop common positions. A particular feature of some of the new coalitions is that they are increasingly topic based, with developed and developing countries aligning their positions. Insights will be provided into the variety of coalitions, their raison d'être and how they work.

Members have also made attempts to extend the multilateral trading system and address other challenges and trade related issues, some of which have been referred to as the "new trade issues'. These include the relationship between trade and investment and between trade and competition policy, trade and environment, electronic commerce and several other issues. Given their relevance for the way trade is conducted, some members explicitly want these to be covered under the rules-based system of the WTO. There is consideration of what 'new' or perhaps 'not so new' trade issues could be included in the trade agenda and the reasons for the difficulties addressing them in the negotiations. 
This chapter thus provides the backdrop against which the key challenges that the WTO multilateral trading system currently faces can be better understood and lays the foundation for issues that will be analysed in the following chapters. It shows that with the creation of the WTO many issues that had gradually undermined the GATT were addressed, leading to a much stronger multilateral trading system. At the same time, it is argued that the rapid evolution of trade and the trading system per se require members to take a fresh look at the rules with a view of refining and expanding them further.

\subsection{From GATT to WTO: History and Background}

The legal foundations for a new institution, the World Trade Organization (WTO) were laid with the conclusion of the Uruguay Round and the signing of the Marrakesh Agreement Establishing the World Trade Organization (15 April 1994). ${ }^{1}$ The WTO came into existence on 1 January 1995 and laid the basis for a 'new world trading system'. In one fell swoop it brought to an end the provisional basis on which the GATT had operated for half a century. Van Grasstek has traced its origins and examined the approach to its initial structure in great detail. ${ }^{2}$ Through his research and interviews, it is shown that the idea behind this new institution first emerged in 1990 at a Conference held at Chatham House where Professor John Jackson presented proposals calling for revision of the terms of the multilateral trading system: these ideas were subsequently published in the Chatham House Series. ${ }^{3}$ Jackson urged the correction of some of what he termed the GATT's 'birth defects' through the creation of a new institutional structure. According to Jackson, the GATT was never intended to serve as a permanent organization and its existence depended on a Protocol of Provisional Application which contained grandfather provisions of non-compliant laws, as well as a weak dispute settlement system. ${ }^{4}$

The GATT was established in 1947-48, at the same time that the negotiators prepared a Charter for an International Trade Organization (ITO). According to Jackson the ITO never came into being because the United States Congress would not approve it. ${ }^{5}$ Conversely the GATT was negotiated under advance authority granted to the US President in the 1945 extension of the Reciprocal Trade Agreements Act. It was applied 'provisionally' because it was expected that the ITO would come into force and that it would then be covered under its umbrella. As the ITO never saw the light of day, the GATT became the focus for

1 The Uruguay Round was the eighth negotiating round conducted under the GATT. It had been launched at a Ministerial Meeting at Punta Del Este, Uruguay, in September 1986 and lasted eight years.

2 C. VanGrasstek, The History and Future of the World Trade Organization (World Trade Organization, Geneva, 2013).

3 J. Jackson, 'Restructuring the GATT System', Chatham House Papers (Council on Foreign Relations, 1990). Jackson is widely considered one of the leading scholars on the GATT, with publications on trade and trade law, including The World Trading System, Law and Policy of International Economic Relations (MIT Press, Cambridge MA, 1999).

4 Ibid., The notion 'grandfathering' of non-compliant laws means that existing laws take legal precedence, which would seriously weaken and undermine the new laws.

5 Ibid., p. 10-12. 
international government cooperation on trade matters. Although it had been remarkably successful over nearly five decades there was a need for a better and more solid institutional structure to address trade issues and an ever expanding agenda.

The creation of the WTO in 1995 ended the GATT era and a new world trading system was established, providing a new institutional and legal basis to regulate international trade. The first study on the implications of the Uruguay Round for trade and WTO resulted from a workshop conducted by the OECD immediately after the conclusion of the Round by the WTO, and brought together key negotiators, policy officials, academics, think tanks and external observers. 6 The Uruguay Round is described in the resulting publication as the most comprehensive trade negotiations round ever taken, and that the implications are more far reaching than the expected and substantial trade benefits as they include effects on the functioning of the multilateral trading system itself. ${ }^{7}$

Indeed, the Uruguay Round lasted eight years - far longer than any previous round, although it is far shorter than the current, ongoing round which was launched in December 2001, the DDA. ${ }^{8}$ Given the outcome of the last Ministerial Conference (MC-X) held at Nairobi in December 2015, the future of the DDA is now uncertain. As will be explained further, members hold different views on the way the negotiations need to be pursued further and concluded.

It has often been observed that the successful conclusion of the Uruguay Round restored credibility to the multilateral negotiating process and was indispensable for governing international trade in an era when the modes of trading were rapidly evolving. Indeed, services trade had become predominant in international trade, with the volume of services trade often competing with the volume of trade in goods. In addition there were many other important new developments in international trade that could not be covered by the GATT, some of which emerged from the rapid diversification of trade, the breaking up of the production process through enhanced specialization, often referred to as globalization, the exponentially fast growing foreign direct investment (FDI) flows, which were increasingly complementary to trade, the emergence of electronic commerce, the growing importance of

6 G. Raby (ed.), The New World Trading System: Readings, OECD; this book resulted from the Workshop that I organised with OECD colleagues (Spring 1994), containing a collection of readings. The workshop brought together key policy makers, representatives of international organisations and specifically from the GATT, think tanks, scholars, trade negotiators, leading commentators and journalists on international trade.

7 Ibid. The 'Uruguay Round was the most comprehensive round of multilateral trade negotiations ever undertaken. Accordingly, the implications of the Uruguay Round go well beyond the expected substantial benefits of trade liberalization to the functioning of the Multilateral Trading System itself. The conclusion of the Uruguay Round has been an achievement in international cooperation and good sense akin to the original decision to establish the GATT in 1947'.

8 Given the duration of the negotiations and the fundamental differences between the Members on how to advance the DDA in specific areas (which will be analysed in the next chapters) the final outcome of the negotiations remains uncertain. As will be explained further, the Ministerial Conferences (MCs) are the highest decision making body in the WTO and are convened every second year. A total of 10 MCs have been held since the creation of the WTO. The DDA was launched at MC-IV at Doha. 
the need to fully recognize the intellectual property rights in international trade and so on. ${ }^{9}$ Perhaps even more importantly, tariffs had been reduced significantly with non-tariff barriers becoming ever more important and the GATT rules requiring a further strengthening to deal with new forms of protection. Finally and very importantly, the GATT was in many ways insufficiently equipped to operate as an effective forum for settling trade disputes. It was therefore urgent to take stock of all the issues and address them through a new institutional framework with a new set of rules.

The WTO will not necessarily provide the immediate answers and solutions to all these issues, but its institutional set-up facilitates the process to address any issues that members put on the table. The WTO primarily provides for the legal provisions for the effective implementation of the substantive rules that have been negotiated in the Uruguay Round. While the WTO itself is entirely institutional and procedural, it incorporates the substantive agreements resulting from the Uruguay Round into annexes. The WTO ties together the various texts developed and re-enforces the 'Single Undertaking' notion of the negotiations, which means that countries accepting the Uruguay Round must accept the entire package, with only a few exceptions. ${ }^{10}$ Furthermore, the WTO facilitates the extension of the institutional structure to the new subjects negotiated in the Uruguay Round, particularly services and intellectual property. Similarly, the WTO contains a unified dispute settlement mechanism for all its members. Finally, the WTO offers considerably more room to deal with policy issues that are likely to arise from the evolution of international trade. One key element in that regard relates to international trade cooperation. ${ }^{11}$ With the WTO focusing on the institutional side, it also offers more flexibility for inclusion of the new negotiated rules or measures which can assist nations to face the constantly emerging problems of world economics. ${ }^{12}$

Van den Bossche and Zdouc observe that 'the Marrakesh Agreement Establishing the World Trade Organization was the most ambitious and far-reaching international trade agreement ever concluded'. ${ }^{13}$ They offer an in-depth analysis of how the rules of the multilateral trading system regulate international trade and how trade is significant as a policy instrument generating economic growth and enhancing levels of welfare. According

9 The features of globalisation and changing patterns of trade will be discussed in the next chapter.

10 The 'Single Undertaking' in essence means that no final agreement can be reached in one area of negotiations, unless there is agreement in all of the other areas under negotiation, thus allowing for trade-offs between concessions to be exchanged. As will be observed further, this concept is often claimed to have created a bottle-neck in advancing the negotiations, largely preventing the DDA to be concluded in some key areas, including agriculture and non-agricultural market access (Chapter 4). Some members have therefore called for abandoning this principle, thus allowing for progress in the negotiations and that is what has happened.

11 As will be argued and explained further (Chapter 5), the WTO's Director General is institutionally required to interact and coordinate policies with his counterparts of other international organisations.

12 Contrary to the GATT, the Director General of the WTO is closely associated with the economic debates and discussions at the highest political levels, including the G-20.

13 P. van den Bossche and W. Zdouc, The Law and Policy of the World Trade Organization (Cambridge Press, 2013), p. 40. 
to these authors, international trade can make a significant contribution to economic development and prosperity in developed as well as in developing countries. ${ }^{14}$ In order to achieve those objectives, and for this potential to be realized, several conditions need to be fulfilled: there is a need for a good governance at the national level, a need to further reduce trade barriers both at the national and international level, the availability of more development aid, and ensuring a better international cooperation and global governance of economic globalization and trade. The authors focus their analysis specifically on the requirement of global governance of international trade, which is perhaps one of the most difficult areas, as it encompasses a whole spectrum of policies that go far beyond the trade policies.

The authors explain the rationale for having international trade rules by referring to $\mathrm{P}$. Sutherland, who wrote in 1997 that

the greatest economic challenge facing the world is the need to create an international system that not only maximizes global growth but also achieves a greater measure of equity, a system that both integrates emerging powers and assists currently marginalized countries in their efforts to participate in worldwide economic expansion... The most important means available to secure peace and prosperity into the future is to develop effective multilateral approaches and institutions. ${ }^{15}$

In the same spirit Jackson noted that

it is very clear that law and legal norms play the most important part of the institutions which are essential to make markets work. The notion that the "rule of law" (ambiguous as that is) or a rule based or rule oriented system of human institutions is essential to a beneficial operation of markets, is a constantly returning theme in many writings. ${ }^{16}$

Van den Bossche and Zdouc explain how legal rules and in particular international legal rules in international trade allow countries to realize the gains of international trade. They present four main and related reasons why there is a need for such trade rules and these are increasingly internationally recognized as the driving factors for developing such rules. The first reason is that: (i) 'countries must be restrained from adopting trade-restrictive measures both in their own interest and in the interest of the world economy': but they admit that there can be reasons for deviation from this principle, such as to promote or protect

14 Ibid., p. 30.

15 P. Sutherland, 'Beyond the Market, A Different Kind of Equity', International Herald Tribune, 20 February 1997.

16 J. Jackson, 'Global Economics and International Economic Law', 1 Journal of International Economic Law (1998), p. 1-18. 
important societal values and interests. ${ }^{17}$ The key question here of course is the margin of manoeuvre, that is, the extent to which countries be allowed to deviate from the principle. ${ }^{18}$ The next reason is that international trade rules (ii) 'provide for a degree of security and predictability.' This argument is often invoked as a key determinant driving trade and foreign direct investment; the business community wants transparency, stability and legally enforceable rules. Another reason is that (iii) 'the greatly increased levels of trade in goods and services, the protection and promotion of important societal values and interests such as public health, a sustainable environment, consumer safety, cultural identity and minimum labour standards is no longer a purely national matter'. The final reason is that (iv) there is a 'need to achieve a greater measure of equity in international economic relations'. These points will recur in the analysis, as they are all of critical importance.

The GATT started with a small membership of 23 contracting parties ${ }^{19}$ when it was set up, and mainly included developed and more advanced developing countries that had a similar trading interest. ${ }^{20}$ The GATT membership has grown dramatically to include most trading nations - with some exceptions. In comparison the WTO had 123 original members when it was initially established. ${ }^{21}$ The total membership has expanded to 164 following the successful accession of around 36 countries since its creation. ${ }^{22}$ With the exception of some smaller nations, most trading nations are now part of the WTO, making it close to being a truly universal system. Equally interesting to observe are the changes in membership: the vast majority of members are now developing countries. Some of them are leading and/or emerging economic powers in the world economy. The political and economic landscape has thus changed drastically over the years and this has important implications for a rapidly shifting balance in economics and politics, and the way the multilateral trading system functions and operates. The issue of the evolving membership and the increasing role and

17 Van den Bossche and Zdouc, Law and Policy, p. 32-34.

18 India invoked this argument during the debates at MC-IX, the WTO's ninth Ministerial Conference held at Bali, on December 2013, on food security and eventually won that debate, as is explained in Chapter 4.

19 According to the GATT 1948, Article XXXII, 'the contracting parties to this agreement shall be understood to mean those governments which are applying the provisions of this Agreement under Articles XXVI or XXXIII or pursuant to the protocol of provisional application'.

20 It is noted that the original membership included China, Syria and Lebanon, who ceased to be a GATT Contracting Party and either joined the WTO later (China) or who are now are in the process of acceding to the WTO (Syria, Lebanon).

21 The WTO Agreement initially provided for two ways of becoming a WTO Member. The first, 'original membership' was provided for in Article XI:1 and allowed Contracting Parties to the GATT 1947 (and the European Communities) to join the WTO by: (1) accepting the terms of the WTO Agreement and the Multilateral Trade Agreements and (2) making concessions and commitments for both trade in goods and services (embodied in national goods and services schedules respectively). According to van den Bossche and Zdouc, this way of becoming a WTO member was only available at the time of establishment of the WTO. Only Yugoslavia did not become a member in this way, mainly due to the breaking up of its territory and the creation of independent countries, each having applied separately for WTO's membership.

22 In accordance with the Marrakesh Agreement, Article XII, 'any state or separate customs territory possessing full autonomy in the conduct of its external relations and of any matters provided for in this Agreement and the Multilateral Trade Agreements may accede to this Agreement, on terms to be agreed between it and the WTO'. Membership and accession related issues will be discussed further below. 
influence of the developing countries will be an important element in the discussions that follow, as in many ways the rapidly changing composition of the membership is a game changer for the functioning of the organization and the way negotiations are conducted.

One of the key questions addressed in this chapter will thus consist of how the establishment of the WTO has provided for a new and solid basis to regulate international trade and led to new ways of addressing trade issues. In order to answer these questions, the institutional set up of the WTO will be analysed, including its key objectives, what the WTO intends to achieve and how it functions.

\subsection{Main Features of the Multilateral Trading System of the WTO}

The operation and functioning of the WTO as an institution is largely determined and governed by its key objectives, its structure and decision making process. How do these differ from the GATT and how are the changes expected to make it more effective in dealing with the current challenges in the trading system? What are the main features and how do they translate in concrete action? These questions are particularly relevant in light of the impasse of the current negotiations that are conducted under the umbrella of the DDA. It will be argued that conducting trade negotiations to liberalize world trade is one of the key functions of the WTO. There is an increasing convergence on the view that this function has not worked as expected.

\subsubsection{Objectives}

The preamble to the WTO Agreement states that the main objectives of the WTO are: 'to increase standards of living, attain full employment, the growth of real income and effective demand and the expansion of production of, and trade in, goods and services' ${ }^{23}$ In pursuing these objectives, members need to take into account the preservation of the environment and the needs of developing countries. The preamble refers to the notion of sustainable development, namely economic development taking into account environmental as well as social concerns. Furthermore, the preamble stresses the importance of the integration of developing countries and in particular least developed countries (LDCs) in the world trading system. ${ }^{24}$ These elements are specifically important in light of the decisions taken later, and with the launch of the DDA, where development issues were put at the heart of the agenda, hence the reference to the Doha 'Development' Agenda. ${ }^{25}$

In order to achieve these objectives, members aim at stable, predictable, transparent and secure trade rules to create an enabling trading environment for the business community

23 Marrakesh Agreement establishing the World Trade Organization, Preamble, 15 April 1994, 33 ILM 1125 (1994).

24 Least developed countries (LDCs) are defined according to the UN Classification (Cf. Annex 2.1).

25 In addition to the insights that will be provided further in this chapter, the main issues relating to developing countries and their participation in international trade will be discussed in Chapter 5. 
(the operators of the system). The rules are there to facilitate trade, eliminate inefficiencies, reduce transaction costs and allow trade to grow. While the critical observers of the WTO pay considerable attention to the difficulties in advancing the DDA negotiations, the reality is that most of these objectives have largely been met, with growth in trade having largely outpaced industrial production since World War II (WWII) and levels of welfare having increased considerably in recent decades. ${ }^{26} \mathrm{It}$ is also generally agreed that much of this is due to the positive correlation between trade and economic growth, with overall levels of poverty having been brought down and consumer welfare increased, with a far larger choice of products than ever before. ${ }^{27}$ At the same time, it should be admitted that the objective of ensuring full employment is a very challenging one, particularly with the current low levels of economic growth and high unemployment rates.

Looking back at the original expectations of the WTO, there now is a fairly stable, secure and predictable trading system with members mostly adhering to the rules. In case of alleged breaches of these rules, and contrary to the past, members now mostly resort to the new and strengthened dispute settlement system. ${ }^{28}$ Trade disputes are solved within the ambit of the system, rather than seeking alternative solutions outside the rule book, as was increasingly the case under the GATT system and which largely undermined the system itself. As was pointed out by Jackson, the weak dispute settlement provisions in the GATT were one of the main drivers for the creation of the new trading system. ${ }^{29}$ Scholars and policy makers now widely acknowledge that the Understanding on Rules and Procedures for the Settlement of Disputes, commonly referred to Dispute Settlement Understanding (DSU), is perhaps the single most important improvement of the system. ${ }^{30}$ Further, a total of over 500 disputes have been put before the WTO's Secretariat. The share of human and financial resources devoted to the DSU has increased to unprecedented levels and yet the Secretariat is facing great difficulties in meeting the deadlines established under the procedures.

\subsubsection{Structure and institutional set-up of the WTO}

\subsubsection{General institutional set-up}

The WTO Secretariat's headquarters are in Geneva. There are no office branches or external representatives. It is a fairly lean structure when compared with other international institutions and the importance of trade in the world economy (see Graph 2.1 below). It consists of some 700 staff, professional and support staff. The WTO Secretariat is headed by the Director General (DG), who is directly supported by his Cabinet, headed by the Chief of

26 This is evidenced in the yearly world trade reports of the WTO and will substantiated and analytically underpinned in following chapters, including Chapters 3 and 4.

27 This argument will be evidenced and substantiated in Chapter 5. Reference is made to WTO World Trade Report 2014, Trade and Development: recent trends and the role of the WTO, Geneva, October 2014.

28 Cf. the discussion on dispute settlement, function 3.

29 Jackson, 'Restructuring the GATT System'.

30 Van den Bossche and Zdouc, Law and Policy, p. 159-160, with specific references to statements made by high levels officials. 
Staff, and has a management of four Deputy Director Generals (DDGs), who are responsible for each division, providing technical expertise and providing services to the members. The WTO is what is generally referred to as 'member-driven', meaning that the Secretariat undertakes functions that are mandated by the members, who take the decisions. Pauwelyn notes that 'the WTO is also "member-driven" in the sense that unlike, for example, the EU institutions or even the International Monetary Fund (IMF) or World Bank (who have executive boards and majority decision-making rules), the WTO as an institution has little or no independent power to make law or take decisions without the consensus of all WTO members. 31 The members are thus in the driver's seat, with the Secretariat providing technical support, when and where requested. The Secretariat has no right of initiative. This is in contrast with the operation of many other international bodies and is increasingly perceived in some quarters as a weakness rather than strength particularly in a situation where there are few drivers or several drivers with different routes in mind. ${ }^{32}$

\section{GRAPH 2.1: Structure of the WTO secretariat}

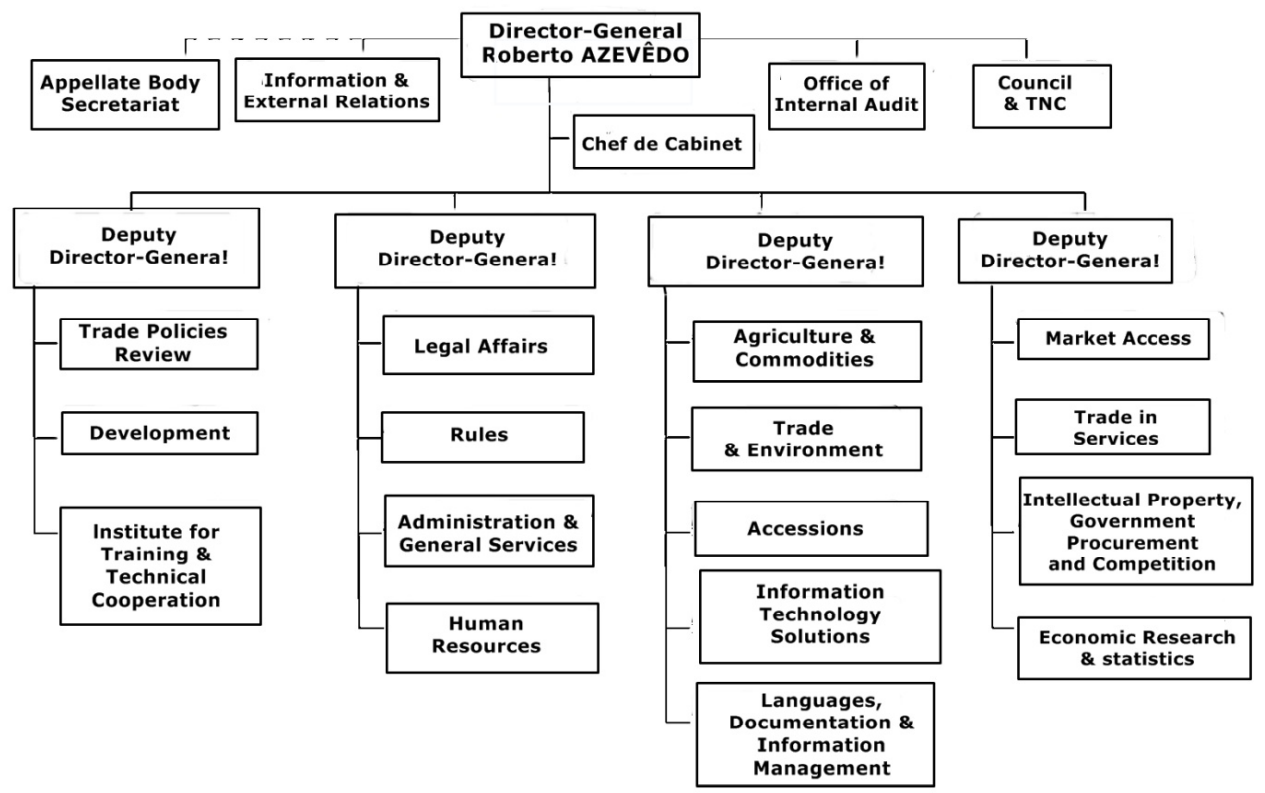

Source: WTO website http://intranet/en/about_wto/divisions/orgchart.htm, last viewed on 1 Dec. 2016.

The central pillar of the WTO structure is the Ministerial Conference (see Graph 2.2 below), which stands at the apex of the WTO and comprises all its members. As provided for

31 Cf. J. Pauwelyn, 'Sources of International Trade Law: Mantras and Controversies at the World Trade Organization', in S. Besson and J. Aspremont (eds.), Oxford Handbook on the Sources of International Law (Oxford University Press, 2016, forthcoming).

32 The OECD, IMF and the World Bank are headed by executives that have a right of initiative and power and mandate to take decisions. 
in the Marrakesh Agreement that established the WTO, the Ministerial Conference is convened at least once every two years. ${ }^{33}$ It carries out the functions of the WTO and takes actions necessary to that effect. It also has the authority to take decisions on all matters under any of the multilateral trade agreements. Institutionally, the decision to hold Ministerial Conferences at regular intervals represents a significant difference with the GATT, which had no equivalent body. ${ }^{34}$ During the GATT Ministers were convened on an ad hoc basis and mostly for launching or concluding trade negotiations. Having a Ministerial Conference every two years was considered an institutional necessity in order to give political direction at regular intervals and obtain commitment at the highest levels. Most if not all international organizations convene Ministerial Conferences at regular intervals and several, including the Bretton Woods Institutions (the World Bank and the International Monetary Fund) meet annually. Most of these meetings take stock of ongoing work, or adopt declarations that are essentially agreed prior to the meetings. This is an important difference with the WTO Ministerial Conferences, where Ministers are required to take important decisions, including on the critical aspects of negotiations, often at a stage where no agreement could be reached at the technical level. This represents a major risk for Ministers as well as for the WTO per se, as no outcome is guaranteed. The WTO has experienced this on many occasions and it has put the credibility of the system at risk.

33 Marrakesh Agreement, Article IV, which states that the Ministerial Conference 'shall meet at least once every two years.'

34 Under the GATT, the Contracting Parties would be convened at Ministerial level when so decided, but there was no institutional provision to that effect. The Ministers would mainly meet in relation to the rounds of trade negotiations. In practice, the General Council was the highest level of decision-making. See also E. Bohne, The World Trade Organization (International Institute of Administrative Sciences, 2010) for a detailed discussion on the structure and functioning of the WTO as a public organization. It offers theoretical and practitioner's views. 


\section{GRAPH 2.2: WTO structure}

\section{WTO structure}

All WTO members may participate in all councils, committees, etc, except Appellate Body, Dispute Settlement panels, and plurilateral committees.

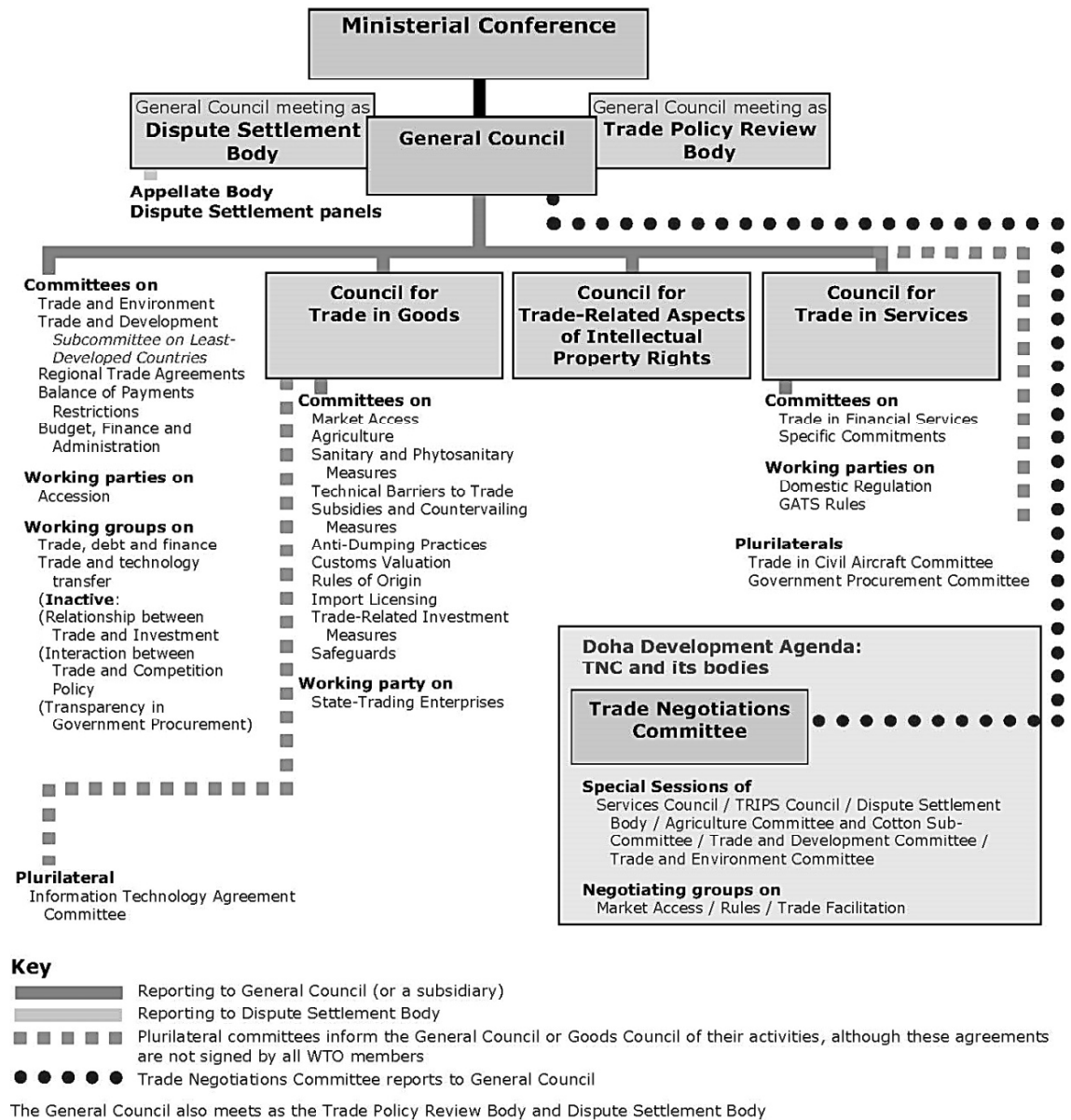

Source: WTO website https://www.wto.org/english/thewto_e/whatis_e/tif_e/org2_e.htm last viewed on 1 December 2016.

Given the biennial frequency of Ministerial Conferences the Marrakesh Agreement sets out that the General Council shall exercise its functions between the sessions, and this Council also comprises the full WTO membership. ${ }^{35}$ As a result it is in fact the General Council that exercises the day to day oversight of the work in the WTO. It supervises all aspects of WTO's work and meets as frequently as needed. Institutionally, the General Council also meets as the Dispute Settlement Body and as the Trade Policy Review Body

35 Marrakesh Agreement, art. IV(2). 
(TPRB) (see Graph 2.2 above). Both functions will be explained in more detail below in the context of the key functions of the WTO.

Institutionally and at the next level in the hierarchy there are several subsidiary bodies reporting to the General Council. ${ }^{36}$ These include three Councils that supervise work arising from the obligations which all member countries have assumed under the three pillars of the Marrakesh Agreement. The three pillars cover the agreement on trade in goods, trade in services and trade related aspects of intellectual property matters. The WTO has thus considerably expanded its coverage and well beyond trade in goods. Whereas the GATT only governed trade in goods, the WTO regulate services trade and aspects of intellectual property rights. This extension of the rules required a major rethinking of the rules and concepts covering trade, as trade transactions in services are fundamentally different from trade in goods. Equally, the GATT did not cover intellectual property rights, which are completely new to the WTO. How to design rules in those new areas and how to transpose the basic GATT principles to GATS and TRIPs were some of the challenging questions. Inserting these rules under the WTO umbrella required fundamental restructuring of the architecture of the multilateral trading system.

The new system thus has three main pillars which were legally translated into a new structure by the Marrakesh Agreement. These are the Council for Goods, technically responsible for all agreements and areas covered under Annex 1A, the Council for Services, responsible for the areas covered under Annex $1 \mathrm{~B}$ and the TRIPs Council, covering Annex 1 C. These Councils are chaired by the WTO members, including Ambassadors and senior government officials (Table 2.1) and meet as often as they deem fit. There is no prescribed frequency of meetings. Each of these Councils can decide to set up any subsidiary bodies if necessary, including specific Committees reporting to the Council. As a result many dedicated and specific committees and sub-committees have been set up under the various pillars in order to address any issues with regard to a specific agreement that the respective Committees oversee. These Committees mostly meet at expert level, often with officials from capitals and report to their respective Councils. The frequency of meetings depends on the Committee and they usually occur a few times per year.

The WTO structure contains other bodies reporting to the General Council but not to any of the three Councils, including the Committee on Trade and Development (CTD) ${ }^{37}$

36 For a discussion on the structure and functioning of the WTO, see also J. Jackson and S. Charnovitz, 'The Structure and Function of the World Trade Organization', in K. Heydon and S. Woolcock (eds.), The Ashgate Research Companion to International Trade Policy (Ashgate Publishing, 2012), p. 387-403.

37 The GATT Committee on Trade and Development was set up to supervise the application of Part IV (Articles XXXVI, XXXVII and XXXVIII) of the GATT. It pursues similar functions in the WTO, with a subcommittee on least developed countries (LDCs), and a primary focus on trade issues affecting developing countries. 
which covers development related areas, such as all aspects relating to trade capacity building, ${ }^{38}$ as well as other dedicated bodies (see Graph 2.2 above).

\section{TABLE 2.1: Chairpersons of the General Council and bodies reporting to it}

\section{(2016)}

\section{Council}

General Council

Dispute Settlement Body

Trade Policy Review Body

Council for Trade in Goods

Council for Trade in Services

Council for TRIPS

Committee on Trade and Development

Committee on Balance-of-Payments

Restrictions

Committee on Budget, Finance and

Administration

Committee on Trade and Environment

Committee on Regional Trade Agreements

Working Group on Trade, Debt and Finance

Working Group on Trade and Transfer of

Technology

\section{Chairperson}

H.E. Mr Harald Neple (Norway)

H.E. Mr Xavier Carim (South Africa)

Ms Irene B.K. Young (Hong Kong, China)

H.E. Mr. Hamish McCormick (Australia)

Excmo. Sr. Gustavo Miguel Vanerio Balbela (Uruguay)

H.E. Mr. Modest Jonathan Mero (Tanzania)

H.E. Mr. Christopher Onyanga Aparr (Uganda)

H.E. Mr. M. Shameem Ahsan (Bangladesh)

H.E. Mrs. Inga Ernstsone (Latvia)

Excmo. Sr. Héctor Casanueva (Chile)

H.E. Mr Daniel Blockert (Sweden)

H.E. Mr. Atanas Atanassov Paparizov (Bulgaria)

Excmo. Sr. Luis Enrique Chávez Basagoitia (Peru)

TABLE 2.2: Chairpersons of bodies established under the Trade Negotiations Committee (2016)

Council

Trade Negotiations Committee

Special Session of the Committee on

Agriculture

and Sub-Committee on Cotton

Special Session of the Council for Trade Ambassador Gabriel DUQUE (Colombia) in Services

Negotiating Group on Market Access

Special Session of the Council for TRIPS

Negotiating Group on

Rules

\section{Chairperson}

Director General Roberto Azevêdo

Ambassador Angelis VITALIS (New Zealand)

Ambassador Remigi WINZAP (Switzerland)

Ambassador Dacio CASTILLO (Honduras)

Ambassador Wayne McCook (Jamaica)

38 This will be discussed in Chapter 5 on 'Trade Capacity Building in the WTO.' 


\author{
Special Session of the \\ Ambassador Dr. Stephen KARAU (Kenya) \\ Dispute Settlement Body \\ Special Session of the \\ Ambassador Dr. Syed Tauqir SHAH(Pakistan) \\ Committee on Trade and Environment \\ Special Session of the Committee on Ambassador TAN Yee Woan (Singapore) \\ Trade and Development
}

Source: WTO website https://www.wto.org/english/thewto_e/secre_e/current_chairs_e.htm, last checked on 1 December 2016.

Separately, for the purposes of the negotiations conducted in the WTO, and in order to avoid a conflict with the regular work undertaken by the Secretariat and the negotiations, a Trade Negotiating Committee (TNC) was established to oversee the negotiating function of the WTO. While the TNC is chaired by the WTO's Director General, it is the members that decide on the course of action to take. The role of the Chair is mainly to drive the process and consult with the Chairs and the members. Its structure closely follows the existing WTO structure (see Graph 2.2 above). It also has subsidiary bodies which operate mostly in parallel to the existing bodies and are chaired by another group of high level officials mostly at Ambassadorial level (see Table 2.2 above). It is important to understand that the two processes work in parallel and the regular committee work is carried out independently from the negotiating process. What it shows however is that the work of the WTO has become much denser than in the GATT, given the sheer number of bodies covering a broader range of issues. This requires a tight management and good and efficient reporting lines.

\title{
2.2.2.2 Decision making
}

Decision-making is an important element in moving the process forward and advancing the trade agenda and the Marrakesh Agreement contains specific provisions to that effect. The first and most important observation is that all decisions are taken by the members and that explains why the WTO is referred to as a 'member-driven' organization. ${ }^{39}$ The WTO Agreement contains language on voting procedures, but in accordance with Article IX:1, it is decided that 'the practice of decision making by consensus followed under the GATT 1947 shall be continued' ${ }^{40}$ It is only when consensus cannot be reached that voting procedures can be applied. Each WTO member has one vote, irrespective of the size or economic weight of the country in the world economy. In practice, the WTO avoids voting and members aim at taking decisions by consensus. ${ }^{41}$ In accordance with footnote 1 to Article IX:1 of the WTO

39 Cf. Pauwelyn, 'Sources of International Trade Law'.

40 Marrakesh Agreement, art. IX.

41 Members want to stick to the principle of consensus. One explanation often provided is the fact that the majority of trading nations are developing and least developed countries, which by far outnumber the developed countries. At the same time, the developing members account for a smaller share in international trade and the developed countries, much fewer in numbers, pay the bulk of the WTO budget. The contributions to the WTO's budget are determined by the relative share of a member in international trade. 
Agreement consensus means that the 'body concerned shall be deemed to have reached consensus on a matter for its consideration, if no Member, present at the meeting when a decision is taken, formally objects to the proposed decision'. This is a key provision, as it allows for progress in a simple and light handed manner, with most decisions taken easily, unless there is opposition to the decision.

Given the importance that members attach to the consensus principle, they always seek to find consensus, even when there is a disagreement. On the few occasions that the consensus risked being undermined, it forced members to continue discussions to bridge the gaps and reach consensus. ${ }^{42} \mathrm{~A}$ most recent example is the division in positions between the members that had become apparent prior to MC-X (Nairobi) and affected the discussions at the Conference itself on the way forward for the DDA. As will be detailed further, a compromise in language was found, leading to a consensus and reflecting the divergence of views. The consensus approach has the very important advantage that decisions are supported by all members with no decisions being imposed against the will of the members (which removes the risk of non-implementation of the decisions). This approach implies a full buy-in and is part of the strength of the system.

The downside of the consensus approach is that it can block progress in the negotiations, undermining the system or at least creating some paralysis. This is what was witnessed in the course of the DDA, with members unable to agree on the way forward on agriculture and non-agriculture market access (NAMA), a lack of progress in discussions on the future trade agenda, as had been mandated by the Ministers at MC-IX (Bali) and so on. This is often seen as a reason for the larger trading nations to move forward outside the WTO, including at the regional and/or bilateral level, with the risk of creating parallel systems. This clearly is an area that warrants further attention and will be discussed further.

\subsubsection{The legalframework}

Turning to the legal framework of the WTO, the WTO Agreement consists of a short basic agreement (including 16 articles) and several specific agreements, which are given legal value through annexes attached to the WTO Agreement. On the relationship between the

Developed countries would presumably never accept being outvoted, particularly when it comes to essential national and economic interests, as well as the legally binding nature of decisions taken in the WTO.

42 One example illustrating a situation where it was hard to reach consensus and voting was considered, but not applied, was at the occasion of the election of the Director General in 2001, when members disagreed on the choice between Mr Mike Moore, a former Prime Minister of New Zealand and Dr P. Supachai, a former Prime Minister of Thailand. In order to avoid voting and not create a precedent, it was finally decided to appoint both for a period of 3 years each, instead of the normal term of 4 years, with Mr Moore assuming the first term. Another example is the Ministerial Conference held at Bali, MC IX, as the consensus that members had reached risked being undermined at the very last minute by a small group of countries that considered that they had not been sufficiently included in the negotiating process and threatened to jeopardize the outcome by putting their veto on the package, thus breaking the consensus. After another night of constructive engagement by the key players with those countries, this contentious issue was resolved, thus permitting the adoption of the Bali package, with nearly one day of delay. 
WTO Agreement and the agreements in the annexes as well as on the binding nature of the latter agreements, Article II of the WTO Agreement states that 'the agreements and associated legal instruments included in Annexes 1, 2 and 3 (hereinafter referred to as "Multilateral Trade Agreements") are integral parts of this Agreement'. Most of the substantive WTO law is found in the agreements contained in Annex 1 of the Marrakesh Agreement, which basically covers the goods area. It consists of three parts generally referred to as the three pillars: Annex 1A, which contains 13 multilateral agreements on trade in goods; Annex 1B, which contains the General Agreement on Trade in Services (GATS) and Annex $1 \mathrm{C}$, which contains the Agreement on Trade related Aspects of International Property Rights (the TRIPs Agreement).

The main features of the three pillars are as follows:

\section{(a) Trade in Goods (Annex 1A)}

The most important of the 13 multilateral trade agreements on trade in goods in Annex 1A is the GATT 1994, which in reality is an updated version of the original GATT. In other words, the GATT has legally been integrated into Annex 1A. The areas covered under the goods provisions include:

- The Agreement on Agriculture

- The Agreement on the Application of Sanitary and Phytosanitary Measures (SPS Agreement)

- The Agreement on Textiles and Clothing, which ceased to exist in 2005

- The Agreement on Technical Barriers to Trade (TBT Agreement)

- The Agreement on Trade Related Investment Measures (TRIMS Agreement)

- The Agreement on the Implementation of Article VI of the GATT 1994 (AntiDumping Agreement)

- The Agreement on the Implementation of Article VII of the GATT 1994 (Customs Valuation)

- The Agreement on Pre-shipment Inspection

- The Agreement on Rules of Origin

- The Agreement on Licensing Procedures

- The Agreement on Subsidies and Countervailing Duties

- The Agreement on Safeguards.

One could argue that one of the most significant new elements under the expanded provisions of the WTO rules relating to goods consists of the inclusion of the Agreement on Agriculture (hereafter Agriculture Agreement) together with the Agreement on Sanitary and Phytosanitary Measures (the SPS Agreement). ${ }^{43}$ The novelty in the SPS Agreement is that it explicitly requires a scientific basis and/or rationale to be provided when import

43 A detailed discussion and analysis of the provisions contained in the Agreement on Agriculture is provided in Chapter 4, as part of the Market Access provisions in the WTO. 
restrictions are taken, thus reducing the scope for taking arbitrary measures. It is worth remembering that the agriculture sector largely remained outside the scope of the GATT rules and has been one of the great problem areas in international trade. ${ }^{44}$ It was a sector with the highest levels of protectionism and distortive government policies, combining border measures, internal support policies, quantitative restrictions and export subsidies, distorting world market prices and leading to major distortions in world trade and inequalities in incomes. Market mechanisms hardly applied to this sector, which was riddled by world-wide restrictions, subsidies and quotas, leading to uncompetitive agricultural production at the expense of efficient producers and leading to excess production, over capacity and distortion of markets and market prices. In addition, under the GATT, the agriculture area has led to many unresolved disputes, which was mainly due to the lack of specific disciplines governing trade in agriculture, as well as the weak DSU provisions under the GATT system.

The Agriculture Agreement is the first in GATT history to explicitly codify trade in agriculture and introduces binding disciplines. Inserting agriculture into the disciplines of the WTO has been a technically complex process, as the sector was riddled by Non-Tariff Barriers (NTBs) and it was very hard to assess and quantify the protective effects of these measures and finding ways to address them in the negotiations. One of the main features of the Agreement and perhaps the key achievement is that it led to the elimination of NTBs in agriculture by converting them into tariff equivalents. ${ }^{45}$ This left the sector with a tariffs-only regime and following this process, the tariffs were subsequently reduced through negotiations and more specifically through the application of the Swiss formula. ${ }^{46}$ While the establishment of Agriculture Agreement did not result in liberalization per se, it explicitly provided the framework for doing so in the next phase. To this effect, the terms of the Agreement indicate that negotiations would be initiated no later than in the year $2000 .{ }^{47}$ Discussions on further liberalization in this sector were already under way well before and independently of the launch of the DDA, as had been mandated by the members. This reflected the deliberate will and commitment of the members to bring more economic efficiency and rationale in this area and liberalize trade in agriculture, an area that has traditionally been highly protected by trading nations.

With regard to the other agreements that emerged from Uruguay Round and that are part of the Marrakesh Agreement, the improvements provided often consisted of clarifications and refinements of existing GATT provisions in light of the experiences gained with the operation of the agreement. Most of these agreements had been in effect as a result

44 WTO Guide to the Uruguay Round Agreements, WTO (1998), p. 51-52.

45 Detailed insights are provided in Chapter 4 covering market access issues.

46 The Swiss formula will be explained in detail in Chapter 4 in the context of the discussions on the negotiations conducted and ways to achieve liberalisation. In short, the Swiss formula consists of a simple mathematical methodology to reduce tariffs in trade.

47 Agreement on Agriculture, Article 20, 1 January 2005, 1867 UNTS 410. A substantive discussion on the negotiations and the key issues are provided in Chapter 4. 
of earlier negotiating rounds, including the Tokyo Round ${ }^{48}$ and previously the Kennedy Round. ${ }^{49}$ Some agreements were negotiated providing specific rules in cases where it was proven that the GATT Agreement had provided insufficient guidance. This includes the agreement on customs valuation which explicitly introduced new provisions and calculations methods for establishing the value of a good, thus building on Article VII of the GATT, as well as the agreement on safeguards, clarifying the conditions under which safeguard measures can be taken and thus building on Article XIX of the GATT. In other cases, new agreements were drafted to cover areas that GATT did not cover, such as rules of origin, trade related investment measures (TRIMs) and the pre-shipment inspection measures. These agreements had been negotiated in view of the perceived necessity to update the rules based system in areas that had become of significant importance and where rules were lacking. The TRIMs Agreement was a first attempt to govern some investment measures in relation to trade, but did not touch upon investment. ${ }^{50}$ One noticeable exception is the agreement on textiles and clothing, which was a termination agreement leading to the full abolishment of restrictions (except tariffs) in trade in textiles and clothing. ${ }^{51}$

\section{(b) Trade in Services (Annex 1B)}

The rapidly increasing importance of services in world trade as an engine for economic growth became particularly apparent in the 1980s. Services are traded in their own right but are also increasingly incorporated in the manufacturing of goods. ${ }^{2}$ Hence, they were both supportive of and driving trade. Trade negotiators felt it to be of the utmost importance to establish multilaterally binding rules for trade in services in similar ways as that for goods. Given the specific features of services, which contrary to goods are intangible, establishing rules governing services presented main challenges. ${ }^{53}$ Nevertheless, negotiators managed to overcome these obstacles and with the conclusion of the Uruguay Round and the creation of the WTO, new disciplines in trade in services were established. According to Adlung, Mattoo, Marchetti and Mavroidis, this is undoubtedly amongst the most important

48 The Tokyo Round was the seventh round of trade negotiations conducted in the GATT, launched in 1973 and concluded in 1978. It resulted in a set of specific agreements, often referred to as 'Codes' mostly providing new and more detailed rules in areas that were already part of the GATT rule book.

49 The Kennedy Round was the sixth round of trade negotiations conducted in the GATT between 1966 and 1968.

50 As will be seen later, further attempts to include investment under the WTO rules failed.

51 The Agreement on Textiles and Clothing is a self-effacing Agreement which ceased to exist after a transition period of 10 years and will be discussed in Chapter 4 .

52 This was observed in the sectorial study that I prepared for the OECD with regard to automobiles: Globalisation of Industrial Activities: Sector Case Study of Globalisation in the Automobile Industry, OECD June 1993 (COM/DSTI/IND/TD(93)55). The literature on Global Value Chains discussed in Chapter 3 confirms the importance of services trade as an essential component in creating economic value in the production process.

53 In the GATS, services are defined according to the way they are provided. This is referred to as modes of delivery as discussed further. 
innovations of the multilateral trading system since the creation of the GATT in $1948 .{ }^{54}$ The negotiations resulted in a similar set of rules as the ones covering goods.

It is likely that the importance of including services in the WTO was not sufficiently stressed given the trends in international trade transactions, which are more and more services based. It is perhaps gaining even more importance in the context of Global Value Chains (GVCs), which increasingly are shaping international trade.55 According to Hoekman

if we account for the value added by services in the production of goods, we see that the service sector contributes over $50 \%$ of total exports in the United States, the United Kingdom, France, Germany and Italy and nearly one third in China, with a significant contribution across all manufactured goods, provided by both domestic and foreign service providers. ${ }^{56}$

The GATS covers most forms of services with the aim of creating as level a playing field and as much liberalization as possible, except for the non-tradable services, which are not covered. Given the very nature of services, which can be provided in different ways and are intangible, it was recognized that they cannot be treated in the same way as goods. Trade in goods is mostly regulated by tariffs, which are measurable and quantifiable. ${ }^{57}$ In contrast to goods, services are mostly governed by domestic policies and regulations, as opposed to border policies. This requires a different negotiating approach, covering regulatory issues, an area in which the WTO had no prior experience. The WTO entered uncharted waters, with members drafting an agreement combining the key principles and concepts of the GATT with regulations. The challenges in the services negotiations were perhaps even more significant, as services are so closely related to domestic policy regulations and part of governance. It is an area where governments tend to exercise much control. In the absence of a clear and simple definition of what constitutes a service, one of the main conceptual difficulties was to find coherent ways to establish rules and disciplines in this field.

54 R. Adlung, R. and A. Mattoo, 'The GATS', in A. Mattoo, R. M. Stern and G. Zanini (eds.), A Handbook of International Trade in Services, (Oxford University Press, 2007); J. A. Marchetti and P. C. Mavroidis 'What are the Main Challenges for the GATS Framework? Don't Talk About Revolution' in 15 European Business Organization Law Review (2004), p. 511-562, 2004; J. A. Marchetti and P. C. Mavroidis, 'The Genesis of the GATS', 22 European Journal of International Law (2011) p. 689-721, 2011; World Trade Organization, A Handbook on the GATS Agreement (Cambridge University Press, 2005).

55 The concept of Global Value Chains (GVCs) relate to a new way of measuring trade in terms of value added in each stage of processing and as explained in detail in Chapter 3.

56 B. Hoekman and S. Jackson, 'Shifting Focus in Trade Agreements - From Market Access to Value Chain Barriers', World Bank (2013) http://blogs.worldbank.org/trade/shifting-focus-in-trade-agreements-frommarket-access-to-value-chain-barriers.

57 The key features of tariffs and how they are reduced are analysed in Chapter 4. 
As it does for trade in goods, the GATS contains specific provisions on Most Favoured Nation (MFN) treatment, ${ }^{58}$ national treatment, ${ }^{59}$ transparency, market access, negotiation, schedules of specific commitments, developing countries, domestic regulation, recognition, emergency safeguard measures, dispute settlement, and also institutional issues. The GATS has several annexes which cover Article II exemptions (MFN), movement of natural persons and financial services. Schedules of Specific Commitments of all WTO members provide information on the members' market access and national treatment commitments and are also attached to the GATS, making them an integral part of it.

Although tariff schedules are established for trade in goods and tariffs are included in each of the members' Tariff Schedules, ${ }^{60}$ members agree to negotiate specific services commitments taking into account the various ways services can be carried out. This is what is mostly referred to as the 'modes of delivery' or 'modes of supply'. ${ }^{61}$ The schedules of commitments are treated similarly to tariff schedules for goods, with equivalent binding obligations.

As a result services are defined in accordance with the way they are carried out and the Agreement recognizes four modes of supply, which include:

Mode 1: Cross border supply, which refers to a situation where a service physically occurs over a border crossing, such as the delivery of a package by mail;

Mode 2: Consumption abroad, an example of which is a consumer going to another country to benefit from a service rendered in the other country (tourism, medical treatment);

Mode 3: Commercial presence, which actually requires a local presence in the other market (banks which need to have a subsidiary in another country in order to be allowed to operate in that market);

58 According to art. I, para. 1 of the GATT 1994, the Most Favoured Nation (MFN) Treatment means that 'with respect to customs duties and charges of any kind... any advantage, favour, privilege or immunity granted by any (Member) to any product originating in or destined for any other country shall be accorded immediately and unconditionally to the like product originating in or destined for the territories of all otherMembers'. See also van den Bossche and Zdouc, Law and Policy, for further reading, p. 317-348.

59 Article III of the GATT 1994 contains specific provisions prohibiting discrimination in the treatment of any product, domestic or imported, once it has entered the market. Accordingly, para. 4 states that:' the products of the territory of any (Member) imported into the territory of any other (Member) shall be accorded treatment no less favourable than that accorded to like products of national origin in respect of laws, regulations and requirements affecting their internal sale, offering for sale, purchase, transport, distribution or use.... For further reading, see also Van den Bossche and Zdouc, Law and Policy, p. 249-417.

60 According to Article II of the GATT, each GATT Contracting Party and now each WTO Member must have a Schedule of Concessions, which contains specific information on its tariffs. Article XVI of the GATS stipulates that each WTO Member must specify its market access conditions in a services schedule.

61 Marrakesh Agreement, art. I(3)(b). 
Mode 4: The presence of natural persons, which includes a situation where a contractor needs to send its specialized staff to the other market to deliver the service (one can think of the construction of a port, which requires foreign architects and technicians to go to the country where the port is built).

The essence of the GATS is the combination of rules that include multilateral binding obligations through the MFN principle and national treatment commitments, with specific commitments in services sectors per mode of supply and where the member is willing to make a commitment. A typical feature of the GATS is that only those sectors that are specifically submitted by WTO members for commitments are included in the schedules. As is noted by the WTO, 'the GATS schedules thus are a combination of a "positive list" of covered services with a "negative list" of scheduled measures'. ${ }^{62}$ In addition, under the aegis of the GATS, several sector specific agreements were negotiated, including on financial services, basic telecommunications and maritime transport, thus easing the rendering of services in those areas. ${ }^{63}$

It could be argued that overall GATS did not lead to much liberalization except in the field of financial services and basic telecommunications and has mostly led to a consolidation of the status quo through the services commitments. ${ }^{64}$ According to the WTO the "majority of commitments negotiated and scheduled in the Uruguay Round were in fact "standstill bindings", committing the country concerned only to maintain the current level of access; more liberalization took place in the 1997 negotiations on basic telecommunications and financial services'. ${ }^{65}$ It is to be recalled that according to the GATS and

in pursuance of the objectives of this Agreement Members shall enter into successive rounds of negotiations, beginning no later than five years from the date of entry into force of the WTO Agreement and periodically thereafter, with a view of achieving a progressively higher level of liberalization. ${ }^{66}$

It could even be argued that the liberalization in GATS has mostly resulted from members acceding to the WTO, as they are required to make significant services commitments covering a wide range of (sub-) sectors, adding to the liberalization of trade in services. ${ }^{67}$ It is noted that the commitments made by the recently acceded members (RAMs)

62 Special Studies 6: Market Access, Unfinished Business Post Uruguay Round Inventory and Issues, WTO (2001), p. 101.

63 Ibid., footnote 61, pages 458-462: Marrakesh Agreement; Decision on Financial Services; Decision on Negotiations on Maritime Transport Services: Decision on Negotiations on Basic Telecommunications; Fifth Protocol to the GATS, S/L/45, 3 December 1997; Reference Paper Negotiating Group on Basic Telecommunications, 24 April 1996.

64 The GATS provides for rules governing services trade and the framework for liberalisation.

65 Special Studies 6: Market Access, WTO, p. 103.

66 Marrakesh Agreement, art. XIX, p. 343.

67 A more detailed discussion on this point is provided in the section on the WTO's extended membership. 
tend to be more detailed and specific than the ones of the original WTO members. ${ }^{68}$ Many Article XII members have committed most services sectors.

The lack of progress in liberalization in services could explain the initiative taken by some members to advance the liberalization in services between like-minded countries and outside the WTO. Given the rapidly increasing importance of services in world trade, several leading services economies are now actively engaged in discussions on ways to effectively liberalize trade in services between themselves and outside the scope of the GATS, which has led to the initiative of the Trade in Services Agreement (TISA). ${ }^{69}$

Adding GATS to the rules of the WTO's multilateral trading system, even if it has not led to the liberalization initially envisaged, is significant in itself. One main reason is that trade in services has gained considerably in importance in world trade and as will be argued in the next chapter, services are more closely related to trade in goods than ever before. They are a determining factor in connecting to markets and linking to GVCs. A second reason is related to the fact that the GATS has considerably broadened the horizon for rule-making through 'behind the border' policies. Given the regulatory nature of the services commitments the spheres of trade policies have moved a step further from border policies to domestic regulations. Markets and economies are becoming increasingly interconnected, and so are the trade policies. The harmonization of rules and regulations between members and the mutual recognition of the policies of trading partners is increasingly important for easing trade flows.

\section{(c) Trade Related Aspects of Intellectual Property Rights (Annex 1C)}

The third pillar of the WTO system relates to the TRIPS Agreement (Annex 3). Institutionally it stands on equal footing with the goods and services pillars and has its own Council. The main objective of TRIPS is contained in the preamble, which refers to the need to 'reduce distortions and impediments to international trade, and taking into account the need to promote effective and adequate protection of intellectual property rights and to ensure that measures and procedures to enforce intellectual property rights do not themselves become barriers to legitimate trade' ${ }^{70}$

The objectives are specified further in Article 7, which, as stated by Taubman, Wager and Watal:

reflects the search for a balanced approach to IP protection in the societal interest, taking into account the interests of both producers and users. IP

68 WTO at Twenty: Challenges and Achievements, WTO (2015), p. 23-24.

69 The Trade in Services Agreement (TISA) will be discussed in Chapter 4 as a separate example analysing recent market access initiatives.

70 Marrakesh Agreement, Annex 1C: Agreement on Trade Related Aspects of Intellectual Property Rights, Preamble, p. 366. 
protection is expected to contribute not only to the promotion of technological innovation, but also to the transfer and dissemination of technology in a way that benefits both its producers and users and that respects a balance of rights and obligations, with the overall goal of promoting social and economic welfare. ${ }^{11}$

In other words, it aims to provide for an adequate and effective protection of intellectual property rights, so that the owners of these rights receive rewards for their creativity and inventiveness, and are thereby encouraged to continue their efforts to create and invent. The TRIPs Agreement covers a total of seven areas of intellectual property, including copyright, trademarks, geographical indications, industrial designs, patents, lay-out designs of integrated circuits and undisclosed information, which also includes trade secrets. For each of these areas, there are minimum standards of protection.

The TRIPS Agreement requires WTO members to have enforcement procedures and remedies to permit effective action against any act of infringement of the intellectual property rights, including civil and administrative procedures and remedies, provisional measures and criminal procedures. ${ }^{72}$ Pursuant to Article 3 and 4 of the TRIPS Agreement, each WTO member must accord other WTO members national treatment and MFN treatment, subject to a number of exceptions. The TRIPS Agreement frequently refers to, and incorporates by reference, provisions of other intellectual property agreements, such as the Paris Convention for the Protection of Industrial Property (1967), the Berne Convention for the Protection of Literary and Artistic Works (1971), the Rome Convention for the Protection of Performers, Producers of Phonograms and Broadcasting Organizations (1961), and the Washington Treaty on Intellectual Property in Respect of Integrated Circuits (1989), making provisions of these agreements applicable to all WTO members. ${ }^{73}$

The TRIPS Agreement has been under continuous review and since its creation has been expanded to incorporate specific decisions and recommendations in various fields. This has also occurred at the Ministerial Conferences.

One of the decisions is on electronic commerce, and at MC-X (Nairobi), Ministers agreed to 'continue the work under the Work Programme on Electronic Commerce ... based on the existing mandate and guidelines and on the basis of proposals submitted by Members in the relevant WTO bodies' and instructed the General Council to hold periodic reviews 'based on the reports that may be submitted by the WTO bodies entrusted with the implementation of the Work Programme and report to the next session of the Ministerial Conference'. In the meantime, 'Members will maintain the current practice of not imposing

71 A. Taubman, H. Wager and J. Watal, A Handbook on the WTO TRIPS Agreement (Cambridge University press, 2012), p. 13. See also Marrakesh Agreement, Annex 1C, Preamble, Article 7, p. 370.

72 Marrakesh Agreement, Annex 1C, Part III of the TRIPS, p. 387 and further.

73 Van den Bossche and Zdouc, Law and Policy, p. 960-961. 
customs duties on electronic transmissions until our next session which we have decided to hold in $2017,{ }^{74}$

Another concerns intellectual property: the TRIPS non-violation moratorium was once again extended by MC-X (Nairobi) until the next conference which is scheduled to be held in $2017 .{ }^{75}$

Pursuant to the Doha Declaration on the TRIPS Agreement and Public Health, the TRIPS Council also made a decision in 2002 to extend the transition period for certain obligations with respect to pharmaceutical products until 1 January $2016 .^{76}$ Under this decision, LDCs were exempted from protecting and enforcing patents and test data for health technologies and were only required to respect the non-discrimination principles enshrined in Articles 3, 4 and 5 of the TRIPS Agreement. The decision in 2002 did not include either a legally binding commitment or a political engagement on standstill. On 6 November 2015, the Council decided to further extend this transition period until 1 January 2033 or when a particular country ceases to be in the least developed category if that happens before 2033. ${ }^{77}$ Like the decision of 2002, this decision does not include a legally binding commitment or a political engagement on standstill.

Both of the decisions giving a general extension and the decision of 2002 on pharmaceutical products were taken pursuant to Article 66.1 of the TRIPS Agreement. However obligations to provide for 'mailbox' applications under Article 70.8 TRIPS Agreement and for exclusive marketing rights under Article 70.9 TRIPS Agreement continued to apply as none of those decisions exempted LDCs from complying with these obligations during the transition period. In 2002, the General Council therefore also adopted a waiver in respect of the obligations of LDC members to provide for exclusive marketing rights under Article 70.9 TRIPS Agreement which supplemented the decision of 2002. While LDC members availing themselves of the extended transition period were thus required to provide a 'mailbox' as foreseen by Article 70.8 TRIPS Agreement, if they did not already provide patent protection for pharmaceutical products, they were exempted from obligations in respect of exclusive marketing rights for such products under Article 70.9 TRIPS Agreement until 1 January 2016. ${ }^{78}$ To complement the TRIPS Council decision of 6 November 2015, the General Council also decided to extend the waiver to the otherwise applicable obligation to provide exclusive marketing rights for pharmaceutical products until 1 January 2033. It also added a new waiver of the obligation to provide for the possibility of filing mailbox applications until that date. ${ }^{79}$

\footnotetext{
$74 \mathrm{WT} / \mathrm{MIN}(15) / 42,21$ December 2015, WT/L/977.

75 WT/MIN(15)/41, 21 December 2015, WT/L/976.

762002 Decision, $\mathrm{IP} / \mathrm{C} / 25$.

772015 Decision, $\mathrm{IP} / \mathrm{C} / 73$.

$78 \mathrm{WT} / \mathrm{L} / 478$.

$79 \mathrm{WT} / \mathrm{L} / 971$.
} 


\subsubsection{The key functions of the WTO}

The WTO performs five specific key functions, as contained in Article III of the Marrakesh Agreement. They relate to multilateral trade agreements, the conduct of trade negotiations, dispute settlement, trade policy reviews and coherence in global economic policy-making. Van den Bossche and Zdouc ${ }^{80}$ refer to a sixth function which relates to technical assistance to developing country members, to allow a better integration into the world trading system, although this is not specifically mentioned in Article III. This aspect is indeed of critical importance to the membership, given the large number of developing countries in the system and will be given a standalone analysis in Chapter 5 , addressing developing country issues and more specifically trade capacity building in the WTO. A short discussion on what these five main functions consist of and how they are performed is provided as follows:

\subsubsection{Function 1: Facilitate the implementation of WTO Agreements}

The first main function of the WTO refers to one of the fundamental tasks of the WTO Secretariat: providing administrative and technical support to members in implementing the agreements. This is not fundamentally different from the GATT, which also accorded limited powers to the Director-General: his main responsibility consisted of leading the Secretariat. Blackhurst explains how the role of the Director-General differs from that of heads of other international organizations, given that the WTO is what is generally referred to as 'member driven': the members are in the lead and not the Director-General. ${ }^{81} \mathrm{He}$ argues that this is not necessarily a constraint as it makes the members directly accountable for all decisions, rather than the Secretariat. Included in the functions of the WTO are the coordination and administration of the agreements, providing support in their implementation, servicing the committee meetings, providing the Secretariat support to the committees, preparing technical notes and input to guide the discussions, conducting factual analysis, preparing reports on meetings and collecting the notifications and circulating them to members, in short, support functions, which are aimed at facilitating the operation of the agreements. Various authors have raised the question whether and how the role of the Secretariat and the DG should be reviewed and expanded in view of the evolving nature of the trading system and the responsibilities of the WTO. ${ }^{82}$ If so, what should be the role of the Director-General and what right of initiative and decision making should be granted? I will address this question again in Chapter 6.

80 Van den Bossche and Zdouc, Law and Policy, p. 85.

81 R. Blackhurst, 'The Role of the Director-General and the Secretariat', in A. Narlikar, M. Daunton, R. Stern (eds.), The Oxford Handbook on the World Trade Organization (Oxford University Press, Oxford, 2012), p. 141-160.

82 D. Steger, 'The Culture of the WTO: Why It Needs to Change?', 10 Journal of International Economic Law (2007), p. 483-495; T. Cottier, 'Preparing for Structural Reform in the WTO', 10 Journal of International Economic Law (2007), p. 497-508. 
Thus, the Secretariat provides the technical work in the various bodies and gives direct support to the chairmen of the bodies, preparing their briefings and background notes. It conducts most of the research and analysis for panel reports in dispute settlement cases and prepares the initial draft decisions to be taken by members in the committees, the General Council or Ministerial Conferences. It prepares, in close consultation with the chairpersons of the relevant bodies, the draft texts of the agreements in the negotiations, such as those on trade facilitation (Trade Facilitation Agreement, or TFA), agriculture and NAMA. It develops different scenarios and makes calculations for the members on the implications of the tariff reduction formula in the NAMA negotiations. The Secretariat assists in and facilitates the accession process of acceding members to the WTO. The Secretariat services the General Council Meetings, and also services the more technical and expert level committees, such as in the area of rules (anti-dumping, subsidies, safeguard measures), SPS Measures, TBT and services.

The WTO Secretariat experts are therefore the main actors behind the member-driven system, providing intellectual and administrative support, with the members remaining the ultimate decision makers. In order for this function to work, there needs to be a mutual trust and a strong and close interaction between the Secretariat and the members at all levels. This generally seems to be the case with members often expressing their gratitude to the Secretariat for the technical support provided and the quality of that support at the WTO meetings, including the expertise, knowledge and skills that are offered to members in the implementation of the Agreements.

\subsubsection{Function 2: Provide the forum for negotiations}

The second function, conducting negotiations is often considered to be the driving force behind trade liberalization, which was mainly achieved through rounds of trade negotiations in the GATT. A total of eight rounds of negotiations were conducted under the GATT. These rounds resulted in a major reduction in tariff protection as well as in reducing nontariff barriers. ${ }^{83}$ The same cannot be said for the WTO, with only one round having been launched in its 22 years of existence: the DDA, which is yet to be completed. Pursuant to the Ministerial Declaration in 2001, the DDA should have been concluded no later than 1 January 2005. ${ }^{84}$ This deadline and subsequent deadlines were not met and negotiations were prolonged. As will be discussed later, and given the outcome of the MC-X (Nairobi), whether and in what form the DDA will be concluded is now uncertain.

This thesis attempts to address some of the difficulties that members encounter in performing this key function. Looking back at the WTO since its creation, a total of 10

83 More insights are provided in Chapter 4, which explains how the average tariffs were reduced from close to $50 \%$ ad valorem duties on industrial products in developed countries at the time of the creation of the GATT, i.e. shortly after World War II, to less than 4\% following the conclusion of the Uruguay Round in 1994.

84 World Trade Organization, Doha Ministerial Declaration, 20 November 2001, WT/MIN(01)/DEC/1, para. 45 . 
Ministerial Conferences was held, including the MC-X (Nairobi). ${ }^{85}$ As the Ministerial Conferences reflect the highest level of the WTO's hierarchy, the decisions taken are of critical importance in giving direction to the negotiations. The record of the Ministerial Conferences in terms of results is mixed, with positive outcomes having been accomplished with great difficulty. This was yet again witnessed at MC-X (Nairobi), where the final declaration could only be adopted by Ministers following an extension of the discussions by one full day. ${ }^{86}$ The Ministerial Declaration confirms the divergence in views between members on the current status of the DDA and its future.

A short discussion of the history of the Ministerial Conferences confirms the challenges that the WTO faces in performing its negotiating function. At the MC-III (Seattle) held in 1999, the intention of Ministers was to launch the so-called Millennium Round. The Conference is mostly remembered for the violent demonstrations conducted by antiglobalization activists. No round was launched and the Conference did not lead to any specific outcome or decision. The outcome of the discussions at the MC-IV (Doha) in 2001 remained uncertain until late in the process and eventually led to a last minute agreement on the launching of the DDA. ${ }^{87} \mathrm{~A}$ few years later the MC-V (Cancún) in 2003 was prematurely aborted without agreement. The MC-VI (Hong Kong) in 2005 also featured strong and violent clashes between anti-liberalization activists and police, but nevertheless led to a last minute agreement following an extension of the negotiations, after the deadline. Some of the Ministerial Conferences held at the WTO's headquarters in Geneva were also seriously undermined by public demonstrations and violent actions against properties as well as against officials, but then and until most recently the perception of what the WTO stands for changed with a more favourable attitude. ${ }^{88}$ Nevertheless, the MC-IX (Bali) in 2013 yet again narrowly escaped failure following interventions at the highest political levels, with mainly a positive outcome in the field of Trade Facilitation. The MC-X (Nairobi) produced a last minute outcome and very much so against the odds, as will be seen later.

There are different factors explaining the difficulties experienced at these Ministerial Conferences. Many included negotiations on draft texts which could not be finalized or

85 The Bali Ministerial Conference is generally referred to as MC-IX. Results of the Conference are contained in WT/MIN(13)/DEC, 11 December 2013. It is noted that the venue for the Ministerial meetings is based on the proposals received from countries indicating their willingness to host the Ministerial Conference. MC-X was hosted by Kenya and took place in Nairobi 15-18 December 2015. Turkey had also offered Istanbul as the venue, but withdrew its application in favour of Kenya.

86 The Nairobi Ministerial Declaration, adopted on 19 December 2015, as contained in WT/MIN(15)/DEC, 21 December 2015.

87 It is often heard that the terror attacks on the twin towers in New York on 11 September 2001 played a significant role and triggered the political determination by world leaders to reach agreement at Doha.

88 It would seem that the efforts of the Secretariat to improve communication and have public debates and exchanges of ideas through the WTO public forum (held annually at the WTO) have resulted in greater appreciation of the key objectives of the WTO, what it stands for, and how all members stand to gain through an equitable process of trade liberalisation. This being said, more recently the anti-globalisation feelings are again on the rise in some corners, with its ramifications on the WTO and its policies. As will be argued later, this suggests that the efforts in communicating the benefits of trade need to be strengthened further. 
advanced sufficiently at the level of Ambassadors prior to the Conferences. The gaps in the negotiations were often so big on the technical side of issues that it was unreasonable to expect Ministers to bridge those gaps in very little time with political decisions and develop compromise solutions. And yet that is required in order to secure a positive outcome. According to the briefings provided by WTO's senior management prior to and following the conclusion of the Ministerial Meetings, as well as based on the feedback received by representatives of delegations and WTO members attending the meetings, and based on my own assessment and experience as a member of the WTO delegation to Ministerial Meetings, the main problem was largely rooted in the insufficient preparation in the lead up to the Conferences. Draft texts were often not sufficiently advanced to be presented to Ministers for their approval, thus requiring substantial negotiations on large portions of texts during the Ministerial Meetings. These observations are confirmed by Odell, who illustrates with examples in the negotiations how the preparatory process works and the difficulties encountered in reaching an agreed text by Ministers, when the draft text contains negotiated brackets, reflecting the various member positions. He argues that: ...'Because many delegations now saw their preferred language in an official text, moving toward agreement meant that many delegates would be required to give up something they felt had been achieved. This cautious tactic might have inadvertently encouraged delegates to dig in their heels.... ${ }^{\text {89 }}$

A second and closely related explanation is found in the way the negotiations are conducted. The experience shows that Members tend to take hard line positions, sticking to their positions, waiting for others to give in first, often showing little room for manoeuvre, keeping their cards close to their chest and perhaps for too long, thus compromising the outcome of the Conferences. While Ministers may have valid economic reasons for the positions they take, one should not lose sight of the fact that Ministers are politicians. Each of them receive a negotiating mandate, defend domestic interests and are required to justify the outcome of the negotiations before their national parliaments and constituency, to whom they are accountable. Ministerial interventions receive much public attention at home, at the domestic level. As the political lives of Ministers are largely determined by the extent to which they defend their domestic interests, they are inclined to stick to their positions and this makes compromises harder to achieve. All parties want to claim victory in the negotiations.

Furthermore, the rounds of trade negotiations have not only become increasingly complex, but more developing country stakeholders now take an active part in the negotiations as they are increasingly aware of the economic opportunities created through trade liberalization..$^{90}$ The more advanced developing countries increasingly take leadership roles, individually or collectively, and through the creation of coalitions. ${ }^{91}$ According to

89 J. Odell, 'How Should the WTO Launch and Negotiate a Future Round?', 14 World Trade Review (2015), p. 130.

$90 \quad$ To be discussed in Chapter 5.

91 In the next section further insights in the nature of the coalitions will be provided. 
Hopewell, China, India and Brazil have increasingly taken a lead role in the negotiations and in doing so they have challenged the traditional dominance of the United States. ${ }^{92}$ The three countries follow different paths, with China's dominance mainly being driven by its economic growth, and a more pronounced role in the shaping of the DDA's agenda. India and Brazil mainly played a leadership role in developing country coalitions. Gao confirms these observations by Hopewell, explaining and analysing the role China has played in the WTO since becoming a member. He notes that 'India and Brazil, two countries with much lower trade volumes, seem to command more power than China, at least during the first seven years after China's accession.' 93 According to Gao, the explanations provided are mainly related to the fact that both countries (India and Brazil) have a long history of working in the GATT. He argues that 'China seems, until very recently, to be uneasy with its newly acquired major player status and unsure how to use such power.'94 As I will argue further in my thesis, the growing influence of developing countries in the debates are undeniably a very positive development in itself, as the trading system becomes more inclusive than ever before. At the same time, the complexity of discussions obviously increases with the number of stakeholders, who often have different priorities and objectives in the negotiations. Wolfe argues that the WTO has not caught up with the shifting centre of gravity in global governance - he argues that 'when negotiators talk about rebalancing, it is not about EU/US, but rebalancing among India, Brazil and China. Members of the WTO have not caught up to this shift in the centre of gravity among developing countries, where the strongest among them must start to open up to the others. 95

In addition, governments are often under domestic pressure to maintain and/or preserve a certain domestic policy space, in order to achieve their domestic objectives of ensuring employment and growth. According to Wolfe, 'domestic factors always matter in trade negotiations. The domestic politics variable is frequently invoked by negotiators, academics and journalists in explaining Doha's difficulties. This factor can be hard to assess.' He observes that 'business support was not strong anywhere, which surely did not help, but that boredom was probably caused by Doha's difficulties rather than being causal in itself.96 These arguments show how the tension between members' desire to support the broader overall objective, including global trade liberalization, and protecting the legitimate domestic

92 K. Hopewell, 'Different Paths to Power: The Rise of Brazil, India and China at the World Trade Organization', 22 Review of International Political Economy (2015), p. 311.

93 H. Gao, 'From the Doha Round to the China Round, China's Growing Role in WTO Negotiations', in L. Toohey, C. Picker and J. Greenacre (eds.), China in the International Economic Order: New Directions and Changing Paradigms (Cambridge University Press, 2015), p. 96. See also M. Kahler, 'Rising Powers and Global Governance: Negotiating Change in a Resilient Status Quo', 89 International Affairs (2013) p. 711729.

94 Gao, p. 96-97.

95 R. Wolfe, 'First Diagnosis, Then Treat: What Ails the Doha Round?', European University Institute Working Papers (RSCAS 2013/85), p. 14.

$96 \quad$ Ibid., p. 4 and 6. 
policy interests make it a bigger challenge to establish the right balance in bringing the DDA to a conclusion. ${ }^{97}$

Directly related to this is the fact that each round of negotiations has become increasingly complex both in scope and issues to be covered as will be argued in later chapters. Whereas the earlier rounds of the GATT consisted of comparatively and relatively simple tariff negotiations for industrial goods and between a few dozen countries, often with similar economic developments and interests, the areas gradually expanded to include non-tariff measures, and later agriculture and services trade. Many of the issues are of a regulatory nature, including non-tariff measures and perhaps more importantly services trade and other areas are politically and economically very sensitive. Some areas (especially agriculture) have been and in many cases continue to be highly protected in most countries around the globe. The issues have become far more complex and at the same time the number of actors has rapidly increased with divergent levels of development and policy objectives. This again makes it harder to find common ground.

Then there is the issue of different levels of ambition with regard to expanding the rules to include new areas. Some members have long attempted and failed to update the WTO rulebook with a new generation of trade issues such as competition policy and investment policy. ${ }^{98}$ Some of these issues were again brought to the table at MC-X (Nairobi) and there was an opening to discuss other issues, which are likely to include trade and investment and trade completion policy, as will be explained further. Despite the resistance to a broader agenda, on the positive side agreement was reached on the Information Technology Agreement (ITA) and progress was made in the discussions on an agreement for environmentally friendly goods.

Reference was made earlier to the concept of 'Single Undertaking' which has been an important and fundamental guiding principle in the negotiations. The Single Undertaking principle effectively means that all areas of negotiations need to be addressed in parallel and no negotiations in one area can be concluded without agreement in the other area. Hence the outcome of the negotiations will be one entity, a single package. This principle was introduced to avoid a partial outcome in some areas, without agreement in other areas, which were considered more sensitive in the negotiations, such as agriculture and producing a balanced outcome, taking into account the many different demands. ${ }^{99}$ The underlying notion was to allow for the exchange of concessions between the various areas under

97 This tension became clearly apparent at MC-X (Bali) and in the aftermath of Bali in the spring and summer of 2014, with India strongly defending its rights to provide domestic subsidies in support of domestic food security. As a result, members could not endorse the protocol on Trade Facilitation by the set date of 31 July 2014, which led to a new stalemate in the DDA negotiations, and which was eventually overcome in autumn 2014.

98 The reasons for this failure will be discussed further below.

99 This argument was again advanced in the post Bali context, where some members insisted on linking the Trade Facilitation Agreement to the other areas, i.e. in line with the Single Undertaking Approach. 
negotiation in a horizontal manner. In reality this has not been translated into practice during the present negotiations. ${ }^{100}$ While the negotiations at times advanced more in one or the other area, no agreement could be reached in NAMA if no agreement was achieved in agriculture. ${ }^{101}$ Hence the Single Undertaking approach, which was meant to ensure a steady and parallel progress in all areas, can be considered at least in part responsible for the lack of progress in the DDA. Negotiators seemed unwilling to making further commitments in services or NAMA unless there was progress in agriculture, effectively holding up progress in the negotiations for many years. Hoekman and Mavroidis raise the question whether negotiators should stick to this approach, and whether there is room for more 'plurilateral' agreements, i.e. agreements applicable to members that sign up to the agreements, rather than being applicable to the entire membership, thus allowing for agreements to be negotiated that are only applicable to those members subscribing to them. They provide the arguments both in support and against plurilateral agreements, but come to the conclusion that there should be room for what is referred to a 'variable geometry' to be pursued under the umbrella of the WTO. ${ }^{102}$ As will be argued further, the Single Undertaking approach has gradually been abandoned over time and seems to have been given up at MC-X (Nairobi), with new partial agreements having been agreed. This view is underscored by Steger, who argues that 'the WTO has moved away from the single undertaking in several key decisions that have been taken since 1995.' 103 The examples she then provides include the information technology understanding and resulting commitments agreed in 1998, and the telecommunications reference paper agreed in 1997.104 As will be argued further, providing more flexibility in terms of negotiating plurilateral agreements between like-minded members and on specific topics could be beneficial to advancing the objective of achieving more trade liberalization and the outcome is not necessarily limited to the parties signing up to the agreement.

There have been many occasions on which the trade negotiators felt the need to secure the partial results obtained in the negotiations while maintaining the concept of Single Undertaking. The collective thinking led to the introduction of the concept of 'early harvest', meaning plucking the low hanging fruits, such as cash in the results in areas that were ripe for conclusion and continue negotiations in the other areas, where no agreement was reached. While this is a very tempting approach, one of the concerns was and to a large extent continues to be the case, that this would affect the overall balance of the outcome of the negotiations. At the same time it was felt that the only way to secure some progress was exactly by cashing in on early results and not waiting for the total package to come together. The concept found support at MC-IX (Bali) where members adopted the so-called 'Bali

100 The underlying idea was that a country having little economic interest in agriculture, would be able to exchange a concession in services, or IPR etc.

101 These two main critical areas will be analysed in Chapter 4.

102 B. Hoekman and P. Mavroidis, 'WTO “à la carte' ou menu du jour?”: Assessing the Case for More Plurilateral Agreement', 26 The European Journal of International Law (2015), p. 319-343.

103 Cf. Steger, p. 489.

104 Ibid. 
package', which includes agreements in some areas and not in the others. This concept was replicated at MC-X (Nairobi), with agreements reached in some sensitive areas including agriculture and more specifically on export subsidies.

The counterpart of the deal was to agree on a roadmap, designed to find acceptable ways on how to conclude the DDA negotiations in all the other remaining areas. According to the Ministerial Declaration agreed at MC-IX (Bali), a work programme needed to be established in 2014 on the way forward, but the process was delayed following unexpected obstacles in the final stages of establishing the TFA. ${ }^{105}$ A new deadline was fixed for July 2015, but was missed yet again. ${ }^{106}$ With the conclusion of MC-X (Nairobi), the roadmap may now be permanently off the table.

Compared to the WTO, the achievements of the GATT are far better as it has a solid record of successful rounds of trade negotiations, which have considerably liberalized trade and eliminated barriers to trade, both for tariffs and non-tariff barriers. The explanations for the achievements attained in GATT are likely related to the fact that the GATT counted fewer participants in the negotiations, and of those, most were like-minded, and who largely shared the same goals. In addition, the negotiations in the GATT largely focused on tariff reductions, which, as will be argued further, are much easier to address than many of todays' more complex and sensitive issues, which have emerged from the growing interdependency of markets and policies. The WTO has initiated only one trade negotiations round: the DDA which faces continued difficulties. Only one multilateral trade agreement was accomplished during MC-IX (Bali) - the TFA. ${ }^{107}$ Other agreements reached are of a plurilateral nature, including the ITA, but with the benefits of the agreement being extended to the entire membership, following the MFN principles.

As the WTO is member-driven, the role of the WTO's Secretariat is mainly limited to facilitating and servicing the negotiations, thus providing the technical support in the negotiations, preparing draft texts, developing scenarios and convening meetings with the membership. The Director General, in his capacity as the Chair of the TNC, has a leadership role and convenes meetings with the Chairs of the various negotiating bodies and with the membership to advance the process. ${ }^{108}$ His actions are in many ways decisive for the progress achieved. ${ }^{109}$

105 As will be explained further in Chapter 4, a new government was elected in India after MC-IX, which decided to take a hard line and contested some of the agreements reached at MC-IX by the previous government and more specifically with regard to food security. The result was that a new compromise solution had to be found acceptable to all the members. This took most of the year 2014. See also footnote 86 .

The initial deadline for this roadmap was set at MC-IX (Bali) for end of 2014, but the deadline was pushed back until July 2015.

107 Bali Ministerial Declaration, 11 December 2013, WT/MIN(13)/DEC. Adopted on 7 December 2013.

108 Cf. Blackhurst footnote 81;

109 This was particularly noticeable in the preparatory process of MC-IX (Bali) as well as during the conference at Bali itself. DG Azevêdo had accelerated the process of negotiations which were conducted around the clock in the final stages before Bali. The same pro-active stance was witnessed at Bali, with key Ministers 
The lack of progress in the negotiations raises two concerns. One relates to the systemic implications of an organization that does not deliver or perhaps only partially delivers on what many consider to be its key function, carrying out multilateral trade negotiations. This drives some members with higher levels of ambition to find solutions outside the system, including through regional trade agreements (RTAs). The second concern is equally important, given the general agreement that trade liberalization contributes in significant ways to the main objective of enhancing overall levels of welfare for the consumer. As will be shown in the following chapters, various international organizations, including the OECD and the World Bank as well as think tanks have calculated that the economic gains that could be obtained from the implementation of DDA amount to several billions. ${ }^{110}$ The absence of a conclusion of the DDA deprives the world economy from these considerable economic gains. Perhaps even more importantly, the poorest countries would stand to gain the most given their high dependency on international markets for the outlet of their products. This again underscores the urgency of reviving this second function of the WTO. The positive outcome of MC-X (Nairobi), even if limited in overall scope, is thus very encouraging as it not only secured the future of the WTO multilateral trading system, but offered new perspectives for advancing the negotiations in various areas.

\subsubsection{Function 3: Dispute Settlement}

The Dispute Settlement system in the WTO, as contained in the Dispute Settlement Understanding (DSU), is radically different from the GATT. ${ }^{111}$ It has been widely analysed in the literature and there seems to be a general agreement that the new DSU provisions are one of the most important elements of the WTO's multilateral trading system. According to Jackson and Charnovitz, 'It has been described as the most important and most powerful of any international law tribunals.....'112 Van den Bossche and Zdouc observe that the 'WTO dispute settlement system has been operational for eighteen years now. In that period it has arguably been the most prolific of all international state-to state dispute settlement systems'. ${ }^{113}$ In support of their argument, they refer to Claus-Dieter Ehlermann, a former Appellate Body Member and top EU official, who noted in 2003 that 'the successful negotiation of the DSU is an extraordinary achievement that comes close to a miracle'. ${ }^{114}$ Shaffer et al. discuss the historical development of the DSU and evaluate what they refer to

negotiating around the clock even until after the scheduled closing date and time set for the Conference in order to find solutions to unblock the negotiations. This positive result of the MC-IX at Bali is very much accredited to the negotiating style of Director General Azevêdo, who followed an open and all-inclusive process of negotiations.

110 G. Hufbauer et al., 'Payoff from the World Trade Agenda', Peterson Institute for International Economics, 2013.

111 Marrakesh Agreement, Annex 2: Understanding on Rules and Procedures Governing the Settlement of Disputes.

112 Cf. Jackson and Charnovitz, p. 394.

113 Van den Bossche and Zdouc, Law and Policy, p. 157

114 Ibid., p. 160; C.D. Ehlermann, 'Six Years on the Bench of the World Trade Court: Some Personal Experiences as Member of the Appellate Body of the World Trade Organization', 36 Journal of World Trade (2002), p. 639. 
as 'this move to law' and assess the operation of the WTO dispute settlement system in a political context across different governance stages. ${ }^{115}$ They observe that 'The WTO dispute settlement system represents a significant legalization of world politics, arguably the greatest amount of legalization that we know at the multilateral level. Yet the WTO dispute settlement system remains fragile. Its crown jewel, the Appellate Body, remains 'a young plant that need(s) protection". ${ }^{116}$

One of the weaknesses of the GATT became apparent in the 1980s: it no longer effectively solved trade disputes between the Contracting Parties, which started to undermine the system. As van den Bossche and Zdouc note,

the GATT 1947 contained only two brief provisions on dispute settlement (Articles XXII and XXIII), which neither explicitly referred to "dispute settlement" nor provided for detailed procedures to handle disputes. However, the Contracting Parties "transformed" in a highly pragmatic manner over a period of five decades, what was initially a rudimentary, power-based system for settling disputes through diplomatic negotiations into an elaborate, rules-based system for settling disputes through adjudication. ${ }^{117}$

In the view of the authors, this had worked very well until the 1980s, when one of the main shortcomings became apparent, namely that the findings and conclusions of the panels of experts adjudicating disputes only became legally binding when adopted by consensus by the GATT Council'. This meant that the responding party could prevent any unfavourable conclusions from becoming legally binding upon it and that is what increasingly started to happen. In other words, the system lacked the mechanisms to enforce the rights and obligations upon the members. Panel findings and reports could easily be blocked by the party negatively affected by its outcome and meant the recommendations would not be implemented. This in turn started to undermine the functioning and the credibility of the system.

Given the lack of enforcement of the legal system, the countries increasingly resorted to measures that fell outside the ambit of the rules of the multilateral trading system. This contributed to the undermining of the system. The measures resorted to were referred to as so-called 'grey area measures', which were often in conflict with the GATT provisions or fell outside the rules of the trading system. ${ }^{118}$ While quantitative restrictions are prohibited per

115 G. Shaffer, M. Elsig and S. Puig, 'The Law and Politics of WTO Dispute Settlement', University of California Legal Studies Research Paper (Series No. 2016-10) p. 1.

116 Ibid., p. 24.

117 Van den Bossche and Zdouc, Law and Policy p.159.

118 These were often referred to as Orderly Market arrangements (OMAs) and Voluntary Export Restraints (VERs), which were neither orderly nor voluntary, in addition to which they were economically most inefficient and disruptive and generating high economic cost to both the governments and consumers. See M. 
se under the GATT rules, in practice little could be done about them as they were presumably 'agreed' on a 'voluntary' basis. In reality they could hardly be voluntary and were accepted as a way to avoid tougher import restrictions. They were largely disguised import restrictions. Specific examples of such voluntary export restraints (VERs) are discussed in sectors studies prepared at the OECD on automobiles and semi-conductors. ${ }^{119}$ These two sectors were in many ways considered in the 1980s and early 1990s as illustrative for two sectors in which the VERs mostly prevailed. As the studies show, the use of these import restrictions contributed to the relocation of production facilities around the globe, a process that is now linked to the globalization of trade, and which will be analysed in the next chapter.

The GATT had thus operated well for many decades in terms of addressing trade disputes, but the lack of power to enforce the rules became apparent at a critical juncture in the 1980s, thus risking undermining the rules based system. The GATT could be compared with a 'toothless tiger', as the system had rules, but these rules could not effectively be applied and hence did not have any bite. These realities increasingly pointed at the need for a revamping of the rules based system. This required taking a fresh look at the dispute settlement provisions with a view to design more effective and enforceable rules. These objectives were accomplished with the adoption of the WTO agreement, of which the DSU is a central element (Annex 2 of the Marrakesh Agreement ${ }^{120}$ ).

According to Van den Bossche and Zdouc, 'the prompt settlement of disputes under the WTO Agreement is essential for the effective functioning of the WTO and maintaining a proper balance between the rights and obligations of Members'. ${ }^{121}$ According to Article 3.2 of the DSU, the 'Dispute Settlement System of the WTO is a central element in providing security and predictability to the multilateral trading system'. ${ }^{122}$ Thus, the WTO dispute settlement system of the WTO mainly serves the purpose of preserving a balance between the rights and obligations of members under the WTO agreements, as well as to clarify the provisions of those agreements.

The DSU provides a single set of rules to cover disputes that may arise under any element of the Uruguay Round package, namely the WTO itself, the GATT and all the agreements on trade in goods attached to it, and the GATS and TRIPS agreements. Compared to the GATT the new dispute settlement provisions are far more detailed, and provide for strict deadlines and approval procedures that will speed up the whole dispute

Smeets 'The Success of the Economic Dragons', 76 Economische Statistische Berichten (1991). A further discussion on VERs and OMAs is provided in Chapter 3.

119 M. Smeets 'Grey Area Measures: Automobiles and Semi-conductors', 6 International Economic Law Society (1993).

120 Annex 2: Understanding on Rules and procedures Governing the Settlement of Disputes, Marrakesh Agreement, WTO 1994.

121 van den Bossche and Zdouc, Law and Policy, p. 94.

122 Ibid; Article 3.2 DSU. 
settlement process and prevent it from being blocked. ${ }^{123}$ An appeals procedure has been introduced through the Appellate Body, as well as the possibility of compensating for injury in one sector of trade by taking action in another sector. ${ }^{124}$ In the new system there is no room for unilateral action and the multilateral process is assured.

The effective functioning of the system and the fact that disputes are now clearly within the ambit of the multilateral trading system is illustrated with data and statistics presented below. ${ }^{125}$ Since the creation of the WTO, a total number of 513 cases have been brought to the WTO for consultations up to December 2016 (Cf. Table 2.3). Most cases were brought in the early years following the creation of the WTO. According to the statistics provided by the WTO, 25 consultations were conducted in the first year of the existence of the WTO, peaking at 50 consultations in 1997. The logical explanation is that in the GATT contracting parties had become reluctant to bring new cases given the weak dispute settlement provisions contained in the GATT law. Hence the new system was tested early on. While the trend has declined from then onwards, other (relative) peaks occurred in 2002, with 37 consultations and 2012/2013, with 47 consultations over those two years. According to the WTO, the disputes have covered a wide range of WTO Agreements, with the largest number of cases having been brought under the GATT 1994, followed by anti-dumping disputes, subsidies, agriculture, TBT and SPS measures, safeguards, licensing, TRIPS, TRIMs and GATS.

\section{TABLE 2.3: Overall figures on disputes in the WTO (as of 1 December 2016)}

O Requests for consultations

O Mutually agreed solutions:

O Panels established:

O Panels composed:

O Panel reports adopted:

O Appellate Body reports adopted:

O Compliance panels:

- Appeals of compliance panels:

O Arbitrations on 'retaliation':

O Authorizations to 'retaliate':
513

112

$242 / 294$

$211 / 259$

167

108

31

22

21

20

Source: Data kindly provided to me by the WTO Legal Affairs Division on 1 December 2016.

123 As disputes affect trade, there is a cost implication for the parties, with foregone opportunities and economic losses, hence the importance to conclude a case rapidly and specific timelines established for the procedures, which according to Article 20 of the DSU should normally not exceed 12 months, in cases where the panel report is appealed.

124 According to Article 17 of the DSU, the Standing Appellate Body is established by the DSB and is composed of seven persons, three of whom shall serve on any one case.

125 The data presented here were provided by the Legal Affairs Division of the WTO, as contained in their statistics data base, and which can be found on the WTO's official website. 
The majority of cases were brought by the largest trading nations, EU and the United States, but increasingly a variety of developing countries are equally actively resorting to the DSU, including Brazil, Mexico, Argentina, India, Korea and China (Table 2.4). In fact, in the first year of operation half of the cases brought before the WTO were raised by developing countries. This was followed by a period in which most cases were raised by developed countries, but since the year 2000, the balance of number of cases raised by developing countries is mostly in favour of developing countries. The fact that the use of the DSU procedures is not limited to the developed countries, but the developing countries are equally and increasingly defending their rights in the system and resort to the DSU as a means to establish these rights confirms that the system is becoming truly universal in its application. The access to the DSU provisions by developing countries has been supported through the WTO's technical assistance programmes, thus allowing them to better gauge their rights and obligations. ${ }^{126}$ Furthermore the Advisory Centre on WTO Law (ACWL) was established, based in Geneva, and is funded mainly by developed donors, with the specific purpose to provide legal support and advice to developing countries and at more reasonable rates. Hence there is a commitment by the membership as a whole to make the DSU more widely accessible.

The data in Table 2.3 show that many of the cases have been solved at an early stage through the consultation process, which occurred in nearly one quarter of cases, as mutually agreed solutions were found. In half of the cases panels were established, which then followed the regular DSU procedures. It is noted that in a number of cases panels addressed issues that had been raised by several members, which effectively meant that the number of panels established can be and actually is lower than the number of disputes.

Equally, the review procedures, through the Appellate Body, have been applied extensively. The Appellate Body is a standing body composed of seven persons (three of them serve on any one case) of recognized authority, with demonstrated expertise in law, international trade and the subject matter of the covered agreements generally, and they shall be unaffiliated with any government. According to its mandate, Article 17 DSU, its work is to hear appeals from panel cases, limited to issues of law covered in the panel report and legal interpretations developed by the panel. ${ }^{127}$ The Appellate Body may uphold, modify or reverse the legal findings and conclusion of the panel. The proceedings shall not exceed 60 days, and the maximum is 90 days. In the majority of the cases that were appealed, the Appellate Body modified the findings (over $80 \%$ ) and in a relatively small number of cases the findings were upheld. As to the composition of panels, according to the Secretariat, in two-thirds of the cases the Director General had to intervene in accordance with the DSU

\footnotetext{
126 Article 27 of the DSU and more specifically arts. 27.2 and 27.3 contain provisions on the technical support and legal advice to be provided to developing countries.

127 Article 17 of the DSU. Appeals can only be requested by the parties to the dispute, and not by third parties.
} 
procedures $^{128}$ and in order to compose the panels. Only in a third of the cases was the composition agreed by the parties themselves.

TABLE 2.4: Most frequent complainants/respondents

\begin{tabular}{|l|c|l|c|}
\hline \multicolumn{1}{|c|}{ Member } & No of cases initiated & Member & No of cases defended \\
\hline US & 108 & US & 124 \\
\hline EC / EU & 97 & EC / EU & 97 \\
\hline Canada & 34 & China & 34 \\
\hline Brazil & 27 & India & 22 \\
\hline Mexico & 23 & Argentina & 18 \\
\hline India & 21 & Canada & 15 \\
\hline Argentina & 20 & Japan & 16 \\
\hline Japan & 21 & Brazil & 14 \\
\hline Korea & 17 & Mexico & 15 \\
\hline Thailand & 13 & Korea & 22 \\
\hline
\end{tabular}

Source: Data kindly provided to me by the WTO Legal Affairs Division on 1 December 2016.

Based on the data presented, it can be concluded that the DSU is performing its function. In a way, the DSU is a victim of its success, given the frequency of disputes and panels which are all serviced by the WTO's Secretariat and put much pressure on the its human and financial resources. It not only involves the lawyers in the Legal Affairs Division, but increasingly the technical and legal experts from other divisions. Their specific knowledge of and expertise in the Agreements is mostly required in the panel proceedings. The servicing of the panels is very time consuming and comes in addition to the responsibilities of the same officials servicing the committees. With the increase in panel related work, the WTO is gradually turning into more of a legal body.

Despite the success of the DSU, Pauwelyn raises some questions for further research. He argues that 'even though the mantras of WTO dispute settlement, treaty-based and memberdriven, are straightforward, after twenty years of WTO operation the questions of who can make WTO-relevant legal norms, where and in what form remain major controversies.'129

128 Article 8.7 of the DSU foresees that if the parties cannot agree on the composition of the panels within a set time-frame, the Director General will use his prerogative to appoint the panellists.

129 Cf. footnote 31. 
He then raises three questions that, according to him merit further attention and research, including whether the WTO should open-up more or less to sources of international law outside the WTO covered agreements? What is the appropriate role of the Appellate Body? And what has been the impact of consensus decision-making in WTO rule making for the dispute settlement branch of the WTO?

\subsubsection{Function 4: The Trade Policy Review Mechanism}

One of the key principles of the GATT/WTO system is enhancing transparency and strengthening monitoring and surveillance. This can be achieved in various ways and through different mechanisms, including the notification procedures, which require governments to render public by way of notifications any laws, regulations and practices that are introduced or changed. More fundamentally, transparency is achieved through the regular conduct of reviews of members' trade policies and regulations, namely the entire system as it is, in each of the WTO members. This function is performed under the WTO's Trade Policy Review Mechanism (TPRM), which 'enables the regular collective appreciation and evaluation of the full range of individual Members' trade policies and practices and their impact on the functioning of the multilateral trading system'. ${ }^{130}$ The TPRM is a direct result of the Uruguay Round negotiations and was already put into effect 'on an interim basis' in 1989, 131 before its conclusion, following the 'mid-term review' of the negotiations conducted by ministers in Montreal in $1988 .{ }^{132}$ In a way it was an early harvest of the Uruguay Round and it became permanent with the conclusion of the Round. ${ }^{133}$

The main purpose of the TPRM is: (i) to achieve greater transparency in, and understanding of, the trade policies and practices of Members; and (ii) to contribute to improved adherence by all members with their WTO obligations. ${ }^{134}$ As the meaning of 'adherence' can been understood in different ways, it is established and clearly understood that the TPRM is neither a substitute for dispute settlement procedures nor not an enforcement mechanism. ${ }^{135}$ This means that any measure found to be in conflict with WTO law cannot be challenged through the TPRM: a separate track under the DSU would have to be followed. The reviews provide an opportunity for a country under review to gain the

130 Marrakesh Agreement, Annex 3A(i), p. 434.

131 J. Francois, 'Maximizing the Benefits of the Trade Policy Review Mechanism for Developing Countries', Tinbergen Institute and CEPR (February, 1999), p. 2. See also J. Francois, 'Trade Policy Transparency and Investor Confidence: Some Implications for an Effective Trade Policy Review Mechanism', 9 Review of International Economics (2001), p. 303-316.

132 The Uruguay Round had been scheduled to be concluded in 1990, which explains the mid-term review conducted in 1988.

133 For a detailed discussion on the establishment of the TPRM, see P. Mavroidis, 'Surveillance Schemes: The GATT's New Trade Policy Review Mechanism', 13 Michigan Journal of International Law (1991-1992), p.374-414.

134 'The Results of the Uruguay Round of Multilateral Trade Negotiations', Marrakesh Agreement Establishing the World Trade Organization, Annex 3A(i), 'Objectives', p. 434.

135 Ibid., 'it is not however, intended to serve as a basis for the enforcement of specific obligations under the Agreements or for dispute settlement procedures, or to impose new policy commitments on Members'. 
understanding of other members for problems it is facing and to explain how its trade policies relate to broader economic growth and development plans. Thus, in addition to enhancing transparency, the TPR mechanism aims to ensure a better and fuller compliance and good governance.

According to the TPR provisions, all WTO members are subject to a regular review, albeit at different frequencies. The four largest developed economies, according to their share in world trade in a representative period, are reviewed every two years (the European Union, United States, Japan and China ${ }^{136}$ ) followed by the 16 next largest developed countries that are reviewed every four years. All other members are reviewed every six years, including the LDCs, unless decided otherwise by the TPRB. As will be discussed further the cycle was adjusted in 2016. According to Francois the TPR has main benefits for developing countries, including the improved monitoring of trading partner commitments under the various WTO agreements and the credibility of domestic policy reform and how such reform is viewed by domestic and international investors. ${ }^{137}$

The reviews are always based on two reports, one of which is drafted by the Secretariat and one by the reviewed member. The Secretariat's report is based on publicly available information and with data provided by the member under review and complemented with information provided in the discussions during the country visits. The other report is prepared by the member and includes a description of the member's trade policies and practices. The reports, together with the concluding remarks by the TPRB Chairperson and the minutes of the meeting are published by the Secretariat and rendered public, thus ensuring full transparency. The information comes directly to the benefit of the policy makers and business community in the country and is relevant for potential exporters who need to be informed about the laws and regulations in place in the country they want to export to. It is also beneficial to scholars and academics, all of whom can explore that data and put the information to use.

Laird explains that there has been some debate in the literature concerning the objectives of the TPRM and the importance of the mechanism as part of the enforcement of GATT/WTO legal obligations and presents the different views. ${ }^{138}$ Qureshi observes that '... on the question posed whether the TPRM constitutes an exercise in transparency or enforcement, there is, in fact, a prior question, namely whether the dichotomy between transparency and enforcement, implicit in the question exists at all. There is no dichotomy if enforcement is understood in its wider sense. This transparency is a pre-condition, an aspect, and a facet of the enforcement function. In theory it has been pointed out that the TPRM has elements which are conducive to this function. In the narrow sense of enforcement, the

136 Following its accession to the WTO, and given its place in world trade, China was added to the category of countries undergoing a biennial review, replacing Canada.

137 Cf. Francois footnote 131.

138 S. Laird; 'The WTO's Trade Policy Review Mechanism - From Through the Looking Glass', 22 The World Economy (1999), p. 742. 
question can be meaningfully posed. In that context the answer is, of course, that the TPRM is not an exercise in such enforcement but is, in theory at any rate, an exercise in transparency. ${ }^{139}$ In his view, 'the mechanism was specifically considered by some contracting parties as providing symmetry in GATT surveillance by focusing particularly on the major trading contracting parties with a significant impact on the multilateral trading system.' ${ }^{140}$ Chaisse and Chakraborty analysed whether there is any relation between the findings emerging from the TPR and the outcomes of cases presented through the Dispute Settlement Body. ${ }^{141}$ Their research leads to the conclusion 'that the TPR puts pressure on a government at the end of the consultation....'142 They then note that ...'it intervenes before the dispute resolution, as an attempt to avoid any litigation with a combination of consultation and negotiation.' ${ }^{143}$

Conzelmann addresses the question 'of whether, under which organizational conditions, and through which mechanisms soft compliance instruments can contribute to rule adherence. ${ }^{144} \mathrm{He}$ finds that ...'there is as yet considerable debate concerning the functions the instrument fulfils within the broader WTO context and its overall significance for increased rule adherence.' ${ }^{145} \mathrm{He}$ notes that ...'the TPRM shows certain institutional features making a rationalist compliance logic more possible, but cannot prove that this logic is solely or even predominantly responsible for any instances of increased rule adherence that may be attributed to the TPRM.'146 In a later work, Conzelmann compares the peer review mechanisms operated by three different international organizations, including the WTO, the African Union and the Organization for Economic Cooperation and Development, with particular emphasis on the role of non-state actors. His analysis leads to the findings that '.... Peer reviewing procedures have become a significant aspect of global governance. While they are 'soft' instruments which have few direct consequences for state autonomy, they hold the potential to democratize the assessment of policy performance and many undermine

139 A. H. Qureshi, 'The New GATT Trade Policy Review Mechanism: An Exercise in Transparency or "Enforcement'”, 24 Journal of World Trade (1990), p. 159. See also A. Qureshi, 'Some Reflections on the GATT TPRM, in the Light of the Trade Policy Review of the European Communities - A Legal Perspective', 26 Journal of World Trade (1992), p. 103-120; R. Abbott:, 'GATT and the Trade Policy Review Mechanism', 27 Journal of World Trade (1993), p.117-119.

140 Qureshi, 'The New GATT Trade Policy Review Mechanism', p. 148.

141 J. Chaisse and D. Chakraborty, 'Implementing WTO Rules Through Negotiations and Sanction: The Role of Trade Policy Review Mechanism and Dispute Settlement System', 28 University of Pennsylvania Journal of International Economic Law (2007), p. 153-187

142 Qureshi, 'The New GATT', p.179.

143 Ibid.

144 T. Conzelmann, 'Beyond the Carrot and the Stick: (How) Do State Reporting Procedures Matter?', paper for presentation at ECPR Uppsala Joint Sessions, 13-18 April 2004, p. 3. See also T. Conzelmann: 'Beyond the Carrot and the Stick: How Effective are State Reporting Procedures in the WTO and OECD?', paper presented at the International Studies Association meeting, Chicago, IL, 28 February-4 March 2007, offering a detailed analysis of the peer review mechanisms in the OECD and the WTO and their effectiveness in influencing policy behaviour.

145 Ibid., p. 20.

146 Ibid. 
states' capacity to give direction autonomously to domestic policy. It is however, an empirical question whether and to what extent peer reviews actually manage to be successful on these accounts.....international bureaucracies and civil society organizations can play a key role in this respect, in particular through structuring information, monitoring performance and in legitimizing or enacting public pressure on states whose conduct is found to be wanting.' 147

The TPR is now well embedded in the WTO and with a solid track record. A total of 452 reviews were conducted over the last 27 years (1989-2016), covering all regions and a total of 31 out of 34 LDCs were reviewed (see Table 2.5 below).

TABLE 2.5: Trade Policy Reviews - WTO members reviewed,

1989-2016

\begin{tabular}{|c|c|c|c|}
\hline $\begin{array}{l}\text { Europe/ } \\
\text { Middle East }\end{array}$ & $\begin{array}{l}\text { Asia/ } \\
\text { Pacific }\end{array}$ & Africa & America \\
\hline Albania (2) & Australia (7) & Angola $^{\mathrm{b}}(2)$ & Argentina (4) \\
\hline Armenia & Bangladesh $^{\mathrm{b}}(4)$ & Benin $^{b, 2}(3)$ & Antigua and Barbuda² (3) \\
\hline Austria $^{1}$ & Brunei Darussalam (3) & Botswana $^{2}(4)$ & Barbados (3) \\
\hline $\begin{array}{l}\text { Bahrain, Kingdom of }{ }^{2} \\
\text { (3) }\end{array}$ & Cambodiab $^{\mathrm{b}}$ & Burkina Fasob, 2 (3) & Belize (2) \\
\hline Bulgaria $^{1}$ & China (6) & Burundi $^{\mathrm{b}, 2}(2)$ & $\begin{array}{l}\text { Bolivia, Plurinational State of } \\
\text { (3) }\end{array}$ \\
\hline Croatia $^{1}$ & Fiji (3) & Cape Verde & Brazil (6) \\
\hline Cyprus $^{1}$ & & Cameroon $^{2}(4)$ & Canada (10) \\
\hline Czech Republic ${ }^{1}(2)$ & Hong Kong, China (7) & $\begin{array}{l}\text { Central African Republic }{ }^{b, 2} \\
\text { (2) }\end{array}$ & Chile (5) \\
\hline European Union (12) & India (6) & $\operatorname{Chad}^{\mathrm{b}, 2}(2)$ & Colombia (4) \\
\hline Finland $^{1}$ & Indonesia (6) & $\begin{array}{l}\text { Congo, the Democratic } \\
\text { Republic of }{ }^{b}(2)\end{array}$ & Costa Rica (4) \\
\hline \multicolumn{4}{|l|}{ Georgia (2) } \\
\hline Hungary $^{1}(2)$ & Japan (12) & Congo, Republic of ${ }^{2}(2)$ & $\operatorname{Dominica}^{2}(3)$ \\
\hline Iceland (4) & Korea, Rep. of (7) & Côte d'Ivoire (2) & Dominican Republic (4) \\
\hline Israel (4) & Kyrgyz Republic (2) & Djibouti $^{\mathrm{b}, 2}(2)$ & Ecuador (2) \\
\hline Jordan (2) & Macao, China (4) & Egypt (3) & El Salvador (4) \\
\hline Kuwait, the State of & Malaysia (6) & Gabon$^{2}(3)$ & Guatemala (3) \\
\hline Liechtenstein $^{2}(4)$ & Maldives (3) & The Gambiab ${ }^{\mathrm{b}}(2)$ & Grenada $^{2}(3)$ \\
\hline Moldova, Rep. of & Mongolia (2) & Ghana (4) & Guyana (3) \\
\hline
\end{tabular}

147 T. Conzelmann, 'Reporting and Peer Review in the Implementation of International Rules: What Role for Non-State Actors?'; in B. Reinalda, (ed.), The Ashgate Research Companion to Non-State Actors (Radboud University Nijmegen, 2011), p. 331. 


\begin{tabular}{|c|c|c|c|}
\hline Norway (6) & Myanmarb & Guinea, Republic of ${ }^{\mathrm{b}}(3)$ & Haitib $^{(2)}$ \\
\hline $\operatorname{Oman}^{2}(2)$ & Nepalb & Guinea-Bissau ${ }^{\mathrm{b}}$ & Honduras (3) \\
\hline Poland ${ }^{1}(2)$ & New Zealand (5) & $\operatorname{Kenya}^{2}(4)$ & Jamaica (3) \\
\hline $\operatorname{Qatar}^{2}(2)$ & Pakistan (4) & Lesotho $^{\mathrm{b}, 2}$ (4) & Mexico (5) \\
\hline Romania $^{1}(3)$ & Papua New Guinea (2) & Madagascarb (3) & Nicaragua (3) \\
\hline $\begin{array}{l}\text { Russian Federation }{ }^{\mathrm{a}} \\
\text { Saudi Arabia, Kingdom } \\
\text { of (2) }\end{array}$ & Philippines (4) & Malawib (3) & Panama (2) \\
\hline Slovak Republic ${ }^{1}(2)$ & Singapore (7) & $\operatorname{Malib}^{1}, 2(3)$ & Paraguay (3) \\
\hline Slovenia $^{1}$ & Solomon Islands $\mathrm{b}$ (3) & Mauritania $^{\mathrm{b}}(2)$ & Peru (4) \\
\hline Sweden $^{1}(2)$ & Sri Lanka (4) & Mauritius $^{2}$ (4) & St. Kitts and Nevis ${ }^{2}(3)$ \\
\hline Switzerland $^{2}(6)$ & Chinese Taipei (3) & Morocco (5) & St. $\operatorname{Lucia}^{2}(3)$ \\
\hline The FYR of Macedonia & Thailand (7) & 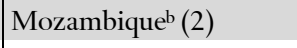 & St. Vincent \& Grenadines ${ }^{2}(3)$ \\
\hline Turkey (6) & Tonga & Namibia $^{2}(4)$ & Suriname (2) \\
\hline \multirow{13}{*}{$\begin{array}{l}\text { Ukraine }^{\mathrm{a}} \\
\text { United Arab Emirates } \\
\text { (2) }\end{array}$} & Vietnam & $\operatorname{Niger}^{\mathrm{b}, 2}(2)$ & Trinidad and Tobago (3) \\
\hline & & Nigeria (4) & United States of America (13) \\
\hline & & $\operatorname{Rwanda}^{\mathrm{b}}(2)$ & Uruguay (4) \\
\hline & & Senegal ${ }^{b, 2}(3)$ & $\begin{array}{l}\text { Venezuela, Bolivarian Rep. of } \\
\text { (2) }\end{array}$ \\
\hline & & Sierra Leone ${ }^{b}$ & \\
\hline & & South Africa ${ }^{2}$ (5) & \\
\hline & & Swaziland ${ }^{2}(4)$ & \\
\hline & & $\operatorname{Tanzania}^{\mathrm{b}, 2}(4)$ & \\
\hline & & $\operatorname{Togo}^{\mathrm{b}}(3)$ & \\
\hline & & Tunisia (2) & \\
\hline & & Uganda $^{\mathrm{b}, 2}(4)$ & \\
\hline & & Zambia $^{\mathrm{b}}(4)$ & \\
\hline & & Zimbabwe (2) & \\
\hline $\begin{array}{l}49 \text { Members } \\
\text { (85 reviews) }\end{array}$ & $\begin{array}{l}29 \text { Members } \\
(122 \text { reviews })\end{array}$ & $\begin{array}{l}42 \text { Members } \\
(121 \text { reviews })\end{array}$ & $\begin{array}{l}33 \text { Members } \\
(124 \text { reviews })\end{array}$ \\
\hline
\end{tabular}

Source: Trade Policy Review Mechanism, Report of the Trade Policy Review Body for 2016, Document WT/TPR/387, 7 November 2016, Annex 1.

The parentheses indicate the number of reviews completed (where this is greater than one).

a First review in 2016

b Least developed member

$1 \quad$ Now included in European Union (EU-28)

2 Joint review but counted as individual members for statistical purposes from 2009. 


$\begin{array}{ll}\text { Reviews conducted at end of } 2016 & =452 \text { reviews at } 345 \text { TPRB meetings } \\ \text { WTO members reviewed } & =153 \text { out of } 164 \text { Members } \\ \text { Least Developed WTO members reviewed } & =31 \text { out of } 36\end{array}$

The TPR process has evolved considerably with time and new elements have been introduced in the analysis, taking into account the rapid evolution of the trading system. Zahrnt takes a critical look at the original objectives of the TPR and how the process has evolved. ${ }^{148}$ The author argues that it is time for a thorough review of the TPR and be strengthened with as a primary aim to shaping domestic policies. In his view, the TPR should be redesigned and the scope of analysis considerably be broadened so as to include other elements in the analysis, including trade and welfare effects.

The format has seen some changes in light of the recommendations made by the members. The fifth appraisal of the TPRM conducted in the winter of $2013^{149}$ reviewed the implementation of the earlier appraisal conducted in 2011.150 The appraisal provided guidance on how the TPR process can be further improved and streamlined, how the reports can be adapted to cover behind-the-border policies, how trade capacity building can be organized in a more structured and systematic manner, and how to follow up to the recommendations that emerge from the review process. It also includes a review of how the debates of the TPRB can be structured differently to enhance efficiency. The TPR process remains under constant review in order to enhance its efficiency and effectiveness and in the fall 2016, consensus was reached in the sixth Appraisal to make further key changes and more specifically with regard to the frequency of the review cycle, which will be changed from 2, 4 and 6 years to 3, 5 and 7 years, thus reducing the burden on the Secretariat. ${ }^{151}$

The additional attention given to developing country members and LDCs in the TPR process is an important development in itself and was not fully anticipated with the creation of the TPR. The explanation for this largely resides in the fact that it became evident that despite the lower review frequency for developing countries' reviews, they stand to gain more from these very reviews. Most developed countries' policies are already considered rather transparent and well known and laws and regulations are mostly accessible to the public at large. This is often not the case with developing countries. The practice and the reality has shown that developing countries stand to benefit more from the trade policy reviews, as they provide a non-binding and free audit conducted by the WTO through the TPR process. It contributes to enhancing the efficiency of policy making and eliminating

148 V. Zahrnt, 'The WTO’s Trade Policy Review Mechanism: How to Create Political Will for Liberalization?', European Centre for International Political Economy, Working Paper No. 11/2009, p. 20-21.

149 Trade Policy Review Mechanism: Fifth Appraisal of the Trade Policy Review Mechanism, WTO, 28 October 2013,WT/MIN(13)/5.

150 Trade Policy Review Mechanism: Fourth Appraisal of the Trade Policy Review Mechanism, WTO, 29 November 2011, WT/MIN(11)/6.

151 These decisions were adopted by the TPR Body at its meeting of 21 December, following completion of the Sixth Appraisal of the Trade Policy Review Mechanism. (WTO News, 21 December 2016), https:www.wto.org/English/news.e/news16 e/tpr 21dec16 e.htm, viewed on 22 December 2016. 
inefficient and distortive policies and practices. This also explains an increased interest on the side of developing and LDCs to undergo the review.

Another reason for the increased interest is the way the TPRM has evolved as a tool for identifying needs for trade capacity building in the countries under review. ${ }^{152}$ For developing countries, the reports often include a chapter on the Aid for Trade initiatives and more specifically includes language on the needs for technical assistance and training. ${ }^{153}$ This then provides a basis for the design of support activities. The reviews provide valuable information on strengths and weaknesses in the policy making, the challenges a country faces with regard to the implementation of its rights and obligations, including on the notification requirements and perhaps even relating to market access issues. The reports provide a good starting point for defining strategies between the WTO Secretariat, partner institutions and the beneficiary on how to address these challenges, thus facilitating a better and fuller integration of the country into the multilateral trading system. This illustrates how a country can use policy tools to its advantage and demonstrates the supportive role of the WTO Secretariat.

In addition to the national country reviews, the TPRM Agreement calls for an annual overview of developments in the international trading system and which have an impact on the multilateral trading system. ${ }^{154}$ The report sets out the major activities of the WTO and highlights significant policy issues relating to the trading system. The analysis provides a basis for making policy recommendations and determining future policy directions. At the request of the G-20 leaders, the Secretariats of the WTO, OECD and United Nations Conference on Trade and Development (UNCTAD) prepare reports on trade and investment measures taken by the G-20 countries in the face of the crisis: these are the basis for discussions by the world leaders. ${ }^{155}$ Since 2008 the official G-20 Declarations have regularly featured a paragraph on trade and investment measures taken by their members. ${ }^{156}$ This not only contributes to building public and political support for trade negotiations, but also underscores the importance that trade has in stimulating economic growth and creating jobs.

152 The trade capacity building elements are covered in Chapter 5, where it will be argued that needs assessment are an essential step prior to the delivery of the technical support.

153 This initiative largely finds its origin at the Hong Kong Ministerial Conference (MC-VI) in 2005. It consists of looking in a more holistic manner at the various aid flows and programs of international organisations and bilateral donors. As part of the process, a Global Review on Aid for Trade is held every second year, with the fifth such Aid for Trade Global Review having been conducted in July 2015.

154 Overview of Developments in the International Trading Environment: Annual Report by the Director General (Mid-October 2014 to Mid-October 2015), 17 November 2015, WT/TPR/OV/18; presented by the Director General to the General Council on 9 December 2015.

155 Reports on G-20 trade and Investment Measures (Mid-May to Mid-October 2015), OECD, WTO, UNCTAD, 30 October 2015.https://www.wto.org/english/news_e/news15_e/g20_wto_report_oct15_e.pdf.

156 Cf. G-20 Trade Minister's Meeting Statement, adopted at Shanghai 9-10 July 2016, https://www.wto.org/english/news_e/news16_e/dgra_09jul16_e.pdf. See also G-20 Leaders' Communiqué, Antalya Summit, 15-16 November 2015, para. 11-12, http://g20.org.tr/g20-leaders-commenced-the-antalyasummit 
The reports are public and provide very valuable information including on the introduction of new protective measures, which in a way measures the climate of the trading system. The trends identified find their way into the official declarations of world leaders and provide the basis for further actions to redress them and stem the trend towards protectionism. It is noted that trade developments and more specifically trends in protectionism are also monitored through the 'Global Trade Alert', a private initiative, which provides real-time information on state measures that are likely to affect foreign commerce. ${ }^{157}$

The most recent trade monitoring report issued by the Secretariat shows an increase in new trade restrictive measures by G-20 countries. ${ }^{158}$ This will need to be kept in check as Ministers agreed once again, at the G-20 Ministers meeting in Shanghai. ${ }^{159}$ There has been a coordinated response by the G-20 countries on macroeconomic policy and on trade with a commitment to refrain from erecting new barriers. This partly explains why there has not been a large scale outbreak of trade protectionism during the economic crisis, particularly in comparison with the experience during the Great Depression. ${ }^{160}$

Other transparency mechanisms operated by the WTO relate to monitoring and documenting regional trade agreements, officially referred to as the Transparency Mechanism for RTAs. ${ }^{161}$ The main purpose of the mechanism is to provide members with advanced information on RTAs, prior to their entering into effect and also create an opportunity to discuss the RTAs. The importance of RTAs was again underscored at MC-X (Nairobi). Ministers reaffirmed

the need to ensure that Regional Trade Agreements (RTAs) remain complementary to, not a substitute for, the multilateral trading system. In this regard, we instruct the Committee on Regional Trade Agreements (CRTA) to discuss the systemic implications of RTAs for the multilateral trading system and their relationship with WTO rules. With a view to enhancing transparency in, and understanding of, RTAs and their effects, we agree to work towards the transformation of the current provisional Transparency Mechanism into a permanent mechanism in accordance with the General Council Decision of 14 December 2006, without prejudice to questions related to notification requirements. ${ }^{162}$

Global Trade Alert (www.globaltradealert.org) goes beyond other monitoring initiatives by identifying the trading partners likely to be harmed by these measures.

WTO press release, 'WTO Report: G20 Trade Restrictions Reach Highest Monthly Level Since Crisis', 21 June 2016.

159 Cf. WTO press release, 11 July 2016.

160 Cf. World Trade Report 2014: Trade and Development: Recent Trends and the Role of the WTO, WorldTrade Organization, (2014). World Trade Report 2014, p. 186.

161 Transparency Mechanism for Regional Trade Agreements, Decision of 14 December 2006, WT/L/671.

162 WT/MIN(15)/DEC, 21 December 2015, para 28. 
Separately, at MC-XI (Bali), a specific monitoring mechanism was set up to keep a close watch on how developed countries implement decisions in favour of developing countries. ${ }^{163}$ A meeting takes places twice a year to review developments in this field. ${ }^{164}$

In short, transparency is now a key feature of the WTO and an element that has been strengthened over the 20 years since its creation. The TPRM, which was already launched under the aegis of the GATT, provided the basis for the transparency provisions and has been considerably expanded since. The reviews have enhanced transparency with regard to trade policy measures and thus contributed to a better understanding of how trade can contribute to economic growth and development.

\subsubsection{Function 5: Coherence in Policy making}

The WTO Agreement (Article III) states that 'with a view to achieving greater coherence in global economic policy making, the WTO shall cooperate, as appropriate, with the International Monetary Fund and with the International Bank for Reconstruction and Development and affiliated agencies' ${ }^{165}$. This is complemented by Article V, which invites the General Council to 'make appropriate arrangements for effective cooperation with other intergovernmental organizations that have responsibilities related to those of the WTO' and 'make appropriate arrangements for consultation and cooperation with non-governmental organizations concerned with matters related to the WTO' 166 Specific reference is thus made to the World Bank and the IMF, and in this way confirms the inherent relation between trade, financial and monetary policies. ${ }^{167}$ This is an important new addition to the WTO provisions as compared to the GATT, which did not establish any such links. The main purpose of this provision is to ensure that the international institutions with responsibilities in these areas follow coherent and mutually supportive policies. ${ }^{168}$

163 Monitoring Mechanism on Special and Differential Treatment, Ministerial Decision of 7 December 2013, WT/MIN(13)/45, WT/L/920.

164 Ibid., para. 9.

165 Marrakesh Agreement, art. III.

166 Ibid., Marrakesh Agreement, art. V(1) and (2).

167 Cf. M. Auboin, 'Fullfilling the Marrakesh Mandate on Coherence: Ten Years of Cooperation Between the WTO, IMF and World Bank', WTO Discussion Paper No. 13 (2007). See also L. A. Winters, 'Coherence with No "Here": WTO Cooperation with the World Bank and the IMF', Centre for Economic Policy Research, London School of Economics (November, 2001).

168 The need for addressing the issue of coherence in a more rigorous way in part finds its origin in a concrete situation that I experienced during a field trip to Georgia in the late 1990s to assist Georgia in its accession to the WTO. During the seminars and discussions, I was approached by the then Minister for Trade, responsible for Georgia's accession and indicating that the IMF, under the Article V consultations, required the introduction of fiscal policy measures in Georgia. The proposed measures included raising tariffs at the border for the purpose of increasing fiscal revenues. This requirement stood in direct conflict with the WTO requirements of reducing tariffs and other restrictions as specifically requested by WTO members in the accession process. I brought this situation to the attention of the Director General at the time, Mr Mike Moore. This led to further discussions with other institutions and a recommendation to strengthen the policy coherence in order to avoid conflicting policy recommendations. 
The initial WTO Coherence Mandate dates back to 1996 and is supported by two joint cooperation agreements between: (i) the WTO and the IMF; and (ii) the WTO and the World Bank. The WTO now operates in close consultation with the IMF and the World Bank as required by Article III.5 of the WTO Agreement, with regular communication between the relevant agencies. While the mandate was mainly geared towards the relationships with World Bank and IMF, cooperation arrangements have been pursued with many other institutions and working relations are more or less intense and frequent with them. Other institutional arrangements for formalized cooperation also exist, such as through the Enhanced Integrated Framework for Trade Related Technical Assistance (EIF), to which the IMF and the World Bank, as well as UNCTAD, United Nations Development Programme (UNDP) and International Trade Centre (ITC) are all parties and the Aid for Trade initiative, which resulted from MC-VI (Hong Kong). ${ }^{169}$ Several other cooperation structures are also in place, including through the Standards and Trade Development Facility (STDF) or through direct cooperation with specialized agencies. ${ }^{170}$ The mandate essentially aims at ensuring that trade issues play a predominant part in development strategies, notably in the context of the DDA, including for the implementation of the TFA, the EIF and the Aid for Trade initiative.

The Director General is also part of the Chief Executive Board (CEB), ${ }^{171}$ which consists of an inter-organizational body, and meets regularly to take stock of and discuss and coordinate joint actions. This is the highest level possible executive meeting, bringing together the heads of the main international organizations, thus allowing for policy exchanges and defining lines of action in a coherent fashion.

The need for policy coherence and close cooperation between institutions is perhaps most explicit in the TFA, which makes specific reference to support to be provided by other international agencies as a key component in the delivery of trade capacity building. ${ }^{172}$ In fact, the implementation of the TFA will mostly depend on the cooperation between agencies, donors and beneficiaries. The Secretariat has developed a comprehensive work plan in support of trade capacity building in the beneficiaries and in close partnership with all stakeholders. The Trade and Competitiveness Global Practice of the World Bank Group launched the Trade Facilitation Support Program (TFS Program) to provide technical assistance for developing countries. This will help countries to reform their trade facilitation practices in a manner consistent with the main components of the new TFA, reached at the MV-IX (Bali). The TFS Program will focus on the effective implementation of trade facilitation reforms in developing countries to enhance private sector competitiveness, thus leading to increased trade, investments and job creation. ${ }^{173}$

169 The Aid for Trade initiative will be discussed in Chapter 5.

170 Van den Bossche and Zdouc, p. 947. See also www.standardsfacility.org.

171 To be discussed in Chapter 5.

172 Cf. Trade Facilitation Agreement, 11 December 2013, WT/MIN(13)/36 WT/L/911. Detailed explanations are provided in a case study on the TFA in Chapter 5 .

173 The World Bank representative to the WTO circulated that official announcement in June 2014. 
Other examples of efforts to ensure coherence can be provided as it is closely related to the notion of interdependence and globalization, with policies in one area impacting policies in other areas. This extends the coherence debate to trade and environment, labour standards, sanitary and phytosanitary measures, food security, intellectual property, trade capacity building and many other areas.

Coherence is a new element of the WTO that the GATT did not have, but is also of critical importance to the functioning of the system and its relevance in the current trading context. It has shifted the multilateral trading system from being a single entity dealing mainly with tariffs and non-tariff measures, to a much stronger and relevant body capable of addressing a much wider range of issues that one way or another affect trade and trade policies. This makes the WTO much stronger and gives it new relevance as an institution, addressing domains that were previously excluded from its agenda. It reflects the fundamentally changing nature of the world economy in the last 22 years. It also strengthens its ability to work hand in hand with the Bretton Woods institutions (the IMF and World Bank) in addressing the challenges that all institutions are facing, calling for closer cooperation and policy coherence. The efforts to ensure better policy coherence and defining common lines of action are therefore key features of the WTO and are likely to grow further in width and depth.

\subsection{Expanding the WTO's Membership through Accession}

One of the ways to achieve the objective of the universal application of the rules of the multilateral trading system is by increasing the WTO membership to ensuring that more or all trading nations play by the same rules. Liberia and Afghanistan concluded their accession negotiations to the WTO in December 2015 (MC-X, Nairobi) and officially joined in spring 2016, thus bringing the WTO membership to a count of 164 members. The membership now represents $98 \%$ of world trade. How is membership obtained and how does the WTO membership compare to that of the GATT?

There are two methods to acquire membership of the WTO. ${ }^{174}$ The 'original membership' was available for a GATT Contracting Party that had accepted the WTO Agreement at its date of entry into force, 1 January 1995 under Article XI (1). This option was available for a limited period of time: up to the end of $1996 .{ }^{175}$ The vast majority of the present WTO members joined the WTO as original members bringing the total WTO membership at its creation in 1995 to 128 members. This number increased to 130 before the 1996 deadline, two of which joined under the provisions of Article XII.. These members were obliged to have made concessions and commitments for goods and services: these were embodied in schedules and had been duly annexed to the GATT 1994 and the GATS 1995. These requirements, and in particular the fact that all original members had to accept the

174 Cf. footnote 21. According to WTO Agreement, art. XI(1) membership is open to any state or separate customs territory possessing full autonomy in the conduct of its external commercial relations.

175 By that time 130 had completed the domestic procedures and joined the WTO. 
WTO Agreements without reservations, resulted in the all-embracing nature of the WTO and of the universal nature of rights and obligations for which it provides. While this requirement applies to all new members alike, there is an exception for LDCs, which are 'only ... required to undertake commitments and concessions to the extent consistent with their individual development, financial and trade needs or their administrative and institutional capabilities'. ${ }^{176}$

Another 34 members joined the WTO through the formal accession process, negotiations regulated by Article XII of the WTO Agreement. They are referred to as 'Article XII Members'. Time and experience has shown that obtaining WTO membership is a long, arduous and complex process. ${ }^{177}$ According to the WTO's Director General's latest annual report it takes an average of 10 years and 2 months to complete. ${ }^{178}$ The accession of LDCs on average takes 2 years and 4 months longer than the accession of the other, non-LDC countries. The adoption of the above mentioned LDC decision has reduced the length of this process by nearly 2 years.

There are many reasons that the process is so lengthy. One is that the conditions for membership are not specifically set out in legal texts and are not defined, which complicates matters. The provisions simply indicate that membership can be obtained 'on terms to be agreed between it and the WTO' which is a rather open notion and can have a different meaning for different countries and situations. ${ }^{179}$ There are no specific benchmarks and each accession is unique, reflecting the economic situation of the applicant and the commitments it is willing to make. This also explains why acceding countries are mostly required to assume higher levels of obligations than the original members, often referred to as 'WTO plus' provisions for the acceding countries. According to the WTO, the newly acceded countries make considerably more concessions both in the area of goods and services, with nearly $100 \%$ of all tariff lines bound, mostly at lower levels and also covering far more services subsectors. ${ }^{180}$ Their commitments go beyond what most original members have committed to, thus pointing at a two-speed process. In addition, most acceding countries have an obligation

176 Marrakesh Agreement, art. XI(2). Following the launch of the DDA, members adopted in December 2002 a set of Guidelines to ease and accelerate the accession of LDCs, as contained in WT/L/508. The guidelines were further strengthened in July 2012 following the adoption of a Decision by the General Council, to 'further strengthen, streamline, and operationalise the 2002 LDC accession guidelines (WT/L/508/Add.1). The guidelines basically establish benchmarks on market access negotiations on goods and services.

177 U. Dadush and C. Osakwe, 'WTO Accessions and Multilateralism: Case Studies and Lessons Learned', WTO (2015).

178 WTO Accessions 2016: Annual Report by the Director-General' December 2016, WT/ACC/28, Annex 4. The shortest negotiations lasted 2 years and 10 months (Kyrgyz Republic), whereas the accession of some of the largest nations took much longer, including 19 years and 2 months for the Russian Federation and 15 years and 5 months for China, which formally joined in December 2001 during the Ministerial Conference at Doha. The Russian Federation formally became a member on 22 August 2012, after it had ratified the WTO Agreements in July of the same year. The signing ceremony had taken place in Geneva during the $8^{\text {th }}$ Ministerial Conference (MC-VIII), December 2011.

179 Article XII: 1 of the Marrakesh Agreement.

180 WTO at Twenty: Challenges and Achievements, WTO (2015), Table 5. 
to initiate the process of joining the Government Procurement Agreement (GPA) following their accession, thus expanding its membership and coverage.

Related to the previous explanation is the fact that the new members have to sign off on all rights and obligations and need to provide sufficiently convincing evidence that access to their markets is ensured in similar ways as the access that they will benefit to world markets as a result of their accession. After all, through WTO membership, a new member, by virtue of the MFN principle, acquires in one stroke all rights and obligations that have been negotiated in the GATT/WTO for over 50 years. The advantage and the acquired rights thus obtained need to be matched at the domestic level. The members want to ensure that they will get access to these markets in the same ways that the new member has access to the WTO members' markets.

The initiative to apply for membership always comes from the applicant that wants to join the WTO. ${ }^{181}$ The WTO's Secretariat facilitates the process, but membership is entirely voluntary. The process can only begin if there is a clear expression of interest from the applicant. Such interest has become stronger with the establishment of the WTO for various reasons. One is the recognition that the WTO is the only international organization governing trade with multilateral trade rules. It is increasingly understood that it is hard to stay out of the system, as the cost of staying out is too high. As all members abide by the same set of rules, staying out implies ipso facto that the multilateral trade rules do not apply. As a result there is no need for any member to apply the key WTO rules principles including the non-discriminatory treatment measures: MFN treatment and national treatment to nonmembers. ${ }^{182}$ This creates uncertainty in trade and is a key factor in the decision making process to join the WTO. The alternative, i.e. staying out is less and less a viable option given the rapidly growing interdependency between economies and the need to have a level playing field.

There are many other sound reasons for joining, including the need to bring domestic legislation in line with international norms and standards. Various case studies presented by Osakwe and Dadush show that being a member of the WTO provides a unique opportunity to accelerate the domestic reform process, leading to greater openness and a better and more efficient economic resource allocation. ${ }^{183}$ After the collapse of the Soviet Union and the end of the Cold War, leading to the creation of fifteen new independent states, often referred to as 'transition economies', joining the WTO became a key objective for most of the newly

181 It is an entirely voluntary process, with no pressure being exerted by any outside source. It shows that the country expressing an interest to join the WTO sees a need and an economic advantage in being a WTO member. It is also recalled that the membership needs to be vetted by Parliament, thus completing a duly democratic process with the parliamentarians being accountable to their electorate.

182 It could be said that for non-WTO Members 'the law of the jungle applies', as no rules prevail between members and non-members. Any measure whether in accordance with the WTO rules or not can be applied, including quotas or any other form of discrimination and without needing to provide justification.

183 Cf. footnote 177: Dadush and Osakwe 
established states. ${ }^{184}$. What drove them to do so, as stated by Broadman was that 'the dismantling of the Soviet Bloc brought economic chaos and a collapse of trade flows that compelled countries in the region to begin to reintegrate into the global economy'. ${ }^{185}$ In the early years of the transition, many countries in the region started to adopt liberal import policies, in many cases largely driven by willingness and policy objectives to join the WTO.

Integrating transition economies into the multilateral trading system was a major challenge both economically and politically because of the way centrally planned systems operated. Their economic systems were largely based on quota regimes, administered by central governments, as opposed to market based regimes, where markets determine prices based on offer and demand. Structural, institutional and economic reforms were required, largely accompanied by international organizations including the OECD, the IMF, World Bank and the European Bank for Reconstruction and Development (EBRD) ${ }^{186}$ providing them with specific advice on how to conduct the reforms. ${ }^{187}$ The WTO played a key role, as the WTO membership would anchor the transition to market based regimes. The reform process was very challenging, as the inefficiencies of the domestic markets in the transition economies could lead to a surge in imports competing with domestic goods of lower quality and foreign direct investment with the risk of depressing the domestic economy at first. The longer term perspective would be a more efficient economy, with a better integration into world markets, higher quality of goods at competitive prices and a larger consumer choice. However, this process takes time to materialize and requires a potentially significant price to be paid. Even today this adjustment process continues to be challenging in several countries, with difficulties in diversifying production and connecting to global markets. ${ }^{188}$

Most of the 12 countries that were also part of the then newly established Commonwealth of Independent States (CIS), together with the three Baltic countries (Estonia, Lithuania and Latvia) actively pursued WTO membership in order to lock in the reforms, and to restructure and liberalize the economy. ${ }^{189}$ The same applies to other Eastern European Countries that were not yet WTO members, including some countries in the Balkan region and those that emerged after the breakup of Yugoslavia in the early 1990s, as

184 The Cold War ended with the collapse of the Berlin Wall in Fall 1989, leading to the reunification of the two Germanys and following which the former Soviet states gained independence. The establishment of the WTO was seized as an opportunity to undertake domestic economic and structural reforms and join the multilateral trading system.

185 H.G. Broadman, 'From Disintegration to Reintegration, Eastern Europe and the Former Soviet Union in International Trade', World Bank (2005) p. 2.

186 European Bank for Reconstruction and Development (EBRD), created shortly after the end of the cold war to assist the formerly centrally planned economies in their reform process, based in London.

187 Sometimes the financial support to accompany the reform is made conditional upon the reforms.

188 This is evidenced by S. Sutyrin, A. Koval and O. Trofimenko in 'Integrating into the Multilateral Trading System', in M. Janssen, M. Sadni Jallab and M. Smeets (eds.), Connecting to Global Markets, Case Studies Presented by WTO Chairs (WTO, 2014).

189 Established in December 1991 and consisting of Armenia, Azerbaijan, Belarus, Kazakhstan, Kyrgyz Republic, Moldova, Russian Federation, Turkmenistan, Tajikistan, Ukraine, Uzbekistan and Georgia. 
well as the three Caucasus countries (Georgia, Azerbaijan and Armenia). ${ }^{190}$ In most cases this required much more than simply addressing border policies by replacing quantitative restrictions (quotas) with tariffs. A complete policy agenda was pursued, affecting border and behind the border policies, in order to make the domestic markets function more efficiently. Such reforms can hardly take place without a cost to the domestic economy, thus affecting established interest groups. Most acceding countries explicitly recognize that the short term costs associated with the adjustment process are largely outweighed in the longer run by substantial efficiency gains.

Acceding countries have often underestimated one of the challenges: prior to the commencement of the accession process domestic reforms are required to bring them in line with WTO rules and regulations. As a recent WTO study notes these domestic reforms are the key to the completion of the accession process.191 A forthcoming publication by Arveladze and Smeets on Georgia's accession to the WTO focuses on the reforms that were undertaken in the accession process. ${ }^{192}$ It is argued in the study that the domestic reform process mostly preceded the WTO accession and was a pre-requisite for joining the WTO. The reforms were pursued following accession with a view of further aligning Georgia's domestic policies with prevailing international norms and good practices and even continue to date. It also provides evidence on how it has benefited from the reform process, as reflected in its economic growth in recent years.

In another example and according to the WTO, China introduced and/or modified over 2,300 legislative reforms, and the Russian Federation modified almost 1,200. ${ }^{193}$ The new WTO members need to prove that all domestic laws and regulations are in conformity with WTO law and that all institutional arrangements are effectively in place to put its legal system into full operation. The laws and regulations are carefully scrutinized by the membership during working party meetings dedicated to each accession. ${ }^{194}$ This is a

190 It is noted that Azerbaijan, Turkmenistan, Uzbekistan are still not members of the WTO. Azerbaijan was determined to conclude the process in 2016, but did not achieve that goal and continues its accession negotiations. Turkmenistan has not yet committed to membership but contacts at the highest levels of government were made with the top management of the WTO early 2016. Uzbekistan's accession seems to be on hold.

191 WTO at Twenty, Table 5.

192 G. Arveladze and M. Smeets, ‘Georgia’s post-accession structural reform challenges', WTO Working Paper Series, ERSD-2017-10, June 2017.

193 The WTO at Twenty, Table 3.

194 Each accession is conducted through a working party, composed of members that have expressed an interest in following the debates and discussions on the terms of accession of the candidate country. Hence, the composition and number of countries in the working party varies from one accession to the other. The Chairman of the working party is appointed by the membership and in close consultation with the applicant country. It is also noted that in addition to the multilateral process, which is conducted through the working party, the applicant conducts bilateral negotiations to agree on the market access conditions, tariff schedules and services commitments with each of the members of the working party. Hence, in the accession process the distinction is made between the multilateral and the bilateral tracks, which are mostly conducted in parallel. 
particularly intensive duty and the difficulty often lies here, as domestic law makers often want to get evidence confirming the advantages that WTO membership will bring. It is not always easy to demonstrate that the long term balance will tip in the favour of the country joining the WTO and outweigh the short term costs. ${ }^{195}$ Parliamentarians often change during the (long) accession process. Many have little knowledge of the WTO system and rules and regulations, which may mean little to their local constituencies. It thus becomes a challenge to convince them of the longer term advantages of membership and accept the short term costs. ${ }^{196}$ Indeed, the economic advantages of membership are not immediate. Some accession processes have become 'dormant' for a while as a result, and there are longer periods that pass without negotiations or any activity. ${ }^{197}$ It has often been a challenge for the government to get the law makers on board within the set time-frame to ratify the WTO Accession Protocol. ${ }^{198}$

According to the WTO the accession of Article XII members, especially those with large economies like China, has significantly lowered protection and expanded trade opportunities over the past 20 years. ${ }^{199}$ Concerning goods trade, acceding members have made binding commitments on virtually all their agricultural and non-agricultural tariffs, significantly improving the certainty and predictability of their trade regimes. Also, according to the same report, the binding commitments are at substantially lower levels than those made by the original WTO members. The report goes on to observe that with the overall more liberal commitments, Article XII members have consistently had stronger trade growth performance than the original members. Since 1995, the average trade growth rate of Article XII members was $12.4 \%$, almost double that of original members $(7.4 \%)$, including after the financial crisis of 2008. China's average growth rate for the period 1995-2013 is $16.0 \%$, and it largely outperforms the other countries. It goes without saying that there are numerous other macroeconomic factors that contribute to growth, many of which are unrelated to WTO accession.

195 It is not easy to measure and quantify in economic terms the benefits that WTO membership brings following the accession process, as many of the advantages are gradually obtained during the accession process, when the domestic reforms are conducted and laws are introduced. Contrary to a common belief, little immediate change occurs on the day following membership, as most conditions are already met on that day.

196 Loss of competitiveness, jobs, support measures etc.

197 This was the case with Vanuatu, and is the case with several countries, including Algeria, Ethiopia, Lebanon (which recently resumed its process after many years of inaction), and Sudan to mention but a few.

198 According to Article XII the applicant member has a period of 6 months to complete the domestic ratification process, following completion of the accession negotiations and the adoption of the Protocol of Accession by the membership. I have personally experienced and witnessed the difficulties involved in convincing parliaments, as I was called upon on many occasions to speak to parliaments in formerly acceding countries (Russian Federation, Ukraine, Moldova, Lithuania, Latvia, Kyrgyz Republic etc.) and have had bilateral meetings with lawmakers to explain the WTO, including the main elements of the WTO rules based system and possible implications of membership. These meetings often turned out to be decisive in getting the support of Parliament.

199 Cf. WTO at Twenty, Table 5. 
Finally, is it worth noting that the geo-political developments of previous decades not only explain the rapidly expanded membership of the WTO in recent years, but have considerably contributed to the diversity of the membership and the system, bringing together different economic systems under one umbrella organization, the WTO. This has had fundamental economic and policy implications, as it not only strengthened further the basis on which the multilateral trading system of the WTO is based (market based principles) but it also extended the rules to a new family of countries that had based their economic systems on a fundamentally different economic and political philosophy. It triggered a process of further trade liberalization and a wider adherence to the rules based trading system, which in itself are remarkable achievements that cannot be underestimated. In this respect the WTO again differs fundamentally from the GATT system.

\subsection{Coalitions: how members defend common interests?}

WTO members often share common policy objectives in the negotiations and create coalitions to defend and reflect their interests. Such coalitions can be formal and/or informal and their composition often changes as the negotiations evolve. Other explanations for the creation of coalitions include the rapidly expanding membership of the WTO with its 164 members and its increased diversity. More than ever before, the WTO has brought into its ambit economies with different levels of economic development and different economic systems. The specific interests of the members and their goals and objectives in the negotiations often vary considerably. Coalitions can lead to building more strength and influence in the negotiations, as common interests stand a better chance of being defended than individual interests.

The GATT system consisted of a smaller number of countries and the process was mainly driven by the largest trading nations, essentially developed countries that set the agenda. This has changed with the WTO. As argued earlier, the number of issues addressed in the GATT was more limited and they were less complex. Today there is considerably less room for the strongest economic actors to set the agenda. The process has evolved and all decisions are inclusive, with collective decisions taken by the membership. It could even be argued that with the economic balance gradually shifting from the West to the East, ${ }^{200}$ some of the main Asian economies and more specifically China and India have become increasingly influential in the debate. In the GATT days, the spheres of influence were mainly transatlantic, with the US and EU largely dominating the debates. While they remain of critical importance in the discussions and decision-making process, given their share in international trade, the role and influence of the developing countries has grown. The wider interest in trade by developing countries and their growing influence are the result of various factors including the increased awareness that trade should be considered as a priority for

200 The shift in the economic balance from the West to the East will be discussed in Chapter 3. 
pursuing development goals. ${ }^{201}$ As will be evidenced, many developing countries moved from inward looking policies to more liberal policies, as trade is a driving force of economic growth.

Equally, and as was argued earlier, the countries that were part of the central planning system of the former Soviet Union were mostly not part of the multilateral trading system of the GATT. Many became interested in the GATT/WTO after gaining their independence from the Soviet Union and with a view to developing their own economic and trade policies based on market principles. Their economic systems were largely incompatible with the WTO market based system, as their interventions were mostly based on central planning, quota systems, subsidies and support measures and so on. They conducted major structural reforms to align their policies with market based policies as advocated by the WTO. These countries often share common interests in the WTO as many of them face and need to address the same post-accession concerns and challenges. Many of them are not in a position to provide additional concessions in the negotiations, given that the accession process implied a wide range of market liberalization measures. Some new members are still in the process of implementing those concessions. As will be argued in the subsequent chapters, their common interests are reflected in the draft agreements that are part of the DDA negotiations, especially with regard to agriculture and NAMA negotiations.

As in the WTO all decisions are taken by consensus, the decisions need to reflect the divergent economic interests of the wide range of stakeholders. The process thus becomes more complex, time consuming and challenging, but at the same time more inclusive. Some of these challenges will be explained further in Chapter 4, particularly with regard to sensitive areas as agriculture and NAMA negotiations. As will be shown, the many attempts to satisfy all the parties in the negotiations explain the difficulties of concluding the DDA.

Broadly speaking, the GATT made reference to developed countries, developing countries and LDCs. LDCs are defined according to the UN classification. ${ }^{202}$ Developing countries are a more heterogeneous group, originally based on the concept of self-election, meaning that a country could itself determine this status in the GATT. Some developing countries would today rather fall in the category of developed countries, given their rapid economic developments and growing shares in world trade. LDCs frequently act as a coalition in the WTO and often take common positions in addition to taking national positions. Their common actions and determination have been effective with many decisions taken in response to their specific demands and concerns. ${ }^{203}$ Developing countries organize

\footnotetext{
201. See J.A. Laker, African Participation in the World Trade Organization, Legal and Institutional Aspects, 199-2010 (Martinus Nijhoff Publishers, 2014). The economic rationales for the shifting policies and approaches will be presented in Chapter 5

202 In the WTO, only the LDCs are defined in accordance with the UN classification, Cf. Annex I; the developed countries are mainly the OECD countries.

203 Examples of the results of their actions will be provided and discussed in Chapter 5.
} 
themselves in various formats and their positions are sometimes aligned with those of developing countries in specific areas. Some of the results will also be discussed later.

WTO membership has gradually included an additional range of categories of countries in the negotiations. The 'transition economies' are those members that have moved from centrally planning systems to market based economic policies. As many of them have joined the WTO only recently or very recently, they have been categorized as 'recently acceded members' (RAMs) and 'very recently acceded Members' (VRAMs). As time passes, it is not always clear who joined 'recently' and or 'very recently'. The question of how far back one should go is answered in the specific draft agreements, where RAMs and VRAMS are explicitly listed. ${ }^{204}$ The main concerns of the RAMs and VRAMs are related to the commitments made during their accession to the WTO and their implementation. It would be difficult for them to economically and politically accept that in addition to the reductions that need to be performed as part of their accession package, they would have to cut their duties by another $50 \%$ or so, depending on the outcome of the DDA negotiations and the manner in which tariffs will need to be reduced. ${ }^{205}$ These concerns are explicitly recognized and reflected in the negotiations as they have endeavoured to ensure that no strict binding obligations are imposed on them so shortly after the conclusion of their accession to the WTO. They have successfully fended off such attempts, as the agreements containing reduction commitments mostly exempts them from implementing such further reductions.

A relatively young and new group that has become influential with time is the Small and Vulnerable Economies (SVEs). Its origin dates back to the DDA's launch in 2001, with a specific call by Ministers to give specific attention to SVEs. Paragraph 35 of the Ministerial Declaration calls for a work programme to be conducted with regard to SVEs with as a main objective 'to frame responses to the trade-related issues identified for the fuller integration of small, vulnerable economies into the multilateral trading system, and not to create a subcategory of WTO Members'. ${ }^{206}$ This provided the starting point for establishing a work programme on SVEs from spring 2002 onwards. The MC-V (Hong Kong) reaffirmed the importance of the work program for SVEs and their specific concerns have had the attention of every Ministerial Conferences since then and resulted in several follow up decisions. ${ }^{207}$

Interesting enough, the Ministers decided not to create a sub-category of WTO members as is stated in the declarations. The main reason for this is probably that there is no agreed definition of SVEs. The interests of SVEs and their specific concerns are taken into consideration in both the draft agreements on agriculture and NAMA (see Chapter 4).

204 Detailed information and concrete examples of how the concerns are addressed are provided in Chapter 4.

205 Depending on how the DDA negotiations will be pursued and what will be agreed as a benchmark for the reductions to be performed, but which is likely to be in that order of magnitude for the developed countries, as will be discussed in Chapter 5 and less for developing countries.

206 Doha Ministerial Declaration, 20 November 2001, WT/MIN(01)/DEC/1.

207 Hong Kong Ministerial Declaration, 18 December 2005, WT/MIN(05)/DEC, para. 41; Work Program on Small Economies, (17 December 2011, WT/L/844) and (7 December 2013, WT/L/908). 
According to the draft text on agriculture, a member is considered to be a small economy when its average share for the period 1999-2004: (a) of world merchandise trade does not exceed $0.16 \%$; and (b) of world NAMA trade does not exceed $0.10 \%$; and (c) of world agricultural trade does not exceed $0.40 \%{ }^{208}$ According to Annex 1 of the draft modalities text for agriculture, there are 45 countries that meet those criteria. ${ }^{209}$ The main characteristic of SVEs is their small market size, a narrow resource base and small or restrictive economies of scale, that they are vulnerable due to their geographical location (for example some countries in the Caribbean are regularly hit by hurricanes) or are dependent on single crops or products for their exports, and so highly dependent on world market prices for that individual product. Clearly their economic wellbeing depends greatly on factors that are beyond their control. The group is increasingly recognized in all parts of the negotiations and as will be seen, specific provisions are proposed in the various draft agreements, taking into account the particular situation of the SVEs. The importance that members attach to their fuller integration is reflected in the many different ways that their specific concerns are reflected in the negotiations and of which the secretariat has made a compilation and which underscores both the economic and political importance of the SVEs in the WTO.210

There is a category of countries that are generally referred to as the emerging markets or the so-called BRICS (Brazil, Russia, India, China and South Africa).211 Most of these countries grew very rapidly until a few years ago and more particularly until the start of the financial crisis in 2008, which resulted in a slowdown of the world economy and affected their growth rates. ${ }^{212}$ Within the BRICS it was mainly China that grew exponentially, followed by India and with the other countries stagnating. The share in world trade of China and to a smaller extent India grew very rapidly and so did their influence in the decision making at the WTO, as will be shown in Chapter 3. The BRICS are not a coalition per se and do not necessarily share the same objectives in the negotiations.

Many coalitions coordinate their positions and often speak with one voice, depending on the format of the coalition and their structure. Given its degree of integration and the treaties on which it is founded, in the EU and given that it is a Customs Union, the EU Commission

208 The Revised Draft Modalities for Agriculture, 6 December 2008, TN/AG/W/4/Rev.4. It is noted here that the status of the draft modalities paper is unclear following the MC-X at Nairobi.

209 As is observed in a WTO study on SVEs entitled 'Challenges and opportunities experienced by small economies when linking to into global value chains in trade in goods and services', 1 May 2015, $\mathrm{WT} / \mathrm{COMTD} / \mathrm{SE} / \mathrm{W} / 31$, p. 2-3, small sized countries are frequently referred to differently. UNCTAD refers to small Island Developing Countries (SIDS) and the World Bank refers to small island states. As is observed, while the terms may differ, the lists of countries are quite similar.

210 Work Program on Small Economies, compilation paper prepared by the Secretariat, 16 October 2015, WT/COMTD/SE/W/22/Rev.7.

211 A detailed analysis is provided in the next chapter on the growing influence of some of the BRICS in the world economy.

212 Brazil is now in recession and the drop in oil prices in 2015 and early 2016, combined with the economic sanctions applied by a coalition of countries (Cf. Chapter 3) have affected the Russian Federation. 
speaks on behalf of the Members states on most trade issues. ${ }^{213}$ Other groupings include the Association of South East Asian Nations (ASEAN) and the Group of Latin America and Caribbean Countries (GRULAC) at the regional level. At the global level, there is the group of African Caribbean and Pacific Island Countries (ACP) whose members do not necessarily always share the same interests, Its composition is very heterogeneous and to the extent that common positions are taken, they mostly reflect the larger common dominator. However through its Secretariat the ACP does provide analytical support and back up in the negotiation process, which facilitates the preparation of common positions.

The LDCs and African Union expanded the ACP group at Cancún, meeting as the G90. ${ }^{214}$ Clearly their positions can only be common on specific points, where their interests are addressed in a more global and horizontal manner. ${ }^{215}$ In addition, this does not prevent any members of the alliance from pursuing their national interests through other topic based coalitions or directly and on their own.

In the context of the DDA negotiations, African countries have developed a cohesive structure for negotiations through the African Group, which has been instrumental in increasing its participation in the negotiations. The creation of the African Group in 1995 resulted from a recognition by African delegations that they were individually facing a number of constraints. ${ }^{216}$ These included limited human resources, the difficulties in addressing the complexity of the issues in the WTO negotiations - which were best addressed in concert with others, the recognition of the need to draw from each other's strengths, the need to harmonize positions and develop more coherence between the continent's trade agenda and WTO negotiations. The African Group operates on a system of focal points, who are in fact the delegates of African countries and who lead work in each technical area by attending key meetings in specific areas, reporting back to the group, preparing draft proposals, seeking group consensus on draft proposals and leading on technical discussions (on the group's behalf) in the negotiations. The UNECA and the African Union participate in all meetings of the African group.

One of the very well-known coalitions is the Cairns group: it was created at a meeting in Cairns (Australia) and consisted of like-minded developed and developing countries that share a common vision and economic interest in the production and exports of agricultural

213 The European Union, with very few exceptions, speaks on behalf of all its 28 Member States, as embedded in the EU law. The positions are coordinated in advance through the Trade Policy Committee.

214 The G-90 finds its origin at the Fifth Ministerial Conference MC-V, held at Cancún, September 2003.

215 In practice these countries often have different positions, as some are LDCs, some benefit more from preferences than others and are not ready to engage in commitments that risk eroding those preferences etc. This makes it often hard for the group to speak with one voice and develop common positions. This was again witnessed during the Trade Facilitation negotiations, with several African countries openly dissenting from the common positions.

216 Cf. Laker, p. 24: 'the mandate of the African Group is established by African Ministers responsible for WTO matters in their annual meetings and at extraordinary sessions held inter-alia in preparation of WTO ministerial conferences.' 
goods. Their policies are based on a common belief that trade in agriculture should be liberalized and follow market based principles. This group includes Brazil and Indonesia, who are two main agriculture exporting developing countries. The original Cairns group has largely been substituted by a perhaps even more powerful group, referred to as the ' $\mathrm{G}-20$ ', which was created at the MC-V (Cancún), in order to better defend their collective interests. This G-20 is distinct from the G-20 economic leaders referred to earlier. In addition to the original Cairns members, it includes China, India, Indonesia, Brazil, Egypt, Argentina and South Africa, all developing countries. They are demanding the dismantling of the trade distorting and protectionist agricultural policies of the European Union, the United States and other industrialized countries. Narlikar and Tussie provide a detailed review and analysis of the origins of the G-20 and how it has managed to play a significant role in the negotiations as a coalition. ${ }^{217}$

An example of a small, but very influential coalition brought together by a common topic is the Cotton-4, comprising Benin, Burkina Faso, Chad and Mali and which are some of the poorest West African countries. Despite its small size this group manages to influence the negotiations, perhaps precisely because they are small and vulnerable as their economies depend mostly on the production and export of essentially one good - cotton. According to calculations made by Anderson and Valenzuela, achieving their main objective, i.e. the removal of the distortive subsidies provided by the developed countries and affecting world market prices, would significantly contribute to enhancing their overall levels of economic welfare. ${ }^{218}$ As is observed by Sumner 'the failure of the Cancún ministerial to reach a framework agreement was attributed in part to the failure to address the cotton initiative adequately. For that reason, the December 2003 meeting of the General Council of the WTO devoted considerable attention to the cotton initiative and reported enough progress to allow the general Doha negotiation to proceed. ${ }^{219}$ Cotton is the lifeline for many people in these countries and their incomes fully depend on cotton production. ${ }^{220}$ The revenues are very unpredictable, as they depend very much on the world market prices for cotton, which they claim are heavily influenced by subsidies provided by the richer nations and against which they cannot compete. ${ }^{221}$ Their request in the negotiations mainly consists of the full elimination of subsidies for cotton.

217 A. Narlikar and D. Tussie, 'The G-20 at the Cancún Ministerial: Developing Countries and Their Evolving Coalitions in the WTO', 27 The World Economy (2004), p. 947-966.

218 K. Anderson and E. Valenzuela, 'The WTO Cotton Initiative: a Tale of Two issues', 30 The World Economy (2007), p. 1281-1304.

219 D. Sumner, 'Reducing Cotton Subsidies: The DDA Cotton Initiative', in K. Anderson and W. Martins (eds.), Agricultural Reformand the Doha Development Agenda (Pelgrave MacMillan, World Bank, 2006), p. 274

220 Cf. A. Sneyd for a discussion on the importance of cotton for African countries, in Governing Cotton, Globalization and Poverty in Africa (Palgrave MacMillan, 2011).The cotton issue will be analysed further as part of the discussion on agriculture in Chapter 4.

221 D. Sumner, 'U.S. Farm Programs and African Cotton', International Food \& Agriculture Trade Policy Council (IPC Issue Brief 22, 2007). 
Another coalition is the so-called G-5, which includes the European Union, the United States and interestingly India, Brazil and China, thus confirming the increasing influence the three emerging economies have in world trade and policy making. ${ }^{222} \mathrm{Without}$ the agreement of these powers, decisions cannot be taken, as was witnessed at the last two Ministerial Conferences (MC-IX and MC-X) where the G-5 played a key role in leading the way to a consensus. The G-5 has overtaken the previously powerful coalition referred to as the Quad, which included the European Union, the United States, Japan and Canada. During the Uruguay Round, the Quad successfully set the agenda and determined the course of action. This confirms a shifting balance in the powers between the GATT and the WTO. It also reflects the new realities of world politics and a shift of power from the West to the East and South, which will be analysed more closely and argued in the next chapter.223

Other coalitions as referred to in Annex 2.2 include various 'friendship' groups, including 'friends of fish', 'friends of rules', 'friends of ambition', and 'friends of the Chair', which, as the name of the group suggests, are countries that associate themselves closely with specific initiatives in specific fields. Most recently, the 'friends of e-commerce' was created, including countries interested in pursuing a discussion on e-commerce. They work closely with the Chair in charge of those issues in order to support and perhaps even promote and/or revise rules in those areas. The interesting aspect here is that often the 'friends' include developed and developing countries alike, something that was less common in the GATT period.

A specific example of an important and topic based coalition can be found in the discussions around intellectual property rights and more specifically on geographical indications. According to VanGrasstek, 'the coalitions that emerged around the negotiations on geographical indications (GIs) offer a more complex example of how developed and developing countries can form diverse groupings on opposing sides of an issue'.224 According to Article 22.1 of the TRIPS Agreement, GI's are 'indications which identify a good as originating in the territory of a member, or a region or locality in that territory, where a given quality, reputation or other characteristic of the good is essentially attributable to its geographical origin'. VanGrasstek illustrates this with examples relating to specific types of wine (Champagne) or cheese (Gouda). He explains that

at issue in the Doha Round are the rules by which GIs might be enforced on wine, an initiative that divides countries into two camps that defy the usual North-South divide. The European Union is among the sponsors of a paper known as W52. The paper proposes a multilateral registry for wines and spirits and extending a higher level of protection beyond wines and spirits, as well as stricter rules of disclosure under which patent applicants would be required to

\footnotetext{
222 Their growing influence and share in international trade will be explained in the next chapter.

223 See M. Smeets, 'Changing Patterns in International Trade', 5 Journal of WTO and China (2015).

224 Cf.. VanGrasstek, The History and Future, p. 105-107.
} 
disclose the origin of genetic resources and traditional knowledge used in the inventions. Most of the developing countries that joined the European Union in sponsoring W52 are also members of the ACP; the sponsors also include Brazil, Colombia, Ecuador, India and Peru. Most of the significant wine-producing countries outside of Europe, whether they are developed or developing, are opposed to the strict enforcement of Old World GIs. ${ }^{225}$

An indicative list of the type of groupings, alliances and coalitions that were created is provided for in Annex 2.2. It shows the widely differing nature of the coalitions, based on topics or geographical interests. The composition of these groups can change easily, as alliances are dynamic and not static. An image of the coalitions is provided by VanGrasstek (Graph 2.3), including an analysis of how some of the alliances pursue their offensive and defensive interests ${ }^{226}$ and how specific groupings develop negotiating positions. ${ }^{227}$ It gives a clear indication of the complexity of the issues and the multitude of different interests. It is a true reflection of an evolving world economy, with more complex and intricate economic relations between countries.

225 Ibid p. 105; W52 is the short reference to WTO document 'Draft Modalities for TRIPS Related Issues', $\mathrm{TN} / \mathrm{C} / \mathrm{W} / 52$. The illustration is also interesting to the extent that this underscores the argument that will be made later that the classical North/South divide is losing its meaning.

226 Cf. VanGrasstek, The History and Future, Table 3.1, p. 101.

227 Cf. Ibid., p. 97-108. 
GRAPH 2.3: Groupings, coalitions and alliances.

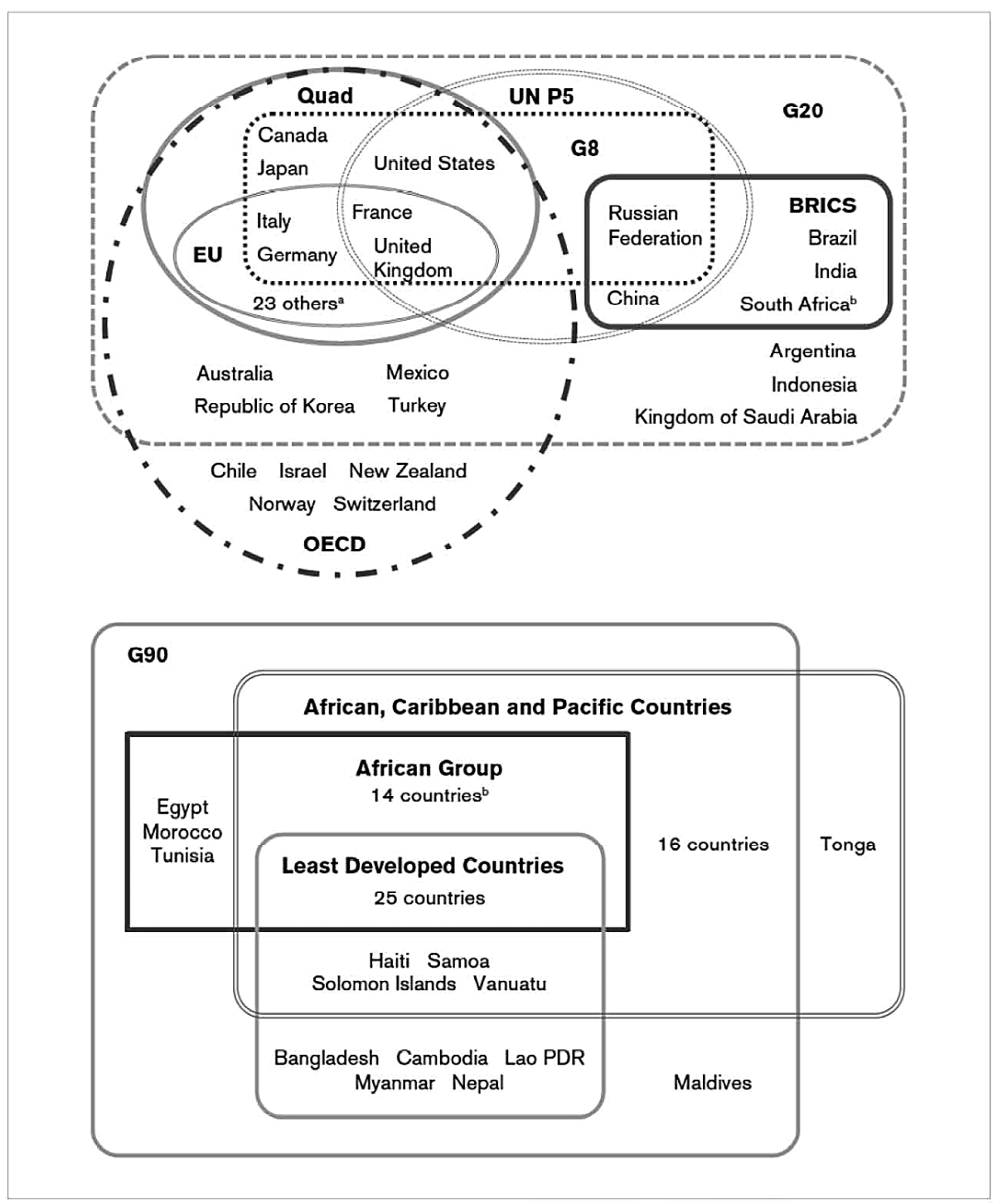

Source: WTO Secretariat, www.wto.org/english/tratop_e/dda_e/negotiating_groups_e.htm.

Notes: Groups that are principally blocs are inside solid lines; groups that are principally forums are inside dashed lines. ${ }^{\text {BB }} \mathrm{Bulgaria}$ Cyprus, Latvia, Lithuania, Malta and Romania are members of the European Union (and therefore the Quad and the G20) but not the OECD. 'South Africa is a member of the African Group (and the ACP and the G90) as well as the G20.

Taken from VanGrasstek, C. (2013), The History and Future of the World Trade Organization, Geneva, World Trade Organization, Figure 3.1., p. 101, membership in selected blocs and forums. 
Thus, the larger than ever number of WTO members has led to a new dynamic in the DDA negotiations, with different actors often collectively pushing for outcomes in areas of interest to them. Never before in the history of the GATT have there been so many different groups and alliances between WTO members, each aligning themselves with specific interests and issues. This is a distinct new feature of the trade negotiations of the WTO. Perhaps even more significantly, the alliances are increasingly interest based, cutting across levels of development. In other words, the alliances are no longer a juxtaposition of developed versus developing countries, which is a significant development in itself and a move away from the North/South divide that was more characteristic of the GATT. This important evolution and new development was clearly evidenced in a statement made by the Kenyan Chair of MC-X (Nairobi), Foreign Minister, H.E. Mrs Amina Mohamed.228 This also confirms that the traditional look at the world economy in terms of a North/South divide whereby economic interests are simply divided between the so-called rich and the poor is too simplistic and now becoming part of history. Developing countries are increasingly active players in all parts and activities of the WTO, with a better capacity to understand the issues and making their voice heard, shaping the negotiating agenda and influencing the final outcome of the discussions. ${ }^{229}$

Coalitions have thus grown in significance and influence and are part of the new realities of the WTO's multilateral trading system. ${ }^{230}$ As for the rationale of the coalitions they make countries more powerful and influential in the discussions, as their positions are no longer individual positions, but reflect common interests. ${ }^{231}$ In addition to the economic and political explanations provided to forge alliances, this is also driven by the increasing complexity of the issues, which require more and more specialized knowledge and expertise, which is not always available to each negotiating member, particularly in smaller delegations. Given the capacity constraints in developing countries, many therefore organize themselves through alliances. As observed by Van den Bossche and Zdouc, ${ }^{232}$ the common interest groups, coalitions and alliances play an important role in helping developing country members to overcome, or at least to mitigate, their lack of resources and expertise and to participate more effectively in WTO negotiations and decision-making. A similar argument is built by Narlikar, explaining how developing countries gain strength in the negotiations

228 WTO Trade News, 20 December 2015: "For me, Nairobi will be remembered as having made that leap from a time when we were divided along this developed and developing divide," she said.

229 Cf. Chapter 5.

230 Cf. B. Hoekman and M. Kostecki, The Political Economy of the World Trading System, the WTO and Beyond (Oxford University Press, 2009), p. 151-160. See also J.H. Barton, J.L. Goldstein, T.E. Josling, \& R. H. Steinberg (eds.), The Evolution of the Trade Regime; politics, law, and economics of the GATT and the WTO (Princeton University Press, 2006), p. 153-181.

231 Cf. S. Rolland, 'Developing Country Coalitions at the WTO: In Search of Legal Support', 48 Harvard International Law Journal (2007), p.483-552

232 Cf. van den Bossche and Zdouc, p. 107-108, which includes a detailed discussion of the multiple, often overlapping, groups, coalitions and alliances pursuing different goals. 
through the building of coalitions. ${ }^{233}$ This is typically the case for the G-90, with the ACP countries as a driving force and which provides analytical support and technical expertise in the negotiations. ${ }^{234}$ A good example is the TFA, where the negotiators directly benefited from technical expertise provided by outside consultants hired by the ACP for that purpose, advising in the technical discussions and drafting textual inputs and proposals. ${ }^{235}$ The text contains specific and binding language that would benefit developing countries to apply it, and with the TFA having been made conditional upon binding commitments for technical assistance to be provided by developed countries. As will be argued further, this makes the TFA unique and sets an example of how support can be provided to beneficiaries.

Other explanations for the mushrooming of coalitions since the creation of the WTO can be found in the rapid increase in the number of negotiations on so many different topics, often taking place in parallel. Many (smaller) delegations lack the human capacity to attend the different meetings and have their voice heard. As is pointed out by J.A. Laker, 'physical establishment of trade policy negotiators, on-site, at the WTO in Geneva carry effects for the effectiveness and quality of legal and institutional participation/engagement in the rules based multilateral trading system'. ${ }^{236}$ As she points out, in 1995, half of the 33 African WTO members had a representation in Geneva. This share had increased to $68 \%$ at the time of the launch of the DDA in 2001 and to $92.8 \%$ in $2010 .{ }^{237}$ At the same time, many countries have increased their staff at Geneva-based permanent missions specifically focusing on WTO matters. The number of missions dealing separately from the global missions dealing with the UN bodies has increased. Between 1982 and 2012, the number of WTO related staff at the Permanent Missions grew more than five-fold, and the number of Permanent Missions also rapidly increased, with currently only 18 non-resident members ${ }^{238}$, compared to 28 non-resident members in $1997 . .^{239}$ In other words, members manifest a growing interest in direct representation at the WTO, so as to be able to fully participate in the negotiating process.

How can all the different economic interests be reconciled? And how can negotiations be conducted between so many diverse members reflecting different economic and trade interests? What are the institutional implications and what do these developments mean for the negotiating structures? Given the large number of WTO members and the challenge this poses to reaching agreement, the practice has been developing to undertake some of the initial WTO negotiations in a smaller format, namely between limited numbers of members. This format is often referred to as the 'green room', which initially consisted of the Director

233 A. Narlikar, International Trade and Developing Countries: Bargaining Coalitions in the GATT \& WTO (Routledge, 2003).

234 The G-90 is the largest constituency or coalition (see Graph 2.3).

235 The specific features of this Agreement will be discussed in Chapter 5.

236 Laker, p. 14.

237 Ibid., p. 15-16.

238 Non-residents are those countries that do not have a permanent mission representing the country at the WTO. They mostly cover WTO issues from their permanent mission at the UN.

239 Cf. van den Bossche and Zdouc, p. 86-89 and Table 3.1, p. 88. 
General's Conference Room. ${ }^{240}$ The central idea of the green room was to include the key actors in the discussions, including the main protagonists of a specific issue. The role of coalitions became important in order to ensure that smaller delegations could have their views represented. The green room concept has been the main vehicle for negotiations in smaller format during most of the negotiations. ${ }^{241}$ With the enlarged membership and a more active engagement by a growing number of delegations, the limited green room format was found to be exclusive, outdated and inappropriate. All topics are of interests to all members, who need to know about all aspects of the negotiations. This notion is reinforced by the fact that the negotiations are part of the single undertaking in the DDA, meaning that a decision affecting one policy area has direct implications for all other areas. It was also felt that the green room could not substitute the formal discussions and decision-making at the level of the General Council or the Trade Negotiating Committee. ${ }^{242}$ The calls for change became more frequent and louder and could no longer be ignored.

In response to this reality and the calls to open up the debates, one of the first actions and decisions taken by the new Director General Mr Azevêdo in the autumn of 2013 was to change the format of the meetings. He turned the green room into an open format, allowing all delegations to engage in the discussions and fully take part in the decision making process. It created transparency and a sense of ownership of the decisions taken. It also worked given that certain strictly imposed auto-disciplines were respected. ${ }^{243}$ According to Katz, who conducted a series of interviews with key negotiators in Geneva in spring 2015, 'several ambassadors said Director General Roberto Azevedo has improved the operation of the Green Room. ${ }^{244}$ Now he convenes a wide variety of countries in different configurations based on the issues under discussion'. This new format paid off and paved the way particularly for the results achieved at MC-IX (Bali) through an efficient, transparent and inclusive preparatory process.

In short, coalitions are a clear sign of the new era and have become an integral part of the panorama of the WTO's multilateral trading systems. One of the many merits of the coalitions is the circulation of information to all the stakeholders, thus enhancing

240 The green room has little to do with the colour of the wall paint, but essentially refers to a process whereby only a small number of delegations can attend meetings, as opposed to the total membership. The composition of the green room meetings mostly depend on the issues at stake. Those countries having a specific interest were normally invited to attend. Hence the process was ad hoc and variable.

241 Former Director General Lamy saw it as a starting point for his 'concentric circle' theory, by which the green room would be the centre of a set of concentric circles; the outcome of the discussions would then be presented in a larger format, the next circle (general council) and thus, through the ripple effect, reach all members.

242 The green room had gradually become an executive board meeting, i.e. the body where the key decisions were not only prepared, but essentially taken.

243 The time allocated to each speaker was reduced and strictly monitored.

244 S. Katz, 'Senior Advisor: Perspectives of Key WTO Ambassadors on Current Challenges in Global Trade Talks, Centre for the Study of the Presidency and Congress (Spring, 2015). 
transparency and inclusiveness in the decision-making process. It has changed the way negotiations are conducted and the process of building consensus.

\subsection{Moving from Traditional to 'new' Trade Issues in the WTO}

Since the creation of the WTO several efforts have been made to include a generation of what could be referred as 'new but not so new' trade related policy issues. The results have been mixed. What are the issues, what is the rationale for including them and what is the current position?

Less than two years after the entry into force of the WTO and at the first Ministerial Conference, MC-I (Singapore) held in December 1996, Ministers discussed the expansion of the trade agenda to include what are now mostly referred to as the 'Singapore issues'. ${ }^{245}$ The topics that were considered include labour standards, competition policy, investment, government procurement and trade facilitation. Generally, developing country members opposed the inclusion of some or all of these issues on the agenda and for many different reasons. One of the main arguments was that they felt that these were developed country priorities and that their own priorities lay elsewhere - more specifically in the field of development. ${ }^{246}$ As will be explained further, they feared that the introduction of labour standards would mainly serve protectionist arguments in developed countries. In the field of trade and investment and trade and competition policy, developing countries showed no interest, given that their domestic laws and regulations were often either non-existent or inadequate. Other topics raised at Singapore include the relationship between trade and environment, electronic commerce, information technology and regional integration. Despite some resistance, a work programme was launched and the Secretariat was mandated to undertake analytical work on some of the issues. What has happened since these initiatives were taken 20 years ago and what are the current discussions?

Five years after MC-I (Singapore), when the DDA was launched at MC-IV (Doha), the issues were raised again and with mixed results. Ministers decided that there would be no negotiations in the context of the WTO on the relationship between trade and core labour standards. This issue thus was technically removed from the agenda. With regard to the other Singapore issues such as the relationship between trade and competition law, the relationship between trade and investment policy, transparency in government procurement and trade facilitation, the WTO members decided that 'negotiations would start after the fifth Session of the Ministerial Conference and after they had agreed "by explicit consensus"

245 Ministerial Declaration adopted on 13 December 1996 at the Ministerial Conference, 18 December 1996, WT/MIN(96)/DEC, and 13 December 1996, WT/MIN(96)/16.

246 Looking at the discussions conducted in preparation for the Ministerial Declaration at MC-X (Nairobi) and the declaration that resulted from the Conference, the positions seem, with the exception of some topics (e.g. trade facilitation), not to have evolved much in nearly 20 years, with a continued resistance to bringing in some of the issues into the WTO discussions. 
at that session on the modalities of the negotiations'. ${ }^{247}$ In other words, the formal decision was deferred in order to allow for time to reflect further on these issues and conduct more research on the modalities to be agreed at the next session of the Ministerial Conference.

The fact that these issues were highly sensitive and divisive was seen at the fifth Ministerial Conference, MC-V (Cancún), which took place in September 2003 and failed largely due to the Singapore issues. Developing countries were unwilling to consent to the request of the European Communities and others to start negotiations mainly on the issues of trade and investment and trade and competition policies. This led to a major and unprecedented crisis at the WTO, as the Conference was simply ended before its conclusion, without a roadmap or backup plan. The deadlock that followed the collapse of MC-V (Cancún) lasted for nearly a year until summer 2004, when members agreed to a new Doha Work Programme at the General Council on 1 August $2004 .^{248}$ This is mostly referred to as the 'July package', as the agreement was reached at the very last minute in July: the final deadline that had been set by members. One of the key elements of that decision was the agreement not to start negotiations on the Singapore issues with the exception of trade facilitation, eventually resulting in the TFA which is currently subject to the ratification process by members. Positions have largely remained unchanged until MC-X (Nairobi), where the issues came up once again, providing for some opening for initiating a discussion on the issues. A later chapter of this study (Chapter 6) will review in more detail on how Ministers agreed on possible ways for expanding the trade agenda. The Ministerial Declaration contains language which has the potential to address a new generation of trade issues, but at the time of writing this study, it is unclear how the declaration will lead to follow up actions and in what ways.

The following part will mainly present an overview of where the discussions stand at the institutional level in the WTO on each of the topics.

\subsubsection{Trade and labour standards}

The link between trade and core labour standards is not new per se, as Hanson explains, and it has been addressed at different times since the creation of the International Labour Organization (ILO). ${ }^{249}$ The issue has become more prominent in recent decades with the globalization of trade and the increased interdependency between markets, alongside the rising competitiveness of developing countries in world trade. Formally, it was first raised in the WTO during MC-I (Singapore), and subsequently removed at MC-IV (Doha). The subject has always been highly contentious, with (mostly) developing countries being concerned that labour standards (and environmental issues) would be used by developed

247 Cf. Doha Ministerial Declaration, Articles 20, 23, $26,27$.

248 General Council, Doha Work Programme Decision adopted by the General Council on 1 August 2004, 2 August 2004, WT/L/579, often referred to as the 'July Package 2004'.

249 G. Hanson, 'Trade and Labour Standards' in K. Heydon and S. Woolcock (eds.), The Ashgate Research Companion to International Trade Policy (Ashgate Publishing, 2012), p. 279-290. 
countries as a pretext for protectionism, which would undermine the comparative advantage of developing countries in international trade. Much has been written in the academic literature on the role that international trade plays with regard to the adoption of international labour standards and how, in return, different labour standards affect trade, a country's comparative advantage, and likely implications for flows of foreign direct investment. ${ }^{250}$ Sapir addresses the issue from an ethical and economic angle, explaining the rationale for labour standards and how they interact with trade. ${ }^{251}$ Based on a review of the economic literature, Sapir finds that 'the economic case in favour of a social clause' is weak. There is no denying that poor social conditions are an important problem, on both ethical and economic grounds. The root of the problem, however, lies much less (if at all) with alleged artificial labour standards aimed at assisting competitiveness (so-called 'social dumping') than with poverty itself.'252 Bhagwati argues why 'many of the demands, emanating principally from the rich countries for imposing 'higher' environmental and labour standards on the poor countries as precondition for trade liberalization, ought to be rejected. ${ }^{253}$ More recently, Dehejia and Samy conducted empirical research on the relation between trade and labour standards and more specifically on the question if countries with lower standards obtain (unfair) advantages as well as the relationship between openness and labour standards. ${ }^{254}$ Their research concludes that 'the relationship between labour standards and trade may not be as clear as one would hope. Our estimates provide rather weak evidence in favour of the conventional wisdom and we find no evidence that trade openness has led to a worsening of labour standards (i.e. child labour).255

Some industrialized countries argued that the WTO should study labour standards as a first step toward bringing core labour standards into the organization, but developing countries argued that the WTO is not the appropriate forum to address labour rights. The statement made at the Conference was:

We renew our commitment to the observance of internationally recognized core labour standards. The International Labour Organization (ILO) is the competent body to set and deal with these standards, and we affirm our support for its work in promoting them. We believe that economic growth and development fostered by increased trade and further trade liberalization contribute to the promotion of these standards. We reject the use of labour standards for protectionist purposes, and agree that the comparative advantage of countries, particularly low-wage

250 D. Brown, 'International Trade and Core Labour Standards: A Survey of the Recent Literature', OECD Labour Market and Social Policy Occasional Papers(No. 43, 2000).

251 A. Sapir, 'The Interaction Between Labour Standards and International Trade Policy', 18 World Economy (1995), p. 791.

252 Ibid., p. 802

253 J. Bhagwati, 'Trace Liberalization and "Fair Trade" Demands: Addressing the Environmental and Labour Standards Issues', 18 World Economy (1995), p. 745.

254 V. Dehejia and Y. Samy, 'Trade and Labour Standards: A Review of the Theory and New Empirical Evidence', International Policy Center Working Paper (No. 49, 2007).

255 Ibid., p. 2. 
developing countries, must in no way be put into question. In this regard, we note that the WTO and ILO Secretariats will continue their existing collaboration. ${ }^{256}$

In accordance with the decision taken by members, no work is to be pursued on labour standards, but joint cooperation between the organizations is undertaken and perhaps has even intensified since that time, with many relevant studies and publications having been made analysing the interrelation between trade and employment. ${ }^{257}$ While in many ways the interaction between the institutions is working well, there is no initiative to reinsert the issue of core labour standards on the trade agenda for the purpose of rule-making.

\subsubsection{Trade and investment and trade and competition policy}

Two areas that had not been addressed in any specific way in the GATT are trade and investment, and trade and competition policies. In view of the globalization of trade and investment, both were considered of great significance by developed countries, but initially found a strong resistance on the side of developing countries, who felt that their main concerns had not been addressed. ${ }^{258}$ Nevertheless, ministers agreed at MC-I (Singapore) to set up two new working groups to examine the relationship between trade and investment and trade and competition policy.259 The working groups' tasks were analytical and exploratory, which is a rather common way for the WTO to proceed. First, there is analysis of the issues, then reflection on the policy issues and possible recommendations that may emanate from that process, possibly followed by a decision to establish rules. As stated in paragraph 20 of the Ministerial Declaration, the work would proceed 'on the understanding that the work undertaken shall not prejudge whether negotiations will be initiated in the future' and they would establish working groups 'to examine the relationship between trade and investment' and 'to study issues raised by Members relating to the interaction between trade and competition policy, including anti-competitive practices, in order to identify any areas that may merit further consideration in the WTO framework'.

The provision stated that the General Council will 'keep the work of each body under review, and will determine after two years how the work of each body should proceed', but that 'future negotiations, if any' would 'take place only after an explicit consensus decision is taken among WTO Members regarding such negotiations'. Consensus was never reached and the two topics were effectively put on hold at MC-V (Cancún) in 2003. Following the $\mathrm{MC}-\mathrm{V}$, the General Council of the WTO decided, as part of the 'July package'260 of 2004,

256 Ibid.

257 International Labour Office, A Fair Globalization: Creating Opportunities for All (The World Commission on the Social Dimension of Globalization, 2004); International Labour Office and World Trade Organization, Trade and Employment, Challenges for Policy Research (2007); International Labour Office and World Trade Organization, Globalization and Informal Jobs in Developing Countries (2009); M. Bacchetta and M. Jansen (eds.) Making Globalization Socially Sustainable(ILO and WTO, 2011).

258 Cf. Laker, p. 65.

259 Cf. Singapore Ministerial Declaration (1996)

260 Ibid. 
that no further work would be undertaken toward negotiations on competition policy and trade and investment for the duration of the DDA.

What is the rationale for having rules covering trade and investment and trade and competition policy and where do the discussions stand at present?

\subsubsection{Trade and investment}

The growing importance of the relationship between trade and investment in the globalizing world economy is an undeniable reality and much associated with the way business is conducted. As will be discussed in the next chapter, 'globalization' of world trade has strengthened the nexus between trade and investment, making them very tightly linked to each other. Trade generates investment and in return investment generates more trade. These are essentially two sides of the same coin, becoming ever more interlinked and making it harder to separate the policy aspects related to each. The discussions on the nexus between trade and investment is even more apparent in the context of the discussions on Global Value Chains (GVCs) and the challenges faced by some countries to better connect to international markets for their products. ${ }^{261}$ For many companies the question is no longer whether to choose between whether to trade or to invest, but to do both: to trade and invest as the two policy decisions are complementary. As is argued by the Peterson Institute, the logical implication would be to address the interlinkages between trade and investment decisions from a rules' based perspective. ${ }^{262}$ Trade is governed by multilateral trade rules, but investment is not governed by any multilateral rules. Various initiatives in that respect have been taken in the past and outside the WTO framework but without much success. The negotiations on a Multilateral Investment Agreement (MIA) at the OECD lasted from 1970 to 1998 and finally failed. According to the International Institute for Economics, there are two main reasons that could explain the failure of the Multilateral Investment Agreement, one that is related to differences between the negotiators on substantive issues and one that is more closely related to the role played by the NGOs. ${ }^{263}$

The logic or rationale of addressing investment in the GATT/WTO system had become particularly evident in the 80 s and early 90s, with flows of FDI growing exponentially. ${ }^{264}$ As Gary Hufbauer observes, 'in the three decades since 1980, nominal world GDP has expanded three times; merchandise trade has expanded six times, while the stock of FDI has expanded twenty times'. ${ }^{265}$ Despite the economic realities, investment issues have never been fully addressed in the GATT and again are not on the current WTO negotiating agenda.

261 The challenges related to connecting to markets through Global Value Chains will be illustrated in Chapter 3.

262 A. Aslund, 'The World needs a Multilateral Investment Agreement', Peterson Institute for International Economics, Policy Brief (2013).

263 E. M. Graham, 'The MAI and the Politics of Failure: Who Killed the Dog?' in E. M. Graham, Fighting the Wrong Enemy, Anti Global Activists and Multinational Enterprises, (The Institute for International Economics, Washington DC, 2000).

264 Data on FDI flows will be presented in Chapter 3.

265 G. C. Hufbauer, 'FDI Facts and Figures', World Economic Forum 2012: Global Agenda Council for Trade. 
It is one of the issues on which the results of the Uruguay Round had not met the expectations of developed countries. Investment related issues are only partially addressed in the TRIMS Agreement, where the relevant provisions consist of little more than a ban on certain performance requirements. ${ }^{266}$ The most important Uruguay Round provisions that touch upon investment are the Mode 3 (commercial presence) commitments that members made under the GATS and which address the conditions for services providers to establish in a market of supply. ${ }^{267}$ Other than that, there are no stand-alone provisions on trade and investment in the WTO as such.

This also explains why following the failed Ministerial Conference at Cancún no work was undertaken by the WTO on the connection between trade and investment. The protagonists have strong arguments in favour of renewing the efforts and based on various economic reasons, to reflect on a possible MIA. Aslund argues that a future Multilateral Investment Agreement should be ambitious in order to be meaningful. ${ }^{268}$ Given the likely opposition that this will find, he suggests that the Multilateral Investment Agreement should be a plurilateral agreement within the framework of the WTO and not a universal one. In his view, this should not be a problem in the sense that the WTO already harbours other plurilateral agreements, some of which are likely to extend the benefits to the membership as a whole.

As will be discussed in chapter 6, the outcome of the last Ministerial Conference, MC-X (Nairobi) may offer new perspectives on addressing the relationship between trade and investment. Since the beginning of this year, the Secretariat has initiated internal talks on the matter to encourage reflection without making any premature decisions.

\subsubsection{Trade and competition policy}

The discussion on the relationship between trade and competition policy dates back to the time that the Havana Charter was drafted, which should have resulted in the International Trade Organization. It was then referred to as 'restrictive business practices'. The issue was also tentatively taken up in the late 1950s in the GATT, and later by both UNCTAD and the OECD, who are still actively pursuing analytical and policy work in this field. The attempts to bring this onto the WTO agenda faltered following MC-V (Cancún). The July package reconfirmed the positions taken at MC-V and effectively halted any work on the issue. ${ }^{269}$

266 The Agreement on Trade-Related Investment Measures (TRIMs), Marrakesh Agreement 1994. According to the illustrative list in the Agreement (Annex), there are five broad categories of measures that are considered as TRIMs and are thus prohibited. These include local content requirements, trade balancing requirements and trade balancing restrictions, foreign exchange balancing restrictions and domestic sale and/or exportation restrictions.

267 This was discussed in section 2 with regard to services.

268 Cf. Aslund, p. 7.

269 'July Package 2004'. 
As is observed by Anderson and Muller, since the work at the WTO was put on hold, international cooperation in the field of policy has moved ahead in various fora, including the International Competition Network, the UNCTAD Intergovernmental Group of Experts on Competition Law and Policy and the OECD Competition Committee. ${ }^{270}$ As these authors note, some and perhaps the majority of competition law practitioners would take the view that such international cooperation as is needed with respect to the field of competition policy is already being effectively implemented in these fora. The authors also explain how competition policy already made its way into the WTO by way of the GATS and the TRIPS Agreement, both of which contain important though limited provisions relating to fair conditions of competition and international cooperation to facilitate the control of anticompetitive practices. ${ }^{271}$ In that regard, they observe that

it has proven impossible to exclude competition policy considerations altogether from the WTO Agreements. Indeed, the importance for the system of measures to ensure the competitive operation of markets is reflected in a number of provisions and subordinate instruments that have been incorporated in the various agreements over the years, particularly with the 1994 transition from the GATT to the WTO.

It is also observed that the North/South divisions were not quite as firm on competition policy as they were on other topics. Anderson and Muller argue that 'Developing countries mainly opposed negotiations, citing both a lack of negotiating capacity and apprehensions concerning the implications of a multilateral framework for related policies and "policy space"..272 While these arguments have their merits, Teh points to some other realities, which seem to contradict these points. Teh analysed 76 RTAs and states that 'nearly threequarters of the RTAs contain competition policy provisions'. Despite the reluctance of many developing countries to enter multilateral negotiations on competition policy, 50 of the 68 RTAs with developing countries as members have a competition policy provision or chapter. ${ }^{273} \mathrm{He}$ goes on to argue that the importance of competition policy rules is again underscored as

[m]ore than 40 percent of the RTAs in the sample stipulate promotion and advancement of the conditions of fair competition as an objective of the RTA suggestion that competition considerations are not necessarily subordinate to the goal of expanding trade and investments. A large number of the RTAs in this

270 R. Anderson and A. Muller 'Competition Policy and the Multilateral Trading System: Three Propositions, an Observation and some Questions for Reflection’, discussion paper, 6December 2013.

271 Ibid p. 10.

272 R. Anderson and A. Muller, 'Competition Law/Policy and the Multilateral Trading System: A Possible Agenda for the Future', Think Piece for the E 15 Expert Group on Competition Policy and the Trade System, ICTSD and the World Economic Forum (2015), p. 1.

273 R. Teh, 'Competition Provisions in Regional Trade Agreements' in A. Estevadeordal, K. Suominen and R. Teh, Regional Rules in the Global Trading System (Cambridge University Press, 2009), p. 418-491. 
survey included competition disciplines in the chapters on investment, services, government procurement and intellectual property. ${ }^{274}$

This shows that developing countries are already involved in competition rules. Another study by Anderson and Muller explains how competition policy can contribute to poverty reduction. ${ }^{275}$ This led the same authors to argue that on the basis of research and scholarly writings published before and after the work undertaken by the WTO in conjunction with other bodies and organizations that

while clearly there is no agreement in the international community on the objectives and "modalities" for multilateral negotiations in this area - or even the need for such a project - there is also little disagreement, at least among those that have studied the issues, that trade liberalization and competition policy are both important for development; that they are mutually supportive in important ways; and that both fields can learn from and be reinforced by the other. ${ }^{276}$

They then provide specific examples of their proposition that effective national competition policies are vital to the success of the multilateral trading system, including its contribution to development.

Finally, in another study Anderson and Evenett (2006) observe that 'competition elements in many recent RTAs go well beyond the degree of cooperation that was envisioned in the proposals for a multilateral framework on competition policy in the WTO'. ${ }^{277}$ They continue their reasoning by observing that

indeed, in light of the large and growing number of provisions on competition policy in regional trade agreements, the issue is no longer whether competition policy and trade liberalization can be meaningfully linked but whether the relevant synergies will be harnessed only in regional arrangements or also in the multilateral context.

To conclude, there is much more convergence in the policy relevance of competition rules in relation to trade than what might have been suggested. Obviously it remains up to the members to decide on if, whether and/or when this area should formally be included on the agenda and on how to take it forward. The outcome of MC-X (Nairobi) may offer new perspectives on the issues.

274 Ibid.

275 R. Anderson and A. Muller, 'Competition Policy and Poverty Reduction: A Holistic Approach', Staff Working Paper, Economic Research and Statistics Division(ERSD 2913-02, 2013).

276 Ibid., p. 3.

277 R. Anderson, and S. Evenett, 'Incorporating Competition Elements into Regional Trade Agreements, Characterization and Empirical Analysis,' working paper available at http:/www.evenett.com/research/workingpapers/ComprincInRTAs.pdf. 


\subsubsection{Government Procurement Agreement}

Initially and prior to the creation of the WTO, the GATT rules included four plurilateral agreements: on civil aircraft, dairy products, bovine meat and the government procurement. Contrary to multilateral trade agreements, this type of agreement consists of a small number of members who subscribe to these agreements, mostly on a voluntary basis. ${ }^{278}$ The agreement on civil aircraft mainly relates to tariffs, with the subscribers consisting of members that are either producing aircraft or repairing parts and components of aircraft. The agreements on dairy products and bovine meat are no longer in operation as they were made redundant by the Agriculture Agreement covering the same matters following the conclusion of the Uruguay Round.

The Government Procurement Agreement (GPA) resulted from the Tokyo Round negotiations in 1979, thus extending competition to the domestic spheres. This was already considered a major step forward at that time and as bringing more economic efficiency in public procurement, including by the reduction of costs. ${ }^{279}$ The GPA aims to ensure that its signatories do not discriminate against the products, services or suppliers of other parties to it with respect to the government procurement opportunities that are opened to foreign competition. ${ }^{280}$ The GPA also requires transparent and competitive purchasing practices in the markets covered. The GPA applies only to those WTO members that have agreed to be bound by it. The GPA has been updated and revised several times, most recently in 2012 . The revised GPA entered into force on 6 April 2014. ${ }^{281}$ The main requirement for it to enter into force was that two thirds of the parties accept the Protocol of Amendment. This objective was achieved on 7 March 2014 when Israel approved the Protocol.

According to various studies, the government procurement market represents $15-20 \%$ of the world economy and is an increasingly strategic focus for governments. ${ }^{282}$ It is estimated that the parties to the revised GPA will see gains in market access of an estimated US\$ 80 billion to US\$ 100 billion annually for their businesses. ${ }^{283}$ These gains in market access are expected to be obtained as a result of adding a large number of government entities (ministries and agencies) to the scope of the GPA and from new services and other areas of public procurement activities being included in its expanded coverage.

278 While in principle members decide for themselves whether or not to join a plurilateral agreement, countries acceding to the WTO are mostly required to take a commitment to become a member of the Government Procurement Agreement (GPA) as part of their accession package. This implies more stringent rules for the newcomers compared to the original WTO Members, even if it is widely agreed that the membership to the GPA economically should be beneficial and support economic efficiency.

279 The Agreement on Government Procurement, Marrakesh Agreement 1994, Annex 4.

280 The Agreement is very specific in terms of the thresholds above which international competition needs to be ensured and how contracts can be awarded, i.e. which tender procedures can be applied.

281 Government Procurement: Opening Markets and Promoting Good Governance, WTO (2015).

282 R. Anderson, and S. Arrowsmith, (eds.) The WTO Regime on Government Procurement: Challenge and Reform (Cambridge University Press, 2011), p. xxvi. See also ‘WTO at Twenty', p. 29.

283 As contained in WTO Press release of 7 April 2014. 
The GPA has been reviewed and was extended to include provisions on the use of electronic procurement tools. A number of revisions were introduced with a view to prevent corrupt practices in the parties' procurement systems, to promote the conservation of natural resources and to protect the environment through the application of appropriate technical specifications. In addition, the new GPA has made it easier for developing and least-developed economies to join. After all, it provides a means to save revenue and reduce transaction costs.

In addition to the procedural amendments, the coverage of the GPA has been expanded to more than 500 additional central, sub-central and other government agencies. This led to a further improvement in the coverage of goods, a lowering of the thresholds applied by some parties, coverage of new services sectors by almost all of the parties, including telecommunications services by almost all parties, construction services by all parties, and also the elimination of miscellaneous restrictions on market access by several parties.

To further illustrate the rapidly growing importance of the GPA, it is noted that at the time of the creation of the WTO, the GPA had a total of 22 WTO members. This number has more than doubled to include 19 parties covering 47 members at present. In addition to the current WTO members in the GPA (including the European Union's 28 Member States), nine other WTO members - Albania, Australia, China, Georgia, Jordan, the Kyrgyz Republic, Oman, Russian Federation and Tajikistan and- have applied to join. ${ }^{284}$ A further six WTO members - Afghanistan, Kazakhstan, Mongolia, Seychelles, Saudi Arabia and the former Yugoslav Republic of Macedonia — have provisions regarding accession to the GPA in their respective WTO accession protocols. ${ }^{285}$ The economic benefits that can be drawn from the GPA are tremendous, both for the world as a whole and more specifically for individual countries. For most of the Article XII members, the application of the GPA is a big challenge as generally they did not have a government procurement tradition and history under their central planning systems. This required introducing new laws and regulations as well as changing practices, which ultimately led to economic savings at the national level, by introducing completion in an area that was mostly reserved to traditional suppliers.

The revised WTO agreement on government procurement will open markets and promote good governance in the participating member economies. The improved provisions and coverage of the GPA thus represent an important and welcome extension of the trading system to an area that was mostly closed to competition and has an enormous potential for new trade opportunities, enhancing competition and efficiency and is a tangible and measurable outcome of the negotiations.

\footnotetext{
284 Ukraine ratified the revised GPA on 16 April 2016 and subsequently became a full GPA member..

285 Data from WTO website, https://www.wto.org/english/tratop_e/gproc,_e.ht, last visited 24 January 2017.
} 


\subsubsection{Trade Facilitation Agreement}

It is recalled that the initiative to include trade facilitation under the WTO umbrella of trade rules goes back to the MC-I (Singapore) and led to a successful conclusion at MC-IX (Bali). It resulted in the Trade Facilitation Agreement (TFA), which is the first multilateral agreement concluded at the WTO since its creation. The TFA could only be implemented following the signing of the protocol by two thirds of them, a process which came to a successful conclusion in February of this year. The TFA will be discussed in detail in Chapter 5 by way of a case study on how trade capacity can be provided to developing countries in an effective manner.

\subsubsection{Information Technology Agreement}

The first Ministerial Conference, MC-I (Singapore) led to the first Information Technology Agreement (ITA) agreed by the WTO members. ${ }^{286}$ It is a typical example of a sectorial initiative aimed at liberalizing trade in a specific area and providing new market access opportunities. The first ITA initially counted 29 members, but that number increased rapidly. The ITA now includes 82 WTO members, who collectively account for $97 \%$ of world trade in IT goods. ${ }^{287}$ Given the rapid technological developments as well as the expansion and evolution of trade in technology goods, members decided at the celebration of the ITA's 15th anniversary to expand coverage to a wider range of products. The negotiations involved all the key producers and traders of IT products. While the negotiations were challenging, they resulted in a far reaching sectorial agreement and covers the widest range of IT products. As will be explained and analysed in detail in Chapter 4, the agreement followed a critical mass approach, thus involving all stakeholders. ${ }^{288}$ It is noteworthy that the ITA members inscribe the tariff concessions, that is, elimination of duties in their tariff schedules, which de facto implements the ITA on a MFN basis. In other words, all the benefits of the ITA are automatically extended to the entire WTO membership by virtue of the MFN principle. Ministers endorsed the results of the negotiations at MC-X (Nairobi) and in accordance with the Ministerial Declaration, the first set of tariff cuts were implemented in July 2016, with a second tranche of cuts to be implemented in 2017.289

\subsubsection{Trade and environment}

The issue of trade and the environment has from the outset encountered less opposition in the debates and has most recently led to a constructive and encouraging engagement and outcome of the discussions. It predates MC-I (Singapore), as the Marrakesh Ministerial Decision on Trade and Environment already contained a work programme designed to

286 As contained in the Ministerial Declaration on Trade in Information Technology Products, 13 December 1996, https://www.wto.org/english/docs_e/legal_e/itadec_e.pdf, last consulted on 24 January 2017.

287 Cf. https://www.wto.org/english/news_e/news16_e/ita_01nov16_e.htm last consulted at 24 January 2017.

288 Chapter 4 will provide insights in the various negotiating techniques applied in the GATT and WTO.

289 Cf. Ministerial Declaration on the Expansion of Trade in Information Technology products, 16 December 2015, MC-X (Nairobi). 
clarify the relationship between trade measures and environmental measures and to develop recommendations on whether any modifications of the rules of the multilateral trading system were required. ${ }^{290}$ This was followed by a formal decision at MC-IV (Doha), contained in the DDA paragraphs 31(i) and (ii), which state that:

with a view to enhancing the mutual supportiveness of trade and environment, we agree to negotiations, without prejudging their outcome, on (...)

(i) the relationship between existing WTO rules and specific trade obligations set out in multilateral environmental agreements (MEAs). The negotiations shall be limited in scope to the applicability of such existing WTO rules as among parties to the MEAs in question. The negotiations shall not prejudice the WTO rights of any Member that is not party to the MEA in question;

(ii) the procedures for regular information exchange between the MEA Secretariats and the relevant WTO committees, and the criteria for the granting of observer status.

These decisions have provided the backbone for the work undertaken since. At MC-I (Singapore), developed countries tried to ensure compatibility between the multilateral environmental agreements (MEAs) and the WTO system. This was not supported by developing countries, many of whom raised concerns over 'green protectionism'. Nevertheless, an agreement was reached to establish the Committee on Trade and Environment as a permanent body of the WTO, recognizing that ' $[\mathrm{t}]$ he breadth and complexity of the issues covered by the Committee's Work Programme shows that further work needs to be undertaken on all items of its agenda'. Paragraph 16 further noted that the ministers 'intend[ed] to build on the work accomplished thus far, and therefore direct[ed] the Committee to carry out its work, reporting to the General Council, under its existing terms of reference'. ${ }^{291}$

Separately, the Doha Ministerial Declaration paragraph 31(iii) stated that 'With a view to enhancing the mutual supportiveness of trade and environment, we agree to negotiations, without prejudging their outcome, on (...)

(iii) the reduction or, as appropriate, elimination of tariffs and non-tariff barriers to environmental goods and services'.

In order to pursue this objective, members have considered various approaches identifying the goods to be considered and the tariff treatment to be accorded, as well as the way non-tariff measures should be tackled. These ideas and approaches are reflected in the proposals, including the 'list approach', consisting mainly of establishing lists of goods to be

290 Marrakesh Decision on Trade and Environment, Marrakesh Agreement, p. 457, Marrakesh, 14 April 1994.

291 Cf. Singapore Ministerial Declaration, 18 December 1996, WT/MIN(96)/DEC. 
subject to reduction commitments, the 'integrated approach', including a multilaterally agreed list of environmental activities agreed by members, subject to reduction commitments, and the 'request and offer approach', which evidently is based on offer and request of environmental goods to be subjected to the reductions or combinations of various approaches. ${ }^{292}$

The discussions on ways to liberalize trade in environmental goods and services advanced in 2015, but mostly outside the formal multilateral framework. There is the perspective of extending the outcome of the liberalization efforts to the WTO membership by virtue of the MFN principle. As was reported by WTO's Deputy Director General Brauner at the occasion of the Conference of the Parties (COP) 21 discussions in Paris on the environment, a group of WTO members are negotiating an Environmental Goods Agreement to lower their trade barriers on a number of important environmental products. ${ }^{293}$ There are currently 17 members involved in those negotiations, which account for the majority of global trade in environmental goods. The discussions include around 450 environmental goods. As stated by Brauner, 'success would help to disseminate cutting-edge technologies at much lower costs while also stimulating innovation and strengthening the green economy around the world. Importantly, the benefits would apply to the whole WTO membership'. ${ }^{294}$

With regard to non-tariff barriers, the work in the Committee has been more limited, given the complexity of the issues involved, including on customs procedures, standards, technical regulations, conformity assessments procedures, labelling schemes, intellectual property rights and so on.

As was observed by the Chairman of the Environmental Goods Agreement, the Australian Minister for Trade and Investment, Andrew Robb, 'considerable progress is under way in the liberalization of environmental goods and to the benefit of the entire WTO's membership. The work will be actively pursued in 2016 with a view of bringing these to a successful conclusion'.295

\subsubsection{Electronic Commerce}

In view of the rapidly increasing significance in the 1980s and early 1990 s of electronic commerce as a vehicle for trade, members recognized the need to consider developing specific trade rules to cover this area. Mainly at the initiative of some of the more advanced

292 The negotiating techniques applied in tariff negotiations are discussed in Chapter 4.

293 Deputy Director General Karl Brauner, speaking at an event at the UN climate change conference-COP21

- in Paris on 9 December, called on the international trade community to support collective efforts to address climate change. The 21st Conference of the Parties (COP) met in Paris 30 November to 11 December 2015. See WTO News item, 9 December 2015.

294 Ibid.

295 Statement by the Chair of the EGA, the Hon Andrew Robb AO MP, Minister for Trade and Investment, Australia, Nairobi, Kenya, 14 December 2015. 
developed countries, this subject was brought into the ambit of the WTO. The WTO work programme on electronic commerce resulted from the MC-II (Geneva) and was adopted by the General Council on 25 September 1998. ${ }^{296}$ As is normally the practice in the WTO, the first stage consists of analysis and a better understanding of the issues involved. The work programme that was subsequently agreed includes an examination of all trade-related issues relating to global electronic commerce. The work will need to take into account the economic, financial, and development needs of developing countries.

Electronic commerce has been on the agenda of most if not all Ministerial Conferences, but without substantive progress. At these conferences Ministers generally content themselves taking note of the reports from the General Council and subsidiary bodies on the Work Programme on Electronic Commerce. Efforts have been made to reinvigorate that work, based on Ministerial decisions to that effect, but until most recently little movement has been observed. Ministers have so far largely agreed that members would maintain their current practice of not imposing customs duties on electronic transmissions and this position was reconfirmed at the following Ministerial Conferences, including at Nairobi. ${ }^{297}$ Following MC-X (Nairobi), the discussions on electronic commerce are again picking up and in different formats.

\subsubsection{Regional trade integration}

A development that is certainly not new but that has gained considerable ground in recent years and which directly affects the multilateral trading system concerns regional trade integration - more specifically by way of establishing RTAs. According to Acharya, as at15 October 2015, '265 RTAs had been notified to the WTO and were in force', with the estimate being that 'around a hundred RTAs are in force but have not been notified to the WTO, and that an equal number are currently being negotiated.298 She explained how the nature of the RTAs has changed. They are more sophisticated than before, and frequently include provisions on services, investment, intellectual property rights, competition policies, as well as on labour and environment. This suggests new standards are being created, standards which are different from the WTO. Azevedo observes that 'the goal of modern RTAs is to provide preferential market access but also increasingly to go behind the borders to address other potential barriers to trade.' 299 While the relationship between regionalism and multilateralism merits an in-depth analysis, the time and space constraints in this thesis do not allow for that. Instead, a brief discussion is offered on the main elements in the current debate with regard to the interrelation between the two distinct approaches and with a view of achieving further and deeper trade liberalization.

\footnotetext{
296 Ministerial Conference, Second Session, Ministerial Declaration, 25 May 1998, WT/MIN(98)/DEC/1.

297 Work Programme on Electronic Commerce, Ministerial Decision of 19 December 2015, WT/MIN(15)/42, $\mathrm{WT} / \mathrm{L} / 977$.

298 R. Acharya, 'Regional Trade Agreements: Recent Developments' in R. Acharya (ed.), Regional Trade Agreements and the Multilateral Trading System (Cambridge University Press, 2016), p. 1.

299 Ibid.,, R. Azevêdo, 'Foreword'.
} 
Regional integration stands in stark contrast with multilateral trade liberalization and the two approaches thus differ considerably. The benefits of trade liberalization under RTAs are by definition limited to those parties subscribing to the RTAs and so they are exclusive. This stands in contrast with the GATT/WTO system, which is universal and inclusive, mainly as a result of the MFN principles, ensuring that all benefits accrue to the entire membership. Regional integration is explicitly tolerated under the legal system of the GATT and again in the multilateral trading system of the WTO. Article XXIV of the GATT is designed to ensure that countries which form regional trade agreements move to genuinely free trade among themselves and provide adequate compensation for any damage done to the trade interests of other WTO members. ${ }^{300}$ While the rules provide the legal basis for regional arrangements in the WTO, they can be of major concern. Winters explains the processes of regional integration and argues that 'the mega-regionals violate multilateralism because either the countries excluded from them cannot accept their rules for world trade, thus fragmenting the world trading system, or they do accept the rules but have played no role in their design.'301

Taking into account the various forms in which regional integration can be achieved, the Agreement provides guidance on how to proceed and the criteria to take into account ensuring that regional integration does not become an obstacle to trade. In economic terms, it is generally held that the 'trade creation' effects of regional integration initiatives should outweigh the 'trade distortive' effects. ${ }^{302}$ In other words, the overall net balance of the regional integration initiative should be a positive one, with a net benefit for the world as a whole. As is discussed in the economic literature and in various studies and reports, including those prepared by the WTO Secretariat itself, this is a tricky exercise and hard to actually establish. ${ }^{303}$ In the case of a customs union or free trade area, members must remove

300 Article XXIV of the GATT contains specific language detailing the conditions and criteria applying to regional integration initiatives, e.g. customs union, free trade arrangements, preferential schemes etc. These provided the legal basis for the European Union to establish its customs union in the 1950s and later to cover its preferential schemes with its overseas territories. It also became evident that the provisions of Article XXIV had some shortcomings, as the question whether the condition in the relevant provisions had been met could never be answered. This hampered the discussions and debates for many years, until improvements in the provisions were finally adopted, enhancing the transparency principles on regionalism.

301 L. Winters, 'The WTO and Regional Trading Agreements: Is it All Over for Multilateralism?' University of Sussex Working Paper (No. 82-2015).

302 Regional integration can lead to trade creation by eliminating trade obstacles through tariff reduction and/or elimination between the constituent parties as well as a reduction of non-tariff measures. It can also lead to trade diversion as the conditions provided to the parties of the regional entity are better than those provided to the non-parties, thus giving an economic advantage to the region. The difficulty consists of making the economic calculations between the trade creation and trade diversion effects and draw conclusions on the over-all effects.

303 WTO's World Trade Report 2011, The WTO and Preferential Trade Agreements: From Co-existence to Coherence (Geneva, 2011); R. Baldwin and C. Freund, 'Preferential Trade Agreements and Multilateral Trade Liberalization' in Preferential Trade Agreement Policies for Development: A Handbook (World Bank, 2011). 
duties and other restrictions affecting 'substantially all trade' among them. ${ }^{304}$ Other rules require a detailed plan and schedule to show how the members will move to free trade, and these are examined to confirm that Article XXIV's requirements have been met.

In the GATT, it was very difficult and challenging to define when these conditions had been met. This led members to consider ways to strengthen the rules and disciplines with a view to bringing more transparency and clarity on how the agreements can be applied. Through the Marrakesh Agreement, further clarifications were provided, as contained in an Understanding that was negotiated to that effect. ${ }^{305}$ The new Understanding clarifies and/or touches upon most of the concerns that had come up and was considered to make it easier to reach agreement on whether regional agreements meet Article XXIV rules. The Agreement also contains provisions on the examination of regional trade agreements, which are mostly procedural. ${ }^{306}$ While some of these procedures were already applied under the GATT, they have now explicitly been codified and been strengthened further, notably by a decision that if any interim agreement does not contain the required plan and schedule, the WTO working party examining the Agreement shall make appropriate recommendations to fill the gap, and the Agreement shall not be brought into force unless the recommendations are accepted.

As discussed by Acharya et al, the reality of today is that some rather important new and economically significant initiatives were taken in recent years and cover basically all regions, including most of the key players and world traders. ${ }^{307}$ Most large economies are in one way or another associated with a regional integration initiative, receiving much public attention. The two largest initiatives include the Trans-Pacific Partnership (TPP) and Transatlantic Trade and Investment Partnership (TTIP), both involving the United States, reaching out to both its transatlantic and Pacific partners. Separately there is the Regional Comprehensive Economic Partnership (RCEP) which includes some 16 Asian and Pacific countries ${ }^{308}$ Interestingly enough, China is not included in the TPP discussions, which could explain China's interest in RCEP, and could also explain its recent initiative referred to as 'One belt, one road', with the idea of reviving a modern version of the ancient silk road linking East and West by land and sea. ${ }^{309}$ As will be argued in the next chapter, regional integration is becoming increasingly important in the context of the emerging GVCs as well as regional

304 One of the often unresolved questions is what is meant by 'substantially all trade' and how to measure it? How can the economic effects of the harmonisation technical regulations, standards, laws in the area of services and intellectual property rights, agricultural regulations be quantified?

GATT 1994: Understanding on the Interpretation of Article XXIV of the General Agreement on Tariffs and Trade 1994.

306 Transparency Mechanism for Regional Trade Agreement, Decision of 14 December 2006 (WT/L/671).

307 Cf. Dehejia and Samy; also, R. Acharya et al., 'Landscape', in J.P. Chauffour and J.C. Maur (eds.) Preferential Trade Agreement Policies for Development: A Handbook (World Bank, 2011).

308 The Trans-Pacific Partnership (TPP) brings together a dozen of countries in North America and Asia, the Transatlantic Trade and Investment Partnership (TTIP) is a partnership that includes the US and Europe, the Regional Comprehensive Economic Partnership (RCEP) includes some 16 Asian and Pacific countries, to mention just a few important initiatives.

309 The 'One Belt One Road' initiative was launched by Prime Minister Li Keqiang in March 2016, Cf. website English.gov.cn, last consulted 11 August 2016. 
production networks. The integration in Asia plays a significant role in facilitating that process.

While there is considerable concern about RTAs being exclusive, the two paths to liberalization - regional and multilateral - can converge in order to spread the economic benefits to the world as a whole. The WTO report (2011) offers a number of options for increasing coherence between the regional agreements and the trading system regulated by the WTO. As is pointed out by the WTO the global production networks may be prompting preferential trade agreements to go deeper and deeper as good governance on a range of regulatory areas is far more important to these networks than further reductions in already low tariffs. ${ }^{310}$ It is found that the two approaches are not mutually exclusive and actually can be supportive for overall trade liberalization, provided certain conditions are met. ${ }^{311}$ Acharya points out that 'the research in this book has shown that, while RTAs are introducing new standards for some issues, the extent to which this is happening is perhaps not as dramatic as one would have expected from the spectacular increase in RTAs. Moreover, for certain issues including those for which there are as yet no WTO rules, policy changes brought about through RTAs would be beneficial to all trading partners including third parties.' 312 She suggests addressing these points through a broader discussion among WTO members.

Given the complementary features between the two approaches, increasing thought needs to be given on the compatibility issues in relation to the regional integration initiatives and the multilateral trading system, rather than simply focusing on how to improve and strengthen the rules. For many of the issues addressed in RTAs, there are currently no WTO standards. It is for that reason that Acharya suggests 'to look more closely at such provisions in RTAs to see to what extent they are creating new standards, whether there are particular patterns by which these standards are set, and whether by creating such standards, a certain group of WTO members is pulling away from the rest. If this is the case, we must also ask the question whether those same rules and standards would be beneficial for all members or whether different speeds and different standards are acceptable and desirable for the membership.' 313 The related question is what scope exists for convergence, given that some of the regional integration schemes cover elements that are negotiated at the multilateral level? This is the key question and could not only bring to an end the academic debate, but also assist in providing some practical solutions to the trade negotiators and be beneficial for the world trading system.

\footnotetext{
310 A detailed discussion on this point is offered in Chapter 3.

311 Cf. Baldwin and Freund, 'Preferential Trade Agreements', as well as the WTO report 2011, which contains specific references to the literature supporting this argument.

312 Cf. Dehejia and Samy, p. 705.

313 Ibid., p. 706.
} 


\subsection{Conclusion}

This chapter analysed the WTO system to better understand how it differs from the GATT, and included a discussion of the challenges that members face in the new multilateral trading system. The GATT system had reached its limits in the ways it could address trade issues, which made it indispensable that it be replaced by the WTO as a permanent institution. The number of trade measures escaping the multilateral trading rules had steadily increased over the years and undermined the rules based system. The ways in which trade was conducted, including the growing importance of services in world trade, had been another determining factor leading to a revision and expansion of the trade rules. Agriculture for example, a sector that had mostly escaped the trade rules in the GATT, not only needed to be covered by specific rules but also be subjected to liberalization. Finally, given the growing importance of intellectual property rights in international trade, the WTO needed to establish trade related rules in that area.

In the comparison of the WTO system to the GATT, particular attention was given to the institutional framework of the WTO, its objectives, main functions and the ways in which it operates. Each of the functions was reviewed and information provided on how the functions are being performed. It was argued that in particular the revamped dispute settlement system has been a key element in the new multilateral trading system enhancing the credibility of the rules-based system. Trade disputes are now again addressed within the ambit of the trading system, instead of outside the rules, and this strengthens the system. It was also shown that the WTO has a much stronger institutional basis and addresses a broader range of issues than the GATT.

It is evident that the WTO's negotiating function, one of the central pillars of the WTO, is not working as initially envisaged and has not led to the expected results. Explanations were provided as to why the DDA has stalled and what perspectives the outcome of the MC-X (Nairobi) may offer on the ways forward. It was argued that the rapidly expanded membership boasts an increasingly diverse range of WTO members in recent years, and that this means that any decision will need to take into account a broader range of views. There is a stronger interest for developing countries to take fuller part in trade and trade negotiations, driven by the recognition that trade can help them in pursuing their economic growth and development objectives. Given the increased diversity of the membership and taking into account different levels of economic developments and ambitions of the members, it is a challenge to reconcile all the aspirations and objectives in the negotiations. While the process is challenging, it was also argued that the result would be inclusive and ensure a universal application of the rules of the multilateral trading system. As WTO decision-making requires consensus by the membership, it brings all members on board on all decisions.

This chapter also showed how coalitions can play a critical role in assisting members aligning their positions on specific topics and defending common policy objectives. The alliances and coalitions are increasingly topic-based, with developed and developing 
countries often joining forces. This process of consultation and coordination between the members with regard to the issues under negotiation is a productive way of moving forward and at the same time testifies to the dynamics of the process and engagement by all stakeholders.

It was argued that in addition to the increased membership the larger number of topics covered by the WTO rules compared to the GATT make the negotiations increasingly complex. Each of the areas is very technical, requiring advanced levels of specific knowledge and skills. Moreover, the single undertaking approach in the DDA was meant to ensure that the negotiations would move forward in parallel and that trade-offs could be made between the areas under negotiation. In reality, negotiations progressed at different speeds and tradeoffs between the areas under negotiation were not pursued. It was argued therefore that the single undertaking approach turned out to be a stumbling block for progress of the DDA rather than a building block.

With regard to attempts made to bring a new generation of trade related issues on the WTO agenda, the results have been mixed. The relationship between trade and investment policies and trade and competition policies had initially been put on the agenda for consideration, but were removed from the negotiating agenda shortly after the launching of the DDA. It is argued that these trade-related issues logically would need to be covered in one way or another under the trade rules. Arguments to that effect will be provided in the following chapters. Their inclusion would serve the interests of developing and developed countries alike. The outcome of MC-X (Nairobi) may have provided new conditions to revive the debates in some areas, but it is too early to say how this will translate into concrete analysis and debates.

For some countries with higher levels of ambitions the process of trade liberalization is considered too slow and as not going far enough, which could in part explain the regional trade liberalization approaches pursued by some WTO members. As is explained, the regional integration initiatives are an exception to the MFN principle, but at the same time they can contribute to further global trade liberalization. They have become a reality in economic life involving the largest trading nations. It is argued that there should be consideration of ways to ensure that the benefits from liberalization at the regional level can be of benefit to the larger membership.

The analysis provided in this chapter provides the backdrop against which some of the questions raised will be considered further. The next chapter will address the question how trade patterns in the world have changed since the creation of the WTO and look more specifically at the issue relating to globalization, and their implications for trade and trade policies. 


\section{ANNEX 2.1: List of least developed countries}

(as of May 2016)

\section{(UN Classification)}

\begin{tabular}{|c|c|c|c|}
\hline Country & $\begin{array}{l}\text { Date of } \\
\text { inclusion } \\
\text { on the } \\
\text { list }\end{array}$ & Country & $\begin{array}{l}\text { Date of } \\
\text { inclusion } \\
\text { on the } \\
\text { list }\end{array}$ \\
\hline 1 Afghanistan & 1971 & 25 Madagascar & 1991 \\
\hline 2 Angola & 1994 & 26 Malawi & 1971 \\
\hline 3 Bangladesh & 1975 & 27 Mali & 1971 \\
\hline 4 Benin & 1971 & 28 Mauritania & 1986 \\
\hline 5 Bhutan & 1971 & 29 Mozambique & 1988 \\
\hline 6 Burkina Faso & 1971 & 30 Myanmar & 1987 \\
\hline 7 Burundi & 1971 & 31 Nepal & 1971 \\
\hline 8 Cambodia & 1991 & 32 Niger & 1971 \\
\hline 9 Central African Republic & 1975 & 33 Rwanda & 1971 \\
\hline 10 Chad & 1971 & 34 Sao Tome and Principe & 1982 \\
\hline 11 Comoros & 1977 & 35 Senegal & 2000 \\
\hline 12 Dem. Rep of the Congo & 1991 & 36 Sierra Leone & 1982 \\
\hline 13 Djibouti & 1982 & 37 Solomon Islands & 1991 \\
\hline 14 Equatorial Guinea & 1982 & 38 Somalia & 1971 \\
\hline 15 Eritrea & 1994 & 39 South Sudan & 2012 \\
\hline 16 Ethiopia & 1971 & 40 Sudan & 1971 \\
\hline 17 Gambia & 1975 & 41 Timor-Leste & 2003 \\
\hline 18 Guinea & 1971 & 42 Togo & 1982 \\
\hline 19 Guinea-Bissau & 1981 & 43 Tuvalu & 1986 \\
\hline 20 Haiti & 1971 & 44 Uganda & 1971 \\
\hline 21 Kiribati & 1986 & 45 United Rep. of Tanzania & 1971 \\
\hline 22 Lao People’s Dem. Republic & 1971 & 46 Vanuatu & 1985 \\
\hline 23 Lesotho & 1971 & 47 Yemen & 1971 \\
\hline 24 Liberia & 1990 & 48 Zambia & 1991 \\
\hline
\end{tabular}

Source: United Nations, Department of Economic and Social Affairs, Development Policy and Analysis Division, Committee For Development Policy, last checked in December 2016. 


\title{
ANNEX 2.2: Groups in the WTO
}

\author{
Updated 1 April 2016
}

A number of countries have formed coalitions in the WTO. These groups often speak with one voice using a single coordinator or negotiating team. These are some of the most active groups in the WTO.

\begin{tabular}{|c|c|c|}
\hline Groups & Description / issues & Countries \\
\hline $\mathrm{ACP}$ & $\begin{array}{l}\text { African, Caribbean and } \\
\text { Pacific countries with } \\
\text { preferences in the EU } \\
\text { Nature: geographical } \\
\text { Issues: preferences, and so } \\
\text { on } \\
\text { http://www.acp.int/ }\end{array}$ & $\begin{array}{l}\text { WTO members (61): Angola, Antigua \& Barbuda, } \\
\text { Barbados, Belize, Benin, Botswana, Burkina Faso, } \\
\text { Burundi, Cameroon, Cape Verde, Central African } \\
\text { Rep., Chad, Congo, Côte d'Ivoire, Cuba, Congo } \\
\text { (Democratic Rep.), Djibouti, Dominica, Dominican } \\
\text { Rep., Fiji, Gabon, Gambia, Ghana, Grenada, Guinea, } \\
\text { Guinea Bissau, Guyana, Haiti, Jamaica, Kenya, } \\
\text { Lesotho, Madagascar, Malawi, Mali, Mauritania, } \\
\text { Mauritius, Mozambique, Namibia, Niger, Nigeria, } \\
\text { Papua New Guinea, Rwanda, St Kitts \& Nevis, St } \\
\text { Lucia, St Vincent \& the Grenadines, Samoa, Senegal, } \\
\text { Seychelles, Sierra Leone, Solomon Islands, South } \\
\text { Africa, Suriname, Swaziland, Tanzania, Togo, Tonga, } \\
\text { Trinidad \& Tobago, Uganda, Vanuatu, Zambia, } \\
\text { Zimbabwe } \\
\text { WTO observers (7): Bahamas, Comoros, Equatorial } \\
\text { Guinea, Ethiopia, Liberia, São Tomé and Principe, } \\
\text { Sudan } \\
\text { Not WTO members or observers (11 ): Cook } \\
\text { Islands, Eritrea, Kiribati, Marshall Islands, Micronesia, } \\
\text { Nauru, Niue, Palau, Somalia, Timor-Lesté, Tuvalu }\end{array}$ \\
\hline African group & $\begin{array}{l}\text { All African WTO } \\
\text { members } \\
\text { Nature: regional } \\
\text { Issues: general }\end{array}$ & $\begin{array}{l}\text { WTO members (43): Angola, Benin, Botswana, } \\
\text { Burkina Faso, Burundi, Cameroon, Cape Verde, } \\
\text { Central African Rep., Chad, Congo, Congo } \\
\text { (Democratic Rep.), Côte d'Ivoire, Djibouti, Egypt, } \\
\text { Gabon, Gambia, Ghana, Guinea, Guinea Bissau, } \\
\text { Kenya, Lesotho, Madagascar, Malawi, Mali, } \\
\text { Mauritania, Mauritius, Morocco, Mozambique, } \\
\text { Namibia, Niger, Nigeria, Rwanda, Senegal, Seychelles, } \\
\text { Sierra Leone, South Africa, Swaziland, Tanzania, } \\
\text { Togo, Tunisia, Uganda, Zambia, Zimbabwe }\end{array}$ \\
\hline
\end{tabular}




\begin{tabular}{|c|c|c|}
\hline Groups & Description/issues & Countries \\
\hline $\begin{array}{l}\text { Developing } \\
\text { Asian } \\
\text { members }\end{array}$ & $\begin{array}{l}\text { Developing countries in } \\
\text { Asia that are WTO } \\
\text { members. Announced in } \\
\text { document } \\
\text { WT/GC/COM/6 of } 27 \\
\text { March } 2012 \\
\text { Nature: regional } \\
\text { Issues: general } \\
\end{array}$ & $\begin{array}{l}\text { WTO members (31): Bahrain, Bangladesh, } \\
\text { Brunei Darussalam, Cambodia, China, } \\
\text { Hong Kong China, India, Indonesia, Jordan, } \\
\text { Rep. Korea, Kuwait, Kyrgyz Rep., Lao PDR, Macao } \\
\text { China, Malaysia, Maldives, Mongolia, Myanmar, } \\
\text { Nepal, Oman, Pakistan, Philippines, Qatar, } \\
\text { Saudi Arabia, Singapore, Sri Lanka, Chinese Taipei, } \\
\text { Thailand, Turkey, United Arab Emirates, Vietnam }\end{array}$ \\
\hline APEC & $\begin{array}{l}\text { Asia Pacific Economic } \\
\text { Cooperation forum } \\
\text { Nature: regional } \\
\text { Issues: general } \\
\text { www.apec.org }\end{array}$ & $\begin{array}{l}\text { WTO members (21): Australia, Brunei Darussalam, } \\
\text { Canada, Chile, China, Hong Kong China, Indonesia, } \\
\text { Japan, Rep. Korea, Malaysia, Mexico, New Zealand, } \\
\text { Papua New Guinea, Peru, Philippines, Russia, } \\
\text { Singapore, Chinese Taipei, Thailand, US, Vietnam SR }\end{array}$ \\
\hline ASEAN & $\begin{array}{l}\text { Association of } \\
\text { Southeast Asian } \\
\text { Nations } \\
\text { Nature: regional } \\
\text { Issues: general } \\
\text { www.asean.org } \\
\end{array}$ & $\begin{array}{l}\text { WTO members (10): Brunei Darussalam, } \\
\text { Cambodia, Indonesia, Laos, Malaysia, Myanmar, } \\
\text { Philippines, Singapore, Thailand, Vietnam SR }\end{array}$ \\
\hline Mercosur & $\begin{array}{l}\text { Common Market of the } \\
\text { Southern Cone (Mercosul } \\
\text { in Portuguese) } \\
\text { Nature: customs union } \\
\text { Issues: general } \\
\text { www.mercosur.int }\end{array}$ & $\begin{array}{l}\text { WTO members (4): Argentina, Brazil, Paraguay, } \\
\text { Uruguay }\end{array}$ \\
\hline
\end{tabular}




\begin{tabular}{|c|c|c|}
\hline Groups & Description / issues & Countries \\
\hline G-90 & $\begin{array}{l}\text { African Group + ACP + } \\
\text { least-developed } \\
\text { countries } \\
\text { Issues: general }\end{array}$ & $\begin{array}{l}\text { WTO members (70): Angola, Antigua \& Barbuda, } \\
\text { Bangladesh, Barbados, Belize, Benin, Botswana, } \\
\text { Burkina Faso, Burundi, Cambodia, Cameroon, } \\
\text { Cape Verde, Central African Rep., Chad, Congo, Côte } \\
\text { d'Ivoire, Cuba, Congo (Democratic Rep.), Djibouti, } \\
\text { Dominica, Dominican Rep., Egypt, Fiji, Gabon, } \\
\text { Gambia, Ghana, Grenada, Guinea, Guinea Bissau, } \\
\text { Guyana, Haiti, Jamaica, Kenya, Lao PDR, Lesotho, } \\
\text { Madagascar, Malawi, Maldives, Mali, Mauritania, } \\
\text { Mauritius, Morocco, Mozambique, Myanmar, } \\
\text { Namibia, Nepal, Niger, Nigeria, Papua New Guinea, } \\
\text { Rwanda, St Kitts \& Nevis, St Lucia, St Vincent \& the } \\
\text { Grenadines, Samoa, Senegal, Seychelles, Sierra Leone, } \\
\text { Solomon Islands, South Africa, Suriname, Swaziland, } \\
\text { Tanzania, Togo, Trinidad \& Tobago, Tunisia, Uganda, } \\
\text { Vanuatu, Yemen, Zambia, Zimbabwe } \\
\text { WTO observers (9): Afghanistan, Bahamas, Bhutan, } \\
\text { Comoros, Equatorial Guinea, Ethiopia, Liberia, São } \\
\text { Tomé \& Principe, Sudan } \\
\text { Not WTO members or observers (12): Cook } \\
\text { Islands, Eritrea, Kiribati, Marshall Islands, Micronesia, } \\
\text { Nauru, Niue, Palau, Somalia, South Sudan, Timor- } \\
\text { Lesté, Tuvalu }\end{array}$ \\
\hline $\begin{array}{l}\text { Least } \\
\text { developed } \\
\text { countries } \\
\text { (LDCs) }\end{array}$ & $\begin{array}{l}\text { Least developed countries: } \\
\text { the world's poorest } \\
\text { countries. The WTO uses } \\
\text { the UN list (pdf) available } \\
\text { here: } \\
\text { www.un.org/en/developm } \\
\text { ent/desa/policy/cdp/ldc_in } \\
\text { fo.shtml } \\
\text { Issues: general } \\
\text { Official website: } \\
\text { www.ldcgroups.org }\end{array}$ & $\begin{array}{l}\text { WTO members (35): Angola, Bangladesh, Benin, } \\
\text { Burkina Faso, Burundi, Cambodia, Central African } \\
\text { Rep., Chad, Congo (Democratic Rep.), Djibouti, } \\
\text { Gambia, Guinea, Guinea Bissau, Haiti, Lao PDR, } \\
\text { Lesotho, Madagascar, Malawi, , Mali, Mauritania, } \\
\text { Mozambique, Myanmar, Nepal, Niger, Rwanda, } \\
\text { Samoa, Senegal, Sierra Leone, Solomon Islands, } \\
\text { Tanzania, Togo, Uganda, Vanuatu, Yemen, Zambia } \\
\text { WTO observers (8): Afghanistan, Bhutan, Comoros, } \\
\text { Equatorial Guinea, Ethiopia, Liberia, São Tomé \& } \\
\text { Principe, Sudan }\end{array}$ \\
\hline
\end{tabular}




\begin{tabular}{|c|c|c|}
\hline Groups & Description / issues & Countries \\
\hline $\begin{array}{l}\text { Small, } \\
\text { vulnerable } \\
\text { economies } \\
\text { (SVEs) }\end{array}$ & $\begin{array}{l}\text { Group of developing } \\
\text { countries seeking } \\
\text { flexibilities and enhanced } \\
\text { special and differential } \\
\text { treatment for small, } \\
\text { vulnerable economies in } \\
\text { the negotiations. } \\
\text { Issues: general }\end{array}$ & $\begin{array}{l}\text { WTO members (26): Antigua \& Barbuda, Barbados, } \\
\text { Belize, Bolivia, Cuba, Dominica, Dominican Rep., } \\
\text { El Salvador, Ecuador, Fiji, Grenada, Guatemala, } \\
\text { Honduras, Jamaica, Mauritius, Nicaragua, Panama, } \\
\text { Papua New Guinea, St Kitts \& Nevis, St Lucia, St } \\
\text { Vincent \& the Grenadines, Samoa, Seychelles, Sri } \\
\text { Lanka, Tonga, Trinidad \& Tobago } \\
\text { WTO observers (1): Bahamas }\end{array}$ \\
\hline $\begin{array}{l}\text { Article XII } \\
\text { Members }\end{array}$ & $\begin{array}{l}\text { Article XII Members or } \\
\text { recently acceded members } \\
\text { (RAMs): countries that } \\
\text { negotiated and joined the } \\
\text { WTO after 1995, seeking } \\
\text { lesser commitments in the } \\
\text { negotiations because of the } \\
\text { liberalization they have } \\
\text { undertaken as part of their } \\
\text { membership agreements. } \\
\text { Excludes least-developed } \\
\text { countries because they will } \\
\text { make no new } \\
\text { commitments, and EU } \\
\text { members } \\
\text { Issues: general } \\
\end{array}$ & $\begin{array}{l}\text { WTO members (22): Albania, Armenia, } \\
\text { Cape Verde, China, Ecuador, FYR Macedonia, } \\
\text { Georgia, Jordan, Kazakhstan, Kyrgyz Rep., Moldova, } \\
\text { Mongolia, Oman, Panama, Russian Federation, Saudi } \\
\text { Arabia, Seychelles, Chinese Taipei, Tajikistan, Tonga, } \\
\text { Ukraine, Vietnam SR }\end{array}$ \\
\hline $\begin{array}{l}\text { Low-income } \\
\text { economies in } \\
\text { transition }\end{array}$ & $\begin{array}{l}\text { Seeking to secure the same } \\
\text { treatment as least- } \\
\text { developed countries. } \\
\text { (Georgia formally } \\
\text { withdrew, but in the } \\
\text { agriculture draft the full list } \\
\text { is: Albania, Armenia, } \\
\text { Georgia, Kyrgyz Rep, } \\
\text { Moldova) } \\
\text { Issues: Agriculture }\end{array}$ & $\begin{array}{l}\text { WTO members (3): Armenia, Kyrgyz Rep., } \\
\text { Moldova } \\
\\
\end{array}$ \\
\hline Cairns group & $\begin{array}{l}\text { Coalition of agricultural } \\
\text { exporting nations lobbying } \\
\text { for agricultural trade } \\
\text { liberalization. } \\
\text { Issues: agriculture } \\
\text { www.cairnsgroup.org }\end{array}$ & $\begin{array}{l}\text { WTO members (19): Argentina, Australia, Brazil, } \\
\text { Canada, Chile, Colombia, Costa Rica, Guatemala, } \\
\text { Indonesia, Malaysia, New Zealand, Pakistan, Paraguay, } \\
\text { Peru, Philippines, South Africa, Thailand, Uruguay, } \\
\text { Vietnam (SR) }\end{array}$ \\
\hline
\end{tabular}




\begin{tabular}{|c|c|c|}
\hline Groups & Description / issues & Countries \\
\hline $\begin{array}{l}\text { Tropical } \\
\text { products } \\
\text { group }\end{array}$ & $\begin{array}{l}\text { Coalition of developing } \\
\text { countries seeking greater } \\
\text { market access for tropical } \\
\text { products } \\
\text { Issues: Agriculture } \\
\end{array}$ & $\begin{array}{l}\text { WTO members (8): Bolivia, Colombia, Costa Rica, } \\
\text { Ecuador, Guatemala, Nicaragua, Panama, Peru }\end{array}$ \\
\hline G-10 & $\begin{array}{l}\text { Coalition of countries } \\
\text { lobbying for agriculture to } \\
\text { be treated as diverse and } \\
\text { special because of non- } \\
\text { trade concerns (not to be } \\
\text { confused with the Group } \\
\text { of Ten Central Bankers) } \\
\text { Issues: agriculture }\end{array}$ & $\begin{array}{l}\text { WTO members (9): Chinese Taipei, Rep. Korea, } \\
\text { Iceland, Israel, Japan, Liechtenstein, Mauritius, } \\
\text { Norway, Switzerland }\end{array}$ \\
\hline G-20 & $\begin{array}{l}\text { Coalition of developing } \\
\text { countries pressing for } \\
\text { ambitious reforms of } \\
\text { agriculture in developed } \\
\text { countries with some } \\
\text { flexibility for developing } \\
\text { countries (not to be } \\
\text { confused with the G-20 } \\
\text { group of finance ministers } \\
\text { and central bank } \\
\text { governors, and its recent } \\
\text { summit meetings) } \\
\text { Issues: agriculture }\end{array}$ & $\begin{array}{l}\text { WTO members (23): Argentina, Bolivia, Brazil, } \\
\text { Chile, China, Cuba, Ecuador, Egypt, Guatemala, India, } \\
\text { Indonesia, Mexico, Nigeria, Pakistan, Paraguay, Peru, } \\
\text { Philippines, South Africa, Tanzania, Thailand, } \\
\text { Uruguay, Venezuela, Zimbabwe }\end{array}$ \\
\hline G-33 & $\begin{array}{l}\text { Also called 'Friends of } \\
\text { Special Products' in } \\
\text { agriculture. } \\
\text { Coalition of developing } \\
\text { countries pressing for } \\
\text { flexibility for developing } \\
\text { countries to undertake } \\
\text { limited market opening in } \\
\text { agriculture } \\
\text { Issues: agriculture }\end{array}$ & $\begin{array}{l}\text { WTO members (48): Antigua \& Barbuda, Barbados, } \\
\text { Belize, Benin, Bolivia, Botswana, China, Congo, Côte } \\
\text { d'Ivoire, Cuba, Dominica, Dominican Rep., Ecuador, } \\
\text { El Salvador, Grenada, Guatemala, Guyana, Haiti, } \\
\text { Honduras, India, Indonesia, Jamaica, Kenya, Rep. } \\
\text { Korea, Madagascar, Mauritius, Mongolia, } \\
\text { Mozambique, Nicaragua, Nigeria, Pakistan, Panama, } \\
\text { Peru, Philippines, St Kitts \& Nevis, St Lucia, St Vincent } \\
\text { \& the Grenadines, Senegal, Sri Lanka, Suriname, } \\
\text { Chinese Taipei, Tanzania, Trinidad \& Tobago, Turkey, } \\
\text { Uganda, Venezuela, Zambia, Zimbabwe }\end{array}$ \\
\hline
\end{tabular}




\begin{tabular}{|c|c|c|}
\hline Groups & Description / issues & Countries \\
\hline Cotton-4 & $\begin{array}{l}\text { West African coalition } \\
\text { seeking cuts in cotton } \\
\text { subsidies and tariffs } \\
\text { Issues: agriculture } \\
\text { (cotton) }\end{array}$ & WTO members (4): Benin, Burkina Faso, Chad, Mali \\
\hline NAMA 11 & $\begin{array}{l}\text { Coalition of developing } \\
\text { countries seeking } \\
\text { flexibilities to limit market } \\
\text { opening in industrial goods } \\
\text { trade } \\
\text { Issues: NAMA } \\
\end{array}$ & $\begin{array}{l}\text { WTO members (10): Argentina, Brazil, Egypt, India, } \\
\text { Indonesia, Namibia, Philippines, South Africa, Tunisia, } \\
\text { Venezuela }\end{array}$ \\
\hline $\begin{array}{l}\text { 'Paragraph 6' } \\
\text { countries }\end{array}$ & \begin{tabular}{|l|} 
Group of countries with \\
less than $35 \%$ of non- \\
agricultural products \\
covered by legally bound \\
tariff ceilings. They \\
have agreed to increase \\
their binding coverage \\
substantially, but want to \\
exempt some products. (In \\
paragraph 6 of the first \\
version of the NAMA text, \\
later paragraph 8.) \\
Issues: NAMA \\
\end{tabular} & $\begin{array}{l}\text { WTO members (12): Cameroon, Congo, Côte } \\
\text { d'Ivoire, Cuba, Ghana, Kenya, Macao China, } \\
\text { Mauritius, Nigeria, Sri Lanka, Suriname, Zimbabwe }\end{array}$ \\
\hline $\begin{array}{l}\text { Friends of } \\
\text { Ambition } \\
\text { (NAMA) }\end{array}$ & $\begin{array}{l}\text { Seeking to maximize tariff } \\
\text { reductions and achieve real } \\
\text { market access in NAMA. } \\
\text { (Some nuanced differences } \\
\text { in positions.) } \\
\text { Issues: NAMA }\end{array}$ & $\begin{array}{l}\text { WTO members (35): Australia, Austria, Belgium, } \\
\text { Bulgaria, Canada, Cyprus, Czech Rep., Denmark, } \\
\text { Estonia, EU, Finland, France, Germany, Greece, } \\
\text { Hungary, Ireland, Italy, Japan, Latvia, Lithuania, } \\
\text { Luxembourg, Malta, Netherlands, New Zealand, } \\
\text { Norway, Poland, Portugal, Romania, Slovak Rep., } \\
\text { Slovenia, Spain, Sweden, Switzerland, UK, US }\end{array}$ \\
\hline $\begin{array}{l}\text { Friends of } \\
\text { Anti- } \\
\text { Dumping } \\
\text { Negotiations } \\
\text { (FANs) }\end{array}$ & $\begin{array}{l}\text { Coalition seeking more } \\
\text { disciplines on the use of } \\
\text { anti-dumping measures } \\
\text { Issues: Rules (anti- } \\
\text { dumping) }\end{array}$ & $\begin{array}{l}\text { WTO members (15): Brazil, Chile, Colombia, Costa } \\
\text { Rica, Hong Kong China, Israel, Japan, Rep. of Korea, } \\
\text { Mexico, Norway, Singapore, Switzerland, Chinese } \\
\text { Taipei, Thailand, Turkey }\end{array}$ \\
\hline
\end{tabular}




\begin{tabular}{|c|c|c|}
\hline Groups & Description / issues & Countries \\
\hline $\begin{array}{l}\text { Friends of } \\
\text { Fish (FoFs) }\end{array}$ & $\begin{array}{l}\text { Informal coalition seeking } \\
\text { to significantly reduce } \\
\text { fisheries subsidies. From } \\
\text { time to time other WTO } \\
\text { members also identify } \\
\text { themselves as 'Friends of } \\
\text { Fish' } \\
\text { Issues: Rules (subsidies) }\end{array}$ & $\begin{array}{l}\text { WTO members (1 1): Argentina, Australia, Chile, } \\
\text { Colombia, Ecuador, Iceland, New Zealand, Norway, } \\
\text { Pakistan, Peru, US }\end{array}$ \\
\hline $\begin{array}{l}\text { 'W52' } \\
\text { sponsors }\end{array}$ & $\begin{array}{l}\text { Sponsors of TN/C/W/52, } \\
\text { a proposal for 'modalities' } \\
\text { in negotiations on } \\
\text { geographical indications } \\
\text { (the multilateral register } \\
\text { for wines and spirits, and } \\
\text { extending the higher level } \\
\text { of protection beyond } \\
\text { wines and spirits) and } \\
\text { 'disclosure' (patent } \\
\text { applicants to disclose the } \\
\text { origin of genetic resources } \\
\text { and traditional knowledge } \\
\text { used in the inventions). } \\
\text { The list includes as groups: } \\
\text { the EU, ACP and African } \\
\text { Group. } \\
\text { *Dominican Rep. is in the } \\
\text { ACP and South Africa is in } \\
\text { the African Group, but } \\
\text { they are sponsors of } \\
\text { TN/IP/W/10/Rev.2 on } \\
\text { geographical indications } \\
\text { Issues: Intellectual } \\
\text { property (TRIPS) }\end{array}$ & $\begin{array}{l}\text { WTO members (109): Albania, Angola, Antigua \& } \\
\text { Barbuda, Austria, Barbados, Belgium, Belize, Benin, } \\
\text { Botswana, Brazil, Bulgaria, Burkina Faso, Burundi, } \\
\text { Cameroon, Cape Verde, Central African Rep., Chad, } \\
\text { China, Colombia, Congo, Côte d'Ivoire, Croatia, } \\
\text { Cuba, Cyprus, Czech Rep, Congo (Democratic Rep.), } \\
\text { Denmark, Djibouti, Dominica, Dominican Rep.*, } \\
\text { Ecuador, Egypt, Estonia, EU, Fiji, Finland, FYR } \\
\text { Macedonia, France, Gabon, Gambia, Georgia, } \\
\text { Germany, Ghana, Greece, Grenada, Guinea, Guinea } \\
\text { Bissau, Guyana, Haiti, Hungary, Iceland, India, } \\
\text { Indonesia, Ireland, Italy, Jamaica, Kenya, Kyrgyz Rep., } \\
\text { Latvia, Lesotho, Liechtenstein, Lithuania, } \\
\text { Luxembourg, Madagascar, Malawi, Mali, Malta, } \\
\text { Mauritania, Mauritius, Moldova, Morocco, } \\
\text { Mozambique, Namibia, Netherlands, Niger, Nigeria, } \\
\text { Pakistan, Papua New Guinea, Peru, Poland, Portugal, } \\
\text { Romania, Rwanda, St Kitts \& Nevis, St Lucia, St } \\
\text { Vincent \& the Grenadines, Senegal, Sierra Leone, } \\
\text { Slovak Rep., Slovenia, Solomon Islands, Spain, Sri } \\
\text { Lanka, Suriname, Swaziland, Sweden, Switzerland, } \\
\text { South Africa*, Tanzania, Thailand, Togo, Tonga, } \\
\text { Trinidad \& Tobago, Tunisia, Turkey, Uganda, United } \\
\text { Kingdom, Zambia, Zimbabwe }\end{array}$ \\
\hline Joint proposal & \begin{tabular}{|l|} 
Sponsors of \\
$\mathrm{TN} / \mathrm{IP} / \mathrm{W} / 10 / \mathrm{Rev} .2$ \\
proposing a database that \\
is entirely voluntary \\
www.wto.org/trips\#issues \\
Issues: TRIPS GI register
\end{tabular} & $\begin{array}{l}\text { WTO members (20): Argentina, Australia, Canada, } \\
\text { Chile, Costa Rica, Dominican Rep., Ecuador, El } \\
\text { Salvador, Guatemala, Honduras, Israel, Japan, Korea, } \\
\text { Mexico, New Zealand, Nicaragua, Paraguay, Chinese } \\
\text { Taipei, South Africa, US }\end{array}$ \\
\hline
\end{tabular}

Source: WTO website (https://www.wto.org) > home > trade topics > Doha agenda > negotiating groups. Last checked 1 December 2016. 


\section{CHAPTER 3: GLOBALIZATION, GLOBAL VALUE CHAINS AND THE RISE OF ASIA}

\subsection{Introduction}

Globalization is a complex phenomenon which raises many questions. Is it new or is it old? Is it driving new patterns of trade and investment or is it the other way around and are trade and investment driving globalization? What are these new patterns? How does globalization affect the classical trade theory and notion of comparative advantage? Who benefits from globalization and the new patterns in trade and investment? What are some of the policy implications of globalization? What options do governments have to adequately respond to globalization? What are the implications on governance? What are the threats, challenges and opportunities created by globalization? Does it create or destroy jobs? Is globalization inclusive or divisive? What is the role for the WTO? Does it affect multilateralism or is the globalization process driving regional approaches to trade liberalization?

This chapter will discuss the main features of globalization, how it has evolved since the 1990s and its significance for trade? This will be followed by a discussion on GVCs as a new way for countries to connect to markets and take advantage of the breaking up of the production process. The questions that will then be considered are how trade and investment have evolved, how both have triggered globalization and been driven by globalization. It will be shown that the process of change through globalization has been very dynamic and allowed new economic actors to become important players in world trade. The analysis will show how the economic balance is gradually shifting from the West to the East. Asia has emerged as a leading region, and within Asia China has become a leading trading nation. China's share in world trade has increased at an exponential rate and as a result China now has the highest rankings in world trade for both goods and services. At the time of the creation of the WTO, China was not even a member of the WTO and its share in world trade was almost non-existent. There are different ways in which can be assessed how Asia has become the center of economic gravity for trade and investment as well as for consumption.

There is also a rapid growth of the so-called middle class in Asia, a process which is a result of the forces driving globalization. In addition, some Asian countries are adapting particularly well to the new competitive trade environment and are increasingly getting connected to GVCs. This in turn contributes to the rapid diversification of production of goods and services and to value adding in the region. It also implies increased specialization and outsourcing within the region, thus generating more trade, revenue and hence, higher levels of economic welfare. It will be argued that globalization has mainly benefited countries with relatively open economies that are attractive to foreign direct investment (FDI). 
This chapter will then take a closer look at the policy implications of globalization and how to best respond to the challenges emanating from it. Here again it can be observed that while the understanding of globalization and its economic implications has evolved, much more needs to be done to explain the benefits of trade liberalization better in order to counter the backlash against globalization. There is a growing misperception of the contribution that globalization can make to overall levels of economic welfare and the benefits it can yield to the consumer and producers alike. The risk is that the new antiglobalization trend that can be observed in some parts of the world triggers off the wrong policy responses, including calls for protectionism in order to prevent job losses. Such policies would run counter to the principles that the WTO stands for and that have proven to generate economic growth and higher levels of welfare, e.g. the opening of markets through trade liberalization It will be argued that since the 1990s the policies have shifted from initially defensive policies, geared towards protecting domestic markets and industries, to more liberal and open policies, based on harmonization, policy coordination and coherence. The world economy has witnessed a deepening of the integration of economies and markets, thus leading to a stronger connection between markets. It will be argued that the policy responses to globalization will therefore need to move further into the same direction. In addition to more coordination and coherence in policies, the multilateral trading system needs a further strengthening, the rules expanded and deepened and more liberalization pursued.

\subsection{Understanding Globalization}

Trade patterns have changed significantly since the creation of the WTO. Many different factors are driving the process of change, including globalization, which in turn is driven by the changing patterns of trade and investment. Both processes are mutually reinforcing. Globalization was mainly associated with the rapid changes in business structures in the 1990s. These led to often highly contested circumstances, as enterprises started to move or relocate their business operations around the globe in order to take advantage of the shifting comparative advantage, thus becoming increasingly footloose. This process intensified in the years that followed. Businesses structures also evolved rapidly in recent years and globalization has undergone various mutations. The focus of attention has shifted from globalization to Global Value Chains (GVCs) as a way of organizing economic and production activities. GVCs can be seen as a continuation of globalization in a different form. It is of interest to better understand their economic significance in order to design appropriate policy responses.

Considerable analysis has been undertaken in this field by academics and international institutions, addressing the questions at a macro and micro level - globally and at the industry and business levels and offering very different perspectives. Huwart and Verdier consider few subjects as controversial as globalization, particularly when it comes to its economic and financial impact. ${ }^{1}$ Those who take a positive view on globalization point to the vast array of

1 J. Y. Huwart and L. Verdier, 'Economic Globalisation, Origin and Consequences', OECD Paris, 2013. 
new products, greater choices and cheaper goods for consumers, owing to intense international competition - not to mention technological advances, greater comfort and ease of everyday life, expanded leisure time and so on. Those who oppose globalization often advance the argument that it leads to loss of jobs.

In earlier texts I had put forth that the economic rationale and driving force for globalization was the need for companies to be closer to the customer in order to adapt the product to local taste and the particular conditions of the local market, often referred to as 'customization'.2 The world's largest businesses look to all nations to gain an advantage in production, marketing and research, in effect reducing the comparative advantage of a country to its contribution to their global strategies, such as through international sourcing. These strategies triggered the breaking up of the production processes from wholly manufactured goods in one location to the manufacturing of parts and components around the globe, which could then be assembled at any given geographical location. The choice was no longer between trade and FDI as alternative ways to penetrate markets, but FDI is a vehicle to enhance productivity and complement trade. Servan Schreiber describes how in the sixties, American companies started to relocate some of their business activities from the US into Europe through FDI, mainly following the creation of the EU in the late ' $50 \mathrm{~s} .{ }^{3}$ The main purpose was to 'jump' over the tariffs that resulted from the creation of the customs union and that had affected the export of the US products. Following a wave of FDI more than ever before trade and investment became two sides of the same coin reinforcing each other, rather than acting as substitutes for each other. Trade requires investments in order to market the good, but also tailoring to the needs of the customer. FDI is only the initial vehicle, through which firms are established in their target market, but which at the same time triggers new trade flows and related economic activities. These trade flows are mostly in intermediate goods and increasingly in services, including for the after sales services. As argued further in this chapter, this intrinsic relationship between FDI, trade and production has intensified further and even accelerated in recent years.

In order to better understand how globalization works in reality, I conducted several specific sector studies on globalization at the OECD which are contained in case studies on the automobile industry ${ }^{4}$ as well as the pharmaceutical industry. ${ }^{5}$ The main purpose of the studies was to understand the scope of globalization at a sectorial level, measure the degree

2 M. Smeets, 'Globalisation and the Trade Policy Response', 24 Journal of World Trade (1990), p. 57-73; M. Smeets, 'Globalisation of International Trade and Investment', in F. Buelens (ed.), Globalisation and the Nation State (Edward Elgar, 2000); M. Smeets, 'Aspects of Multinational Corporations' in C.J. Jepma and A. Rhoen (eds.), International Trade: A Business Perspective (Open University, Netherlands, 1996); M. Smeets, 'Changing Patterns in International Trade', 5 Journal of the WTO and China (2015). The analysis presented below draws on the main findings contained in these publications.

3 J.J. Servan Schreiber, Le Défi Américan (Denoel 1968).

4 Globalisation of Industrial Activities: Sector Case Study of Globalisation in the Automobile Industry, OECD, 16 June 1993, (Com/DSTI/IND/TD(93)55).

5 Sector Case Study of Globalisation in the Pharmaceutical Industry, Working Party of the Trade Committee, OECD, 15 March 1993, (TD/TC/WP(93)23. 
of globalization based on specific indicators developed to that effect, see what forms globalization could take and what lessons could be drawn from it. ${ }^{6}$ In many ways the findings in these studies confirm the complementarity between trade and FDI. According to these case studies, the trade flows are often much larger than the initial FDI flow and generally continue for many years after the investment has taken place. ${ }^{7}$ The study on automobiles revealed that both intra- and inter-regional trade in parts and components largely outpaced trade in assembled cars. It was also shown through those same case studies that the changes that have gradually taken place in the organization of business operations (including the establishment of production networks, the strengthening of intra-firm trade and the international fragmentation of production) are equally important.

There is a need to provide more clarity on the concept of globalization, how it can be defined and how it is manifested in real life. As I have argued in earlier publications there is not a single accepted definition of globalization, and the term is understood differently by protagonists and antagonists. ${ }^{8}$ It will be argued that the new concept of GVCs is very closely related to globalization and in a way a continuation of globalization and suggestions will be made for new ways of looking at the breaking up of the international production process and the challenges related to the new opportunities created as a result. As I will show further, the recent literature widely confirms that the world of trade and investment has become very complex which makes it increasingly difficult to anticipate developments and design an economic policy that can serve as a guide for business decisions and be used by countries to develop a sound economic and growth strategy. The literature also suggests that the internationalization of technology is an important characteristic of the current globalization process, with increasing flows of technology between countries. The wider availability of technology and access to technology is itself a driver of economic growth. Separately and in addition, trade liberalization has led to unprecedented specialization, with production patterns changing to exploit (on a world-wide scale) comparative advantages at all stages of the production process. Moreover, globalization is unprecedented - there is a high degree of economic integration, a surge in FDI flows, technological developments and innovations, financial and domestic market liberalization and deregulation, and it shapes a new environment that has a direct bearing on consumption patterns, business behaviour and overall levels of welfare.

Looking back in time, one could easily argue that globalization is not a new phenomenon per se and historically goes back a long way. The trade conducted along the silk-road at the time of Marco Polo was a very initial form of globalization. It connected distant markets by opening new trade routes it involved specialization with different sources of inputs, based on the notion of comparative advantage, required investment in skills and technology and so on.

6 Cf. OECD, 'Globalisation of Industrial Activities: Sector Case Study of Globalisation in the Automobile Industry, Com/DSTI/IND/TD(93)55, and 'Globalisation in the Automobile Industry: Trade Related Issues', $\mathrm{TD} / \mathrm{TC} / \mathrm{WP}(92) 50$, and more recently, the OECD developed a set of indicators measuring globalization: 'Economic Globalisation Indicators, Measuring Globalisation', OECD (2010).

7 OECD, Com/DSTI/IND/TD(93)55.

8 Cf. Smeets, 'Globalisation and the Trade Policy Response'. 
In a similar way, the Dutch East India Company developed the 'spice route' between Asia and the West which led to further specialization and connecting geographically distant markets. It led to trade based on specialization and affected the lives of people in many ways. Both examples are very basic forms of globalization which gradually developed further over time with deeper specialization and technology. In a way they set the stage for more advanced and sophisticated forms of globalization, which is shown by China's recent initiative to build on that former model of the silk-road, referred to as 'One Belt and One Road', thus again linking East and West by land and by sea. ${ }^{9}$ As argued further, China is both a significant driver and beneficiary of globalization and hence a main actor in the process.

An initial and early starting point for globalization is often considered to be the industrial revolution in the 19th century, mostly driven by the United Kingdom, leading to the introduction of current modern production techniques. Baldwin refers to that as the first 'unbundling', which was followed by a second 'unbundling', as is explained further below. ${ }^{10}$ Globalization however is mostly associated with developments in the early 1990s, when international trade evolved rapidly, accompanied by new forms of FDI and the relocation and reorganization of production facilities around the globe. Globalization led to new forms of specialization and an intensification of competition in world markets. The process is dynamic and subject to constant change, which also is in line with the dynamics of international trade, based on comparative advantage.

Porter was perhaps one of the first authors to explain how the notion of comparative advantage has gradually moved to a more dynamic process which he refers to as the 'competitive advantage': the production process became increasingly flexible and shifted in accordance with a variety of factors. ${ }^{11}$ According to Porter 'competitive advantage' means that a country has - or more specifically local firms of a country have - the ability to use location-bound resources in a way that will enable it (or them) to be competitive in international markets. A country has a number of attributes which shape the environment in which local firms compete, that promote the creation of a competitive market. ${ }^{12}$ The strength, composition and sustainability of a nation's competitive advantage will be revealed in the value of its national product (more specifically, the part that enters into international transactions), and/or the rate of growth of that product, relative to that of its leading competitors.

In 2000 Friedman defined globalization as

9 Action Plan on the Belt and Road Initiative Issued by the National Development and Reform Commission, Ministry of Foreign Affairs, and Ministry of Commerce of the People's Republic of China, March 28, 2015. Information found on English.gov.cn, the State Council, The People's Republic of China, 1 July 2016.

10 R. Baldwin, 'Trade and Industrialization After Globalisation's 2nd Unbundling: How Building and Joining a Supply Chain are Different and Why It Matters?', Working Paper 17716, National Bureau of Economic Research (2011).

11 M. Porter, The Competitive Advantage of Nations (Free Press, New York, 1990).

12 Ibid., p. 71. 
the inexorable integration of markets, nation states and technologies to a degree never witnessed before - in a way that is enabling individuals, corporations and nation-states to reach around the world farther, faster, deeper and cheaper than ever before, and in a way that is enabling the world to reach into individuals, corporations and nation-states farther, faster, deeper and cheaper than ever before. ${ }^{13}$

Stiglitz defines economic globalization as

the closer integration of the countries and peoples of the world which has been brought about by the enormous reduction of costs of transportation and communication and the breaking down of artificial barriers to the flows of goods, services, capital, knowledge and (to a lesser extent) people across borders. ${ }^{14}$

This comes closest to what are generally understood to be the main features of globalization.

Van den Bossche and Zdouc note that 'Economic Globalization is a multifaceted phenomenon. In essence, however, economic globalization is the gradual integration of national economies into one borderless economy. It encompasses both (free) international trade and (unrestricted) foreign direct investment. Economic globalization affects people everywhere in many aspects of their daily lives'. ${ }^{15}$

Baldwin presents a long-term view of what has driven globalization over several centuries and that it can basically be divided into two distinct periods. ${ }^{16}$ A summary of Baldwin's view is that the first drive towards globalization was triggered by the industrial revolution in the developed world and the second one by the revolution in information and communication technologies and which drove the industrialization process in the emerging economies. He also set out that the first period led to a sharper divide between the North and the South, with a widening of the income divide between the North and the South, and that the second wave led to the industrialization of the emerging economies and a reduction in the income disparities. ${ }^{17}$

13 T. Friedman, The Lexus and the Olive Tree: Understanding Globalisation (2 ${ }^{\text {nd }}$ edition, First Anchor Books, 2000).

14 J.E. Stiglitz, Globalisation and its Discontents (W.W. Norton and Co., 2000); J.E. Stiglitz, Making Globalisation Work (W.W. Norton and Co., 2006).

15 P. van den Bossche and W. Zdouc, The Law and Policy of the WTO (Cambridge University Press, 2013), p. 5.

16 R. Baldwin, 'Global Supply Chains: Why They Emerged, Why They Matter, and Where They Are Going?’, in D.E. Elms and P. Low, Global Value Chains in a Changing World (WTO, 2013); R. Baldwin and P. Martin, 'Two Waves of Globalization: Superficial Similarities, Fundamental Differences' in H. Siebert (ed.), Globalisation and Labour (J.C.B Mohr for Kiel Institute of World Economics, Tubingen, 1999), p. 3-59

17 Ibid., Baldwin and Martin, p. 2-6. 
In an earlier study on the same topic, Baldwin observed that 'from the steam revolution till the mid or late 1980s, globalization was mostly about falling trade costs; this was globalization's first unbundling. Since 1980, trade costs changed little but the ICT revolution radically lowered transmission costs; this was globalization's $2^{\text {nd }}$ unbundling'. ${ }^{18}$ He notes that the differences are significant and the nature of globalization has changed, as

globalization driven by lower ICT costs is fundamentally different than globalization driven by lower trade costs. In the first unbundling (per-1980s) international competition occurred mainly at the level of sectors (say Japanese versus Thai cars). In the 2nd unbundling (post-1985), international competition occurs at a finer degree of resolution- the level of production stages (Thai cars may contain Japanese components and vice versa). ${ }^{19}$

He goes on to explain the important policy implications of this change and argues that 'Globalization's $2^{\text {nd }}$ unbundling created a new type of win-win situation in international commerce. The old type was "my market for yours"; the new type is "my factories for your reform"'. ${ }^{20}$ In a more recent study, Baldwin argues that the world is now witnessing what he refers to as 'globalizations' third unbundling' and which is triggered by two technological developments: one is related to the development of technologies that can be "good substitutes for people crossing borders to share "brain services." Such technologies, known as "telepresence", are not science fiction. They exist today but are expensive. The second would be the development of really good substitutes for people traveling to provide manual services. This is called "telerobotics" and it involves people in one place operating robots that perform tasks in another place.'21

The WTO makes a similar analysis and distinguishes the first period which started around the mid-19th century and ended with the commencement of WWI.22 The second episode began in the aftermath of WWII and continues today. As the report notes, in both of these episodes of globalization, rapid trade and output growth went together with major shifts in the relative size of economies involved. It argues that the main forces that have driven global integration were technological innovations, broader political changes and economic policies. In the case of technological innovations, chief among these driving forces of globalization were inventions that improved the speed of transportation and communications and lowered their costs. The other dramatic change was the revolution in information and communication technology. The report explains that new products such as the microprocessor, the personal computer and the cellular phone have contributed to profound socio-political and economic transformation. This is equally true of the internet,

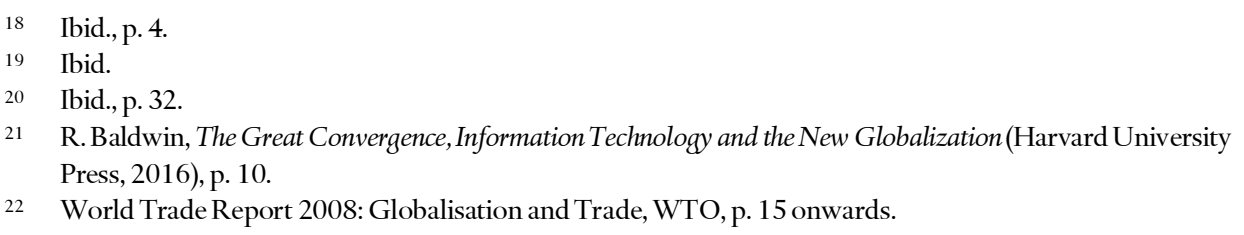


which has changed the citizen's everyday life and reduced transaction costs. The WTO notes that a key driver of globalization has been economic policy, which resulted in deregulation and the reduction or elimination of restrictions on international trade and financial transactions.

The WTO's World Trade Report of 2008 also provides for a detailed analytical discussion of the trade theories and more specifically of specialization based on the relative factor endowment of countries in a globalizing world. ${ }^{23}$ According to the new trade theory presented in the study, the gains obtained result from economies of scale, product variety and increased competition that are characteristic for the new trade patterns for trade in goods, services, intermediates, intra-firm trade and what is now increasingly referred to as 'trade in tasks', referring to the breaking up or fragmentation of the production process. A more recent WTO Report argues that globalization is increasingly embraced today for the development perspectives it offers. ${ }^{24}$ This is in line with the general view that more specialization leads to more trade and more jobs, as well as to higher living standards. More competition leads to better quality and more consumer choice. What is required, however, in order to remain competitive, is to invest in research and development (R\&D), education and infrastructure, thus creating the enabling environment. The positive relationship between trade and growth and economic development is systematically underscored by the WTO arguing that trade liberalization has been a catalyst of globalization, leading to a wider consumer choice of better quality products, available at affordable prices. ${ }^{25}$

Despite the benefits generated by globalization, there has been a growing resistance against it, mostly driven by the perceived negative impact it has on jobs and employment perspectives in some main OECD countries. It is increasingly evidenced and recognized that globalization not only has winners but also losers and that perhaps too little attention has been given to the question on how to address the negative repercussions of globalization. Bhagwati observed already in 1988 that there are losers as well as winners from market opening and it is important to give support to those who are likely to lose. ${ }^{26}$ Such support is less costly than taking protectionist measures. This point is re-enforced by Heydon, who argues that more should be done to communicate the potential gains from market opening. ${ }^{27}$ Globalization has had a considerable attention in the press in the course of 2016 and the Economist underscores that 'Trade creates many losers, and rapid immigration can disrupt communities. But the best way to address these problems is not to throw up barriers. It is to devise bold policies that preserve the benefits of openness while alleviating its side-effects. ....but don't equate managing globalization with abandoning it.'28 China's President Mr Xi

23 Ibid., p. 13.

24 It is increasingly acknowledged that trade is essentially a development tool, a means to enhance growth and economic development, as is explained and analysed in the WTO Trade Report of 2015.

25 Cf. World Trade Report 2008.

26 J. Bhagwati, Protectionism (MIT Press, 1988).

27 K. Heydon, 'The Political Economy of International Trade', in K. Heydon and S. Woolcock (eds.), The Ashgate Research Companion to International Trade Policy (Ashgate, 2012).

28 The Economist, 'The New Political Divide', 30 July 2016, p. 7. 
Jinping made a strong pitch in support of globalization at the most recent meeting of the World Economic Forum held at Davos, January 2017, where he pleaded countries to 'remain committed to developing global free trade and investment, promote trade and investment liberalization and facilitation through opening-up and say no to protectionism. Pursuing protectionism is like locking oneself in a dark room. While wind and rain may be kept outside, the dark room will also block light and air. No one will emerge as a winner in a trade war.'29

Recently, Braga questioned whether globalization had reached its peak. ${ }^{30}$ In the same vein, Wolf suggests that the tide of globalization is turning. ${ }^{31}$ Rodrick had already raised the question of whether globalization had gone too far 20 years ago. ${ }^{32}$ These questions suggest however that one can perhaps manage globalization. In reality, globalization is driven by market forces and not by governments, and the more important question perhaps is how the economic benefits can be derived from globalization in inclusive ways. This then leads to the question what policy responses can be provided in order to reap the benefits and to which I will turn further below.

The opponents of globalization not only consider that it leads to the destruction of jobs, to economic imbalances but also has a negative impact on the environment from the increasing trade flows. ${ }^{33}$ The opposition against globalization is used as an argument to protect domestic markets. It is well known among economists that it is much easier to identify sectors that are affected by competition and lead to job losses than the jobs created as a result of efficiency gains and the lower cost of inputs. The benefits of trade liberalization are generally spread over the economy. This explains why most studies, including the WTO study referred to above, focus on the ways the efficiency gains can be obtained and how they translate into increases in the overall levels of welfare. ${ }^{34}$ According to the WTO, global integration in product, capital and labour markets has resulted in a more efficient allocation of economic resources over time. Consumers have a wider choice of products and services, at lower prices. According to Wolf 'The era of globalization has seen a first fall in global inequality of household incomes since the early 19th century. Between 1890 and 2015, average global real income rose by 120 per cent. The opportunities provided by globalization are vital. Our future cannot lie in closing ourselves off from one another.' ${ }^{35}$ It is

29 President's Xi's speech to Davos in full, taken from https://www.weforum.org/agenda/2017/01/full-text-ofxi-jinping-keynote-at-the-world-economic-forum

30 C. A. Primo Braga, 'World Trade: Have We Reached Peak Globalization?' (IMD, Summer 2015).

31 Financial Times, 'The Tide of Globalization is Turning', 7 September 2016, p. 9.

32 D. Rodrick, 'Has Globalisation Gone Too Far?', Institute for International Economics (1997).

33 These views are not always substantiated. Analytical work undertaken at the WTO on the relation between trade and environment in the WTO's World Trade Report of 2010 on natural resources suggests that specialization generates more trade, which is not necessarily incompatible with environmental objectives and can be mutually supportive.

34 Cf. World Trade Report 2008.

35 Cf. Financial Times. 
admitted that it is often easier to identify the downsides or economic costs of globalization as compared to the overall benefits it yields and which are more significant.

What can be retained from the discussion of the various definitions of globalization is that globalization refers to a very dynamic process of trade and investment in a world economy that is increasingly characterized by strong interdependence through production and trade linkages, higher degrees of specialization and production centres being spread out on a world- wide scale. Technology has played and plays a significant role and so do services as an increasingly important factor in the production process. Both trade and FDI are drivers of globalization and more specifically through mergers and acquisitions, alliances and the creation of production networks. This requires a deeper look into how trade and FDI have evolved and how they were drivers of globalization. Before turning to the interaction between trade, FDI and globalization, a closer analysis will be provided on the contribution of GVCs in the production process, which is closely associated with globalization.

\subsection{Connecting to Markets through Global Value Chains}

The breaking up of the production processes resulting from globalization has meant more specific attention has been paid to GVCs as a way for countries to connect to markets and become part of the production and supply process. The essence of GVCs is that countries are increasingly fused together by joint production arrangements which in a way are an extension of the globalization process. Involvement in GVCs allows incremental specialization through the production and trading of tasks and components rather than entire products. The former WTO Director General P. Lamy observed that global value or supply chains are not new per se, as parts and components for the finished goods have been traded for decades. ${ }^{36} \mathrm{He}$ points out that the transactions have however become far more complex, a main difference to the way trade was conducted before. This is confirmed in the academic literature on GVCs and in the developments of trade and FDI, as will be shown in this chapter.

The public debate mostly focuses on the question and perhaps even concerns about the implications of globalization and GVCs for the world economy, for individual economies and for development. This debate takes place against a backdrop of constantly shifting circumstances and evolving technology which in return affect the comparative advantage at any given time in the production process. In order to dispel these concerns, a better understanding of the theoretical positions on GVCs is required.

Gereffi was one of the initial researchers analysing GVCs and publishing on the meaning and implications of GVCs on trade, overall levels of welfare and policies in the early 1990s

36 P. Lamy, speech delivered at the WTO-MOFCOM-OECD-UNCTAD Seminar on Global Value Chains in Bejing, 19 September 2012, entitled 'Global Value Chains are Binding Us Together'. 
and this led to various other texts by the same author on this topic. ${ }^{37}$ More analytical work has followed since then by other academics, deepening the understanding of GVCs, the organization of production networks and their policy implications. Gereffi and FernandezStark explain that

Globalization has given rise to a new era of international competition that is best understood by looking at the global organization of industries and how countries rise and fall within these industries. The global value chains framework has evolved from its academic origins to become a major paradigm used by a wide range of international organizations... Global value chains highlight how new patterns of international trade, production, and employment shape the prospects for development and competitiveness, using core concepts like "governance" and "upgrading". 38

According to the same authors

By focusing on the sequence of tangible and intangible value adding activities, from conception and production to end use, GVC analysis provides a holistic view of global industries- both from the top down (for example, examining how lead firms "govern" their global- scale affiliate and supplier networks) and from the bottom up (for example, asking how these business decisions affect the trajectory of economic and social "upgrading" and "downgrading” in specific countries and regions). ${ }^{39}$

The significance of GVCs for the world economy is equally underscored by international organizations including the WTO, OECD and World Bank and IMF. The OECD and the WTO jointly pursued their efforts to develop new ways of calculating wealth creation through value added chains. ${ }^{40}$ This initiative is based on the recognition that the data used at present are inadequate to measure the real contribution of countries at each stage of the production process. According to the WTO measuring trade in gross value terms no longer makes sense in a world where trade in intermediate goods - a reasonable proxy for global value chain activity - constitutes more than half of world merchandise trade. ${ }^{41}$ Trade flows must be measured today in terms of the value added by each production link along a supply chain to the final value of goods and services.

37 G. Gereffi, 'The Organization of Buyer-Driven Global Commodity Chains: How US Retailers Shape Overseas Production Networks', in G. Gereffi and M. Korzeniewicz (eds.), Commodity Chains and Global Capitalism (Praeger, 1994), p. 95-122; G. Gereffi, J. Humphrey and T. Sturgeon, 'The Governance of Global Value Chains', 12 Review of International Political Economy (2005), p. 78-104.

38 G. Gereffi and K. Fernandez-Stark, 'Global Value Chain Analysis: A Primer', Centre on Globalization, Governance \& Competitiveness, Duke University (2011), p. 35.

39 Ibid., p. 4.

40 WTO World Trade Report 2014 addresses Global Value Chains and ways to measure them.

41 Ibid. 
The WTO observes that the recent research activity on trade in value-added terms mainly derives from the notion of vertical specialization developed by Hummels et al. (2001) and defined as 'the value of imported intermediates embodied in a country's exports' or import content of exports'. ${ }^{42}$ This work was followed by more recent studies by Daudin et al. 43 (2006 and 2009), Escaith ${ }^{44}$ (2008) and Koopman et al. (2010), ${ }^{45}$ who refer to a measurement of the added value trade with empirical data based on an international inputoutput framework. One way of measuring the participation of countries in GVCs is to show what percentage of a country's exports are part of GVCs, either because of upstream links (foreign value added in exports) or downstream links (exports that are incorporated in other products and re-exported). In other words, the GVC participation rate indicates the share of a country's exports that is part of a multi-stage trade process: it is the foreign added value that is part of a multi-stage trade process; it is the foreign added value used in a country's exports (downstream), divided by total exports.

Cattaneo et al. in a 2010 World Bank Report state that 'given that production processes in many industries have been fragmented and moved around on a global scale GVCs have become the world economy's backbone and central nervous system'. 46 Neilson et al. consider that given the developments with regard to GVCs and global production networks it is time for 'a critical reappraisal of the conceptual development and empirical manifestations of GVCs and GPNs as the core features of the international political economy'. ${ }^{47}$ They look more specifically at the implications of GVCs on the shifting economic balance, the growing influence and the role of China and India, and more generally the role of the state with regard to these developments, namely governance related issues which will be addressed later.

In a publication by the IMF, Saito et al. look primarily at the evolution of the GVCs since the mid-1990s and what these developments mean for the work of the IMF.48 They examine

42 D. L. Hummels, J. Ishii and K-M. Yi, 'The Nature and Growth of Vertical Specialization in International Trade', 54 Journal of International Economics (2001), p. 75-96.

43 G. Daudin, C. Riffart and D. Schweisguth, 'le commerce Extérieur en Valeur Ajouté', 98 revue de l'OFCE: Observatoire et diagnostiques économiques (2006), p. 129-165; G. Daudin, C. Riffart and D. Schweisguth, 'Who Produces for Whom in the World Economy?' Observatoire Français des Conjonctures Economiques (OFCE), Document de travail de l'OFCE No. 2009-18(2009).

44 H. Escaith, 'Measuring Trade in Value Added in the New Industrial Economy: Statistical Implications', Munich Personal RePEc Archive MPRA Paper (No. 14454, 2008); H. Escaith and H. Gaudin, 'Clustering ValueAdded Trade Profiles: Structural and Policy Dimensions', WTO Working Paper (2014).

45 R. Koopman, W. Powers, Z. Wang and S-J. Wei, 'Give Credit Where Credit is Due: Tracing Value Added in Global Production Chains’, National Bureau of Economic Research (NBER) Working Paper (No. 16428, 2010).

46 O. Cattaneo, G. Gereffi and C. Staritz (eds.), Global Value Chains in a Postcrisis World: A Development Perspective (World Bank, 2010).

47 J. Neilson, B. Pritchard and H. Wai-chung Yeung, 'Global Value Chains and Global Production Networks in the Changing International Political Economy: An Introduction', 21 Review of International Political Economy (2014), p. 1-8.

48 M. Saito, M. Ruta and J. Turunen, 'Trade Interconnectedness: The World with Global Value Chains', International Monetary Fund (2013). 
the implications of GVCs for jobs and growth, competitiveness, and protectionism and trade-related policies. They observe that 'Existing evidence suggests that GVCs have contributed to productivity gains and growth' ${ }^{49}$ Their observations are based on the work undertaken through the International Collaborative Initiative on Trade and Employment (ICITE), which brings together all major international organizations and is coordinated by the OECD. The surveys, research and analysis conducted led to the conclusion that '[i]mports may cause job displacement in the short-run, due to adjustment costs... In the long-run, there appears to be a positive relationship between imports and employment ${ }^{50}$ With regard to the effect of intermediate inputs on productivity and growth, it appears that 'higher trade flows of intermediates are correlated with higher productivity'. ${ }^{51}$

The IMF also observes that based on official data

GVCs are creating more and more world income, including labor income. This is by no means limited to manufacturing; indeed more income is generated by exporting services within GVCs. Moreover, the fragmentation of the production process across different countries has led to a strong trade-investment nexus. Data at the individual country level indicate that being part of GVCs is associated with a higher growth rate since the mid-1990s. ${ }^{52}$

The WTO's World Trade Report of 2014 equally underscores the contribution that GVCs can make to the development perspectives of developing countries and notes that developing countries are increasingly involved in international production networks and South-South global value chains are becoming more important. ${ }^{53}$ It is observed that developing countries' participation in GVCs through services exports has increased. The advantage of focusing more on services for developing countries is that it requires less the setting up of an infrastructure for production, thus lowering transaction costs. Hence GVCs offer an opportunity to integrate in the world economy at lower costs, but gains from GVC participation are not automatic. There is not one single policy on how to achieve that and all the factors that contribute to the end product need to be taken into consideration when analysing GVCs. The key question is to better understand who contributes to what, at what stage and to what extent? Governments are particularly interested in securing a profitable place on global supply chains and deriving as much as possible of the total added value.

Dedrick et al. conducted specific research on GVCs and presented a case study with regard to iPods, notebook PCs and iPhones, which reveal more of the economic realities with regard to who gains what and how in the GVCs. ${ }^{54}$ The case study makes the point that

49 Ibid., p. 6.

50 Ibid.

$51 \quad$ Ibid.p. 43.

52 IMF August 2013, p. 1.

53 World Trade Report 2014, WTO, p. 78. Developing country issues will be discussed in detail in Chapter 5.

54 J. Dedrick, K. Kraemer and G. Linden, 'Who Profits From Innovation in Global Value Chains? A Study of the iPod and Notebook PCs', Alfred P. Sloan Foundation Annual Conference, May 1-2, 2008, Boston, MA. See 
'earlier we found that for every \$299 iPod sold in the US, the US trade deficit with China increased by about 150 USD. For the iPhone and the iPad, the increase is about $\$ 299$ and $\$ 275$ respectively. Yet the value captured from these products through assembly in China is around $\$ 10,{ }^{5}$ In other words the Chinese contribution to the value of the final product represents only some $5 \%$ of the total value. In terms of employment, the authors calculate that the US has a third of the total jobs, but this accounts for more than twice the wages. They estimated that the production of iPods represented 41,000 jobs worldwide in 2006, of which 16,000 jobs are located in the USA, including 6,000 highly specialized jobs. Since the American workers are very qualified and get a better pay, they received more than $\$ 750$ million, but only $\$ 320$ million - less than half of this - went to foreign workers. The United States thus provides for the high-skilled engineering and professional jobs. In addition, of course, the wages in the United States are far higher. ${ }^{56}$ They argue that the Chinese contribution in the manufacturing process is very limited (to a fraction of the end value of the product) and consists of labour skills required for assembly.

It would therefore be wrong to attribute the $\$ 150$ as added value due to an import coming from China which would widen the commercial imbalance between the two countries. If instead the origin of the added value included in this importation is considered, an important part is the result of American re-importation and for the remaining part it is the result of the bilateral trade between for example Japan and South Korea, and that needs to be accounted for according to their contribution to the added value. Their analysis shows that the technology input is what generates the most revenue and jobs in the United States. Koopman et al. take a closer look at the real contribution of China in the production process. ${ }^{57}$ Based on econometrics they find that 'First the share of foreign content in manufacturing exports from China was close to 50 per cent during 1997-2002 ... second, the share of domestic content increased from 51 per cent in 2002 to 60 per cent in 2007, which corresponds to the first five years of China's membership in the WTO'.58

These examples and explanations illustrate the complexity of the issues and the challenges emanating from the recent developments which require balanced and well thought out approaches and responses, rather than over-simplifying the realities and providing quick fixes by way of protectionist measures and which risk being costly to consumers and producers alike and providing the wrong economic signals. In order to deepen the understanding of the new realities, further insights are provided on how trade and investment have evolved, before addressing the policy approaches responding to globalization.

also J. Dedrick, K. Kraemer and G. Linden, 'Capturing Value in Global Networks: Apple's iPad and iPhone', University of California, Irvine, University of California, Berkeley and Syracuse University (2011) http://citeseerx.ist.psu.edu/viewdoc/download?doi=10.1.1.466.3897\&rep=rep1\&type=pdf.

55 Dedrick, Kraemer and Linden, 'Capturing Value in Global Networks', p. 7.

56 Ibid.,, p. 12-13.

57 R. Koopman, Z. Wang, S-J.Wei, 'How Much of Chinese Exports Is Really Made in China? Assessing Domestic Value-Added when Processing Trade is Pervasive', NBER Working Paper (No. 14109, 2008). 


\subsection{Changing Patterns of Trade and Investment}

\subsubsection{New patterns of trade}

International trade patterns are constantly changing in view of shifting comparative advantage, new forms of specialization, changing technologies, consumer preferences and demands. ${ }^{59}$ Globalization and GVCs are a main factor behind the changes that make trade more dynamic and drive economic growth. They are also largely held responsible for a shifting dynamic in economic activity, including trade and investment moving from the West (Europe, US) to the East (Asia).

For almost 20 years, trade grew at an average of $5 \%$ per year. This changed dramatically following the economic and financial crisis in 2008. According to the WTO, world trade had dropped by minus $12.5 \%$ in $2009 .{ }^{60}$ Since then, trade and world output growth have been erratic and mostly at lower levels than the average of 5\% that characterized much of the post WWII period. In 2010, world trade surged by $14.5 \%$ and a $3.6 \%$ growth in global output was witnessed. World trade grew by $5 \%$ and global output by $2.4 \%$ in 2011 , which is a considerable slowdown compared to the previous year. Comparable figures are $2 \%$ and $2.1 \%$ respectively for growth in world trade and world output in 2012. In 2013, world trade and output grew at a similar pace of $2.2 \%$ and data were again roughly the same in 2014 , with a growth of the trade volume and output of $2.5 \%{ }^{61}$ The volume of world trade continued to grow slowly in 2015 , recording a growth of 2.7 per cent. Trade growth was roughly in line with world GDP grow th of 2.4 per cent. ${ }^{62}$

The most noticeable developments that the world has witnessed are the shifts in relative shares in international trade which have occurred between 1980 and 2015. The WTO's World Trade Report of 2008 provides an analysis of the main trends and shifts in the economic trade balance since WWII and until 2007, arguing that the dominant share of the United States in world trade in the early 1950s was eroded in subsequent decades. ${ }^{63}$ The report notes that the reduced share of the industrial countries in world trade can be attributed to the rise of China, the recovery of the Commonwealth of Independent States (CIS), and in more recent years to the boom in commodity prices. ${ }^{64}$ It also notes that in the two decades following 1963, the share of the Asian Newly Industrialized Economies (NIEs)

59 Smeets, 'Changing Patterns in International Trade'; M. Smeets, 'Global Governance and Main Challenges', in Economic Theory and Business Performance, Global Challenges, (Department of World Economy, St Petersburg State University, 2013); M. Smeets, 'Recent Developments in International Trade' in International Economic Relations, Theoretical and Practical Issues (Skifia Print, 2013); M. Smeets, 'Is the Economic Balance Shifting from the West to the East?', Conference Paper published by St Petersburg, State University, Department of World Economy, October 2015.

60 World Trade Report 2010, WTO.

61 Data presented in this section are based on the various WTO's World Trade Reports from 2010-2015

62 The World Trade Statistical Review 2016, WTO, p. 18.

63 Cf. World Trade Report 2008.

64 Ibid., p. 19. 
grew from $2.4 \%$ to $9.7 \%$ of world merchandise exports. ${ }^{65}$ The data presented further below confirm the continuation of this trend in more recent years and up to 2015, with a steady increase in the share of Asian economies in world trade.

It is observed that the minor role of developing countries in international trade was largely due to the mixed system in which governments tended to intervene in order to encourage industrialization. In general, this led to import substitution policies that relied on high tariffs and non-tariff barriers to protect domestic industry. ${ }^{66}$ In other words, in the case of developing countries, their early commercial policies had an inward-looking focus. Industrialization through import substitution was the favoured route for pursuing economic development. This was followed by a shift towards liberalization because many developing countries (mainly from the 1980s onwards) undertook trade reforms unilaterally and at the same time engaged in the multilateral trade negotiations. It will be argued that this may have been in part triggered by the success of a number of Asian newly industrializing countries that adopted an export-led growth strategy. It is also partly due to the debt-crisis in the early 1980s, which exposed the limitations of inward looking policies. Koopman and Piermartini provide evidence that the trade landscape has changed with a rapid rise of developing countries in international trade. ${ }^{67}$ They argue that trade and the WTO have contributed to the development successes of the past decade and a half, with the rapid rise of developing countries. One explanation for this development are the higher commodity prices from which the developing countries largely benefited.

Based on WTO data and statistics, it can be observed that the shares in total merchandise trade (exports and imports) have changed significantly in favour of Asia as a region and more specifically China (Tables 3.1 and 3.2 and graphs 3.1 and 3.2). Data provided in the tables cover developing countries as a group, Asian developing countries, Brazil, India and China, who were considered to be the fastest growing economies. The tables clearly confirm that developing countries have increased their share in world exports by some 50 per cent over the last 35 years. This is mainly due to the rapid growth in Asia, with Asian developing countries having increased their exports by some $350 \%$ in that period. China has been the fastest growing economy. India's growth rate was considerably lower. Brazil's share has remained almost unchanged at a low level. By way of comparison, data for the African continent show that Africa's relative share in world trade declined over the past 35 years from $6 \%$ to $2 \%$. The share of Africa in merchandise trade is slightly higher than India's relative share.

While the tables compare the evolution of trade among developing countries and regions, the graphs illustrate best how China's rapid growth has outpaced the growth rates of the developed countries and which have traditionally dominated world trade in goods and

65 NIEs: Chinese Taipei, Hong Kong, China, Rep. of Korea, Malaysia, Singapore and Thailand.

66 A more detailed analysis and review of the merits of import substitution policies is provided in Chapter 5.

67 R. Koopman, and R. Piermartini, '20 Years of Trade Growth - An In-Depth Look at Latin America and the Rising South in the Broad Context of Global Trade Growth', Workshop held at the WTO, 21 June 2016. 
services (the United States, Germany and Japan). The rapid growth of China is best seen in graphs 3.1 and 3.2, which show a steep increase of China's share in world trade over the last 35 years in comparison to the leading developed trading nations. While the developed countries' shares have gradually declined, China has managed to catch up and overtaken all the leading exporting nations for their goods exports.

TABLE 3.1 Developing economies' share in world trade by selected regions and countries, 1980-2015: merchandise exports (\%)

\begin{tabular}{|c|c|c|c|c|c|c|}
\hline & $\begin{array}{c}\text { Developing } \\
\text { Economies }\end{array}$ & $\begin{array}{c}\text { Developing } \\
\text { Asia }\end{array}$ & Africa & Brazil & China & India \\
\hline $\mathbf{1 9 8 0}$ & 30 & 8 & 6 & 1 & 1 & 0 \\
\hline $\mathbf{1 9 9 0}$ & 24 & 12 & 3 & 1 & 2 & 1 \\
\hline $\mathbf{2 0 0 0}$ & 31 & 18 & 2 & 1 & 4 & 1 \\
\hline $\mathbf{2 0 1 0}$ & 41 & 25 & 3 & 1 & 11 & 2 \\
\hline $\mathbf{2 0 1 2}$ & 44 & 25 & 4 & 1 & 11 & 2 \\
\hline $\mathbf{2 0 1 3}$ & 43 & 26 & 3 & 1 & 12 & 2 \\
\hline $\mathbf{2 0 1 4}$ & 44 & 27 & 3 & 1 & 13 & 2 \\
\hline $\mathbf{2 0 1 5}$ & 44 & 29 & 2 & 1.2 & 13.8 & 1.6 \\
\hline
\end{tabular}

Source: WTO Secretariat World Trade Reports, various years; World Trade Statistical Review, WTO 2016; WTO Statistics Division.

TABLE 3.2: Developing economies' share in world trade by selected regions and countries, 1980-2015: merchandise imports (\%)

\begin{tabular}{|l|c|c|c|c|c|c|}
\hline & $\begin{array}{c}\text { Developing } \\
\text { Economies }\end{array}$ & $\begin{array}{c}\text { Developing } \\
\text { Asia }\end{array}$ & Africa & Brazil & China & India \\
\hline $\mathbf{1 9 8 0}$ & 25 & 8 & 5 & 1 & 1 & 1 \\
\hline $\mathbf{1 9 9 0}$ & 22 & 12 & 3 & 1 & 2 & 1 \\
\hline $\mathbf{2 0 0 0}$ & 28 & 16 & 2 & 1 & 3 & 1 \\
\hline $\mathbf{2 0 1 0}$ & 38 & 24 & 3 & 1 & 9 & 2 \\
\hline $\mathbf{2 0 1 2}$ & 40 & 25 & 3 & 1 & 10 & 3 \\
\hline $\mathbf{2 0 1 3}$ & 41 & 26 & 3 & 1 & 11 & 3 \\
\hline $\mathbf{2 0 1 4}$ & 41 & 26 & 4 & 1 & 11 & 2 \\
\hline $\mathbf{2 0 1 5}$ & 41 & 25 & 3 & 1 & 10 & 2 \\
\hline
\end{tabular}

Source: WTO Secretariat World Trade Reports, various years; World Trade Statistical Review, WTO 2016; WTO Statistics Division. 
GRAPH 3.1: Evolution of merchandise exports 1980-201568

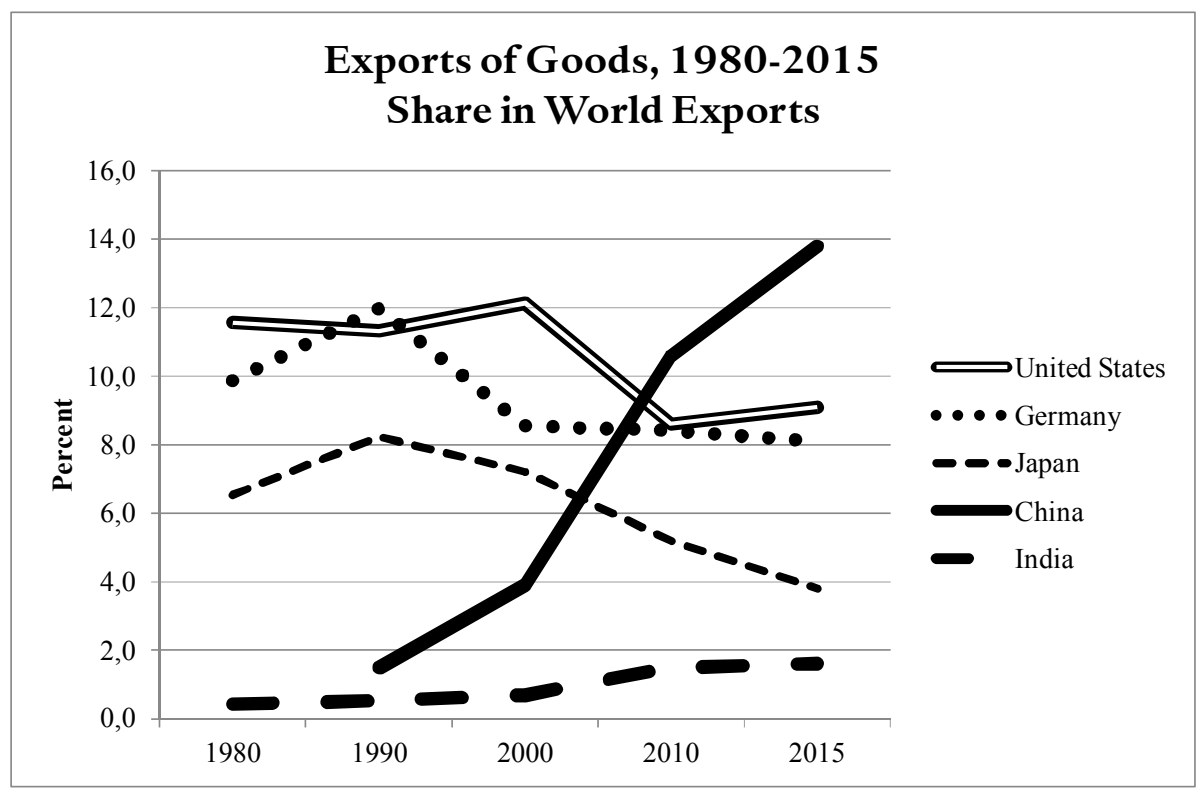

GRAPH 3.2: Evolution of merchandise imports 1980-2015

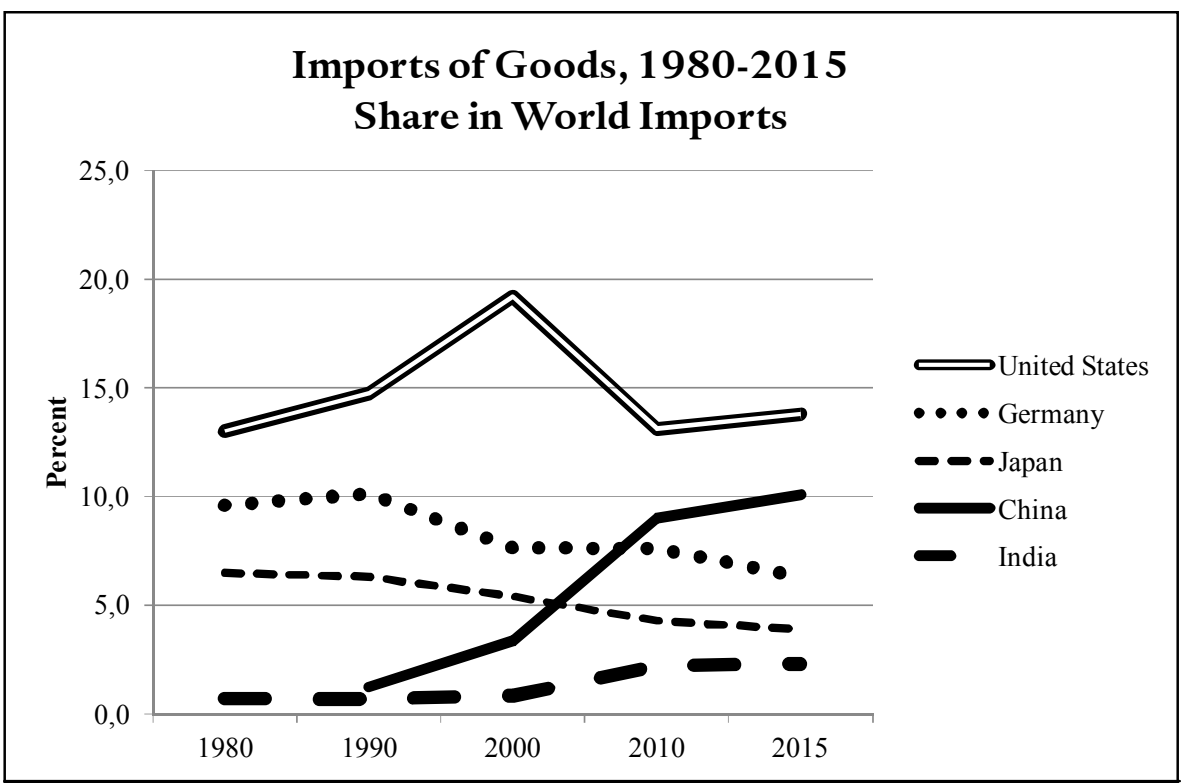

68 This graph, and the graphs which follow are created on the basis of the WTO Secretariat's trade data. 
As for services trade (Tables 3.3 and 3.4 and graphs 3.3 and 3.4), China now is the third largest exporter of services after the United States and the United Kingdom and has overtaken Germany and France. It is the second largest importer of services after the United States, followed by Germany and France. ${ }^{69}$ The export of high value-added services showed fairly significant growth and became an important driving force for restructuring China's trade in services. China's relative shares in services were nearly non-existent in the 1980s, thus making this rapid evolution even more significant. According to the TPR Report on China, trade in services developed rapidly but the trade services deficit continued to expand..$^{70}$ The share of service exports in China's total exports increased from $8 \%$ in 2013 to $10.6 \%$ in 2014 and to $12.3 \%$ in 2015 , which confirms a rapid growth in services trade. The share of services imports in total imports showed a growth from $15.6 \%$ in 2013 to $17.5 \%$ in 2014 and to $22.9 \%$ in 2015. In other words, services imports were notably higher than that of services exports, thus increasing the expansion of deficit in services trade. The services trade deficit expanded from $\$ 79.7$ billion (2012) to $\$ 182.4$ billion (2015), mainly due to increases in the sectors such as travel and transportation.

TABLE 3.3: Developing economies' share in world trade by selected regions and countries, 1980-2015: commercial services exports (\%)

\begin{tabular}{|l|c|c|c|c|c|c|}
\hline & $\begin{array}{c}\text { Developing } \\
\text { Economies }\end{array}$ & $\begin{array}{c}\text { Developing } \\
\text { Asia }\end{array}$ & Africa & Brazil & China & India \\
\hline $\mathbf{1 9 8 0}$ & 21 & 8 & 3 & 0 & & 1 \\
\hline $\mathbf{1 9 9 0}$ & 19 & 10 & 2 & 0 & 1 & 1 \\
\hline $\mathbf{2 0 0 0}$ & 24 & 14 & 2 & 1 & 2 & 1 \\
\hline $\mathbf{2 0 1 0}$ & 29 & 20 & 2 & 1 & 4 & 3 \\
\hline $\mathbf{2 0 1 2}$ & 31 & 21 & 2 & 1 & 4 & 3 \\
\hline $\mathbf{2 0 1 3}$ & 30 & 21 & 2 & 0 & 4.4 & 3.2 \\
\hline $\mathbf{2 0 1 4}$ & 31 & 22 & 2 & 0 & 4.6 & 3.1 \\
\hline $\mathbf{2 0 1 5}$ & 32 & 22 & 2 & 0.7 & 6 & 3.3 \\
\hline & & & & & \\
\hline
\end{tabular}

Source: WTO Secretariat World Trade Reports, various years; World Trade Statistical Review, WTO 2016; WTO Statistics Division.

69 World Trade Statistical Review 2016, which contains data for all countries including the United Kingdom and France, which don't appear in this table. See also table 3.5.

70 WTO's Trade Policy Review, Government Report, 15 June 2016, WT/TPR/G/342; WTO Secretariat Report, 15 June 2016, WT/TPR/S/342, p. 9. World Trade Statistical Review 2016. 
TABLE 3.4: Developing economies' share in world trade by selected regions and countries, 1980-2015: commercial services imports (\%)

\begin{tabular}{|l|c|c|c|c|c|c|}
\hline & $\begin{array}{c}\text { Developing } \\
\text { Economies }\end{array}$ & $\begin{array}{c}\text { Developing } \\
\text { Asia }\end{array}$ & Africa & Brazil & China & India \\
\hline $\mathbf{1 9 8 0}$ & 31 & 8 & 7 & 1 & & 1 \\
\hline $\mathbf{1 9 9 0}$ & 24 & 10 & 3 & 1 & 0 & 1 \\
\hline $\mathbf{2 0 0 0}$ & 28 & 16 & 3 & 1 & 2 & 1 \\
\hline $\mathbf{2 0 1 0}$ & 35 & 21 & 4 & 2 & 5 & 3 \\
\hline $\mathbf{2 0 1 2}$ & 38 & 22 & 4 & 2 & 7 & 3 \\
\hline $\mathbf{2 0 1 3}$ & 37 & 23 & 4 & 1.9 & 7.5 & 2.8 \\
\hline $\mathbf{2 0 1 4}$ & 38 & 24 & 4 & 1.8 & 8.1 & 2.6 \\
\hline $\mathbf{2 0 1 5}$ & 39 & 25 & 3 & 1.5 & 10.1 & 2.7 \\
\hline
\end{tabular}

Source: WTO Secretariat World Trade Reports, various years; World Trade Statistical Review, WTO 2016; WTO Statistics Division.

GRAPH 3.3: Evolution of services exports 1980-2015

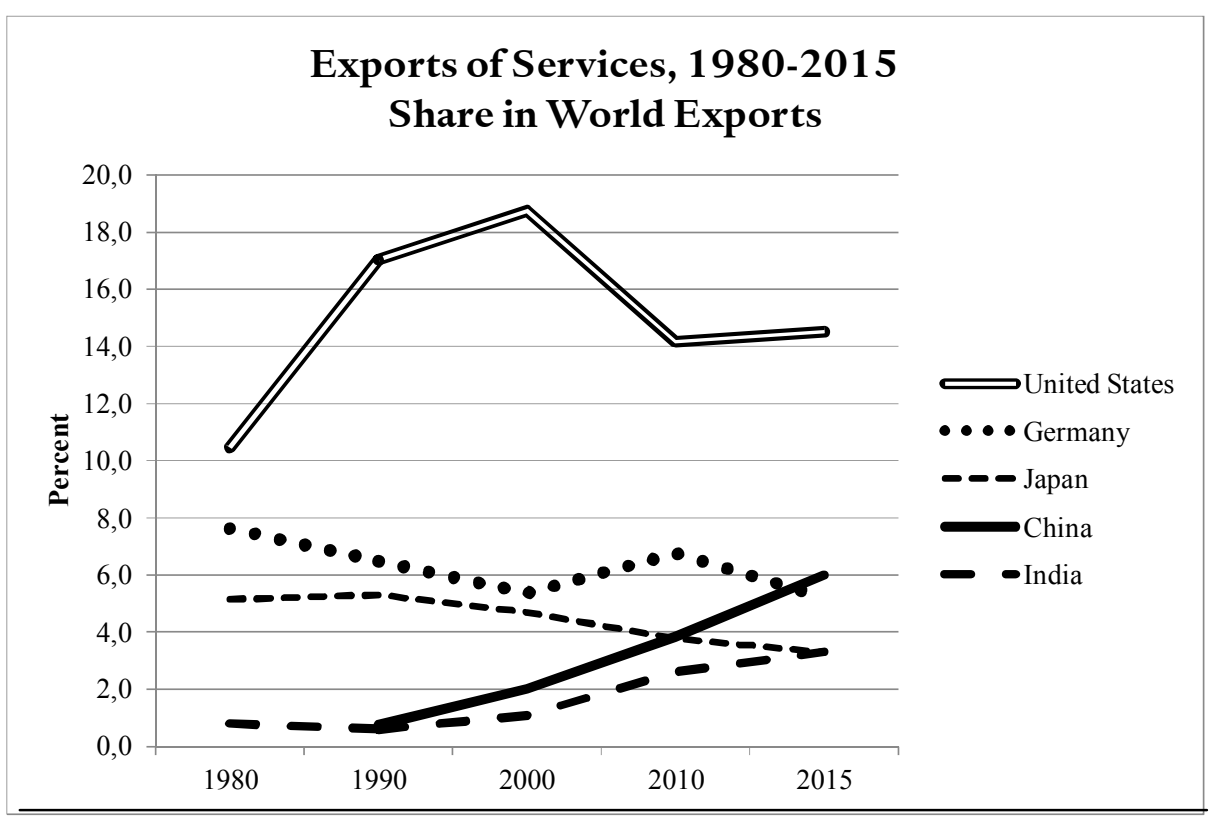


GRAPH 3.4: Evolution of services imports 1980-2015

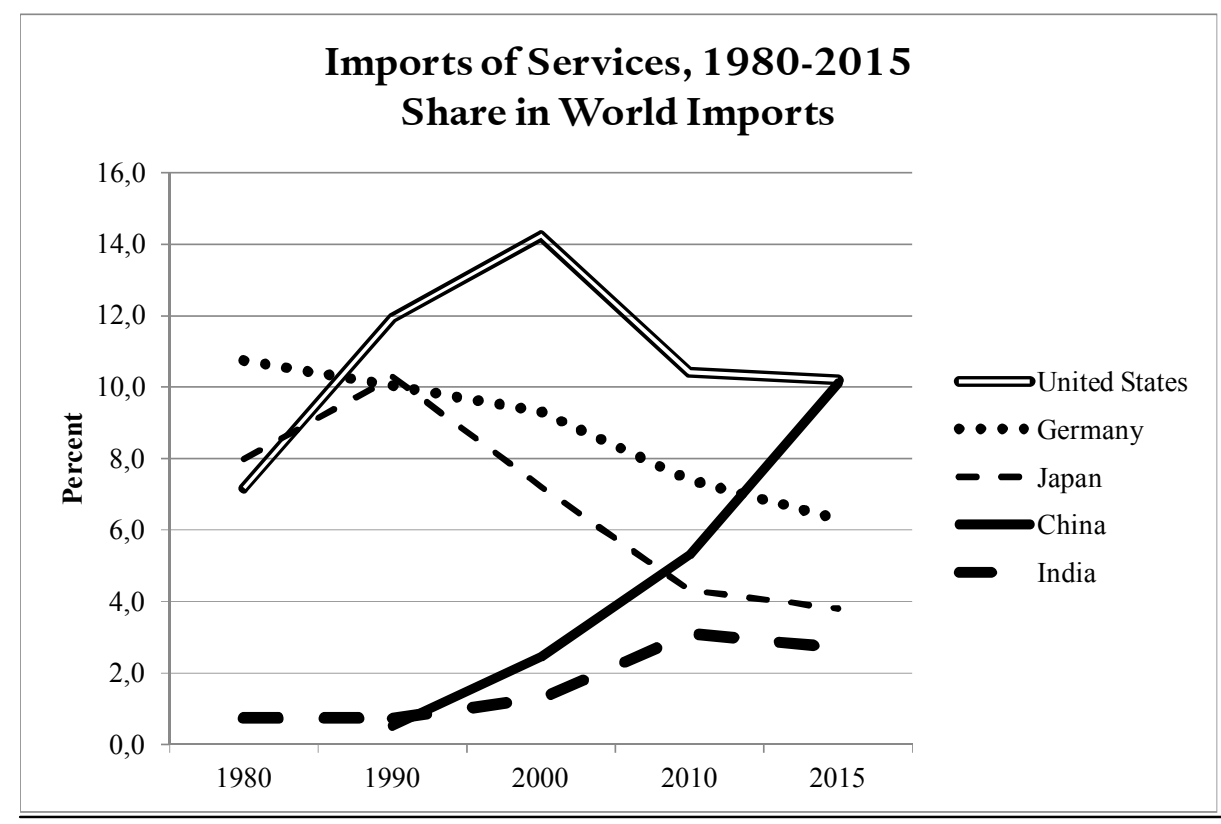

These developments have thus affected the ranking of the main traders in the world since 1980 and for both goods and services, with a relative declining position of the traditional exporters in favour of China and to a smaller extent India (see table 3.5). According to WTO reports, China is now occupying the top spot as the main exporter in merchandise trade, before the United States, and is the second largest importer of total merchandise, just behind the United States. ${ }^{71}$ It accounted for $13.8 \%$ of world exports in 2015 against a mere share of $0.9 \%$ in 1980. . With the United States taking a share of $9.1 \%$ in exports of world merchandise trade, the gap between shares of the United States and China has risen to nearly 5\%, thus strengthening China as the lead and main exporter of manufactures.

In the span of 25 years, China moved from an initial $18^{\text {th }}$ position in 1990 to seventh place in the year 2000 and finally took the first place in 2015. In addition to the United States it overtook Germany and Japan in a relatively short period of time. India's position also improved from the $42^{\text {nd }}$ position in 1980 to a $19^{\text {th }}$ position in 2015. On the import side, China took a second position in 2015, behind the United States, having overtaken Germany and Japan. In terms of services exports, China takes a third position behind the United States and the United Kingdom, which is not shown in the table. China takes a second position in terms of services imports, after Germany.

71 See WTO's World Trade Reports of various years and World Trade Statistical Review 2016; it is noted that data include EU exports and imports per country and not a total for the EU as a collective entity, which would change the rankings. 
The data thus confirm a trend of a shifting economic balance and which is moving from the West to the East, mainly to China and to a much lesser extent India.

TABLE 3.5 : Evolution of ranking of the main traders (1980-2015)

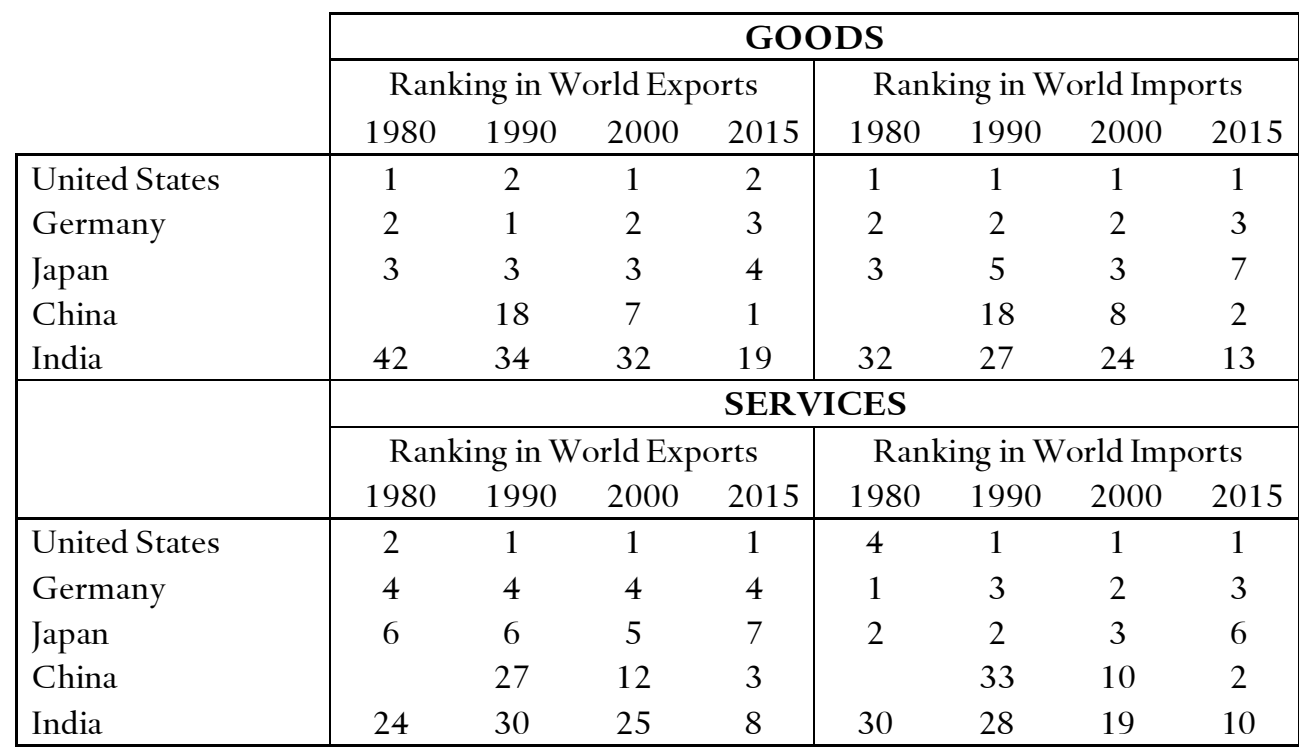

Source: World Trade Statistical Review 2016, WTO, Statistics Division

According to the most WTO reports as well as the recent Trade Policy Review (TPR) reports prepared by the WTO Secretariat and the Government of China for China's review conducted in summer 2016, China's total merchandise imports and exports declined in 2015 compared to $2014 .{ }^{72}$ The combined value had reached $\$ 4,160$ billion, up $7.6 \%$ yearon-year. The export value was $\$ 2.28$ trillion in 2015, down from $\$ 2.34$ trillion in 2014 . Import values were $\$ 1.68$ trillion, down from $\$ 1.96$ trillion. These figures show a significant contraction more specifically on imports, which is in part explained by the lower oil prices. Despite the decline, this still confirms the significant dynamics of Asia's trade.

Several explanations can be provided for China's performance and rapid economic growth. It mainly resulted from an adjustment process conducted in China in relation to its accession to the WTO and the need for change, reforms and adaptation to the new economic challenges. ${ }^{73}$ This is also reflected in statements made by former Chinese leaders and the

72 Ibid.

73 Cf. Yuan Yuan, 'Looking Back 14 Years after Accession: Case of China', statement made at China Round Table on Accessions, Dushanbe, Tajikistan, June 2015. It is observed in the TRP report that structural changes continue to be a main feature of the Chinese official policies. 
present General Secretary of the Communist Party in relation to China's accession to the WTO: $:^{74}$

- Deng Xiaoping: The more reform is conducted and the wider China opens its markets, the stronger its ability to withstand risk.

- Jiang Zemin: WTO membership has pros and cons, the opportunities it brings will triumph over the challenges it imposes if we do our homework well.

- Hu Jintao: Only by adhering to reform and opening up can we make progress and address the thorny problems occurring in the process of our development.

- Xi Jinping: The more we develop the more open we are. China's open door will never be closed. Reform and opening up have no end, and they will always be underway.

Closely linked to these points is China's accession to the WTO in 2001, which offered new trade opportunities. China was very much determined to integrate more fully into the world economy and this led to subsequent deliberate efforts in that regard. It has succeeded and done so well: China is performing a key function in international trade. According to the recent WTO reports some of the BRICS countries, especially China and India, have experienced a growth rate of about $10 \%$ in the last decade, compared to only $2 \%$ for most western economies. ${ }^{75}$ These rates have weakened since and currently are more in the range of $6 \%$ for China. With a growth rate 3 to 4 times higher than the European rate, China is now ahead of Germany as the largest world exporter and the second importer after the United States. Hence, China's share in world merchandise exports has grown exponentially in less than a decade, whilst other main traders have seen their share stagnate at best or decline. China's growth was mainly export driven.

In another development, and according to the same TPR report, China managed to diversify its trading partners. Imports and exports with its three traditional major trade partners (the United States, the European Union and Japan) retained modest growth but their relative shares have been falling. Trade with the Association of Southeast Asian Nations (ASEAN) and other emerging markets maintained a growth trend. The total share of exports from China to ASEAN increased from 9.0\% in 2011 to $12.2 \%$ in 2015 and its share of imports from ASEAN remained steady at $11.3 \%$, up from 11.15 in 2011 . The shares of exports to the United States remained stable at around $25.1 \%$ and imports increased from $15.1 \%$ to $16.7 \%$. Exports to the EU declined from $18.8 \%$ in 2011 to $15.6 \%$ in 2015. Imports from the EU remained stable at $12.4 \%$. Hence, the trend shows a reorientation of its trade focus towards Asian countries. It will be argued further that this development is closely related to the regional production networks that China is developing in Asia and the focus of China on Asia to serve as a hub for GVCs.

$74 \quad$ Ibid.

75 World Trade Report 2014. 
Another illustration of China's diversification strategy can be observed from the $\mathrm{OECD}^{76}$ and WTO reports, ${ }^{77}$ which show that China has now become the first trading partner of Brazil, India and South Africa. According to the OECD study ${ }^{78}$ the BRICS countries doubled their share of global imports between 2000 and 2012 and now account for $18 \%$ of the total. They also currently account for $20 \%$ of global world production, which is largely due to China's contribution (a share of approximately 13\%). If developed countries accounted for $70 \%$ of the global wealth back in 1990 this very percentage is reduced to almost $50 \%$ today.

The data presented thus confirm that the former patterns of world trade dominated by the advanced economies in the West and North are gradually being transformed as emerging economies in the South and the East are becoming new points of trade expansion. It is also interesting to note that according to the World Trade Report of 2014 since 1990 South-South trade - that is trade among emerging and other developing economies - has grown from $8 \%$ of world trade in 1990 to around 25\% today and is projected to reach $30 \%$ by $2030 .{ }^{79}$ Table 3.6 shows the rapid evolution in this regard and the historical trend. This implies that developing countries increasingly trade goods and services between themselves, rather than depending on access to the markets of the developed countries. This not only is an encouraging development in itself, it confirms a changing pattern of trade and a growing diversification in markets of supply for goods and services originating in developing countries.

TABLE 3.6: Importance of South - South trade in world merchandise trade, by product categories, 1995-2015 (\%)

1995

$2000 \quad 2005$

2010

2015

Share in world

merchandise

10

11

14

20

23

trade

Share in world

trade in

agricultural

12

14

20

22

products

Share in world

trade in fuels

and mining

products

Note: Data prior to 2000 are based on a slightly different definition of the developing economies.

Source: WTO Secretariat estimates, data provided by the Secretariat.

\footnotetext{
76 'Shifting Wealth and the Productivity Challenges for Middle-Income Countries', in Perspectives on Global Development 2014: Boosting Productivity to Meet the Middle-Income Challenge, (OECD Publishing, 2014).

77 World Trade Report 2014.

78 See OECD, "Shifting Wealth', p. 26.

79 See World Trade Report 2014, p. 42.
} 


\subsubsection{Changing patterns of Foreign Direct Investment}

FDI is an essential way to penetrate foreign markets, both for the production and sales of goods, after sales service and establishing customer/producer relations. Patterns of FDI and their underlying motivations have evolved considerably. FDI surged in the 1980s due to globalization. Multinational firms aimed at finding a balance between reaping some of the scale advantages of global markets and exploiting the often geographically determined diversity of consumers and production factors. According to the World Investment Report (WIR) prepared by the United Nations Conference on Trade and Development (UNCTAD), total global FDI was as low as $\$ 27$ billion in $1982 .{ }^{80}$ It rapidly increased in the second half of the 1980s and quadrupled in the 1990s. It reached $\$ 1.47$ trillion in 2013, followed by a drop of $16 \%$ in 2014 to $\$ 1.23$ trillion, and regained strength last year when FDI flows rose by $38 \%$ to reach $\$ 1.76$ trillion in 2015.81 The WIR notes that these levels are still $10 \%$ of the 2007 peak which occurred shortly before the financial crisis of 2008.82

Outward FDI flows from developed economies reached \$1.1 trillion, representing a 33\% surge over the year before. ${ }^{83}$ FDI has become more diversified with some developing countries taking an increasingly important share in both the outward and inward flows, especially Asia. ${ }^{84}$ According to the WIR, inflows into developing countries reached a new high of $\$ 765$ billion, representing a 9\% surge over the year before. Developing Asia received FDI inflows of $\$ 541$ billion and thus remained the largest recipient region in the world. The inflows were mainly driven by a strong performance in East and South Asian economies, with a surge of $16 \%$. It confirms the dynamics of the region compared to other regions including Africa, with a drop of $7 \%$ of inflows in 2015 compared to the year before. The report notes that developing Asia remained the largest recipient region in the world. FDI flows to China increased by $6 \%$, reaching $\$ 136$ billion. ${ }^{85}$ China's outward FDI also rose by some $4 \%$ to $\$ 128$ billion, thus remaining the third-largest investing country world-wide after the United States and Japan. ${ }^{86}$ In South Asia, India's FDI inflows increased by some $22 \%$ to reach $\$ 44$ billion, which became the fourth largest recipient of FDI in developing Asia and the tenth largest in the world. 87

The data show that FDI is increasingly becoming a two-way street with outflows from developing countries often matching the outward FDIs of developed countries. In other words, FDI is no longer the exclusive domain of developed countries, but is increasingly becoming an issue of interest to developing countries. In the 1980s and early 1990s, about two-thirds of FDI inward stock and $90 \%$ of FDI outward stock were moved in developed

\footnotetext{
80 World Investment Report 2015: Reforming International Investment Governance, UNCTAD.

81 World Investment Report 2016: Investor Nationality: Policy Challenges, UNCTAD.

82 Ibid., p. 2.

83 Ibid.

84 The changing trends are discussed in Smeets, 'Changing Patterns in International Trade'.

85 World Investment Report 2016, p. 45.

86 Ibid., p. 48.

87 Ibid., p. 47.
} 
countries. The Triad (the EC, Japan and the United States) accounted for some $70 \%$ of worldwide inflows. One explanation for the initial predominance of FDI in the developed countries was the existence of large consumer markets in the OECD countries and the gradual liberalization of capital markets within OECD countries, thus easing FDI flows.

The growth in FDI in China was driven mainly by an increase in FDI to the services sector, which rose by $17 \%$, and now accounts for $61 \%$ of all FDI. ${ }^{88}$ FDI in manufacturing stagnated, especially in industries that are sensitive to rising labour costs. FDI inflows in services surpassed the share of manufacturing for the first time in 2011. Low provides explanations on the question why the role of services in trade and more specifically in GVCs has become so important, as 'services have sometimes been referred to as the glue that holds supply chains together and ensures that they function in a fluid manner'. ${ }^{89}$ He goes on to say that 'this is only one aspect of what services do. They are also part of the production and sales process ... Modern communication and transportation technologies have enhanced the tradability of services. This has facilitated their incorporation in supply chain production as traded inputs'..$^{90}$

Developing Asia became the world's largest region receiving FDI with a widespread growth, including in the major Asian economies and sub-regions. Within the region, China went from being an importer of FDI to become an important exporter of FDI, directly investing in the West as well as in Asia and Africa. The extent to which it invests in Asia, representing the bulk of its FDI, underscores the necessity for proximity between producers and consumers. It is essential in order to effectively respond to the needs of the client and assure an after-sale service. It is also in line with the arguments made with respect to GVCs as an extension of globalization. This trend is in accordance with Gereffi's observations and a confirmation of a trend that China is actively creating what could be referred to as regional production networks and 'hubs'. ${ }^{91}$ Gereffi et al. explain that the world is witnessing a shift from the West to emerging economies and observe that:

Until recently, trade integration and growth in many developing countries were fueled by the insertion of local producers in GVCs feeding into high-income economies. Recently, however, low growth or stagnation in historically dominant Northern economies along with sustained growth in emerging countries, in particular in China and India, have spurred a shift in primary drivers in trade and growth to emerging economies with crucial implications for global demand, structures of production and innovation. ${ }^{92}$

\footnotetext{
88 Ibid., p. 45.

89 P. Low, 'The Role of Services in Global Value Chains', in Elms and Low, Global Value Chains in a Changing World, p. 63.

90 Ibid.

91 Ibid.

92 Cf. Gereffi and Fernandez-Stark, 'Global Value Chain Analysis', p. 36.
} 
China thus relocates parts of its production processes in other markets. According to the UNCTAD's earlier WIR (2015), Chinese FDI in neighbouring countries is growing rapidly, thus creating jobs and adding value not only in China, but in the region. China outsources according to the principles of comparative advantage and specialization and delocalizes parts of its production in order to benefit from skilled workforce and competitive conditions in neighbouring countries. While China developed very strongly, other countries in the region also benefited directly from strong economic growth, such as Vietnam, Taiwan, Thailand, Malaysia and others. In the same line of argument, this can also be explained by what Baldwin suggests, namely that 'supply chains are regionalized rather than globalized: Factory Asia, Factory North America and Factory Europe'. ${ }^{93}$

This logic is also much in accordance with the information contained in the WIR with regard to the mega regional trade integration initiatives and which increasingly shape patterns in trade and investment. ${ }^{94}$ According to the WIR, the three main regional groups currently under negotiation (Trans-Pacific Partnership (TPP), Transatlantic Trade and Investment Partnership (TTIP), Regional Comprehensive Economic Partnership (RCEP)) each account for a quarter or more of global FDI flows. ${ }^{95}$ Asia-Pacific Economic Cooperation (APEC) remains the largest regional economic cooperation grouping, with $54 \%$ of global inflows. It is also interesting to note that most of the investment issues are governed bilaterally between countries in the form of bilateral investment treaties and which have significantly increased over the most recent years. According to the WIR, there are presently 3,304 bilateral investment agreements between over 180 countries. ${ }^{96}$ The treatment of investment is also increasingly part of regional integration initiatives.

\subsection{The Shifting Economic Balance from the West to the East}

Various academic studies, reports by international organizations and the data presented above show that the changing patterns and trends in world exports emanating from different regions have led to a rising influence of Asia and more specifically of China in the world economy. ${ }^{97}$ A significant shift in the economic balance is occurring and at a steady pace. De la Torre et al. refer in this regard to 'Tectonic Shifts in the Global Economic Landscape'. 98 The evidence they provide shows that the global economic activity that was concentrated in the Northern countries in the 20th century has moved in a very short period to the developing countries and more specifically in South East Asia (China) and other large

93 Cf. Baldwin, 'Trade and Industrialization', p. 30.

94 World Investment Report 2016.

95 Ibid., p.8.

96 Ibid., p. xii. See also United Nations Conference on Trade and Development, IIA Issues Note (No. 1, 2015).

97 'Perspectives du Développement Mondial 2010; le basculement de la richesse', OECD (2010); J. Kharabi,

'Asia's Rising Middle Class', Asia: Weekly Insight and Features from Asia (2011), http://asiafoundation.org/2011/01/26/asias-rising-middle-class/?; H. Kharas, 'The Emerging Middle Class in Developing Countries, OECD Development Centre Working Paper (No. 285, 2010).

98 A. de la Torre et al., 'Latin America and the Rising South: Changing World, Changing Priorities' (World Bank Group, Washington DC, 2015), p. 2. 
emerging economies. Most of the process took place in the last 10-15 years. ${ }^{99}$ The spectacular growth is not only seen in the expansion of trade, but equally in the South's share of global capital inflows, including FDI. This also confirms what was indicated earlier in terms of shifting FDI flows with Asia taking an increasingly dominant position. According to these authors, 'the increase in economic weight of the South is likely here to stay: it is probably neither short lived, not reversible'. 100 The authors refer to various other studies from the World Bank and the Asian Development Bank, which point in the same direction. They indicate that according to the World Bank, the share of the South in global GDP will reach $55 \%$ by 2025.101 The Asian Development Bank forecasts that the share of exports from the South will rise to $64 \%$ of global exports by $2030 .{ }^{102}$

De la Torre et al. go on to show that the North is no longer the centre of the global trade network and that the South is no longer its periphery, as was the case for a long time, with the South largely playing a secondary role in the economy. ${ }^{103}$ The comparison of the density of regional trade networks in the world is presented by the authors in several maps, which clearly show how Asia is becoming a very significant actor, creating closely knit networks. In addition, these networks are mostly situated within Asia and in Asian trade relations with the West. These are significant developments which confirm yet again that the centre of gravity of the economic activity is shifting from the West to the East. This point is confirmed in various other studies as will be argued further. At the same time, there are significant differences across the South countries and particular regions. Asia and more specifically China take a dominant position in trade and investment and it has become a main hub for trade relations.

There is a variety of factors that explain these developments, several of which have already been pointed out, including the surge of GVCs which have contributed to the regional production networks. They are contributing to and reinforcing the gradual shift in the centre of gravity from the West to Asia. Neilson et al. explain that "The rise of China as "factory of the world" and to a lesser extent, India as the "world's back office" were contingent upon the global expansion of captive forms of chain/network governance in manufacturing and services'. ${ }^{104}$ They also argue that the relocation of production to lower cost production sites in developing countries create the conditions for economic growth in these countries and a shift in the balance. According to the authors, this became even more important after the financial crisis in 2008, which mostly affected Western countries, whereas China continued to grow and expand. They then point out that

\footnotetext{
99 Ibid., p. 2-3.

100 Ibid., p. 3.

101 Ibid., See Global Development Horizons (World Bank, Washington DC, 2013).

102 These data are found in K. Anderson and A. Strutt, 'Asia's Changing Role in World Trade: Prospects for South-South Growth to 2030', Asian Development Bank Working Paper (No. 264, 2011).

103 Cf. de la Torre et al., p. 4-7, which illustrates graphically how the global trade network in 2012 shifted.

104 Cf. Neilson, Pritchard and Wai-chung Yeung, 'Global Value Chains', p. 4.
} 
Perhaps most significant in this regard is the shifting end-markets for consumer goods as the balance of purchasing power shifts towards Asia and other emerging economies (e.g. Brazil, South Africa, Russia, and elsewhere). This shift is characterized by the widespread expectations that Chinese demand will be the prime catalyst capable of leading the world out of economic stagnation. ${ }^{105}$

This argument of the rising consumption in Asia can be found in other studies, including in various OECD publications which confirm the trend of a shifting balance from the West to the East and South. ${ }^{106}$ According to the OECD reports, the balance moved from OECD members to developing countries, a trend it refers to as the 'shift of wealth'. This shift is illustrated with the charts presented below, showing the evolution of the global economy between 2000 and 2010 and a forecast of 2030. ${ }^{107}$ Accordingly since 2000, the non-OECD members' shares of the world economy continue to rise, while the OECD shares decline (graph 3.5). What does this mean? In 2000, OECD members' global wealth accounted for $60 \%$ of the total, against $40 \%$ for non OECD members. The OECD predicts an inversion of the trend and in 2030 non-OECD members will have a total share of $57 \%$ against $43 \%$ for the current OECD members. This readjustment of the global economy is considered to be of a structural nature, thus suggesting a permanent change. 108

\section{GRAPH 3.5: Share of the global economy in purchasing power parity terms} (\% of global GDP, PPP basis)

2000

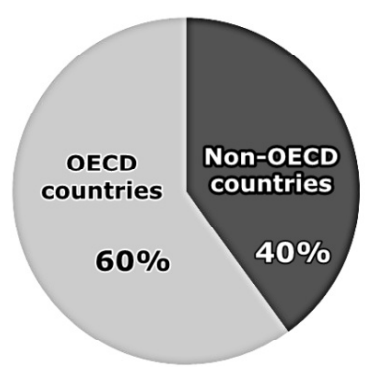

2010

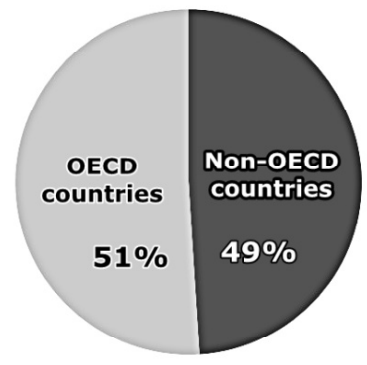

2030

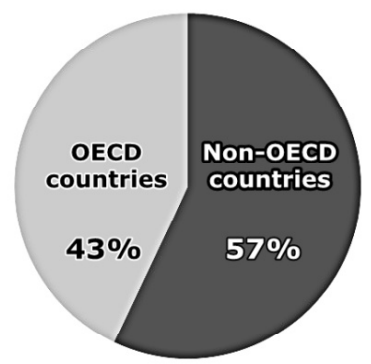

Source: OECD Perspectives on Global Development 2010: Shifting Wealth, page $2^{109}$

Another way of analysing the shifting balance is to look at the evolution of the global consumption patterns by the middle class, as was also done by the OECD. ${ }^{110}$ Here again

\footnotetext{
105 Ibid., p. 5.

106 Perspectives on Global Development 2014: Boosting Productivity to meet the Middle-Income Challenge, OECD (2014); Perspectives on Global Development 2010: Shifting Wealth, OECD (2010).

107 Perspectives on Global Development 2010, OECD, p. 2. See also H. Kharas, 'The Emerging Middle Class in Developing Countries', OECD Development Centre Working Paper (No. 285, 2010).

108 See also Smeets, 'Changing Patterns in International Trade'.

109 See also Kharas, 'The Emerging Middle Class'.

110 Ibid., p. 26-29.
} 
major developments and changes can be observed, as illustrated in Graph 3.6 which provides information on the expected trend in the spending of the middle class between now and 2030. In the next 15 years spending in Europe and the United States is expected to sharply drop and grow exponentially fast in Asia Pacific, driving a big wedge and tilting the balance strongly in favour of the East. While these remain projections, they are based on evidence and data collection that seem to strongly point in that direction and which confirm the shift of the economic balance moving from West to the East.

\section{GRAPH 3.6: Share of the Global Middle Class in various regions in the world (\%)}

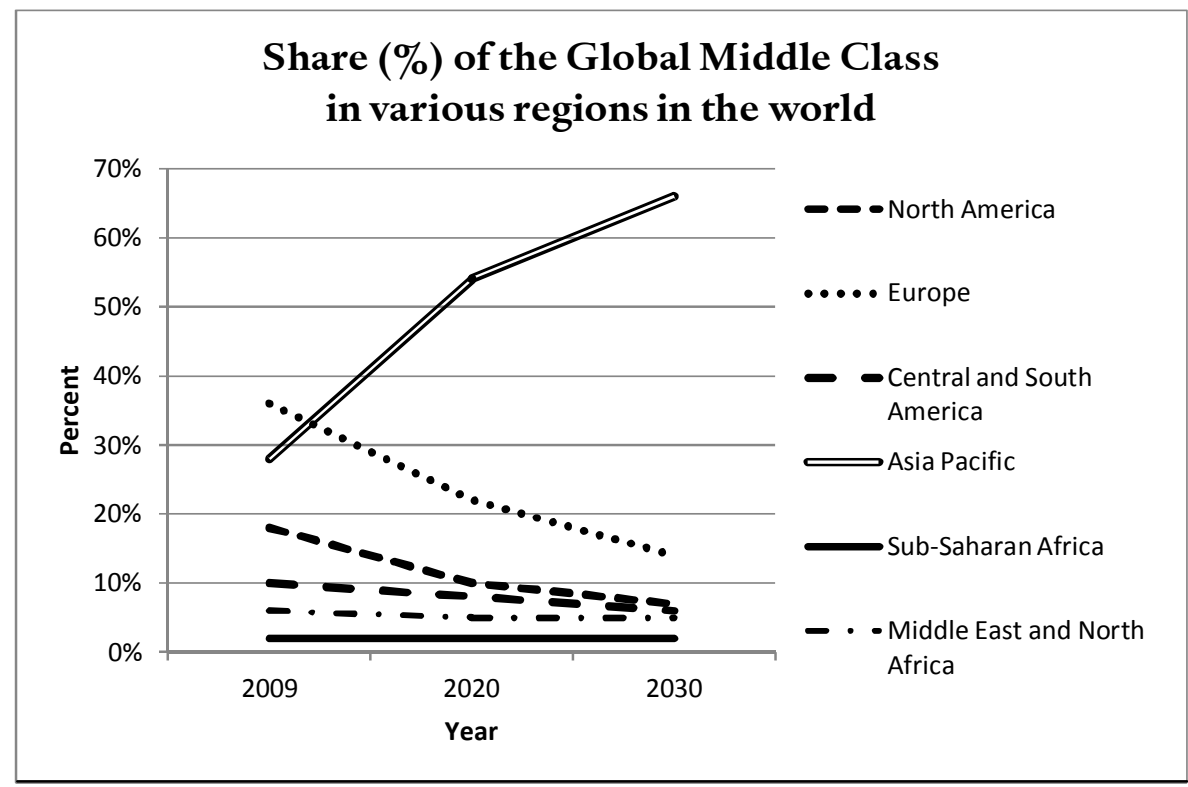

Source: This graph was created on the basis of data contained in Table 2, Kharas, H., 'The emerging Middle Class in Developing Countries', OECD Working Paper No.285 (2010), p.28.

According to the OECD and looking more specifically at the geographic evolution of the middle class, this category, i.e. the middle class might increase from 1.8 billion consumers to 3.2 billion in 2020 and to close to 5 billion in 2030. This is significant by any standard. Asia's share in the increase in middle class would amount to $85 \%$ while the percentage of middle class consumers in the United States and Europe remains steady. Hence, the OECD studies confirm that global consumption is moving rapidly towards the East as Asian countries become wealthier. Even though Asia currently represents less than a quarter of the middle class, in the coming years more than half of the middle class will be in Asia, and the Asian consumers would represent more than $40 \%$ of the global consumption. It is also clear that, as a result of the demographic evolution, the expected economic growth will mostly depend on intra-Asian consumption, which would imply a decrease in dependence on western markets for its consumption. The density of the intra-Asian regional networks shown before is likely to confirm that trend, with an increased interdependency between the Asian economies. 
This could have important implications for the economic growth perspectives of the West. In other words, and provided these trends are confirmed, the global economy will increasingly be characterized by a world in which Asia trades with Asia. Given the economic decline of the world economy and more specifically in the OECD countries since the financial crisis in 2008, the decreasing reliance of Asia's exports to the Western economies seems even more likely. The East will focus more on its domestic or perhaps rather regional consumption. This also suggests the West will no longer perform the pull function for the world economy as it used to - this function would be performed by the Asian economies. The extent to which this may happen is uncertain, as the slowdown in the world economy affects all countries in one way or another and is already leading to a falling demand in China, as pointed out by the most recent OECD Economic Outlook. ${ }^{111}$

The growth of the middle class can also be observed in other parts of the world. De la Torre et al. show how Latin America has significantly benefited from the economic growth of Asia and more specifically China as a big consumer of commodities and consumer goods. The strong demand in Asia has resulted in a very spectacular growth of the middle class in the region and a dramatic reduction of the poor. ${ }^{12}$ According to the data presented, the share of the population that now finds itself in the middle class nearly doubled between 1995 and 2014, the number of poor people halved from $45 \%$ to $23 \%$ in the same period. ${ }^{113}$ In other words, the rise of the middle class is spreading beyond Asia and, actually, has resulted largely due to growth in Asia. Given the significant size of Asia as a region and its population, it is set to provide the conditions for world economic growth, not Latin America.

What are the likely implications of these developments and do they require a policy response? Morris in his book 'Rise of the Rest' suggests that the net gains of higher levels of world welfare could be beneficial to the prosperity in developed, developing and least developed countries alike. ${ }^{114}$ The question is how to achieve this win-win game where the west is seen as being in decline and the east is rising? It can easily be argued that the broader range of higher quality of products, the new dynamics in technological developments, a better outlook for corporations due to a stronger consumption base are some of the main factors that could generate economic benefits more widely, as was already shown to have been the case in Latin America. The notion of comparative advantage is not static and is likely to shift again. In addition, given the increased interdependency of markets, all countries are affected when the world economy declines, including China, as is presently witnessed $^{115}$. Also, looking further back at the history, Paul Kennedy ${ }^{116}$ and Ian Morris ${ }^{117}$

111 OECD Economic Outlook, Issue 2 (2015).

112 A. de la Torre and D. Lederman, 'Latin America and the Rise of the South at a Crossroads', World Bank Group, Presentation made at WTO Workshop on '20 Years of Trade Growth - An In-Depth Look at Latin America and the Rising South in the Board Context of Global Trade Growth', WTO, 21 June 2016.

113 Ibid.

114 I. Morris, Why the West Rules for Now? (Farrar, Strauss and Giroux, New York, 2010).

115 Cf. World Trade Statistical Review 2016, Chapter III, p. 18. 
illustrate particularly well how Asia has regained the power it held for many centuries and that it had then lost. Indeed, before the industrial revolution, which found its origin in Europe, specifically in the United Kingdom close to some 200 years ago, the world economic activities were mostly concentrated in Asia and particularly in China. The world has known long periods with the East taking a dominant position in global trade, especially with flows of goods coming from China to Western markets. As Winston Churchill is reported to have said, 'the farther backwards you can look the farther forward you are likely to see'.

\subsection{Trade Policy Responses to Globalization}

The shift in the economic balance from the West to the East is driven by the dynamics of trade and investment. Any trade policy response should take these realities into account and rather than resisting this trend, find constructive ways ensuring that the benefits from trade liberalization are equally spread. The question then is how the trade policy response to globalization has evolved and what would be the most adequate response today? What policies should be pursued in order to best take advantage of the opportunities that globalization provides? The sector studies on automobiles and pharmaceuticals and which were discussed by the OECD membership in the early 1990s in the Meetings of the Working Party of the Trade Committee with a view to addressing the policy responses that could be provided to globalization showed that it is not possible to define one single policy response to globalization. The main reason was that the ways sectors are globalized differ and so do the policy responses. ${ }^{118}$ Suggestions and possible responses to these questions were provided to the OECD Members in another document which triggered a deeper reflection on the implications of globalization on trade policy at that time. ${ }^{119}$

It will be argued that the responses provided in the early years of globalization consisted of a mix of defensive and offensive strategies. The defensive strategies were mostly geared towards protecting domestic industries, domestic employment and hence the national market. The offensive policies consisted of defining strategies of targeting industry 'winners' and designing policies in support of domestic leaders. The policy approaches followed in recent years focus more on facilitating economic adjustments, reducing transaction costs, further market opening, reducing barriers to trade and (de-) regulation. These new approaches take a better account of the complexities of trade and investment, the role of services in the production process of goods and the GVCs, which are characteristic for the way international transactions occur. The policies are increasingly geared towards enhancing the connection to the market and for countries to make a contribution into the value adding

116 P. Kennedy, The Rise and Fall of the Great Powers (Random House, 1987). The author analyses the historical developments of power relations between continents and provides examples of how the shift in economic power evolved over time.

117 Cf. Morris, Why the West Rules for Now?

118 Cf. Raby.

119 'Changing Realities for World Trade and Consequences for Trade Policy', OECD, 4 June 1991, TD/TC/WP (91)38. 
process. The discussion that follows analyses how this process has evolved and what the current approach is in terms of the best response to be provided. ${ }^{120}$

The case study that was conducted with regard to the automobile industry can again provide a good illustration of the tensions that can exist between globalization of production by 'going global' and staying regional or local and the policies employed by governments to protect the industry. A recent study by Sturgeon, van Biesebroeck and Gereffi shows how the complexity of the production networks evolved considerably over the last two decades and the implications for governance. ${ }^{121}$ The authors note that the automotive industry is very global and expanded its global reach in the 1990s through a wave of offshore investments, mergers, acquisitions and equity-based alliances. Outsourcing became very significant. Their research illustrates the tensions between conducting global, regional and national policies. They conclude that in the automotive industry, technical necessity, political sensitivities and market variation have kept the final vehicle assembly, and by extension much of parts production, close to end markets'. ${ }^{122}$ Equally, they note that

regional and national production structures remain surprisingly strong and coherent in comparison to other volume producing industries where global sourcing of parts and materials is the norm and world-wide demand for finished goods can be met from a handful of giant production clusters. As a result, political pressures go a long way toward explaining patterns of direct investment in the automotive industry. ${ }^{123}$

What then are the policy options for governments in a world of globalization? The $1980 \mathrm{~s}$ and early 1990s were characterized by a combination of defensive government policies and targeting strategies with the defensive policies mainly geared towards protecting domestic industries and markets, and targeting policies towards identifying 'winners'. The following section will first take a closer look at the policies that are applied with a view of protecting the domestic industry, followed by a discussion of targeting strategies, aimed at creating winners.

\subsubsection{Defensive trade policies}

While markets in the 1980s and 1990s gradually opened up to foreign competition as a result of liberalization efforts pursued in the GATT and followed by the WTO negotiations, governments nevertheless tried to protect domestic markets from undesired market penetration. The multilateral trade rules of the GATT and WTO provide for various

120 The discussion on the early policy responses to globalization provided in the eighties and early $1990 \mathrm{~s}$ is based on my earlier writings, including 'Globalization and the Trade Policy Response and 'Globalization of International Trade and Investment', in Buelens, Globalization and the Nation State.

121 T. Sturgeon, J.H. van Biesebroeck and G. Gereffi, 'Value Chains, Networks and Clusters: Reframing the Global Automotive Industry', 8 Journal of Economic Geography (2008), p. 297-321.

122 Ibid., p. 317

123 Ibid. 
measures that can be taken by governments in order to fend off and address situations of 'unfair' competition (for example dumping, subsidies that distort trade), but as will be observed, governments increasingly resorted to measures that fell outside the rules based system. ${ }^{124}$ Equally, it provides for measures that can be taken in situations when countries consider that domestic producers need to be protected against 'fair' competition. These are two different sets of situations for which rules were already established in the GATT. Some of the relevant provisions have been adjusted and refined in the course of the rounds of negotiations, adjusting them to changing and new realities. They are again part of the WTO set of rules. A brief review of the policy instruments is provided as follows:

\subsubsection{Anti-dumping and anti-circumvention}

One of the defensive policy instruments in the GATT are the anti-dumping policies. During the Uruguay Round, the negotiations led to the Agreement on the Implementation of Article VI of the General Agreement on Tariffs and Trade 1994, generally referred to as the Anti-Dumping Agreement. ${ }^{125}$ This Agreement addresses situations where a product is being introduced into the commerce of another country at less than its 'normal value'. ${ }^{126}$ In order to escape from anti-dumping investigations companies sometimes resorted to new measures which were referred to as the 'circumvention' of anti-dumping duties. A situation of circumvention was deemed to occur when a company was suspected of relocating parts of the production process or assembly operations to other countries than those where the production initially took place in order to escape anti-dumping duties. The relocation of the production meant a change in the origin of the good, thus affecting the basis for the investigation. As MNEs increasingly became footloose, it could be argued that globalization contributed to undermining the trade rules. These developments triggered a call to refine the rules and establish clear criteria to determine the origin of the good. Negotiations on the Agreement on Rules of Origin were launched in order to prevent these rules from being a source of uncertainty and unpredictability in international trade. ${ }^{127}$ One of the main objectives of agreeing on specific criteria for conferring origin to a good was to prevent what were considered to be simple 'screwdriver operations' to be sufficient to change the origin of

124 The notions of 'fair' and 'unfair' trade or competition are not defined as such in the GATT rules, but generally refer to a situation of practices that are WTO consistent or inconsistent, as will be explained further. An example of unfair competition is when a good is 'dumped', i.e. sold in the market below the 'normal value', as defined in the Agreement on the Implementation of Article VI of the General Agreement on Tariffs and Trade 1994 (Anti-Dumping Agreement).

125 The Agreement can be found in 'The Results of the Uruguay Round of Multilateral Trade Negotiations', Marrakesh Agreement, June 1994, 1869 UNTS 14 (1999).

126 For a complete and precise definition of the concept of dumping, reference is made to the Agreement on the Implementation of Article VI of the General Agreement on Tariffs and Trade 1994, Article 2.1, Marrakesh Agreement 1994, 33 ILM 1153 (1994).

127 At the OECD I prepared several policy papers discussing the criteria that could be applied in order to confer origin to a good. The options included the notion of what constitutes 'substantial transformation' of a good, in other words what inputs are required into the production process to determine a change of the good, or whether this can be determined on the basis of a change in the tariff classification. The discussions and debates on what would allow conferring origin to a good still continue, as part of the members' negotiating mandate. 
the good and thus influence the treatment the product receives at the point of importation. 128

The Agreement on Rules of Origin is part of Annex IA to the WTO Agreement. ${ }^{129}$ A distinction is made between non-preferential and preferential rules of origin. According to Van den Bossche and Zdouc, most of the disciplines set out in the Agreement on Rules of Origin concern non-preferential rules of origin. A complex and lengthy technical process of negotiations followed to determine the basis of conferring origin to goods for all goods. ${ }^{130}$ The tedious technical work carried out in this regard by customs officials of the WTO and the World Customs Organization turned out to be much more complex than was initially anticipated and the three years that were allocated to accomplish this task of harmonizing the widely differing practices applied by countries in determining the origin of goods turned out to be insufficient. The work on rules of origin is still in progress, given the complexities of a globalizing world and the discussions on GVCs. It is a daunting task to confer origin based on any of the criteria under consideration. The issue of origin of goods remains very important, but the nature of debate has changed with less public attacks on the issue of circumvention. The Agreement on Anti-Dumping has been strengthened in a way that any allegations and concerns are handled through the procedures established to that effect. This is an area with one of the highest number of litigation cases in the WTO.

\subsubsection{Voluntary Export Restraints and Orderly Marketing Arrangements}

Another feature of the 1980s and early 1990s was the frequent resort to GATTinconsistent measures taken outside the rules of the multilateral trading system. This included the so-called Voluntary Export Restraints (VERs) and Orderly Marketing Arrangements (OMAs), often referred to as 'grey area measures', which were claimed to be applied on a voluntary basis and contributed to the gradual erosion of the multilateral trading system. They were meant to govern imports and exports between countries on a voluntary basis, but the reality was different, as exporters often had no choice but to accept the voluntary restrictions set by the importing country. The alternative consisted of harder and more direct import restrictions, with the risk of being excluded from the market. The GATT already contained provisions to provide temporary import relief measures in order to protect the domestic industry under Article XIX, but these provisions were hardly used. There are two main reasons why safeguards were often circumvented through the grey area measures: it took longer to put safeguards in place in accordance with the GATT rules, in addition to which the safeguard provisions under Article XIX provide that compensation be offered to exporters affected by the safeguard measures. In the case of VERs and OMAs, there is no need to provide for compensation, as the measures are deemed to be 'voluntary'

\footnotetext{
128 The notion of 'screwdriver' basically refers to simple operations which do not significantly add value in the production process, but could be sufficient in order to technically change the origin of the good and hence the treatment it would receive at the border.

129 Cf. van den Bossche and Zdouc, p. 461.

130 See Article 9.1 of the Agreement on Rules of Origin.
} 
and can be put into effect instantly. ${ }^{131}$ Kostecki argues that 'export restraint arrangements provide a short cut to protection against imports because no legislative struggle is needed'. ${ }^{132}$ According to Kostecki, 'the grey area measures are fundamentally at variance with the principle of non-discrimination, as expressed in Article I and Article XIII of the GATT, and with the multilateralism of the international trading system'. ${ }^{133}$

Contrary to the safeguard measures, the VERs and OMAs thus effectively undermine the trade rules and discriminate between suppliers. They explicitly target those suppliers that affect the domestic competition and/or industry. They undercut the free functioning of the market. Jones shows how economically, the measures generate economic rents to the benefit of the importer, through the application of quotas, thus artificially raising prices for the consumers. ${ }^{134}$ Hence, these measures not only were in conflict with the rules based system, they were economically ineffective and costly to the consumer. These findings are again confirmed by various economic studies. Harris shows that the VERs applied to Japanese cars increased prices did not change the Japanese share in world exports (which remained constant), but generated economic rents for Japanese firms. ${ }^{135}$ It leads him to conclude that 'VERs are a particularly bad form of protectionism'. ${ }^{136}$ Berry et al. undertook a detailed analysis of the effects of VERs on automobiles for the US consumer. ${ }^{137}$ The study once again confirms the earlier findings that prices for cars increased to the detriment of consumer welfare, which fell significantly. ${ }^{138}$ Walker analyzed the effect of VERs placed on Japanese automobiles from 1977 to 1999 by the United Kingdom and concludes that the policy failed to assist the British domestic car industry. ${ }^{139}$ Similarly to the previous studies, the economic rent was to the benefit of Japanese manufacturers and a substantial cost to UK consumers.

Instead of resorting to VERs and OMAs, the way to provide relief to domestic producers is through the application of safeguard measures, as provided for under the GATT provisions. ${ }^{140}$ Both from an economic and rules-based view, safeguard measures are the preferred policy instrument and this led to the effective banning of VERs and OMAs. The

131 Other explanations on why and how safeguard measures are applied can be found in my publication, 'Changing Patterns in International Trade'.

132 M. Kostecki, 'Export-restraint Arrangements and Trade Liberalization', 10 The World Economy (1987), p. 425.

133 Ibid.

134 K. Jones, 'The Political Economy of Voluntary Export Restraints Agreements', 37 Kyklos (1984), p. 82-101.

135 R. Harris, 'Why Voluntary Export Restraints are "Voluntary”, 18 The Canadian Journal of Economic (1985), p. 799-809.

136 Ibid., p. 800.

137 S. Berry, J. Levinsohn and A. Pakes, 'Voluntary Export Restraints on Automobiles: Evaluation a Trade Policy' 89 American Economic Review (1999), p. 400-430.

138 Ibid., p. 428.

139 J. Walker, 'Strategic Trade Policy, Competition and Welfare: The Case of Voluntary Export Restraints between Britain and Japan (1971-2002)', Discussion Paper, Henley Business School, University of Reading (IBH-2015-01, 2015).

140 'Agreement on Safeguards' in 'The Results of the Uruguay Round of Multilateral Trade Negotiations', Marrakesh Agreement. The safeguards agreement allows countries to take import restrictions in a situation of a surge in imports and by way of quotas or increases in tariffs under certain conditions. 
Agreement on Safeguards that resulted from the Uruguay Round negotiations brought an end to the OMAs and the VERs, resulting in a stricter adherence to the GATT/WTO rules and a further strengthening of the system.

This analysis (re-) confirms that grey area measures are not the adequate trade policy response to globalization. To the contrary, they generate economic inefficiencies and costs to the consumer and producers alike, hence these policies were banned in the WTO and are no longer applied.

\subsubsection{Offensive trade policies: industrial targeting}

The notion of 'industrial targeting' refers to governmental policies, initiatives and strategies to attract FDI for what could be considered as strategic industries. Such policies were mostly associated with the 1990s, with governments much inclined to support industries that were perceived as 'winners' and that would significantly contribute to creating economic value to the domestic economy. Industries that were considered of strategic value included sectors with a considerable technology input, including aerospace, computers, semi-conductors, automobiles, and so on. According to the OECD, there is not a single agreed definition of a strategic industry, but globally, there seems to be agreement that 'an industry is considered strategic if it engenders large innovative spillovers and if it provides substantial infrastructure for other firms in the same or related industries'. ${ }^{141}$ Supporting strategic industries entails the implementation of a set of complementary measures aiming at protecting markets, attracting multinationals, securing a competitive environment, but most of all attracting technology. One way of creating an economic advantage was by way of providing special incentives in the form of fiscal advantages, including direct or indirect subsidies, tax breaks, often directly linked on performance requirements imposed on, or negotiated with the foreign investor. Governments could thus play a pro-active role in attracting FDI and encourage the creation of tangible and organizational capabilities that could influence the MNEs' decision as to where to invest. The OECD study notes that such policies assume that the 'winners' can be identified and that a comparative advantage can be created and which seems highly questionable. ${ }^{142}$

A main motivation for governments to pursue targeting policies thus was the desire to promote the technological content of the economic activities and the potential spin-off that this could have to related industries. In other words, governments considered that investments should generate activity in value adding or 'high tech' industries, which add to the economy's competitive strength on world markets in leading products. ${ }^{143}$ Targeting thus resulted in a fierce competition in knowledge intensive goods, including consumer electronics, computers and telecommunication, which were most typical for the 1980s.

141 W. Michalski, 'Support Policies for Strategic Industries: An Introduction to the Main issues' in Strategic Industries in A Global Economy: Policy Issues for the 1990s (OECD International Futures Programme, Paris, 1991), p. 9.

142 Ibid., p. 8-9.

143 Cf. Smeets, 'Changing Patterns in International Trade'. 
These sectors often have rather short product cycles, but were generally believed to contribute most to the economy's overall performance, through backward and forward linkages, as they often embody state of the art technologies.

While the objective to support industries that were likely to bring the biggest contribution to the national economy seemed quite legitimate in itself, the way in which this was sometimes achieved was objectionable. The advantages that governments have granted to attract one type of investment in order to favor one economic activity over another distorted competitive conditions both for domestic and foreign competitors. In fact, the domestic competitive effects of the investment incentives were not necessarily limited to producers of the like products, but could extend to the supplying industries of intermediary products, that is, affect the down-stream production. While the targeting policies were geared towards industries that were considered to be of fundamental importance to the development of the economic potential of a country, the strategic choices of the government policies had wider implications. It led to a race for support and protectionist measures that distorted markets and competition. It also led to an intensification of the policy debates on how to address the issues. International recognition grew that competition in world markets should not be pursued on the basis of the availability of public funds and which explains the determined efforts to eliminate subsidy schemes that distort trade.

As Michalski points out, the debates led to various policy options which included reinforcing the international policy dialogue, agreeing on guidelines with regard to government actions (such as local content requirement), strengthening international rules (such as GATT rules) and multilateral surveillance and finally harmonizing policies, thus creating a level playing field. ${ }^{144}$ In the years that followed, the negotiations conducted in the GATT and WTO resulted in the design of stricter rules and surveillance on government subsidies, stricter disciplines on local content requirements, a better policy coordination and harmonization of rules and regulations. The Subsidies Agreement in the WTO is far more explicit on the definition of subsidies than its predecessor in the GATT and much less tolerant on the ways in which support is provided. ${ }^{145}$ The OECD has intensified its work on industry subsidies and the multilateral surveillance at the WTO on public subsidies granted and government support has been strengthened, thus making it harder for governments to grant subsidies.

While governments continue to be directly concerned with the quality of FDI and the creation of jobs in the domestic economy, the recognition of the interdependency of markets resulting from globalization has further reduced the room for manoeuvre for individual governments to intervene in a discriminatory manner in the market and to grant an advantage to the domestic industry.

\footnotetext{
144 Ibid., p. 13.

145 Agreement on Subsidies and Countervailing Measures, 15 April 1994, Marrakesh Agreement, 1869 UNTS 14(1999).
} 
This leaves the question unresolved as to whether governments should be making choices for the conduct of industrial policies and pick winners. Should there be room for governments to pursue industrial policies and what should they consist of? Aggarwal and Evenett suggest that the WTO pursues a work program with regard to state decision-making on industrial policy by measures taken in key sectors of the global economy. ${ }^{146}$ They suggest that

the work would be open to all the WTO members and the sectors considered could be chosen so as to be of interest to the broadest range of WTO members, bearing in mind their different stages of development and sectoral specialization. The work should be objective and involve all stakeholders, including other international organizations, independent analysts and researchers. ${ }^{147}$

In essence the proposal consists of identifying and determining the conditions of industrial policies that do not discriminate between domestic and foreign interests and do not in any way violate the WTO principles. This proposal reflects the new realities in international trade that resulted from globalization and where one should no longer try to distinguish between the domestic and international actors, but design policies that contribute to the growth of the domestic economy.

As will be argued further, the approach to support policies has evolved considerably and the new policies are fundamentally different from the past policies: governments focus more on the question of how to create an enabling environment and reducing transaction costs, thus providing for the conditions of ensuring high quality economic activities that contribute to a country's wealth. More emphasis is put on stimulating research and development, education, training, reducing transaction costs and trade facilitation rather than pursuing industrial targeting policies.

\subsubsection{A new look at the trade policy response to globalization, the role of the nation state and sovereignty in the WTO.}

It was argued that neither defensive, nor strategic policies provide for the appropriate policy responses to globalization and the thinking has evolved considerably in the WTO with a specific focus on a strengthening and deepening of the rules of the multilateral trading system. The WTO rules need to be adjusted further in order to reflect and take more fully into account the various policy challenges that globalization has generated.

The policy challenges emanating from globalization and GVCs mainly relate to the concerns of governments on how best to respond to global issues at the national level and

\footnotetext{
146 V.K. Aggarwal and S. Evenett, 'The Return of Industrial Policy: A Constructive Role for the WTO', in S. Evenett and A. Jara (eds.), Building on Bali, A Work Programme for the WTO (VoxEU.org eBook, Centre for Economic Policy Research (CEPR), London, 2013), p. 179.

Ibid.
} 
how to address a wider set of issues in an interdependent world. The two challenges are closely interrelated, as the scope for conducting independent policies by national governments has been reduced as a result of the increased interdependency between economies. At the same time, domestic policies also increasingly have repercussions on international markets as a result of the growing interdependency. Equally there seems to be an increased recognition of the need to move towards more policy convergence. Steger states that issues cannot be solved by nation states acting alone. Strong and effective institutions are needed to manage global interdependence... Nations states cannot, by themselves, regulate effectively to deal with global problems - they need a strong multilateral institution to do this.' 148 She then argues that the WTO has not responded to the new realities. The questions that still need answering are what scope remains for governments to conduct national trade policies and how such policies relate to policies conducted by other governments.

Consideration should be given to both the domestic and international aspects of policy making and domestically it should be ensured that there is an internal policy coordination and clarity about the national objectives that are pursued. Hoekman and Kostecki observe that as many parts of government are involved in trade policy, ...'in both the process of formulating and implementing policy there is a need for coordination and a common understanding of the overall objectives of the government and its implications of trade agreements for national policy.'149

Ohmae argued in the mid-1990s that the nation state is becoming obsolete because it is no longer the optimal unit for organizing economic activity. ${ }^{150}$ The concept of the 'nation state' is closely associated with the notion that the national authorities of a country hold a decisive control over the domestic economy and is perceived as being eroded as a result of globalization. ${ }^{151} \mathrm{He}$ asserted that the important decisions are taken at the level of the economic region or regions, often crossing national boundaries. He seems to be proven right, as attention is increasingly shifting from domestic production to regional production networks, requiring harmonization of policies, standards and so on. Various authors referred to earlier in this chapter make precisely that point, with an increased emphasis on harmonization of policies at the regional level. The question then arises as to whether governments can still conduct a national industrial policy in the presence of multinational enterprises that take the globe as their field of action. ${ }^{52}$ The answer to the question has evolved in light of the new realities.

\footnotetext{
148 Steger, p. 493.

149 B. Hoekman and M. Kostecki, The Political Economy of the World Trading System: The WTO and Beyond (3 ${ }^{\text {rd }}$ edition, Oxford University Press, 2009), p. 660.

150 K. Ohmae, The End of the Nation-State: The Rise of Regional Economies (Simon and Schuster, 1995).

151 There is no single definition of the 'nation state'. According to Wikipedia a nation state corresponds to a geographical area that can be identified as deriving its political legitimacy from serving as a sovereign nation. A state is a political and geographical entity, while a nation is a cultural and ethnic one. The term 'nation state' implies that the two coincide.

152 See also Smeets, in Buelens, Globalisation and the Nation State.
} 
Given the changing features of international enterprises, becoming increasingly footloose, Reich posed the question some 25 years ago: 'Who is us'?153 Friedman reinforced this question a few years later with specific examples of globalized American companies which have their base in the United States but operate on a worldwide scale to such an extent that how 'American' the company is becomes rather questionable. ${ }^{154}$ The school of thought on this has evolved since then, largely as a result of globalization and the emergence of GVCs. The nationality of the largest MNEs becomes increasingly blurred, with companies having multiple passports. The most recent UNCTAD WIR (2016) cautions policy makers for the complexity of the ownership of MNEs and their implications with regard to policy decisions on how to treat domestic and what could be perceived to be foreign companies. ${ }^{155}$ According to the WIR:

For more than 40 per cent of foreign affiliates worldwide, investor nationality is not what it seems. Affiliates are sometimes directly owned by a foreign company but actually controlled (ultimately owned) by a domestic company; they are often directly owned by a domestic company but actually controlled by a foreign company; they are frequently directly owned by a company in foreign country A, but ultimately controlled by a company in foreign country B. ${ }^{156}$

Parts, components and services incorporated in the end product come from an increasingly wide range of sources. At the same time many economic activities and operations are centered in regional production networks by companies that operate globally. All these developments point in the same direction and a stronger than ever need for policy coherence.

The question of multinational corporations versus national authority is often addressed from the angle of responsibilities of the host government towards their citizens, which include ensuring economic activity and national security. The main question seems to be to what extent MNEs and/or their subsidiaries contribute to the objective of the government in the host country and irrespective of nationality? What matters most is that jobs created by companies abroad generate jobs, employment and wealth in the home country. The examples with regard to the iPod and iPhone given earlier are illustrative in that regard, as they showed that global policies can go hand in hand with national policies, as the production process of iPods and iPhones generate quality jobs and high revenues in the US.

Neilson et al., argue that the role of the state needs to be reviewed in light of the GVCs and the emergence of the Global Production Networks, but do not offer a specific solution

153 R. Reich, 'Who is Us?', 38 Harvard Business Review (1990), p. 53-64.

154 T. Friedman, The World is Flat, A Brief History of the Twenty-first Century (Farrar, Strauss and Giroux, 2005), p. 208.

155 Cf. World Investment Report 2016, p. 182-187.

156 Ibid., p. 182. 
on what that role should consist of. ${ }^{157}$ In their analysis, they explain the divergent views in the literature, including those expressed by Gereffi, Yeung, Neilson and Lee, who all offer different perspectives but without providing conclusive answers to the question. It is not surprising, as it is a difficult question to answer and domestically a very sensitive one, as the policies that are applied can lead to job creation and job losses.

One of the policy implications resulting from closer economic integration of national economies is that boundaries between economies are gradually blurring, and the scope for governments to confine a domestic policy to national firms is limited. As Steger puts it 'By engaging in international co-operation and entering into treaty obligations, governments necessarily cede some sovereignty.' 158 Policy instruments themselves become more closely interrelated and the distinction between border policies vs. domestic policies becomes increasingly artificial, particularly with the extension of the WTO rules covering services, TRIPs, technical regulations etc.. Also, industrial and trade policies cannot always easily be separated, and their impact not easily isolated. In addition, FDI flows and trade are so closely intertwined and FDI can easily jump over borders thus circumventing the intended protection and undermining the conduct of isolated domestic policies.

The notion of sovereignty and the role of the nation state thus have evolved over time and more specifically with the rapid globalization of trade. It had a more individual connotation in the past: the issue today is one of the management of the sovereignty, which is increasingly 'shared' among nations through policy coordination and policy coherence. Policy-making has moved from within a country's boundaries towards more openness and sharing of responsibilities between nations and the desire to work towards policy coherence and coordination. The recognition of this new reality is reflected by the extent to which countries coordinate positions in smaller or larger settings, including the G-7 and the more recent G-20, which includes all the main economic and political actors of the world. As one of many consequences of interdependence, national interest may thus no longer be confined within the traditional narrow geographic boundaries of the national economy.

So how can the WTO best respond to the challenges that globalization poses with regard to governance? The members of the WTO should continue re-enforcing the primacy of the multilateral trading system, providing for a level playing field, advancing trade liberalization, reducing transaction costs and adjusting the rules of the system in light of these challenges. That is why the negotiating agenda should be adjusted as well as expanded with those areas where the WTO can have the most direct impact, as will be argued further in the thesis.

There has been a growing recognition of the need for the WTO to adjust its rules to globalization and remain up to date with the economic realities. This was first explicitly recognized as far back as in 1998 by the then Director General of the WTO, Renato Ruggiero and the approach to policy options has evolved greatly since. The celebration of

157 Cf. Neilson, Pritchard and Wai-chung Yeung, ‘Global Value Chains', p. 3-4.

158 Steger, p. 488. 
the 50th Anniversary of the GATT in spring 1998 was the time when globalization was fully at work with governments debating on the appropriate response. There was an increased recognition that the rules needed further updating and adjustment in light of the developments that had occurred in the 1980s and 1990s. In his statement ${ }^{159}$, Ruggiero essentially emphasized the need for:

- Strengthening and updating the rules of the multilateral trading system;

- Bridging the gap between national concerns of governments and global issues;

- Keeping pace with the economic changes resulting in borderless technologies;

- Addressing a wider set of issues emanating from the interdependent world; and

- Strengthening coherence.

These elements provided a starting point for developing a roadmap, which was followed by Ministers in subsequent years. Several issues were addressed at the Ministerial Conferences organized under the auspices of the WTO and most prominently led to the DDA, which was expected to address most of these issues. As globalization has proven to be a moving target, several key challenges still remain, but the key point is that the issues and challenges need to be addressed in an interrelated and coordinated fashion, more than ever before.

The IMF argues in that regard that

the internationalization of production processes implies that cross-border flows of goods, investment, services, know-how, and people often complement each other. This fact opens ... new policy coordination problems that go well beyond the negotiation of reciprocal market access concessions through the reduction of traditional border measures such as tariffs. Behind-the-border measures and domestic policies have become a more important barrier to supply-chain trade. For example, weak protection of intellectual property rights (IPR) and of investment rights has a negative impact on GVCs as firms' knowledge and capital have more international exposure. "Deep" FTAs often aim at coordinating these new policy problems by including disciplines on areas such as competition policy, IPR protection, investment, and movements of capital. The increasing importance of deep FTAs is, however, creating a potential risk of regulatory segmentation of the multilateral trading system and of exclusion or discrimination in trade relations. ${ }^{160}$

This statement underscores the need to go beyond merely addressing border issues in the classical sense, and supports the arguments that will be made here. The world has changed and border measures are no longer the main obstacle to trade.

159 Symposium held at the WTO, May 1998; statement delivered by WTO Director General M. Moore at the Friedrich Ebert Foundation, June 1998; speech delivered at the ICC's World Business Dialogue Geneva, 23 September 1998.

160 Cf. Saito, Ruta and Turunen, 'Trade Interconnectedness', p. 5. 
For the IMF the key point in terms of policy implications of the GVCs or perhaps even the policy response is to maintain an open trading system and address trade facilitation bottlenecks. Teh et al show that the economic literature is unanimous on the contribution that TFA can make to economic growth, economic development, increasing trade and GDP, export diversification and linking to GVCs. ${ }^{161}$. Their contribution builds the argument around specific case studies at the country and regional level, showing how the reduction of transaction costs will be beneficial to enhancing economic revenue, growth and development.

The IMF believes that the classical trade restrictive measures have become less effective due to more vertical specialization, but the threat of protectionism continues to be significant and is even more costly for GVCs. For that reason it is important to monitor the trends in trade policy measures implemented by the members and that is one of the key functions of the Secretariat as was explained in the previous chapter ${ }^{162}$. In that regard the various WTO reports show that the protectionist measures that were feared to creep in as a result of the economic crisis that started in 2007 have largely been kept in check until recently. ${ }^{163}$ In addition, the spread of GVCs increased linkages among countries, creating a common interest in preventing the spread of protectionism.

In a similar vein to the IMF, Baldwin observes that

Complex cross-border flows demand complex rules. Since most supply-chain trade is regional, there is a strong tendency to establish the necessary complex rules at a regional rather than multilateral level. Multilateral rules would almost surely have been more efficient, but negotiating them in the GATT would have been too cumbersome and slow; most GATT members were not involved in this type of international commerce. ${ }^{164}$

As a result, he strongly recommends that the WTO members review and update the rules, taking into account the recent developments with regard to GVCs and supply chains. The WTO centrality with regard to multilateral trade governance risks to be eroded further. He observes that

161 For a thorough review of the literature, reference is made to R. Teh, M. Smeets, M., Sadni Jallab and F. Chaudhri, 'Introduction', in Teh, R., Smeets, M., Sadni Jallab, M. and Chaudri, F. (Eds.), Trade Costs and Inclusive Growth, Case studies presented by WTO chair-holders WTO, November 2016, (WTO, 2016), p. 1-21. A detailed review of the literature and more specifically the contribution of the TFA to economic growth will be provided in Chapter 5.

162 Cf. Chapter 2 section 2.2.3.4.

163 This is underscored in the WTO's World Trade Report 2014, with explanations provided why such protectionist measures could largely be resisted. It is recalled that the trade monitoring is conducted by the WTO and the collective reviews are undertaken by the G-20. The most recent report issued by the directorgeneral shows that there is a steady increase in the stock of protectionist measures taken by the members. 
The demands for new rules and disciplines governing the trade-investmentservices-IP nexus are being formulated outside the WTO. Developing nations are rushing to unilaterally lower their tariffs (especially on intermediate goods) and unilaterally reduce behind the border barriers to the trade-investment-servicesIP nexus. All of this has markedly eroded the WTO centrality in the global trade system. ${ }^{165}$

The WTO Report (2014) follows a similar logic and underscores that the focus of policy makers should not only be on traditional border policies, but also on trade costs and supply side constraints, including domestic policies. As the WTO notes, at the national level there should be more public investment in physical infrastructure essential to carrying out production and trade or allowing traders cheaper access to international markets. ${ }^{166} \mathrm{~A}$ second and equally important action would be to make changes to policies or regulations that prevent efficient use of already existing infrastructure, deter private-sector investments to build infra-structure or act simply as 'red tape'. GVCs have had implications for the ways negotiations are conducted between main trading nations, who seem to increasingly favour regional trade integration arrangements which include disciplines on competition policy, investment and several other areas which are not covered under WTO rules. This point is equally underscored by Orefice et al., who explains the logic behind an increased demand for deep integration, which is a result of the creation of production networks that have led to the unbundling of the various stages of production. ${ }^{167}$ The authors point out that:

The harmonization of certain national policies allows cross-border production to operate smoothly and therefore facilitates business activities taking place in several countries. This generates a demand for deep forms of integration. In other words, agreements including disciplines such as infrastructure, institutions, competition policy and the standardisation and harmonization of product regulations would make production-sharing activities more secure and efficient. ${ }^{168}$

Eckhardt et al. explain along similar lines of reasoning why the European Union is strengthening its bilateral trade relations with Asian countries. ${ }^{169}$ The EU policy is largely based on what they refer to as 'the political role of import-dependent firms - i.e. firms which rely on the income engendered by imported goods or on the import of intermediate products for their production processes'. ${ }^{170}$ According to the authors, 'In an international economy increasingly organized around global value chains, the preferences, patterns of

\footnotetext{
165 Ibid., p. 207.

166 Cf. World Trade Report 2014, p. 148.

167 G. Orefice and N. Rocha, 'Deep Integration and Production Networks: An Empirical Analysis', 37 The World Economy (2014), p.106-136.

168 Ibid., p. 106.

169 J. Eckhardt and A. Poletti, 'The Politics of Global Value Chains: Import-dependent Firms and the Signing of EU-Asia Trade Agreement', Journal of European Public Policy, (August, 2015) p. 1-20.

170 Ibid., p. 1.
} 
political mobilization, and influence of European producers and retailers that stand to gain from cheaper access to imports from low-cost sources around the globe cannot be neglected'. ${ }^{171}$ These new policy approaches are indeed a logical implication of the way GVCs work by increasing interaction between local, regional and global policies.

An earlier book prepared under the WTO Chairs Programme addresses these very same questions from an academic perspective, looking more specifically at the issue how developing countries can better connect to GVCs. ${ }^{172}$ The book presents findings from different country and regional perspectives. It illustrates the challenges countries are facing in view of the new ways of organizing production, how to connect to the trading system and how this is expected to lead to a quicker and easier path to growth and economic development. The studies underscore the increased awareness of the economic opportunities provided through international trade and GVCs, confirm that connecting to markets and overcoming supply-side constraints are of critical importance to integrate into the multilateral trading system, and argue that there is a need for a coherent policy mix to address supply side constraints with complementary policies. The authors see the main challenges that countries face in their strategies to be the need to diversify exports and to upgrade their production in order to participate in GVCs.

Lamy notes that technology has intensified the degree of global interdependency, which affects the future cooperation between nations and more specifically the policy decisions that need to be taken. ${ }^{173} \mathrm{He}$ observes that intensified interdependency in international production relationships through GVCs inevitably implies greater mutual policy dependency'. ${ }^{174}$ Accordingly, this involves many policy spheres. He then states that 'the way supply chains are configured and supplied makes it less relevant than it ever was to think of individual markets as independent of one another. Markets are complementary and whatever affects supply and demand in one market will have ripple effects in other markets'. ${ }^{175}$ Another significant implication is that 'the internationally joined-up nature of GVCs means that the impact of an upstream policy applied by one country on the supply chain will be multiplicative as goods and services cross successive jurisdictions downstream'. This again underscores the need for and importance of policy coherence. He then stresses the rapidly growing importance of services trade and its interlinkage with trade in goods. Lamy observes that ${ }^{176}$

Analysis of value-added trade has shown that services account for almost half of world trade-considerably more than traditionally estimated. This is not just a quantitative. The nature of the contribution of services is also important. It goes

\footnotetext{
171 Ibid., p. 23.

172 M. Janssen, M. Sadni Jallab and M. Smeets (eds.), Connecting to Global Markets, Case Studies Presented by WTO Chairs (WTO, 2014).

173 P. Lamy, 'Foreword' in Elms and Low (eds.), Global Value Chains in a Changing World.

174 Ibid., p. xvii.

175 Ibid.

176 Ibid.
} 
political mobilization, and influence of European producers and retailers that stand to gain from cheaper access to imports from low-cost sources around the globe cannot be neglected'. ${ }^{171}$ These new policy approaches are indeed a logical implication of the way GVCs work by increasing interaction between local, regional and global policies.

An earlier book prepared under the WTO Chairs Programme addresses these very same questions from an academic perspective, looking more specifically at the issue how developing countries can better connect to GVCs. ${ }^{172}$ The book presents findings from different country and regional perspectives. It illustrates the challenges countries are facing in view of the new ways of organizing production, how to connect to the trading system and how this is expected to lead to a quicker and easier path to growth and economic development. The studies underscore the increased awareness of the economic opportunities provided through international trade and GVCs, confirm that connecting to markets and overcoming supply-side constraints are of critical importance to integrate into the multilateral trading system, and argue that there is a need for a coherent policy mix to address supply side constraints with complementary policies. The authors see the main challenges that countries face in their strategies to be the need to diversify exports and to upgrade their production in order to participate in GVCs.

Lamy notes that technology has intensified the degree of global interdependency, which affects the future cooperation between nations and more specifically the policy decisions that need to be taken. ${ }^{173} \mathrm{He}$ observes that intensified interdependency in international production relationships through GVCs inevitably implies greater mutual policy dependency'. ${ }^{174}$ Accordingly, this involves many policy spheres. He then states that 'the way supply chains are configured and supplied makes it less relevant than it ever was to think of individual markets as independent of one another. Markets are complementary and whatever affects supply and demand in one market will have ripple effects in other markets'. ${ }^{175}$ Another significant implication is that 'the internationally joined-up nature of GVCs means that the impact of an upstream policy applied by one country on the supply chain will be multiplicative as goods and services cross successive jurisdictions downstream'. This again underscores the need for and importance of policy coherence. He then stresses the rapidly growing importance of services trade and its interlinkage with trade in goods. Lamy observes that ${ }^{176}$

Analysis of value-added trade has shown that services account for almost half of world trade-considerably more than traditionally estimated. This is not just a quantitative. The nature of the contribution of services is also important. It goes

\footnotetext{
171 Ibid., p. 23.

172 M. Janssen, M. Sadni Jallab and M. Smeets (eds.), Connecting to Global Markets, Case Studies Presented by WTO Chairs (WTO, 2014).

173 P. Lamy, 'Foreword' in Elms and Low (eds.), Global Value Chains in a Changing World.

174 Ibid., p. xvii.

175 Ibid.

176 Ibid.
} 
beyond providing the glue that holds supply chains together. Services are often produced in conjunction with goods and represent crucial production components and potential sources of innovation and value-added.

Low substantiates this point further by explaining how the interaction between goods and services works and their contribution to the GVC.177

The challenge for policy makers thus is to design policies that reflect the realities on the ground and stay in tune with the developments. The scholarly and policy debates are mainly centred around the question how countries can better connect to markets through the GVCs in order to reap the benefits of higher levels of specialization, revenue growth, technology transfer, foreign direct investment and employment. This is consistent with and underscores the arguments that I am building in my analysis. The policy responses move in the direction of encouraging $R \& D$, training and education, creating an enabling environment for trade and investment, trade facilitation and reduction of transaction costs, improvement of domestic infrastructures and access to capital.

What can the WTO do to address globalization and what are the key challenges? What is the right policy response in the WTO and how is it different from previous policy responses? As I will argue further in the thesis the WTO's trade policy response to globalization requires a strong multilateral trading system with rules that are adapted to the challenges that have emerged from globalization. It also required taking a fresh look at the adequacy of the current rules and an expansion of rules to new areas, including trade in investment and trade and competition policy. Some of these issues have been addressed in the previous chapter, including the strengthened WTO multilateral trading system which was created over two decades ago and the other aspects of the policy response will be offered in the next chapters.

It was shown that the institutional basis of the WTO was very much strengthened in order to address some of the challenges of the new millennium (see Chapter 2). The rules were expanded to include services trade and TRIPs and agreements were reached in new areas, including on the Information Technology Agreement (ITA) and the TFA. Considerable efforts were deployed to assist developing countries and more specifically LDCs to integrate into the multilateral trading system, as will be argued further. The multilateral trading system can only work to the benefit of all provided it is inclusive and that goal is pursued by building and strengthening the human and institutional capacities in beneficiary countries. Explanations will be provided on how this is done and what was achieved in chapter 5 . On coherence, it was pointed out in chapter 2 that the Marrakesh Agreement explicitly recognized that the increased interdependence requires a strengthening of coherence in policy-making. The coherence mandate was an essential element of the mandate of the WTO and is gradually been given more substance through policy coordination at the highest levels between the leaders of the world's main trading nations.

177 P. Low, 'The Role of Services in Global Value Chains', in Elms and Low (eds.), Global Value Chains in a Changing World, p. 61-81. 
story. It will be argued that the inclusion of these topics in the WTO rule book and taking into account their interaction, thus ensuring policy coherence seems more desirable than ever in light of the rapid evolution of international trade and production patterns.

Finally, the economic opportunities generated through globalization should not be taken for granted. As globalization leads not only to winners but also to losers, this is an area that requires the particular attention of policy makers. Of critical importance are the social implications of liberalization and globalization, which require both general and specific policies to assist those that are negatively affected by trade. Examples include social protection systems, active labour market policies, redistribution policies, specific trade adjustment programmes for workers and so on, some of which are discussed in the WTO's Report of 2008. ${ }^{179}$ These issues cannot be ignored as they are too important in the context of global governance, and require a collective approach, as they are part of a collective responsibility. They are of critical importance for maintaining a free flow of goods and services with a view of enhancing overall levels of economic welfare.

\subsection{Conclusion}

This chapter discussed how changing patterns of trade and investment have driven globalization and how in turn globalization has driven new patterns of trade and investment. It was argued that globalization followed from a gradual process of trade liberalization, shifting comparative advantages and increasing deregulation by governments in recent decades. This stimulated the free flow of goods and services, a deeper specialization and new ways of organizing production by multinational enterprises which increasingly broke up the production process of parts, components and final assembly. Geography mattered less, given the progress in technology and a reduction in transport costs. The globalization process has had various implications, including the emergence of new players in the trade arena. It was observed that the economic performance of China has been particularly strong, and more specifically following its WTO accession. It now has the highest rankings for trade in goods and services as well as for FDI, both in inward and outward flows. The globalization of markets has contributed to the rapid integration of China in world markets and the growth it has experienced and in return China has contributed to globalization. Globalization and the changing patterns of trade and FDI have triggered a shift in the economic balance in world trade, with the economic gravity rapidly shifting from the OECD countries to Asia. The Asian region has become very dynamic and led to an expansion of its economic ties within the region and with other parts of the world.

It was argued that the focus of attention is increasingly on GVCs which in many ways can be seen as a continuation or perhaps even an advanced form of globalization. A careful analysis of GVCs allows a better understanding of how the production process for goods and services is organized and who contributes to it. It was also argued that the TFA plays an important role in reducing transaction costs and domestic policies should be geared towards

179 WTO World Trade Report 2008, WTO, Geneva, 2008. 
facilitating trade in order to be part of the GVCs. In addition, the practice shows that countries that have successfully integrated in the GVCs generally provide for good infrastructure and focus their policies on innovation and $R \& D$, thus making countries attractive for FDI. This supports the argument that much can be done at the domestic level, rather than through border policies to enhance competitive conditions.

The policy response to globalization has also fundamentally altered since the 1990s. Globalization was often perceived negatively and increasingly is so again today, given its effects on domestic employment and competitiveness. As a result, the policies conducted by governments tended to be geared towards the protection of the domestic market and industries on the one hand and targeting 'winners' on the other hand. The former policies were driven by the desire to protect certain established industries and business activities, even if the economic rationale pointed in the opposite direction, given the costs associated with protecting and/or supporting the domestic industry. The latter policies were thought to generate higher quality production and thus lead to positive spill-overs to other economic activities in the country. The 'targeting' policies were designed to create winners in industry and gear policies in support of those industries, which were considered to have an economic potential. Hence, policies tended to be protective, defensive and aggressive at the same time, but led to false competition and distorting markets. It became increasingly obvious and recognized internationally that these policies were unsustainable, thus triggering a change in policy approaches.

The policies gradually shifted and in recent years the government policies focus more on the question of how the economy can best take advantage of the competitive forces at play. As a result the policies are now directed at facilitating a better connection of the economies and business activities to global markets. This is where the notion of GVC finds all its relevance, with efforts being directed towards reaping the benefits of specialization and being more closely connected to the market. The policy response today is more directed towards policy coherence, policy coordination, deregulation, harmonizing, reducing transactions costs, building and improving domestic infrastructures, stimulating R\&D and developing new technologies. This is not to suggest that globalization can only lead to winners. It is well understood that globalization also leads to losers and this has become more evident in recent times, with a growing backlash against globalization. It is the duty of the WTO and other international institutions to better explain how trade liberalization and globalization has come to the benefit of the economy as a whole and how these benefits trickle down to the consumer and producer. In order to limit the negative consequences of globalization and resist protectionism from creeping in, it is not only the responsibility of governments to provide the right conditions for globalization to generate jobs, welfare and employment, but also to provide for social safety nets for those who lose out in the process.

Questions were raised about what globalization means for governance by the national authorities and about the meaning of the nationality of products. The analysis led to the conclusion that what matters most is the contribution that the production can make in the 
chain of value adding of goods and services for a country. It has become increasingly difficult to attribute a nationality to goods, given the complex ways business is structured and organized and the ownership of companies, the nationality of which is often difficult to identify. The key questions therefore are how can a country be competitive for its goods and services in international markets and what can governments do to facilitate a country's better integration into world trade? It was argued that domestic policies can hardly be effective without due consideration being given to the policies conducted by the trading partners. Globalization can only work to the benefit of a larger group by a strengthening and deepening of policy coordination and coherence between the policy makers, which perhaps is the biggest challenge today. This new reality explains the efforts at the international level to better coordinate policies. It also explains why countries make deliberate efforts to deepen their integration at the regional or sub-regional level. The challenges for policy makers are ensuring that these processes do not undermine the multilateral efforts, but rather would be mutually supportive. 


\section{CHAPTER 4: MARKET ACCESS IN THE WORLD TRADE ORGANIZATION}

\subsection{Introduction}

From the very outset the GATT's key objectives were to liberalize trade and enhance market access and these continue with the WTO: they are at the very heart of the Doha Development Agenda (DDA). The methods of achieving these aims have evolved with time. This chapter discusses the key issues relating to market access and analyses how they were formerly addressed in the GATT and how they are presently negotiated in the WTO. It focuses particularly on tariffs as they are one of the most important trade policy instruments in the multilateral trading system. In doing so it discusses the various negotiating approaches and techniques that have been considered and were applied for reducing tariffs, and how they work. Despite the long and extensive experience that negotiators have with tariff negotiations and the various techniques available and tested in the past to achieve substantial cuts in tariffs, progress in the DDA negotiations has mainly been held up precisely because of disagreement between the Members on the approaches to the market access negotiations. The issues relating to market access will be analysed in this chapter from a historic perspective, followed by explanations for the difficulties encountered in the negotiations which have undermined progress in the DDA, including in agriculture and NAMA. New approaches to the negotiations are suggested.

It will be argued that tariffs continue to be highly relevant and even of critical importance as a trade policy instrument, despite the substantial reductions in tariffs that have already been achieved. There are many reasons that particular attention has been given to tariffs in the negotiations. They mainly relate to the elimination of quantitative restrictions in the Uruguay Round in some specific sectors, thus increasing the amount of attention that can be paid to tariffs. Quantitative restrictions for textiles and clothing were fully eliminated, resulting in the full integration of this sector in the multilateral trading system. Grey area measures such as Orderly Market Arrangements (OMAs) and Voluntary Export Restrictions (VERs) which seriously undermined the trading system were banned. The complete elimination of quantitative restrictions in agriculture resulted in a tariff only regime for this sector. This further strengthened the multilateral trading system and the renewed need to focus on tariff negotiations. The importance of tariffs and their reduction is also shown by the expansion of the Information Technology Agreement (ITA) agreed at MC-X (Nairobi), which led to either the reduction or elimination of tariffs in a critical economic area.

The DDA negotiations on tariffs have the potential to considerably improve market access conditions both for agriculture products and manufactured products by reducing high tariffs and addressing the issue of tariff escalation. It appears increasingly difficult to reach agreement on how to tackle tariff issues both in the area of agriculture and goods and such 
despite the long history of tariff negotiations in the GATT. The lack of agreement between the members has hampered the negotiations and is a core contributor to the stalemate in the DDA negotiations. It is argued that the negotiating approaches that were developed are too complex and include too many exceptions in order to address specific country concerns thus reducing transparency and undermining the overall negotiating objectives. Suggestions will be made as to how these approaches could be simplified.

As the world economy becomes increasingly globalized, the current discussions on market access go far beyond the traditional border measures. This is particularly the case in the negotiations on market access in services, an area which is mostly governed by domestic regulations and which are much harder to tackle. The debate on market access is becoming more complex, as the issues are gradually shifting from negotiations on border measures, including tariffs, to negotiations involving both border and domestic policy issues and which are increasingly intertwined. At the same time, little progress has been made in the negotiations on services, which is of some concern given the increased role services play in the international production process of goods and Global Value Chains (GVCs). The production of goods can hardly continue to be dissociated from services and particularly those which represent a rapidly increasing share of the value of goods. Yet, this interlinkage remains largely ignored. One could argue that the transition in the debates which have gradually shifted from market access issues addressed under the 'old economy' of the GATT to the 'new economy' remains incomplete. The old economy was characterized by a combination of tariffs and quantitative restrictions, such as in the agriculture, textiles and clothing sectors. The new economy includes trade in services, regulatory issues and information technology. It would thus seem natural that more work is done to capture the new trading realities in an integrated fashion, including the links between trade in goods, services and technology in a time of a rapidly evolving digital economy.

This chapter is structured as follows. The first part reviews how tariffs were addressed in the GATT. This is followed by a discussion of two sectors, one illustrating how the elimination of quotas and non-tariff barriers was pursued in the textiles and clothing sector, and one providing an illustration of how tariff escalation has affected trade in leather and leather products. These discussions are based on my own publications and updates to these. The choice of including these two examples is based on the fact that the textiles and clothing sector provides a good illustration of how its integration in the WTO has strengthened the WTO as a 'tariffs only' regime. All quantitative restrictions that governed trade in textiles and clothing during many decades and which considerably distorted trade were eliminated and replaced with tariffs. The discussion on leather and leather products shows how tariff escalation was reduced in a sector of specific interest to developing countries, thus enhancing new trade opportunities for developing countries. Reducing tariff escalation is again an explicit goal in the DDA negotiations.

Then there will be consideration of the question of how market access issues are being pursued in the DDA negotiations. It includes a review of the different approaches proposed 
for enhancing trade liberalization. Specific attention will be given to the complexity of the market access negotiations in the field of agriculture and non-agricultural market access (NAMA), and the ways negotiators try to take into account specific concerns of both individual countries and groups of countries. This is followed by a discussion of two examples and analysing market access in areas that are characteristic for the 'new economy'. One relates to the ITA and the second example relates to trade in services and more specifically the Trade in Services Agreement (TISA).

The conclusion that can be drawn from the analysis is that despite the obstacles encountered in the negotiations, substantial progress has been made in trade liberalization in specific areas and this is economically very meaningful. The difficulties encountered in making overall progress under the DDA negotiations hide those realities. At the same time, the negotiations on market access have become increasingly challenging given the ways members go about them and due to the complexity of the discussions. The attempts to cover all the specific members' situations have reduced the chances of coming to an agreement and undermine transparency. The question then raised is whether members should stick to the current negotiating technique or pursue alternative approaches that are acceptable to all the members. The answer provided is that a selective and step-by-step approach is more likely to yield results and would facilitate to progressively achieving one of the key objectives in the DDA, i.e. enhancing market access.

\subsection{Market access: Main features of tariffs}

\subsubsection{Introduction}

Tariffs have traditionally been a main trade policy instrument to protect domestic markets against the import of foreign products. ${ }^{1}$ They have been at the heart of multilateral trade negotiations since the origin of the GATT and their reduction during the eight GATT rounds of trade negotiations has been the main vehicle for trade liberalization and the opening of markets. $^{2}$ The inclusion of tariffs on the agenda of the Uruguay Round (1986-1994) negotiations once again therefore seemed to be a formality. It was believed to build an element of success into the negotiations from the outset, but negotiations turned out to be much more complex than expected. Fundamental problems arose that were related to the approach for reducing or eliminating tariffs and how to focus on remaining tariff issues. It was also hard to agree on tariff reductions in areas and sectors where high tariffs were most pervasive.

Despite the difficulties encountered, the negotiations were concluded successfully and most tariffs on aggregate have been brought down to historically low levels. This does not detract from the fact that according to the $\mathrm{WTO},{ }^{3}$ considerable work remained to be done,

1 M. Smeets, 'Tariffs: Features and Remaining Issues', 29 Journal of World Trade (1995), p. 91-105.

2 World Trade Report 2007, WTO, Table 5, p. 207, which illustrates the reductions performed in each of the rounds between 1947 and 1999.

3 Special Studies 6: Market Access, Unfinished Business Post Uruguay Round Inventory and Issues, WTO (2001). 
specifically in some sectors which continued to have high tariffs, including textiles and clothing, and leather and leather products. ${ }^{4}$

Since the creation of the WTO and more specifically the launch of the DDA negotiations, tariffs were once again a prominent item on the agenda. However members have not been able to agree on a common approach to address tariffs in the DDA negotiations, despite the ambitious objectives that were set at the launch of the DDA. The discussions have been stuck for many years on the question of how to pursue the objectives and which approach to follow on the tariff negotiations. Francois and Martin point out that 'while there was an urgent need for the WTO Members to identify a set of feasible and effective modalities for establishing market access commitments, this could not be accomplished as fundamental differences between Members remain, including on the reduction formula to be applied'. ${ }^{5}$

How then did the outcome of the Uruguay Round negotiations reinvigorate tariffs as a trade policy instrument and what were some of the key aspects of tariff negotiations? It will be argued that the accomplishments in the area of tariffs, namely the bindings (maximum level of duties that can be applied to that product) and reductions, were essential in enhancing market access, transparency and predictability in the trading system. At the same time, these positive results have brought new challenges, including the reduction of tariff escalation and tariff peaks, which are specifically addressed in the DDA.

To better understand the current challenges relating to market access issues, a short analysis is provided on how tariffs were negotiated in the past. The first part essentially discusses earlier findings from a publication in the Journal of World Trade (1995) and includes, where relevant, updates and references to more recent literature. What were the key issues on tariffs in the GATT at the time of the Uruguay Round and how were they addressed?

\subsubsection{Characteristics of the tariff negotiations}

While recognizing that tariffs are the most transparent and the least distorting trade barrier from an economic perspective, and thus the preferred trade policy instrument, they are still second best to free trade. Hoekman and Kostecki observe that the preference of tariffs is consistent with economic theory and there are many reasons provided why tariffs are preferred over quantitative restrictions, including the fact that they assure nondiscriminatory treatment and are transparent. ${ }^{6}$ Tariffs or customs duties can be calculated and applied in different ways and each method will have a significantly different economic impact. The most common customs duties are ad valorem duties which are duties applied on

4 Both sectors are discussed in two case studies.

5 F. Francois and W. Martin, 'Formula Approaches for Market Access Negotiations' 26 The World Economy (2003), p. 1.

6 B. Hoekman and M. Kostecki, The Political Economy of the World Trading System, The WTO and Beyond ( $3^{\text {rd }}$ edition, Oxford University Press, 2009), p. 185-187. 
the value of the good: in other words it is a percentage applied on the value of the imported good. ${ }^{7}$ Tariffs directly affect prices, whereas most non-tariff measures are related to quantitative restrictions, with indirect and thus less transparent effects on prices. According to Deardorff 'the reduction of tariffs is facilitated by their very nature, as they are easily divisible and can be offered as concessions'. ${ }^{8}$ Tariffs thus serve as a currency of exchange in trade negotiations. As Jackson puts it, 'the elimination of tariffs, as well as other barriers to trade, has been much desired and the GATT has performed a central function in achieving this objective, by providing the forum for various rounds of multilateral trade negotiations' ${ }^{9}$

While tariff negotiations have been at the heart of most GATT rounds of multilateral trade negotiations, the method of reducing duties has often varied. In fact there is not one single accepted approach to tariff negotiations. ${ }^{10}$ One of the basic rules in the negotiations, as contained in Article XXVIII bis of the GATT 1994 is that negotiations on the reduction of customs duties, in short tariff negotiations, are conducted on a reciprocal and mutually advantageous basis'. ${ }^{11}$ The choice of technique to be applied is important though, as each can yield different qualitative and quantitative results. ${ }^{12}$ This also explains the difficulties that were encountered in the Uruguay Round in reaching agreement on the method: not one single technique of tariff reductions seemed to satisfy all parties.

Some key features of different techniques are:

- The 'linear' tariff reduction formula, which was applied in the Kennedy Round (1964-67). It broadly consists of an overall reduction of all rates in the tariff schedules across the board by a specific and equal percentage. This approach is often referred to as a 'flat cut'. ${ }^{13}$ While this lowers duties overall, it does not affect the structure of tariffs. Any imbalance in duties is thus maintained.

- A 'harmonization' formula, which was proposed by Switzerland and adopted in the Tokyo Round (1974-1979) implies cutting high tariffs ('tariff peaks') by a greater percentage than low tariffs, the goal being both to lower and level ('harmonize') tariff rates. ${ }^{14}$ This

$7 \quad$ P. Van den Bossche and W. Zdouc, The Law and Policy of the World Trade Organization (Cambridge Press, 2013), p. 421-2. The 'ad valorem' tariff is the most common type of tariff applied within the OECD and is calculated as a constant proportion of the value-for-duty of the imported good. Some countries including Switzerland and Austria apply 'specific' tariffs, expressed as a fixed monetary amount per physical unit of the product imported. An ad valorem tariff is a relatively transparent form of protection as it provides an amount of assistance that is a fixed proportion of the imported commodity's price and can be increased only by raising the tariff rate.

8 A. Deardorff, Readings, The New World Trading System, OECD Paris, 1994.

9 J.Jackson, The World Trading System, Law and Policy of International Economic Relations(MIT Press, 1999).

10 P. Low and R. Santana, 'Trade Liberalization in Manufactures: What is left after the Doha Round?', 3 Journal of International Trade and Diplomacy (2009), p. 63-126.

11 Cf. van den Bossche and Zdouc, p. 429.

12 J. M. Finger and A. Olechovski, 'The Multilateral Trade Negotiations', World Bank (1987).

13 Low and Santana, 'Trade Liberalization in Manufactures', p. 79.

14 Ibid., p. 80. This is also referred to as the 'non-linear formula'. 
'Swiss formula', as it is often referred to, initially found much support in the Uruguay Round. Francois and Martin observe that 'the potential benefits from use of a formula are large'. ${ }^{15}$ They argue that 'if a suitable top-down formula can be identified and implemented, one can be relatively sure that it will lead to a global welfare gain, since the social costs of tariffs generally rise more rapidly than the rates themselves'. According to Stewart 'the formula facilitates cuts in high tariffs by a higher percentage than low tariffs, thus contributing to harmonization of tariffs'. ${ }^{16}$ Under the formula, tariffs are slashed across the board, irrespective of the product. The Swiss formula also reduces variations in tariffs.

- The 'offer-request' procedure implies the exchange of concessions on a product-by-product basis; countries are thus required to make concessions to obtain market access. ${ }^{17}$ This was the standard way the tariff negotiations were initially conducted in the GATT, before moving to more elaborate and complex methodologies. ${ }^{18}$ While negotiations are conducted on a reciprocal basis, the results are made multilateral, or 'multilateralized' through the Most Favoured Nation (MFN) principle, the cornerstone of GATT. In the Uruguay Round it was favoured by those countries wanting to achieve the total elimination of tariffs on particular products, an objective that would be hard to achieve under any formula approach.

- The sectorial approach is another methodology which can lead to a reduction or elimination of tariffs in a specific sector or on a limited number of products. ${ }^{19}$ According to Low and Santana, the term was first used in the negotiations of the Tokyo Round. It initially served the purpose of addressing non-tariff measures. ${ }^{20}$ Nowadays, it is commonly used as a tool for tariff negotiations. In addition the 'zero-for-zero' sectorial negotiations aim at fully liberalizing trade in a given sector. Efforts to negotiate on a sectorial basis were pursued in the Uruguay Round, leading to the agreement between countries to negotiate 'zero-for-zero' deals for agricultural equipment, beer, construction equipment, distilled spirits, furniture, medical equipment, paper, steel, toys and pharmaceuticals. One of the concerns with this approach is the risk of the so-called 'free-riders', namely parties that benefit from the concessions without making any concessions. This explains the need to have a critical mass of parties, as will be illustrated when discussing the ITA which was concluded in 2015.

There are good arguments for all these approaches, each of them with their own advantages and disadvantages. These are discussed by Francois and Martin (2003) and based on several scenarios that they developed for the application of different formulas. For that reason, it was decided by negotiators in the Uruguay Round that contracting parties were

15 Francois and Martin, 'Formula Approaches', p. 3.

16 P. Stewart, 'The GATT Uruguay Round, a Negotiating History (1986-1992)', Kluwer Law International, Vol. 1 (1993).

17 Low and Santana, 'Trade Liberalization in Manufactures', p. 73

18 The offer-request approach works for obvious reasons better and is easier when a limited number of parties are involved exchanging concessions on a limited number of goods.

19 Low and Santana, 'Trade Liberalization in Manufactures', p. 83.

20 Ibid. 
free to apply any method, provided the reduction would be at least equivalent to overall reductions achieved in the Tokyo Round (which corresponds to a reduction of more than a third of prevailing bound duties). The offer-request approach was used, again by a large number of countries. ${ }^{21}$ In addition, the 'zero-for-zero' negotiations were successfully conducted in the Uruguay Round and contributed to the full elimination of duties in specific sectors. These two features of tariff negotiations combined ensured the success of tariff negotiations in the Uruguay Round. Nevertheless, it was inevitable that certain sectors in the economy would remain excluded from liberalization: either requests were not tabled or concessions not granted. Moreover, as is argued in the WTO study on market access (2001), wide disparities in tariffs often prevail both across countries and sectors, which makes it difficult to agree on reductions in specific areas. Hence the continued need to address tariffs in the multilateral trade negotiations.

\subsubsection{New tariff commitments}

According to the Ministerial Declaration, the main objective in the Uruguay Round negotiations was to reduce or eliminate tariffs, including the reduction or elimination of high tariffs and tariff increases. ${ }^{22}$ High tariffs or tariff peaks are generally defined as tariffs that exceed a selected reference level. The OECD establishes a distinction between national peaks, where the reference is three times the national mean tariff, and international peaks, where the reference level is $15 \% .^{23}$ According to WTO studies, 'tariffs escalate when they increase with the level of processing, as when they are fixed at a higher level on semiprocessed and processed products than on unprocessed products and raw materials'. ${ }^{24}$

Despite an overall low average level already existing in OECD countries, WTO and OECD studies as well as analytical reports all confirm that substantive tariff cuts were again achieved: the trade weighted ad valorem reductions on industrial products in industrialized countries corresponded to $40 \%{ }^{25}$ In addition, duty free trade was ensured for $44 \%$ of developed economies' imports of industrial products. After their implementation, developed countries' tariffs on industrial products fell from $6.3 \%$ to $3.8 \%{ }^{26}$ Tariff levels represented one-tenth of the average tariff level after WWII and before the GATT was applied in 1948 through the Protocol of Provisional Application. Also, the overall level of bindings was significantly increased, mainly in countries with few tariff bindings before the start of the Uruguay Round (developing countries and Central and Eastern European Countries). These were essential for business confidence and hence for the expansion of trade: unpredictable tariffs are a strong disincentive to invest in export capacity. At the same time, as illustrated by

21 While the US adopted an offer-request/product-by-product approach, Canada, the European Union and Japan applied a formula approach to produce their initial offers.

22 GATT, Ministerial Declaration of the Uruguay Round, Punta Del Este, September 1986.

23 Post Uruguay Round Tariff Regimes, Achievements and Outlook, OECD, Paris, 1999, p. 39.

24 Special Studies 6: Market Access, p. 12.

25 Cf. Francois and Martin, 'Formula Approaches', Special Studies 6: Market Access (WTO, 2001) and Post Uruguay Round Tariff Regimes (OECD, 1999).

26 Cf. Ibid. 
Francois and Martin in tabular format, large differences remain in the level of commitments between the members, both in terms of bindings and levels of bindings, which need to be addressed. ${ }^{27}$

\subsubsection{The significance of 'bindings'}

The 'binding' of a tariff on a product is economically very important as it provides the maximum level of duties that may be applied to that product. ${ }^{28}$ This is why the distinction needs to be made between the 'binding' of the duty and the 'applied duty', which by definition is always lower or at worst equal to the bound duty. ${ }^{29}$ According to the WTO 'differences between bound and applied rates do generally occur, but the applied rate can never exceed the bound rate'. ${ }^{30}$ While in economic terms the lower applied rate benefits the foreign exporter, differences between applied rates and bound rates create uncertainty in trade: governments retain the right at any time to raise the duty up to the level of the binding without formally affecting levels of obligations and commitments in the GATT. This also means that the wider the gap, the higher the margin of uncertainty, which is often referred to as 'water in the binding'. In addition, it reduces the immediate significance of the tariff concession, as the bound (not the applied) rate provides the basis for the reductions. This explains why in the current negotiations efforts are pursued to reduce the gap between the applied duty and the bound duty.

Van den Bossche and Zdouc explain how in legal terms the binding level clearly establishes the rights and obligations that apply to governments, which is essential for creating a predictable environment for the exporters. ${ }^{31}$ In economic terms, however, the efficacy of tariffs will mostly be determined by the level of the binding: either the tariff binding is low, thus ensuring few distortions in access to markets, or the tariff binding is high, thus creating more distortions in the economy. High bound and high applied duties obviously affect trade more directly as they raise costs for the exporter and consumers more often. Moreover, it can also have an immediate impact on patterns of Foreign Direct Investment (FDI), which can act as substitutes to trade in obtaining market access and thus 'jump' over the tariff wall. Such decisions, when not based on economic efficiency grounds but triggered by price distortions caused by tariffs, are second best to free trade, and lead to the misallocation of production factors. Tariff peaks can prevent trade occurring altogether.

27 Cf. Ibid., Table I, p. 5.

28 Cf. Hoekman and Kostecki, p. 190.

29 A tariff concession, or a tariff binding, is a commitment not to raise the customs duty on a certain product above an agreed level. Cf. Van den Bossche and Zdouc, p. 438.

30 Cf. Special Studies 6: Market Access, p. 13-17 and Table II.4, providing data on the wedge between the bound and the applied duties. It can be seen that several developed countries, including Australia, Iceland and Turkey have a rather significant gap between the bound and applied duties. The differences are even more striking for Latin American countries, most of which apply a uniform ceiling level to most of their tariff lines.

31 Tariff commitments are reflected in Schedules of Concessions and administered in the WTO. Modifications of bound duties can only occur through formal tariff negotiations under Article XXVIII. Cf. Van den Bossche and Zdouc, p. 439 and further. 
As the overall levels of tariffs are already low, differences between applied and bound rates are generally very limited within the OECD countries. After the implementation of the results of the Uruguay Round, the two became very close and/or similar for most products in OECD trade. This is why priority was given to addressing high tariffs in this Round and this is again the case in the DDA. There are two aspects to the issue, as high tariffs can prevail between countries, but can also be limited to specific sectors, such as when overall tariff levels are low. Some OECD countries like Australia and New Zealand had only recently conducted major reviews of their tariff structures in view of fundamental liberalization and structural adjustment programs, with binding and reduction of duties being an essential element in economic policies. Their bindings tended to be higher than the OECD average. ${ }^{32}$

On a sectorial level, tariff lines with bindings on high or even very high levels can be identified in tariff schedules on lower levels of aggregation, namely within specific tariff lines. One reason for having high tariffs on specific products obviously relates to the level of protection that a government wants to provide. In view of that objective, some tariff lines were not part of negotiations. Differences between the bound and applied rates in specific sectors can also occur when a domestic company, in view of changes in production and marketing strategy, requests lower tariff protection or even the exemption of duties. In pursuit of globalization strategies, companies may switch from in-house production of parts and components to out-sourcing (for example car manufacturers, or the electronics industry). Duties on parts and components can be temporarily waived, if the company that requests the waiver can convince the government of the country where it is located that the duty free imports of the inputs are essential for the company's competitiveness on world markets. It can easily be argued that the globalization of trade and the drive for countries to link to production networks through GVCs enhances the drive towards trade liberalization even further.

Studies show that many developing countries have fixed high binding ceilings, thus reducing the significance of the commitments. ${ }^{33}$ A significant number of countries also continue to have their tariffs unbound. Some developing countries that had relatively few tariff bindings had bound most of their tariff lines on fairly high levels. Many agreed however to bind all customs tariffs up to a maximum ceiling level, which was considered to be an economically meaningful. In other words a ceiling could be fixed at a rate of $35 \%$, meaning that the bound duties would never go beyond that ceiling rate. This was mostly done by countries that did not have a tradition of tariff protection and therefore had no basis on which to establish the rate. Tariffs that were already lower would remain bound at the lower rate. The applied rates could again differ for specific products, and in practice often were in the range of $15 \%$. While this was certainly welcome from an economic perspective, it carried an element of uncertainty for exporters who could suddenly face a higher tariff than anticipated, though within the limit of the ceiling. The argument however seemed to ignore the importance of the binding in itself, as it implied a firm and legal commitment not to raise tariffs on the imported product beyond that level at any time in the future. Indeed, the ceiling

32 Cf. Post Uruguay Round Tariff Regimes, OECD.

33 Ibid; Special Studies 6: Market Access, WTO; and Francois and Martin 'Formula Approaches'. 
binding implied a clear and predictable maximum charge.

Finally, Van den Bossche and Zdouc explain that 'while the binding of a duty provides the maximum ceiling that can be applied, increases in bound rates are still permitted through formal tariff negotiations under Article XXVIII and Art. XXVIII bis'. ${ }^{34}$ One aspect of these provisions is the requirement for the party that raises the binding in one product to provide compensation through the reduction of binding in another product of an equivalent value. This sounds straightforward but it has often turned out to be very difficult for parties to reach agreement on the economic implication of the concessions and what constitutes reasonable compensation. In any case, the lowering (and not the increase) of tariffs is the object of formal rounds of multilateral trade negotiations, using the bound rate as a basis for reductions. This fundamental concept of using the binding as a starting point for the reductions to be performed applied in trade negotiations and was reaffirmed in the Uruguay Round. This is again mostly the case in the DDA negotiations, except in certain specific situations, which will be addressed further.

According to the WTO calculations (Table 4.1) it was anticipated that after the implementation of the agreements of the Uruguay Round, 99\% of developed economies' tariff lines of industrial products (corresponding to the same amount of imports) would be bound, compared with $78 \%$ of tariff lines before implementation (or $94 \%$ of imports). ${ }^{35}$ The outcome of a considerable increase in bindings by all members is confirmed in studies conducted after the conclusion of the Round and the implementation of the commitments, as well as by the data provided by the WTO and the OECD. ${ }^{36}$ While the economic impact of this increase may have been limited, as the binding in itself does not create trade but enhances predictability, it was significant in terms of tariff lines covered and further reduced the arbitrary use of tariffs as a trade policy instrument. It is also observed that the percentage of imports with bound tariffs was higher than the percentage of tariff lines bound for Western Europe. The opposite applies for developing countries. This could either mean that unbound tariffs were prohibitive and exclude imports, or that unbound tariffs applied to items of little economic significance.

34 Van den Bossche and Zdouc, p. 449 and further, explain the procedures to be followed in that regard. With regard to provisions for tariff negotiations, additional criteria for determining who has 'principle supplying interest' were included, which favor small suppliers: their export share of the product affected by the tariff modification is important compared to overall exports, even if it is not an important exporter in absolute terms.

35 The Uruguay Round of Multilateral Trade Negotiations, GATT, April 1994. It should be noted that the data on developing economies cover 26 participants which account for approximately $80 \%$ of the merchandise imports, and roughly $30 \%$ of the tariff lines of the 93 developing country participants in the Uruguay Round.

36 Cf., Francois and Martin, 'Formula Approaches', Table I, p. 5; Special Studies: Market Access, Table II.1, p. 8 and Post Uruguay Round Tariff Regimes, Table I, p. 49. 
TABLE 4.1: Binding of tariffs on industrial products

\begin{tabular}{|c|c|c|c|c|}
\hline Country Group & $\begin{array}{c}\text { Number of } \\
\text { Lines }\end{array}$ & $\begin{array}{c}\text { Import } \\
\text { Value(1) }\end{array}$ & $\begin{array}{l}\text { Percentage of } \\
\text { tariff lines } \\
\text { bound }\end{array}$ & $\begin{array}{l}\text { Percentage of } \\
\text { imports under } \\
\text { bound rate }\end{array}$ \\
\hline & & & $\underline{\text { Pre }} \underline{\text { Post }}$ & 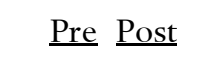 \\
\hline $\begin{array}{l}\text { Developed } \\
\text { economy }\end{array}$ & 86.968 & 736.9 & $78 \quad 99$ & $94 \quad 99$ \\
\hline $\begin{array}{l}\text { Developing } \\
\text { economy }\end{array}$ & 157.805 & 350.5 & $21 \quad 73$ & 1361 \\
\hline $\begin{array}{l}\text { Transition } \\
\text { economy }\end{array}$ & 28.962 & 34.7 & $73 \quad 98$ & $74 \quad 96$ \\
\hline \multicolumn{5}{|l|}{ By selected region: } \\
\hline North America & 14.138 & 325.7 & $99 \quad 100$ & $99 \quad 100$ \\
\hline Latin America & 64.138 & 40.4 & $38 \quad 100$ & $57 \quad 100$ \\
\hline Western Europe & 57.851 & 239.9 & $79 \quad 82$ & $98 \quad 98$ \\
\hline Central Europe & 23.565 & 38.1 & 6398 & $\begin{array}{ll}68 & 97\end{array}$ \\
\hline Asia & 82.545 & 415.4 & 16 & 32 \\
\hline
\end{tabular}

Source: GATT, The Results of the Uruguay Round of Multilateral Trade Negotiations; Market Access for Goods and Services: Overview and Results, (Geneva, November 1994).

\section{Note:}

(1) in billions of US dollars

(2) tariff lines which were fully bound prior to the Uruguay Round.

The WTO and OECD studies confirm that the main efforts in the Uruguay Round were particularly undertaken by developing countries who bound $73 \%$ of their tariff lines (or $61 \%$ of total imports), up from $21 \%$ of tariff lines (or $13 \%$ of the import value). ${ }^{37}$ In fact, this was the first round where developing countries fully participated in the negotiations on tariffs and made concessions. The new commitments, in addition to providing new market and trade opportunities, contributed to cementing liberalization programmes that have been undertaken in these countries since.

Looking at the accomplishments of bindings on a regional level (Table 4.1) and bindings with or without reductions (Table 4.2), some important differences appear. Latin America

37 Special Studies: Market Access (WTO); Post Uruguay Round Tariff Regimes (OCED); Smeets, 'Tariffs: Features and Remaining Issues'. 
has bound $100 \%$ of its tariff lines, compared to $38 \%$ before the Uruguay Round (corresponding to $100 \%$ of imports, compared to about half, before). Asia has increased overall bindings dramatically, covering $68 \%$ of tariff lines (compared to only $16 \%$ before) or $70 \%$ of imports (compared to $32 \%$ before). Despite these efforts, Asia remained the area with the lowest overall level of bindings. These facts may hide efforts undertaken in lowering applied duties, thus effectively enhancing market access, without anchoring the reductions through bindings. Such efforts are not reflected in the schedules of concessions.

TABLE 4.2: Bindings with reductions for industrial products (\%)

\begin{tabular}{|c|c|c|c|c|c|c|c|c|}
\hline & \multicolumn{2}{|c|}{$\begin{array}{c}\text { Already bound duty } \\
\text { free (1) }\end{array}$} & \multicolumn{2}{|c|}{$\begin{array}{c}\text { Binding } \\
\text { with } \\
\text { reductions }\end{array}$} & \multicolumn{2}{|c|}{$\begin{array}{l}\text { Binding without } \\
\text { reductions }\end{array}$} & \multicolumn{2}{|c|}{ No offer } \\
\hline & $\begin{array}{c}\text { Share } \\
\text { of } \\
\text { lines }\end{array}$ & $\begin{array}{c}\text { Share } \\
\text { of } \\
\text { imports }\end{array}$ & $\begin{array}{c}\text { Share } \\
\text { of } \\
\text { lines }\end{array}$ & $\begin{array}{c}\text { Share } \\
\text { of } \\
\text { imports }\end{array}$ & $\begin{array}{c}\text { Share } \\
\text { of } \\
\text { Lines } \\
\end{array}$ & $\begin{array}{c}\text { Share } \\
\text { of } \\
\text { imports }\end{array}$ & $\begin{array}{c}\text { Share of } \\
\text { lines }\end{array}$ & $\begin{array}{c}\begin{array}{c}\text { Share } \\
\text { of } \\
\text { imports }\end{array} \\
\end{array}$ \\
\hline \multicolumn{9}{|c|}{ Country group } \\
\hline $\begin{array}{l}\text { Developed } \\
\text { economies }\end{array}$ & 17 & 18 & 67 & 64 & 9 & 3 & 7 & 16 \\
\hline $\begin{array}{l}\text { Developing } \\
\text { economies }\end{array}$ & 0 & 1 & 46 & 32 & 24 & 26 & 29 & 42 \\
\hline $\begin{array}{l}\text { Transition } \\
\text { economies }\end{array}$ & 6 & 12 & 83 & 76 & 0 & 1 & 11 & 10 \\
\hline \multicolumn{9}{|c|}{ By selected region } \\
\hline $\begin{array}{l}\text { North } \\
\text { America }\end{array}$ & 18 & 11 & 72 & 64 & 0 & 1 & 10 & 24 \\
\hline $\begin{array}{l}\text { Latin } \\
\text { America }\end{array}$ & 0 & 2 & 72 & 71 & 26 & 19 & 2 & 8 \\
\hline $\begin{array}{l}\text { Western } \\
\text { Europe }\end{array}$ & 16 & 24 & 58 & 63 & 1 & 0 & 25 & 13 \\
\hline $\begin{array}{l}\text { Central } \\
\text { Europe }\end{array}$ & 6 & 11 & 67 & 70 & 17 & 9 & 11 & 10 \\
\hline Asia & 2 & 8 & 43 & 41 & 21 & 19 & 33 & 32 \\
\hline
\end{tabular}

Source: GATT, The Results of the Uruguay Round of Multilateral Trade Negotiations; Market Access for Goods and Services: Overview and Results, (Geneva, November 1994).

These overall figures however also hide significant efforts undertaken on an individual country level. While the level of bindings is rather comparable for most developed countries, some countries have made more efforts than others. Australia and New Zealand, who had only few tariff bindings prior to the Uruguay Round, bound $96 \%$ and $100 \%$ of their tariffs, 
up from $36 \%$ and 58\% respectively. South Africa also more than tripled its bindings, covering $99 \%$ of total imports. Only Iceland stands out with relatively few bindings, covering two thirds of its total imports.

Amongst the developing countries the efforts have not always been even on an individual country level. Several countries bound all of their import duties, in particular all of the Latin American countries. Others bound a good part of their duties, including India, Indonesia, the Philippines, Singapore, the Republic of Korea, Malaysia, and Thailand, whereas they had only few bindings prior to the Uruguay Round. At the same time, and as noted by the OECD, some of these countries continued to have a fairly high proportion of their tariffs unbound as a percentage of MFN imports. ${ }^{38}$ After the Uruguay Round, India still had one third of its tariffs unbound, Malaysia 30\%, Sri Lanka over $80 \%$, Tunisia and Turkey nearly half of their tariff lines, two thirds of tariffs in the Philippines, and $73 \%$ in Thailand. Global figures are also distorted by a country like Hong Kong, which accounted for over a third of total imports in the GATT statistics on developing countries, but which has not reduced any tariff bindings, as it did not and does not apply tariffs. The figures thus understate overall efforts.

Singapore, which accounted for more than $10 \%$ of total imports in the same statistics, had initially left its tariffs unbound, but had $73 \%$ of its tariffs bound after the implementation of the results of the Uruguay Round. Interesting enough, the trade-weighted tariff average of Singapore increased after the implementation of the Uruguay Round from $0.4 \%$ to $5.1 \%$. The logical explanation for this lay in the fact that Singapore had not bound import duties prior to the Round, and nor did it apply duties. It continued its policy of not charging import duties while maintaining the right to apply tariffs in future up to the bound rate. The binding thus provided a safety net, but was also of strategic value for future tariff negotiations, as it was better placed to obtain tariff concessions in export markets, in return for lowering its import duties.

Central European countries also made considerable efforts, having $98 \%$ of tariff lines bound (compared to $63 \%$ before), which roughly corresponds to the same value of imports. Central Europe bound more tariff lines than Western Europe, including the European Union.

\subsubsection{Lowering and full elimination of duties}

In addition to the overall increase in the number of bindings, which contribute to establishing a stable and predictable trading environment, enhanced market access was to be ensured through the overall reduction of tariffs by an average of almost $40 \%$. The economic impact would be more noticeable when the lower bound duties also imply a reduced applied rate. The results of the Uruguay Round negotiations are presented in Table 4.2, featuring the tariff bindings and cuts for major country groups. It shows that the efforts made were

38 Post Uruguay Round TariffRegimes, p. 17. 
uneven when looking at various categories of countries and regions.

Two-thirds of developed economies' bound tariff lines were lowered (67\%), whereas only $7 \%$ of all tariff lines were not included in the offers. It should be kept in mind that in some sectors tariffs were already below average. In other sectors, tariffs were harmonized. Most developed economies' tariff schedules were thus affected by the negotiations. Although they started at different levels, the economies in transition outperformed the developed economies: bindings with reductions affected $83 \%$ of all tariff lines, corresponding to $76 \%$ of total imports. Only $11 \%$ of imports were not included in the offers. While recognizing that their share in world trade was very modest, the new commitments were important in enhancing transparency and predictability and facilitating trade flows into that region.

Developing countries as a group have offered reductions in bound rates on $46 \%$ of tariff lines (corresponding to a quarter of the value of imports), but within that category, Latin America agreed to reduce $72 \%$ of its tariff lines, compared to $43 \%$ for Asia. While the Asian reductions compared to the average, Latin America thus stood out in terms of reductions achieved. These important reductions can partly be explained by the introduction of ceiling rates, fixed on $35 \%$. Developing countries as a group made no offers on nearly a third of their tariff lines. This figure is only $2 \%$ for Latin America. This again showed the extent to which reforms in the tariff structures in Latin American countries have been undertaken: less reliance on tariffs as an instrument for economic policy, but reinvigorating market principles and the functioning of the price mechanism as a basis for economic decisions.

Separately, it can be observed that the category of products on which developed countries would charge low tariffs (between $0.1 \%$ - 5\%) had also decreased (Table 4.3). Only $32 \%$ of total imports (in value) remained subject to duties of less than $5 \%$, compared to $41 \%$ of tariffs prior to the Uruguay Round. This effectively meant the elimination of the lower duties, as these tariffs probably had little economic impact and caused few distortions in the economy. While recognizing their limited significance also compared with other macro-economic factors (for example exchange rate fluctuations or other domestic taxes) they undeniably provided an administrative barrier to trade, and were thus undesired. 
TABLE 4.3: Developed country tariff and trade profiles by industrial product categories (excluding petroleum)

\begin{tabular}{|c|c|c|c|c|c|c|c|c|c|c|c|c|c|}
\hline \multicolumn{14}{|c|}{ (Millions of US dollars and percentages) } \\
\hline \multirow{3}{*}{$\begin{array}{l}\text { Product } \\
\text { category }\end{array}$} & $\begin{array}{c}\text { Total } \\
\text { import }\end{array}$ & \multicolumn{12}{|c|}{ Percentage of imports } \\
\hline & & \multicolumn{2}{|c|}{ Duty-free (2) } & \multicolumn{2}{|c|}{$0.1-5 \%$} & \multicolumn{2}{|c|}{$5.1-10 \%$} & \multicolumn{2}{|c|}{$10.1-15 \%$} & \multicolumn{2}{|c|}{$15.1-35 \%$} & \multicolumn{2}{|c|}{ Over $35 \%$} \\
\hline & & Pre- & Post- & Pre- & Post- & Pre- & Post- & Pre- & Post- & Pre- & Post- & Pre- & Post- \\
\hline $\begin{array}{l}\text { All industrial } \\
\text { products } \\
\text { (excluding } \\
\text { petroleum) }\end{array}$ & 736,946 & 20 & 44 & 41 & 32 & 24 & 15 & 7 & 5 & 6 & 4 & 1 & 1 \\
\hline $\begin{array}{l}\text { Textiles and } \\
\text { clothing }\end{array}$ & 66,355 & 2 & 4 & 6 & 14 & 27 & 29 & 30 & 25 & 33 & 27 & 2 & 1 \\
\hline Metals & 69,392 & 36 & 70 & 36 & 21 & 23 & 7 & 3 & 1 & 2 & 1 & 1 & 0 \\
\hline $\begin{array}{l}\text { Mineral } \\
\text { products \& } \\
\text { precious } \\
\text { stones } \\
\end{array}$ & 72,949 & 59 & 81 & 28 & 9 & 10 & 9 & 3 & 1 & 2 & 1 & 0 & 0 \\
\hline $\begin{array}{l}\text { Electric } \\
\text { machinery }\end{array}$ & 86,014 & 5 & 30 & 54 & 55 & 26 & 6 & 11 & 7 & 3 & 2 & 1 & 0 \\
\hline $\begin{array}{l}\text { Leather, } \\
\text { rubber, } \\
\text { footwear \& } \\
\text { travel goods }\end{array}$ & 31,670 & 16 & 19 & 17 & 29 & 47 & 37 & 7 & 4 & 11 & 9 & 3 & 2 \\
\hline $\begin{array}{l}\text { Wood, pulp, } \\
\text { paper \& } \\
\text { furniture }\end{array}$ & 40,590 & 50 & 84 & 24 & 6 & 20 & 7 & 2 & 2 & 4 & 0 & 1 & 0 \\
\hline $\begin{array}{l}\text { Fish \& fish } \\
\text { products }\end{array}$ & 18,527 & 21 & 24 & 42 & 44 & 18 & 21 & 18 & 8 & 7 & 3 & 0 & 0 \\
\hline $\begin{array}{l}\text { Non-electric } \\
\text { machinery }\end{array}$ & 118,126 & 11 & 48 & 74 & 42 & 10 & 7 & 2 & 1 & 2 & 2 & 1 & 0 \\
\hline $\begin{array}{l}\text { Chemicals \& } \\
\text { photographic } \\
\text { supplies }\end{array}$ & 60,958 & 14 & 34 & 31 & 27 & 40 & 37 & 10 & 2 & 5 & 1 & 1 & 0 \\
\hline $\begin{array}{l}\text { Transport } \\
\text { equipment }\end{array}$ & 96,312 & 16 & 21 & 52 & 50 & 21 & 19 & 2 & 2 & 5 & 4 & 4 & 3 \\
\hline $\begin{array}{l}\text { Manufactured } \\
\text { articles n.e.s. }\end{array}$ & 76,053 & 15 & 49 & 38 & 37 & 40 & 10 & 5 & 3 & 2 & 1 & 0 & 0 \\
\hline
\end{tabular}

Source: GATT (1994) 
More importantly however was the extent to which duties were fully eliminated thus effectively achieving free trade: the level of bound duty free imports into the developed economies more than doubled from $20 \%$ of imports before to $44 \%$ of imports after the implementation of the cuts. This objective was accomplished in two different ways: in some instances, it was decided to bind at zero tariffs on products for which duties had been waived. In addition, the objective of eliminating tariffs through the zero-for-zero negotiations had become particularly prominent after a meeting held by the G-7 in Tokyo in July 1993. The negotiations, mainly conducted between the 'Quad' group (the United States, the European Community, Japan and Canada) resulted in the full elimination of tariffs on pharmaceutical products, construction equipment, medical equipment, steel products, furniture, agriculture equipment, beer, distilled spirits. In these cases it was expected that there would be a real economic impact.

The new levels of duty free treatment meant that for nearly half of the imports into the developed economies, tariffs, irrespective of the source of trade, no longer mattered. While this figure is significant in itself, it even understated the situation in the real world, as this information pertains to MFN trade only. Duty free trade effectively provided under regional arrangements (namely, intra-regional trade or free trade arrangements), as well as under other preferential trading arrangements (for example the Generalized System of Preferences) are by definition not captured in these statistics. (Intra-EC trade and intra-North American trade, however, together accounted for nearly $40 \%$ of world trade.)

While recognizing that free trade enhances overall economic welfare, the implementation of these new commitments regarding tariff reduction had two separate but important side effects. One is that it implied a loss of fiscal revenues for government, which is inherent in tariff reductions. This argument is mostly associated with developing countries, for which import duties have traditionally been an important source of fiscal income. It also was essential in domestic debates in developed countries, given increasing budget constraints. As will be argued in the next chapter, the argument however seems to ignore the dynamic and positive effects of tariff reductions, that is, better resource allocation, efficiency, enhanced economic activity, and therefore income for the government. The medium to long-term economic benefits outweigh the short-term loss of revenues. ${ }^{39}$ In addition, the loss of fiscal revenue at the border can be compensated through domestic taxes, including value added tax (VAT), which is the most common and least distortive means of tax collection.

The other side effect of the increase in the share in duty free treatment, as well as the overall lowering of duties, was the reduction of the significance of preferential trade, including the hollowing out of preferences for developing countries, under various preferential schemes. This issue again plagues the DDA negotiations, where some developing countries that are most affected by preference erosion would like to seek

39 The rationale of the economic benefits of liberalizing trade by developing countries is provided in the World Trade Report 2014: Trade and Development: Recent Trends and the Role of the WTO (2014). 
measures to compensate for the loss in competitiveness endured as a result of the erosion of preferences. While most of the arguments are provided in support of maintaining preferences opposing arguments can also be presented. It is often argued that in the long run developing countries might be better off by having to rely less on autonomous preferences and more on bound duties. ${ }^{40}$ After all, preferences can be modified or withdrawn. In addition, it could be argued that the preferences diminish incentives to diversify and adjust, thus increasing the dependency on the preferences per se. Competitive conditions in world trade are shifting increasingly rapidly, as was shown previously, with a need to be closer to the markets and linking to GVCs. The dependency of preference may hinder the rapid adaptation to the new world realities. Finally, it brings to an end the discriminatory treatment between exporters that is inherent in schemes of preferences. The new trading system provides guaranteed market access opportunities under clear and predictable conditions.

\subsubsection{Remaining high tariffs after the Uruguay Round}

\subsubsection{1 (a) Tariffs peaks and tariffescalation}

In spite of the tariff reductions performed and the phasing out of duties in several sectors, studies by the WTO (2001), OECD (1999) and Francois and Martin (2003), show that tariffs continue to be higher than average rates and have a high share of tariff peaks mainly in four sectors: (i) textiles and clothing; (ii) leather, rubber, footwear and travel goods; (iii) fish and fish products; and (iv) transport equipment. ${ }^{41}$ The relevant data with regard to the tariffs applicable to various sectors and their relative weight are contained in Tables 3.3 and 3.4. Most of these sectors are of particular interest to developing countries and have undergone lower than average cuts. In addition, some of these sectors feature tariff escalation, which means that the tariff rates increase with the level of processing. In other words, the more value that is added in the production process, the higher the duties, thus effectively working against value adding (as is shown below). Hoekman and Kostecki observe that 'escalation is a feature of almost all tariff structures. The exceptions are the few economies that essentially have a free trade stance (e.g. Hong Kong) or have implemented a uniform tariff, that is, apply the same tariff to imports of all goods.....At the product level, tariff escalation may occur, even if the overall structure exhibits little or no escalation. This is often the case for textiles and clothing and leather products, where inputs - cotton, yarn, raw hides - tend to have lower duties than does the finished product. ${ }^{42}$

40 This point will be developed further below in the part on market access issues in the DDA as well as in the next chapter, where it is argued that preferences are not necessarily in the best interests of developing countries when seen from a longer term perspective.

41 It will be argued in section B that the quota regime for textiles and clothing was gradually eliminated as a result of the Uruguay Round Agreement. In another example it is shown how tariff escalation affects exports of leather and leather products originating from developing countries (section C).

42 Hoekman and Kostecki, p. 197. 
TABLE 4.4: Reductions in bound tariffs of developed countries by industrial product group

\begin{tabular}{l|c|c|c|c}
\hline \multicolumn{1}{c|}{ Product category } & $\begin{array}{c}\text { Import } \\
\text { value(2) }\end{array}$ & Pre & Post & Reduction \\
\hline All industrial products & 736.9 & 6.3 & 3.8 & 40 \\
\hline Textiles and clothing & 66.4 & 15.5 & 12.1 & 22 \\
\hline Metals & 69.4 & 3.7 & 1.4 & 62 \\
\hline $\begin{array}{l}\text { Mineral products, } \\
\text { precious stones/metals }\end{array}$ & 73.0 & 2.3 & 1.1 & 52 \\
\hline Electric Machinery & 86.0 & 6.6 & 3.5 & 47 \\
\hline $\begin{array}{l}\text { Leather, rubber, footwear } \\
\text { \& travel goods }\end{array}$ & 31.7 & 8.9 & 7.3 & 18 \\
\hline $\begin{array}{l}\text { Wood, pulp, paper \& } \\
\text { Furniture }\end{array}$ & 40.6 & 3.5 & 1.1 & 69 \\
\hline Fish \& fish products & 18.5 & 6.1 & 4.5 & 26 \\
\hline Non-electric machinery & 118.1 & 4.8 & 1.9 & 60 \\
\hline Chemicals \& photography. & 61.0 & 6.7 & 3.7 & 45 \\
\hline Transport equipment & 96.3 & 7.5 & 5.8 & 23 \\
\hline Manufactured articles & 76.1 & 5.5 & 2.4 & 56 \\
\hline
\end{tabular}

Source: GATT, ibid.

Notes:

(1) Tariff averages weighted by imports from all sources

(2) In billions of US dollars

Grubel and Johnson point out that there are various methodological difficulties that arise when it comes to calculating tariff escalation, that there are a number of ways of measuring the degree of tariff escalation and its potential impact on trade, but that its distortive effect is well recognized. ${ }^{43}$ The effects of tariff escalation on the processing of products is often measured in terms of effective rates of protection (ERP) and which is the extent to which the protection favours the value added by the domestic producer relative to imports of the same product. Recognizing the pernicious effects of tariff escalation, some countries have made a deliberate effort to reduce tariffs at the higher end of the value-adding process. This has narrowed the gap (sometimes called the tariff 'wedge') between rates for inputs and outputs at each stage of production. It is generally agreed that tariff escalation can only be analyzed in a meaningful manner on a product by product basis, and focusing specifically on different levels in the production chain. Tariff escalation is eliminated when the tariffs applied to processed and unprocessed versions are the same. In other words, there is no progression in the level of the duty with a higher value addition in the production process. The reduction of

43 Cf. H.G. Grubel and H. G. Johnson, 'Effective Tariff Protection', GATT (1971). 
duties in the Uruguay Round negotiations and more specifically the higher duties have thus contributed to the further reduction of tariff escalation.

Nevertheless, according to calculations by the GATT (2001), imports subject to tariff peaks, defined as tariffs higher than $15 \%$, continue to affect a relatively high share of imports in value, both in developed and developing countries. ${ }^{44}$ Within sectors tariffs can be well above this average for specific products, in some instances reaching over $35 \%$. For a quarter of products in the category of textiles and clothing (Table 4.3), duties continued to be in the range of $15.1 \%-35 \% .{ }^{45}$ The comparable figure is $9 \%$ for leather. Such high duties can be prohibitive for exporters. While the aggregate figures show average tariff bindings on overall low levels, these figures thus concealed a wide dispersion in bindings both between countries and sectors. ${ }^{46}$ The greater the level of tariff peaks, the greater the potentially distorting effect on competition and trade, particularly if such peaks are found alongside much lower rates for similar (highly substitutable) products.

The structure of tariffs can thus influence the type of economic activity in a country, as the tariffs are most likely to create a disincentive to moving to higher value adding with an increase in the tariffs. ${ }^{47}$ This argument is often brought forward by developing countries, claiming that the developed economies' tariff structure is such as to discourage developing countries from moving to a higher level in the value-added chain. In practice, however, tariff escalation can be found both in trade between developed and developing countries, as well as in trade between developing countries, as is illustrated in a recent WTO report and which will be shown in the case of leather and leather products. ${ }^{48}$

\subsubsection{2 (b) Tariffs for agricultural products}

While tariff negotiations are at the heart of the DDA negotiations, the Uruguay Round provided the first opportunity to address the ways to liberalize trade in agricultural products. The WTO Agreement on Agriculture (hereafter Agriculture Agreement) that resulted from the negotiations led to little liberalization per se, but provided the framework for future liberalization and irrespective of a next round of negotiations. ${ }^{49}$ High tariffs and tariff peaks

44 'Special Studies 6', Table II.5, p. 19.

45 With the integration of textiles and clothing into the WTO after the transition period in 2004, all quotas and bilateral restraints disappeared, with tariffs remaining as the sole instrument of border protection.

46 'Special Studies: Market Access' which provides specific data with regard to duties applied by countries and in specific sectors, as well as the duties at various stages of processing.

47 Effective rates of protection provided to a certain economic activity can be considerably higher than suggested by the nominal duty. While there are various ways of looking at economy-wide effects of protection, the theory of effective protection contributes substantially to the understanding of how the structure of nominal tariffs affects the production pattern of a country. It does this by specifying what effects tariffs have on the value added process of an industry rather than of the price of the protected industry's output. Grubel and Johnson, 'Effective Tariff Protection'.

48 Cf. Special Studies: Market Access, Table II.3.

49 WTO Agreement on Agriculture, see chapter 2. The Agreement contains a so-called built-in agenda, instructing members to start negotiations with a view to liberalize this sector further and to do so five years 
continued to prevail for agricultural products, following 'tariffication', which was a particular feature of the Uruguay Round negotiations on trade in agricultural products. The notion of tariffication refers to the provision in the Agreement that members were committed to convert all non-tariff barriers on agricultural trade into tariff equivalents followed by reductions of these tariffs. A WTO study shows the tariff schedules negotiated during the Uruguay Round before and after implementation of the reductions. It lists the base rate of duty in relation to which reductions in the first and subsequent years of the 1995-2000 implementation period are calculated, as well as the final bound rate of duty valid at the end of the six-year implementation period.50 Developing countries could offer ceiling bindings and where non-tariff measures had to be converted into tariffs, the base rate was the result of the tariffication exercise. This is illustrated in Table III. 1 of the WTO study. ${ }^{51}$ Bound duties were to be lowered by an average of $36 \%$ in six years in the case of developed countries with a minimum rate of reduction of $15 \%$ for each tariff line. This obligation was equivalent to $24 \%$ in 10 years in the case of developing countries. ${ }^{52}$

One particular difference in tariff reductions for industrial and agricultural products is that the reductions for agricultural products were on a simple average basis. Moreover, in nearly all instances, the new tariffs on agricultural products consisted of 'specific' duties, for which the ad valorem equivalents could not easily be calculated. ${ }^{53}$ The WTO study shows that the analysis of agriculture statistics is complicated by the prevalence of non-ad valorem tariffs. ${ }^{54}$ The study goes on to show that some members have bound all their agricultural tariffs in ad valorem terms, but others have bound many of their agricultural tariffs in other forms, including specific, mixed (ad valorem or specific), compound (ad valorem plus specific) or technical tariff rates (for example based on alcohol or sugar content), the economic impact of which is harder to assess.

Overall, the tariffication requirements resulted in high levels of initial tariffs which many countries had entered into their Schedules. This was both a consequence of high levels of protection in the base period, but also to the particular choice of prices used in establishing base period tariff equivalents. In a number of cases the tariffs which countries had included were high and amounted to several hundred per cent, which would normally prevent trade to occur at all. To the extent that this was the result of countries' deliberate policies, it was often referred to as 'dirty' tariffication.

after the implementation of the Agreement, i.e. in the year 2000. The Agriculture Agreement and the efforts undertaken to reduce tariffs on agriculture products will be analysed more closely further in this chapter.

50 Cf. Special Studies: Market Access, p. 46.

51 Ibid.

52 Cf. van den Bossche and Zdouc, p. 432-433.

53 In addition, the Uruguay Round negotiations imply the maintenance of existing market access opportunities and the establishment by product of minimum access tariff quotas equivalent to 3 to $5 \%$ of domestic consumption through a tariff quota at a low or minimal rate, without providing an obligation to import such quantities.

54 Special Studies: Market Access (WTO), p. 46. 


\subsubsection{Tariffs vs non-tariff measures in the Uruguay Round}

Strict disciplines in the field of non-tariff measures (NTMs) are essential to prevent the gains from liberalization through tariff reductions to be offset by alternative measures aimed at effectively protecting domestic producer. ${ }^{55}$ This motivation largely drove trade negotiators to address non-tariff measures in the Tokyo Round, followed by an intensification of these efforts in successive rounds. NTMs were particularly prevalent in the areas of agriculture and created market distortions. The main objective in the Uruguay Round was to ensure that NTMs could not be used as disguised forms of protection. ${ }^{56}$ The concerns related to NTMs continue to be highly relevant in today's discussions on market access and again are an important element in the DDA negotiations. The negotiations in the Uruguay Round included efforts to refine and strengthen rules covering standards, technical regulations and barriers to trade (TBT) sanitary and phyto-sanitary measures (SPS), as well as any other measures that can be considered NTMs.

Some trade policy instruments have a stronger resemblance to tariffs, including what is referred to as 'any form of duties and charges', than others and were thus more likely to nullify the tariff concessions. ${ }^{57}$ Van den Bossche and Zdouc argue that 'para-tariffs can significantly undermine the effect of the tariff binding and thus nullify the concession on a specific product'. ${ }^{58}$ Negotiators explicitly recognized this risk, and addressed it through the Understanding on the Interpretation of Article II:1(b) of GATT 1994, requiring that all 'other duties and charges' must be recorded in a country schedule of tariff concessions against the tariff to which they apply. Where a duty or charge is included in a country schedule, it will be bound at a maximum level. Any duty or charge omitted from a schedule may not be subsequently be added.

Quantitative restrictions and other non-tariff measures, but also price-related measures (such as variable import levies), tend to be much less transparent than tariffs. From an economist's perspective, tariffs are not only less distortive than NTMs, but also far more economically efficient as a policy instrument. As I argued before, tariffs yield revenues to the government, are measurable, transparent and price-based. The equivalent scarcity 'rents' (the difference between the domestic price of imports and world price) associated with the quantitative restrictions usually accrue either to domestic importers or to foreign exporters. Economically quantitative restrictions are more harmful than tariffs, as they stop trade from occurring altogether once the quota is filled. This explains why they are prohibited under the GATT and WTO provisions. This is in contrast with tariffs, which even when they are high do not prevent trade from occurring. Quantitative restrictions undermine the functioning of

55 Post Uruguay Round Tariff Regimes (OECD) refers to core non-tariff barriers as export price constraints, variable charges, anti-dumping and countervailing actions, non-automatic licensing, export restraints and other quantitative restrictions.

56 Marrakesh Agreement, Agreement on Agriculture, 1 January 1995, 1867 UNTS 410, Part III, Market Access. See also Smeets, 'Tariffs: Features and Remaining Issues'.

57 General Agreement on Tariffs and Trade, 15 April 1994, 33 ILM 1153 (1994), Article II(1)(b).

58 Van den Bossche and Zdouc, p. 465. 
markets and distort prices and competition, but also reduce flexibility in production and consumption decisions, and encourage rent-seeking behavior. Given their distortive and harmful effects on trade, the negotiators agreed to completely ban the use of the so-called 'grey area measures' including VERs or any similar measures affecting imports or exports such as OMAs and that is precisely what happened. Given the recognition that non-tariff measures are generally perceived as having been most pervasive in agriculture, the Agriculture Agreement resulted in the elimination of all quantitative restrictions and other non-tariff measures. It became a tariff only regime. Tariffs are now the principle trade policy instrument applicable to this sector, thus largely enhancing transparency and establishing clear and unambiguous international levels of obligations. ${ }^{59}$

Anti-dumping duties can act in a similar way to tariffs and tend to undermine tariff concessions. They directly intervene at the price level of the imported good by placing a tax on foreign products dumped on the domestic market, in the case of price undercutting under the Agreement on the Implementation of Article VI of the GATT 1994. ${ }^{60}$ Their purpose is to protect the domestic producer against unfair price discrimination. The notion of dumping is mostly linked with 'unfair' price setting, which means that the price is not the true reflection of production cost. The key objective in the Uruguay Round negotiations was to ensure stricter discipline in this area to prevent abuse of anti-dumping for protectionist purposes, which could also be a deterrent to free trade. The relevant provisions contained in the Agreement on the Implementation of Article VI of the GATT 1994 and the Agreement on Subsidies and Countervailing Measures in the Marrakesh Agreement specifically address these concerns. ${ }^{61}$

This is different from safeguard measures, which are the main instrument for providing temporary relief to domestic industries in case of unforeseen surges in imports. In other words, and as I explained in the previous chapter, safeguard measures are meant to address what could be referred to as normal or 'fair' trade conditions, when a company cannot cope with competition coming from abroad. Thus, while they are fully legitimate, if taken in accordance with the relevant provisions of the Agreement on Safeguards, they nevertheless risk undermining tariff concessions. ${ }^{62}$ This is explained as follows: relief measures can either be taken in the form of temporary increase in duties and even above the bound rates, or

59 These arguments will be developed further in the discussion of the Agriculture Agreement further below.

60 According to Article 2 of the Agreement on the Implementation of Article VI of the GATT 1994, 'for the purpose of this Agreement, a product is being considered as being dumped, i.e. introduced into the commerce of another country at less than its normal value, if the export price of the product exported from one country to another is less than the comparable price, in the ordinary course of trade, for the like product when destined for consumption in the exporting country'.

61 Ibid.

62 Agreement on Safeguards, Article 2, in 'The Results of the Uruguay Round of Multilateral Trade Negotiations (Legal Texts)' (GATT, Geneva 1994), 1867 UNTS 410: ‘A member may apply a safeguard measure to a product only if that Member has determined, pursuant to the provisions set out below, that such a product is being imported into its territory in such increased quantities, absolute or relative to domestic production, and under such conditions as to cause or threaten to cause serious injury to the domestic industry that produces like or directly competitive products'. 
through quantitative restrictions. The general rule does not indicate a preference. In the case of provisional measures, the Safeguard Agreement stipulates that they be taken in the form of tariff increases, which must be refunded to the exporters or importers in the event that final safeguard measures do not appear justified. ${ }^{63}$ The new rules on safeguard measures should address the so-called grey-area measures and GATT-illegal bilateral deals specifying import/export levels, mostly under surveillance of the exporting countries. The Safeguard Agreement is generally considered as one of the main accomplishments in the Uruguay Round. The Agreement provides for stricter disciplines with regard to the conditions under which safeguard action is permitted and has led to abolishing the grey area measures, including VERS and OMAs. It also provides that governments will abstain from encouraging private measures that restrain trade.

Reference should also be made to the many other non-tariff measures, including TBT as well as SPS measures that have gained considerable importance in international trade since the 1980s. As discussed in Chapter 2, the Uruguay Round developed specific rules in these areas which are contained in the TBT Agreement and in the SPS Agreement. The rules are designed to address any trade related issues in the two respective areas and aim at reducing the risk that the trade liberalization through tariff reductions is undermined by new barriers to trade. While the two Agreements mostly address technical regulations that fall under the responsibility of the public authorities, trade is increasingly affected by private standards which fall outside government control. This is certainly an issue for further consideration, but at the same time a considerable challenge as they largely fall outside the public domain and are much harder for the authorities to govern and regulate.

Finally, and this goes beyond the issue of NTMs, the Uruguay Round has provided more detail with regard to Balance of Payments Provisions, which now specify that with regard to the application of both Articles XII and XVIII:B

Members undertake: (a) to announce publicly, as soon as possible, time-schedules for the removal of restrictive import measures taken for balance-of-payments purposes; (b) to give preference to "price-based measures", which have the least disruptive effect on trade; and (c) to seek to avoid the imposition of new quotas for balance-of payments purposes, unless, because of a critical balance of payments situation, price-based measures cannot arrest a deterioration in the external payments position. ${ }^{64}$

This again strengthens the provisions with regard to the use of price-based measures.

\subsubsection{Conclusion}

The evidence presented thus suggests that tariffs on industrial products have largely been

63 GATT Uruguay Round, Final Act; Agreement on Safeguards, Article 6.

64 'Understanding on the Balance of Payments provisions of the General Agreement on Tariffs and Trade 1994', Marrakesh Agreement, p. 27. 
reduced and that these reductions and new commitments contributed in essential ways to underpinning the multilateral trading system. This is less so for agricultural products, for which tariffs continue to be high. Predictability in trade has been considerably enhanced through the increase in the overall level of bindings and new market opportunities provided by the lowering of duties. An analysis conducted in 1995 also showed that the objectives spelled out in the 1986 Declaration of Punta del Este with regard to tariff negotiations had largely been achieved and led to significant tariff reductions, as agreed by Ministers. Despite the overall low levels of tariff protection following the implementation of the cuts, there were still some main discrepancies, including in levels of binding, both across countries, sectors and within sectors, which were to be addressed in the future negotiations. Tariffs thus continue to remain highly relevant in trade. The attention given to the binding of tariff lines by all countries, to be followed by reductions, continues to be essential to liberalizing trade. It is again one of the principal objectives of the trade negotiations in the DDA, as the bindings bring transparency, security and predictability. Developed countries now focus more specifically on distortions caused by tariffs, including tariff peaks and escalation, and market access through the DDA. Before doing so, the liberalization undertaken in two specific sectors will be discussed, beginning with textiles and clothing (example 1) and followed by leather and leather products (example 2).

\subsection{Example 1: The Integration of Textiles and Clothing in the Multilateral Trading System}

The first example discusses how a sector largely governed by a quota regime was fully brought under the multilateral trade rules of the WTO's and is now governed by tariffs only. The discussion is based on a publication written shortly after the conclusion of the Uruguay Round on the question of how trade would be liberalized in the textiles and clothing sector and updated with more recent literature. ${ }^{65}$ This sector has long been known as having the highest levels of protection and is typical for the 'old' economy. The study first presents the mechanism for the integration of this sector into the multilateral trading system. Then follows an analysis based on the recent literature of how the ending of the protection in this sector has changed trade patterns, and looks at which countries are the main beneficiaries of the trade liberalization.

\subsubsection{Introduction}

It is recalled that from 1974 until the end of the Uruguay Round, trade in textiles and clothing goods was governed by the Multifibre Arrangement (MFA). The MFA essentially consisted of a framework for bilateral agreements and/or unilateral actions that established quotas that limited imports into countries whose domestic industries were facing serious damage from rapidly increasing imports. ${ }^{66}$ The restrictions were primarily taken on by

65 M. Smeets, 'Main Features of the Uruguay Round Agreement on Textiles and Clothing and Implications for the Trading System', 29 Journal of World Trade (1995), p. 97-109.

66 Trade in Textiles and Clothing has been governed by successive Multi-Fibre Arrangements (MFA) since 1974. The last (and fourth) one entered into force on 31 July 1986 for a period of five years. The provisions 
developed countries which had long maintained important economic activities in the textiles and clothing sectors, thus generating jobs and employment, revenues and income for an important number of households. These quotas were taken in deviation of the GATT's main principles, which essentially prohibit the use of quantitative restrictions and which have a strong preference for customs tariffs. They were also exceptions to the MFN principle because they specified how much the importing country was going to accept from individual exporting countries. As a result the calls to eliminate those quantitative restrictions were becoming increasingly stronger. The efforts to liberalize were met with opposition from those levels of society that had an interest protecting the industry, as well as business and economic activities and such, despite the economic cost to society. Economically though, this protection did not make sense, given the relatively higher cost of production in the developed countries as compared to developing countries, thus undermining specialization and the notion of comparative advantage to work.

Under the terms of the Agreement on Textiles and Clothing (ATC), the Agreement itself would cease to exist after 10 years. ${ }^{67}$ Its main feature was the inclusion of a mechanism to bring this whole sector under the umbrella of the multilateral trading system and it did. The Agreement was thus designed as a 'temporary; or rather transitional arrangement leading to the full integration of textiles and clothing into the trading system. This would bring to an end the 'temporary' protection of the textiles and clothing sectors by developed countries that had lasted 40 years - since the first restrictions were introduced in 1962 under the Long Term Agreement regarding International Trade in Cotton Textiles (LTA). ${ }^{68}$ Following the attainment of this objective, the Agreement ceased to exist at the end of 2004. Various studies and publications anticipated ${ }^{69}$ and others underscored ${ }^{70}$ the fact that trade in textiles and clothing would be considerably liberalized following the conclusion of the Uruguay Round through the Agreement, and that trade patterns would change as a result - and this is what happened in reality. The Agreement contributed to restoring the price mechanism as the principal guide in consumption and production decisions. Whalley argued that this

were extended temporarily pending the conclusion of the Uruguay Round and its entry into force. At the end of 1992, there were 42 signatories to the Protocol extending the MFA IV, with most OECD members being members of it; only Japan and Switzerland did not apply MFA restrictions. Sweden withdrew from the MFA and dismantled all its MFA restrictions on 31 July 1991.

67 According to art. 2, para 8(c) of the Agreement 'on the first day of the $121^{\text {st }}$ month that the WTO Agreement is in effect, the textiles and clothing sector shall stand integrated into the GATT 1994, all restrictions under this Agreement having been eliminated'. According to art. 9, following the full integration into the GATT 1994, the Agreement shall be terminated and cannot be extended.

68 H.K. Nordas, 'The Global Textile and Clothing Industry Post the Agreement on Textiles and Clothing', Discussion Paper No 5, WTO (2004).

69 C. Buelens, 'Trade Adjustments Following the Removal of Textiles and Clothing Quotas', CEPS Working Document No.222 (2005); D. Audet, 'Structural Adjustment in Textiles and Clothing in the Post-ATC Trading Environment', OECD Trade Policy Working Paper No.4, OECD (2004).

70 J. Whalley and D. Yao, 'Assessing the Effects of the MFA/ATC From US and World Trade Data After its Removal', National Bureau of Economic Research (NBER) Working Paper (No. 21299, 2015); A. K. Khandelwal, P. K. Schott and S-J.Wei, 'Trade Liberalization and Embedded Institutional Reform: Evidence from Chinese Exporters', 103 American Economic Review (2013), p. 2169-2195; WTO International Trade Statistics, as presented in the WTO's World Trade Reports (2006 and later years). 
allowed patterns of trade and investment to better reflect the comparative advantage of countries and contributed to achieving economic efficiency. ${ }^{71}$ How was the ATC designed to work and what was the result?

\subsubsection{Main elements of the Agreement on Textiles and Clothing}

The GATT Uruguay Round negotiations in the area of textiles and clothing aimed to secure the integration of this sector in the GATT on the basis of strengthened GATT rules and disciplines by bringing to an end the MFA. The ATC established clear and transparent new disciplines which governed trade in this sector until the completion of the integration process. During the transition period, there was basically co-existence of two sets of rules that governed trade in textiles and clothing: those for 'integrated' products (those that were already covered by the WTO rules) and those for products 'not yet integrated' (those that were under restriction and needed to be covered by the WTO rules). It was important that the system remained manageable and that both exporters and importers could see clearly what their legal rights and obligations were.

The mechanism to achieve the integration of textiles and clothing in the WTO rules were anchored in the ATC itself and basically followed a dual approach, namely integration of products into the GATT rules under a fixed timetable and the increased growth rates of quota levels for products that remain under restrictions. One important element in the provisions was that the ATC was not renewable (Article 9). This was one of a rare number of WTO Agreements that had a limited life span. This effectively ruled out an extension of the ATC and further protection in this sector beyond the year 2004. This is what happened and from 1 January 2005, textiles and clothing products were fully integrated into the WTO rules, with no quotas and only tariffs as a means of protecting markets.

\subsubsection{Membership of the Agreement on Textiles and Clothing}

Through the principle of the 'Single Undertaking', the provisions of the ATC were binding upon all members of the WTO. In addition to the MFA signatories (just over 40), the ATC was thus automatically applicable to former non-MFA signatories. While a priori there was no reason for countries that did not participate in the MFA (and thus did not apply restrictions in these sectors) to invoke the special conditions of the ATC, they could opt for the gradual integration approach contained in the ATC, provided they notified their actions under the integration program to the Textiles and Monitoring Body (TMB) before the end of the first year (that is, prior to 1 January 1996). Alternatively, they could decide to fully integrate their textiles and clothing regime into the multilateral trading system at once, which was the most preferable decision from a trade liberalization perspective. In doing so, these importing countries would thus be committed to treat textiles and clothing products like any other good under GATT/WTO rules. Few followed that approach, however.

71 Whalley and Yao, 'Assessing the Effects of the MFA/ATC'. 
Another consequence of the ATC being an integral part of the WTO provisions was that bilateral restrictions applied under the MFA by members of the WTO to non-members, but who were signatories to the MFA (such as China), would be discontinued. In other words, a distinction was made between the treatment of the WTO members and the non-members. Indeed, members were allowed to seek or continue to apply bilateral and other discriminatory restrictions with major exporters of textiles and clothing which were not party to the ATC in order to prevent a surge in imports which would disrupt markets. No rules applied to the non-members.

A main difference between the MFA and the ATC thus was that China, for example, a main textile and clothing exporter, which at that time was seeking WTO membership, was not covered by any multilaterally surveilled trade rules. China would thus benefit from WTO membership and claim the same rights as the other WTO members, meaning that it could have unrestricted access to the markets of all WTO members for its textiles and clothing products. It is recalled that China formally became a WTO member in 2002 and thus shortly before the end of the transition period of the ATC, and put itself on equal footing with other members under its terms. This created much fear amongst other developing exporting countries that they would lose their established market shares, which in a way were 'guaranteed' or at least secured through the quota system. The way this concern was addressed was through the Transitional Safeguards Agreement negotiated with China as part of its Accession package to the WTO and which continued for several years after the ending of the ATC. Whalley noted this also implied that the 'normal' trade patterns could only occur after the expiry of the transitional arrangement with China. ${ }^{72}$ As will be shown further, China's market shares expanded considerably after all restrictions were ended.

\subsubsection{Integration of textiles and clothing into GATT 1994}

The MFA was to be phased out in four stages over a ten year period. Once a product was integrated, it automatically became subject to the GATT rules and lost recourse to any of the transitional provisions of the ATC. In stage one (on 1 January 1995), at least 16\% of the total import volumes in 1990 (which was the reference year for import levels) had to be integrated (Article 2). At the beginning of the fourth year (stage two, 1 January 1995) and eighth year (stage three, 1 January 2002), a further 17 and 18\% (minimum) of the reference volume level had to be integrated. On the first day of the eleventh year (stage four, 1 January 2005), all remaining restrictions had be removed -- potentially a maximum of $49 \%$ of the reference import volumes. Members were free to integrate more products and at a faster pace. While the ATC specified four groups of products that had to be integrated, members remained free to choose, within those groups, the products to be integrated at each stage. It is noteworthy that it was the importing country who decided on the products to be integrated, rather than the exporting country.

72 Ibid., p. 2. 
A country could thus decide to integrate those products first, for which no restrictions prevailed (the main importing countries followed that line). Such a decision meant that there would not be any trade effect or economic impact, either for the importing or the exporting country. It would however lock these products into the multilateral trading system, subject them to regular trade rules and exclude the member from invoking any future exceptional circumstances under the more permissible provisions of the ATC. Similarly, a country could decide to first integrate products under restriction, but for which quota had not been filled. This again meant that there would not be an immediate impact, but such a measure excluded any future emergency protection under the terms of the agreement on the side of the importer. Separately, it is noteworthy that the ATC required the integration to take place on a 'volume' basis, which objectively is the most practicable, but does not necessarily correspond to the equivalent 'value' share. In fact, it was thus possible to integrate a high volume share, corresponding to a relatively low import value, thus meeting the obligations of the ATC, but deferring the economic impact.

The gradual integration foreseen under the terms of the ATC implied that after seven years of operation (namely, on the first day of the eighth year) and until the end of the transition period, only $51 \%$ of total textiles and clothing trade would be integrated into the GATT 1994. The remaining $49 \%$ would be integrated at once at the very end of the life span of the ATC. This was referred to as 'back-loading', with much of the integration deferred to a later stage. Policy makers felt strong pressure from the domestic industry to delay the integration of sensitive products to the end of the process, thus preventing foreign competition on domestic markets. The back-loading, while legitimate under the terms of the agreement created some imbalance, and implied that the adjustment process of textiles and clothing in the importing countries was effectively postponed until the very last moment.

Special mention should be made of those members of the MFA - Japan, Switzerland and Sweden -, that had already dismantled their MFA restrictions and therefore de facto did not apply any quotas. In other words, they were ahead in the process and in a similar position to those countries that did not maintain any restrictions in this sector. These countries had the option of integrating textiles and clothing into the GATT 1994 rules according to the procedures laid out above, which would also allow invoking safeguard measures under the terms of the ATC, if economic conditions necessitated. Alternatively, they could fully integrate the whole sector at stage one.

\subsubsection{Elimination of remaining restrictions}

With regard to other, non-MFA restrictions, whether or not consistent with the GATT 1994, members had to notify these to the TMB within 60 days following the entry into force of the ATC (Article 3). Non-MFA restrictions could take different forms, such as import licensing programs, quantitative restrictions, price surveillance system and bilateral agreements with non-MFA participants. All restrictions, except those justified under a GATT 1994 provision, had to be brought into conformity with the GATT 1994 within one year of the entry into force of the ATC (that is, prior to 1 January 1996) or phased out 
progressively according to a program that had to be submitted to the TMB not later than six months after the entry into force of the ATC (which was 1 July 1995). The program provided for the phasing out of all restrictions within a period not exceeding the duration of the ATC, namely 10 years, and which effectively meant by 31 December 2004.

With regard to the quantitative restrictions, the ATC specified for each stage growth rates of quota levels for products remaining under restrictions. During the first three years, the annual growth rate would be $16 \%$ over and above the quota level that prevailed in the period immediately preceding the entry into force of the ATC, and reflected in the bilateral agreements under the MFA (Article 2). During the second stage, the growth rate for respective restrictions in stage one had to be increased by at least $25 \%$. During the third stage, the growth rate for respective restrictions in stage two had to be increased by at least $27 \%$. The expected impact of these provisions on the volume of imports as calculated at that time is illustrated in Table 4.5. Three different scenarios were developed, with each based on growth rates of the quota under bilateral agreements of $1 \%, 3 \%$ and $6 \%$ respectively. A comparison between column (7) and (8) shows that the difference under the 'ATC scenario' and the 'MFA scenario' (based on a fixed $6 \%$ growth rate) would only be significant during the second half of the integration period. Differences between quota levels widened considerably in the last three years of the transition period, as the growth rates under the terms of the ATC increased. Provided these quotas were filled, the growth rates would have a real impact on trade, and affect the level of integration, both in absolute and in relative terms. At the same time, higher import levels were expected to create more competition in textiles and clothing in the importing countries and thus put additional pressures for carrying out the adjustment necessary to face this new competition.

Nordas questions whether or not the quota growth represented a significant liberalization. He points out that

the EU, Canada and the US argued that the quota growth was insufficient to render the quotas de facto non-binding by the end of the ten-year period for most of the restricted items, while a number of restricted members complained that quota increases had not significantly improved their market access. ${ }^{73}$

The ATC also included a quasi de minimis provision which required importing members to provide 'meaningful improvement' to access for exports subject to restrictions which represented $1.2 \%$ or less of the total volume of restrictions applied by an importing member. According to the ATC, this was to be achieved through advancement by one stage of the growth rates set out above, or through at least equivalent changes as could be mutually agreed with respect to a different mix of base levels, growth and flexibility provisions. In practice, this meant that concerned countries would see an increase of their quotas of $25 \%$ in stage one (compared with $16 \%$ for other countries), followed by a $27 \%$ increase in the

73 Nordas, 'The Global Textile and Clothing Industry', p. 14. 
subsequent two stages (see Table 4.5). Obviously, the differences with a constant growth rate under the MFA scenario were even more important.

TABLE 4.5: Integration of textiles and clothing into WTO rules

\begin{tabular}{|c|c|c|c|c|c|c|c|c|c|c|}
\hline \multicolumn{11}{|c|}{ (various scenarios) } \\
\hline Stage & Year & $\begin{array}{l}(1) \\
\text { Initial } \\
\text { growth } \\
\text { rate }\end{array}$ & $\begin{array}{l}(2) \\
\text { Growth } \\
\text { rate at } \\
1 \%(b)\end{array}$ & $\begin{array}{c}\text { (3) } \\
\text { Quota } \\
\text { increase } \\
\text { (b) }\end{array}$ & $\begin{array}{c}(4) \\
\text { Growth } \\
\text { rate at } \\
3 \%(c)\end{array}$ & $\begin{array}{c}(5) \\
\text { Quota } \\
\text { increase } \\
\text { (c) }\end{array}$ & $\begin{array}{c}(6) \\
\text { Growth } \\
\text { rate at } \\
6 \%(d)\end{array}$ & $\begin{array}{c}(7) \\
\text { Quota } \\
\text { increase } \\
\text { (d) }\end{array}$ & $\begin{array}{c}(8) \\
\text { MFA } \\
\text { scenario } \\
(\mathrm{e})\end{array}$ & $\begin{array}{c}(9) \\
\text { Degree of } \\
\text { Integration } \\
(\%)\end{array}$ \\
\hline I. & $\begin{array}{l}1995 \\
1996 \\
1997 \\
\end{array}$ & 16 & $\begin{array}{l}1.16 \\
1.16 \\
1.16 \\
\end{array}$ & $\begin{array}{l}101.16 \\
102.33 \\
103.52 \\
\end{array}$ & $\begin{array}{l}3.48 \\
3.48 \\
3.48 \\
\end{array}$ & $\begin{array}{l}103.48 \\
107.08 \\
110.81 \\
\end{array}$ & $\begin{array}{l}6.96 \\
6.96 \\
6.96 \\
\end{array}$ & $\begin{array}{l}107.00 \\
114.40 \\
122.40 \\
\end{array}$ & $\begin{array}{c}106.00 \\
112.4 \\
119.1 \\
\end{array}$ & 16 \\
\hline II. & $\begin{array}{l}1998 \\
1999 \\
2000 \\
2001 \\
\end{array}$ & 25 & $\begin{array}{l}1.45 \\
1.45 \\
1.45 \\
1.45 \\
\end{array}$ & $\begin{array}{l}105.02 \\
106.54 \\
108.08 \\
109.65 \\
\end{array}$ & $\begin{array}{l}4.35 \\
4.35 \\
4.35 \\
4.35 \\
\end{array}$ & $\begin{array}{l}115.63 \\
120.52 \\
125.76 \\
131.23 \\
\end{array}$ & $\begin{array}{l}8.70 \\
8.70 \\
8.70 \\
8.70 \\
\end{array}$ & $\begin{array}{l}133.00 \\
144.57 \\
157.15 \\
170.82 \\
\end{array}$ & $\begin{array}{l}126.3 \\
133.8 \\
141.8 \\
150.4 \\
\end{array}$ & 33 \\
\hline III. & $\begin{array}{l}2002 \\
2003 \\
2004 \\
2005 \\
\end{array}$ & 27 & $\begin{array}{l}1.84 \\
1.84 \\
1.84\end{array}$ & $\begin{array}{l}111.67 \\
113.72 \\
115.81\end{array}$ & $\begin{array}{l}5.52 \\
5.52 \\
5.52\end{array}$ & $\begin{array}{l}138.47 \\
146.11 \\
154.18\end{array}$ & $\begin{array}{l}11.05 \\
11.05 \\
11.05\end{array}$ & $\begin{array}{l}189.70 \\
210.66 \\
233.94\end{array}$ & $\begin{array}{l}159.4 \\
168.9 \\
179.1\end{array}$ & 100 \\
\hline & & & & & $(\mathrm{B})(2)$ & & & & & \\
\hline & & $(1)$ & $(2)$ & (3) & $(4)$ & $(5)$ & (6) & $(7)$ & $(8)$ & (9) \\
\hline I. & $\begin{array}{l}1995 \\
1996 \\
1997 \\
\end{array}$ & 25 & $\begin{array}{l}1.25 \\
1.25 \\
1.25 \\
\end{array}$ & $\begin{array}{l}101.25 \\
102.52 \\
103.80 \\
\end{array}$ & $\begin{array}{l}3.75 \\
3.75 \\
3.75 \\
\end{array}$ & $\begin{array}{l}103.75 \\
107.64 \\
111.67 \\
\end{array}$ & $\begin{array}{l}7.50 \\
7.50 \\
7.50 \\
\end{array}$ & $\begin{array}{l}107.50 \\
115.56 \\
124.23 \\
\end{array}$ & $\begin{array}{l}106.0 \\
112.4 \\
119.1 \\
\end{array}$ & 16 \\
\hline II. & $\begin{array}{l}1998 \\
1999 \\
2000 \\
2001 \\
\end{array}$ & 27 & $\begin{array}{l}1.59 \\
1.59 \\
1.59 \\
1.59 \\
\end{array}$ & $\begin{array}{l}105.45 \\
107.13 \\
108.83 \\
110.56 \\
\end{array}$ & $\begin{array}{l}4.69 \\
4.69 \\
4.69 \\
4.69 \\
\end{array}$ & $\begin{array}{l}116.91 \\
122.39 \\
128.13 \\
136.97 \\
\end{array}$ & $\begin{array}{l}9.53 \\
9.53 \\
9.53 \\
9.53 \\
\end{array}$ & $\begin{array}{l}136.07 \\
149.04 \\
163.24 \\
178.80 \\
\end{array}$ & $\begin{array}{l}126.3 \\
133.8 \\
141.8 \\
150.4 \\
\end{array}$ & 33 \\
\hline III. & $\begin{array}{l}2002 \\
2003 \\
2004 \\
2005\end{array}$ & 27 & $\begin{array}{l}2.02 \\
2.02 \\
2.02\end{array}$ & $\begin{array}{l}112.79 \\
115.07 \\
117.39\end{array}$ & $\begin{array}{l}5.96 \\
5.96 \\
5.96\end{array}$ & $\begin{array}{l}145.13 \\
153.78 \\
162.95\end{array}$ & $\begin{array}{l}12.10 \\
12.10 \\
12.10\end{array}$ & $\begin{array}{l}200.43 \\
224.68 \\
251.87\end{array}$ & $\begin{array}{l}159.4 \\
168.9 \\
179.1\end{array}$ & 100 \\
\hline
\end{tabular}

Source: own calculations; see also UNCTAD, 1994.

(1) A Increase in quotas foreseen under Article 2.13 and 2.14

(2) B Increase in quotas foreseen under Article 2.18

(a) Annual percentage of increase in quotas under terms of the Agreement on Textiles and Clothing

(b) Under scenario of $1 \%$ growth foreseen in bilateral agreement under MFA 
(c) Under scenario of 3\% growth foreseen in bilateral agreement under MFA

(d) Under scenario of $6 \%$ growth foreseen in bilateral agreement under MFA

(e) Volumes under quota assuming a fixed $\%$ growth rate

The treatment of MFA and non-MFA restrictions thus were quite different in terms of conditions attached to their phasing out were. MFA restrictions had to be phased out according to a timetable established in the ATC and leading to the full integration of this sector into the multilateral trading system, whereas members applying non-MFA restrictions were required to either eliminate such restrictions within one year or submit a program of integration to the TMB. The TMB could make recommendations to the member concerned in respect of such a program, although it did not have the authority to give binding directions. This implied that countries could delay the elimination of such restrictions until the final stages of the transition period, thus adding to the backload of the ATC.

\subsubsection{Safeguard provisions in the Agreement on Textiles and Clothing}

The ATC established a recourse to a transitional safeguard measure (Article 6) when it was demonstrated by a member that 'a particular product is being imported into its territory in such increased quantities as to cause serious damage, or actual threat thereof, to the domestic industry producing like and/or directly competitive products'. Transitional measures could be applied to products that were not integrated but could not be applied to the exports of any member whose exports of the particular product were already under restraint. $^{74}$ Logically, safeguard provisions under Article XIX of GATT 1994 could be invoked for other products, once integrated, as the new provisions of the multilateral trading system would apply.

The determination of serious damage included in the ATC, which was required before a transitional safeguard measure could be applied, was similar to the determination of market disruption used under the MFA arrangements to justify the application of MFA restrictions. The minimum level of support under the transitional safeguard was also set on the same reference basis as for the establishment of the quota level under the MFA. One distinct feature was that transitional safeguard measures could remain in place for up to three years without extension or until the product was integrated in the GATT 1994 - whichever came first. This was a welcome change from the MFA where restrictions had become quasipermanent features for more than three decades.

The transitional safeguard measures differed substantially from the safeguard provision under Article XIX of the GATT 1994 in several respects: under the GATT 1994 provision,

$74 \quad$ The Annex to the Agreement specified that safeguard measures could not be applied to developing country member's exports of handloom fabrics of the cottage industry, or handmade cottage industry products made of such handloom products, or traditional folklore handicraft textile and clothing products, historically traded textile products and products made of pure silk. 
safeguard measures could be taken for a longer period of time and up to eight years. They included specific provisions on compensation that should be provided to the affected party, who, under well-defined circumstances could be authorized to retaliate. Moreover, whereas the safeguard provisions under GATT 1994 were based on the principle of nondiscrimination, with selectivity being permitted under exceptional circumstances, the transitional safeguard provisions of the ATC explicitly foresaw selectivity, as measures were based on a 'member-by-member basis' (Article 6.4). Recourse to transitional safeguard measures was only permitted for products which had not been integrated. As it was likely that the most sensitive products that were subject to MFA restraints would continue to be protected, if their integration was scheduled towards the end of the life span of the ATC, by definition these were excluded from transitional safeguard measures. The intention was not to extend the application of the restrictions beyond the time frames included in the MFA. Moreover, when a safeguard measure remained in force for a period exceeding one year, the restrained level had to be increased annually by not less than $6 \%$. On the basis of a mutual understanding among members concerned, the restraint was fixed at a level not lower than the actual level of exports in the prescribed reference period. If no mutual understanding was reached, the member which proposed the safeguard could, within 30 days of consultations apply a restraint and at the same time refer the matter to the TMB for examination and recommendation.

Nordas explains that

the extensive use of the safeguard measures according to Article 6 in the ATC during the first stage of liberalization contributed to the perception of lack of will to liberalize. No less than 33 requests for consultations were registered from January 1995 to July 1997 (i.e. stage 1); 26 from the US and 7 from Brazil. A total 24 came in the first half of 1995 , hence immediately after the entry into force of the Agreement. ${ }^{75}$

Most of the measures were found to be unjustified when challenged by the TMB. ${ }^{76}$ During the second phase there were 29 requests for consultations regarding safeguard measures and no requests were made during the year 2000. One explanation according to Nordas was that the TMB's findings had clarified the criteria for using safeguards, which discouraged countries from launching unjustified cases. ${ }^{77}$

75 Nordas, 'The Global Textile and Clothing Industry', p. 15.

76 Cf. section below for a discussion on the role of the Textiles Monitoring Body.

77 Nordas, 'The Global Textile and Clothing Industry', p. 15; Cf. also Special Studies: Market Access (WTO); 'Comprehensive Report of the Textiles Monitoring Body to the Council of Trade in Goods on the Implementation of the Agreement on Textiles and Clothing during the Second Stage of the Integration Process', G/L/459, 31 July 2001. 


\subsubsection{Circumvention of the disciplines of the Agreement on Textiles and Clothing}

The possibility that members would circumvent the restrictions was a major concern for parties to the MFA, as it would effectively undermine the provisions. The rules of the ATC (Article 5) specified more clearly the process of consultation, the nature of collaboration, the possible remedies that an importing member could apply and recourse that could be made to the TMB. Circumvention includes such practices as transshipment, rerouting and false declaration concerning country or place of origin which would have frustrated the implementation of the ATC. Procedural provisions (Article 5.2) aimed at assisting members in reaching mutually satisfactory solutions in dealing with such circumvention. Where circumvention was alleged, members were obliged to cooperate fully to establish the relevant facts including the exchange of documents and facilitating plant visits and contacts. Members agreed to take action to the extent necessary to address the problem including legal actions against circumvention practices within their territory (Article 4). Any actions, including the denial of entry of goods, could be taken after consultations between members concerned and had to be notified to the TMB with full justification. If a mutually satisfactory solution was not reached, any member concerned could refer the matter to the TMB for prompt review and recommendations.

The determination of circumvention was by no means easy, as it is related to the question of what constitutes a domestic product. This includes first and foremost the determination of the origin of the product and whether substantial transformation had occurred. Rules of origin provisions can vary from one product to another and also between countries. Such issues were explicitly addressed in the discussions that were underway at that time for completing the work program under the terms of the Agreement on Rules of Origin. The WTO's program of work provided for negotiations with respect to the objective of harmonizing rules of origin was considered of crucial importance for the implementation of this Agreement. Multilateral disciplines should further facilitate the resolution of concern

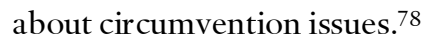

\subsubsection{The Textiles Monitoring Body}

The Council for Trade in Goods established the TMB to supervise the implementation of the ATC (Article 8). The main functions of the TMB inter alia consisted of reviewing any particular matter which any member considered to be detrimental to its interest and to make observations or recommendations. At the end of each stage of the integration process, the TMB prepared a comprehensive report on the implementation of the ATC to be transmitted to the Council. The responsibilities of the TMB were thus broadly similar to those previously empowered in the Textiles Surveillance Body (TSB) under the MFA.

\footnotetext{
78 The reality shows that the discussions on rules of origin were never concluded and thus were of little help in
} the context of the ATC and the anti-circumvention rules. 
If members were in disagreement, the TMB could make recommendations. Members endeavored to accept in full the recommendations of the TMB. In instances where a member was unable to conform to the recommendations made by it, it would have to provide reasons for not doing so. Only after the TMB issued any further recommendations on this matter could a member bring the issue before the Dispute Settlement Body.

\subsubsection{Trade and policy implications of the Agreement on Textiles and Clothing}

There is a common view in the literature that the provisions under the ATC fundamentally altered the trade regime that had governed the textiles and clothing sector for several decades and which was characterized by managed trade. On 1 January 2005, all quotas in the sector came to an end, and importing countries were no longer able to discriminate between exporters. This is a remarkable achievement, given the strong opposition against liberalization that was characteristic for this sector for many decades. Market forces were again allowed to work, based on the principle of comparative advantage and the efficient allocation of economic production factors. Trade in textiles and clothing grew rapidly from then and patterns of trade changed. The WTO estimates that as a result, imports of textiles and clothing increased from $\$ 319.4$ billion in 1995 to $\$ 494.2$ billion in 2005 and to $\$ 804$ billion in $2013 .{ }^{79}$ The progressive reduction of tariff protection also contributed to the growth of the textile and clothing sector. Whalley observes that 'the trade of clothing is larger and increase was quicker than textiles trade and trade in textiles and clothing outpaced the average growth rates for manufactured goods' ${ }^{80}$

The economic impacts associated with the MFA have been extensively reviewed over many years and there is broad consensus on the types of effects but a range of opinions prevails on the magnitude of these effects. Consumers undoubtedly were the main beneficiary of the ATC, as a result of reduced prices and a wider economic choice. At the same time, and as argued previously, there was much uncertainty on the new directions of trade and investment flows that would occur following the ending of the MFA and particularly through the relocation of production facilities. The sector had been characterized by major distortions, giving the wrong signals to the private sector for their trade and investment decisions. It was hard to anticipate the time needed for the benefits to materialize and predict who would benefit the most. So what were some of the main implications of the ending of restrictions?

\subsubsection{Implications for prices, trade and investment}

Economically, MFA restrictions and other non-tariff measures on both textiles and clothing aimed at limiting supplies into the import market, thus driving up prices. Whalley argues that

\footnotetext{
79 WTO at Twenty, p. 38.

80 Cf. Whalley and Yao, 'Assessing the Effects of the MFA/ATC', p. 9.
} 
with the trade volume reduced, restricted products would have a higher price in import markets, for two reasons: One is the exporters who can get the quota will send higher priced products to export to make full use of the scarce quota. The other is the limited supply in the importing country which will lead to a higher market price. ${ }^{81}$

Thus, while the benefits of these higher prices were reaped by the foreign producer, the costs were directly passed on to the consumer. The elimination of the quota system ipso facto implied lower prices. In view of the gradual integration, the price effects were likely to be spread out. In order to calculate the cost of protections, the restrictiveness of MFA quotas on world trade in textiles and clothing was provided by estimates of MFA 'quota price wedges', which was felt to give an indication of the tariff-equivalent of the bilateral quotas. These were generally based on the prices of licenses by product and destination, in the market of certain exporting countries. Calculations were made in various studies which showed that the tariff-inclusive prices of restricted products imported from various sources into the US or the EU had increased as much as $15-27 \%$.

The United States International Trade Commission estimated the average quota price wedge on clothing products entering into the US from all sources at $16.8 \%{ }^{82}$ In their earlier work, Trela and Whalley estimated quota premiums for MFA exporting countries that ranged between $78 \%$ and $300 \% .83$ These high margins are explained by the fact that the exporter could basically mark up the price, given the quota restrictions which implied quota rent seeking behavior by the exporters. In addition to price effects, the MFA also distorted the pattern of trade by providing the wrong economic incentives for production and investment decisions. Rather than basing these decisions on efficiency grounds the producer was guided by profitability associated with the quota and, for example upgraded the quality of its products. This tended to cause new inefficiencies in the economy through the misallocation of production factors. In his most recent study on the sector, and consistent with what was said earlier and what is to be expected, Whalley found that the average price of clothing and textiles was lower after the quota system expired. ${ }^{84}$

\subsubsection{Tariffs as a main trade policy instrument in textiles and clothing}

Through the implementation of the ATC, the exceptional treatment of textiles and clothing products came to a halt and all industrial products are now treated equally. Tariffs

\footnotetext{
${ }^{81}$ Ibid., p. 6 .

82 US International Trade Commission, 'The Economic Effects of Significant U.S. Import Restraints Phase I: Manufacturing', Publication 2222 (1993). See also C. Hamilton, 'An Assessment of Voluntary Restraints on Hong Kong's Exports to Europe and the United States', 53 Economica, (1986), p. 339-350; J. Whalley, 'The Multifibre Arrangement and China's Growth Prospects', in K. Anderson (ed.), New Silk Roads (Cambridge University Press,1992).

83 I. Trela, and J. Whalley, 'Unravelling the Threads of the MFA', in C. Hamilton, (ed.) Textiles Trade and Developing Countries: Eliminating the Multi-Fibre Arrangement in the 1990 (World Bank, 1990).

84 Whalley and Yao, 'Assessing the Effects of the MFA/ATC', p. 4.
} 
rather than quotas remain the principal trade policy instrument through which protection to the domestic textiles and clothing industry can be granted. Under the MFA quotas rather than tariffs were generally the restrictive factors although it has often been questioned to what extent the MFA effectively restrained trade in textiles and clothing. ${ }^{85}$ Then there is the question of the quota utilization. Not only do the data not present conclusive evidence as to the degree of restrictiveness of MFA quotas against developing countries, but in addition quotas could be circumvented. Some of the main economic ways through which circumvention of quotas could occur (and which are quite distinct from those discussed earlier), was through quality upgrading, product diversification, or geographical diversification in the form of quota hopping through foreign direct investment in lowerwage, less quota restricted countries. This point is again underscored by Nordas. ${ }^{86}$

While ad valorem tariffs are relatively transparent they continued to remain particularly high for textiles and clothing after the conclusion of the Uruguay Round. At present and according to the WTO, they are on average just over $12 \%$, which compares to some three times the average ad valorem duties for industrial products. ${ }^{87}$ The liberalization and reduction of tariffs in this sector is also far below the average. The tariff reductions by $22 \%$ in developed countries fell short of the average tariff cuts of $38 \%$ for all industrial products, which brought the average tariff levels for industrial products in developed countries to $3.8 \%$ ad valorem. More than half of all tariffs applied in this sector remain above $10 \%$. More than one-quarter of all textiles and clothing products are charged with a duty in the range of 15.1$35 \%$. Only $4 \%$ of textiles and clothing trade became duty free.

Several explanations can be provided for the relatively high tariffs that continue to prevail in this sector. Tariffs reflect the degree of protection governments want to grant to the domestic industry. ${ }^{88}$ This is typically the case for textiles and clothing, a sensitive sector in many countries. Moreover, as tariffs were not the main instrument of protection for countries applying MFA or non-MFA restrictions, the focus of the negotiations was more on the management of bilateral quantitative restrictions through the successive renewals of the MFA, rather than on tariff reductions. Members have thus been less willing to provide substantial tariff concessions.

\subsubsection{New trading opportunities}

A key effect of the MFA has been to restrain exports of textiles and clothing by developing countries. Most studies have found the decline in export opportunities from the MFA to be substantial for developing countries. In 1986, UNCTAD estimated that complete non-discriminatory liberalization (involving tariffs and MFA quotas) could increase developing country exports of clothing by $135 \%$ and textiles by $78 \% .{ }^{89}$ Kirmani, Molajani

85 J. Whalley, 'The Agreement on Textiles and Clothing', in OECD, The New World Trading System (Paris, 1994).

86 Nordas, 'The Global Textile and Clothing Industry'.

87 Francois and Martin, 'Formula Approaches', p. 6.

88 M. Smeets, 'Tariff Issues in the Uruguay Round'.

89 'Protectionism and Structural Adjustment', UNCTAD (1986). 
and Mayer estimated that 'developing country exports to major OECD countries could increase by $82 \%$ for textiles and $93 \%$ for clothing if both restrictions were removed'. ${ }^{0}$ There was no unanimous view as to what the real implications of the MFA on developing countries were and ipso facto the real effects of liberalization. A main problem was to capture all the possible effects of the MFA in the studies and to determine 'normal' patterns of trade and investment, based on comparative advantage, in view of the distortions that were characteristic of this sector.

Whalley calculated that the top 10 exporters in textiles and clothing have changed more dramatically since 2001 than the top 10 importers. ${ }^{91}$ In both sectors China remains the largest exporter in the world, and its share increased to nearly half of the top ten exporters' total value. As a share of world exports, China had $11.1 \%$ and $18.4 \%$ in textiles and clothing respectively in 2001, and this has increased to $35.9 \%$ and $40.3 \%$ respectively in 2013 . Despite the China containment agreements before 2013, China has acquired an advantage in the world exports of textiles and clothing and the advantage in clothing is more obvious. ${ }^{92}$ Looking at the top 5 exporters to the US, he observes a very strong shift between 2001 and 2013 in favor of China and India for exports ${ }^{93}$ of textiles, with China increasing its market share from $13 \%$ to $37 \%$ and India from $7 \%$ to $13 \%$. Again China is the main winner in the clothing sector, as it has seen an increase of its share from $13 \%$ to $39 \%$. Vietnam is another main winner with a share of $10 \%$ in 2013 and because it was not previously in the top 5 . India increased its share from $4 \%$ to $6 \%$. Interesting enough the shares of Mexico and Canada of exports to the US declined.

In a similar vein, in 2005 Buelens analyzed the possible effects of the elimination of the restrictions into the EU, another main export destination for textiles and clothing. $\mathrm{He}$ observes that

countries that were previously restricted will benefit under the post-quota situation. Vertically-integrated production chains, a good infra-structure, a sound, domestic regulatory framework and proximity to the final market will magnify their gains. Conversely, some smaller, less-developed countries that have profited from the shelter offered by the MFA and the quota-induced trade diversion will emerge as losers. Adverse effects on the industry are also likely to be considerable in the EU and other industrialized countries. Particularly in the clothing industry, he observes that it is clear that the pressures for adjustment will be strongest in those segments and countries that have specialized in low

90 N. Kirmani, P. Molajani, and T. Mayer, 'Effects of Increased Market Access on Exports of Developing Countries', IMF Staff Paper (1984).

91 Whalley and Yao, 'Assessing the Effects of the MFA/ATC', p. 22.

92 As part of China's accession conditions to the WTO, a transition safeguards arrangement on textiles and clothing was included for 10 years. This limited its market access for textiles and clothing for the duration of the transition period.

93 Whalley and Yao, 'Assessing the Effects of the MFA/ATC', p. 17. 
value-added production. EU consumers on the other hand will benefit from access to a wider variety of products, available to them at lower prices. ${ }^{94}$

This confirms the previous observation that while the developing countries experienced a cap on their exports through the MFA, many benefitted from the system through the predictable environment which it created as well as through the quotas rents. Restrictions through global quotas under safeguard measures (Article XIX of the GATT), or through voluntary export restraint arrangements, would probably have posed more binding constraints for them than the restrictions established under the MFA. They obtained guaranteed market shares of developed country's markets, something they would not have had under a tariff-based protection regime. In particular smaller exporters would have, in the absence of quota allocation, faced more competition in this segment of the market. Also, under the MFA, developing countries administered the export licences and captured the economic rent associated to them. Altogether, the MFA protection created strong vested interests in developed countries but also in developing countries with the largest quotas and developing countries benefitting from preferential market access arrangements, while shifting the cost of protection onto textiles and clothing consumers in developed countries. These inefficiencies disappeared at the end of the transition period.

Nordas, along the lines of Buelens, argues that

any analysis should take into account the developments in the organization of the textiles and clothing sector, where vertical specialization is an important feature. Vertical specialization implies that the inputs embodied in the final product cross borders several times and such trade is very sensitive to the tariff level. Hence the outcome of the phasing out of the quotas will depend much more on the prevailing tariff rates and the preference margins of the countries receiving such preferences than is captured by the conventional estimates. In addition, time to market is important and increasingly so, particularly in the fashion clothing sector. Therefore, countries close to the major markets are likely to be less affected by competition from India and China than has been anticipated in previous studies. ${ }^{95}$

As he observes, Mexico, Caribbean, Eastern Europe and North Africa are therefore likely to remain important exporters to the US and EU respectively. This is by and large confirmed in Whalley's findings, as referred to earlier. He also notes that the losers include those distant countries that have benefitted from tariff and quota-free access to the US and the EU markets.

94 Cf. Buelens, 'Trade Adjustments'.

95 Nordas, 'The Global Textile and Clothing Industry', p. 34. 


\subsubsection{Conclusions}

The decision to dismantle the MFA contributed to encouraging trade liberalization and to strengthening the integrity of the system by accepting that textiles and clothing would be treated like any other manufactured good. The integration of this sector into the multilateral trading system through the elimination of MFA and non-MFA restrictions thus was one of the major achievements of the Uruguay Round negotiations. It effectively brought to an end the GATT-legitimized discriminatory quantitative restrictions, which lasted for over four decades and caused inefficiencies in the economy.

In terms of market access provided, tariffs in textiles have gradually come down as a result of the negotiations, even if tariff protection in textiles and clothing for developing and least developed countries still continue to be considerably higher than for other industries, with $7.9 \%$ and $4.9 \%$ for respectively clothing and textiles duties imported into developed countries, and with $6.7 \%$ and $3.2 \%$ for clothing and textiles imports from least developed countries into developed countries. This compares with initial rates in the year 2000 of $10.8 \%$ and $6.6 \%$ for clothing and textiles imports from developing countries and $7.8 \%$ and $4.1 \%$ from least developed countries into developed countries. This shows that new market access opportunities were created through the reductions performed, bearing in mind that these are averages and a more detailed look is needed to analyse more specifically the levels of tariff protection within the sector and for specific product categories. It also shows that this sector requires further specific attention in terms of tariff reductions in the future as it features many tariff peaks, and this is addressed in the next section.

Nevertheless, it continues to be a sector with relatively high tariffs compared to the average tariffs for goods of less than $4 \%$ and tariff peaks in sub-sectors. Tariff escalation also continues to be pervasive in this sector. In short, the textiles and clothing sector can now be considered as fully integrated into the trading system, and specific and exceptional conditions are no longer applicable. Clearly, a milestone was achieved in terms of liberalization, even though it will require further attention in the negotiations on tariffs. As will be seen, the discussions on the way the tariff negotiations should be conducted aim specifically to cut more drastically high tariffs and reduce tariff peaks, thus further reducing the levels of protection in this sector.

\subsection{Example 2: Tariffs on Leather and Leather Products}

\subsubsection{Introduction}

The second example focuses on tariffs and more specifically on tariff escalation for leather and leather products, a sector which is particularly important for developing economies as it generates employment and revenues to a large number of households. Given the structures of production and levels of protection in developed markets, the economic activities in developing countries are mainly limited to the basic production processes. It has the potential to allow these countries to add better value in the production process and better 
linking to the GVCs, but this is hardly the case. Following a discussion of the evolution of patterns of trade in this sector, an illustration will be provided of how tariff escalation works as a disincentive to adding value in the production chain, depriving some developing countries, mainly in Africa, of the opportunity to enhance their revenues and climb up the production ladder by manufacturing goods that are of higher value. Others, including in Asia and the Middle East nevertheless managed to develop a competitive position in the higher end market. It then explains how regional value chains could be developed on the African continent as a way to upgrade production and generate added value. This section draws on the main findings contained in a WTO publication written by the present author and Fournier, with more recent data from the FAO. ${ }^{96}$ This is then followed by more recent analysis on how the value of production could be upgraded in Sub-Saharan Africa.

\subsubsection{Main patterns of trade in leather and leather products}

Leather and leather products can broadly speaking be divided into three categories according to the degree of processing: raw leather (the least-processed group); prepared leather (essentially, intermediate processing); and finished leather products (the highest level of processing). ${ }^{97}$ Raw leather (hides and skins) falls into the category of agricultural products and is thus covered by the rules of the Agriculture Agreement. All other leather products are defined as industrial goods (manufactures).

Trade in all leather and leather products has grown rapidly since the 1990s when this study was undertaken - that is, from $\$ 13.3$ billion in 1990 to (according to the FAO) an average value of $\$ 68$ billion in annual trade in the period 2009-2011.98 The world also witnessed a rapid change in the patterns of trade.

According to the FAO, the share of exports of products from Asia and the Middle East in world trade saw a rapid increase, reaching $37 \%$. Most of this growth was generated by one country, the People's Republic of China, which had developed into a strong exporter of leather and leather products to North America and Europe, as well as supplying neighbours in the region. The bulk of this trade occurs at the high end of the market, i.e. for finished leather, Asia and the Middle East have a share of nearly $44 \%$. The same regions also have a share of nearly $30 \%$ in semi processed leather and another $5 \%$ in raw hides and skins. It is also noted that the region of Asia and the Middle East was the single largest importer of raw leather as an input for the next stage of processing, in particular the production of finished leather. Asia and the Middle East obtained more than $47 \%$ of their imports from North America, and over 20\% from Europe. This shows that North America and Europe were

96 M. Smeets and C. Fournier, 'Trade and Tariffs in Leather and Leather Products', Special Studies, WTO (1998); 'World Statistical Compendium for Raw Hides and Skins, Leather and Leather Footwear 1993-2012', Trade and markets Division Food and Agriculture Organization of the United Nations, 2013

97 According to the WTO HS 1996 Nomenclature, they are covered in Chapters 4 and 6.

98 'World Statistical Compendium for Raw Hides and Skins, Leather and Leather Footwear 1993-2012', Trade and markets Division Food and Agriculture Organization of the United Nations, 2013, Table X, p. xxiii, which provides data for the period 1993-1995 and 2009-2011. 
initially suppliers of raw material as well as manufacturers of more processed leather products.

These developments suggest that Asia and the Middle East were able to both exploit their comparative advantage at the higher end of the market, potentially its most lucrative segment, and to also maintain a dominant position in that segment. It also suggests that the Asian countries were not affected by the tariff structures in this sector, which are characterized by tariff escalation, and which will be discussed later. The Asian countries were able to benefit from low duties on raw materials and were not hindered by tariff escalation in the market of supply, namely in the developed countries. This can perhaps best be explained by the availability of skilled labour and the introduction of new production techniques, giving Asian countries a competitive edge.

African countries benefitted little from the rapid growth in trade and continued to mostly rely on exports of the lower end products, including hides and skins. Their share in each of the three stages of processing ranges from less than $1 \%$ for raw hides and skins, to $2.5 \%$ for semi processed leather and $1.2 \%$ for finished leather. Tariff escalation is one of the factors that could explain this reality. ${ }^{99}$ The higher the added value, the higher the tariffs applied by the importing countries. This has deprived many of opportunities to increase revenues, which are mostly generated at the higher end of the market and which was also the fastest growing, as it is fashion related, with new designs influencing consumer behaviour. This required some further reflection on economic policies with a view to upscaling the production to the higher end segment of the market. The situation in Africa is perhaps even more significant considering the relative importance of leather exports for Africa as a share of African exports of all products. While leather exports had doubled in absolute numbers, its relative share of all African exports also declined. In other words, the growth in leather exports had not kept up with the growth in exports of other goods originating from Africa. This confirms the decline in Africa's comparative advantage in this sector compared to other regions, especially Asia and the Middle East.

Exports of leather and leather products from North America to the world which had long dominated the sector declined rapidly: the share of exports halved from $16.1 \%$ to $8.1 \%$ between 1990 and 1996, despite a rapid growth in the absolute volume of trade in leather products. According to the FAO data, North America exports predominantly raw hides and skins, with a $37 \%$ market share, and yet does little processing, with only $1.2 \%$ of the value in world trade for finished leather and $2 \%$ in semi-processed leather. Additionally, in less than a decade it had turned from being a net exporter of leather products to Asia and the Middle East into a net importer from that same region. In other words, there was relatively little processing taking place in North America, with exports largely being concentrated in raw materials.

99 See the next section on tariffs in leather and leather products. 
This stands in stark contrast with Europe which concentrated more in exporting the high end, higher value added goods. Europe dominates the market for the finished products with a $51 \%$ market share in value, a $41 \%$ market share in raw materials and $40 \%$ share in semifinished leather. The average annual revenue from the finished leather is 10 times higher compared to the revenue obtained from the raw hides and skins. What this shows is that the higher the stage of processing, the larger the value of Europe's exports to the world.

World trade in finished leather products was nearly nine times larger than trade in raw leather. Over two-thirds of the value of world leather trade was obtained in finished products. At the same time, the changing patterns in trade confirm that the production of higher-end finished leather products was concentrated in certain regions and mainly in Europe and Asia. The reasons for the changes, as for any shifts in economic activity, are determined by various factors that influence comparative advantage:

- relative costs of production at various stages of production differing from country to country (shifting comparative advantage), affecting competitiveness;

- progress in the technological developments leading to a further splitting up of the production process, which implied more specialization with specific types of production taking place in different geographical locations. Improvements and reduction of costs in transportation have supported this process, allowing materials and intermediate and final products to be shipped cheaply, easily and efficiently among production locations and markets;

- some countries have been more successful than others in attracting foreign direct investment into leather and leather product manufacturing. Countries that are more likely to attract foreign investment tend to have better infrastructure, fewer administrative barriers, and more technology or skilled labour and craftsmanship available.

A closer examination of Africa's position for products at various levels of processing showed that with an increase in the level of processing, Africa's market share decreased.

Looking at the exports of leather from Africa into some main markets, it is noted that patterns of specialization vary within Africa, particularly between North Africa and SubSaharan Africa. The variations also depend on product categories and the stage of processing. For exports to the European Union, the Southern African Customs Union (SACU) and Ethiopia together account for half of all raw leather (hides and skins) exports, followed by Libya, Nigeria, Mali and some other countries with substantially smaller market shares. Nigeria specialized in the manufacturing of prepared leather, thus generating higher value. The category of finished leather products is dominated by two main producers, Morocco and Tunisia, who together accounted for some $80 \%$ of all exports to the European Union, followed by Mauritius, SACU and Egypt, all with substantially smaller amounts. 
Morocco and Tunisia seemed to have developed a particularly strong comparative advantage in these finished products.

Similar findings for Africa are observed in a more recent study undertaken by the Commonwealth Secretariat with regard to developments in this sector. ${ }^{100}$ As the study shows, the leather industry is a traditional industry in Sub-Saharan Africa, but it has never been a significant foreign-exchange earner for the region. Its share in Sub-Saharan Africa's total exports is less than $1 \%$. However, this industry is critical to the region, both in terms of providing largescale employment to low-skilled labour and in terms of raising the region's share in global exports and imports in leather and leather products, which increased from $0.4 \%$ in the 1980 s to $1.5 \%$ in the 2000 s.

The Commonwealth study also examines potential Regional Value Chains (RVCs) between the three regional blocs, COMESA (Common Market for Eastern and Southern Africa), ECOWAS (Economic Community of West African States) and SACU. It observes that RVCs in Africa can provide an opportunity to link up into GVCs and increase their bargaining power with the leading firms/global markets. However, one of the most important challenges facing Sub-Saharan Africa is triggering structural transformation in the economies of the region and raising domestic value addition in their exports to generate higher employment. Nonetheless, as the industry is labour intensive, Sub-Saharan Africa has comparative and competitiveness advantages as well as raw materials. The study confirms the availability of a large base of natural resources available within the region and tremendous opportunities to form RVCs and add greater values to the exports of the region. It also suggests regional integration and pooling of resources to form RVCs as an important step to trigger transformation and the competitiveness of producing and exporting counties.

\subsubsection{Tariffs and tariffescalation in leather and leather products}

The sector of leather and leather products is characterized by high duties, tariff peaks and tariff escalation. ${ }^{101}$ Leather and leather products continue to face high import duties, both in terms of bindings and applied duties and the rates are progressively higher with each stage of processing. The data confirm the theory: the escalation of tariffs from low rates for raw materials to high rates for highly processed products protects domestic producers who import raw materials and semi-finished products. In particular it penalizes those countries producing the raw materials that want to add value by further processing the products and

100 Commonwealth Trade Policy Discussion Papers, 'Trade-Led Regional Value Chains in Sub-Saharan Africa (SSA): Case Study on the Leather Sector' (2015). The study discusses the shift of industry development from developed world to developing and least developed countries (increasing labour cost and stringent laws relating to environment are factors of the shift). It confirms the increasing regional and global demand and supply of the leather inputs and outputs thus underscoring the potential Sub-Saharan Africa has in the industry.

101 In addition to the data provided in the study on leather and leather products (Smeets and Fournier), detailed tariff information is provided by M. Bacchetta and B. Bora, 'Industrial Tariff Liberalization and the Doha Development Agenda', WTO (2003), p. 2 and Tables 2, 3, 4, 12 and 13. 
then exporting them. ${ }^{102}$ This holds particularly true for leather and leather products which face tariffs above-average $(7.3 \%$ ) ad valorem (see Table 4.3 ). Tariff escalation creates distortions in international trade, acts as a deterrent to product diversification, and as a disincentive to invest in higher stages of processing in potential exporting countries. It also creates distortions in the importing country because the protection undermines the efficient functioning of the market, where the allocation of scarce economic resources should be based on comparative advantage. Different levels of protection at various stages of processing give the wrong signals to the market.

In order to better understand the effect of tariffs and tariff escalation on production and trade patterns, tariff rates are considered for three stages of production: the importation of raw leather (base products), prepared leather (intermediate products) and finished leather products (finished goods). Most importing countries do not charge duties on raw leather imports in order to encourage the purchase of hides, skins and the like at lower prices for use as inputs for processing industries. For intermediate and finished products, the situation is different. These are value-adding stages of production and the domestic industries in the importing (mostly developed) countries are generally well protected.

The analysis compares the MFN tariffs of the importing countries before and after the Uruguay Round and provides insights into variations of tariffs between products at the level of prepared and finished products, given that the base products (hides and skins) are mostly given a zero duty. The specific data are provided in Tables 4.6 and are discussed further below.

\subsubsection{Prepared leather}

Prepared leather (the intermediate stage of production) generally faces moderate levels of tariff protection. The tariff reductions performed before and after the Uruguay Round are not too far from the averages and all together few tariff peaks can be observed. By way of illustration, in the European Union, over half of all products were charged the average duty rate, and $30 \%$ of all products faced duties of between 5.1 and $10 \%$ after the reductions performed in the Uruguay Round. There were no tariff peaks. In Canada, there were also no tariff peaks, and $80 \%$ of all products faced a duty of between 5.1 and $10 \%$ after the Uruguay Round. Before that two thirds of products were charged tariffs exceeding $10 \%$. Canada had therefore sharply cut its tariff rates as a result of the negotiations. In the United States the duty-free treatment of prepared leather had been increased with nearly $20 \%$ of all products benefitting from zero duties. The other $80 \%$ of products faced a duty between 0.1 and $5 \%$. In Japan, tariff protection in this segment of the market remained significant with tariff peaks remaining for over a third of products facing duties between 15.1 and 35\%. The Uruguay Round contributed to the elimination of Japanese duties exceeding $35 \%$.

New Zealand reduced the number of products that face tariff peaks, leaving $31 \%$ of products charged at 15.1 to $35 \%$. Switzerland continued to apply low duties with all but one

102 Cf earlier in this chapter section 1.4 (a), which provides a definition of tariff escalation. 
product facing duties between 0.1 and $5 \%$. Norway eliminated all duties for prepared leather, thus fully liberalizing its market. For Argentina, the Uruguay Round implied no change in the level of duties, but the main feature of Argentina's tariff structure was that it had fully bound all duties, adding to the security and predictability of trade. Singapore continued not to impose duties on prepared leather. Malaysia's tariff rates in this category were all at peak levels (above 15\%) before the Uruguay Round. It reviewed its rates, however, with some $30 \%$ of products remaining above $15 \%$ and the remaining $70 \%$ of products in the range of 5.1 to $10 \%$. The situation in South Africa remained unchanged, with one third of products facing tariff peaks, but like Argentina, South Africa had bound all duties in this sector.

\subsubsection{Finished leather products}

The European Union lowered its duties in the top segment of the market, finished leather products, during the Uruguay Round. A duty lower than 5\% applied to two thirds of all products, less than one third between 5 and $10 \%$ and only two products faced tariff peaks above $15 \%$. Canada also made major efforts to reduce the incidence of duties. The majority of products face tariffs between 5 and $10 \%$, which is above the average for industrial goods. While over $45 \%$ of products faced tariff peaks prior to the Uruguay Round negotiations, this was reduced to $16 \%$ of products after the conclusion of the Round. In Australia, three quarters of all products faced tariff peaks, with over one third facing duties higher than $35 \%$. These numbers were halved as a result of the Uruguay Round, with one third of duties continuing to face tariff peaks. Some $43 \%$ of all products however faced duties in the range of 10 to $15 \%$. In the United States the number of tariff peaks was reduced from roughly one quarter of products to one fifth. Over half of all products faced duties between 0 and $10 \%$. In Japan there was relatively little change, with nearly $45 \%$ of all products facing tariff peaks. One third of all tariffs were between 15 and $35 \%$.

New Zealand had tariff peaks on two thirds of all products after the Uruguay Round, compared to tariff peaks on three quarters of all products before the negotiations were started. Half of all duties were between 15 to $35 \%$. Switzerland had rationalized its tariffs and eliminated a tariff peak it applied on one product. It had also further reduced its tariffs: $80 \%$ of all products are now charged between 0 and $5 \%$ duty and the remaining products have duties below $10 \%$. Argentina consolidated the situation that prevailed before, with tariff peaks on nearly $80 \%$ of all products. Singapore eliminated all tariff peaks, whereas previously over one third of all products faced peak-level tariffs. Rates on these were reduced to between 5 and $10 \%$. At the same time Singapore continued to allow nearly two thirds of its products to be imported duty free. In Malaysia nearly $28 \%$ of all products faced duties of between 0 and $5 \%$, with the remaining $72 \%$ facing tariff peaks. In fact, the number of products facing peaks increased after the Uruguay Round. South Africa consolidated the situation that prevailed before the Uruguay Round, with nearly $83 \%$ of all products facing peaks. Three quarters of all products faced duties between 15 and 35\%.

The degree of tariff escalation has thus been reduced, which means that a key objective of the negotiations was accomplished. As is illustrated in Table 4.6, in the European Union the 
reduction in average tariffs for prepared leather amounted to $18.3 \%$, whereas the reduction for leather products was $27.7 \%$. As a result, the discrepancy between tariffs (the tariff wedge) for prepared leather and leather products diminished, thus reducing the tariff escalation. In the case of Canada, the reduction was approximately the same magnitude in the two stages of processing, but the cuts were made on higher original duty levels, thus resulting in higher cuts, narrowing the margins of the duties. While average duties continue to be high in Australia, tariffs were reduced considerably at the end of the production chain, thus effectively diminishing tariff escalation. With regard to the United States, the cuts for intermediate products (nearly $36 \%$ ) were larger than for finished products $(13.3 \%$ ), which implied an actual increase in the tariff wedge and higher levels of tariff escalation. A similar observation can be made in the case of Japan, which performed more reductions at the intermediate stage in comparison to the high end goods, thus also increasing the absolute level of tariff escalation. Rates for prepared leather were cut by $44.6 \%$, whereas for finished leather products they were much smaller at $14.5 \%$. Before the Uruguay Round, average duties for prepared leather and leather products were almost identical. Now the gap is nearly $7 \%$, with higher duties on the finished product.

New Zealand made almost equal reductions, albeit from different levels, and as a result the gap was closed, moving from nearly $21 \%$ to $12 \%$. Switzerland reduced its duties a slight amount more for finished leather products, compared to prepared leather, also reducing tariff escalation. Norway eliminated duties for prepared leather and slashed duties by $50 \%$ on leather products, again decreasing tariff escalation. In South Africa and Argentina there was no change in tariff escalation as no reductions were made. Malaysia followed a similar pattern as the United States, and Japan and actually created tariff escalation. Initially, leather products faced lower duties than prepared leather. The situation was reversed, with higher tariff protection for the finished product.

In short, significant efforts were made during the negotiations to address the issue of tariff escalation and tariff peaks. This is also confirmed in the FAO study, which notes that 'considerable trade liberalization was achieved in recent years, under the Uruguay Round, and more gains have been made since then.' 103 They refer to the concessions provided by the EU, the United States and Japan in granting duty-free entry to imports from LDCs. The reality today is that the sector still stands out with its high tariffs and share in tariff peaks. This is illustrated by the WTO study which shows the shares in applied duties and tariff peaks by WTO members with regard to leather products. This is also confirmed by the FAO in their statement that 'nevertheless, many countries continue to apply significant barriers against imports of leather and leather products. Where higher tariffs are applied to processed and manufactured goods, the benefits that developing countries might gain from adding value to their raw material before exporting it are undermined.' ${ }^{104}$ The data confirm that considerably more work is required to bring the duties in this sector closer to the averages for other sectors.

\footnotetext{
103 FAO, page. xii.
}

104 Ibid. 
TABLE 4.6: Tariff escalation in selected markets

Simple average tariffs for products defined according to Harmonized System (HS) categories

$[\mathrm{RL}=$ Raw Leather, $\mathrm{PrL}=$ Prepared Leather, $\mathrm{FLP}=$ Finished leather products, Red. $=$ Reduction $]$

\begin{tabular}{|c|c|c|c|c|c|c|c|c|c|}
\hline & \multicolumn{3}{|c|}{ Switzerland } & \multicolumn{3}{|c|}{ Norway } & \multicolumn{3}{|c|}{ South Africa } \\
\hline & Pre-UR & Post-UR & Red. & Pre-UR & Post-UR & Red. & Pre-UR & \begin{tabular}{|l|} 
Post-UR \\
\end{tabular} & Red. \\
\hline RL & 0.05 & 0.00 & -100.00 & 0.00 & 0.00 & & 0.00 & 0.00 & \\
\hline PrL & 1.03 & 0.78 & -24.22 & 1.04 & 0.00 & -100 & 10.54 & 10.54 & 0.00 \\
\hline \multirow[t]{3}{*}{ FLP } & 4.94 & 3.49 & -29.36 & 15.58 & 7.75 & -50.27 & 24.02 & 24.02 & 0.00 \\
\hline & \multicolumn{3}{|c|}{ Argentina } & \multicolumn{3}{|c|}{ Singapore } & \multicolumn{3}{|c|}{ Malaysia } \\
\hline & Pre-UR & Post-UR & Red. & Pre-UR & Post-UR & Red. & Pre-UR & Post-UR & Red. \\
\hline $\mathrm{RL}$ & 0.00 & 0.00 & & 27.00 & 10.00 & -62.96 & 7.00 & 5.00 & -28.57 \\
\hline $\operatorname{PrL}$ & 1.58 & 1.58 & 0.00 & 0.00 & 0.00 & & 27.41 & 12.96 & -52.71 \\
\hline \multirow[t]{3}{*}{ FLP } & 18.97 & 18.97 & 0.00 & 7.33 & 3.67 & -49.99 & 22.20 & 21.96 & -1.29 \\
\hline & \multicolumn{3}{|c|}{ US } & \multicolumn{3}{|c|}{ Japan } & \multicolumn{3}{|c|}{ New Zealand } \\
\hline & Pre-UR & Post-UR & Red. & Pre-UR & Post-UR & Red. & Pre-UR & Post-UR & Red. \\
\hline RL & 0.00 & 0.00 & & 0.00 & 0.00 & & 0.00 & 0.00 & \\
\hline $\operatorname{PrL}$ & 3.91 & 2.51 & -35.88 & 21.23 & 11.77 & -44.57 & 13.85 & 9.19 & -33.61 \\
\hline \multirow[t]{3}{*}{ FLP } & 10.50 & 9.10 & -13.32 & 21.80 & 18.64 & -14.51 & 34.50 & 21.83 & -36.74 \\
\hline & \multicolumn{3}{|c|}{ EU } & \multicolumn{3}{|c|}{ Canada } & \multicolumn{3}{|c|}{ Australia } \\
\hline & Pre-UR & Post-UR & Red. & Pre-UR & Post-UR & Red. & Pre-UR & Post-UR & Red. \\
\hline RL & 0.00 & 0.00 & & 0.00 & 0.00 & & 0.00 & 0.00 & \\
\hline PrL & 3.76 & 3.08 & -18.30 & 8.22 & 5.41 & -34.20 & 9.59 & 8.55 & -10.91 \\
\hline FLP & 7.60 & 5.49 & -27.71 & 15.53 & 10.27 & -33.88 & 28.46 & 18.48 & -35.09 \\
\hline
\end{tabular}

Source: Own calculations by the authors, based on data from the WTO Integrated Database.

\subsubsection{Conclusions}

The analysis addressed the question of how tariff escalation affects competitive conditions in a specific sector of particular interest to developing countries. The Uruguay Round negotiations led to a reduction in tariff escalation in most countries, but tariffs remained particularly high compared to the average tariffs. This underscores the need to further address tariff escalation in the DDA negotiations as a way to provide new market opportunities for developing countries. This would allow countries, mainly those on the African continent, to connect better to markets and benefit from higher skilled labour income. But this may not be sufficient in itself and so other ways may need to be considered to encourage value adding in the production process. Tariffs and tariff escalation are a major hindrance in this sector, but their simple reduction or elimination will not be sufficient to generate trade, growth, employment and revenue for the region. In order to achieve that objective, this needs to be complemented with other policies, including those that lead to the facilitation of trade and investment flows. The Commonwealth studies identified major 
infrastructure deficiencies as key factors holding back foreign direct investment inflows, and particularly intra-Africa trade including: poor transport and communications; deficient maintenance of road networks; inflexibility; unreliability and inefficiency of rail transport; power supply and water. Low labour productivity associated with the low level of technology as well as low quality of trade related infrastructure in leather and leather products can also be one of the major hindrances to extra-regional foreign direct investment.

So what is the way forward, particularly for Sub-Saharan Africa? High tariffs remain the major challenge to trade as well non-tariff barriers to intra-regional trade and global trade. Removing tariffs on leather and leather products has the potential to increase intra-regional trade almost fourfold while it is also observed that if all tariffs and non-tariffs were removed, the existing average intra-regional trade could increase tenfold. ${ }^{105}$ Intra-regional cooperation and trade agreements are critical to accelerating and deepening intra-regional trade including trade facilitation and promoting the intra-regional value chains in leather and leather products. The study suggests a tripartite trade agreement between COMESA, ECOWAS and SACU for that purpose through which harmonization of regulations and procedures along with lowering tariffs and non-tariffs barriers can be discussed to develop tangible outcomes.

\subsection{Market access in the WTO and the achievements in the Doha Development Agenda}

The Doha Ministerial Declaration stipulated that both in the field of agriculture and NAMA negotiations should be conducted 'with a view of substantially improving market access'. ${ }^{106}$ While no decision was taken on the extent to which tariffs should be reduced, it has always been understood that ambitions should be no less than they were during the Uruguay Round and which had led to tariffs cuts of nearly $40 \%$. In fact, during the initial stages of the negotiations, it quickly appeared from the discussions between the members that levels of ambition would go much beyond the targets in that Round, with reductions of over $50 \%$ proposed, to be achieved through a modular formula approach both for agriculture and NAMA. How to accomplish this ambitious target remains an issue as much depends on the methodology to be adopted, and no agreement has been reached so far.

This section will take a closer look at the market access provisions in the agriculture negotiations of the DDA, followed by a discussion on the negotiations with regard to industrial products as part of the NAMA. In addition to providing insights into the state of play of the negotiations in each area on the technical aspects, it will discuss and analyse some economic and political considerations that can partly explain the current deadlock in the negotiations. It will be argued that one explanation for the stalemate in the negotiations is that they have become far too complex to manage. In addition to the high number of

\footnotetext{
105 Commonwealth Trade Policy Discussion Papers, Trade-Led Regional Value Chains' p. 8.

106 WTO Ministerial Declaration, Doha, 9 - 14 November 2001, WT/MIN(01)/DEC/1, 20 Nov.2001. Cf.. para. 13 on Agriculture and para. 16 on Market Access for Non-Agricultural Products.
} 
countries involved in the negotiations, too many countries and groups of countries try to build too many flexibilities and exceptions into the agreements and more specifically in the Agriculture Agreement, thus reducing the potential and initially expected gains from liberalization. Given the state of the negotiations, which were quite advanced until the deadlock in 2008, positions are increasingly divided between those who believe the difficulties raised should be addressed within the existing framework of the draft agreements and those who feel that a new approach needs to be developed in order to achieve tangible and realistic outcomes. This applies to both draft agreements (discussed below), the status of which are now uncertain. Following the MC-X (Nairobi), it is no longer clear whether the texts that were on the negotiating table prior to the Conference are still valid as a basis for the discussions. There has been little movement since the MC-X in bridging the differences of views and approaches, thus reducing chances to break the deadlock.

\subsubsection{Multilateral negotiations on market access in agriculture}

\subsubsection{The rationale for liberalizing trade in agricultural products}

No decision was required at Doha to launch the negotiations on agriculture, as a decision to that effect was already explicitly contained in the Uruguay Round Agreement and is part of the so-called 'built-in agenda' which calls for continuing the process of liberalization that began in 2000. ${ }^{107}$ The Uruguay Round therefore provided the starting point from which to launch the negotiations to liberalize trade in agriculture and discussions on the liberalization for agriculture products already commenced prior to the launch of the DDA. The Uruguay Round had led to a 'tariffication' of all trade restrictions in agricultural goods, including for all non-tariff measures, but with little liberalization as such. ${ }^{108}$ The Agriculture Agreement certainly was one of the main achievements of the Round and a novelty, but little reduction was achieved as a result of it: this was left for the next stage of negotiations.

The Agriculture Agreement establishes that

the long term objective is to establish a fair and market-oriented trading system through a programme of fundamental reform encompassing strengthened rules and specific commitments on support and protection in order to correct and prevent restrictions and distortions in world agriculture markets....Members are committed to substantial improvements in market access, reductions of, with a

107 Article 20 of the Agriculture Agreement specifies that 'Members agree that negotiations for continuing the process will be initiated one year before the end of the implementation period', which effectively meant in the year 2000.

108 It was explained earlier that the process of 'tariffication' consisted of converting all non-tariff measures into 'tariff equivalents', thus providing a basis for reductions, based on an agreed methodology. 'Tariffication' also meant that in the agricultural sector all non-tariff measures were eliminated and the sector would only be governed by tariffs, thus easing the negotiations and reducing overall levels of tariffs. 
view of phasing out, all forms of export subsidies and substantial reductions in trade distorting support. ${ }^{109}$

In economic terms, the agricultural sector is of relative little importance, but in political terms and from a domestic policy perspective it is of critical importance to most economies. Laborde and Martin observe that 'trade in agricultural products made up only $12 \%$ of world trade in 1988 and declined to just over $6 \%$ of trade in 2006, before beginning to increase largely in response to higher agricultural prices - to almost $9 \%$;.110 The exports from developing countries followed a similar, but sharper profile to that for the world as a whole, declining from $17 \%$ in 1988 to $6 \%$ in 2006 before increasing to $8 \%$ in 2009 . With over $90 \%$ of world trade being conducted in non-agricultural goods, Tangerman raises the question why this sector gets so much attention. ${ }^{11} \mathrm{He}$ observes in his conference paper that 'it seems paradoxical that agriculture accounts for a small and declining share of global trade, less than $10 \%$ in 2013 and yet, in trade negotiations agriculture continues to cause immense trouble'. As he puts it, 'the cast of combatants changes and the acute issues debated are somewhat variable, but the sector is continuously in the headlines. Agriculture remains an Achilles heel of the world trading system'.

Anderson and Martin put it more bluntly and ask the question: 'Why all the fuss over agriculture?' 112 They observe that 'it is precisely because agricultural farming earnings are so important to a large number of developing countries that the highly protective farm policies of a few wealthy countries are being targeted in the negotiations'.113 In addition, in many countries - often the poorer ones, agricultural policies are not necessarily economically efficient, given their often small size and because they are widely dispersed. As a result many farmers benefit one way or another from government support as well as from protective measures.

The same authors note that the way protection evolved in developed and developing countries is not the same. They observe that 'agriculture protection in developing countries has continued to trend upwards, whereas protection in high-income countries has come down by a third, following a peak in the late 1980s'. ${ }^{114}$ Accordingly, they observe that 'this decline correlates in timing with the prospect, and then reality, of the UR agreement, bringing some disciplines to developed-country agriculture. In developing countries, where the disciplines resulting from the UR were considerably weaker, the apparent underlying

109 The Agreement on Agriculture, 'Preamble', p. 39.

110 D. Laborde and W. Martin, 'Agriculture Trade, What Matters in the Doha Round', IFPRI Discussion Paper (No. 01251, 2013).

111 S. Tangermann, 'Agriculture: Food Security and Trade Liberalization', paper prepared for Conference on 'Challenges Facing the World Trading System', Columbia University and John Hopkins University, 29 September-2 October 2014.

112 K. Anderson and W. Martin, 'Agriculture Reform and the Doha Development Agenda', World Bank, 2005, p. 1301.

113 Cf. Ibid., p. 1302.

114 Cf. Laborde and Martin, 'Agricultural Trade', p. 5. 
trend of increasing agricultural protection as incomes rise appears to have continued'. ${ }^{115}$ One often invoked argument for protection in this sector relates to the need for countries to ensure their food security in times of war or crisis. This argument became particularly important in the discussions at MC-IX (Bali), with India being the strongest advocate of exceptions being made to the rules in that regard and in order to give members more room to provide support to domestic farmers. Tangerman challenges the economic rationale of the arguments made on food security and argues that room is already largely available in the current Agriculture Agreement for providing such support measures as demanded by India. ${ }^{116}$

\subsubsection{Negotiating the Agriculture Agreement}

While the objectives stipulated in the Agriculture Agreement to proceed with the reform process were undisputed and the process for further liberalization was launched in accordance with it, this turned out to be very challenging, given the important and sometimes conflicting domestic interests at stake. The various chairmen that presided over the negotiations have painstakingly attempted to put a text on the table. Most of the text contained many unresolved issues, which were technically put in brackets, meaning that they required further discussions and negotiations, before agreement could be agreed. The texts have been revised many times and undergone many modifications, in order to reflect members' positions. The latest such text was presented to the members in the summer of 2008 by the Chair of the Negotiating Committee on Agriculture, a former Ambassador of New Zealand to the WTO. ${ }^{117}$ What are the key elements of the proposals and what is the current position?

The draft text presented then has three main pillars, which include market access provisions, domestic support measures and export support (export subsidies). This section will focus on the market access provisions. Various academic studies show that market access barriers contribute around $90 \%$ of the economic cost of agricultural distortions, which also justifies the primary focus of attention in the agricultural negotiations on this pillar. ${ }^{118}$ The market access barriers are both important in developed and developing countries. Following the discussion on the market access issues, a few observations will be made on some of the contentious issues that were part of the MC-IX (Bali) discussions, including food security and the outcomes achieved at MC-X (Nairobi).

115 Cf. Ibid.

116 Cf. Tangermann, 'Agriculture: Food Security and Trade Liberalization', p. 19-21.

117 'Revised Draft Modalities for Agriculture' (TN/AG/W/4/Rev.4, 6 December 2008) is a chairman's text, which reflected the status of discussions at that time, as summarized by the Chair. The text has not been amended since and its status at present is unclear and forms part of the debate in Geneva as to whether it should continue to provide the basis for the negotiations or whether a new approach should be adopted).

118 T. W. Hertel and R. Keeny, 'What is at Stake: The Relative Importance of Import Barriers, Export Subsidies and Domestic Support' in K. Anderson and W. Martin (eds.), Agriculture Trade Reform and the Doha Development Agenda, (Palgrave-Macmillian, 2006), p. 3762; B. Hoekman, F. Ng and M. Olarreaga, 'Agriculture Tariffs versus Subsidies: What's More Important for Developing Countries?' 18 World Bank Economic Review (2004), p. 175-204; K. Anderson, W. Martin and E. Valenzuela, 'The relative importance of Global Agricultural Subsidies and Market Access', 5 World Trade Review (2006), p. 1-23. 
On a closer look at the market access related aspects of the 2008 draft modalities, and more specifically the formula approach that is proposed, the complexity and the large number of provisions made to accommodate specific interests of individual or groups of countries are most striking. Laborde and Martin note that 'negotiators tried a different approach as compared to earlier Rounds, by specifying constraints on the range of products that could be exempted from the formula treatment, while leaving specific products to be given less-than-formula cuts to the discretion of each country's policy makers'.119 They then observe that 'while this was an important new approach to trade reform, it encountered several difficulties that may have contributed to the travails of the negotiations'. In addition, the level of ambition for reforms is very high, which is welcome in itself given the high levels of protection that are characteristic for this sector, though at the same time leads to some resistance.

The draft text outlines a tiered formula approach to reduce tariffs in six annual instalments over five years with different cuts taking place depending on the levels of the final bound tariff or ad valorem equivalent. Laborde and Martin observe that the formulas chosen were particularly progressive in their application, cutting the highest tariffs by the largest percentage. This appears to have contributed to pressure for the comprehensive and complex set of exceptions. More specifically, looking at the tiered system, developed country tariffs in the range between $0-20 \%$ (first tier) would be reduced by $50 \%$. For the second tier, tariffs between $20-50 \%$ would have to be slashed by $57 \%$. For the third tier, tariffs in the range of $50-75 \%$, a $64 \%$ cut would need to be applied. Finally for any tariffs higher than $75 \%$, the reduction would need to be $70 \%$. In other words, the higher the duty, the higher the cut, which would at the same time take care of tariff escalation and tariff peaks, as discussed previously. The minimum average cut on final bound tariffs that a developed country member would be required to undertake is $54 \%$, thus largely exceeding the average cuts of the Uruguay Round.

The cuts would not be the same for all countries, as different provisions are made for each members depending on their economic levels of development, thus adding to the complexity. In accordance with the special and differential treatment provisions for developing countries, they will undertake cuts over a 10 year period. In addition, the average required reductions will be much less and at only two-thirds of developed country reductions. In other words, developing countries will benefit from a longer transition period, combined with a lesser reduction commitment. The draft text also foresees that the maximum overall average cut on final bound tariffs any developing country member shall be required to undertake as a result of the application of the formula will be $36 \%$, and taking into account the provisions made on sensitive products, developed separately in the agreement. A specific question with regard to developing countries commitments relates to levels of bindings and if a cap should be foreseen. Some other specific issues relating to

119 D. Laborde and W. Martin, 'Formulas for Failure? Were the Doha Tariff Formulas Too Ambitious for Success?' World Bank Group Policy Research Working Paper(No. 7303, 2015), p. 3. 
developing countries, including special products, safeguards, erosion of preferences, will briefly be explained as follows.

According to Laborde and Martin, 'the pressure for exceptions, and the poorly-defined nature of some of the exception rules, resulted in the loss of the benefits of transparency that is meant to be one of the key advantages over one based on the offer-request procedures'.120 In this regard, they refer to comments that had been made by chief negotiator of the United States, who expressed concern that the draft agreement was a 'black box' in terms of its impact on market access.

Exceptions are foreseen for the Recently Acceded Members (RAMs) as well as for Small and Vulnerable Economies (SVEs) for which the texts includes several footnotes , detailing to which countries this applies as well as the specific circumstances when this applies. ${ }^{121}$ The logic is that it would be unreasonable to expect recent RAMs that are already committed to reducing their duties as part of their accession protocol to reduce tariffs in addition by these substantial percentages as part of the DDA package. As for the SVEs, given their special economic and geographical conditions and being vulnerable to external shocks, which are beyond their control, flexibilities are part of the draft agreement.

The draft foresees specific provisions on Sensitive Products, which basically allow a country to designate a percentage of tariff lines (for example 4\%) as 'sensitive' and in doing so, exempting the country to subject it partly from the formula cuts. The text specifies the circumstances and conditions under which this can be done. These are rather complex and stand in direct relation to market opening provisions that would need to be provided under another pillar of the draft agreement, that is through the establishment of tariff quotas. In other words, while placing restrictions on the one hand, there would be a commitment to liberalize on the other hand, in order counterbalance the restrictions.

Given the complexity of the draft agreement resulting from the numerous exceptions Martin and Laborde argue that one of the main challenges is to manage the exceptions. In addition, it makes it hard to calculate the real expected effects of the market opening measures, taking into account the specific conditions for different categories of countries as well as the exceptions for individual countries foreseen in the draft agreement. They observe that

by focusing attention on the defensive concerns of individual countries, this approach appeared to encourage a strong focus on exceptions, with sensitive product exceptions available to all countries, special product exemptions available only to developing countries, and a range of exceptions for particular country groups. A major problem with disciplining exceptions by constraints on the share of tariff lines is that most trade under highly protective tariffs occurs

120 Ibid., p. 3.

121 See footnotes 11 and 12 of the AoA. 
under a very small share of tariff lines, so that exempting a seemingly small share of tariff lines can result in a very large reduction in the degree of liberalization achieved. ${ }^{122}$

This is what the negotiators try to avoid. The flexibilities seem to do serious damage to economic efficiency which leads to the question 'whether negotiators should aim for a less aggressive tariff formula combined with much righter disciplines on exceptions. ${ }^{123}$

Despite the blockage in the discussions on agriculture since July 2008, new efforts were undertaken to revive the negotiations at least in part, with some progress recorded prior to MC-IX (Bali). The key elements of the specific agreements reached with regard to agriculture at the MC-IX and MC-X (Nairobi) include the following four areas:

- General services; ${ }^{124}$

- Public stockholding for food security purposes; ${ }^{125}$

- Tariff rate quota administration; and ${ }^{126}$

- Export competition. ${ }^{127}$

General services: The definition of 'general services' has been broadened compared to the initial agreement to provide for more leverage for government programmes to be tolerated under the WTO rules and disciplines. ${ }^{128}$ General services are services generally available and do not confer a 'specific' advantage. ${ }^{129}$ The extension of the definition was acceptable to the members and not contentious.

Food security: the second issue, relating to specific provisions with regard to food security, became one of the contentious issues at the MC-IX (Bali). Tangermann observes that the issue was not new, as the G-33 had for some time already demanded a relaxation of WTO constraints on government policies regarding stockholding of food. ${ }^{130}$ India spearheaded

122 Cf. Laborde and Martin, 'Agricultural Trade', p. 12-13.

123 Ibid., p. 13.

124 WT/MIN(13)/37-WT/L/912 (General Services).

125 WT/MIN(13)/38-WT/L913 and WT/MIN(15)/44- WT/L/979 Ministerial Decision of 19 December 2015 on Public Stockholding for Food Security Purposes.

126 WT/MIN(13)/39-WT//L914 (TRQA).

127 WT/MIN(13)/40-WT/L915 and WT/MIN(15)/45-WT/L/980 Ministerial Decision of 19 December 2015 on Export Competition.

128 General services are defined in Annex 2 to the Agreement on Agriculture and include expenditure in relation to programmes which provide services or benefits to agriculture or the rural community. They need to meet specific criteria as defined in paragraph 1 of the Annex to the agreement, as well as a number of policyspecific conditions. The agreement establishes that such general services should not provide a specific benefit and are publicly available, including research programmes, pest and disease control, inspection services etc.

129 The notion of specificity is key in this regard, as, and in accordance with the Agreement on Subsidies and Countervailing Duties, subsidies that are generally available are less likely to be contrary to the WTO rules.

130 Cf. Tangermann, 'Agriculture: Food Security and Trade Liberalization', p. 18. Tangermann's paper provides a detailed analysis of the economic and political rationales of the provisions with regard to the public stockholding provisions contained in the Agreement. 
that request and made a solution on this use a condition sine qua non for an overall agreement at MC-IX. The Decision that resulted from MC-IX is essentially an interim peace clause in which WTO members have agreed not to bring disputes against a developing country that violates certain commitments. In other words, the MC-IX led to a temporary solution, allowing more room for governments to maintain public stock holding programmes, and without the risk of these policies being challenged under the dispute settlement provisions of the WTO, until a permanent solution could be found by way of negotiation. The Declaration states that the aim is to find a permanent solution no later than the $11^{\text {th }}$ Ministerial Meeting, which de facto means by $2017 .{ }^{131}$ It also states that a work programme was to be established to pursue the issue in the Committee on Agriculture. It was envisaged that developing countries could designate $12 \%$ of the tariff lines as 'special products' on the basis of the food security argument, rural development and livelihood security, with up to $5 \%$ of lines having no cut. The Indian government was mainly concerned that if the permanent solution was not found by 2017, it would be in breach of the WTO provisions and its policies would be legally challenged. According to Tangermann, based on calculations following the depreciation of the Indian rupee, there was actually little risk of India breaching the WTO provisions, as it stays well within the tolerated margins of the Agreement.

While the issue thus seemed to be solved at MC-IX Bali as an agreement was reached, and one which was much in accordance with India's demands, India saw no effort to pursue the discussion to find a lasting solution in early 2014 and raised the issue again. It had concerns with regard to the willingness and commitment of the members to discuss a durable solution. This led India to again block the procedures finalizing the process of implementation of the Trade Facilitation Agreement (TFA), and for which the Protocol of acceptance was due to be signed by the end of July 2014. As stated by the Director General during the General Council meeting in July, it once again put the system at risk. ${ }^{132}$ Hence, India requested and insisted that the provisional arrangement be indefinite for as long as it took to find an adequate solution. This led to intense discussions and negotiations. The issue was resolved following constructive engagement and discussions between India and its main trading partners, more specifically between the United States and India, just prior to the G20 meeting held in Australia in November 2014. Basically India again obtained what it had requested and the positive outcome of the discussions was confirmed by the General Council at its meeting of 27 November 2014. This unblocked the way forward on the TFA, with its Protocol open for ratification by the membership. The issue was again addressed at MC-X (Nairobi), and led to an agreed solution, thus solving the issue. ${ }^{133}$

131 Cf. WT/MIN(13)/38-WT/L913 and WT/MIN(15)/44-WT/L/979.

132 Following the impasse that resulted from India's position, the WTO Director General R. Azevêdo expressed himself in the clearest possible way at the General Council Meeting in July 2014 and later in the autumn about the negative repercussions of the stalemate for the WTO and the multilateral trading system as a whole, stressing that the system was in serious danger and perhaps more so than ever before.

133 Public Stockholding for Food Security Purposes, Ministerial Decision of 19 December 2015, WT/MIN(15)45-WT/L/980. 
Tariff rate quotas: The provisions have been clarified further with regard to the third issue, the understanding on tariff rate quota administration provisions for agricultural products as defined in Article 2 of the Agriculture Agreement. The agreement reached by Ministers specifies how quotas can be filled.

Export Competition: Concerning the fourth issue, the Decision on Export Competition, an initial agreement was reached and was strengthened at MC-X (Nairobi). ${ }^{134}$ The initial understanding addresses a situation that had emerged from MC-VI (Hong Kong) in 2005, when it was decided that all forms of export subsidies were to be eliminated by the end of 2013. Given the deadlock in the negotiations since 2008, this objective had not been pursued. Ministers had committed to a best endeavour provision aiming at reducing export subsidies and with a view to eliminating them altogether as provided for at MC-VI (Hong Kong). The MC-X (Nairobi) Decision also included transparency and monitoring provisions, to avoid any backslide. One of the most significant outcomes of MC-X (Nairobi) relates precisely to the provisions on the full elimination of export subsidies by the developed countries and with immediate effect. ${ }^{135}$ This is followed by the elimination of export subsidies by developing countries by the end of 2018.136

Special Safeguard Mechanism: Another critical and highly technical and complex issue in the debates on market access relates to the Special Safeguard Mechanism (SSM). It is often believed to be one of the issues that triggered the collapse of the negotiations in July 2008, as the United States and India could not agree on the threshold of the volume trigger to activate the SSM. The issue has not formally been addressed since. Wolfe argues that 'negotiators were not prepared to address the issue and should not have been addressing this point, which was ill-prepared'. ${ }^{137}$ The underlying idea of the SSM was to allow developing countries to increase tariffs in case of a surge of imports or a decline in the prices of commodities. The SSM would thus have a trigger based on volume and price - the specific conditions are defined in the draft Agreement. The application of the SSM would stand in close relation to GATT Article XIX and Article 5 of the Agriculture Agreement. India claimed that the SSM could be invoked when imports increase by $15 \%$, but the United States, together with other agriculture producing nations wanted to set the trigger at much higher levels $(40 \%)$. No agreement could be reached and so the discussions stalled and remained that way for many years. According to the most recent decision taken by Ministers at MC-X (Nairobi), the ways developing countries can have recourse to the SSM will be subject to negotiations. ${ }^{138}$

Cotton: Decisions were also taken at MC-IX (Bali) with regard to Cotton Market Access, a politically very sensitive issue, given the economic importance of cotton for a small number

134 Export Competition, Ministerial Decision of 19 December 2015, WT/MIN(15)45-WT/L/979.

135 Cf. Ministerial Declaration WT/MIN(15)45-WT/L/980, para. 6.

136 Cf. Ministerial Declaration WT/MIN(15)45-WT/L/979, para 7.

137 Cf. R. Wolfe, 'The Special Safeguard Fiasco in the WTO: The Perils of Inadequate Analysis and Negotiation', 8 World Trade Review (2009), p. 517.

138 Special Safeguard Mechanism for Developing Country Members, Ministerial Decision of 19 December 2015, WT/MIN(15)45-WT/L/978. 
of countries, the so-called 'cotton-four': Bénin, Burkina Faso, Chad and Mali. The economies of the cotton-four basically depend on the revenues of cotton. ${ }^{139}$ Their main points included giving special attention to cotton subsidies provided by the developed countries, elimination of subsidies and provision for compensation for the subsidies granted and the economic losses endured. According to the MC-IX (Bali) Ministerial Declaration, Ministers undertook to enhance transparency and monitoring in relation to the trade-related aspects of cotton. ${ }^{140}$ As a result of that decision dedicated discussions were held in the Committee on Agriculture focusing in particular on export subsidies, as well as on domestic support for cotton and tariff and non-tariff measures applied to cotton exports from Least Developed Countries (LDCs) in markets of interest to them. These discussions are held regularly, in principle twice a year. They contribute to providing more transparency in the developments in this sector and measures taken by the members and address issues relating to the way forward. The cotton issue was again addressed at MC-X (Nairobi), resulting in a decision on the way forward. ${ }^{141}$ The decision contains more specific provisions with regard to market access to be provided by developed and developing countries, to domestic support, export competition and development aspects.

Other issues: There are a number of other provisions in the draft agreement, including on tariff escalation, and a formula which is applicable to a list of products detailed in Annex D of the draft agreement, as well as on tariff simplification, provisions on commodities, including on price fluctuations, the liberalization of trade in tropical and diversification products, Special and Differential Treatment (S\&D) provisions for developing countries and more specifically disciplines for LDCs, who are not committed to undertake reductions in bound duties and who should benefit from Duty Free Quota Free (DFQF) Market Access, ${ }^{142}$ as well as the long-standing preferences and preference erosion. On the issue of preference erosion, which is important to a number of developing countries, the concern raised is that those countries that are beneficiaries of preferences will be negatively affected by the tariff cuts to be performed, as the margin of preferences by definition will diminish and hence will get 'eroded'. As a result, the Agreement foresees a list (in Annex H) to be applied with the items on which no tariff cuts will be performed for 10 years. Tariff cuts shall only commence after those 10 years and be implemented in five equal years.

\subsubsection{Liberalization in agriculture with and without the conclusion of the DDA}

From the reports regularly presented by the Chair of the Trade Negotiation Committee (TNC) and based on the reports by the Chair of the agriculture negotiations, there has been little movement in the negotiations on agriculture since the deadlock in 2008 and also

139 The relevant decisions with regard to cotton are contained in the WTO's General Council Decision of 1 August 2004 (WT/L/579) and the 2005 Hong Kong Ministerial Declaration (WT/MIN(05)/DEC), which calls in paragraph 11 to address cotton 'ambitiously, expeditiously and specifically' within the agriculture negotiations, as called for in the DDA. The issue therefore continues to have the attention of the members.

140 See WT/MIN(13)/41, W/L/916.

141 Cotton, Ministerial Decision of 19 December 2015, WT/MIN(15)45-WT/L/981.

142 This is a particular outcome of the Bali Ministerial Conference (MC-IX). 
between MC-IX (Bali) and MC-X (Nairobi). Even if globally there has been little progress in the DDA negotiations, more specifically with regard to agriculture, there has nevertheless been some significant progress in the liberalization pursued, including through the negotiations as well as through efforts undertaken autonomously by WTO members. Prior to the creation of the WTO and more specifically in the period of the GATT, the general view was held that the agricultural policies conducted mainly by the EU and the United States resulted in world market distortions of agricultural trade. They were considered to be the main culprits distorting world market prices through a combination of defensive and offensive policies. This was closely related with the domestic support measures, export subsidies and high levels of import protection applied by the two world trading nations. Hence, it was generally believed that any outcome of the negotiations was in the hands of the EU and the US, who were required to adjust their policies.

This no longer seems justified and perhaps no longer the case, as the debate has shifted and the EU and the US are no longer subject to finger pointing by the critics and held solely responsible for the distortions in the world markets for agriculture. The EU conducted a drastic and fundamental domestic reform process with regard to its agricultural policies, which led to reducing its internal support programmes and budgetary outlays as well as its export subsidy schemes. ${ }^{143}$ The EU Common Agricultural Policies (CAP) have been reformed periodically and the latest reform process was concluded in 2013, with the overall EU budgetary framework being adopted for the period 2014-2020 by the European Council and the European Parliament in Autumn 2013. ${ }^{144}$ The new CAP not only drastically cuts the domestic support but also revisits the ways and conditions under which the allocations are made and reduces distortions it may cause on international markets. The policy changes had become a necessity in part because of the pressure of the support measures performed through the CAP on the EU budget, but also as a result of the increasing external pressures to reform. In a similar way, the US has liberalized its markets and presented ambitious offers to further open the market for agricultural products.

According to Laborde and Martin 'in 2005 the United States offered in the negotiations a $90 \%$ cut in the highest tariffs, the abolition of export subsidies and cuts in domestic support of $60 \%$. It would limit to $1 \%$ the number of tariffs classified as 'sensitive' and subject to reduced cuts'. ${ }^{145}$ In terms of market access, the EU was willing to cut its highest tariffs by $60 \%$, subject to treatment of $8 \%$ as sensitive. By 2005, it was also willing to eliminate export subsidies and which became a reality 10 years later during MC-X (Nairobi). On domestic support the EU agreed to a $70 \%$ reduction in domestic support, compared with a $60 \%$ cut in the US domestic support. A WTO report indicates that in the area of domestic support,

143 P. Boulanger and G. Philippidis, 'The EU Battle: Assessing the Trade and Welfare Impacts of CAP Budgetary Reform', 51 Food Policy (2015), p. 119-130; K. Erjavec, and E. Erjavec, 'Greening the CAP - Just a Fashionable Justification? A Discourse Analysis of the 2014-2020 CAP Reforms', 51 Food Policy (2015), p. 53-62.

144 Erjavec and Erjavec, 'Greening the CAP' notes that this is the first time that (in accordance with the Lisbon Treaty) the European Parliament was required to adopt the proposed regulations.

145 Cf. Laborde and Martin, 'Agricultural Trade', p. 8. 
between 1995 and 2012, significant reductions have been witnessed. ${ }^{146}$ Since 1995, the current total Aggregate Measure of Support (AMS) has decreased by almost $90 \%$ in the case of the EU, by $82 \%$ in the case of Japan and by $48 \%$ for Switzerland. In the case of the US, the current total AMS has shown a clear downward trend since 2000 with a reduction of $60 \%$. It should be recognized that the price evolution (increasing price levels) in the agricultural sector has also played an important role, reducing the need for governments to provide support. These developments are quite significant and mean that the markets are less distorted than they used to be.

According to the WTO's Report, during the period 1995-2012 the use of export subsidies by WTO members as notified to the WTO has significantly decreased. Here again the overall higher international food prices since 2000 provide a good explanation, but the reality is that as a consequence there are less distortionary policies in place on the export side. These developments cleared the way for the agreement to eliminate export subsidies altogether. Export subsidies and related export measures have been a key element in the negotiations and are directly related to the continuation clause in Article 20 of the Agriculture Agreement. WTO members agreed in the course of the negotiations that the final outcome should be the parallel elimination of all forms of export subsidies and disciplines on all export measures with the equivalent effect, consisting in international food aid, export credits, export credit guarantees or insurance programmes and agricultural exporting state trading enterprises.

The efforts undertaken go in the directions of the demands of the Cairns group and their objectives of eliminating all distortions in agricultural trade, even if their ambitions go much further. ${ }^{147}$ This group is the most ambitious in terms of what would need to be accomplished in the three pillars of the agriculture negotiations: cuts in tariffs, reduction of domestic support and elimination of export subsidies. Their demands are supported by the G-20 group, which basically is an expanded version of the Cairns group, consisting of a coalition of widely differing developing countries. As was explained in chapter 2, it was created at MC-V (Cancún) and includes large countries like Brazil, China and Indonesia who are all seeking far more ambitious levels of reductions in developed countries, especially for domestic support measures.

The agreement reached at MC-X (Nairobi) to fully eliminate export subsidies thus came to many negotiators as an unexpected and welcome surprise. It is generally seen as a major achievement, bringing more stability to world markets. It offers new opportunities to countries that are not in a position to compete against subsidized products, thus artificially depressing world market prices. While the agreement is very significant and economically meaningful, it nevertheless addresses only one aspect of the negotiations, leaving aside the

146 WTO at Twenty, p. 43-44 and Figure 9, which shows the significant decrease in members' budgetary outlays between 1995 and 2013.

147 Cf. Chapter 2. The Cairns group defends the most liberal trade regime for agriculture. 
market access negotiations and domestic support. The positions continue to largely diverge between the members on the question of how to further liberalize the agricultural sector.

The unresolved issue is what alternative ways could be considered in order to move forward. The outcome of MC-X (Nairobi) has made the task even more challenging because of the divergence between the members on the status of the initial draft text and the ways forward. ${ }^{148}$ The fact that tangible and economically meaningful results were achieved in the area of export subsidies and progress was made on the issue of food security shows that a selective and partial approach works and outcomes are achievable.

\subsubsection{Multilateral negotiations on non-agricultural market access}

The Agriculture Agreement has its counterpart in the goods area, officially referred to as the Agreement on Non-Agriculture Market Access (NAMA). Goods are referred to in this manner because agricultural products are defined in Annex I of the Agriculture Agreement and industrial products are ipso facto all other products.

According to paragraph 16 of the MC-IV (Doha) Ministerial Declaration, members agreed

to negotiations which shall aim, by modalities to be agreed, to reduce or as appropriate eliminate tariffs, including the reduction or elimination of tariff peaks, high tariffs, and tariff escalation, as well as non-tariff barriers, in particular on products of export interest to developing countries. Product coverage shall be comprehensive and without a priori exclusions. The negotiations shall take fully into account the special needs and interests of developing and least-developed Members, including through less than full reciprocity in reduction commitments, in accordance with the relevant provisions of Article XXVIII bis of GATT 1994 and the provisions cited in paragraph 50 of the Doha Ministerial Declaration. To this end, the modalities to be agreed will include appropriate studies and capacity-building measures to assist least-developed countries to participate effectively in the negotiations. ${ }^{149}$

The discussions between the members thus have focused on all these elements and the latest state of play is reflected in a document referred as the Fourth Revision of Draft Modalities for Non-Agricultural Market Access. ${ }^{150}$ As far as agriculture is concerned, this document goes back to 2008 and its status is uncertain in light of the outcome of MC-X (Nairobi).

The challenge in the DDA is to find an approach that would yield the desired results in accordance with the Declaration and which includes bringing further down overall levels of

\footnotetext{
148 This point will be elaborated in chapter 6.

149 MinisterialDeclaration adopted on 14 November 2001, 20 Nov 2001, WT/MIN(01)/DEC/1, para 16.

150 See NAMA, TN/MA/W/103/Rev.4.
} 
tariffs, with a specific emphasis on the highest tariffs (namely tariff peaks) and addressing tariff escalation. So how are these objectives pursued? As was discussed earlier in this chapter, the literature provides for various negotiating techniques, which each have their own specificities, advantages and downsides in terms of objectives to be achieved. Hoda provides insight into the way the tariff negotiation objectives were achieved in previous rounds. ${ }^{151}$ Francois and Martin provide illustrations of the different tariff-cutting formulas that have been considered and their possible effects on the outcome of the negotiations. ${ }^{152}$ One of the approaches that had proven to be effective in that regard was the so-called 'Swiss formula', which had been used in the Uruguay Round and had led to major reductions in duties. Initially, the 'simple' Swiss formula applied in the Uruguay Round had one coefficient and worked as follows:

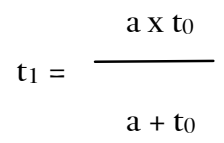

where,

$\mathrm{t}_{1}=$ Final bound rate of duty

$\mathrm{t}_{0}=$ Base rate of duty

$\mathrm{a}=8=$ Co-efficient for developed members

Given its proven usefulness, in the DDA negotiations it was again proposed to use the Swiss formula, but slightly more elaborate than the one used in the Uruguay Round, with more co-efficients, thus taking into account different economic levels of development of the WTO members. It was also proposed that the following formula would apply on a line-byline basis. The proposed formula was as follows:

$$
\mathrm{t}_{1}=\frac{\{\mathrm{a} \text { or }(\mathrm{x} \text { or } \mathrm{y} \text { or } \mathrm{z})\} \mathrm{x} \mathrm{t}_{0}}{\{\mathrm{a} \text { or }(\mathrm{x} \text { or } \mathrm{y} \text { or } \mathrm{z})\}+\mathrm{t}_{0}}
$$

where,

$\mathrm{t}_{1}=$ Final bound rate of duty

$\mathrm{t}_{0}=$ Base rate of duty

$\mathrm{a}=8$ = Co-efficient for developed members

$\mathrm{x}=20, \mathrm{y}=22, \mathrm{z}=25$ (to be chosen as provided in paragraph 7 ) $=$ Co-efficients for developing members.

\footnotetext{
151 A. Hoda, Tariff Negotiations and Renegotiations under the GATT and the WTO, Procedures and Practices (Cambridge University Press, 2001).

152 Cf. Francois and Martin, 'Formula Approaches', p. 8.
} 
The determination of the co-efficients is of critical importance as it has been mathematically proven that a lower co-efficient leads to a higher cut. The effects of using a different co-efficient can be calculated easily. Give their widely different economic effects one of the difficulties is to agree on the co-efficients that members can resort to. There is no agreement on the co-efficients yet, and this is still open for discussion. From the discussions it seems most likely that developed countries would use a co-efficient of 8 , while developing countries would use either the co-efficient of 20, 22 or 25, but nothing is fixed yet. A higher co-efficient implies less tariff reduction. To counterbalance the lower cuts, the member would have less flexibility on how to perform the reductions. Hence, while leaving developing countries with the option to use a higher co-efficient, thus cutting less, they would also have less flexibility in the ways liberalization is to be pursued.

The draft agreement is quite explicit on this point and foresees the inclusion of some other commitments and conditions for doing so as a counterpart to the lesser reductions. In case a developing country would opt for the first co-efficient of 20, it would be allowed to make less than formula cuts on $14 \%$ of its tariff lines, on the condition that the cuts are no less than half the formula cuts and these tariff lines do not exceed $16 \%$ of the total value of the total value of its NAMA imports. Another provision allows the member to keep as unbound $6.5 \%$ of its tariff lines or exempt from any cuts, provided they do not exceed $7.5 \%$ of the total value of its NAMA imports. Similar provisions apply for the other co-efficients ' $y$ ' and ' $z$ '. The draft agreement foresees that no flexibilities will apply when a developing country uses ' $z$ ' as a co-efficient. In other words, any country wanting to make the least reductions will have no flexibilities. An important additional element is that the built-in flexibilities cannot be used to exempt entire Harmonized System (HS) chapters from tariff cuts, often referred to as the 'anti-concentration' clause. It reduces the scope for countries to leave out important sectors in the economy as a whole.

The objectives of the negotiations are designed to ensure that the product coverage is comprehensive and without a priori exclusions. Cuts will have to be performed from the bound rates and the draft agreement includes detailed provisions on how to technically treat unbound duties, thus taking care of the fact that quite a large number of members still have a fairly high share of unbound duties. It is recalled that the binding of the duties is essential in providing security and predictability in the treatment of products at the border. Francois and Martin note that 'the choice of the current bound rates as the base would mean that some countries would have to make only small or no reduction in the applied rates'. ${ }^{153}$ This will particularly be the case for countries with high bindings and much lower applied duties, often referred to as 'water in the tariffs'. In other words, while the binding is reduced, it will enhance the level of security, but not lead to real improvement in market access. They observe that this may pose a problem, as WTO negotiations depend on meeting the needs of all participants. The baseline for the reductions to be performed by countries with high levels of unbound duties will be the applied duty plus 25 basis points.

153 Francois and Martin, 'Formula Approaches', p. 17. 
Another important element of the application of the formula is that it will automatically imply a higher cut on the high duties, thus addressing the issue of tariff escalation and tariff peaks and at the same time leading to some harmonization of tariffs. Hoekman and Olareaga note that 'peak applied tariffs in the industrial countries are now around 50 times as high as the average rate'. ${ }^{154}$ This contrasts with a ratio of five in the developing countries. As was evidenced in the example with regard to leather and leather products, high tariffs discourage specialization and tariff escalation implies an increase in the tariff rate with each stage of processing. It works as a disincentive for countries to generate added value in the production process, knowing that higher duties would automatically kick in. The discussion on leather and leather products showed why many developing countries are confined to the exportation of raw materials and do not manage to penetrate markets in the higher added value segments. The formula approach would normally tackle this concern, provided the formula is adopted.

The NAMA draft text contains flexibilities for developing countries with low binding coverage (less than $35 \%$ ) countries, which are listed in footnote 5 , and they are expected to bind between 75 and $80 \%$ of their tariffs at an average rate of $30 \%$. Also, as has been explained earlier, the reduction of duties would be performed on the basis of the base rate, which is the MFN applied duty, to which 25 basis points are added. The logic here is to create a reasonable gap between the bound and applied duty.

The draft agreement contains specific provisions for SVEs, that is, a total of 23 economies, with a share of less than $0.1 \%$ of world NAMA trade. LDCs, which shall be exempt from tariff reductions, are expected to substantially increase their tariff binding commitments on an ad valorem basis.

Much discussion has taken place on the specific concern of developing countries and LDCs that face 'preference erosion' which would result from the reduction of MFN rates, thus diminishing their margins of preference. ${ }^{155}$ In order to address this issue, preference granting developed countries would be allowed to implement their reductions over a longer period for tariff lines concerning products that are of vital interest to beneficiaries. This concerns a limited number of tariff lines that are of vital importance for developing country members that are beneficiaries of such preferences. The beneficiaries are mainly referred to in paragraph 28 of the draft agreement, with the relevant tariff lines listed in Annex 2 for the European Union and Annex 3 for the United States. In particular it affects some of the ACP (African, Caribbean and Pacific) countries that have traditionally been the largest beneficiaries of the EU's preferences. ${ }^{156}$

154 Hoekman, Olarreaga and Ng, 'Agriculture Tariffs versus Subsidies'.

155 A more in-depth discussion of preferences is provided in Chapter 5 on developing countries.

156 According to Wikipedia, last consulted on 27 May 2016, the ACP consists of 'the African, Caribbean and Pacific Group of States and was created by the Georgetown Agreement in 1975. The group's main objectives are sustainable development and poverty reduction within its member states, as well as their greater integration into the world's economy. All of the member states, except Cuba, are signatories to the Cotonou Agreement with the European Union. The Cotonou Agreement signed in Bénin (June 2000) is the successor 
With regard to market access for LDCs, here again a range of specific provisions are foreseen, including the DFQF treatment of products originating from LDCs, which is specifically covered in the Bali package. ${ }^{157}$ Under the DFQF provisions, LDCs would have access to the markets of the developed countries at zero duty and without quantitative restrictions for at least $97 \%$ of trade. RAMs will be given extra time to perform their tariff cuts, and will include an initial grace period of 3 years. The logic (as explained earlier) is that these countries have often made important tariff concessions during their accession process, which prevents them from reasonably making further cuts at this early stage. There are some 20 countries listed in footnote 8 of the draft agreement to whom this provision would apply. In addition, paragraph 20 contains specific provisions for the so-called Very Recently Acceded Members (VRAMs), which, given their very recent accession to the WTO cannot be expected to make any reductions in their tariffs. ${ }^{158}$

Finally, the negotiators aim at the full elimination of low duties, often referred to as nuisance duties. The rationale behind this is that very low duties (below 3\%) generate little revenue, but pose an administrative cost and burden, hence the idea to bring them down to zero.

Laborde and Martin argue that 'the formula with room for exceptions was an important new approach to trade reform, but it encountered several difficulties that may have contributed to the travails of the negotiations'. ${ }^{159}$ They note that the formulas chosen were particularly progressive in their application, which appears to have contributed to pressure for a particularly complex set of exceptions. They observe that the pressure for exceptions and the poorly defined nature of some exceptions resulted in the loss of transparency that is meant to be one of the key advantages of formula-based negotiation over one based on offerrequest procedure. According to the authors, when the negotiations collapsed in 2008, the chief negotiator for the United States, S. Schwab, expressed concern that the draft agreement was a 'black box' in terms of its impact on market access.

In addition to the formula approach for the reduction of tariffs, the draft agreement foresees sectorial negotiations with a specific list of proposed sectors (in Annex 6 to the draft agreement) which would benefit from zero-duty treatment. The list contains over a dozen specific sectors and members are invited to submit more proposals if they so wish.

to the Lomé Convention. One of the major differences from the Lomé Convention is that the partnership is extended to new actors such as civil society, private sector, trade unions and local authorities. These will be involved in consultations and planning of national development strategies, provided with access to financial resources and involved in the implementation of programs'.

157 WT/MIN(13)/44, WT/L/919, Duty Free and Quota Free (DFGF) market access for least developed countries.

158 As was argued in Chapter 2, recently acceded members (RAMs), or Article XII Members, often argue that they are pushed to the maximum in terms of tariff reductions when acceding to the WTO. This reduces the scope of further cuts once they are a member and more specifically when the accession coincides with a negotiating round such as the DDA and they are still in the process of reducing their tariff cuts according to the terms of accession protocol.

159 Laborde and Martin, 'Formulas for Failure?’, p. 3. 
According to the agreement, sectorial initiatives that reach a critical mass of participation will help to balance the overall results of the negotiations on NAMA. The outcome of the negotiations would become multilaterally applicable by virtue of the MFN principle, thus widening the benefits to the WTO's membership as a whole. For this initiative to work, one of the challenges is to reach a critical mass of participants, which is currently far from completion. In a way it is surprising that this sectorial approach receives so little attention, as potentially it holds the key to liberalization in specific sectors. As was shown and argued before, it had proven to be successful in the Uruguay Round, with some initiatives having led to zero duties. Also, and as will be argued in the case study on the ITA, sectorial approaches can have a significant economic impact. As participation in these sectorial agreements is not mandatory the question now is how to encourage more active engagement to achieve the critical mass so that the agreement can have economic significance?

The draft agreement also focuses on the issue of Non-Tariff Barriers (NTBs) and includes both horizontal proposals and vertical proposals. The horizontal proposals include a draft Ministerial Decision on Trade with regard to Remanufactured Goods. On the other hand the vertical proposals include NTBs in the chemical products and substances sector, an understanding on the interpretation of the TBT Agreement as applied to trade in electronics (electrical safety and electromagnetic compatibility of electronic goods), labelling of textiles and clothing, footwear and travel goods and agreement on NTBs pertaining to standard technical regulations and conformity assessment procedures for automotive products. ${ }^{160} \mathrm{As}$ is clear from the text and the regular reports of the Chairmen that are submitted to the Trade Negotiation Committee, the NTBs are a very complex issue and little progress has been made in this domain. Given the difficulty of the discussions in this field, it is generally believed that the negotiations will only focus on the NTBs once more substantial progress is achieved on the other aspects of the negotiations. It is one of the most complex issues, as many of the questions directly affect the domestic policy space.

As can be observed from the discussions on agriculture and NAMA, there are many proposals on the table to achieve the set objectives in the negotiations, but no tangible outcome as of yet. There has been no significant progress since 2008, and this is blocking the overall progress in the negotiations. Members continue to be engaged in the discussions on the way forward and how to re-launch the discussions on concluding the DDA, but with little clear perspective as to what this will mean in practice. Members at the General Council in November 2014 again agreed to postpone the deadline to establish a roadmap to conclude the DDA, initially set for the end of 2014, to July 2015, but to no avail. The consultations undertaken by the Director General in conjunction with the Chairs continue with a view to

160 While there is not yet an agreed definition of a 'remanufactured good', according to one of the texts presented by the Chair of the NAMA negotiating group (TN/MA/W/103/Rev.3/Add1, 21 April 2011, p. 87), some proponents understand it to mean a non-agricultural good that (1) is entirely or partially comprised of parts (i) that have been obtained from the disassembly of used goods; and (ii) that have been processed, cleaned, inspected, or tested to the extent necessary to ensure they are in original working condition; and (2) has a warranty. 
reaching agreement on acceptable approaches and allowing progress to be made in all the outstanding areas.

Despite these efforts, it is hard to see a way out of the impasse and it seems even harder in view of the most recent developments. One of the questions addressed by members is whether the negotiations should be pursued on the basis of the initial draft texts, and on which no consensus could be found, or whether the texts should be abandoned. That would mean developing new and alternative ways and means to making progress. There thus are two opposite positions: on one side the position maintains that the draft agreement should continue to be the basis for the negotiations as it reflects the closest members have come to an agreement. The other side argues that a new approach needs to be developed, given that the present one does not seem to lead to agreement, and also because the economic realities have changed.

\subsection{Example 3: The Information Technology Agreement}

The Ministerial Conference (MC-X) held at Nairobi resulted in an important Declaration on the Expansion of Trade in Information Technology Products. ${ }^{161}$ The Declaration is generally referred to as the Information Technology Agreement II (ITA-II), as it concerns the expansion of the first ITA originating from MC-I (Singapore). It essentially aims at easing trade by reducing and eliminating tariffs on trade in information technology goods. The decision taken by Ministers was followed by a speedy implementation, as under the terms of the Declaration the implementation is to be staged over a three year period, with the first cut implemented in July 2016. The elimination of tariffs and/or their cuts are expected to have a significant economic impact to the benefit of consumers and producers alike, both in developed and developing countries. The Declaration thus follows from a 20 year process of negotiations on information technology goods, stretching back to the creation of the WTO. The objective from the outset was to establish a sectorial agreement for technology intensive goods.

The Declaration and its immediate implementation provide a good example of the WTO's relevance and capacity to address current challenges in a world characterized by changing patterns in international trade, the emergence of GVCs and global and regional production networks. The ITA responds to the need to take into account the splitting up of the production process and an increase in trade of parts and components, which are used as inputs all over the world. In addition, the IT inputs into the production process are rapidly increasing, thus further strengthening the argument in favour of the ITA. The reduction of their costs will lead to more efficiency and lower prices.

161 WTO Ministerial Declaration on the Expansion of Trade in Information Technology Products, Nairobi, 16 December 2015, WT/MIN(15)/25.The Declaration should be read in conjunction with the Annex, WT/L/956, 28 July 2015, which is an integral part of the Declaration itself. 
The negotiations in 1996 were largely driven by the express will of the private sector to reduce transaction costs by lowering duties. The ITA thus focused essentially on tariff liberalization and covered $97 \%$ of world trade. ${ }^{162}$ It initially had 29 signatories, and the number increased to 42 participants by the time the ITA was implemented in mid-1997.163 Rapidly evolving developments in information technologies and the highly competitive trading environment meant that the ITA needed to be expanded. The parties to the ITA therefore initiated a review process of the product coverage almost immediately after the implementation of ITA-I which led to the ITA-II negotiations. These turned out to be particularly challenging, but the end result was very good. At various points in time participants were not able to accommodate their differences with regard to the product coverage for the expansion of the agreement. Negotiating a broader coverage of the ITA-II was mostly conducted between the participants bilaterally and outside the purview of the WTO. After lengthy and difficult negotiations this process came closer to a conclusion after agreement was reached between the United States and China on the inclusion of what were considered to be sensitive products by China. ${ }^{164}$ The agreement between the United States and China on what should be included in the expanded ITA had to be shared with and agreed by the other WTO parties such as Japan and the European Union before the ITA could be concluded and endorsed by all the participants. The discussions again hit a wall between China, Korea and Chinese Taipei with regard to the inclusion and coverage of some sensitive IT products. The issue was finally resolved, leading to the successful conclusion of ITA-II, which was ready for implementation. The first tranche of tariff cuts was implemented in July 2016, with the second tranche foreseen no later than 1 July 2017 , followed by successive reductions on 1 July 2018 and the effective elimination no later than 1 July 2019.165

Today, the ITA-II, which for ease of reference will now be referred to as the ITA, counts 52 participants, covering 80 WTO Members including the EU's 28 Member States. ${ }^{166}$ It is not only the first sectorial agreement to be successfully negotiated by developed and developing countries, but also the first one to liberalize trade in products in a specific sector after the Uruguay Round. Under the ITA, customs duties on IT products are eliminated and tariff concessions are included in the WTO Schedules of Concessions of each and all of the ITA participants, which implies that the benefits of the ITA are extended to the entire membership by virtue of the MFN principle. The decision to 'multilateralize' the outcome of pluri-lateral negotiations is significant in itself and illustrates that sectorial initiatives that are negotiated by a limited number of parties are not necessarily exclusive, as is often suggested. On the contrary, they can and in this case do benefit the entire WTO membership, thus

162 Cf. '15 Years of the Information Technology Agreement, Trade Production and Global Production Networks', WTO report prepared for the $15^{\text {th }}$ anniversary of the ITA (2011).

163 WTO at Twenty, p. 36.

164 In late October 2014, the press reported that the US, in bilateral discussions with China, demanded that the deal include tariff cuts on advanced semiconductors and flat panel displays, something China had resisted. In November, following a visit by the US Trade Representative (Mr Froman) to China, the bilateral negotiations led to an agreement which was presented to the negotiating parties of the ITA in Geneva.

165 WTO news item, 18 April 2016, https://www.wto.org/english/news_e/news16_e/

166 WTO at Twenty, p. 36. 
furthering the overall objective of trade liberalization. As international trade patterns have changed and new production techniques created new opportunities for developing countries, the lower costs of the intermediates should benefit developing and developed countries alike. Production is increasingly segmented into many different steps spread over different geographical locations. Keeping the cost of international transactions as low as possible is essential in determining industrial competitiveness. This makes the elimination of tariffs and other barriers to trade ever more important.

The economic meaning of the ITA is evidenced through the product categories that are covered by the ITA. It includes computers, semiconductors, semiconductor manufacturing equipment, telecommunication equipment, instruments, data-storage media and software, and parts and accessories. Parties to the ITA significantly reduced the rates of both the bound and MFN applied tariffs and eliminated duties on products altogether, thus effectively generating trade liberalization and market opening. The expanded ITA coverage resulted in the elimination of tariffs on an additional 201 IT products valued at over $\$ 1.3$ trillion per year. ${ }^{167}$ The lowering and elimination of duties imply price reductions of both the final and intermediate products, which are then used as inputs in the manufacturing of the final goods. According to the WTO, ITA participants accounted for $97 \%$ of global exports and $96 \%$ of global imports of IT products in 2013. Exports of IT products reached an estimated $\$ 1.6$ trillion in 2013 - almost triple the 1996 value, and accounted for approximately $9 \%$ of global merchandise exports. ${ }^{168}$ The ITA is important for facilitating international production and trade in light of the increased reliance by producers on global production networks. This also explains why the largest exporters of IT products are simultaneously the largest importers of these products.

According to the WTO trade patterns for IT goods have changed considerably over a 20 year period in terms of main traders and products, which is equally interesting to observe. It is no longer a domain reserved for developed countries' exports, as developing countries have consistently increased their participation in global trade of IT products, increasing from approximately $31 \%$ of exports and $27 \%$ of imports in 1996 to approximately $64 \%$ of exports and $51 \%$ of imports in $2013 .{ }^{169}$ Semi-conductors are the largest IT product category and accounted for $33 \%$ of global exports of IT products in 2013. They are followed by parts and accessories of IT products $(24 \%)$, computers and calculating machines $(22 \%)$ and telecommunication equipment $(16 \%)$.

The ITA significantly contributes to lowering the cost of IT products for both consumers and producers, who use the IT as inputs into the production process. Global sourcing has become a common practice in the IT sector. The WTO estimates that currently between $30 \%$

\footnotetext{
167 Cf. WT/MIN(15)/25, Annex, A.

168 Cf. '15 Years of the Information Technology Agreement' p. 50.

169 Cf. Ibid., p. 51; WTO at Twenty, p. 36; and World Trade Report 2015.
} 
and $60 \%$ of IT products are comprised of imported inputs or are used as inputs by others. ${ }^{170}$ The ITA will thus contribute to stimulating economic growth and lowering transaction costs.

In terms of process and institutional set-up, the ITA Committee was established to oversee the implementation of the ITA. Its functions include reviewing the product coverage, consulting on NTBs, considering classification divergences and serving as a forum to work out disagreements between participants. The ITA Committee has played a pivotal role in furthering the objectives of the Information Technology Agreement and ensuring that tariff eliminations are carried out as foreseen.

This example shows that while members face serious difficulties advancing the DDA negotiations, the sector approach followed with regard to information technology is yielding concrete and tangible outcomes with a potentially significant impact on world trade. It also shows that a sector approach that essentially focuses on tariffs and essentially is based on the offer-request procedure can work well and produce outcomes that will come to the benefit of the WTO's membership as a whole. This should not come as a surprise as similar positive results had been achieved previously in the area of civil aircraft: it had resulted in a specific agreement on trade in parts and components of aircraft. ${ }^{171}$

This then leads to the question why this approach is not replicated more systematically in other sectors between countries with similar interests and with the perspective of sharing the benefits more widely. The focus could be on other sectors that are economically meaningful for a sufficient number of economic actors. An important element in the discussion would be to ensure that the 'free-rider' situation is avoided and that all countries with a trade interest in the sector that is negotiated take part in the negotiations and exchange concessions. Another element would be to ensure that the results receive multilateral application, by inscribing the outcomes of the negotiations in the members' tariff schedules, as is the case for the ITA.

The next example will present a similar approach taken by interested members in the field of services trade.

\subsection{Example 4: Trade in Services and the Trade in Services Agreement}

The General Agreement on Trade in Services (GATS) is mostly a framework agreement with the explicit purpose to liberalize trade in services, but it has done little to open markets per se except in some specific sectors like telecommunications and financial services. ${ }^{172}$ The rapidly growing role of services in world trade and their increased use as inputs into the manufacturing of goods means that some of WTO's members that are actively involved in services trade have agreed on the need to advance the liberalization process. In the absence of

\footnotetext{
$170 \quad$ WTO at Twenty, p. 36

171 Cf. discussion in Chapter 2.

172 Ibid.
} 
sufficient progress in the WTO negotiations, they decided to move forward in an attempt to achieve tangible outcomes outside the framework of the WTO.

Services are intangible and hence a typical area governed by regulations rather than by some form of border protection. The regulations mostly determine the degree of openness that governments grant in a particular services sector and the degree of competition. The effects of regulations on the relative openness of a sector are much harder to assess than the liberalization of tariffs, which can more easily be cut in measurable and quantifiable ways. Market access conditions in services trade are determined by the 'commitments' exchanged by members. ${ }^{173}$ They are contained in the Schedules of Commitments - the corollary of 'tariff schedules' and as such determine the extent to which and the conditions under which services can be supplied. ${ }^{174}$ While the objective of the services negotiations in the DDA is to gradually provide for better market opportunities through liberalization, which is why it is part of the 'built-in agenda', little progress was made to that effect in these negotiations. The lack of substantial progress in the multilateral trade negotiations in services is often invoked as a reason why some members, obviously those that advocate further liberalization, decided to pursue discussions on how to further open markets outside the WTO. Marchetti and Roy note that the dynamism and importance in trade in services contrast sharply with the sluggishness of the WTO negotiations in this area, where the latest serious attempt to move things forward dates back to Mid-2008, on the occasion of the services signalling conference'. ${ }^{175}$ They explain that

[f]aced with that state of affairs, and against the background of a proliferation of preferential trade agreements (PTAs) covering services, a group of WTO members, the so-called "Really Good Friends of Services" (RGFs) agreed on 5 July 2012 to start preparing negotiations on an International Services Agreement to reinforce and strengthen the global services market.176

The initiative referred to as the TISA largely followed from that process. It is a private initiative between the interested parties and the WTO Secretariat has no role, not even as an observer. ${ }^{177}$ The negotiating members in TISA are collectively responsible for some $70 \%$ of world services trade.

\footnotetext{
173 Ibid.

174 Ibid.

175 J. Marchetti and M. Roy, 'The TISA Initiative: An Overview of Market Access Issues', 48 Journal of World Trade (2014), p. 683-728.

176 Cf. Ibid. At present there are 24 WTO members participating in the discussions including Australia, Canada, Chile, Colombia, Costa Rica, the European Union, Hong Kong, China, Iceland, Israel, Japan, Korea, Liechtenstein, Mexico, New Zealand, Norway, Pakistan, Panama, Paraguay, Peru, Switzerland, Chinese Taipei, Turkey and the United States.

177 It is noted here that in the context of the DSU reform, there are also negotiations and talks taking place between key WTO members, without the WTO Secretariat. However, and unlike the situation with TISA, these discussions are not referred to as taking place outside the WTO as they involve the membership as a whole.
} 
In many ways the lack of progress in the services negotiations matches the lack of progress in the negotiations on Agriculture and NAMA. In order to give some new energy to the negotiations and test the interest of members to go any further in liberalization in services trade, the so-called services 'signalling conference' was held in summer 2008 and led to very few initiatives. The 'signalling conference' was meant to allow members to provide clear and specific indications on their flexibilities to open markets for services transactions with a view to broaden the commitments, thus enhancing trade liberalization. The conference was part of the broader attempt to ensure steady parallel progress in the three main areas of negotiations: Agriculture, NAMA and services. It was hoped and perhaps even expected that it would provide a basis for a stronger commitment on the side of the members to progress the liberalization process further. The results were rather poor, with little movement and flexibility shown by the members.

Hence, while the ITA was designed from the outset to be part of the WTO negotiations this is not the case for the TISA. It would be designed as a plurilateral agreement, open to signatories willing to commit to services liberalization. In a way the process would be similar to the Government Procurement Agreement (GPA), with a gradually expanding membership to include new members, and that is willing to take higher levels of commitments. A critical difference is that the GPA is part of the WTO and TISA is not. For the very same reasons, these discussions are conducted outside the WTO and the Secretariat is not involved and has no role whatsoever.

The necessity to advance in this area is mostly driven by the economic realities - which have changed over the last 20 years - and with services now being such an important input into the production process that it can no longer be ignored in the market access conditions. According to calculations by Escaith, the share of the services contained in the final product often exceeds the share of the goods, reaching close to $70 \%$ in developed economies and often well above the $50 \%$ mark for developing countries, which makes it hard to ignore. ${ }^{178}$ Looking more specifically at GVCs, the trade statistics show a rapid increase in the role of services in the value adding process. Similar calculations can be found in the WTO annual report 2014, which puts equal emphasis on the steadily increasing importance of services as inputs into the production process and GVCs. ${ }^{179}$ Increasingly, the hard and soft parts in the products are becoming indivisible and are closely interlinked. Hence there is a perceived need and urgency to make progress with regard to liberalization of trade in services.

The study by Marchetti and Roy analyses the question of the potential additional market access that the TISA can generate in light of the multitude of bilateral, regional and subregional Preferential Trade Areas (PTAs) already in place. ${ }^{180}$ They conclude that this is not obvious from the outset, but then they look at the more fundamental question which is of critical importance to the WTO: the relation of the TISA with the multilateral trade rules of

\footnotetext{
178 H. Escaith, 'Measuring Trade in Goods and Services', 1 International Trade Forum (2013).

179 World Trade Report 2014.

180 Cf. Marchetti and Roy, 'The TISA Initiative'.
} 
the WTO. Obviously the WTO membership would benefit from multilateral trade liberalization in services, instead of limiting the benefits to the parties to TISA. The question therefore is whether there would be a way of multilateralizing the outcome of the negotiations, by virtue of the MFN principle. If not, is TISA more likely to become a plurilateral agreement outside the scope of the WTO, with the benefits only limited to its parties? According to the authors, referring to General Council debates in June 2013, participants had indicated that the TISA should be compatible with the WTO and could be multilateralized at some point. It can be seen therefore that there are various possibilities and TISA could be a building block towards further multilateral liberalization of trade in services, although it could also just become the largest 'services only' PTA. ${ }^{181}$

Four possible scenarios for TISA are possible:182 (1) GATS Protocol approach, on a MFN basis; (2) going it alone on an MFN basis; (3) a plurilateral agreement within the WTO; (4) a plurilateral agreement outside the WTO

\subsubsection{GATS Protocol approach, on a MFN basis}

Under this scenario the authors note, 'TISA participants would incorporate their new commitments into their own GATS schedules by way of a protocol'. Doing so would follow the logic of other similar protocols that are already part of the GATS. ${ }^{183}$ The benefits would then be extended by virtue of MFN to all members. In terms of WTO consistency, such approach would be the best and preferred option, as it preserves the multilateral character of the negotiations. It follows the logic that the results of bilateral or plurilateral negotiations are translated into the multilateral arena similar to the way tariff reductions are performed for goods. The authors note that

the precedents that were created with regard to financial services and telecoms led to two important lessons. First the commitments did not concern only market access and national treatment disciplines, but also regulatory principles, which were entered as "additional commitments" in these WTO members' Schedules, particularly in the area of financial services and telecommunications. The basic Telecommunications Reference Paper constitutes the quintessence of the multilateral approach to regulatory disciplines by which relevant WTO members contracted GATS+ disciplines on regulations affecting trade in the sector. ${ }^{184}$ Second, in order to ensure that those new commitments would enter

181 Ibid p. 717.

182 The four bullet points presented are those of the authors and the discussion on each of the four points made try to capture the logic developed by the authors and concepts contained therein. Any error or misrepresentation of the concepts is my own.

183 These include the Second GATS Protocol: Revised Schedules of Commitments on Financial Services, the Third GATS Protocol: Schedules of Specific Commitments relating to the Movement of Natural Persons (Mode IV), the Fourth GATS Protocol: Schedules of Specific Commitments concerning Basic Telecommunications and the Fifth GATS Protocol: Schedules of Specific Commitments and Lists of Exemptions from Article II.

184 Telecommunications Services Reference Paper, WTO, 24 April 1996. 
into force only if a "critical mass" of participants in the negotiations had actually accepted them - a way of reducing free-riding among participants, the protocols provided that in case not all participants had ratified by due date, those who had actually accepted the protocol by the due date would eventually decide on its entry into force. ${ }^{185}$

The Telecommunications Reference Paper provides for a good precedent, as it sets out pro-competitive regulatory principles to reinforce the opening of the telecom markets. It is legally binding for those members that appended it to their services' schedules. It largely encapsulates best practices in telecom regulations with regard to the independence of the regulators, interconnection safeguards, licensing procedures, universal service obligations and the allocation of scarce resources. It codifies members' shared understanding of how competition in the sector should be safeguarded. In this sense it is considered an international blueprint for telecommunications reform. Its principles are sufficiently broad to accommodate country specific regulations, but precise enough to hold to account those governments that have undertaken relevant bindings in their GATS schedules.

The 'critical mass' approach would imply that the new commitments become part of the GATS, and therefore the WTO framework, through incorporation into the schedules of the WTO members concerned. This would be the most WTO consistent approach and the preferred way to proceed in order to extend the benefits to all WTO members.

\subsubsection{Going it alone on an MFN basis}

Under the second scenario, TISA participants could unilaterally improve their existing specific commitments through individual certification procedures. The authors indicate that this option is already applied by 20 members, which have introduced changes to their commitments in this manner outside the context of the WTO negotiations. ${ }^{186}$ The authors explain that this procedure follows a well-established practice dating back to the GATT times, where WTO members would approve individual requests for the introduction of amendments to existing schedules deemed to be improvements of commitments or changes of a purely technical nature that do not worsen the scope or the substance of the existing commitments. Once the approval has been given, the new commitments would be incorporated into the schedule of the WTO member concerned. The new commitments would therefore benefit all other WTO members through the MFN principle.

This procedure would again be consistent with GATT and WTO procedures and would lead to changes in the individual members' schedules, reviewed by the WTO Members collectively.

\footnotetext{
185 Cf. Marchetti and Roy, 'The TISA Initiative', p. 718.
}

186 Cf. Ibid., p. 719. 


\subsubsection{A plurilateral agreement within the WTO}

The third option offered by the authors would be to adopt a plurilateral agreement, which is binding upon only those members that subscribe to it. Article X:9 of the WTO Agreement foresees the addition of new plurilateral trade agreements, subject to a decision by the WTO Ministerial Conference taken 'exclusively by consensus'. The logical implication of this approach is that the advantages are limited to only those members who do not have an obligation to extend the advantages to the WTO membership as a whole. It would therefore still be WTO consistent if this route is to be agreed by the membership, but the economic benefits would automatically be limited to those parties directly involved in the negotiations. This approach is not unique as there are and have been various plurilateral agreements in the WTO, the main one being the GPA. Other examples discussed earlier include the agreements on Trade in Civil Aircraft, Bovine Meat and Dairy Products, but the latter two have been absorbed by the Agreement on Agriculture and no longer operate as plurilateral agreements: they effectively expired in the 1990s. ${ }^{187}$ This option would thus provide for what is referred to as 'a shallower multilateralization', to the extent that commitments and obligations would be non-MFN, but the agreement would still benefit from the multilateral dispute settlement system and might allow for the expansion of its membership. The authors note that 'the challenge would be to obtain consensus from the non-TISA participants'. ${ }^{188}$

\subsubsection{A plurilateral agreement outside the WTO}

The final option would be to conclude a plurilateral agreement outside the scope of the WTO and without extending the benefits to other WTO members. This could take the form of an 'economic integration agreement' as allowed for under Article V of the GATS under specific conditions and which may be a challenging. Marchetti and Roy note that 'the first condition under Article V is that the agreement has "substantial coverage", "understood in terms of number of sectors, volume of trade affected and modes of supply", as clarified in a footnote to that provision'. ${ }^{189}$ In addition, they explain that in order to meet this condition, 'agreements should not provide for the a priori exclusion of any mode of supply'. The second condition imposed is that the agreement must provide for the 'absence or elimination of substantially all discrimination, in the sense of Article XVII, between or among parties, in the sectors covered'. This should happen through the '(i) elimination of existing discriminatory measures and/or (ii) the prohibition of new or more discriminatory measures'. In addition, Article V imposes obligations with a view to protecting third parties. Specifically, Article V:4 provides that economic integration agreements 'shall be designed to facilitate trade between the parties to the agreement and shall not in respect of any member outside the agreement raise the overall level of barriers to trade in services within the respective sectors or subsectors compared to the level applicable prior to such an agreement'. ${ }^{190}$

\footnotetext{
187 Cf. Chapter 2.

188 Cf. Marchetti and Roy, 'The TISA Initiative', p. 720.

189 Ibid., p. 721.

190 Ibid.
} 
Obviously, this solution is the least desired in terms of WTO compatibility, as TISA would squarely remain outside the multilateral framework. Which of the options will be pursued is unclear. The final choice remains a systemic issue for the WTO members to take. What this discussion illustrates, however, is that members have various options at their disposal to further liberalize trade in a specific area and without discriminating against those members that do not take part in those efforts. Increasingly one hears members say that TISA should get a multilateral application, which means that the benefits of the liberalization would accrue in one way or another to the membership at large. At the same time, it is doubtful that this would happen given the fact that some important WTO members are excluded from TISA and which is not by omission. Extending the benefits of TISA free of charge to those countries that did not participate in the negotiations and did not make any concessions would seem rather unlikely, as it would drive the free-riding principle to its extreme.

\subsection{Conclusion}

It is argued in this chapter that enhancing market access opportunities was central to the GATT multilateral trading system and it is again a main objective in the DDA negotiations at the WTO. With the elimination of quota restrictions in their different forms, the role of tariffs as a policy instrument was further strengthened. Overall levels of tariffs had already been considerably lowered during the various rounds of trade negotiations, especially in developed and less developed and developing countries. The latter group had mostly bound their duties, sometimes at ceiling levels and reduced tariffs, albeit to a lesser extent than in developed countries. The focus of attention in the current negotiations is specifically on the reduction of high tariffs, tariff peaks, and reducing tariff escalation, which would largely be of benefit to developing countries. The tariff reduction formulas that were initially proposed in the DDA negotiations directly aimed at high tariffs and tariff escalation and were well suited for the purpose of achieving those objectives. It is argued that members could not agree on them because they are too complex in their practical application and are riddled with exceptions. The negotiators have gone too far in trying to take into account specific country situations, thus undermining transparency and making it unclear what their ultimate impact could be in quantitative terms.

These realities are considered to be the main factors explaining the impasse that the current negotiations of the DDA find themselves in and there has been no viable solution to break the deadlock. It is suggested that in order to advance the liberalization process, alternative ways and means to negotiate the tariff reductions need to be considered. The history of tariff negotiations provides insights in approaches and techniques, including the offer-request procedures, or a combination of request-offer and a tariff reduction formula, which have led to significant results in previous rounds. In addition, sectorial negotiations have proven to yield good results for liberalizing trade - for example through the ITA for technological goods. Hence, there are workable alternatives to the formula approach. It is proposed that these options be given more attention to achieve tangible results and liberalize trade further in sectors that are of economic importance to a critical mass of countries. The 
results in the ITA also show that the results of the negotiations can be extended to the membership on an MFN basis. This was also done in previous rounds and could again serve as future guidance. One could even look more specifically at sectors that make a significant contribution to GVCs and focus on the parts and components most relevant to the global or regional production networks.

Following a discussion on negotiating approaches and techniques, the chapter then provides an analysis on the market access negotiations in the DDA. They are in many ways unique as it is the first time that trade liberalization in agriculture is a specific objective. The political and economic considerations and the sensitivity of the sector made this rather unthinkable during the GATT. The changing economic realities rendered negotiations possible. They have proven to be challenging with no agreement in sight. The negotiations are meant to evolve in three key pillars, but have had only modest success. Export subsidies have been now fully eliminated, which is a significant outcome. Work is not advancing in the market access and domestic support pillars. The three-tiered tariff reduction formula proposes different reduction commitments for different countries, depending on their levels of economic development. The draft agreement is riddled with exceptions, rendering the proposed text less transparent as to what it may achieve. The same holds true for the negotiations on NAMA, which are far more complex than ever before. This is in part due to the large number of members, but more specifically because of the ways the negotiations are pursued. The draft agreements on agriculture and NAMA try to resolve both global and very specific issues in manners that make them very detailed and complex, with all members adding to their wish list. In terms of ways forward, the step by step approach with a view of harvesting partial results as the negotiations progress is again advocated in order to progress and achieve tangible outcomes.

This chapter includes four examples illustrating the evolution of trade liberalization from the GATT to the WTO. The first examples focused on the 'old economy', the next two on the 'new economy'. The example of trade in textiles and clothing illustrated how tariffs and nontariff measures - more specifically quotas - were eliminated over a transitional period of 10 years. This is a significant outcome of the Uruguay Round as textiles and clothing are considered to be highly politically sensitive sectors, accounting for considerable employment in some countries. The ATC meant that this whole sector fully integrated into the multilateral trading system, led to the complete abolishment of the 40 year old quota regime that was characteristic of the sector, and it is now covered by a tariff only regime. Tariffs remain high and will need to be reduced further.

The second example addressed the issue of tariff escalation for leather and leather products. It was argued that the tariff structure in these sectors work in ways as to undermine specialization and value adding by developing countries, thus essentially depriving them from entering into the higher end of the market. The tariff reduction formula proposed in the DDA would contribute to eliminating much of the tariff escalation and harmonizing duties at the various stages of processing. In the absence of an agreement on the formula, 
high tariffs and tariff escalation prevail. It was also argued that there is considerable room for developing countries to move up on the ladder of GVCs in order to benefit more from lowering transaction costs and increasing their revenues. Specific suggestions were made for regional cooperation arrangements between countries, building on the regional strength and capacities and in order to add value to the production process.

In order to advance the liberalisation process and despite the impasse in the DDA, it is suggested to look at areas where progress can be and/or even was made, including in sectors of significant economic interest to the WTO's membership. Even if not all members participate in these negotiations, their outcome can still benefit the entire membership. Two illustrative examples were presented relating to the 'new economy': one concerns efforts pursued by members to achieve tangible results in the negotiations on the ITA and one relating to TISA. While the first agreement is explicitly part of the liberalization efforts undertaken in the WTO following the decision taken by Ministers at Singapore in 1996, the negotiations of the second one, TISA, fall outside the scope of the WTO. The economic benefits that are calculated to emanate from the ITA, including the tariff reductions and zero duty treatment for IT goods that will follow from the implementation of the ITA are undisputable and significant. They are estimated to amount to several billions of economic savings worldwide on a yearly basis. While the ITA was negotiated by a limited number of participants, the benefits will accrue to the WTO membership as a whole by virtue of the MFN principle. The ITA is living proof that the negotiations in the WTO can yield results and agreements which are economically meaningful.

TISA is still being negotiated by a number of countries with high ambitions in the area of services trade. The future legal relation between TISA and the WTO remains uncertain for now. It was argued that the benefits could be extended to the membership as a whole by virtue of the MFN principle, provided that the TISA members decided to do so. From the discussions with those members who are part of the negotiations and others following them closely, this option though seems rather unlikely, given the fact that some of the members who are important service providers are excluded from the negotiations. If nevertheless and in the unlikely case the benefits are multilateralized, that would considerably enhance the multilateral market access conditions in the trading system. The example also shows that market access in services is complex given the regulatory nature of services, the economic impact of which is harder to measure than tariffs. Related to this is the question of what segments should be opened to competition, for example the market, and what should be kept under government control.

To conclude, it can be seen that the trading system has evolved rapidly and so have the market access issues. The debates on complex formulas with its many exceptions have not yielded an outcome since the discussions began in 2001 with the launching of the DDA and positions are increasingly entrenched with little prospect of a solution. The question that is therefore raised is whether the trade negotiators should continue spending their time and capital on pursuing the efforts to achieve results the 'old' way - the one that didn't work for 
16 years and consisting of covering all specific member situations through general formulas, riddled with exceptions, or alternatively, focus more on new approaches to liberalization, with more flexibilities and including in sectors that bring the largest economic gains. An element to bear in mind in those debates is that the economic realities have changed both in the field of agriculture and goods. When the DDA was launched in 2001 the role of technology was nowhere near to the one it plays today and it is increasingly characterized by a digital economy. Equally, services were not integrated in goods in the same way that they are today. These elements need to be captured more fully in the debates. 


\section{CHAPTER 5: TRADE CAPACITY BUILDING FOR THE FULLER INTEGRATION OF DEVELOPING COUNTRIES INTO THE WTO MULTILATERAL TRADING SYSTEM: CHALLENGES AND OPPORTUNITIES}

\subsection{Introduction}

One of the key objectives of the Doha Development Agenda (DDA) negotiations is to facilitate the integration of developing countries into the World Trade Organization's (WTO) multilateral trading system. Some developing countries have been able to take advantage of the rapidly growing interdependency of markets and globalization, generating sustained levels of economic growth in their countries, and participating actively in the multilateral trading system. Others continue struggling economically, remaining on the fringes of the trading system, where they face difficulties coping with the complexities of trade rules and drawing benefits from the trading system. This is particularly the case for the LDCs.

This chapter discusses how trade capacity building contributes to achieving the objective of a better and fuller integration of developing countries in the trading system. It starts with a brief analysis (section 5.1) of the evolution of trade policies conducted by the developing countries to attain their development objectives. One element is a marked and gradual shift, moving away from inward-looking trade policies towards more market-oriented and liberal approaches. The rationale for countries to open their markets and engage in economic reforms is largely based on the awareness and recognition of the fact that trade contributes to generating economic welfare and growth. It will be argued that the trade capacity building efforts undertaken by the WTO Secretariat jointly with other organizations have played a key role in assisting the integration of developing countries in the trading system. It has contributed to a better understanding of the rules and the benefits of trade, resulting in a growing interest in trade and trade policies. Active participation in the WTO and more specifically in the DDA negotiations has enabled them to better understand the stakes and design policies in support of achieving their development objectives.

The key aspects of trade capacity building in the WTO provided to developing countries and more specifically since the launching of the DDA negotiations in 2001 will then be discussed in section 5.2. The evolution of the tools and mechanisms available in the WTO will be reviewed and more specifically how this support has gradually moved from 'learning' to 'practice' and in applying the skills that are acquired. It will be argued that this not only requires a continuous rethinking of and updating of the tools and training material, but more importantly an understanding of how the knowledge acquired is translated into policy. How do the beneficiaries take advantage of the programmes and do these assist them in their 
efforts to integrate more fully into the multilateral trading system? How can the results of the support provided be measured and what are some of the accomplishments?

The answers to some of these questions will be addressed more specifically in section 5.3 which provides an analysis on the extent to which developing countries and Least Developed Countries (LDCs) increased their shares in world trade and became active players in the DDA negotiations. It includes both a quantitative and qualitative assessment of the state of their integration into the multilateral trading system. The data presented confirm the beneficial effects of the collective efforts undertaken by the WTO and the membership to assist developing countries integrating into the multilateral trading system. Developing countries and LDCs, contrary to the time of the GATT, are now actively participating in international trade and shaping the multilateral trade negotiations. This is illustrated by examples of specific proposals they have tabled on issues of immediate relevance to them in pursuing their development objectives. The proposals often address complex and technical issues, which show their increased capacity to understand the issues and defend their legitimate interests in the negotiating process. The positions often reflect common and collective interests, shared by other developing and/or developed countries. Developing countries are also facing a challenge in taking part in Global Value Chains (GVCs). It will be argued that effort will be needed in order to reap the benefits of trade.

This discussion is then followed by a case study, which illustrates how the Trade Facilitation Agreement (TFA) that was negotiated at MC-IX (Bali) is of critical importance to developing countries. There is a general agreement among academics, confirmed by findings contained in studies undertaken by the WTO and other international organizations, that the economic benefits of the TFA are very significant. More importantly, they will mostly accrue to developing and least developed countries. Following the implementation of the TFA, transaction costs will decrease significantly, leading to higher cost efficiency and generating new export opportunities for developing countries and LDCs. At the same time, the TFA includes a new approach for the delivery of trade capacity building and contains binding obligations for both developed and developing countries. It includes not only capacity building measures but also concrete support in reinforcing the infra-structures to implement the agreement. This is a significant departure from the best endeavour provisions that are characteristic for most of the present agreements and holds important promises. It is therefore of critical importance for developing countries and LDCs to ratify the new TFA so as to benefit from the trade capacity building support.

This chapter concludes with a presentation of the findings (section 5.5).

\subsection{Developing Countries in the WTO}

The interest of developing countries in the multilateral trading system has significantly increased since the creation of the WTO and so has their participation in international trade. 
This is confirmed in a recent World Trade Report of the WTO and in an earlier WTO study which discussed the rapid changes in policies in both the developed and developing world. ${ }^{1}$ Hoekman and Kostecki explain how the approaches adopted by developing countries for fuller integration into the trading system have evolved. They observe that 'the terms of developing country participation in the multilateral trading system have oscillated between reciprocity and disengagement.' ${ }^{2}$ They then explain the timelines and major highlights with regard to the developing country approaches in the negotiations from the time of the creation of the GATT to the present time, which, according to the authors, is a shift back to an emphasis on special and differential treatment (S\&D), especially for LDCs. ${ }^{3}$ While there certainly is a strong emphasis on the S\&D provisions in the discussions on how to best assist developing countries integrating into the multilateral trading system, there clearly is a stronger commitment and more active participation of developing countries in the negotiations than ever before. What explains this evolution? Who are the developing countries in the WTO? How do they participate in the multilateral trading system and how do the multilateral trade rules apply to them?

The majority of the WTO membership, some three quarters, is made up of developing countries. As was explained in Chapter 2, the WTO does not provide a definition of a developing country. Like its predecessor the General Agreement on Tariffs and Trade (GATT), it is largely based on self-election, with members themselves declaring whether they consider themselves 'developing countries'. The distinction can be quite important in terms of levels of obligations: developed countries have higher levels of commitments and obligations than developing countries which mostly benefit from special and differential (S\&D) treatment provisions. As will be explained further, the purpose of S\&D provisions is to allow developing countries to integrate more smoothly into the trading system, and not impose the same WTO obligations that apply to developed countries. S\&D provisions vary and can include longer transition periods or lesser commitments.

According to Van den Bossche and Zdouc,

The group of developing country-Members in the WTO is very diverse in its composition, and includes very large countries as well as minuscule island states; fast-growing, export-oriented emerging economies and net-food importing countries; mineral-rich countries and countries less endowed by nature; and democratic, well governed countries and totalitarian, corruption-ridden

1 World Trade Report 2014: Trade and Development: Recent Trends and the Role of the WTO, WTO (2015); WTO Guide to the Uruguay Round Agreements, WTO (1999), p. 223-246. This study provides a detailed analysis of the evolution of the participation of developing countries in the GATT/WTO system including information on how the specific provisions in the various WTO Agreements apply to developing countries.

2 B. Hoekman and M. Kostecki, 'Developing Countries and Economies in Transition', in B. Hoekman and M. Kostecki, The Political Economy of the World Trading System (3rd edition, Oxford University Press, 2009) p. $522-582$.

$3 \quad$ Ibid., p. 535. 
countries. It includes upper-middle income countries, such as Brazil, China, South Africa, Ecuador and Saint Lucia; lower-middle income countries, such as India, Pakistan, Nigeria, Egypt, Ghana and Tonga; and low income and leastdeveloped countries such as Bangladesh, Cambodia, Haiti, Kenya, Mali and Nepal. ${ }^{4}$

Some of the WTO's developing countries are also OECD members, an organization often perceived as being closely linked with the interests of developed countries, including Mexico, South Korea and Chile..$^{5}$ Other developing countries are not generally perceived as such, such as Singapore and Hong Kong. The BRICS, which include some of the world's fastest growing economies, are with the exception of the Russian Federation, considered developing countries in the WTO, even though China has climbed to the highest rankings in international trade (see chapter 3$)^{6}$

Of the $48 \mathrm{LDCs}$ at the WTO, 36 are WTO members, and the majority (25) are located in Africa. A total of nine LDCs have joined the WTO since its creation in 1995. As was explained earlier, the LDCs take a special position in most of the WTO Agreements and are mostly exempted from being subject to the same level of legal WTO obligations and commitments as developed and other developing countries. Given their special status as LDC, which in effect means they are the poorest of the poor members, they mostly press their claims on specific topics of interest to them, more particularly in the debate on the S\&D treatment provisions conducted through the WTO Committee on Trade and Development (CTD).

There is a marked difference between the GATT and the WTO in terms of developing countries' participation in the multilateral trading system. The historical evolution and policy approaches can be described as follows: the period between the 1960s and the 1980s was very much characterized by what was generally referred to as a 'North-South' divide, with the developed countries pursuing open and market-based policies and the developing countries frequently turning inwards in order to shield domestic industries against foreign competition. ${ }^{8}$ The import substitution policies applied by developing countries meant that imports of foreign products were replaced by domestic goods. The underlying economic concept was that a country should stimulate domestic production rather than depend on

4 See P. van den Bossche and W. Zdouc, The Law and Policy of the WTO (Cambridge University Press, 2013), p. 105-106.

5 The Organization for Economic Cooperation and Development (OECD).

6 Some of the BRICS experienced particularly high growth rates until the financial crisis started in 2008, following which their performance mostly disappointed.

7 In order of date of accession: Nepal, Cambodia, Cape Verde, Samoa, Vanuatu, Lao PDR, Yemen, Afghanistan and Liberia.

8 J. Whalley, 'The North-South Debate and the Terms of Trade: An Applied General Equilibrium Approach', Centre for the Studies of International Economic Relations Working Paper, University of Western Ontario (No. 8205C, 1982). 
foreign dependency. While the debates on and arguments in favor or against import substitution policies are not conclusive, the reality is that developing countries largely moved away from these policies, gradually opening their markets. The import substitution policies were largely abandoned, with an increasing number of developing countries pursuing more open and liberal economic policies in an attempt to diversify production and to use their comparative advantage, as advocated in the WTO. Many reasons explain this change of direction and more open approach.

The logic and rationale of these market oriented and liberal policies is underpinned by the economic theory and detailed in the WTO's World Trade Report of 2014, where it is argued that the case for free trade typically rests on the existence of gains from trade. ${ }^{9}$ The World Trade Report advances several arguments confirming that

the opening up of the economy increases a country's GDP, because it improves the efficiency of its resource allocation. There are three main reasons for this: first, trade allows each country to specialize in the production of goods it can produce more cheaply and import the other goods, thus exploiting comparative advantages; secondly, by extending the size of the market in which the firm operates beyond national borders, trade allows firms to exploit economies of scale; thirdly, trade selects the most productive firms in the market. ${ }^{10}$

The link between trade and growth is supported by evidence provided in the economic literature and with specific examples of how the rapid growth of some of the Asian economies was rendered possible due to market opening policies.

The extent to which these positive results can be attributed to trade liberalization per se can also be debated. According to Chang, some countries that have reached a more advanced stage of development have accomplished this with a mix of policies, including what is referred to as behind-the-border and protectionist measures. ${ }^{11}$ The so-called behind the border policies include domestic policy measures favoring domestic production. Trade liberalization was often pursued only after reaching a more advanced level of maturity and this has been the case for some Asian countries in particular. In many other cases, these policies did not yield the expected results. He illustrates this with various examples of African countries and argues that the import substitution industrial policies have not worked in Africa for different reasons. A main reason is related to the alternative policies advocated

9 WTO World Trade Report 2014: Trade and Development: Recent Trends and the Role of the WTO, WTO (2014), p. 60-61.

10 Ibid.

11 H.J. Chang, Kicking Away the Ladder: How the Economic and Intellectual Histories of Capitalism Have Been Rewritten to Justify Neo-Liberal Capitalism (Cambridge University Press, 2002); C. Soludo, O. Ogbu and H.J. Changa (eds.), The Politics of Trade and Industrial Policy in Africa, Forced Consensus? (Africa World Press, Ottawa, ON, 2004). 
by the Bretton Woods Institutions, including the structural reform programs of the IMF and World Bank: these are considered to be more effective in achieving sustainable economic growth. ${ }^{12}$ The merits of the import substitution policies continue to be widely debated by academics with arguments put forward both in favor and against such policies. Dani Rodrik argued in 2007 that import substituting industrialization (ISI) had what he refers to as a 'more-than-respectable productivity record' and is based on economic data. ${ }^{13}$

The case that liberalization may require governments to temporarily resort to trade restrictive policies is also made by Van den Bossche and Zdouc, who argue that

while most economists advise that governments should - in the interest of their country as a whole and that of the world at large - pursue policies aimed at promoting international trade and exchange goods and services on the basis of their comparative advantage, political decision makers do not necessarily heed that advice. ${ }^{14}$

Based on the recent literature, Van den Bossche and Zdouc argue that 'governments have multiple, often overlapping, reasons for restricting trade'. ${ }^{15}$ They advance six main arguments for such restrictions, which can be summarized as follows: (i) to protect a domestic industry and jobs threatened by import competition; (ii) to assist the establishment of a new industry; (iii) to support a domestic industry to establish itself on the world market; (iv) to generate government revenue; (v) to protect national security and ensure selfsufficiency; (vi) to protect and promote non-economic social values and interests, such as public morals, public health, safety, a sustainable environment, human rights, minimum labour standards, consumer safety, and cultural identity and diversity.

While each of the arguments may have its own merits, the beneficial effects of trade liberalization were given increasing weight. Trade liberalization generates competition, thus stimulating efficiency and cost reductions. Imports generate better fiscal revenues at the borders and lead to exports, as imported parts and components are needed for domestic

12 Under the IMF and World Bank Structural Adjustment Programmes (SAPs), and in order to benefit from loans, countries are generally required to undertake market oriented reforms, which include trade liberalization, geared towards enhancing competition.

13 Dani Rodrick's weblog, Unconventional Thoughts on Economic Development and Globalization, 'August 2,

2007: Does Import Substitution Deserve Its Unsavoury Reputation?'

http://rodrick.typepad.com/dani_rodrick_weblog/2007/08. His arguments were countered by The

Economist: Import Substitution: Do Not Resuscitate', 7 August 2007.

14 Cf. van den Bossche and Zdouc, p. 22-26.

15 M. Bacchetta and M. Janssen, 'Adjusting to Trade Liberalization: The Role of Policy, Institutions and WTO Disciplines' in Special Studies Series, WTO (2003), p. 6; B. Hoekman and M. Kostecki, The Political Economy of the World Trading System: The WTO and Beyond (2nd edition, Oxford University Press, 2001), p. 22; J. Stiglitz, 'Addressing Developing Country Priorities and Needs in the Millennium Round', in R. Porter and P. Sauvé, (eds.), The WTO and the Future of the Multilateral Trading System (Harvard University Press, 2000), p. 51-3; P. Krugman, 'Is Free Trade Passé?', 1 Journal of Economic Perspectives (1987), p. 141. 
production, thus enhancing a country's competitiveness on international markets. Trade generates a transfer of technology, skills and foreign direct investment (FDI), thus adding to the productive capacities of a country and this is well documented in the economic literature. ${ }^{16}$ It also had wider implications on the ways the trade negotiations were conducted.

According to Laker, 'research noted the shift from the original passivity, defensiveness and special and differential treatment approach in developing country policy behaviour to reform and trade liberalization behaviour by the mid-1980s'.17 The changing policies, including the trade liberalization that followed in the 1980s and later years yielded tangible results: some countries clearly showed the fruits of market opening policies, generating domestic competition and becoming strong economic actors on world markets. This was seen particularly in some South East Asian economies which in the 1980s gradually opened their markets and introduced liberal policies thus generating economic growth and leading to an increase in their shares in world trade. ${ }^{18} \mathrm{~A}$ typical and more recent example is China, which, as was argued in Chapter 3, has strongly benefited from the liberalization performed following WTO accession. Other countries that developed very fast include South Korea, Singapore and Hong Kong. Countries that have recently done very well economically and have experienced very high growth rates are Vietnam, Indonesia, Turkey and Mexico.

This awareness of how trade can generate economic growth contributed to the radical change in mind-set followed by a shift in policies in other developing countries and leading to liberalization. Such liberalization was initiated both at the multilateral level as well as often undertaken autonomously, without requesting trade concessions. ${ }^{19}$ Some developing countries pursued autonomous liberalization in the 1980s by reducing high tariffs and binding duties at lower levels. Many of these efforts were pursued independently of the trade negotiations, in order to enhance efficiency and competitiveness. ${ }^{20}$ As was argued

16 Cf. WTO World Trade Report 2014, which includes a review of the current literature.

17 J.A. Laker, African Participation in the World Trade Organization, Legal and Institutional Aspects, 1995-2010 (Martinus Nijhoff Publishers, Leiden, 2014), p. 7. The literature that is referred to includes R. Hudec, Developing Countries in the GATT Legal System (Trade Policy Research Centre, London, 1987; also Cambridge University Press, 2009, 2010); J. Whalley, 'The North-South Debate and the Terms of Trade: An Applied General Equilibrium Approach', Centre for the Studies of International Economic Relations Working Paper, University of Western Ontario (No. 8205C, 1982); T.N. Srinivasan, Developing Countries in the Multilateral Trading System (Westview, 1998); C. Michalopoulos, 'The Developing Countries in the WTO', 22 The World Economy (1999), p. 117-143

18 This was argued in M. Smeets, 'The Success of the Economic Dragons, 76 Economische Statistische Berichten (1991), p. 764-767 which provides for a discussion of the emergence of some new, mainly Asian, market leaders in the world economy.

19 The issue of autonomous trade liberalization was explained in chapter 4 and reflects the economic notion that trade liberalization is good for any economy per se, including autonomous tariff reductions, without concessions.

20 This development was particularly noticeable in Latin America and the Caribbean, where many countries had very high tariffs and few tariff bindings. Independently of the negotiations, many decided to introduce ceiling 
previously, this was typically the case in Latin American countries, many of which undertook autonomous liberalization leading to rapid economic growth. ${ }^{21}$ These trends also explain the keen interest of developing countries to actively take part in the WTO negotiations as an effective tool to generate economic growth and enhance levels of welfare. The extent to which and how this was translated into action will be discussed further below.

The push towards liberalization also had implications for the way trade negotiations were conducted, based on the recognition that developing countries would benefit from trade by liberalizing. At the same time, it was felt that they would not be in the same position as the developed countries to exchange concessions. In other words, the widely held view was that liberalization is good, as long as it is a gradual process. The way to address this was by way of granting developing countries S\&D treatment.

The history of the S\&D provisions in the WTO goes back to the GATT in the late 1970s, when the Enabling Clause was created and Part IV added to the GATT rules. ${ }^{22}$ To put matters into historical context, when the GATT was created shortly after WWII, world trade was not conducted in the complex manner that it is conducted today and developing countries played an insignificant role in trade. ${ }^{23}$ The number of developing countries in the GATT was limited and generally there was little interest on the part of developing countries in the world trading system. As a result, there was no specific developing country perspective and the approaches towards assisting developing countries followed mostly what could be referred to as 'an ad hoc approach'. In other words, there was no generic approach, but a case by case solution was developed to problems encountered by developing countries. This reflected the realities at that time. There was little engagement in market access negotiations, as the shares of developing countries in international trade were very small and developing countries largely depended on the preference schemes they had inherited from colonial times. In addition, they were highly dependent on exports of unprocessed raw materials and base products and showed a low degree of diversification of their economic structures.

With the inclusion of the Enabling Clause in the GATT, a jump start was given to a process which led to gradual incorporation of more and more development provisions in the

bindings, often at high levels. Regardless of the levels at which the tariffs are set, they still imply more security and predictability in trade.

21 Cf. Chapter 4.

22 The 'Enabling Clause' was the direct result of the Tokyo Round (1973-1979) negotiations officially referred to as the Decision on Differential and More Favourable Treatment, Reciprocity and Fuller participation of Developing Countries. Among the provisions of the Enabling Clause was a permanent exception from the MFN principle for the Generalized System of Preferences (GSP), legal cover for Special and Differential Treatment provisions (S\&D) with respect to non-tariff measure agreements negotiated in the Tokyo Round, a relaxation of provisions regulating trade agreement among developing countries and the establishment of a separate category of least developed countries.

23 This was argued in Chapter 3, which explained the features of globalization. Trade patterns changed mainly in the 1980s largely driven by globalization and in which most developing countries took little part. 
GATT. With time and during the various rounds of trade negotiations, the S\&D provisions became part of the design of the WTO Agreements, thus changing the nature of the rights and obligations between the members. ${ }^{24}$ While S\&D provisions are generally accepted as a tool to facilitate the integration of developing countries in the trading system, some authors contested that idea. ${ }^{25}$ Hudec argued that the S\&D treatment for developing countries would not be in their best interests, based on the argument that the preferences provided in the GATT had reduced the incentives for developing countries to actively engage in the negotiations and hence active participation in the system. ${ }^{26}$ Nevertheless the S\&D provisions have gradually been expanded, as it was mostly considered a necessity by the beneficiaries. The S\&D provisions continue to be a key element, as seen in the DDA negotiations.

Institutionally, the Uruguay Round was the first round of multilateral trade negotiations which explicitly included initiatives leading to the better inclusion of developing countries into the trading system. It combined different approaches for trade liberalization for developing countries and developed countries. While all countries were required to exchange concessions, undertake tariff reductions and commit to binding obligations with regard to the agreements, it also included multiple provisions on S\&D treatment for developing countries. ${ }^{27}$ The inclusion of S\&D provisions was again based on the argument that developing countries could not make the same concessions and take on the same level of obligations as developed countries. According to the WTO, these provisions play and have played a critical role to support integration into the WTO. ${ }^{28}$

The developing countries thus started engaging in market access commitments during the negotiations of the Uruguay Round in the early 1990s, based on the awareness that trade can act as an engine for growth. At the same time it was again recognized that developing countries would not be in the same position as developed countries to commit to the obligations in the same way and to the same extent. Hence, and in recognition of these difficulties, especially for LDCs, the WTO Agreement explicitly recognizes 'the need for positive efforts by all Members designed to ensure that developing countries and especially the least-developed amongst them, secure a share in the growth in international trade commensurate with the needs of their economic development'. ${ }^{29}$ This explains the large number of specific (S\&D) provisions made in the WTO agreements in favour of developing

24 This reflects the notion that the S\&D provisions need to be an integral part of the approach itself, rather than an afterthought. Related to this is the fact that it creates legal obligations, as opposed to 'best endeavour' provisions, as in the GATT. This fundamentally altered the concept of rights and obligations in the WTO.

25 Cf. Laker, African Participation in the World Trade Organization.

26 Hudec, Developing Countries in the GATT Legal System.

27 Cf.. Chapter 4 on tariff negotiations.

28 WTO and Least Developed Countries: Twenty Years of Support towards a Better Integration into the Multilateral Trading System, 30 September 2015, WT/COMTD/LDC/W/61.

29 The Marrakesh Agreement Establishing the World Trade Organization, Preamble, 15 April 1994, 33 ILM 1125 (1994), para. 2. 
countries, often providing for longer implementation periods of commitments, including a longer timeframe for implementing the tariff reductions and also less specific and stringent obligations. ${ }^{30}$

The Single Undertaking approach that was introduced in the DDA negotiations effectively meant that all members needed to assume their share in the new obligations and make trade concessions. ${ }^{31}$ Given that the DDA is a development round, the main objective is to ensure that the development goals can be attained. This goal essentially consists of facilitating developing countries' integration into the multilateral trading system and benefiting from the economic growth perspectives. ${ }^{32}$ This explains the large number of provisions in favour of developing countries. The inclusion of the development dimension in the agenda was seen as the only way to overcome the reluctance of the developing countries to launch the round, as many developing countries did not see the need for it. Developing countries largely felt that many of the expectations of the Uruguay Round had not yet materialized and that they had signed off on commitments, the legal implications of which had not been fully understood. Apecu Laker refers in this regard to the 'hang-over' of developing countries from the Uruguay Round, stating that the African countries were most reluctant to engage in new negotiations. ${ }^{33}$ She notes that African countries had hardly participated in the Uruguay Round negotiations as they considered that they were still coping with the challenges of earlier commitments, as reflected in the Abuja Ministerial Declaration. ${ }^{34}$

The focus on developmental aspects became of critical importance to the negotiations themselves with much time and effort devoted to defining the S\&D provisions. It is unclear at this time what will happen to these discussions, given that the outcomes of the discussions at MC-X (Nairobi) and the Ministerial Declaration that resulted from this Conference have put into question if and how the DDA will be concluded. ${ }^{35}$ The views on what should happen to the DDA differ widely (see Chapter 6). Developing countries argue that there need to be tangible and clearly visible and economically meaningful outcomes for developing countries. ${ }^{36}$ How this will be translated into concrete action remains to be seen.

30 Some of these efforts were discussed in Chapter 4 with regard to agriculture and NAMA.

31 Cf.. the discussion on the single undertaking in Chapter 2.

32 Cf. footnote 29: Doha Declaration, Ministerial Conference, Doha, 9-14 November 2001.

33 Laker, p. 65.

34 WTO, Organization of African Unity/African Economic Community, Fourth Ordinary Session of the Committee on Trade, Customs and Immigration, 19-23 September 2001, Abuja, Nigeria.

35 This was explained in Chapter 2 and the decisions taken by Ministers and the implications of the MC-X Declaration will be analysed more deeply in Chapter 6.

36 As is discussed in Chapter 6, the Ministerial Declaration reflects the different positions taken by the members with regard to maintaining the objective of concluding the DDA and in which ways the goals of the DDA should be pursued. This also implies that the approaches to reflecting the development dimensions in the agreements may need to be reconsidered. 
In short, the participation in and commitment of developing countries to the multilateral trading system has evolved considerably in recent years. Over three quarters of WTO membership is now made up of developing countries and LDCs. Developing countries have greatly evolved and are more diverse than ever. They have widely different levels of economic development, different economic interests, development paths, patterns of trade and diversification in production. Given their main differences, their defensive and offensive interests in the negotiations also differ greatly which has implications for the adjustment of the rules of the system to their needs. ${ }^{37}$ The world has changed drastically over a short period of time with the rapid economic development of some of the main developing countries. As already discussed (see Chapter 3), South-South trade is becoming ever more dynamic and important to the world economy. Patterns of trade are rapidly changing, with increasingly strong economic ties developing at the South-South level and there is much more potential for economic growth. The dependency of traditional trade patterns (including the preferences) with the northern countries is decreasing, with trade becoming more diversified and the desire and need of developing countries to better connect to GVCs.

Despite their active engagement, the integration of developing countries and LDCs into the multilateral trading system continues to pose challenges. While some have been successful in diversifying their trade, many developing countries have not been able to do so, or attract FDI, connect to global or regional value chains and benefit from new growth opportunities. Others continue to suffer from poverty, from export dependency on few products, low levels of employment and so on. Some challenges continue to be of critical importance to the economic development of developing countries, but steps in the right direction are clearly visible, as argued in the WTO's world trade report of 2014.38 The question then is what the WTO can do to provide support to the developing countries in building their capacity to better integrate in the multilateral trading system.

\subsection{Trade Capacity Building in the $\mathrm{WTO}^{39}$}

\subsubsection{Introduction}

Van den Bossche and Zdouc argue that the functions of the WTO do not explicitly include technical assistance to developing country Members, but yet, this is an important area of activity of the WTO'. ${ }^{40}$ In a recent WTO study, it is noted that 'Beyond modest training and technical assistance programs, the old GATT devoted relatively little attention

37 The concept of 'offensive and defensive interests' is part of the WTO jargon and refers to the interests developing countries defend and pursue, including through the concessions they request from developed countries.

38 Cf. World Trade Report 2014.

39 This section is an updated version of my publication: 'Trade Capacity Building in the WTO: Main Achievements since Doha and Key Challenges', 47 Journal of World Trade (2013), p. 1047-90. Data are updated until the end of 2015.

40 See van den Bossche and Zdouc, p. 101. 
and few resources to assisting developing countries strengthen their technical expertise, participate in the day-to-day work of the organization and strengthen their trade institutions, legal systems and productive capacities'. ${ }^{41}$ According to the WTO Secretariat's reports, ${ }^{42}$ trade capacity building efforts are part of a broader approach to assist beneficiaries, as captured by the so-called Aid for Trade Initiative, an initiative that originates from the MC-V (Hong Kong) in 2005.43

This section will review the main features of the WTO Secretariat's trade capacity building programmes that were designed following the launch of the DDA in $2001 .^{44}$ It provides explanations on the institutional set up in the WTO for the delivery of the trade capacity building programmes which led to the creation of the Institute for Training and Technical Cooperation (ITTC). It then looks at how the WTO's trade capacity building programmes are funded and why the Doha Development Agenda Global Trust Fund (DDAGTF) was created. This is followed by a discussion of how Trade Related Technical Assistance (TRTA) programmes are coordinated within the Secretariat and with partner agencies and how programmes are designed and sequenced with a view to building cumulative and sustainable capacity. As the ultimate goal is to see tangible results and outcomes of the programmes, explanations are provided on how to measure them through the Results Based Management (RBM). It will then provide some insights based on recent findings and available data on what has been achieved.

It is argued that the role of the Secretariat in providing trade capacity building in order to assist beneficiaries to integrate into the multilateral trading system has become a core function of the WTO. The WTO's technical assistance and trade capacity building programmes have been important in allowing developing countries to better understand the rules of the WTO and participate in the trading system. These points will be substantiated with a more detailed discussion on how developing countries are integrating more fully in the trading system.

41 WTO at Twenty: Challenges and Achievements, WTO (2015), p. 26.

42 Biennial Technical Assistance and Training Plan 2008-2009(2007), WT/COMTD/W/160.

43 Cf. the discussion on the single undertaking in Chapter 2; also, para. 55 of the Ministerial Declaration. 'Aid for Trade should aim to help developing countries, particularly LDCs, to build the supply-side capacity and trade-related infrastructure that they need to assist them to implement and benefit from WTO Agreements and more broadly to expand their trade. Aid for Trade cannot be a substitute for the development benefits that will result from a successful conclusion to the DDA, particularly on market access'. The Aid for Trade brings together agencies, donors and beneficiaries that are involved in trade capacity building. Following the MC-V, a task Force was established in early 2006, which produced a report entitled: 'Recommendations of the Task Force on Aid for Trade' (2006) WT/AFT/1. It provides explanations on the mandate, scope and financing of the Aid for Trade program. Every second year a Global Aid for Trade Review is conducted to take stock of the accomplishments. The last review took place in summer 2015.

44 I was given the responsibility to design and coordinate the implementation of the WTO's trade capacity building programs, and developed the technical assistance and training plans, which will be discussed later and which provided for the backbone of the WTO's technical assistance programs. Many statements and observations made in this part of the thesis are therefore based on first-hand insights and experience. 


\subsubsection{How is trade capacity building addressed in the WTO?}

Nearly sixteen years ago, when Ministers launched the DDA, the most ambitious and comprehensive round of trade negotiations ever in the history of the GATT and the WTO, it was agreed to put 'development' at its heart. This was based on the recognition by Ministers that international trade can play a major role in the promotion of economic development and the alleviation of poverty. As a result, the interests of developing countries were placed centrally in the work programme adopted in the Ministerial Declaration. Ministers recognized that 'enhanced market access, balanced rules, and well-targeted, sustainably financed technical assistance and capacity building programmes have important roles to play in securing that developing countries and especially the least-developed amongst them secure a share in the growth of world trade commensurate with the needs of their economic development'. ${ }^{45}$ Given the developmental nature of the DDA and in order to ensure that beneficiaries would be able to fully participate in the negotiations, a dedicated chapter on 'Technical Cooperation and Capacity Building' was inserted in the Declaration (paragraphs 38-41). The language on the support to be provided was stronger than ever before, thus representing a major departure from previous negotiations held during the GATT, when technical assistance and capacity building provisions were mostly non-binding 'best endeavour' undertakings made by developed countries. ${ }^{46}$ This was the first time that a comprehensive approach to trade capacity building with strong commitments on the side of the developed countries was offered. As developing countries account for the majority of the WTO's membership, the multilateral trading system can only function when fully taking into account their needs and priorities. ${ }^{47}$ Thus, 'Doha' provided a starting point for the better and fuller participation of beneficiaries in the system.

Shaffer suggests that 'there are at least four competing rationales for WTO trade related technical assistance efforts:

i. Facilitation of trade liberalization;

ii. Support for WTO-related aspects of a country's development strategy;

iii. Assistance with the costs of the implementation of WTO obligations; and

iv. Enhancement of the capacity of developing countries to participate in the shaping of WTO rules, their interpretation and understanding, and their monitoring and enforcement.' 48

He then provides an overview of how WTO's technical assistance programs have evolved with time, underscoring the importance that this part of the WTO's work has had since the launching of the DDA. Solignac Lecomte notes, with regard to capacity building,

45 Doha Ministerial Declaration para. 2-3.

46 'The Results of the Uruguay Round of Multilateral Trade Negotiation', GATT Secretariat, WTO, June 1994

47 Cf.. discussion on WTO membership and accession in Chapter 2.

48 G. Shaffer, 'Can WTO Technical Assistance and Capacity Building Serve Developing Countries?', 23

Wisconsin International Law Journal (2005), p. 651. 
that there 'can only be one ultimate objective: to empower developing countries in the multilateral trading system, and help their products to penetrate OECD and other world markets.' 49

In preparation of the Doha Ministerial Meeting, the Secretariat had developed a new strategy for WTO technical cooperation, which had been presented to the membership in the fall of $2001 . .^{50}$ The strategy was considered by the CTD and later endorsed by the Ministers. As the WTO's Director General at the time, Mr Mike Moore, stated:

With the adoption of the DDA in November 2001, Trade Ministers have placed development issues at the heart of the multilateral trading system. Ministers have confirmed the very real link that exists between trade and development. They have confirmed that technical assistance and capacity building are core elements of the trading system. They have also confirmed the need for multilateral institutions and countries to work together to ensure that trade helps to reduce poverty and stimulates development. The technical co-operation and capacity building mandates provided in the DDA are extensive and involve specific commitments by Member Governments. Meeting these mandates requires close co-operation and coordination among agencies, donors and beneficiary countries. Beneficiary countries must be precise in defining their needs in the trade-related area. Agencies and donors must base their technical cooperation and capacity building plans around these needs., ${ }^{51}$

Thus, a roadmap was provided by Ministers, who took firm commitments both in general and specific terms in the Ministerial Declaration (see paras 38 to 41) and in relation to areas of the negotiations. ${ }^{52}$ Ministers also provided for a review and follow-up mechanism. In order to keep track of the progress made, the Director General was instructed by Ministers to report to the Fifth Session of the Ministerial Conference in 2003,

49 H. Solignac Lecomte, 'Building Capacity to Trade: A Road Map for Development Partners: Insights from Africa and the Caribbean', European Centre for Development Policy Management Discussion Paper (No. 33, 2001).

50 'Technical Cooperation for Capacity Building, Growth and Integration: The New WTO', note by the WTO Secretariat, February 2002. An earlier version is contained in: 'A New Strategy for the WTO Technical Cooperation: Technical Cooperation for Capacity Building, Growth and Integration', 21 September 2001, WT/COMTD/W/90.

51 Cf. 'Technical Cooperation for Capacity Building', Foreword by the Director General Mr Mike Moore to the New Strategy, February 2002, p. i.

52 Examples include Market Access for Non-Agricultural Products (para. 16), the relationship between trade and investment (para. 21), the interaction between trade and competition policy (para. 24), transparency in government procurement (para. 26), trade facilitation (para. 27), trade and environment (para. 33). In addition, the Declaration contains specific provisions and language with regard to Least Developed Countries (paras. 42 and 43 ). 
with an interim report to the General Council to be provided in December 2002 on the implementation and adequacy of the commitments made. ${ }^{53}$

The trade capacity building efforts of the Secretariat, through the ITTC, established in $2003,{ }^{54}$ have been under constant review by members at all Ministerial Conference sessions and more specifically at their Sixth Session convened at Hong Kong in December 2005.55 Ministers decided that

in order to continue progress in the effective and timely delivery of trade-related capacity building, in line with the priorities Members attach to it, the relevant structures of the Secretariat should be strengthened and its resources enhanced. We reaffirm our commitment to ensure secure and adequate levels of funding for trade related capacity building, including in the Doha Development Agenda Global Trust Fund, to conclude the Doha Work Programme and implement its results. ${ }^{56}$

Thus and in accordance with the Ministerial decisions, the Secretariat had to set up the relevant structures, thus moving away from what could be considered an ad-hoc approach of delivery of TRTA to a more institutionally structured approach. There was also a need to review the funding requirements to cover the costs of the new commitments for the following reasons: until the launch of the DDA, the members had allocated in the WTO's annual budget some 6 million CHF (Swiss Francs) to finance both Geneva-based courses and technical assistance activities undertaken at the national level in beneficiaries. This would clearly not suffice to deliver on the comprehensive and ambitious Doha work programme, which required a complete overhaul in the approach taken to trade capacity building. A work plan needed to be developed on an urgent basis and new sources of

53 Report by the Director General: Paragraph 41 of the Doha Ministerial Declaration, 14 August 2003 (WT/MIN(03)/3), presented at the Ministerial Conference, Fifth Session, Cancún, 10-14 September 2003.

54 The structure of ITTC has evolved considerably with time and the Institute has expanded with a current number of 50 staff. In designing, reviewing and adjusting the functions and priorities of the ITTC, it has benefited from the recommendations that emerged from an external evaluation, conducted in 2005 and 2006 by a team of independent consultants and contained in the Strategic Review of WTO-provided Training and Technical Assistance (TRTA). A recent external evaluation was conducted in 2016, with recommendations contained in the Final report that was submitted to the Secretariat in the fall of 2016, WTO Trade Related Technical Assistance External Evaluation, Final Report, 31 October 2016, SAANA Consulting. The report was circulated to WTO members as an official WTO document: WT/CONTD/89, 2 December 2016. The WTO Secretariat provided a response with regard to the evaluation, as contained in a document entitled: Management Response to the External Evaluation of the World Trade Organization's Technical Assistance, WT/COMTD/90, 13 December 2016 and which contains explanations on the ways in which the Secretariat intends to follow up on the recommendations.

55 Doha Work Programme, Ministerial Declaration, adopted on 18 December 2005 (2005) WT/MIN(05)DEC, paras. 50-52, where Ministers expressed their appreciation for the substantial progress made and increase in the field of trade capacity building since the Fourth Session. Specific reference is made to the new approach of planning as well as the improved quality of the programmes. 
funding explored. As a result, the first Technical Assistance and Training Plan (TA Plan) for 2002 was prepared and presented to members, which put particular emphasis on the coordination of trade capacity building efforts with strategic partners, including multilateral agencies, donors and beneficiaries. ${ }^{57}$ The TA Plan was followed by a series of annual TA Plans, until a first biennial TA Plan was presented to members in autumn 2007 to cover the biennium 2008-2009.58 The biennial plan was mainly developed with a view to securing medium to longer term funding, thus enhancing the stability, predictability and security in funding. Since then, all TA Plans have been biennial, with the latest TA Plan covering the biennium 2016-2017, adopted by members in autumn 2015. 59

The development of TA Plans is a complex undertaking, as technical assistance in the WTO is demand driven. At the same time it is the Secretariat's responsibility to ensure that a structured and balanced approach of trade capacity building is developed that captures all the needs of the beneficiaries. According to the WTO's mandate, all members need to be supported in equal ways, maintaining a geographical balance. In order to achieve the right balance, the Secretariat conducts consultations with the stakeholders in all the regions, to obtain feedback on capacity building priorities in their areas and address the concerns of the beneficiaries in all the regions of the world. ${ }^{60}$ This is what is referred to as the 'regional approach' to trade capacity building, based on the assumption that many of the issues and concerns in each region are to some extent similar. By organizing regional seminars, countries can share experiences with and learn from each other. Such consultations are conducted in Geneva, through the delegation's permanent representation. The regional approach to trade capacity building, covering all WTO agreements through regional seminars, is complemented with support provided at the national level, to address specific needs, based on a needs assessment which cannot necessarily be addressed at the regional level. ${ }^{61}$ Budgetary provisions in the TA Plan are made to hold 250 annual national events. Priority will always be given to the LDCs, who can benefit from three national activities as opposed to two for developing countries. ${ }^{62}$

The Secretariat supports beneficiaries to identify their needs through a needs assessment approach, which aims to ensure that there is a correct match between offer and demand, and

57 Coordinated WTO Secretariat Annual Technical Assistance Plan 2002, dated 8 March 2002, WT/COMTD/W/95/Rev.3.

58 Biennial Technical Assistance and Training Plan 2008-2009, 2 November 2007, WT/COMTD/W/160.

59 Biennial Technical Assistance and Training Plan 2016-2017, 13 October 2015, WT/COMTD/W/200.

60 Such consultations can take different formats and include not only the different geographical regions, e.g. Africa, Asia and Asia Pacific, the Arab countries, Latin America and the Caribbean, Central and Eastern European Countries and Central Asia, but also the LDCs, Africa Group, and regional secretariats.

61 Following the adoption of the TA Plans, the Secretariat issues a circular to all delegations inviting them to submit their specific requests for national activities and guiding them on how to proceed with theirrequests.

62 These numbers are due to the limited human resources in the Secretariat to provide assistance to all the beneficiaries. In practice, these entitlements for requesting national activities are usually underutilized, both in developing countries and in the LDCs. 
that the best technical expertise can be made available by the Secretariat. ${ }^{63}$ Needs assessments are undertaken in close cooperation with the ITTC and the Trade Policy Review Division (TPRD), with the ITTC focusing on countries' trade capacity building needs. ${ }^{64}$ By anchoring the needs identification in the TPRs, a sound basis for targeted technical assistance and follow up is provided.

The new approach to trade capacity building, based on a comprehensive TA Plan, required significantly more funds than was available in the limited regular budget. Taking full advantage of the political momentum, and in order to deliver on commitments following the Ministerial meeting, the DDAGTF was established by decision of the WTO General Council in December 2001.65 The General Council decision included the convening of a Pledging Conference and the setting of a target amount for the DDAGTF of 15 million CHF (Swiss Francs) for 2002. The pledging Conference was held in Geneva at WTO headquarters on 11 March 2002. Following an intensive process of consultations with the members, it was agreed that this Conference would not merely be a fundraising exercise, but include a substantive policy dialogue. Eminent personalities were invited to develop their thoughts on specific trade related technical assistance and capacity building and particularly, the challenges posed by the mandate of the DDA.

The process generated strong interest and commitments from the donor community and resulted in pledges of 30,872,000 CHF including amounts announced for future years. For 2002 alone, pledges amounted to 25,236,000 CHF, combining small and large contributions from nearly 30 countries, including developing country members. The generous contributions received at the time were instrumental in financing not only the first TA Plan, but also later ones, including in recent years, as the target amounts stipulated by the General Council were never equalled. In fact, as will be seen later, the contributions to the DDAGTF have declined to historical lows in the last three years (2014-2016). With the outcome of MC-X (Nairobi) and the resulting uncertainty about the future of the DDA, it can be legitimately questioned whether donors will continue to be forthcoming with their financial contributions. This is a matter of serious concern as will be explained further and because at the date of writing, there are no indications revealing the donors' intentions: only time will tell.

63 Needs assessments are prepared on the basis of a reference paper and under the guidance of the regional desk officers in ITTC.

64 Cf.. the discussion on the main features of Trade Policy Reviews in Chapter 2. Several TPR reports contain a specific chapter identifying the needs of the beneficiaries, which then provide the basis for developing follow up actions.

65 The Committee on Budget, Finance and Administration made its recommendation to the General Council in its report of meetings, contained in WT/BFA/A/56, 18 December 2001, which also details the operation of the DDAGTF and the timing of the expected contributions. 
Since the establishment of the DDAGTF, the first WTO TA Plans were budgeted on the basis of an extra-budgetary funding requirement of 24 million CHF. ${ }^{66}$ These funds were then obtained from the donors and the contributions to date can mostly be attributed to the same donors, who have consistently funded the WTO's TRTA programmes for 15 years with more or less same amounts each year. It is noted here that in recent years a large number of the traditional donors have dropped out. ${ }^{67}$ The initial financial contributions had provided a 'buffer' for the following years. However the buffer has gradually shrunk as a result of the expenditures and lower incomes. Annual donor pledges in earlier years were typically in the order of 15 to 19 million $\mathrm{CHF},{ }^{68}$ and declined to around 8 to 9 million CHF in recent years, an amount insufficient to cover the actual costs. The trend of declining contributions was confirmed again in 2016 with less than 7 million CHF received. ${ }^{69}$ This new reality, which has manifested mainly since 2010, meant the WTO Secretariat had to fundamentally review its Plans and reduce its levels of ambition, with a cut of over $50 \%$ to the previous TA Plan. Real expenditures on the trade capacity building programmes decreased from a peak of 18.7 million CHF in 2007 to a low of 8 million CHF in 2013, 9.3 million CHF in 2015 and 8.5 million CHF in 2016. Obviously, the less that is spent the less the donors feel a need to make contributions. The slowdown in the DDA negotiations with little perspective of tangible outcomes is undoubtedly another factor that explains the lower contributions.

66 It is noted that these figures explicitly refer to the DDAGTF and do not include other dedicated trust funds that were established later, including the Trade Facilitation Agreement Facility and the funding for the STDF and SPS related activities. The internship programmes are funded separately from dedicated funds.

67 The main donors in 2014-2016 included: Norway, Germany, the United States, the Netherlands, France, Denmark, the European Union, Korea, Japan, Australia and Austria. Other main donors that stopped making contributions permanently or temporarily include Sweden, Switzerland, Canada, Finland, Spain and Chinese Taipei.

68 Cf. Table 5.1.

69 The donor contributions have been cut more recently and were at the lowest historical levels in 2016, with CHF 6.8 million in new fresh contributions received, thus beating the previous record low of CHF 7.8 million in 2014, followed by a total of CHF 9.1 million received in 2015. It is observed that this figure for 2015 is misleading to the extent that it includes a multi-year donation of over CHF 2.1 million provided by one donor at the very end of the year and this, according to an internal financial report, has distorted the real financial situation and overstates the reality. The expenditures in 2016 were at around CHF 8.5 million, generating a considerable negative net position for the year. Many of the contributions once again were received at the end of the year, thus generating a transfer to the following budget year. 
GRAPH 5.1: Financial contributions and expenditures ${ }^{70}$
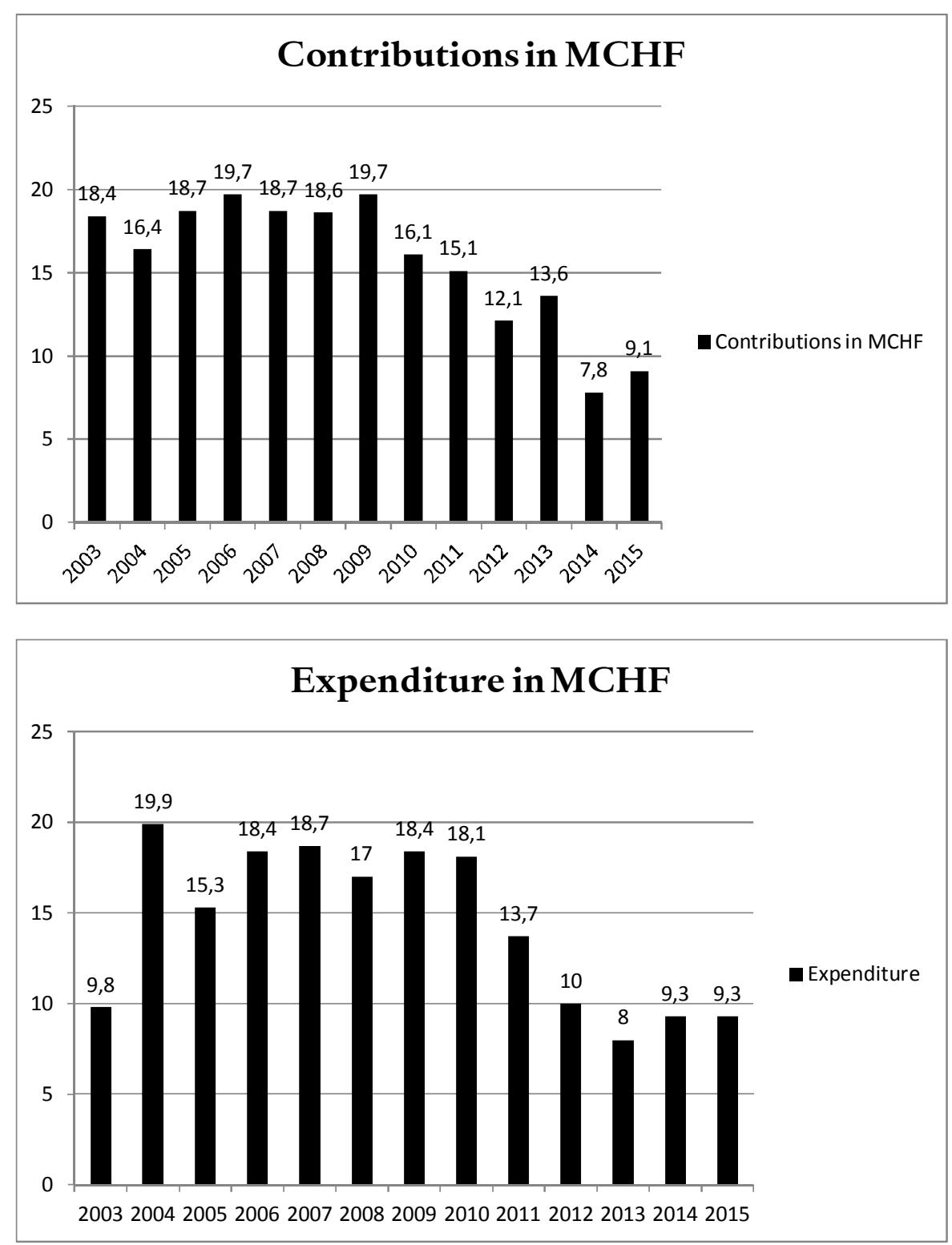
Partnership arrangements have always been of critical importance in the design and delivery of the activities. A broad range of multilateral agencies (the International Trade Centre (ITC), UNCTAD, IMF, World Bank) and regional development banks (InterAmerican Development Bank (IADB), the Islamic Development Bank, Asian Development Bank, Arab Monetary Fund) participated at the 2002 Pledging Conference and committed to making substantive contributions to the fulfilment of the mandates of the DDA. Thus, the Pledging Conference provided a solid basis for the Secretariat to implement its work programme. Today, the partnerships include nearly all the key bodies in all regions and continue to be of critical importance in the implementation of the Plan.

What these developments show is that the approach to trade capacity building radically changed in the WTO, compared to the GATT. It became an integral part of the work of the Secretariat, with a much stronger and expansive financial basis to provide support to beneficiaries, although the financial basis considerably weakened in recent years. The slowing down of the DDA negotiations since 2008, uncertainty about its conclusion following MC-X (Nairobi), as well as the conservative spending approach adopted by ITTC since 2012 are posing new challenges to secure adequate levels of funding and are a source of concern.

\subsubsection{Coordinating TRTA: a main challenge}

Coordinating technical assistance programmes is one of the main challenges, given the sheer number of actors and stakeholders. Technical assistance and support is provided by governments at the bilateral level, as well as by international organizations at the regional and multilateral level. In addition, donors and beneficiaries have their own programmes, undertaken at the bilateral level, with most donors having different target countries, objectives, priorities and methodologies. In order to meet the challenges posed by the Doha work programme and more specifically in the field of coordinating trade capacity building, within the WTO Secretariat, the ITTC was mandated to coordinate with partner organizations and regional bodies. Institutionally, and prior to the establishment of the ITTC, 'training' and 'technical cooperation' were two separate functions, even though these are two sides of the same coin and geared towards enhancing institutional and human capacity in beneficiary countries to address trade policy issues. The two functions were merged to maximize synergies between them.

As mentioned earlier, the Sixth Ministerial Meeting at Hong Kong resulted in the launch of a much wider capacity building initiative, referred to as Aid for Trade. The WTO's TRTA programmes and capacity building efforts are one of many components in the Aid for Trade work programme. ${ }^{71}$ The main objective is to achieve cumulative and sustainable capacity building and to enhance the efficiency and impact of the Secretariat's TRTA. Therefore, it is

71 Cf. van den Bossche and Zdouc, p. 101. 
part of the broader spectrum of ongoing bilateral, regional and multilateral efforts to enhance the delivery of Aid for Trade and substantially improve its impact on the ground.

Coordination is performed in different ways: internally within the Secretariat, as well as externally, with partners and beneficiaries. This function is performed through the Technical Assistance Coordination Task Force (Task Force), which I created to that effect and which I chair. It comprises all the WTO Divisions, usually meets on a monthly basis and addresses all strategic and policy aspects of the preparation and delivery of the capacity building programmes.

With regard to external coordination, which is as an essential part of the preparatory process in line with the demand driven nature of trade related technical assistance, consultations are regularly held with members and partner agencies to ensure that trade capacity building programmes reflect the demands of the beneficiaries. These consultations involve all stakeholders in different formats, for example the regional and sub-regional groupings, LDCs and donors. Such meetings are held once or twice a year and are conducted on the basis of questionnaires sent to members to identify their priority areas for assistance. These consultations are then followed by discussions at the CTD, the supreme body dealing with trade capacity building in the WTO.

To achieve the effective coordination, and to ensure that the regional dimension of TRTA is fully captured in the relevant programmes, the Secretariat seeks out strategies for enhancing its cooperation and relationships with regional institutions and partners. ${ }^{72}$ Roughly half of all WTO Secretariat trade capacity building activities are undertaken with partner agencies. The TA Plans underscore the role of regional economic communities and economic commissions and other relevant regional institutions in the delivery of TRTA, a central element of the WTO TRTA programme. Activities held jointly with those partners have the advantage of allowing for complementary contributions by resource persons with expertise in specific trade issues. The joint cooperation leads to building synergies and are also helpful in creating a base of potential trainers within each region, which could gradually reduce the burden on the Secretariat in the delivery of technical assistance and trade.

In Africa, partnering mostly occurs with the United Nations Economic Commission for Africa (UNECA) and the African Development Bank (AfDB), as well as with sub-regional institutions such as the Southern African Development Community (SADC), the Common Market for Eastern and Southern Africa (COMESA), the East African Community (EAC), the Economic Community of West African States (ECOWAS), the West African Economic and Monetary Union (WAEMU) and the Central African Economic and Monetary Cooperation (CEMAC). The WTO works closely with the Organization Internationale de la

72 The strategies are explained in the Biennial Technical Assistance and Training Plan 2012-2013, 24 October 2011, WT/COMTD/W/180, and have provided the basis for the partnership arrangements since. 
Francophonie (OIF), which is particularly supportive in designing and implementing activities for French-speaking African countries.

In Asia and Asia Pacific, cooperation takes place with regional institutions such as the United Nations Economic Commission for Asia and the Pacific (UNESCAP) and the Pacific Islands Forum Secretariat (PIFS). The involvement of these institutions has enriched WTO's TA Plan by providing technical input and regional perspectives on different WTO issues, in addition to the financial and logistical support. Support is provided by the government of Singapore in the delivery of advanced training on trade related aspects of intellectual property rights (TRIPS). Furthermore, working relations were established with the Asian Development Bank (ADB), the Asian Pacific Economic Commission (APEC), the Association of South East Asian Nations (ASEAN) and the South Asian Association for Regional Cooperation (SAARC).

In Latin America and the Caribbean, partnerships with regional organizations include INTAL, the development institute of the IADB, which has been in operation for many years and which co-financed joint regional activities and provides substantive inputs. Other partnerships include the Organization of American States (OAS), the Caribbean Community Secretariat (CARICOM), the Latin American Integration Association (ALADI), the Secretariat for Centro-American Integration (SIECA), Inter-American Institute for Cooperation on Agriculture (IICA) and the Organization of Eastern Caribbean States (OECS). At the academic level, a good and cooperative relationship exists with FLACSO, the Latin American School of Social Sciences.

In the Arab countries and the Middle East, cooperation at the regional level is sought with the main regional economic organizations, such as the United Nations Economic and Social Commission for Western Asia (UNESCWA), the Arab Monetary Fund (AMF), Islamic Development Bank (IsDB), and the Gulf Cooperation Council (GCC). This cooperation plays a significant role in achieving the desired common objectives of empowering and enhancing the participation of the Arab countries in the multilateral trading system.

In the region that includes Central and Eastern Europe and Central Asia and Caucasus Countries (CEECAC), mainly consisting of the Commonwealth of Independent States (CIS), the Caucasus countries and the Balkan countries, there are not really any regional bodies that deal with trade issues. In reality, it is not a region, but has been labelled by the WTO Secretariat as such for pragmatic reasons and for the purpose of covering the countries in the region through regional events. The constituency is not homogeneous in any way and the different countries clearly have different priorities, challenges and concerns. Many of these countries are in the accession process, some have recently acceded, and others are long standing and well established WTO members. The main regional institution that is 
crucial to the efficient delivery of TRTA for the CEECAC region is the Joint Vienna Institute (JVI) ${ }^{73}$ essentially a training centre, which as the name suggests, has its HQ in Vienna.

The Secretariat thus has a well-defined regional approach to the delivery of trade capacity and mostly cooperates with regional partners in the field. The WTO provides its knowledge and expertise at the technical level and the regional partners complement that knowledge on the ground.

\subsubsection{How to build progressive and sustainable trade capacity}

The key objective of the Secretariat's trade capacity building programmes, as reflected in the Plans, is to enhance the human and institutional capacities of beneficiaries to allow them to take full advantage of the rules-based multilateral trading system, deal with the challenges emerging from it and enforcing their rights and obligations. ${ }^{74}$ Considerable efforts have been made by the Secretariat to develop a comprehensive and coherent approach, with better links between products, programmes and activities with a view to creating synergies, and to build sustainable and cumulative capacity with beneficiaries. This is the essence of the Progressive Learning Strategy (PLS), the progressive, multi-modular sequencing of products in order to improve the delivery of TRTA, and gradually and progressively move to higher levels of learning. ${ }^{75}$ The PLS distinguishes between two broad categories of participants, including 'generalists' and 'specialists'. Generalists are government officials with global responsibilities who need to have general knowledge of the WTO and the agreement. This will mainly include capital-based officials or delegates at permanent missions in Geneva. The specialists are mainly officials that are responsible for specific agreements.

The approaches developed for generalists and specialists are fairly similar in sequencing. In terms of face-to-face advanced training on the 'specialist' path, there is a mixture of regional seminars on the specific agreements and Geneva-based thematic courses, ranging from one to three weeks in duration, addressing specific WTO agreements. ${ }^{76}$ A selection process is always conducted by way of tests, screening questions and any other interactive mode. In all cases, for both generalists and specialists, the use of E-learning is a prerequisite. It allows for easy 'self-training', at any time and any place, at the convenience of the participants. Participants can and trainers can use E-learning from their office or home at any time they wish. It is not a substitute for face-to-face training but is complementary to it. E-learning programmes can be tailor-made for any specific topic. Using the E-learning tool

73 The Joint Vienna Institute (JVI) is a training centre that was established in 1992, immediately following the ending of the Cold War, by the Bretton Woods institutions and in close co-operation with the Austrian authorities, to ease the transition from centrally planned to market based economies. The WTO is an active partner in the JVI and holds many of its annual training courses at the JVI.

74 Biennial Technical Assistance and Training Plans 2012-2013 (WT/COMTD/W/180Rev.1), 2014-2015 (WT/COMTD/W/200) and 2016-2017 (WT/COMTD/W/211).

75 WTO Progressive Learning Strategy (PLS) For Trade-Related Capacity Building in 2012, 6 February 2012, $\mathrm{JOB} / \mathrm{TC} / 3$.

76 Cf. WT/COMTD/W/180/Rev 1, para. 71. 
as a prerequisite has the advantage of harmonizing levels of knowledge and the 'teaching' can be more targeted to a specific audience, with similar levels of knowledge. This will contribute to avoiding situations in which the trainers have to adjust their training to accommodate the weaker participants, which would undermine the objectives of the course. For countries that may have difficulties in accessing the required technology for E-learning, Reference Centres (RCs) may provide the solution. ${ }^{77}$

The second level of training for generalists is conducted through the Regional Trade Policy Courses (RTPCs), which have been running since 2002. The RTPCs are regularly revisited in contents and were relabelled as the 'intermediate level training'. Their duration was shortened from 12 to eight weeks, both for financial reasons and for coherence in designing a gradual approach. The courses have recently been held in all regions. ${ }^{78}$ The objectives of the intermediate level regional training course are to provide an introduction to trade policy and the multilateral trading system, give a regional perspective to the topics covered, increase collaboration and cooperation with regional institutions and create a solid understanding among participants of the regional economic reality, with a focus on trade. In addition, the involvement of regional resources, regional academics, regional organizations and regional secretariats is encouraged, to ensure a solid grounding for the participants with regard to the economic environment in which their countries operate.

The third and highest level of training for generalists is performed through the Advanced Trade Policy Course (ATPC). ${ }^{79}$ This is the most comprehensive advanced WTO training product available under the PLS and lasts for eight weeks. It is aimed at government officials who seek to consolidate and broaden the knowledge of the WTO and the multilateral trading system they have already acquired through prior E-Learning (on the Multilateral Trade Agreements and the WTO) and/or an intermediate regional training activity on the generalist path. One of the advantages of the ATPC is that participants can observe and experience the functioning of the WTO directly through immersion in the WTO environment. The ATPC allows participants to make contacts with WTO experts in line divisions and establish working relations with officials of other international organizations, including the ITC, UNCTAD, the World Bank, ACWL, 80 and WIPO. Given their presence in Geneva, they can meet delegates from the Permanent Missions and from

77 A Reference Centre (RC) essentially consists of a dedicated physical location in the countries that are beneficiaries where any relevant information on the WTO can be accessed via the internet. This requires the installation of computers and other hardware, which are mostly provided by the WTO. RCs are established by the WTO at the request of beneficiaries, who are trained on the use of the RCs. The main hosts of RCs are LDCs, who receive the equipment funded by the Secretariat.

78 Given the constraints of human resources and finances, the RTPCs were initially held in Africa (both for French and English speaking Africa), Asia, Latin America and the Caribbean. They are now also held for the CEECAC and Arab regions, thus covering all geographic regions.

79 Cf. WT/COMTD/W/180/Rev1, paras. 65-71. The ATPC has effectively replaced the Trade Policy Courses that were launched in 1956 and were the entry level training on the GATT. The ATPC now is the highest level of learning.

80 Advisory Centre for WTO Law (ACWL). 
capitals, participate in debates, conferences, meet speakers from NGOs and think tanks, thus making the process dynamic. An additional and important feature of Geneva-based courses is their global reach, as they bring together participants from all regions. This encourages the sharing of best practices beyond the regional contexts. The approach focuses on a combination of theory and practice, thus fully preparing the participants to apply the rules and the system more broadly and equipping them with the tools needed to actively engage in the negotiating process and in committee work.

In terms of face-to-face advanced (level 3) training on the specialist path, the Geneva-based course curriculum features the design and delivery of advanced thematic activities, ranging from one to three weeks in duration, addressing a selection of specific WTO agreements. ${ }^{81}$ Such activities aim to consolidate the knowledge already gained in earlier training steps, and to encourage participants to develop their conceptual understanding of the topic and the autonomy to analyse and critically assess issues through active application of their knowledge.

It is noted that the WTO Secretariat, in accordance with the mandate given by the members, provides neutral and factual information with regard to the WTO agreements and members' rights and obligation in the WTO. The Secretariat does not interpret agreements and is not authorized to provide policy advice. It aims at building human and institutional capacity for countries themselves to formulate and take policy positions. According to Shaffer, the primary aim of a WTO capacity building program can be to "empower developing countries to better understand WTO rules and negotiating mandates in relation to their trade objectives; to integrate these objectives in development plans; and to advance them in negotiations, monitoring, and enforcement, as well as shaping and sequencing internal regulatory policies.' 82

\subsubsection{What are some of the specific achievements of the WTO's trade capacity building?}

\subsubsection{Measuring results through Results Based Management}

Showing the effectiveness of trade capacity building is increasingly becoming a precondition for obtaining donor funding in the WTO, as donors need to be assured that the collective efforts bear fruit and monies are well spent. ${ }^{83}$ This is part of a general trend to enhance transparency and accountability with regard to spending tax payers' money, but perhaps is also dictated by shrinking budgets. In response to these demands, the WTO set up

81 Cf. WT/COMTD/W/180/Rev 1, para. 71.

82 Cf. Shaffer, p. 654

83 The basis for systematic evaluation of WTO Technical Assistance (TA) was laid down in 2001 when the Committee on Trade and Development (CTD) adopted the new strategy for technical cooperation. This was further strengthened by the Doha Ministerial Declaration, which through its repeated reference to TA and capacity-building, recognized TA as an important component of WTO's mandate. Cf. also OFFICE(02)/40. 
an independent Technical Cooperation Audit Unit in 2003 to measure outcomes and impact and show results. It was replaced in 2012 by the Monitoring and Evaluation unit, as part of the ITTC. ${ }^{84}$ One key element in this context is Results Based Management (RBM), which lies at the heart of the Paris Declaration on Aid Effectiveness and which aims at ensuring that aid delivers specific results. ${ }^{85}$ The Paris Declaration 'committed donors and developing countries to change the way technical cooperation is delivered and managed, so as to improve the effectiveness of available assistance and make progress tow ards achievement of the Millennium Development Goals (MDGs)'. The main objectives of the MDGs were contained in a work programme and action plan implemented over a 15 year period (2000 to 2015), focusing on ways to reduce poverty. The MDGs were subsequently replaced by a new action plan referred to as the Sustainable Development Goals (SDGs) which contain a new set of objectives and build on the MDGs. ${ }^{86}$ While RBM is incorporated in most UN development programmes and is more widely applied by the UN bodies, the WTO only recently moved into this field. RBM is increasingly embedded in the design, management and delivery of the WTO trade capacity building programmes. ${ }^{87}$ Evaluation encourages programme managers to integrate evaluative information into the process of policy formulation and decision-making, thus further improving and strengthening the programmes. Hence, an independent external evaluation of the WTO's trade capacity building programs was conducted during 2016, with the results presented in the fall of $2016^{88}$

In order to measure the outcomes of trade capacity building activities, indicators are used to assess progress and determine the change and impact that follow the intervention. ${ }^{89}$ Typical outcomes that the WTO is expected to achieve through its trade capacity building programmes include the greater and better participation of beneficiaries in the work of the WTO and its respective bodies, including in the DDA negotiations and in the dispute

84 In 2012 the Audit unit, which was acting as an independent body, became integral part of the ITTC and was renamed as Monitoring and Evaluation (M\&E). Hence the same unit in charge of developing the TA Plans is also responsible for monitoring their implementation and assess the delivery of the programmes, which raises the question of organization structure, as is pointed out in an external evaluation report of the WTO's TRTA and to which I will refer to further below.

85 The Paris Declaration on Aid Effectiveness (2005), OECD, sets out a roadmap of practical commitments to promote ownership, alignment, harmonization, managing for results and mutual accountability, the five key principles, with each having their own set of indicators of achievement. The Declaration was endorsed by 114 countries and 25 international organizations.

86 The initiative to replace the MDGs with the SDGs finds it origins at the United Nations Conference on Sustainable Development, held at Rio in 2012. It builds on the MDGs and contains a total of 17 specific goals to be achieved by 2030. Particular emphasis is put on the sustainability of the support provided.

87 The monitoring and evaluation function consists of looking at the question of how programmes accomplished their short, medium and longer term objectives and what outputs and outcomes were achieved.

88 Cf. footnote 54.

89 The indicators are contained in so-called logical frameworks (log-frames) that are developed with a view to measuring the results of the interventions, including outputs, outcomes and impact, as they are generally referred to in the jargon. Log-frames and the relevant indicators are provided for in the Annex to the Biennial TA Plans. 
settlement process, and a stronger capacity to implement WTO agreements, to make use of member's rights, and to apply the WTO's transparency mechanisms, such as through submitting notifications. These are rather ambitious goals and are often hard to measure. There is no shortage of anecdotal evidence on the question of how beneficiaries have enhanced their capacity to insert themselves in the multilateral trading system and benefited from the Secretariat's TRTA, very often as delegations, Ministers and high level officials report directly to the WTO on the usefulness of the support provided. It is nevertheless hard to effectively measure the achievement and outcomes, including building of human knowledge, and how that knowledge is used. In addition, one of the related challenges in RBM is to establish a causal link between the training provided and the effect it had, including the action that followed. What can be measured is the number of officials trained and the number of activities delivered through various training programmes. The knowledge acquired during a course can be tested through exams, questionnaires and so on, but the impact of the knowledge transfer and how it was put to use is harder to measure. Some specific answers will be provided further below and the more fundamental question of integration of developing countries in the multilateral trading system will be analysed further below. The evidence that will be presented is supported by findings and conclusions offered by the evaluators of the WTO's trade capacity building programmes.

What do the data show with regard to the overall delivery of TRTA and with regard to specific programmes?

\subsubsection{Global data and figures on the delivery of trade capacity building activities}

The WTO Secretariat has trained over 50,000 officials since the creation of ITTC 2003 and until the end of 2016 and some 55,000 since the launch of the DDA. ${ }^{90}$ This includes nearly 30,000 officials who have completed a WTO E-Learning course since the launch of the E-Learning Programmes in 2005, with an average of nearly 2,500 participants each year and numbers are increasing. A total of some 4,000 participants have been trained through Geneva based training courses since 2002. Under the RTPCs, around 1,500 officials have been trained since its launching in early 2004. Since 2003, nearly 25,000 participants have been trained through field based regional-based training events. Based on calculations made from the WTO annual reports, since the launch of the DDA over 5,000 training events were implemented, of which over half $(54 \%)$ consisted of national activities, nearly one third $(32 \%)$ of regional events. Over the same period, close to 600 Geneva-based training activities were held.

In terms of geographical distribution of trade capacity building activities, the majority of activities were held in Africa, which had a share of $32 \%$ of all the WTO's TRTA, followed by Asia and the Pacific representing 20\%, Latin America (13\%), CEECAC (7\%), the Arab and

90 Data are compiled from the WTO's TRTA databases and the Secretariat's annual reports submitted to members. 
Middle East countries (6\%), and the Caribbean (4\%). Obviously, Africa is a priority area for the WTO Secretariat, as it is the continent with the greatest needs in terms of capacity building.

In line with the Doha Declaration, priority attention continues to be given to LDCs with a view to facilitating their full integration into the multilateral trading system. The LDCs, most of which are on the African continent, have been associated with over $45 \%$ of all activities. Several products in the Plan are geared towards LDCs.

LDCs are also given priority under the RC programme. ${ }^{91}$ The majority of RCs are established in LDCs, to further assist them to keep abreast of WTO-related issues and have better access to information and training. Government officials in LDCs and developing countries used the facilities to complete as many online e-Learning courses as possible in order to fully benefit from the introduction of the progressive learning strategy. To make activities more relevant for LDCs, the ITTC has been working with LDCs to assess their TRTA needs, and it was against that background that priority was given to accessions, notifications, and scheduling in the TA Plan. ${ }^{92}$

\subsubsection{How do the internship programmes strengthen human and institutional capacity?}

Trade capacity building is effectively achieved through hands-on training and this is the main purpose of the internship programmes. The WTO Secretariat implements three main internship programs, often considered as the flagship products, including the: i) Netherlands Trainees Programme (NTP); ii) French-Irish Mission Internship Programme (FIMIP); ${ }^{93}$ and iii) WTO Regional Coordinator Internship (RCI). ${ }^{94}$ These programmes are in very high demand with 150 to 200 applications every year from over 50 countries for 3540 positions. From the launch of the intern programmes until the end of 2016, there have been over 400 interns recruited from 90 countries. ${ }^{95}$ From this total 166 trainees were recruited under the NTP, 184 interns benefited from the FIMIP, and over 80 officials benefited from the RCI programme. In many ways they can be considered as the very highest level of training, as this is where the theory gets fully translated into practice - the training requires the active participation of the trainees in Geneva, they implement assigned

91 Detailed information on the operation of Reference Centres can be found in the WTO's TA Plans and on the WTO's website.

92 The General Council adopted in July the so-called LDC package (WT/COMTD/LDC/W/55Rev.2), which contains specific language on how to further strengthen, streamline and operationalize the 2002 LDC Accession Guidelines. These aim at facilitating the accession process of LDCs to the WTO.

93 This programme was, at the request of the two donors, France and Ireland, in 2015 relabelled as the French Irish Mission Internship Programme (FIMIP), in order to provide more visibility to the donors by clearly associating them with this programme.

94 In addition, there are the regular WTO intern programmes, as well as the so-called 'China's LDCs and Accessions Programme', launched in early 2012 and financed by China.

95 Calculations are based on the internal data base on the recruitment of interns, which provides detailed information on the countries the candidates originate from, their background, objectives etc. 
tasks, attend and report on meetings, prepare briefing notes and take active part in the negotiations per se.

According to the terms of reference, the core objective of these programmes is to respond to the trade-related needs of developing countries and especially LDCs: to strengthen the trade-related knowledge base, negotiation capacity and national trade policy. The majority of beneficiaries are from the LDCs (a total of nearly 240), compared to around 190 from all other countries combined. The programmes provide an opportunity for beneficiary countries to gain exposure to the work of the WTO and they act as key instruments serving to bridge the gap between international trade theory and practice. Specific work objectives are established and progress is monitored through monthly reports and meetings with all the interns.

There are some differences between the programmes. NTP trainees have a contract with the WTO Secretariat, where they work for a maximum period of 10 months. The specific aim of the NTP is to assist in the economic and social development of LDCs, low income countries and poor small and vulnerable economies in areas related to trade policy and to provide essentially junior public officials with an opportunity to learn about matters dealt with in the WTO, under the direction of staff members of the WTO Secretariat staff. In practice, the officials are mostly mid- to high level civil servants, with direct responsibilities for WTO Affairs and specific WTO Agreements.

The FIMIP has a similar objective to the NTP, for the benefit of Geneva-based missions. The officials work in the Permanent Mission of their own country in Geneva for a period of 10 months, funded by the WTO Secretariat. They get their assignments directly from the Ambassador and represent their country in the various bodies within the WTO. They prepare position papers, conduct analyses of policy approaches and report to the capital. They interact with the Secretariat and thus improve their expertise. This programme is available primarily to missions of LDCs and small and vulnerable economies. Preference is given to countries with the least number of staff in Geneva.

The RCI provides for support to the mission that is designated coordinator for a group of countries: the ACP, Africa group, LDCs, ASEAN, CARICOM, PIFS and so on. The interns are paid by the WTO, and can stay for a non-extendable period of six months. Normally, at the end of six months, a new group coordinator is designated, who can then again apply for an intern to provide support.

The tasks and objectives to be accomplished by the interns are spelled out to participants at the start of the programme. In accordance, participants receive specific training on WTO issues, including the operation of the RCs and the Integrated Database, thus enhancing their knowledge on tariffs schedules, and they are required to work on their countries' TRTA needs assessment. They also work on their countries' notification obligations as part of their core objectives. They work closely with ITTC regional desks, so as to better understand the 
policy approaches relevant to their regions and obtain a fuller picture of the overall challenges relating to the region.

Through the intern programmes, the interns gain exposure to the whole range of functions performed by WTO Divisions within the WTO Secretariat, particularly those that work on specific topics with WTO divisions, such as on accessions, on the Standards and Trade Development Facility (STDF), the Enhanced Integrated Framework (EIF), Trade Facilitation Services, agriculture, non-agricultural market access (NAMA), or on the TPRs. It is an integral part of the programme to follow negotiations, including on the DDA, attend the General Council and committee meetings, interact with the regional groups and provide support in terms of briefs and analysis. Trainees also have the opportunity to interact with other Geneva based international organizations (UNCTAD, WIPO, ITC and so on) which work on trade issues in support of developing countries.

Under the terms of the NTP the trainees participate in a week-long training course at the Netherlands Institute for Foreign Relations, better known as 'Clingendael', ${ }^{96}$ organized in close cooperation with the Ministry of International Trade and Development Cooperation of the Netherlands. The course combines theory, policy and practice and includes meetings with various stakeholders - Ministries, academics, business associations, companies, and the Port of Rotterdam. It allows them to better understand how policies are designed in an EU country. The FIMIP interns meet with the French and Irish delegations to receive exposure to their policy making, thus further enriching their knowledge on both domestic and EU policies. In short, the intern programme is hands-on and requires a solid knowledge of the operation of the system before enrolment. This explains the rigorous selection performed at the recruitment level, ensuring that only the best candidates are admitted.

An (earlier) internal WTO evaluation and the testimony of former interns have confirmed that the WTO Internship Programmes have had an impact in two ways: firstly, they have made a substantial contribution in enhancing the knowledge of officials on multilateral trading system issues, and secondly, they have strengthened the capacity of the officials in participating in the work of the WTO. ${ }^{97}$ These conclusions have been reached based on the application of various quantitative and qualitative performance indicators as well as on interviews with former participants and Ambassadors. The evidence, which will be developed further, shows that:

○ Trainees have improved the multilateral trading system-related knowledge that enabled them to assume their day-to-day responsibilities. The expertise that they

96 Institute Clingendael is a leading Dutch think tank and training centre, based in Den Haag, Netherlands.

97 'Ex-post Evaluation of the WTO Trainee and Internship Program 2005-2009', Technical Cooperation Audit Unit, WTO, 9 April 2010. The Secretariat's Trade Capacity building efforts were again scrutinized by the members, as referred to in footnote 54. In addition, the Dutch authorities are conducting an audit on the effectiveness of the trade capacity building programmes, including the NTP, with the results expected in 2017. 
developed through the internship has allowed them to formulate policy positions, draft laws and regulations and implement their WTO commitments. The exposure to WTO trade negotiations also acted as useful training tool to equip them to actively participate in the negotiations, submit position papers and defend their interests in the negotiations themselves. It is noted that this conclusion remains valid as will be argued further below and as was witnessed with regard to the work undertaken on position papers prepared by LDCs in support of the LDC package MC-IX (Bali) and MC-X (Nairobi). ${ }^{98}$

○ Trainees have strengthened their analytical, communicative and collaborative skills and critical thinking. They participated in research and analysis undertaken in the WTO's line Divisions, prepared TRTA needs assessments as part of the TPR process, worked on trade facilitation needs assessments and RCs, and received training on the use of the Integrated Database, enhancing their knowledge on tariffs and schedules. Many trainees became managers of RCs once they returned to their respective capital cities.

- Trainees have provided specific support in advancing the accession negotiations of their country. ${ }^{99}$ Factually, the process of accession has been accelerated in recent years, with several developing countries and LDCs having acceded. However, as noted earlier, one should be cautious about establishing a causal link between the support provided and the accession, as other factors contribute to that outcome. As many of the smaller acceding countries do not benefit from a permanent mission in Geneva, the travel costs to conduct the various rounds of negotiations can represent an unbearable financial effort. Others have assured the follow up on commitments made during the accession process, for example for recently acceded members.

○ Trainees participated in the WTO Ministerial Conferences as part of their country's delegation, including at the Ministerial Conferences, which further strengthened

98 These points will be developed further, substantiated and illustrated with specific examples.

99 In one case, a trainee of an acceding country, who had become Ambassador to the WTO following its country's accession (Vanuatu), indicated that the accession had largely been made possible through the internship, as he, in his capacity as his country's chief negotiator, could do the necessary through his physical presence in Geneva. Other former interns have been appointed chief negotiator for their country's accession (Comores) to the WTO and this was mainly attributed to the internship programme. In another case, in 2015 a FIMIP (Georgia) shortened his internship and returned to capital following his appointment as ViceMinister for Trade and Economic Development. More recently, in 2016, a former intern from Guinea returned to capital to become secretary-general at the Ministry of Trade. Participation in the programme had not only allowed the acquisition of knowledge about the WTO, but also the creation of a network between officials in the Secretariat, which is used for obtaining first-hand information from the experts of the Secretariat. These findings are again confirmed in the external evaluation report in 2016, stating that the internship programmes are highly effective and showing clearly identifiable results. 
their substantive capacities and generated a better understanding of the stakes in the DDA. ${ }^{100}$ It shows that countries use the expertise developed during the internship.

- Trainees have mostly been appointed to a WTO related position upon return to their own capital city, primarily as a consequence of their participation in the intern programme. In some cases they have been promoted to the highest ranks in government.

- Interviewed ambassadors stated that the presence of the interns enabled the mission to have a better and wider coverage of issues and attendance at meetings. In addition it had permitted an increased ability to digest and analyse WTO documents, before being sent off to the capital. Interns had prepared position papers, statements and reports on meetings and their presence had allowed them to better understand the process of the negotiations, which cannot be appreciated in the same way from being in their own capital.

- Many interns have stayed on in Geneva after the completion of their internship, as part of the staff of their delegation's permanent mission. Others were posted at the mission a few years later in senior positions and sometimes as an Ambassador. Several interns were instrumental in setting up and opening their permanent mission to the WTO.

- The tasks performed by the interns under the Regional Coordinator Internship (RCI) programme enhanced the participation of their mission in WTO activities, helping them to absorb the significant amount of extra work generated by their role as coordinator. It allowed feedback to their constituency, which is particularly important for those countries that suffer a significant geographical distance from Geneva and the decision-making process.

The relevance of the internship programmes is again strongly confirmed in the recent external evaluation report, confirming that 'these 'learning-on-the-job' programmes are highly valued by participants and others, and show tangible immediate and longer-term contributions to the overall intended results of the programme at individual, institutional and policy levels. They attracted the highest average score among sample country informants' 101 The programmes are thus ranked first amongst all the trade capacity building products, thus confirming its reputation that the internship programmes are the flagship products for trade capacity building in the WTO.

100 Before the Ministerial Conferences, former interns are contacted to see who will attend the Ministerial Conference as part of their delegation. Around one third of former interns attend the Ministerial Conferences.

101 Cf. 'WTO Trade-Related Technical Assistance External Evaluation', p. 31. 


\subsubsection{Building capacity at the university level: the WTO Chairs Programme}

Another way of building in-country trade capacity is by cooperating with universities and academia. This is best achieved by associating them more closely with the WTO's agenda, promoting research on trade and trade related issues, building a curriculum and encouraging students to further their studies on WTO related issues. Strengthening the academic network would not only have the advantage of providing a better analytical underpinning for policy decisions, but broaden the pool of knowledge in trade and encourage graduate students to pursue a government career in the field of trade policy. The WTO Chair's Programme (WCP) was first launched in spring 2010 for a period of four years and led to the establishment of an initial 15 WTO Chairs in universities around the world. Five Chairs are based in Africa (Kenya, Mauritius, Morocco, Namibia, Sénégal), four in Asia (China, Indonesia, Singapore, Vietnam), four in Latin America and the Caribbean (Argentina, Barbados, Chile, Mexico), one in Europe (Russian Federation) and one in the Middle East (Jordan). The Chairs in Vietnam and Namibia were discontinued, thus bringing the initial total number of 15 Chairs to 13.

Following an internal review of the programme in 2012, in close cooperation and consultation with the WTO's management, and discussions held with the Advisory Board of the WCP, there was a strong recommendation to extend the WCP for another period of four years upon completion of the initial phase in 2013. ${ }^{102}$ As a result, the WCP was renewed for a second phase covering the period 2014-2017. This extension was rendered possible through financing by the Netherlands, who agreed to act as the sole donor for this programme. A rigorous selection process was conducted which led to the selection of seven new Chairs for Phase II of the programme from a range of some 80 Universities that had applied. The selected Chairs include three in Africa (Bénin, South Africa, Tunisia), one in Latin America (Brazil), two from the Middle Eastern region (Oman, Turkey) and one in Asia (Indonesia). While maintaining a regional balance, it also means that two LDCs are now participating in this programme, including Sénégal and Bénin. This brought the total number of Chairs to 20. In 2016, the second Chair in Indonesia was discontinued, thus bringing the total number of Chairs in Phase I and II to $19 .{ }^{103}$

The Chairs receive limited financial support for their work in three main pillars of the programme, including research, curriculum development and outreach activities. ${ }^{104}$ The main purpose of the WCP is to support the building of sustainable capacities in beneficiaries.

102 The Advisory Board of the WCP initially comprised 21 board members from all over the world. The composition of the WCP was reviewed in early 2016 and their number reduced to 15 . The board members are selected based on specific criteria, including their academic background and their specific knowledge of the WTO. They meet once or twice a year mostly back to back with the WCP annual conference.

103 The discontinuation of the WCP in the three countries was based on a thorough independent review of their performance which then culminated in a WTO's management decision.

104 Each Chair receives the amount of CHF 50,000 per annum on the basis of an agreed action and budget plan, which is scrutinized line by line. 
The programme has also been strengthened based on specific suggestions made, which include the following: deepening the interaction between the various chairs, with more research collaboration encouraged; enhancing visibility of the outputs by more publicity of the outcomes of research; and ensuring the policy relevance of some of the research undertaken, which necessitates a closer interaction between the academia and the policy makers. These elements are particularly emphasized in the second phase of the programme. As a result, and as confirmed in the annual reports received from the Chairs, there has been an increase in workshops organized jointly between the public authorities and the universities, including brown bag lunches, public debates, round tables and so on, thus strengthening the collective thinking. This process is further strengthened through the initiatives taken by the Secretariat, including spin off events organized during the Aid for Trade Global reviews, as well as at the Public Forum. Chairs are requested to prepare papers, which are then presented at the Conferences and are eventually published in a book, thus enhancing the visibility of the Chairs' work. ${ }^{105}$ The link between research and policy relevance are becoming increasingly evident in the Chairs' publications.

The progress in work is closely monitored by the Secretariat and the Advisory Board. The Secretariat interacts regularly with each of the Chairs, including through monthly video conferences for each Chair in Phase II. There are also field visits in which the WTO Secretariat's staff participates in the university courses by teaching and providing training. The annual Conferences equally serve as a distinct time at which to review the achievements by each Chair and exchange information on research findings and experiences. These reviews are based on the reports submitted by each of the Chairs, indicating the progress made in each of the three pillars of the programme. This includes research undertaken, numbers of publications produced, including articles published in peer reviewed journals and books, curriculum development as well as outreach activities. The outputs are thus measured against RBM benchmarks and analysed against quantifiable and qualitative criteria. 106 There is general agreement that the Chairs have delivered on their stated targets and that the key objectives of the programme were met.

Given the general success of the programme, the Advisory Board in its spring meeting of 2016 recommended extending the programme for another term under Phase III. Also, the WCP was invited to consider what long term improvements can be made to further strengthen and deepen the programme. It is clearly seen as a tool for long term sustainable capacity building for beneficiaries.

105 A specific example in that regard is the book by M. Jansen, M. Sadni Jallab and M. Smeets, (eds.), Connecting to Global Markets, Challenges and Opportunities: Case Studies Presented by WTO Chair-holders, WTO (2014). A second book was prepared following the Fifth Aid for Trade Global Review in July 2015 by R. Teh, M. Smeets, M. Sadni Jallab and F. Chaudhri, (eds) Trade Costs and Inclusive Growth, Case Studies Presented by WTO chair-holders, WTO (2016) and launched at the annual conference of the WCP in November 2016.

106 Each Chair indicates in its yearly activity plan the deliverables in measurable and quantifiable terms. 


\subsubsection{Achievements: an increase in notifications}

By way of illustration and in addition to the explanations provided earlier on the usefulness of the internship programmes, the results of targeted trade capacity building efforts undertaken with regard to notifications will be discussed. ${ }^{107}$ This will then be followed with a short presentation of qualitative and quantitative information on how the skills and knowledge acquired through training were put to use.

Notifications are of critical importance in the WTO for transparency purposes (see Chapter 2). Work associated with WTO notifications is an inherent part of the NTP and the FIMIP and a specific assignment for interns. Training sessions on notifications are conducted through national seminars as well as in dedicated training courses in Geneva. The hands-on training allows the beneficiary to understand the intricacies related to the notifications, as well as to prepare and submit them to the Secretariat. There seems to be a positive correlation between the training provided and countries' participation in the WTO's internship programmes, and the submission of notifications made by countries that have benefited from the internship programmes.

Overall, the notifications have consistently risen in number, especially from developing countries. The WTO reports that the rapid increase has been witnessed most importantly in the areas of Technical Barriers to Trade (TBT) and Sanitary and Phytosanitary (SPS) measures. The WTO notes that

over the last 20 years, 34,404 notifications have been submitted in the field of TBT. These notifications of draft technical regulations and conformity assessment procedures have been submitted by 126 Members from all regions. And all levels of development. Notifications have grown year-on-year from 389 in 1995 to over 2,000 annually since 2012. In 1995 developed members submitted almost 80 per cent of the TBT notifications. By 2014, however, 80 per cent of the notifications were submitted by developing and least developed country members. A similar trend, both in terms of numbers and share of the notifications by developing country members can be observed in the SPS area. ${ }^{108}$

In 1995 only 35 notifications were submitted by LDC members. This number has increased rapidly in recent years and by 2010 the LDC members had submitted a total of

107 For detailed information, reference is made to my article 'Trade Capacity Building in the WTO', Journal of World Trade (2013) and to the 'ITTC Case Story on Trade Capacity Building in the WTO', 22 June 2011, WT/COMTD/AFT/W/27, which was presented at the $3^{\text {rd }}$ Global Review on Aid for Trade, p. 9.

108 WTO at Twenty, p. 55-56. 
230 notifications. ${ }^{109}$ A large number of LDCs went from making no notifications in recent years to coming forward with one or several notifications. In other cases, there was a noticeable escalation of notifications by developing countries and sometimes a doubling or even more significant increases.

The increase in notifications can at least in part be ascribed to the work of the interns, as several have prepared and subsequently made substantive numbers of notifications during their internship. Some examples are Uganda, Rwanda and the Republic of Congo, whose interns made between 20-30 notifications each during their internship, many of which were submitted upon their return to their own capital. Through the trainee programmes, guidance is given on how to fulfil their notification obligations upon accession, so as to be able to deliver on this following the completion of the accession process. Here again interesting data are presented in the WTO study, showing how the Article XII members (Recently Acceded Members or RAMs) submit far more notifications than the other WTO members. ${ }^{110}$ Dedicated technical assistance programmes are organized to that effect, with the sole purpose of explaining how the notifications obligations are to be fulfilled.

A specific illustration of trade capacity building with regard to notifications in the area of the SPS Agreement relates to the Dominican Republic. ${ }^{111}$ It is an important agreement for ensuring transparency in the field of imports and exports of goods subject to sanitary and phyto-sanitary regulations. An official from the Dominican Republic attended a WTO Secretariat's three-week advanced course on SPS, which comprised a series of sessions and practical exercises related to the implementation of the agreement. This resulted first in the preparation of a national action plan related to the strengthening of the National SPS Committee and the strengthening of interaction mechanisms between the public institutions that make up the National SPS Committee and the private sector. Following the support provided the Dominican Republic had a well-functioning coordination mechanism for its National SPS Committee and created an official SPS related website. So how can one measure the outcomes? The Dominican Republic had only submitted 4 SPS notifications to the WTO between 1995 and 2009. In 2009 and 2010, 23 and 24 notifications were made respectively, followed by another 10 in 2014 and 2 in 2015. The total number of notifications now stands at 62 , compared to a total of 4 up to 2009. This example shows how very targeted and specialized human and institutional capacity building can have an immediate and important impact.

\footnotetext{
109 A challenge in counting notifications and drawing conclusions from the numbers is related to the fact that many of the notifications are so-called 'one-off notifications, meaning that once a notification is made, it will not be made in the following years. This explains the fluctuations in submissions from one year to the next.

110 Cf. WTO at Twenty, p. 25, Figure 6.

111 Cf. Chapter 2.
} 


\subsubsection{Two key challenges: funding and coordination}

One of the significant differences between the GATT and the WTO, as was argued earlier, is the way trade capacity building is organized. In the GATT, the approach was rather fragmented and the delivery mostly ad hoc, as the budget for technical assistance and trade capacity building was very limited. The approach in the WTO, especially following the launch of the DDA, is far better structured, with trade capacity building being an integral part of the rules and the institutional set-up. While the WTO's Secretariat's trade capacity building programmes have been put on a stronger footing, the WTO's Secretariat faces two key challenges, which include:

- $\quad$ ensuring stable, predictable and timely funding of the programmes; and

- coordinating activities with stakeholders and ensuring coherence.

\subsubsection{Ensuring stable, predictable and timely funding}

As the implementation of the TA Plans depends on the availability of funding, with $80 \%$ of the funds being obtained through voluntary contributions, the sustainability of the programmes depends on the generosity of the donors. Sutherland observed in that regard that 'little technical assistance is funded directly through the WTO budget - a situation that could usefully be corrected to ensure some security and predictability for these efforts.' ${ }^{112}$ In recent years, the amount of the financial contributions of the donors have decreased considerably and in fact more than halved, thus making the timely, predictable and adequate levels of funding a main challenge. It should be recalled that the rules on timely financial contributions were established by the donors themselves, adopted by the Budget Committee and confirmed by the General Council shortly after the launching of the DDA.113 This included a funding mechanism and procedure. Accordingly, the Secretariat would dispose of $25 \%$ of the funds for the following year on the first of January of any given year, $75 \%$ by the end of March and all funds by 30 June. This target has never been met and members are no longer reminded of this specific commitment taken at the time of the launching of the DDA. Needless to say that the timely and adequate funding of the WTO Secretariat's TRTA activities is essential for the efficient planning and implementation of the TA plan. Funds received in November of any given year cannot be spent in the same year. The Secretariat

112 P. Sutherland et al., 'The Future of the WTO: Addressing Institutional Challenges in the New Millennium' WTO (2004), page 78.

113 Pursuant to the commitment contained in para. 40 of the Doha Declaration, on 20 December 2001 the General Council approved the creation of the DDAGTF and defined its terms of reference. One of the main purposes of the DDAGTF was to consolidate the numerous extra-budgetary resources of the WTO in a single un-earmarked fund, so as to provide a stable financial basis for WTO TA and capacity-building. The Committee on Budget, Finance and Administration (CBFA) and the Committee on Trade and Development (CTD) jointly bill the plan and recommend a target amount for the DDAGTF to the General Council. This amount corresponds to the budget for each of the two years of the biennial TA Plan taking into account the resources available for TA in the regular budget, and resources contributed by partner institutions. 
has reiterated the importance of timely funding at sessions of the Ministerial Conferences. ${ }^{114}$ This has had little effect. Several important donors have dropped out and ceased making contributions without providing further explanation. ${ }^{115}$ The current financial situation in the world has made it even harder to obtain funds and the uncertainty about the future of the DDA since MC-X (Nairobi) is likely to make it more of a challenge to ensure timely and adequate levels of funding. In 2016, as was mentioned before, the WTO reached the lowest level of contributions ever, for any given year. It is evident that the Secretariat can only implement its current program due to the underspending in previous years, which have generated carry-overs from one year to the next. This is not sustainable, and with the current spending rate will soon lead to an unavoidable serious cash flow problem. The Secretariat should become more pro-active and encourage members to make their contributions in line with commitments and preferably in the form of un-earmarked ${ }^{116}$ multi-year pledges. ${ }^{117}$

There are several ways to decrease the deficit in funding the TRTA programmes including the following: ${ }^{118}$

○ One option is to further downsize the capacity building programmes. This implies diminishing the support given to the beneficiaries and thus giving the wrong signal to those most in need of such support, and so this does not seem to be a viable option. One could even argue that given the importance of assisting developing countries in the MTS and the rapid changes in the world economy, challenges relating to the globalizing world economy require more capacity building, not less - hence the need for more funding.

- A second option consists of reviewing the balance between budgetary and extrabudgetary funding of the activities, in favour of the regular budget. This would imply strengthening the regular budget and would be a logical consequence of acknowledging that trade capacity building is a core function of the WTO Secretariat. This option is challenging, however, for two main reasons: one is that the Secretariat operates on a zero growth budget; the second reason is related to the fact that developing countries contribute to the regular budget, even if their contributions are very small, and they consider that they cannot be expected to pay a share of the capacity building to which they are entitled. 119 This option should be explored

114 Cf. Hong Kong Ministerial Declaration, 22 December 2005 WT/MIN(05)/W/3/Rev.1, para. 50-52.

115 Cf. footnote 67.

116 There is a newly emerging trend for members who seek to earmark their financial contributions for specific programmes, particularly those that attract high visibility. This entails the risk that while some attractive programmes are funded, others are not, whereas the DDAGTF was set up as a truly 'global' trust fund.

117 Very few donors make multi-year pledges (for three to five years), including Canada, the Netherlands, France.

118 It is noted that the external evaluation includes recommendations on funding and suggest enhancing the regular budget of the WTO.

119 It is recalled that the members' contribution to the WTO's budget is determined by their relative share in world trade and which is rather insignificant for the LDCS and very small for most developing countries. 
further, as suggested by some members during the last meeting of the Committee on Trade and Development held in January 2017.

- A third option would consist of identifying new donors or encouraging present donors to raise their contributions and expand their support. ${ }^{120}$ Although BRICS comes to mind, the declining economic situation in some of these countries makes this option considerably less viable. ${ }^{121}$ One could consider oil rich countries, but given the sharp decline in oil prices, this may also be a challenge, on top of which they are often actually beneficiaries themselves.

- Funding could perhaps be obtained through other channels, including through foundations and perhaps even the private sector. In order to avoid a conflict, it is of the essence to determine clear terms of reference, ensuring neutrality and sticking to the objectives and mandate provided for by the WTO Secretariat.

- In short, there are not that many viable alternative solutions that could be considered to extend the funding, other than reminding members of their current commitments and by showing the relevance and effectiveness of the assistance provided through an independent external evaluation and as was done most recently. ${ }^{122}$

\subsubsection{Coordination and ensuring coherence}

The second main challenge includes the coordination of the delivery of trade capacity building programmes and activities, building synergies between the programmes and ensuring coherent approaches. These challenges are related to the sheer number of actors and stakeholders, bilateral donors and international organizations and bodies associated with the delivery of TRTA. There is a considerable amount of capacity building on offer. Donors and agencies have their own specific priorities, mandates, objectives, targets, programmes, reporting requirements, time lines, skills, expertise, knowledge, methodologies, funding and accountability mechanisms. Some focus more on trade, some on infrastructure, others on educational training, business practices and so on. This led to introduction of the Aid for Trade concept at MC-VI (Hong Kong), in an attempt to capture all the various initiatives under one umbrella. ${ }^{123}$ Other agencies also have their own line of interventions.

In addition to the Aid for Trade initiative, there are several institutional set ups and mechanisms to address the coherence and coordination issues. At the level of the OECD the

120 These include by way of example Singapore, Korea, China, Separate Customs Territory of Taiwan, Penghu, Kinmen and Matsu (Chinese Taipei), and Qatar. In some cases they make a financial contribution, in other cases they make training centres available and provide 'in-kind' support.

121 China is already providing support to the Secretariat through the so-called 'China programme'. It is mainly geared towards assisting (a) acceding countries to become WTO members and (b) LDCs in the WTO.

122 Cf. footnote 54.

123 Cf. footnote 43. 
Development Assistance Committee (DAC) plays a central role in development policies and building partnerships. At the UN level, coordination of policies between agencies is conducted through regular meetings with the heads of agencies in the Chief Executive Board (CEB). ${ }^{124}$ Another mechanism is the EIF, which is a joint effort between key agencies and beneficiaries to coordinate lines of action to assist LDCs to mainstream trade in their national development programmes and plans. ${ }^{125}$ The WTO provides for the Secretariat of the EIF. Coordination mechanisms exist in specific fields, such as the STDF, which is housed at the WTO. ${ }^{126}$ Many other international institutions have their own systems for trade capacity building programmes with dedicated resources. UNCTAD was set up in the 1960s specifically to provide support to developing countries and as was mentioned earlier in this section, there is a whole range of agencies at the regional level that design and deliver trade capacity building.

At the level of the beneficiaries, the coordination of TRTA activities has often proven to be a key challenge, particularly when it comes to the domestic institutional set up and internal coordination between the departments. Developing countries often lack the institutional capacity to align the various and often numerous programmes offered by agencies and donors and ensure coherence. The support offered may be directly relevant for a country, as it may imply a transfer of knowledge, skills and perhaps funding, but how can these programmes be managed with the limited availability of human resources?

The challenge therefore is to structure the support in accordance with the priorities and the needs identified by the beneficiaries, but there is no real effective coordination mechanism at the international level. That task is left to the beneficiary, who often simply cannot handle that task, given the limited resources. This is a real challenge that needs to be addressed.

124 The CEB brings together 27 executive heads from UN bodies, the WTO and Bretton Woods institutions. Its main role is to coordinate actions and policies, thus ensuring coherence in approaches within the UN system. It meets under the chairmanship of the UN Secretary-General.

125 According to the EIF website, 'The EIF programme creates a genuine partnership among all EIF stakeholders to show results on the ground. Working in close cooperation are donors, six core partner agencies, observer agencies, the Executive Secretariat (ES) and the Trust Fund Manager (TFM) and other development partners who are supporting LDCs' own drive to: mainstream trade into national development strategies; set up structures needed to coordinate the delivery of trade-related technical assistance; and build capacity to trade, which also includes addressing critical supply-side constraints. The EIF process aims to strengthen donors' support to a country's trade agenda. LDCs can use the EIF as a vehicle to assist in coordinating donors' support and to lever additional Aid for Trade resources, whereas donors can sign up to the EIF as a vehicle to deliver on their initial Aid for Trade commitments'.

126 According to the WTO website, 'The Standards and Trade Development Facility (STDF) is a global partnership that supports developing countries in building their capacity to implement international sanitary and phytosanitary (SPS) standards, guidelines and recommendations as a means to improve their human, animal and plant health status and ability to gain or maintain access to markets'. See also www.standardsfacility.org. 


\subsubsection{Conclusion}

In this part it was argued that with the launching of the DDA a new and strong footing for the delivery of the WTO's trade capacity building programmes was created, but that the future of these programs is now being put at risk given a poor financial situation. The main features of the programmes were discussed as well as their main objectives, which consist of gradually building the knowledge and providing the skills to government officials to move from learning to doing. A few examples were provided on how the human and institutional support provided to beneficiaries has helped them to integrate in the system and deliver on their obligations. It was argued that two key challenges remain, which include securing timely and adequate funding as well as the coordination of the trade capacity building programs, strengthening the synergies and ensuring full coherence.

It was argued that all the beneficiaries will need to continue to benefit from the trade capacity building programmes, irrespective of the progress and future of the DDA negotiations. As trade is increasingly recognized as a key vehicle for growth, developing countries need to be supported in their efforts to mainstream trade in their national development plans, by giving them the full capacity to understand and apply the WTO agreements, enforce their rights and obligations and reap the benefits of trade liberalization.

The question that needs to be analysed further is to what extent developing countries have benefited from the programmes and how this can be shown. Are they in a better position to take active part in the negotiations, define their strategic objectives, defend their economic and trade interests, create alliances based on specific negotiating issues of direct concern to them and submit position papers and proposals on complex issues? The following section will provide some answers, bearing in mind the constraints in quantifying how much of this can directly be attributed to the TA programmes.

\subsection{A fuller participation of developing countries in the multilateral trading system}

The findings and outcomes of the external evaluation presented to the WTO show that: 'The widespread impact of WTO TA on the human capacities of beneficiary countries is real and tangible, and the Evaluation found highly plausible evidence that WTO TA has also contributed to capacities at institutional levels in trade-policy-making, legislative compliance, multilateral/regional trade negotiations and implementation of international trade agreement. Drawing on its different lines of evidence, the Evaluation has been able to trace demonstrated results from the training of individuals (including interns) and groups through to strengthened contributions and rising levels of responsibility in their work, to more effective institutions in the field, and finally to collecting an unexpectedly large volume of plausibly-linked, concrete examples of more effective participation in the system by countries concerned. This body of evidence meets and exceeds the conditions for a 
reasonable causal claim that the training interventions made substantial contributions to countries' more effective participation in the MTS.' ${ }^{127}$

The fuller participation of developing countries and their gradual integration into the multilateral trading system can be assessed in two different ways. One consists of a quantitative assessment: measuring how developing and least-developed countries effectively benefited from trade and whether their trade flows and shares in world trade have increased. Data essentially cover the period 1980-2015 and are based on WTO statistics, as contained in official documents and for which the sources are provided. The second way consists of a qualitative appreciation of the extent to which developing and least-developed countries are in a position to make inputs and contributions in the DDA negotiations and influence the outcome of the negotiations through specific submissions. The assessment of this part is again based on official WTO documents as well as information found in the recent literature. Accordingly this section is divided in two parts, first assessing the quantitative aspects, followed by a second part discussing the qualitative aspects.

The WTO Secretariat regularly presents a factual analysis of quantitative appreciation to the membership, including an annual report on the participation of developing countries in the global trading system and an annual report on the evolution of world trade. ${ }^{128}$ The reports contain detailed information on the participation of developing countries in the WTO and provide an occasion for the membership to collectively review progress made in this regard. Members undertake an annual review with regard to the participation of the LDCs in the trading system for which the Secretariat prepares separate reports. ${ }^{129}$ The reports include a factual presentation on trade developments and opportunities regarding LDCs as well as an overview of the trade capacity efforts undertaken to the benefit of the LDC community. ${ }^{130}$ In addition, the Secretariat prepared a detailed and specific report in 2015 on the participation of LDCs in the WTO, which is part of the broader analysis conducted in light of the 20th anniversary of the WTO. ${ }^{131}$

Based on the quantitative data and figures presented in the official WTO reports, it will again be shown and confirmed that developing countries have increased their shares in world trade and are thus participating better in international trade. The question of attribution remains, though, namely to what extent this positive finding can be attributed to

127 Cf. 'Ex-post Evaluation of the WTO Trade-Related Technical Assistance External Evaluation', p. viii.

128 WTO World Trade Report 2014; Participation of Developing Economies in the Global Trading System, 2 November 2015 (WT/COMTD/W/212).

129 Market Access for Products and Services of Export Interest to Least-Developed Countries, 5 October 2015 (WT/COMTD/LDC/W/60).

130 The reports include my inputs and contributions, in addition to which I provide a detailed review before the WTO sub-committee for LDCs of all trade capacity building activities for LDCs with a view to assisting them integrate into the multilateral trading system.

131 WTO and Least Developed Countries: Twenty Years of Support Towards Better Integration into the Multilateral Trading System, Note by the Secretariat, 30 September 2015(WT/COMTD/LDC/W61). 
the trade capacity building efforts pursued by the Secretariat and other organizations. ${ }^{132}$ Clearly, there are many factors at play affecting trade flows and access to markets, including domestic reform policies, trade liberalization and many market related factors that are beyond the control of the public authorities. It is believed that the collective efforts to build capacity have contributed to the countries' own reform policies, which are mostly dictated by a better understanding of the role that trade and trade policy can play in pursuit of their policy objectives. The reform policies have contributed to a more competitive environment in developing countries.

As for the qualitative assessment, the analysis focuses more specifically on the participation of African countries in international trade negotiations, based on an appreciation of their contributions and interventions in the negotiation process of the DDA. As is argued, developing countries are much better prepared and informed on the technical issues in the negotiations and often seem to be in a position to develop their national policy positions and defend their interests in the negotiations. This has led to an active engagement in the discussions and negotiations.

\subsubsection{A quantitative assessment of developing countries' participation in international trade}

According to the WTO, and as was shown in Chapter 3, the share in world trade of developing economies' exports and imports of goods and commercial services had grown steadily in recent years and had attained $44 \%$ and $41 \%$ respectively in 2015 for world merchandise exports and imports, up from 30\% and 25\% respectively in 1980 (see Table 3.2). ${ }^{133}$ These data testify of a marked improvement of developing countries' overall position in world trade amounting to an increase of some $50 \%$ in their relative shares. This is significant by any standards, but the overall figures hide the differences in performances per region and in some cases per country, as was illustrated in chapter 3 . These figures remained largely unchanged since 2015, which is explained by the slowdown in the economy and more specifically world trade. ${ }^{134}$ The comparable data for commercial services exports and imports were $32 \%$ and $39 \%$ for exports and imports of services in 2015 , up from $21 \%$ and $31 \%$ respectively in 1980 . Here again the data show an overall increase of their relative shares by some $50 \%$ for exports of services and around $25 \%$ for imports of services. This shows that the increase in exports of services from developing countries has outpaced the

132 According to the log frame contained in the WTO's Biennial TA Plan 2016-2017, Annex 1, p. 36, the expected impact of the TA programmes is that the 'developing and LDC members secure a share in the growth in world trade commensurate with their needs of their economic development'. It refers to a baseline and a target which should exceed the baseline. Given the small size and limited funding of the WTO's TA programmes and the related issue of attribution, as referred to earlier, this probably is far too ambitious and therefore questionable.

133 See also Participation of Developing Economies in the Global Trading System, 2 November 2015 (WT/COMTD/W/212), Table 1, p. 6.

134 Cf. Chapter 3, Tables 3.1 and 3.2. 
relative share of imports. There are however marked differences within the various developing countries with the continued dominance of China in international trade and more specifically in services. From a narrower geographical angle, all the developing regions saw their merchandise exports and imports increase faster than world trade. The Middle East's exports rose, spectacularly driven by high fuel prices and production until a sharp decline in the oil prices set in, starting in the second half of 2014, followed by an even steeper drop in 2015. ${ }^{135}$ More than others, developing countries suffered depressed demand from their developed neighbours.

Another significant development concerns the evolution of so-called 'South-South trade', i.e. trade between developing countries and which continued its steady rise: The contribution of South-South trade to developing economies accounted for $54 \%$ of developing countries' exports in 2014.136 According to the WTO, this represents a 6\% increase since 2012 and is a slowdown compared to the period 2010-2012, when the increase was $33 \%$. According to the World Trade Report, since 1990, South-South trade has grown overall from $8 \%$ of world trade in 1990 to nearly $25 \%$ at present and could reach $30 \%$ by $2030 .{ }^{137}$ These data confirm the significance of the growing share of trade that is conducted between developing countries, further reducing the North-South trade dependency by developing countries, i.e. trade between developed and developing countries. The dynamics is not the same in all regions as was shown in chapter 3: the most dynamic evolution in trade patterns is found in Asia, with mainly China accounting for the bulk of the trade.

It is also noted that 'trade corridors between Asia and North America, and between Asia and Europe, now surpass the old transatlantic trade corridor, while trade corridors between Africa and Asia or Latin America and Africa are growing in importance'. ${ }^{138}$ Developing Asia's and more specifically China's exports to developing economies outside Asia increased quickly over the last 35 years. As was shown in chapter 3 (Table 3.1), Asia's share for exports more than tripled from $8 \%$ to $29 \%$. This is mostly accounted for by China, which, it is recalled, had a share of $1 \%$ for merchandise trade in 1980 , which rose to nearly $14 \%$ in 2015.139

Africa's relative share in world trade, despite its rapid growth in recent years, declined from $6 \%$ to $2 \%$ in 2015, which can mainly be explained by the more sustained growth in the other regions and its relatively small share in world trade. ${ }^{140}$ According to the Africa

135 Which actually have come down again and dropped further, thus affecting the longer term growth of oil exporting countries.

136 Cf. WT/COMTD/W/212, para 3.1, p. 8 and table 3.6.

137 Cf. World Trade Report 2014, Appendix Table 1, p. 42 and World Trade Statistical Review 2016. See also Table 3.6 in Chapter 3.

138 Cf. Ibid.

139 Ibid.

140 Ibid. 
Economic Outlook 2014, Africa has been the fastest growing continent in recent years, even though its relative share in international trade decreased. In terms of sectorial performance, the services sector continues to be a primary engine of growth, with increasing development in both traditional and new services sectors. The agriculture sector, on the other hand accounts for $60 \%$ of Africa's employment and $25 \%$ of its GDP. The manufacturing sector is relatively small and on average contributes $10 \%$ to GDP. However, the extractive industries account for almost $80-90 \%$ of exports to some African oil producing countries.

Looking more specifically at the integration of LDCs into the multilateral trading system, the participation of LDCs in global trade has seen a gradual improvement over the last 20 years. LDCs managed to increase their share in world trade of goods and services from $0.59 \%$ in 1995 , to $0.80 \%$ in 2005 and to $1.23 \%$ in $2013 .{ }^{141}$ The reports observed that these developments are the fruits of the policies put in place by LDCs and complemented by flexibilities in the WTO rules for LDCs both with regard to implementing rules and disciplines as well as in undertaking commitments. As the WTO observes, "Members have shown willingness to respond favourably to concerns and needs to beneficially integrate them into the MTS'. ${ }^{142}$ The Secretariat lists some three dozen LDC specific S\&D provisions in WTO agreements and decisions taken at the WTO in favour of LDCs. ${ }^{143}$ These go above and beyond the decisions and measures taken in the GATT as well as the multilateral nonreciprocal LDC preference schemes undertaken by WTO members. ${ }^{144}$ The vulnerability of the LDCs was again testified with a declining share in both 2014 and 2015, bringing the combined export share of LDCs for goods and services to $0.9 \%$, thus falling below the level of 1 per cent for the first time since the economic crisis in 2009.145 The main explanation provided in the report for the lower values of merchandise exports is related to the lower prices of commodities.

The World Trade Report of 2014 draws clear conclusions from the analysis and observes that

Trade has allowed many developing countries to benefit from opportunities created by emerging new markets, to integrate into the world market through global value chains at lower costs, and to reap the rewards from higher commodity prices. The WTO has played a key role by providing certainty regarding commitments of its members, thereby creating a predictable

141 Cf. WT/COMTD/LDC/W/61, para 1.2, p. 2

142 Ibid., p. 2.

143 Ibid., Annex II, p. 29-31.

144 A discussion of recent initiatives to improve market access for LDCs including an illustrative list of nonreciprocal preference schemes and measures introduced by WTO Members on an autonomous basis is provided in WT/COMTD/LDC/W/60, p. 49 and Annex Table 7, p. 66. A more detailed listing is provided in document WT/COMTD/LDC/W/61, Annex II.

145 Market Access for Products And Services of Export Interest to Least Developed Countries: Summary of Recent Developments, 23 September 2016(WT/COMTD/LDC/W/64), p. 3. 
environment that allowed economic activity to flourish. It has also given flexibilities to developing countries to address their specific economic needs. ${ }^{146}$

Despite the positive developments, the reality is that the shares of LDCs in world trade remain low and concentrated in a very limited number of products. Developing countries thus face significant policy challenges, one of which consists of the lack of product diversification and a high dependency of exports in a small range of products. According to the WTO, 'on average, almost 70 per cent of total merchandise exports depended only on three main products in 2014', which implies a high vulnerability to fluctuations in international trade. ${ }^{147}$ The situation has deteriorated since 1995 , as only around $40 \%$ of LDCs' exports were attributable to the top three products.

A related and main challenge for the better integration of developing countries in the multilateral trading system concerns their participation in GVCs, a subject of analysis in the WTO Chairs Programme. As was explained in chapter 3, the research focused on a number of country experiences, the results of which were presented to the WTO members in February 2014. ${ }^{148}$ The book prepared by the Chairs discusses the challenges emanating from globalization and provides various policy options for developing countries to better connect to international markets. As was also shown in chapter 3, the literature on GVCs is expanding rapidly and there is a general consensus emerging around the importance of GVCs for stimulating economic growth and development. The WTO and the World Bank observe that 'the emergence of global value chains has been an important driver of developing country participation in the global economy'. ${ }^{149}$ Another WTO study looks more specifically at the challenges and opportunities as well as some of the policy options available for small economies to better connect to the markets. ${ }^{150}$ According to the WTO reports, GVCs provide several opportunities and challenges which can be summarized as follows:151

- It can lead to better integration into the trading system and advancement of economic development, as countries can specialize in tasks or stages within the value chain. On the risk side, Baldwin makes the point that 'activities might be relocated, as easier

146 Cf. World Trade Report 2014, p. 210.

147 WT/COMTD/LDC/W/60, p. 9.

148 Cf. P. Lamy, 'Foreword' in D.E. Elms and P. Low (eds.), Global Value Chains in a Changing World (WTO, 2013); M. Jansen, M. Sadni Jallab and M. Smeets, (eds.), Connecting to Global Markets Case Studies Presented by WTO Chairs (WTO, 2014).

149 The Role of Trade in Ending Poverty, joint publication by the World Bank Group and the World Trade Organization (2015), p. 14.

150 Challenges and Opportunities Experienced by Small Economies when Linking into Global Value Chains in Trade and Commercial Services, WTO, 1 May 2015, WT/COMTD/SE/W/31.

151 Ibid., p. 5-6; World Trade Report 2014, p. 94-95; World Bank and WTO, The Role of Trade in Ending Poverty, p. 24. 
entry and exit into value chains also implies a fiercer competition among countries'.152

- GVCs contribute to diversifying developing countries' production and export structure away from natural resources or primary agricultural commodities to manufacturing services, where labour productivity and wages are higher.

- In addition to the employment it creates, the WTO report underscores the dynamic gains from increased trade integration and FDI, which often accompany GVC integration, including the transfer of technology and skills.

- The report notes that developing countries that are interested in having their firms join GVCs are likely to face two interlinked challenges. First they need to establish policies and a business environment that allow domestic firms to improve their productivity and secondly developing countries compete against each other in their efforts to attract FDI through investment promotion and related policies. ${ }^{153}$

These findings are not surprising, as similar conclusions can be found in the other studies referred to earlier, including the WTO's annual report of 2014, the study undertaken jointly by the WTO and the World Bank, as well as the findings presented by the WTO Chairs. ${ }^{154}$

The same studies therefore advocate these countries to focus more specifically on developing their strengths in services in the GVCs, as this would be less costly in terms of investment in infrastructure and production facilities. The WTO underscores that 'more than 30 per cent of developing countries' exports consist of services value added, with services having become an important input into the manufactured goods. This underlines the important role of services for GVC efficiency and development'. ${ }^{155}$ The WTO furthermore underscores the growing importance of GVCs in South-South trade, which has increased significantly: 'the share of trade in parts and components between developing countries has risen from around 6 per cent in 1988 to almost 25 per cent in 2013. ${ }^{156}$

Related to this is the need to reduce transaction costs in developing countries, for which the TFA can play a vital role. This point will be substantiated further below in a case study on

152 See R. Baldwin, ' $21^{\text {st }}$ Century Regionalism: Filling the Gap Between $21^{\text {st }}$ Century Trade and 20 $0^{\text {th }}$ Century Trade Rules', CEPR Policy Insight 56, Centre for Economic Research, 2011.

153 WT/COMTD/SE/W/31, p. 5.

154 See Jansen, Sadni Jallab and Smeets, (eds.), Connecting to Global Markets and World Bank and WTO, The Role of Trade in Ending Poverty.

155 WTO World Trade Report 2014, p. 121.

156 Cf. Ibid. 
the TFA and on the basis of a recent WTO study prepared by the Secretariat with the WTO Chairs. ${ }^{157}$

\subsubsection{A qualitative assessment of the developing countries' participation in the DDA}

The qualitative approach with regard to the fuller participation of developing countries in the trading system is based on a closer look at how developing countries are more actively engaged in the negotiations. As is shown, developing countries and LDCs are participating more in the DDA and multilateral trade negotiations.

A commonly held critique by the African constituency is that previous negotiations were mostly shaped by the interests of larger more powerful members. ${ }^{158}$ Developing countries did not actively engage in earlier negotiations and were mostly 'takers' of the outcomes and decisions, with little power to influence the agenda per se and ensure that their interests were addressed. As Laker observed, many developing countries, particularly those in Africa, were reluctant to launch a new round of negotiations in 2001 (the DDA) as according to African countries, there was much unfinished business, including with regard to the implementation of existing commitments - which needed to remain the focus. ${ }^{159}$ The Doha Round could only be launched on the condition that implementation related issues and concerns would be dealt with, as well as that the Round would focus on development. This also meant that in every negotiating area developing countries would be looking for an outcome that was sensitive to and reflective of their development concerns.

The concerns are contained in the Decision on Implementation and Related Issues and Concerns, as summarized in Annex 1, which gives a sense of some of the concerns that African countries had in the period prior to the launch of the Doha Round. ${ }^{160}$ In this Decision, Ministers expressed their determination to take concrete action to address issues and concerns that had been raised by developing-country members regarding the implementation of some WTO agreements and decisions, including the difficulties and resource constraints that had been encountered in the implementation of obligations in various areas.

On the question of whether developing countries participated more actively in the negotiations and how that can be measured, the evidence clearly confirms a strong engagement and commitment on the side of the developing countries. The fact that Kenya hosted the 10th Ministerial Conference (MC-X) at Nairobi in December 2015 confirms the

157 Teh, Smeets, Sadni Jallab and Chaudhri, (eds), Trade Costs and Inclusive Growth, Case Studies Presented by WTO chair-holders (WTO, 2016). This publication contains a collection of readings that resulted from the sideevent organized by the WTO Chairs during the Fifth Aid for Trade Global Review, July 2015.

158 Cf. Laker, African Participation in the World Trade Organization, p. 7.

159 Cf. Ibid., p. 13 and 65.

160 See Decision on Implementation Related Issues and Concerns, WTO, 14 November 2001. 
keen interest Africa has in trade and giving direction to the DDA negotiations. ${ }^{161}$ It was the first ever Ministerial Conference organized on the African continent and chaired by an African leader. It can also be seen as a confirmation that the African continent attaches to trade as a vehicle for generating economic growth. In the lead up to MC-X, Kenya had gathered strong support from the African countries.

Since the launching of the DDA developing countries and LDCs have (either as a group or individually) submitted a considerable number of proposals, many of which address specifically (sub-) regional interests or more global interests and cover most of the areas under negotiation. Specific examples of groups and coalitions were provided in Chapter 2, which showed that there are also many groups that unite developed countries and developing countries defending common positions and interests. ${ }^{162}$ Developing countries are increasingly associating themselves with positions of other developing and/or developed countries by way of creating coalitions, thus building a stronger capacity to defend legitimate economic interests. These coalitions can be small or large and are mostly topic based, addressing specific interests for these countries in a sector or a policy area of economic importance to these countries. This is in itself is an interesting development, as it confirms a trend towards seeking a pragmatic and solution-oriented approach in the negotiations, rather than sticking to dogmatic positions. Positions are thus increasingly based on economic and policy interests. The group proposals made by coalitions of developing countries are mostly geared towards easing a fuller integration of beneficiaries into the multilateral trading system. In view of the limited resource capacities, developing countries increasingly engage in the negotiations through coalitions in order to defend their economic and trade policy interests. 163

LDCs have submitted over 50 specific proposals covering eight different areas of negotiations. ${ }^{164}$ As will be discussed below, they have made 129 specific S\&D-related proposals. The proposals mostly resulted in tangible outcomes, with specific provisions made for developing countries and LDCs in the agreements. Nearly half of all the Decisions contained in the Ministerial Declaration that were adopted at MC-IX (Bali) address developing country related issues, including specific commitments and actions. ${ }^{165}$ The MC$\mathrm{X}$ (Nairobi) once again resulted in general and specific decisions that would benefit developing countries and LDCs directly or indirectly, including the significant decision with regard to the elimination of export competition for agricultural products. ${ }^{166}$

161 Kenya initially competed with Turkey to host MC-X. Turkey withdrew its application, freeing the way for Kenya to host this event, a first on the African continent.

162 Annex 2.2 in Chapter 2 lists the various groupings that cooperate on specific topics, including NAMA, Agriculture, TRIPs etc.

163 Cf.. discussion in Chapter 2 on coalitions.

164 WT/COMTD/LDC/W/61, p. 32.

165 Ministerial Conference Ninth Session, Bali, 3-6 December 2013; Ministerial Declarations and Decisions, 11 December 2013, WT/MIN(13)/DEC,.

166 WT/MIN(15)/45, WT/L/980, 21 December 2015. 
Specific text and negotiating proposals that are technically complex and often sensitive were made in areas such as NAMA, agriculture, intellectual property, services, trade facilitation, S\&D treatment, dispute settlement, and Aid for Trade. This again confirms the pro-active stance of developing countries in the negotiations. The discussion on NAMA in Chapter 4 showed that the draft agreements contain a broad range of specific exceptions and S\&D provisions for developing countries. These were meant to ease the implementation of the two draft agreements by developing and least developed countries, but had at the same time added to the complexity of the agreements. Some specific examples of the active commitment by developing countries in the negotiations are as follows:

- With regard to NAMA, the African group was a key player in the negotiations on the issue of low binding coverage by developing countries and managed to get this recognized as a category for special treatment in the negotiations. ${ }^{167}$

- In the negotiations on the Agreement on Agriculture, Africa has fiercely defended the continuation of the preferences granted by developed countries, built a strong case in support of the smaller cotton dependent African producers and defended the Special Safeguard Mechanism as a key element to the Agreement.

- In the negotiations on the TFA, developing countries have been successful in negotiating firm commitments on the side of the donors and ensuring that financial assistance will be provided in support of implementation of commitments. This will be discussed in detail in a case study presented in the next section. ${ }^{168}$

- Developing countries and LDCs have successfully defended the arguments built to strengthen the S\&D provisions in the WTO, as they remain of critical importance for them. The WTO Agreements contain some 129 S\&D provisions, several of which make explicit reference to LDCs or provide LDCs with more favourable treatment. ${ }^{169}$ The initial LDC Work Programme ${ }^{170}$ goes back to shortly after the launching of the DDA. The S\&D related provisions have been strengthened with time and now include a Monitoring Mechanism (MM) on S\&D, which was agreed at MC-IX (Bali). ${ }^{171}$ The function of the MM is to 'review all aspects of the implementation of $S \& D$ provisions with a view to facilitating integration of developing and least-developed Members into the multilateral trading system'. ${ }^{172}$ In other words, it is designed to closely follow, analyse and discuss between the members the progress made in the implementation of the commitments.

\footnotetext{
167 Cf.. the discussion on tariffs and tariff bindings in Chapter 4.

168 Cf. section 5.4.

169 Cf.WT/COMTD/LDC/W/61, p. 3.

170 WTO Work Programme for the LDCS (WT/COMTD/LDC/11/Rev.1) 11 June 2006.

171 Cf. discussion on transparency in Chapter 2.

172 WT/MIN/(13)/45, WT/L/920 Bali 2013.
} 
- Many of the proposals tabled in the DDA negotiations contain S\&D elements and have led to specific decisions in favour of LDCs. By way of illustration:

In the area of services, the GATS recognizes that special attention needs to be given to LDCs in implementing Article IV of GATS (relating to increased participation of developing countries), taking into account the difficulties encountered by LDCs in accepting negotiated commitments, owing to their particular needs. Special consideration should also be given to LDCs with regard to encouraging foreign suppliers to assist in technology transfers, training and other activities for developing countries. This is reflected in the Decision taken at MC-IX (Bali), which outlines the process for a services waiver for LDCs in recognition of the need to strengthen their domestic services capacity: to make use of existing opportunities and any preferences granted in the future. ${ }^{173}$

- TRIPS (Article 66.1): Following a one year transition period, LDCs can further delay (for up to 10 years) the implementation of most TRIPS obligations other than those containing the core non-discrimination principles. The general transition period was extended several times and following a decision on 11 June 2013, again extended until 1 July 2021. ${ }^{174}$

- Duty-Free and Quota Free Market (DFQF) Access for LDCs, which finds it origin at the MC-V (Hong Kong), as contained in the relevant Ministerial Declaration. ${ }^{175}$ This led to follow up decisions, including one which called on developed members that are not yet providing DFQF access for at least $97 \%$ of products originating from LDCs to improve their existing DFQF coverage prior to MC-X (Nairobi). ${ }^{176}$ Developing countries were also encouraged to do the same to the extent that they are in a position to do so.

- Guidelines on accessions, which include provisions strengthening, streamlining and operationalizing an earlier decision taken in 2002 on the accessions of the LDCs to the WTO. The guidelines established benchmarks on market access negotiations on goods and services, and provisions with regard to S\&D treatment (including transition goods), transparency and technical assistance. ${ }^{177}$

○ Other S\&D provisions apply to rules of origin and tariff treatment for LDCs.

173 Operationalization of the waiver concerning preferential treatment to services and service suppliers of LDCS, 7 December 2013, WT/L/918.

174 Decision of the Council for TRIPS, 11 June 2013, IP/C/64.

175 WT/MIN(05)/DEC.

176 Duty Free and Quota Free Market Access for LDCs, 7 December 2013, WT/L/919.

177 Accessions of LDCs of 25 July 2012, WT/L/508/add.1, which complements the decision taken on accession guidelines in $2002(\mathrm{WT} / \mathrm{L} / 508)$. 
- In all these discussions, trade capacity building for developing countries is a key issue, driven by the need to build the capacity to improve market access conditions. Given the weak infrastructures in developing countries, the requests for capacity building increasingly go beyond enhanced knowledge of the multilateral trading system. The focus is more on issues that are of importance in the implementation of the agreements and strengthening the infrastructures. This largely drove members to adopt the Aid for Trade initiative at MC-V (Hong Kong). ${ }^{178}$ Separately, the LDCs benefit from the EIF which is generally viewed as an effective tool to assist LDCs integrating into the multilateral trading system. These dimensions are important because even though they do not turn the WTO into a development organization, they are nonetheless a reflection of the WTO members' acknowledgement of the importance of building supply-side capacity to enable countries to use trade as a tool for economic development.

Based on the foregoing, it can be concluded that developing countries and LDCs have actively contributed to shaping the DDA negotiations and continue looking after their economic and policy interests. The LDCs have made a significant number of general and/or agreement and topic-specific textual and negotiating proposals, which testifies to a greater capacity to develop positions on complex issues. The efforts to secure preferences through the S\&D provisions reflects the fact that LDCs and developing countries more generally see that as a necessity in order to integrate more fully into the multilateral trading system. The question can nevertheless again be raised: does the approach of focusing on the preferences provide for the optimal policies, bearing in mind the earlier discussion on the merits of preferences as opposed to multilaterally binding commitments? As was pointed out earlier, the literature offers different views. ${ }^{179}$ Irrespective of the position one takes on preferences, the reality is that the more world trade is liberalized, the more preferences will unavoidably be eroded. Developing countries may ultimately be better off taking upon themselves more obligations and commitments in the WTO at the multilateral level, as they are legally binding now and will be in the future. It provides for a more secure and sustainable path of development. It is therefore very important for developing countries to continue engaging in the negotiations of the rules themselves, and securing their interests through the rules, thus diminishing the need to rely on preferences. This would have the additional advantage for them to secure their longer term interests, as many of the preferences are autonomous and provide limited legal rights.

The trend to decrease the preference dependence and work more towards reciprocal arrangements can also be seen in discussions that have taken place in the context of the establishment of the Economic Partnership Arrangements (EPA) between the European

\footnotetext{
178 Cf. footnote 43.

179 Cf. Hudec, Developing Countries in the GATT Legal System.
} 
Union and the ACP countries. ${ }^{180}$ The EPA negotiations reflected a legal necessity for the EU to bring the preferences in line with the WTO's obligation and commitments, by specifically introducing the concept of reciprocity in the discussions and with a view to obtaining better market access conditions for the beneficiaries.

An important consequence of the more active engagement of developing countries in the negotiations is that their positions can no longer be ignored, as was largely the case in the GATT. Developing countries increasingly seek concessions from the developed countries. They have increasingly become 'demandeur' in the negotiations instead of having to accept what is put on the table, referred to as the 'takers' of the outcome of the discussions between developed members. That had mostly been the case in the previous rounds and led to the discontent of developing countries, a state that now largely belongs to the past. Given the wider and active interests by developed and developing countries in the negotiations, the format of the discussions has also changed in order to reflect the broader spectrum of views in the discussions. The Director General Azevêdo responded to the calls from developing countries, including the smaller delegations, by deciding to open the so-called 'green room' process. It now includes all delegations, as opposed to the previous process which allowed only for a limited number of selected members to sit in on the negotiations (Chapter 2). All countries can now be represented in the process and the debates are no longer limited to those countries that have a specific and direct interest in the topic discussed. The process is open and inclusive and a priori does not exclude any delegation. Discussions are no longer taking place behind closed doors, but are open, thus enhancing transparency and inclusiveness in decision-making.

In short, what can be observed is that developing countries have an active and consistently growing interest in the trade negotiations, and more than ever before they are keen to secure their policy and economic interests based on economic rationales. This was again evidenced at MC-X (Nairobi), where developing countries were actively involved in the negotiations and several decisions were taken of particular interest to developing countries and LDCs. The increased and active participation also explains a number of significant developments that make the DDA different from previous negotiating rounds in terms of addressing specific issues of concern to developing countries and have contributed to the better and fuller integration of developing countries in the multilateral trading system.

180 The EPA includes a new set of preferential arrangements governing relations between the EU and ACP countries, following the ending of the Cotonou Partnership Arrangement (CPA) in 2014. The CPA had governed the preferential arrangements between the EU and ACP countries since the year 2000. The CPA was replaced by the EPA as preferences granted to the ACP countries under the CPA were considered in breach of a fundamental principle of the WTO, namely reciprocity. The CPA granted more favourable treatment to ACP countries instead of extending those benefits to all developing country members of the WTO. 


\subsection{Case Study: Trade Capacity Building Provisions in the Trade Facilitation Agreement}

It is recalled that the TFA was negotiated at the MC-IX (Bali) WTO and adopted by the members on 27 November 2014. ${ }^{181}$ The TFA could only enter into force once two-thirds of members have completed their domestic ratification process. According to oral information presented by the WTO Director General to members at the General Council early December 2016 a total of 102 members had ratified the TFA, out of a required total of 110 . This number had increased to 108 in January 2017 and finally reached its critical mass in February, thus allowing the Agreement entering into force. ${ }^{182}$.

This case study underscores with specific examples the economic importance of the implementation of the TFA, especially for developing countries and shows how the innovative approaches developed in the TFA with regard to trade capacity building should lead to tangible results for beneficiary members. The TFA contains new and legally binding provisions for developed countries to provide support to beneficiary countries expressing a need to that effect. The support can include human and institutional capacity building and/or relate to improving and strengthening infrastructures, including at the borders. The innovative part is the very specific nature of the commitments that the donors and beneficiaries will have to commit to and which are binding upon the parties.

There has been a large conversion of thought in the literature on the economic benefits that the implementation of the TFA can yield. ${ }^{183}$ A recent study undertaken jointly by the WTO and the World Bank underscores the role of reducing transaction costs in developing countries in support of trade. ${ }^{184}$ It observes that it is 'a common finding in the literature that trade facilitation can improve export performance and that the potential gains are larger for developing countries that developed countries'. ${ }^{185}$ The WTO estimates that 'the full implementation of TFA could reduce global trade costs by an average of 14.3 per cent'. ${ }^{186}$ According to the Peterson Institute, 'the implementation of the TFA could amount to over US\$ 1 trillion in gains to the world GDP'. ${ }^{187}$ These findings are in line with calculations made by Moise and Sorescu, who estimate that 'the reduction of transaction costs could be

181 Agreement on Trade Facilitation, 11 December 2013, WT/MIN(13)/36, WT/L/911.

182 http://www.tfafacility.org/ratifications, last consulted 25 January 2017 and WTO News Item, 22 February

2017: WTO's Trade Facilitation Agreement enters into force.

183 Cf. WTO World Trade Report 2015: Speeding Up Trade: Benefits and Challenges of Implementing the WTO Trade Facilitation Agreement, p. 80, Table D, which includes a selection of studies that have estimated the effects of trade facilitation on trade flows.

184 World Bank and WTO, The Role of Trade in Ending Poverty, p. 46.

185 Ibid.

186 Cf. WTO World Trade Report 2015, Chapter D, p. 73.

187 G. Hufbauer and J. Schott, 'Payoff from the World Trade Agenda 2013', Report to the ICC Research Foundation, Washington DC (2013), p. 11. 
an average of 14 per cent'. ${ }^{188}$ The WTO estimates on the basis of computable general equilibrium (CGE) simulations that 'export gains from the TFA could amount to US \$750 billion and well over US\$ 1 trillion per annum, depending on the implementation timeframe and coverage'. ${ }^{189}$ It goes on to note that 'other models suggest that the benefits could even be far higher and up to $\$ 3.6$ trillion, depending on the extent to which the provision of the TFA are implemented'. 190

There is wide recognition of the fact that while the implementation of the TFA will benefit all countries, it will mostly come to the benefit of developing countries, as both export and GDP growth will increase more than in developed countries. According to the WTO, the LDCs will benefit in particular, as the implementation of the TFA would create significant diversification gains and also facilitate their efforts to participate in the global value chains. Other beneficial effects for LDCs include a better revenue collection and it should be more attractive for FDI. ${ }^{191}$ Beverelli et al. calculate that 'improved trade facilitation can lead to an increase in the number of products exported by destination of up to 16 per cent'. 192

\section{According to the OECD}

even modest reductions in trade transaction costs, such as lengthy border procedures, translate into significantly increased trade. This is true for both rich and poor countries, but developing countries would show higher relative trade gains because of the relative inefficiency of their current systems and because agro-food and small and medium enterprise (SME) trade, which are severely affected by inefficient procedures that are central for the economy of those countries. Taking into account how trade facilitation measures to reduce transaction costs affect different sectors of the economy and different types of trades, OECD research shows that developing countries stand to gain two thirds of total world welfare benefits from trade facilitation. ${ }^{193}$

Similar conclusions on the gains of the TFA are contained in a series of case studies presented by WTO Chairs, in which the cost and benefits of the implementation of the TFA are analysed for countries and regions and more specifically for Africa and Arab

188 E. Moise and S. Sorescu, 'Trade Facilitation Indicators: The Potential Impact of Trade Facilitation on Developing Countries', OECD Trade Policy Papers (No. 144, 2013), p. 35. See also 'The Cost and Benefits of Trade Facilitation' Policy Brief, OECD (2005).

189 Cf. WTO World Trade Report 2015, p. 73.

190 Ibid.

191 Ibid., p. 73.

192 C. Beverelli, S. Neumuller and R. Teh, 'Export Diversification Effects of the WTO Trade Facilitation Agreement', Working Paper No. 137, FIW Vienna (2015), p. 20.

193 OECD, 'The Cost and Benefits of Trade Facilitation', p. 3. 
countries. ${ }^{194}$ Not surprisingly, the studies once again lead to positive findings for the implementation of the TFA and the economic gains. Given the broad consensus on the benefits that can be derived from the implementation of the TFA, the authors in the study analyse more closely how the cost and benefits of the implementation of the TFA could materialize and what legal and institutional mechanisms need to be put in place to achieve the positive outcomes. This is specifically illustrated in case studies with regard to Brazil, ${ }^{195}$ Bénin, ${ }^{196}$ Jordan, ${ }^{197}$ Kenya, ${ }^{198}$ Mauritius, ${ }^{199}$ Oman, ${ }^{200}$ and South Africa. ${ }^{201}$ This WTO study thus contributes to the debate on how to enhance efficiency at the border and within the markets to stimulate trade and economic growth. The findings show that the gains that can be obtained are largely due to a reduction in transaction costs, easing the movement of goods and simplifying customs procedures.

Evenett and Hoekman argue that

many WTO Members and mostly developing country members have long recognized the importance of cutting red tape at customhouses, improving efficiency, and reducing unnecessary delays affecting cross-border commerce, but they do not have adequate infra-structures allowing them the benefits of the TFA to materialize and are in need of technical support and assistance. ${ }^{202}$

Given these realities, it is of the essence to assist developing countries and more particularly the least developed amongst them to implement the TFA. Trade capacity building is a key element in the TFA and of critical importance in order to achieve the main objectives of the TFA.

\footnotetext{
194 Teh, Smeets, Sadni Jallab and Chaudhri, (eds.), Trade Costs and Inclusive Growth.

195 V. Thorstensen, L. Ferraz and T. Nogueira, 'The Trade Facilitation Agreement and Its Impact on the Brazilian Transformation Industry', in Teh, Smeets, Sadni Jallab and Chaudhri, (eds.), Trade Costs and Inclusive Growth.

196 F. Amoussouga Gero, A. Alinsato and A. Babatounde, 'MCA Grants and Port Reforms in Bénin: The Effects of Trade Facilitation', in Teh, Smeets, Sadni Jallab and Chaudhri, (eds.), Trade Costs and Inclusive Growth.

197 N. Saqfalhait, 'Trade Facilitation in the Arab Region', in Teh, Smeets, Sadni Jallab and Chaudhri, (eds.), Trade Costs and Inclusive Growth.

198 C. Onyango and T. Kiriti-Nganga, 'Trade Facilitation and FDI Flows in Kenya', in Teh, Smeets, Sadni Jallab and Chaudhri, (eds.), Trade Costs and Inclusive Growth.

199 B. Seetanah, R.V. Sannassee and S. Fauzel, 'Trade Facilitation and Trade Flows: Evidence from Africa', in Teh, Smeets, Sadni Jallab and Chaudhri, (eds.), Trade Costs and Inclusive Growth.

200 H. Boughanmi, 'Regional Integration in the MENA Region: Deepening the Greater Arab Free Trade Area through Trade Facilitation', in Teh, Smeets, Sadni Jallab and Chaudhri, (eds), Trade Costs and Inclusive Growth.

201 E. Steenkamp, S. Grater and W. Viviers, 'Streamlining South Africa's Export Development Efforts in SubSaharan Africa: A Decision Support Model Approach', in Teh, Smeets, Sadni Jallab and Chaudhri, (eds), Trade Costs and Inclusive Growth.

202 E.J. Evenett and B.M. Hoekman, Economic Development and Multilateral Trade Cooperation (World Bank, Washington, DC, 2005), p. 289.
} 
The TFA has three main sections. The first one spells out the substantive parts of the agreement, including the specific elements that need to be put into place by the members and what needs to be done. The provisions are closely related to the GATT 1994 rules with regard to transit (GATT Article V) for fees and formalities, with regard to clearance of imports and exports of goods (GATT Article VIII) and the publication and administration of trade regulations (GATT Article X). It largely builds on those provisions and clarifies them further. It also includes procedures on how customs can improve their cooperation.

The second section is innovative in the ways it offers concrete options for developing countries on how they can benefit from support measures to be provided by the donors. In other words, it contains binding S\&D treatment provisions. Developing members and LDCs can largely determine themselves the extent to which they are in a position to implement the TFA and when and how they will commit more fully to the TFA obligations. They are given the option to implement the TFA in part and make that dependent on the receipt of technical assistance and support for capacity building. According to Article 1.2 of Section 2:

The extent and the timing of implementing the provisions of this Agreement shall be related to the implementation capacities of developing and leastdeveloped Members. Where a developing or least-developed country Member continues to lack the necessary capacity, implementation of the provision(s) concerned will not be required until implementation capacity has been acquired.

In order to take advantage of the S\&D provisions, the TFA establishes that each developing country and LDC member shall self-designate, on an individual basis, the provisions it is including under each of the categories A, B and C. ${ }^{203}$ The member also needs to notify other WTO members about how they categorized the measures and the timelines they are seeking for implementation. The three categories contain the following provisions:

- Category A includes provisions that developing country members or LDCs designate for implementation upon entry into force of the Agreement. LDCs are granted one extra year to do so.

- Category B contains provisions allowing the member to delay the implementation until a later date. In other words, a transition period will be accorded for the measures contained in this category, as well as for the following category (C). The TFA however is very specific in terms of the commitments that need to be taken by the donors and beneficiaries in order to ensure the implementation of the measures at the dates convened.

203 WT/MIN(13)/36, WT/L/911, section II, para. 2. 
- Category C contains provisions that are in a way similar to Category B, except that it refers to the need for the acquisition of implementation capacity through the provision of assistance and support for capacity building.

In addition, the TFA contains various institutional requirements, including the establishment of a permanent committee on trade facilitation at the WTO. Members are required to have or establish a national committee to facilitate domestic coordination and implementation of its provisions.

One of the significant elements of the TFA is that it contains provisions on technical assistance to be provided by the WTO as an institution, as well as by WTO members and other intergovernmental organizations. In that sense, the TFA is unique, as it establishes clearly structured lines for working cooperation between international organizations. It involves not only the WTO as a lead agency, but benefits from the active contributions of the World Customs Organization (WCO), the World Bank, UNCTAD, the ITC and the OECD. ${ }^{204}$ Separately, the United Nations Regional Commissions play an active role in the implementation of the TFA in each of the geographic regions in the world. ${ }^{205}$ Furthermore, the regional development banks will need to provide the financial support, as the implementation requires substantial funds. The role of the African Development Bank (AfDB) and the Inter-American Development Bank (IADB) will be of critical importance. The TFA makes explicit reference in the cooperation between the institutions to ensure the maximum effectiveness of and results from the assistance. ${ }^{206}$ The determination to make the TFA effective is not only reflected in the way the trade capacity building efforts are contained in it, but in order to facilitate its implementation, the Trade Facilitation Agreement Facility was launched in July 2014 and receives earmarked funding from donors to ease the implementation of the TFA. ${ }^{207}$

The innovative approach to trade capacity building is underscored by Neufeld, who explains that the S\&D treatment for developing countries is a crucial aspect of the mandate that had been given to the members and which dramatically breaks new ground. ${ }^{208}$ Neufeld observes that

S\&D treatment in most WTO Agreements focuses on transition periods. While grace periods are still foreseen in the TF mandate, they are but one part of a much

204 Cf. WTO World Trade Report 2015, p. 51-54.

205 This includes for example the United Nations Economic Commission for Europe (UNECE), the United Nations Economic and Social Commission for Asia and the Pacific (UNESCAP), the UN Economic Commission for Africa (UNECA).

206 Cf. WT/MIN(13)/36, WT/L/911, section II, para. 9.3.d, e and f.

207 This Fund will be operated separately from and alongside the other funds covered under the DDAGTF, discussed earlier in this chapter.

208 N. Neufeld, 'The Long Winding Road: How Members Finally Reached a Trade Facilitation Agreement', WTO Staff Working Paper ERSD (No. 2014-06, 2014). 
more comprehensive flexibilities package, crucially complemented by the introduction of a conditional link between the existence of implementation capacity and requirements to undertake a commitment. This novel concept was further expanded by determining that developing and least-developed countries would not be obliged to implement aspects of a TF Agreement when required support for infrastructure was not forthcoming'. Neufeld goes on to argue that "overall, the mandate represented a new way of negotiating a multilateral trade agreement. The novel S\&D terms clearly broke new ground and created new confidence in the negotiation. Implementation was no longer an afterthought but an upfront consideration - indeed it was integral to the entire undertaking. ${ }^{209}$

In the years before the TFA's conclusion the WTO's Secretariat was heavily involved in undertaking field based missions on all parts of the world, organizing national and regional seminars in order to assist countries undertaking self-assessments. These missions were conducted in partnership with other specialized agencies, including the World Customs Organization, other agencies referred to earlier and donors, in order to have the largest pool of experts available. In other words, the ground was thoroughly prepared to get the members on board and based on a good understanding of what the new requirements of the TFA would consist of. This presents a main departure from earlier negotiations and took away the argument of beneficiaries that they were not aware of what commitment they were signing off on. ${ }^{210}$ The TRTA provided was certainly of critical importance in building momentum for the TFA to be concluded and in providing support to beneficiaries. The support went far beyond building capacity for a better understanding on what they signed off to, but more importantly, in providing support in the implementation phase of the TFA. The efforts are also a good example of how partnerships can be put to work in effective manners, with each of the agencies putting forward their expertise.

From the analysis presented, it can be concluded that with the TFA, members took a big step forward in developing a new approach to the provisions on trade capacity building. Even better, members are enabling the beneficiaries to take real advantage of the TFA, to reap the benefits of trade liberalization and integrate further into the multilateral trading system. The extent to which WTO members are ratifying the TFA is encouraging, but it is particularly important for the developing countries which stand to gain the most from the TFA.

Given the positive experience with the TFA, a question that would need to be considered further is to what extent the trade capacity building approach developed for the TFA can be replicated in other areas where technical assistance is required. Can this approach be

209 Cf. WTO World Trade Report 2015, p. 8.

210 As discussed earlier, after the conclusion of the Uruguay Round negotiations many developing countries argued that they were not aware what they had committed to and were therefore reluctant to engage in new negotiations. That argument has now been taken away. 
transposed, or is it unique to this agreement, which combines providing both 'soft' and 'hard' support, namely a strengthening of the human and institutional capacities and providing for the hardware, the equipment to implement the agreement? This is worth exploring for other agreements, thus adding a new dimension to the meaning of S\&D, making it harder and legally binding upon all the stakeholders and moving away from the best-endeavor provisions.

\subsection{Conclusion}

Based on quantitative and qualitative indicators, evidence was provided that developing countries are now participating more fully in the multilateral trading system of the WTO compared to the GATT and have a better understanding of the stakes in the negotiations. These findings are confirmed in the conclusions of the report presented by the independent external evaluators, who conducted a thorough review of the WTO's TRTA and its effectiveness efficiency, sustainability and impact and provided strong evidence to that effect.

The relative shares of developing countries in international trade have increased significantly over the last 30 years, albeit with marked differences between regions. Asia has grown the fastest, mostly driven by China. While Africa's share in world trade remains overall very low, it has nevertheless grown very fast with merchandise exports and imports outpacing world trade. Developing countries have become active participants in the negotiations taking positions on all the issues of direct interest to them.

Different factors explain the rising shares of developing countries in international trade. One such explanation relates to a shift in economic and trade policies performed by developing countries since the mid-1980s. The awareness has steadily grown that structural reforms and trade liberalization are important tools for economic growth and development. Trade liberalization is increasingly perceived to be of critical importance for generating jobs and enhancing levels of economic welfare. Developing countries thus gradually moved away from inward looking economic and trade policies to more open and liberal policies, thus stimulating competition, FDI and transfer of technology. This also explains an increased interest and more active participation of developing countries in the multilateral trading system and more specifically in the trade negotiations. Trade capacity building has been an enabling factor to build knowledge of the rights and obligation in the multilateral trading system.

WTO members committed to provide the developing and least developed countries with the necessary technical assistance in support of their efforts to deliver on commitments negotiated in earlier rounds and engaging more fully in the negotiations of the DDA. New approaches to trade capacity building were designed with a view to facilitate the integration of developing countries in the multilateral trading system, combining theory and hands-on 
training. It was argued that the trade capacity building efforts pursued by the WTO since the launch of the DDA and undertaken in close collaboration with partner institutions have contributed to gradually building higher levels of knowledge and human and institutional capacity to address some of the main challenges.

On the quantitative side, it was argued that the growing shares of developing countries in international trade can at least in part be attributed to the collective efforts undertaken by the WTO together with other major international organizations to facilitate their integration into the trading system. A better understanding of the rationales of the economic and trade policies and more specially the benefits of trade liberalization have contributed to a shift in their trade policies. The import substitution policies were largely abandoned making room for a gradual opening of markets. This has facilitated the competitive forces to create more favourable economic conditions to compete on international markets. The trade liberalization efforts were accompanied with measures aimed at facilitating their integration in the trading system, including through a range of S\&D provisions developed to that effect and built into the WTO agreements.

With regard to preferential treatment provisions for developing countries, it was argued that while there is a long history in the GATT/WTO system on preferential trade, the development issues are for the first time specifically and fundamentally addressed in the WTO. While much attention is given in the negotiations to preferences, there is a better recognition of the fact that countries are generally better off relying on multilaterally agreed outcomes than on preferential trade. Hence, developing countries will need to consider ways to gradually further diminish their dependency on preferences. As argued above, they are mostly autonomous, not binding and are in any case gradually losing their significance as a result of trade liberalization, including tariff reductions. The countries' dependency on preferences reduces incentives for diversification of production, enhances the vulnerability of the economies that are dependent on a limited range of products and deprives them from new market opportunities.

It was argued that the debate with regard to assisting developing countries integrating further in international trade is focusing increasingly on their capacity to be part of GVCs. This has turned out to be a serious challenge, but holds great potential. Some developing countries and more specifically those located in Asia, are already benefiting from the new potential and contributing increasingly to the GVCs. The share of South-South trade is showing important strides in this regard, but overall developing countries stay behind, compared to the developed countries. There is a need for developing countries to consider further designing economic policies with regard to GVCs and how to add value in the production chain. One suggestion made to that effect was to focus more on services, rather than on manufacturing. How can developing countries that are not well connected to GVCs adopt policies to that effect? What policies would allow a country's comparative advantage to be best exploited? How can it be made more attractive for FDI and the transfer of 
technology? There is a clear need for countries to permanently adjust to the changing market requirements in order to create the enabling environment and remain competitive. The process is very dynamic not static.

On the qualitative side, it was argued that developing countries and LDCs have moved from a passive stance in the negotiations prior to the creation of the WTO. In the GATT they were mostly observers and bystanders, exercising little influence in setting the agenda and facing the consequences of decisions taken by others. In the WTO developing countries demonstrate an active and constructive engagement, with substantive and concrete inputs in the debate in support of their economic and trade interests. This is a significant development and has set the stage for the future of the multilateral trading system: developing countries have moved to the core of the MTS and their concerns can no longer be ignored. Developing countries are today in a far better position to formulate their policy interests and make specific proposals in the negotiations either individually or collectively than any time before. They are in a stronger position to actively engage in the discussions and defend their legitimate rights. The large number of proposals made by developing and least-developed countries in the negotiations confirms their enhanced capacity to master often complex and technical issues in the negotiations. Many of the proposals made individually or as a group were subsequently translated into action and led to decisions taken by the membership in favour of developing and least developed countries. It was argued that a large share of decisions taken at the most recent Ministerial Conferences are directly of interest to developing and least developed countries. All measures taken in favour of beneficiaries are designed to allow them to take part more fully in the system and take advantage of new economic opportunities.

This chapter included a case study on the TFA, which contains innovative approaches to trade capacity building and making the relevant provisions specific, stricter and binding between donor countries and beneficiaries. The literature confirms that the TFA holds many significant economic gains for developing countries. It is therefore in their direct interest to ratify the TFA as soon as possible. Developing countries stand to gain most from the provisions both in terms of enhancing efficiency, reducing transaction costs as well as through the trade capacity building provisions contained therein. The question was raised whether the new approach to capacity building introduced in the TFA could serve as a model for trade capacity building efforts undertaken in favour of developing countries in other areas of the negotiations. 


\section{ANNEX 5.1: MINISTERIAL DECISION ON IMPLEMENTATION}

\section{RELATED ISSUES AND CONCERNS 211}

\section{(Decision of 14 November 2001)}

- Reaffirmed that Article XVIII of the GATT 1994 is an S\&D provision and recourse to it should be less onerous than to Article XII of the GATT 1994;

- Approved recommendations in the Decision on Measures Concerning the Possible Negative Effects of the Reform Programme on Least-Developed and Net FoodImporting Developing Countries regarding (i) food aid; (ii) technical and financial assistance in the context of aid programmes to improve agricultural productivity and infrastructure; and (iii) financing normal levels of commercial imports of basic foodstuffs;

- Emphasized that Article 15 of the Agreement on the Implementation of Article VI of GATT is a mandatory provision;

- Agreed to treat measures implemented by developing countries with a view to achieving legitimate development goals, such as regional growth, technology research and development funding, production diversification and development and implementation of environmentally sound methods of production as non-actionable subsidies in the context of the Agreement on Subsidies and Countervailing Measures;

- Instructed the TRIPS Council to continue examining the question of nullification or impairment of benefits based on non-violation and situation complaints; and reaffirmed that the provisions on technology transfer in Article 66.2 of the TRIPS Agreement are mandatory;

- Instructed the CTD to identify those S\&D provisions that are already mandatory in nature and those that are non-binding in character, to consider the legal and practical implications for developed and developing members of converting S\&D measures into mandatory provisions, to identify those that members consider should be made mandatory, to examine additional ways in which S\&D can be made more effective, and to consider how S\&D can be incorporated into the architecture of WTO rules. It also reaffirmed that preferences granted to developing countries pursuant to Enabling Clause should be generalized, non-reciprocal and non-discriminatory.

- Requested the Director General to ensure that technical assistance focuses on assisting developing countries to implement existing WTO obligations as well as on increasing their capacity to participate more effectively in future multilateral trade negotiations.

211 The points presented in this annex are taken from the relevant decision contained in WT/MIN(01)/17 20 November 2001. 


\section{CHAPTER 6: THE FUTURE OF THE MULTILATERAL TRADING SYSTEM: CHALLENGES AND OPPORTUNITIES}

\subsection{Introduction}

It was argued that the establishment of the WTO provided a more solid institutional basis for governing trade. Areas hitherto uncovered by trade rules were added to the WTO rule book and strong disciplines governing trade disputes were created. Members abide by the rules and resolve any disagreements within the multilateral framework of the WTO. The organization has also largely managed to fend off and hold in check any attempts to reintroduce trade protectionism, even during times when economic activities declined and more specifically after the financial crisis of 2008. Its monitoring and transparency mechanisms have played a key role in that regard. Nevertheless, the trend towards introducing new restrictive measures is on the rise again, as is the backlash against globalization. It is argued that this, combined with the lack of progress in the DDA negotiations, including on trade issues relevant for a globalizing trading environment puts new pressure on the multilateral trading system and undermines its credibility. There is an urgent need to take a fresh look at some of the key aspects of the WTO, update and expand the rules, address the challenges and opportunities emerging from globalization and intensify efforts to pursue trade liberalization. Before turning to the challenges and opportunities, this thesis underlines that even in the absence of a DDA conclusion, trade has been more liberalized over the past two decades than is generally suggested.

\subsection{Trade liberalization accomplished in the WTO}

Despite the lack of expected outcomes from the DDA, it was shown in the thesis that trade liberalization has occurred specifically as follows:

- Liberalization measures were undertaken by the members of the WTO, including autonomous trade liberalization, without requesting concessions by trade partners. This was driven by the understanding that trade liberalization enhances economic welfare and generates benefits for the country that liberalizes (Chapters 2-5);

- Structural domestic reforms were conducted as a key condition for WTO accession and significant trade liberalization undertaken by the Article XII members, who aligned their policies with the rules of the multilateral trading system, and opened their markets to foreign competition. It was argued that structural reforms are often more significant than the enhanced market access that arises from WTO accession (Chapter 2);

- The elimination and/or reduction of quantitative restrictions was accomplished in specific areas (textiles and clothing, agriculture) as well as the elimination of the nonconforming VERs and OMAs, as mandated by the WTO, following the conclusion of the Uruguay Round (Chapter 4); 
- There has been a significant reduction of subsidy schemes (including domestic support measures in agriculture by the main trading nations, elimination of export subsidies in agriculture), some of which resulted from the DDA negotiations, for example the elimination of export subsidies (Chapter 4);

- The GPA was expanded and enhanced as a result of negotiations conducted at the WTO and during the DDA, which has opened up huge potential for trade and the reduction of transaction costs. In addition, the number of signatories has increased considerably (Chapter 2);

- Trade liberalization was achieved through sectorial initiatives, including the ITA, leading to zero duties, and the TFA, which significantly lowers transaction costs. Both results emerged from the DDA negotiations (Chapter 4);

- The trade liberalization pursued during the GATT and WTO have facilitated and driven globalization of trade and investment, which includes the breaking up of the production process, as well as GVCs which have generated more dynamics in trade and a reduction of trade and transaction costs (Chapter 3);

- Measures were taken by members in support of trade originating from developing countries and LDCs, including duty free treatment, many of which are granted on an autonomous basis. While these measures can be revoked and are not permanent in the WTO context, they undeniably contribute to the liberalization process. These initiatives were largely driven by the motivation to assist developing countries and LDCs to better and more fully integrate in international trade (Chapter 5);

- Separately and in addition, a gradual process of deregulation has been pursued at the level of the public authorities for services trade, thus leading to more market access, a process that has resulted directly from the inclusion of the GATS in the WTO (Chapters 2 and 4);

- There has also been a steady move towards a better coordination of policies at the international level, as mandated by the WTO, which has contributed to enhancing efficiency in policy making. This process is strengthened through regional trade integration at (sub-) regional levels as well as through trade facilitation measures, thus easing transactions and lowering the cost of doing business (Chapters 2, 3 and 5);

- Despite the fact that regionalism is second best to multilateralism, the evidence provided showed that regional trade integration has contributed to further trade liberalization, and perhaps even in significant ways across some sectors and specific areas (Chapter 2).

Many of these positive outcomes tend to be underrated and overlooked as a result of the difficulties for the WTO members to deliver on key DDA promises, including in agriculture and NAMA. Yet these contributions to world trade are significant by any standard and hold the potential to unlock billions of dollars in economic gains. More could have been achieved in terms of trade liberalization, which was held back by the lack of progress in DDA negotiations. To a large extent, it was argued that the lack of progress could be explained the manner in which negotiations are conducted in the WTO, which require a fresh look. The increasing complexity of the issues and the larger membership of the WTO with a broader 
diversity of members at different levels of economic developments, aspirations and ambitions in the negotiations require new approaches.

Mention must also be made of the backlash against globalization that has been witnessed in recent times, which risks triggering new protectionist measures. More specifically, the trade policies to be pursued by the new United States administration are unknown to date and could put pressure on the trading system if the policy options that have been advocated are implemented. Trade relations with its main trading partners and the benefits of WTO membership could be reconsidered. Separately, the decision taken by the United Kingdom in the summer 2016 to leave the European Union (referred to as 'Brexit') has created uncertainty regarding the UK's future trading relations with its main trading partners and more broadly the UKs trade policies.

The, WTO members and the secretariat could direct more attention towards better explaining how the benefits from trade liberalization and market integration enhance overall levels of welfare, and how it is directly beneficial to the consumer. Doing so would bridge a gap in communication and contribute to a better understanding of what the WTO multilateral trading system stands for and why market openness, as opposed to protectionist markets, generates benefits for all.

\subsection{The way forward}

The DDA is the longest round of negotiations; its more than 15 years almost doubles the time of the Uruguay Round, with no conclusion in sight. Now, more than ever before, it remains questionable whether the DDA will be concluded as was set out at the beginning of the negotiations, especially given the wording of the last Ministerial Declaration adopted by Ministers at MC-X (Nairobi). Some commentators went as far as declaring the DDA 'dead' despite the positive outcomes of the last two Ministerial Conferences. ${ }^{1}$ While this thesis did not pretend to provide for deep analysis of the question why the DDA is stalled, it discussed some of the key challenges encountered in the market access negotiations and more specifically in the area of agriculture and goods (NAMA). Members' positions differ considerably on critical aspects in these discussions, including on the negotiating approaches to be adopted in order to achieve further trade liberalization. Another explanation provided for the difficulties encountered in reaching agreement is the fact that the WTO's membership has increased and diverse, with countries of different economic size and development, thus making it harder to reach consensus.

Related to this is the explicit desire of some members to move faster and conclude agreements in areas that are ripe for a decision. Some members feel the need to expand the trade agenda and include a new generation of issues, while others consider that more attention needs to be given to areas presently on the agenda which have not been resolved

J. Gatdula, 'Trade Tripper: WTO's Doha Round: Dead or Alive?' Business World, 8 January 2016. Baldwin referred to DDA standing for 'Doha Dead Again?' in a tweet on 19 December 2015. 
and are of specific and fundamental interest to them. Many developing countries feel that the DDA has failed to deliver on its development promise, one of its central pillars, adding to a reluctance of moving forward on issues which are off the initial agenda.

In order to move forward given the current situation, what are the challenges, where are the opportunities, and how are they best addressed?

\subsubsection{New approaches towards negotiations on trade liberalization}

This $\mathrm{PhD}$ thesis makes the case for an enhanced adaptation of the WTO's negotiating approaches. Considering its twenty-two years of existence, this recommendation is particularly pertinent in the context of ongoing fundamental changes in the world economy, and more narrowly in the field of global trade and investment. New realities should be addressed, and rules expanded upon, in order to best address the challenges which have emerged from globalization. As will be pointed out further below, a previous call for a review of the negotiating approaches was made shortly after the launch of the DDA, but given little attention. More recently, fresh appeals were made at the last Ministerial Conference, providing another opportunity to address a perceived shortcoming of the WTO.

The Ministerial Declaration leaves various options for the future of the DDA open and suggests considering new ways to address the issues. It reflects the different views of the WTO's membership. Accordingly, it states that:

We recognize that many members reaffirm the DDA and the Declarations and Decisions adopted at Doha and at Ministerial Conferences held since then, and reaffirm their full commitment to conclude the DDA on that basis. Other members do not reaffirm the Doha mandates, as they believe new approaches are necessary to achieve meaningful outcomes in the multilateral negotiations. Members have different views on how to address the negotiations. We acknowledge the strong legal structure of this Organization. ${ }^{2}$

These formulations are acceptable to members of both sides of the spectrum but do not provide clear guidance on what direction the DDA will go. The commitment to negotiate the remaining Doha issues is reconfirmed in paragraph 31 of the Ministerial Declaration, specifically naming the areas where negotiations will be pursued. ${ }^{3}$ This covers all the main bases, the three pillars in agriculture, NAMA and others. Without the consent and active support of the main trading nations, it is hard to see how the DDA can be concluded as a

2 The Nairobi Ministerial Declaration, adopted on 19 December 2015, as contained in WT/MIN(15)/DEC, 21 December 2015, para. 30.

3 Ibid., para. 31. 
package, as some still envisage. ${ }^{4}$ It seems more likely that the discussions will be pursued in a fragmented manner, addressing issue by issue.

One of the main differences with previous Ministerial Declarations is the explicit recognition in the final declaration of some of the difficulties that the institution is presently confronted with, as well as the divergence in views between its members on the ways forward. This is reported as unprecedented in the history of the GATT and the WTO, and in itself is an important step forward. ${ }^{5}$ It presents a new starting point to address the main challenges that have been identified at the Conference, including the future of the DDA and on the ways in which negotiations should be pursued. The declaration includes a recommendation to conduct a process for further reflection on these issues. It invites the Director General to report back regularly on progress made to the members. This is contained in paragraph 33 of the Ministerial Declaration adopted at MC-X (Nairobi), with a call by Ministers to "preserve and further strengthen the negotiating function of the WTO...'. Ministers agreed that '... officials should work to find ways to advance negotiations and request the Director-General to report regularly to the General Council on these efforts' ${ }^{6}$

\section{- The variable geometry, plurilateral agreements and critical mass approach}

Upon analysis presented in chapters 2-5, and given the increasing diversity of membership, there should be more room for WTO rules to apply to members at different levels of economic development in a variety of ways. This is in line with the views expressed by many independent eminent persons, policymakers, academic institutions and think tanks as I will substantiate below. Many of these advocate introducing the concept of a 'variable geometry' in the negotiations. This refers to a situation whereby different rules could apply to different members and/or groups of members, in recognition of varying levels of economic development, as well as of aspirations. How could this approach be translated in practice? How would the WTO work with members operating at different speeds? There are a number of ways of going about this. One such method was explained earlier and consists of the various levels of obligations contained in the TFA and in recognition of the numerous levels of economic development. The other one consists of negotiating plurilateral agreements between a set of countries, which are mostly based on a critical mass approach. Such negotiations should preferably be conducted in the WTO. Alternatively, they can be conducted outside the WTO, if no critical mass can be found in the WTO. The application of the agreements can be limited to those countries only or be extended to membership as a whole by virtue of the MFN principle, which is explained as follows.

4 Following the conclusion of MC-X (Nairobi), and according to 33 Inside U.S. Trade, (December, 2015), the USTR M. Froman issued a statement in which he signalled the American belief that the Single Undertaking of the DDA is no more, despite the absence of a consensus in the Ministerial Declaration.

5 This statement is based on oral reports by several officials that are very close to the organizations' negotiations, including senior WTO staff.

6 Nairobi Ministerial Declaration, para. 33. 
The plurilateral agreements can but do not necessarily include MFN treatment provisions. If the MFN provisions apply, the benefits are automatically extended to the entire WTO membership and hence the agreement obtains a multilateral character. The ITA is a good example of a stand-alone plurilateral agreement negotiated by a limited number of countries, and it has MFN application. Its MFN provisions ensure that the benefits of the outcome of the negotiations are extended to the entire WTO membership. The GPA is an example of a plurilateral agreement in the WTO that does not have MFN application. It is only binding upon the members adhering to its rules. Members sign on the agreement once they are ready to assume its obligations, thereby gradually expanding the benefits flowing from the agreement. The efforts to negotiate the basic telecommunications agreement and the financial services agreement have been successful in similar ways. They were part of the extended services negotiations of the GATS and are thus an integral part of the WTO set of rules.

Negotiating plurilateral agreements offers a viable way forward for the conduct of future trade negotiations in the WTO, if you consider the reality that members are facing today and the apparent difficulties of negotiating multilateral agreements, with the exception of the TFA. Such an approach takes into account the differences between WTO members with regard to their economic development, and the aspirations that some have to move towards further and deeper liberalization in specific areas. They can be stand-alone agreements or part of the WTO, depending on the areas covered. One of the key challenges will be to ensure that the negotiations remain inclusive and that MFN provisions apply to the maximum extent possible. Similarly, partial agreements in specific areas are likely to be negotiated in the future, such as the agreement reached on the elimination of export subsidies as well as the agreement on food security in the field of agriculture. From the analysis conducted in this thesis it clearly emerges that this is the way forward in order to gain results and achieve tangible outcomes in the negotiations. It allows for the pursuit of a progressive and step-by-step process of trade liberalization with ample room to extend the benefits to other members. To the extent that the MFN rule does not apply, it is expected that benefits will be extended with time, as more and more members sign the plurilateral and/or sector agreements.

The plurilateral approach increasingly finds support in the literature and offers workable solutions. It was also explicitly included in the so-called 'Sutherland Report' which had been mandated by former WTO Director-General Supachai Panitchpakdi, with a view to making concrete proposals on possible WTO reforms, including the ways to conduct negotiations. ${ }^{7}$ The report explicitly mentions that there should be a re-examination of the principle of plurilateral approaches to WTO negotiations. ${ }^{8}$ The report recognizes that a small group of

'The Future of the WTO, Addressing Institutional Challenges in The New Millennium', report by the consultative board to the Director General Supachai Panitchpakdi, WTO, 2004, p. 2. The panel included inter alia, such eminent persons as Jagdish Bhagwati, John H. Jackson, and Celso Lafer, a prominent former Brazilian trade negotiator.

8 Ibid., para. 26, p. 82. 
members should not bring issues to the WTO that are strongly opposed by substantial sections of the membership. They recommend, provided there is a political acceptance of the principle, that an expert group be established initially to consider and to advise on the technical and legal implications of such an approach. They also suggest that in certain circumstances a GATS ‘scheduling' approach would be an appropriate option. ${ }^{9}$ In addition, according to the experts, new agreements should contain provisions for a contractual right, including the necessary funding arrangements for LDCs to receive appropriate and adequate technical assistance and capacity building, as they implement new obligations. ${ }^{10}$ This is precisely what happened in the TFA. As observed earlier this could provide the basis for other agreements to be concluded.

In short, the Sutherland report contains specific recommendations with regard to the operation and functioning of the WTO and the ways in which negotiations should be conducted that remain valid and relevant today.

Baldwin explains that the liberalization of international commerce was relatively easy in the 20th century, as trade was more straightforward and less complex than in the $21 \mathrm{st}$ century trading environment. ${ }^{11}$ In his view, the GATT system already took care of the issue of a 'variable geometry', but this changed with the adoption of the Single Undertaking approach, requiring all members to (more or less) accept the same disciplines. In other words, the flexibility to develop partial agreements or plurilateral agreements mostly existed prior to the DDA and the scope for such deals was reduced with the adoption of the Single Undertaking principle. Baldwin supports the view that the WTO is well designed for crafting variable geometry that can accommodate the diverse preferences of its members. He considers that it is about time that the world starts to seriously consider multi-pillar global trade governance with the WTO as the central pillar for both trade and investment.

In a similar way, Lawrence and Draper explain how, in their view, the variable geometry approach could work to the benefit of the WTO. ${ }^{12}$ They argue that if the three regional integration initiatives, including the Regional Comprehensive Economic Partnership (RCEP), the TPP and TTIP (discussed in Chapter 2) all removed barriers in a sector of mutual interest, there would be a strong incentive to consolidate this mutually via critical mass sectoral agreements, as well as plurilateral agreements among willing members at the WTO. Under these circumstances, it is possible to envisage a revitalized WTO, with a variable geometry at the centre of a trading system capable of meeting the diverse interests

9 See chapter 2 for explanations on services schedules.

10 Ibid., para. 27, p. 82.

11 R. Baldwin, 'Restoring WTO Centrality to a Multi-Tiered Global Trading System', World Economic Forum, Geneva, August 2015, p. 10.

12 R. Lawrence and P. Draper, 'Is an Inclusive Trading System Possible? Mega-regional and Beyond', in 'The High and Low Politics of Trade: Can the World Trade Organization's Centrality Be Restored in a New MultiTiered Global Trading System?', World Economic Forum, Geneva, August 2015, p. 26-27. See also R. Lawrence, 'Rulemaking amidst growing diversity: a club-of-clubs approach to WTO reform and new issue selection', Journal of International Economic Law 9(4), (2006) p.825-33. 
of its members. In other words, the future of the WTO really depends on the ways the TTIP and TPP as well as other mega-regional agreements will be shaped. As the authors note, if the deeper regional and plurilateral arrangements are used to complement an inclusive multilateral trading system that accommodates the diverse interests of its members, the frictions between the status quo and emerging powers could be reduced, through enhanced cooperation in trade and investment. On the other hand, if the trading system becomes increasingly divided into exclusionary blocks, with some reflecting the interests of major economic powers and others excluding them, there are dangers that trade and investment frictions could create additional ones.

As to the questions of whether any such negotiations should be conducted on a multilateral basis and whether they should use the Single Undertaking approach, Evenett and Jara hold that neither the multilateral approach, nor the single undertaking should be put on pedestals. ${ }^{13}$ As they point out, the reality is that many WTO agreements and provisions are already partial agreements and hence they suggest, 'let's not make the perfect the enemy of the good'. ${ }^{14}$ In addition to the plurilateral and critical mass approaches, they consider a third option along the lines of the TFA which includes a pragmatic way of tailoring special and differential treatment provisions for developing countries to national circumstances. This compares again to what was suggested in earlier chapters: use of the TFA as a model for other areas with specific Trade Related Technical Assistance (TRTA) provisions. As they note, the desirability of the three alternative approaches will almost certainly vary on a topicby-topic basis. This depends on the types of obligations that might be negotiated and the potential adverse consequences of those obligations for any WTO member who decides against joining the negotiations. The answer to the question that was raised in their study under which conditions the membership could agree to launch negotiations that do not involve every member - was provided at MC-X (Nairobi); namely that the consensus rule would apply.

The plurilateral approach does imply a danger of inciting discrimination, as Harbinson argues, a risk one needs to be aware of. Nevertheless, he is of the view that the possibility of reaching plurilateral agreements within the WTO framework is one avenue that should be kept in mind. ${ }^{15}$ It is better to contain this within the WTO where possible, rather than run the risk of arbitrary fragmentation of the trading system. He suggests using this approach as a testing ground for developing new rule in areas presently not covered in the WTO. The plurilateral agreements could become multilateral agreements, as happened in the Tokyo Round agreements following the conclusion of the Uruguay Round. However there is no guarantee that history will repeat itself in this manner. The critical mass approach may provide for a more promising avenue, as witnessed in the ITA negotiations. Harbinson

13 S. Evenett and A. Jara (eds.), Building on Bali: A Work Programme for the WTO (a VoxEU.org eBook, Centre for Economic Policy Research, London, 2013), p. 5-6.

14 Ibid., p. 6.

15 S. Harbinson, 'How to Reassert the WTO's Negotiating Authority?', in Evenett and Jara (eds.) Building on Bali, p. 22-23. 
suggests engaging in serious policy discussions on the future of the global trading system and improving the effectiveness of the WTO, concluding stand-alone plurilateral agreements with MFN provisions (such as ITA), reactivating the working groups on investment and competition with a view to identifying elements for future negotiations.

Another strong case for plurilateral agreements is made by Hoekman, based on Article II.3 of the WTO. In his view, provision already offers a mechanism for members to form ' $a$ club', as he calls it, to advance an agenda of common interest, without necessarily extending the benefits to other WTO members. ${ }^{16}$ As he points out, the world increasingly fragments into different regional trading blocs, making the rationale of having multilateral agreements covering all members much less compelling and a variably geometry unavoidable. Hence, from his perspective the plurilateral approach offers a viable mechanism for new rulemaking in the WTO, including on investment policies, competition policy and global value chains. Such plurilateral agreements offer significant advantages, as they are most likely issue-specific and there is no need for complex linkages. They are open - any country can join, and they are also transparent.

The case for a critical mass approach is strongly advocated by Low who explains that this approach has already been adopted on a number of occasions, namely in the post-Uruguay Round agreements on basic telecommunications and financial services, and in the ITA. ${ }^{17}$ What stands in favour of this approach, as he argues, is the fact that it would avoid a contentious and quite possibly futile process of trying to adopt discriminatory deals through a consensus decision taken by the entire membership of the WTO. On the other hand, some may fear that even if non-participants were unimportant in the market today, this may cease to be the case in the future. They may become important manufacturers and exporters of a good, thus taking advantage of liberalization without making concessions, often referred to as 'free-riding'. What would then induce these members to accept obligations rather than merely free-riding? He suggests establishing a framework and set of procedures for a critical mass and/or a club-of-clubs approach to advancing the WTO's agenda. He also believes that members could usefully agree to make modifications to the consensus rule. This would mean that when very few countries are opposed to consensus, they would be required to offer a reasoned explanation for this and be willing to discuss it.

Furthermore, reference is made to conclusions reached by Talal Abu-Ghazaleh, who in recognition of the speed at which the international economy is developing and the pressures of the forces of globalization, recommends that the WTO should develop, define and implement a concept of a 'sustainable plurilateral agreement'. ${ }^{18}$ He suggests that such an agreement be developed around emerging and evolving issues and take the form of different

16 B. Hoekman, 'Multilateral Trade Cooperation Post Bali: Three Suggestions', in Evenett and Jara (eds.), Building on Bali, p. 33-34.

17 P. Low, 'Depth and Breadth in the WTO: Can We Square the Circle?', in Evenett and Jara (eds.), Building on Bali, p. 78-79.

18 T. Abu-Ghazaleh, 'WTO at Cross Roads: A Report on the Imperative of a WTO Reform Agenda', informal discussion paper, WTO, January 2013, p. 15. 
geometries of membership. Such an approach would mean different members taking part in different agreements, according to their levels of economic development.

There is thus strong support for providing more room for adopting the plurilateral approach in the WTO negotiations, as it holds promising results.

\section{- Negotiating agreements in agriculture and NAMA}

As the thesis argues (chapter 4), negotiations conducted in the field of agriculture and NAMA have become very complex. The single undertaking approach meant that the outcome of the negotiations between NAMA and agriculture effectively blocked progress in each of these distinct areas. More recently, members have managed to move forward with negotiations on agriculture by agreeing on some specific elements, including on export subsidies and food security, yet hardly any progress was made in two of the main areas of agriculture, namely market access and domestic support.

With regard to market access, members have tried to agree on global approaches, including through the application of variations of the Swiss formula, while at the same time making provisions for numerous exceptions for countries or groups of countries. After years of discussions, this has not led to an agreement, thereby not only blocking further multilateral trade liberalization in two important sectors of the economy, covering both agriculture and goods, but actually bringing the DDA to a standstill. The challenge is in breaking the deadlock and pursuing further liberalization in agriculture and NAMA. How can the procedures be simplified without reducing the levels of ambition? What alternative negotiating approaches could be applied?

The analysis in this thesis presents various specific suggestions of negotiating techniques that have successfully been applied in the past in the goods area, including the offer-request procedure, possibly in combination with a formula approach. In other words, a simple and uniform formula could be applied for goods assuring a certain overall level of liberalization, complemented with higher levels of ambition for specific products and sectors. This procedure could again offer a solution for the way forward on NAMA, even if it may be a complex, lengthy and arduous process given the number of members involved. Priority could be given to areas or sectors that are found to be of key and priority importance. Other methods could consist of including a sector by sector approach, with specific attention to those sectors where tariff peaks, high tariffs and tariff escalation are prevalent. The merits of this approach have been proven with the conclusion of the ITA, which sets an example. Other sectors should be identified which are of critical importance to international trade. In doing so and in selecting the areas and/or sectors for pursuing further liberalization, more specific attention could be given to goods, products or sectors where the GVCs play an important role, thus adding the developmental elements in the debates. In other words, members should try to identify sectors with the potential of generating broader benefits in the sector as a whole, taking into account the value-addition generated in the production 
process. This requires looking at sectors 'vertically', that is, from the early stages of production to the end product.

In addition, more attention should be paid to non-tariff barriers, an area that has been largely unattended to in the negotiations, as the focus of attention has mostly been on the tariff reductions, including the formulae. The reality is that Non-Tariff Barriers (NTBs) often present some of the main obstacles in international trade and need to be addressed. Here again, the focus of attention should be on those NTBs and on the areas where the barriers are most pervasive.

The economic realities have changed since the launch of the DDA, specifically for agricultural goods. The data and figures upon which the initial discussions for concessions were based have largely become irrelevant and/or outdated. Membership has considerably expanded with new important players in the field of agriculture, both importers and exporters, and some subsidizing their producers. The situation in 2017 thus differs significantly from 2001 and certainly from the 1990s, a period often used as a reference point and baseline for the reduction calculations. The suggestion to update the relevant data as a basis for concluding the negotiations, as demanded by some members of the WTO, was not accepted. What is the future of negotiations in this important and sensitive area which was first subjected to new disciplines in the Uruguay Round, but which did not result in much liberalization per se? As the Agriculture Agreement has a built-in agenda, mandating members to pursue liberalization in agriculture, which precedes the launch of the Uruguay Round, negotiations can be conducted irrespective of the DDA. Hence there was already a commitment in place, in addition to the ones taken at the Ministerial Conferences. How to liberalize remains the key question. The analysis in Chapter 4 clearly calls for simplifying the negotiations as the approaches to the formula have become too complex, with too many exceptions undermining the transparency of the outcomes. Therefore these are not the preferred option. The market access approaches should be simplified in order to produce workable outcomes. The efforts pursued to conclude negotiations in specific areas including in agriculture is the way forward, but the hard work in the two pillars of market access and domestic support must be pursued on a priority basis. This can only be accomplished if there is a collective will to put the relevant and most recent facts and data on the table and exchange concessions, however painful they may be.

\section{- The 'Single Undertaking'}

The concept of conducting the DDA negotiations as part of a 'single undertaking', which means that the outcome is a package deal, seemed to have merit at the outset, as it theoretically should ensure a balanced package of multilaterally negotiated outcomes. As was explained in chapter 2, the underlying idea was that trade-offs would be sought in the negotiations between the constituent parts of the package. Concessions in agriculture could be traded off against concessions in services, market access or intellectual property rights. The reality is different as no efforts have been made in that sense. It is argued in the thesis 
that the Single Undertaking started to block progress in areas where agreement was within reach, but could not be concluded because of the connections between the parts of the package. This is additionally thought to be one of the main reasons as to why the services negotiations (TISA) are taking place outside the WTO, so as to delink them from the Single Undertaking. This then also led to the introduction by members of the 'early harvest' concept, which implied the adoption of partial decisions in specific areas, including in sensitive areas such as agriculture. The Single Undertaking approach was thus effectively abandoned.

In order to advance the process of liberalization and harvest results, partial deals were concluded both at MC-IX (Bali) and MC-X (Nairobi). This direction is strongly advocated by independent experts as well as the academics referred to earlier, and follows naturally from the analysis in this thesis. Partial deals and stand-alone agreements seem to offer a way forward for conducting future negotiations. It has proven to be effective in agriculture with agreements on food security and export subsidies. It has also led to the TFA and the ITA. Rather than seeking broad trade-offs between various areas, it is argued that the trade-offs are, and in future should be, established within each specific area. The Ministerial Declaration at MC-X (Nairobi) calls for advancing the negotiations on Doha issues as stated earlier and without reference to the Single Undertaking, thus confirming the new realities and suggesting that the single undertaking has been abandoned.

A study prepared by the Peterson Institute for International Economics suggests a 'Grand Bargain', ${ }^{19}$ should members decide to stick to the negotiating approach set out in Doha, and in order for the WTO to restore its negotiating function. This 'bargain' means that advanced countries should concede the priority demands of developing countries with respect to the DDA - on agriculture and NAMA. In return, developing countries should agree that subsets of WTO members can enter into plurilateral agreements within the WTO framework, provided the agreements are binding only on the signatories. From the view of the Peterson Institute, the Grand Bargain would enable the WTO to pursue 21st Century pacts that keep policymakers, business leaders, and the broader public engaged, while answering the legitimate demands of developing members to reduce longstanding distortions to farm trade and manufacturers. The authors then suggest that over the course of 2017, and prior to the MC-XI, members should launch negotiations on several additional plurilateral agreements, which might include an Investment Framework Agreement (IFA) that would resolve contentious weaknesses surrounding investor-state dispute settlement that are common in free trade agreements. ${ }^{20}$ Moreover, they feel that under the WTO's auspices, an IFA could link more countries to GVCs. Not only would the economic gains from IFA and other new plurilateral agreements be substantial in their view, the pacts would restore the WTO as the foremost global forum for addressing new issues. In other words,

19 G.B. Hufbauer et al., 'From Drift to Deals: Advancing the WTO Agenda', Peterson Institute for International Economics, Commissioned by the ICC World Trade Agenda (2015). 
the authors again support the idea of having different levels of agreements, provided that demands at all levels can be satisfied.

\section{- How to conduct negotiations with an enlarged membership?}

It is challenging to conduct negotiations between an ever-increasing number of WTO members, including developing, developed and new (Article XII) members, who all undertake an active role in their own specific economic and policy interests. The approach adopted thus far, consisting of negotiating agreements between all the members with a range of multiple exceptions for individual countries and for groups of countries, has become far too taxing. It has burdened the negotiations to the point that the draft texts for some of the agreements and more specifically for agriculture and NAMA became too complex and lost much of their meaning. It was argued in the analysis that it became too much of a challenge to calculate the value of concessions made by each of the members, given the many exceptions. In addition, countries increasingly operate by way of topic-based and/or (sub-) regional alliances with changing constituencies. How can one recognize and reconcile the many divergent positions in the negotiations? How can rules be developed in the WTO taking into account the differences between the members? In practice, some members have become developed countries, while maintaining their developing country status in the WTO. Some are at the same time donors and beneficiaries of the WTO's trade capacity building programmes. What concessions can one expect these developing countries to make? How can special and differential treatment provisions be articulated in a way that preferences are granted in an economically meaningful, workable and operational manner, without adding to the complexity of the system? How meaningful is the notion that granting preferences to assist beneficiary countries to integrate more fully into the trading system, and how is it best achieved? Should and could preferences be made binding, as they are in the TFA? Should and could there be a better and fuller recognition of the groupings and alliances in the negotiations?

Again, the variable geometry and flexibility in the approaches can offer ways forward, taking into account the fact that the membership is become increasingly diverse. Why continue attempting to find solutions for all members alike, when it is evident that there cannot be a 'one shoe fits all approach'? Efforts should be made in areas where multilateral agreements are feasible, as proved to be the case for TFA. In other areas where it is harder to find solutions, the approaches should be far more flexible and allow for selective solutions between like-minded countries. This would have the advantage of keeping the agreements within the ambit of the WTO, and would reduce the risk of members finding solutions outside the multilateral trading system.

The flexible approach would also better reflect the developing country concerns in the DDA, whose integration into the multilateral trading system is a priority. The TFA set a model approach for trade capacity building in a meaningful way, including tangible and concrete commitments for both developed and developing countries. It is argued that the 
TFA holds the promise of drastically cutting trade and transaction costs, and that developing countries stand to gain the most from the agreement. The new approach thus provides for S\&D in a concrete and operational manner, in manners likely to generate economic benefits. Moreover, the measures are expected to facilitate a better integration of developing countries into the multilateral trading system.

\section{- Negotiating trade agreements outside the WTO}

In some specific instances, the efforts to negotiate a trade agreement have been pursued outside the ambit of the WTO, such as in services and discussed in chapter 4 . In the absence of a substantial extension of liberalization in trade in services, the WTO has witnessed the emergence of negotiations by WTO members outside the WTO framework, including the ones on the TISA. These discussions involve a group of like-minded countries with higher levels of ambitions in liberalizing trade in services. While the benefits a priori are intended to apply to TISA members, it is argued in this thesis that TISA theoretically holds the potential to extend the benefits to the entire membership, depending on how TISA will be structured and legally shaped. In order to achieve that goal of MFN application, it would be important to ensure that the critical mass approach applies. In other words, the risk of free-riders should be avoided, which means that all the key players in the field of services need to take part in TISA negotiations. This is not the case for now, as China and India are not included, thereby reducing the chances of extending benefits on an MFN basis. It is more likely to at least initially remain a stand-alone plurilateral agreement. The main concern from a WTO perspective is that the negotiations take place outside the scope of the WTO. This is even more remarkable as the GATS explicitly provides for negotiations to be conducted with a view to further liberalization, within the WTO as part of the built-in agenda. What can be done to bring the negotiations within the ambit of the WTO and eventually extend the benefits of trade liberalization to the WTO members by virtue of the MFN? What can be done to ensure that any future negotiations take place within the framework of the WTO? These answers cannot be given at this stage, but members need to be encouraged to make the TISA WTO-compatible in a way for it to receive multilateral and MFN application. This way, the WTO membership can directly benefit from its outcome.

Baldwin observes that the rule-writing mostly occurred outside the WTO system, including through the mega-regionals, including the Trans-Pacific Partnership (TPP), Transatlantic Trade and Investment Partnership (TTIP) and the plurilateral agreements, including in services reference. ${ }^{21}$ The ITA could be added to this, as a plurilateral agreement negotiated within the WTO, and with MFN application and the current negotiations on TISA, which are outside the WTO. There is also no indication if its benefits will be extended to other members. Hence Baldwin considers the world to have a three-pillar system, with the WTO rules as the first pillar, 21st-century regionalism as the second - namely detailed Regional Trade Agreements (RTAs) and the web of Bilateral Investment Treaties (BITs) and the third pillar, being the unilateral reforms undertaken by developing countries locked

21 R. Baldwin, 'Restoring WTO Centrality', p. 10. 
in by their national laws. He considers WTO centrality to have been seriously eroded; regionalism and unilateralism work as vehicles of liberalization, while multilateralism does not.

\subsubsection{New rules required for trade, investment and competition policies}

It is argued in the thesis (chapter 3) that FDI plays an increasingly important role in driving and facilitating international trade, and yet there are no rules governing the interaction between trade and investment. There has been a growing interdependency between markets and a deepening of integration due to increasing levels and new directions of FDI, and the emergence of GVCs which are of critical importance in linking markets. Equally, there are no multilaterally-agreed rules on investment, which continue to be governed mostly through bilateral investment agreements. Simultaneously there is a growing recognition of the relation between trade, investment and competition policy, which are inherently interconnected and are not covered by multilateral rules and principles. The question is whether rules should be established governing the interrelation between the two policy areas and if so, how? The analysis leads to a clearly positive answer to this question. It is strongly recommended to analyse more deeply what rules would be required.

These issues have been on the backburner for circa two decades in the WTO. They are now getting renewed attention, with some members calling for an extension of the rules over the years, and with some Ministers explicitly recognizing the need to extend the discussions to other areas at MC-X (Nairobi). With regard to broadening the issues under discussion, the Ministerial Declaration refers to 'other issues for negotiation' that 'some [members] wish to identify and discuss'. 22 These issues are unspecified and could include trade and investment, trade and competition policy, electronic commerce amongst others. However, it is stated in the same paragraph that 'any decision to launch negotiations multilaterally on such issues would need to be agreed by all Members'. In other words, the consensus rule applies for the opening of negotiations, which is likely to be a challenge given the opposition voiced by some members. Here again, the question is how work can be initiated on the other issues, and to what extent the Secretariat has to prepare factual analysis and provide background notes.

Currently, the Secretariat does not have a mandate from the members to conduct research and analysis addressing the policy aspects and possible implications of the inclusion of these areas for the trade rules. MC-X (Nairobi) has created a new opportunity to look at some of the other issues, without being explicit and/or specific on which areas could be envisaged. This is part of the divergence of views, as reflected in the latest Ministerial Declaration (MC-X, Nairobi), and will need to be examined in the Geneva process, and prior to MC-XI which will be held at the end of this year. The text can be understood differently, presumably including the interrelation between trade and investment, competition policy and e-commerce. However, any decision to launch multilateral negotiations is subject to the

22 Cf. Nairobi Ministerial Declaration, para. 34. 
consensus rule. Does that mean that the reflection process and analysis on these issues can only be undertaken with a new and fresh mandate? How are the debates in the WTO likely to be structured and what mechanisms will be set up for the conduct of the debates? Given the increased prominence of the interlinkages between trade and investment and trade and competition policy, it is important to conduct further research and analysis establishing the facts, and provide for the elements upon which the members can then take their informed policy decisions. As is suggested by Evenett and Jara, who recommend first establishing a clear deliberation process before the launch of any negotiation to help build confidence, the WTO Secretariat could provide informative analysis in support of those countries that have less analytical capacity to assess emergent commercial trends, options for multilateral cooperation and supporting national measures. ${ }^{23}$

I would go one step further and argue that such approaches, such as the research and analysis to be conducted by the Secretariat, should not be limited exclusively to the two areas - specifically the interconnections of trade and competition policy, and trade and investment. It should also be extended to e-commerce, which is an integral function in how trade is currently conducted. It was first put on the trade agenda nearly two decades ago without any follow up. It is time to take a closer look at how e-commerce affects international trade, what links there are with policy instruments, and whether there is a necessity to address some of the aspects from a trade regulations perspective. Some initial efforts were undertaken recently, but the process is in its infant stages and lacks the broader support from the membership that would allow progress.

\subsubsection{Regional trade integration as a vehicle for trade liberalization}

This thesis argues in chapter 2 that in recent years the world has witnessed a rapid emergence of mega-regional trade blocs, or RTAs, involving nearly all trading nations in one way or another. RTAs by their very principle deviate from and seriously risk undermining multilateral trade rules and the trading system per se. Regional and bilateral trade agreements can solve trade issues between countries, but the advantages of the outcome of those discussions remain limited to that group of countries only. In addition, and perhaps even more importantly, regional and bilateral trade agreements are mostly in favour of larger entities, which have the power and leverage to impose their will. Multilateralism guarantees global and inclusive solutions, with rules applicable to all in the same legally binding manner, whereas regional trade agreements can only offer partial solutions. What is the risk of a further proliferation of regional trade initiatives, given that most trading nations are already covered in one way or another? It is increasingly shown that RTAs hold the potential to generate larger benefits to the advantage of the entire WTO membership, depending on how regional accords are being shaped. How can a process be designed to ensure that regionalism and multilateralism coexist in the most constructive and beneficial of manners? How to go about regionalism in terms of trade rules? Are the (enhanced) transparency mechanisms in the WTO designed to shed more light on the nature of the regional entities sufficient, or

23 Evenett and Jara (eds.), Building on Bali, p. 5-6. 
should these rules be deepened? Is there a way to reconcile the conflicting approaches of regionalism versus multilateralism? How can the risk be contained of regionalism eroding the multilateral trading system? Should more analysis be conducted on the key elements contained in each of the regional entities, with a view to opening them more widely to the WTO's membership? Should the Secretariat be mandated to pursue such further study and research, or should this be left to academics and think tanks? What are the ways going forward?

Given the potential that RTAs have for advancing multilateral trade liberalization, it is argued that more analysis and thinking would provide better comprehension of the common elements in the regional entities from a WTO perspective, with a view to broadening them at the multilateral level. There should be a better understanding of the relationship between the rules under the RTA provisions in the WTO, shedding more clarity on what is covered, what is left out and why. This could then lead to a reflection on new approaches with regard to RTAs. It is also well understood that regionalism does not offer an alternative to multilateralism. Hence there is the need to safeguard the multilateral trading system, which falls more in the interest of smaller nations. At the same time, it is worth exploring how the outcomes of regional trade liberalization efforts could become multilateral, so as to ensure larger benefits for the world trade community per se.

\subsubsection{Keep a focus on the development dimension in the negotiations}

Given that the DDA is intended to be a 'development round', the focus of attention should remain on the question at hand; how can developing countries best take advantage of the rules of the multilateral trading system, and participate more fully in the system? It is argued in chapter 5 that more efforts should be pursued in assisting developing countries in achieving that objective. The WTO's trade capacity building programmes should be further strengthened, by securing stable funding from traditional sources. The shift in economic policies by formerly inward-looking developing countries towards more liberal policies, and their deliberate efforts to better connect to global markets, has led to further market opening. However, this largely remains a work in progress for which there is a continued need for support. Trade capacity building efforts should be geared towards empowering the beneficiaries to take advantage of the system and towards benefiting from new trade opportunities. Trade negotiations should specifically take the economic and policy interests of developing countries, and more specifically the LDCs, into account. Developing countries should be assisted in their reforms in order to better connect to markets. It is argued that this is best done by way of making binding commitments between developed and developing countries, as was the case in the TFA. The expected gains from a reduction of transaction costs and more particularly in developing countries are tremendous, hence the need to provide the required support under the terms of the TFA. Such approaches are found to be more promising than extending preferential arrangements, which are mostly autonomous and can often be revoked by the preference-granting members. 
In addition, trade and investment have significantly contributed to economic growth and higher overall levels of welfare in many developing countries, which further facilitated their integration in the multilateral trading system. The shares of developing countries in world trade have grown rapidly and in some cases spectacularly, especially in Asia. The ways in which developing countries have benefited from trade differs across and within regions, and has not always been even between countries. While globalization has offered challenges and opportunities, many developing countries have not benefited from these opportunities and are not part of the GVCs. There is thus a need to provide continued support to beneficiaries and ensure that further liberalization takes the development dimension into account; developing countries can better connect to markets and integrate more fully into the multilateral trading system.

\subsubsection{Is there a need for further institutional reforms in the WTO?}

The thesis argues in chapter 2 that the creation of the WTO was the most significant reform of the multilateral trading system since the establishment of the GATT. The WTO was believed to provide the institutional response to the developments that have occurred in international trade. Yet, as was laid out, some of the weaknesses of the new system have become increasingly apparent in recent years and need to be addressed. The questions of the need for reforms at the WTO and what they would consist of generally arise when progress in negotiations are stalled. The debate on reforms and how to conduct negotiations is thus far from new and goes back to the days of the GATT in the early 1980s. In the past, several former Director Generals sought external advice in handling future direction, the type of reforms required and the available options for future negotiations. A similar approach was adopted in the more recent history of the WTO.

Institutional reforms have mostly been prepared on the basis of reports by eminent persons, academics and think tanks. In 1983, the then Director General (DG) Arthur Dunkel of the GATT established a panel of seven distinguished persons to report on the problems facing the international trading system. This was during a period when globalization became apparent and measures were increasingly taken by members outside the rulebook of the GATT. This initiative resulted in the so-called 'Leutwiler report', named after the former head of the Swiss Central Bank who chaired the panel of eminent persons. ${ }^{24}$ The report contained 15 recommendations to support a more open multilateral trading system as a countermeasure to the crisis prevailing in the trading system at that time. It was written with the aim of breaking the stalemate at the launch of the Uruguay Round negotiations, and it sought to influence the negotiating agenda. The Uruguay Round of trade negotiations was launched only a few years later, in 1986.

Some 20 years later, in June 2003, the then DG Supachai Panitchpakdi sought the support of eight eminent persons to assist in a reflection process on how to reinforce the

24 A. Dunkel, Trade Policies for a Better Future: The Leutwiler Report, the GATT, and the Uruguay Round (Kluwer Academic Publishers, 1987). 
multilateral trading system. This resulted in the so-called 'Sutherland Report' in 2004, named after the first DG of the WTO. ${ }^{25}$ The report contains three dozen conclusions and recommendations, many of which continue to be relevant today. ${ }^{26}$ The recommendations cover a wide range of areas, including the implications of globalization for liberalizing trade, governance and sovereignty issues, coordination and coherence in policy-making, regionalism, preferences, relations with civil society, dispute settlement, the consensus approach to decision-making in the WTO, but it also recommended that different approaches to negotiations should be reviewed outside the context of the DDA. ${ }^{27}$ In other words, irrespective of the DDA, members should revisit negotiating approaches, which they are arguing for again, and they should instruct the DG to look into and report to the members.

The recommendations also include a suggestion of holding Ministerial Conferences on an annual basis. One of the main arguments for this is to take away the pressure of ministers having to deliver concrete results, and instead convert the Conferences into something more akin to a stock taking exercise, reviewing progress made in various areas. This lightens the process, bringing it closer to the practice of the World Bank and IMF, both of which also hold annual meetings. In the GATT only a few countries representing the largest shares in world trade took the main decisions, as perhaps was the case in the early days of the WTO. Hence a few members took decisions for the membership as a whole. This was generally viewed as not inclusive, and as I explain in the thesis, this was a source of concern for developing countries. The majority of members are developing countries whose economic interests are at the heart of the round. As argued, the deeper participation of developing countries in the negotiations implies the need to come to collective and inclusive decisions, taking the diverse economic interests into consideration. With the extended WTO membership ringing in at 164 members, all decisions in the WTO are taken collectively, with the process being more complex than ever before. Furthermore, the shift in economic balance in trade, with several new and significant economic actors, including China and India, is also shifting the balance in the discussions and decision making, with these members wielding a far stronger influence in decision making. Finally, one cannot expect Ministers to solve a broad range of issues through round-the-clock negotiations over three or four days, which remain unresolved in the days, weeks and months preceding the Conference.

More recent thinking of the WTO reforms is contained in an informal paper prepared by Talal Abu-Ghazaleh. He had been appointed by the then DG Pascal Lamy to serve on a panel of WTO experts reflecting on reforms in the WTO. ${ }^{28} \mathrm{He}$ presented his ideas at the WTO in January 2013, which were subsequently debated in a panel discussion. The paper contains a total of 23 recommendations covering a wide range of issues, with considerable

25 Cf. 'The Future of the WTO', footnote 8, p. 2.

26 I will not review all the recommendations and how they were implemented, as that would go beyond the objective of this analysis. Some have been addressed in the second chapter.

27 Cf. 'The Future of the WTO'; in each of these areas specific recommendations were made and are summarized at the end of the report, see p. 79-83. 
emphasis on conducting a reform process on the ways the WTO functions and takes decisions. He is also an advocate of a broader role for the Secretariat, which he believes should be empowered to conduct more independent research and analysis, as well as in close cooperation with other international institutions.

The World Economic Forum issued a study covering some of the very same issues with contributions from leading international economists, academics and policymakers. ${ }^{29}$ In this study, Richard Baldwin argues that whilst it is unlikely that the world can return to a situation of WTO centrality, the WTO remains essential. ${ }^{30}$ His argument is based on the fact that multilateral trade governance today is a far more complex ecosystem of actors for three reasons, which largely confirm the arguments that I have made and substantiated in my analysis throughout this thesis. ${ }^{31}$ Firstly, important elements of international commerce have changed; secondly, these changes vastly deepened and widened the range of necessary 'rules of the road'; and thirdly, the WTO did not adapt to the changes. Baldwin refers to the changing trading environment discussed previously, with increased complexities and interdependence between goods, services and markets. In his view, the new complexity of cross-border flows, including through the GVCs, require a rethinking of the rules. While the GATT led the writing of the 20th century rules of the road, the WTO has had almost no rulewriting role in the 21 st century, with the exception of the TFA.

\subsubsection{Is there a need to review the role of the Secretariat?}

One of the recurrent suggestions made in various independent reports reflects on the role of the Secretariat and whether it should be strengthened. The Sutherland report referred to earlier also contains recommendations on the functions of the DG as well as of the Secretariat. The report suggests that the membership should encourage a greater intellectual output from the Secretariat. A clearer, though always careful, lead on policy issues should be provided by the Secretariat; members should facilitate this.

It is argued throughout this thesis that the WTO is member-driven, meaning members decide on the course of action. The Secretariat provides support to members and responds to their needs. It is argued that this distribution of responsibilities works well. The Secretariat mostly provides analytical support to the committees and the Chairs in response to a request, yet at the same time there is little margin for taking initiative and analysing issues with a view to making policy recommendations. Is this the way the Secretariat should continue to function, or should it have more leeway for its own initiatives and be able to conduct independent research and analysis on a broader range of issues? It was suggested earlier in this thesis that there should be an exploration of the ways that the Secretariat can provide analytical support without prejudging any policy decisions. There are considerable

29 The High and Low Politics of Trade: Can the World Trade Organization's Centrality Be Restored in A New Multi-Tiered Global Trading System? World Economic Forum, Geneva, August 2015.

30 R. Baldwin, 'Restoring WTO Centrality to a Multi-Tiered Global Trading System', World Economic Forum, Geneva, August 2015, p. 10.

$31 \quad$ Ibid., p. 8-9. 
unexploited sources of knowledge and intellectual skills available in the Secretariat. Some of the research and analytical work on economic and trade issues in the WTO is conducted in close coordination with other Bretton Woods institutions, UN bodies and the OECD, thus joining forces and adding value to the collective reflection process. This adds to the impartiality and neutrality of the research findings and contributes to developing a sound basis for policy options that could be presented to members. It would help to advance multilateral trade negotiations and the trade liberalization process.

Specific intellectual input is required, for example, by analysing the relationship between trade and investment, and trade and competition policy, in the role of e-commerce in international trade and its links with the specific WTO agreements. This could also include the relation between trade and exchange rates, a controversial area which is a taboo subject at the WTO. Nevertheless, given the low average tariffs for industrial goods, exchange rate fluctuations have an effect on trade. Another area concerns trade finance, specifically access to finance, which often turns out to be a major constraint for developing countries in finetuning their export potential. With regard to the relationship between trade and investment, the Secretariat was no longer mandated to undertake any work in this area following the Ministerial Conference at Cancún, which eliminated the topic from the agenda. Following the outcome of Nairobi, it would be natural for the Secretariat to undertake fresh analysis in this field, irrespective of whether an agreement is to be negotiated.

One could go even further and extend the mandate of the Secretariat in terms of its trade capacity building to beneficiaries and allow the Secretariat to provide policy advice. Members should consider extending the Secretariat's mandate in this direction, since trade capacity building efforts are demand driven, and many beneficiaries do seek policy advice in their technical assistance requests. Such advice should be based on facts, including the outcomes of WTO studies such as TPR reports. This could extend to sharing the experiences and best practices of others, including newer members to the WTO who acceded under the provisions of Article XII. Members should be provided with a menu of policy options based on case studies and real practice.

In addition to working closely with other international organizations, another option would be to associate the WTO Chairs more fully, in their capacity as independent academic institutions, including in areas where the WTO currently lacks a mandate. As explained earlier in this thesis, the WCP is gradually developing and expanding with more emphasis on the relationship between academic research and policy relevance. The academic community has an important role to play in disseminating knowledge and information on the benefits from trade liberalization to the public at large, whilst simultaneously ensuring that efforts made at the political level best reflect the economic interests of the country. This would help build a better understanding of the main objectives of the WTO's key functions, including its mandate to advance trade liberalization to the benefit of all. 


\subsubsection{The future of the DDA: can it be concluded, and if so, how?}

In spring 2014, following the conclusion of MC-IX (Bali), I argued that the Ministerial Decisions had strengthened the WTO as an institution. ${ }^{32}$ The positive outcomes of MC-IX were very much welcomed by the members, as prior to the Conference there had been much uncertainty about the future of the WTO as an institution in the absence of multilaterally negotiated outcomes. With the agreement reached by Ministers on the TFA, MC-IX had provided a turning point for the WTO. In the same publication I provided five specific reasons why the results of MC-IX were significant and opened the door for further results in other areas:

1. It provided a reconfirmation of the centrality of multilateralism as a basis for governing international trade, which was much needed at the time, as the risk of a fragmentation of the system had become apparent, given the lack of progress in negotiations.

2. The trade liberalization measures agreed at MC-IX would generate economic growth, which was welcome given the slow-down of the world economy.

3. The negotiating function of the WTO had yielded tangible results, which was important for building trust in the system and more specifically in the negotiating function of the WTO.

4. The development dimension had been given due consideration, which after all is one of the central pillars in the DDA.

5. Progress was made on enhancing compatibility between regionalism and the WTO, which is also of significant importance, given the increased interest by WTO members to move forward at the regional level, instead of multilaterally.

Thus, the outcome of MC-IX generated optimism at the time and fresh hope for the WTO to deliver on the DDA. Ministers had also agreed to prepare a roadmap for the future, which should have opened the way to a conclusion of the DDA negotiations, and to eventually address other trade-related issues. This optimism was short-lived as new roadblocks appeared shortly after resuming work in Geneva in spring 2014. Instead of working towards a roadmap, and as discussed in Chapters 2 and 4, much of the WTO members' time was taken up addressing the food security issue, before finalizing the legal procedures for putting the TFA into effect. This also delayed the preparatory process for MC-X (Nairobi). The roadmap for the future, a key commitment taken by Ministers at MCIX, was never established.

32 M. Smeets, 'The Agreements Reached at Bali, a Turning Point for the WTO', 68 Internationale Spectator (2014), p. 37-40. 
Reports by the Chair of the Trade Negotiating Committee (TNC) to the General Council show that there was little movement in positions taken by the members in agriculture and NAMA, despite the commitments taken at MC-IX. ${ }^{33}$ The preparatory process for MC-X clearly suffered delays, with little substantive progress made in most areas covered by the DDA. Whereas one would expect members to work towards a convergence of positions, the opposite happened, according to internal reports and unofficial feedback from delegates who attended the preparatory meetings. The positions hardened, with lesser prospects for compromises prior to MC-X.

Some developed countries and members (such as the EU, US and Japan) clearly indicated their concern with the lack of progress in the DDA negotiations, the full conclusion of which was no longer their top priority. ${ }^{34}$ They expressed the desire to move beyond the DDA, calling for the broadening of the agenda and the inclusion of 'other' issues for negotiation, without specifying which would be included. On the other side, several developing countries (the ACP countries, China, India and so on) resisted that approach arguing that members should first deliver on the development aspects included in the DDA.

There was a clear impasse prior to the MC-X (Nairobi) which risked undermining the MC-X's positive outcomes. At the same time members considered that failure at MC-X was not an option, as this would have dealt a major blow to the WTO as an institution and a negotiating body. MC-X was the first Ministerial Conference ever held in Africa and too much was at stake for developing countries and Africa in particular to miss the occasion. As the Conference started without a draft declaration, ministers had no choice than to be directly involved in the multilateral trade negotiating process and work on a declaration from scratch. ${ }^{35}$ While the chances for a positive outcome seemed to be meagre at the start of the Conference, the collective efforts resulted in a positive outcome. Delegations worked around the clock to find a way out and to put the WTO back on track once again. The declaration that resulted from the four-day meeting provides new hope for the WTO to address the challenges of today and other (unspecified) issues for the future, thus potentially leading to a stronger multilateral trading system.

Thus, the WTO managed to conclude a Ministerial Conference, MC-X (Nairobi) with concrete outcomes, against the odds. As stated by the Chair of the MC-X, Kenya's Foreign Affairs Minister H.E. Amina Mohamed, the credibility of the WTO, which had been affected in the run up to Nairobi, was reinforced as it was able to deliver on a number of issues in the negotiations. ${ }^{36}$ Results were achieved through the WTO membership strong commitment and constructive approach, including its key players. Nevertheless, the WTO again showed the difficulties in assuming one of its key functions - the conduct of trade negotiations. With

33 This is evidenced in various internal reports of the General Council meetings, which are restricted and cannot be specifically referred to.

34 The different positions are referred to in the Nairobi Ministerial Declaration, para 30.

35 According to internal WTO staff briefings following the conclusion of MC-X (Nairobi).

36 A. Mohamed, 'Nairobi Trade Talks Made History', All Africa, WTO press release, 8 January 2016. 
the perspective of the next Ministerial Conference coming up at the end of this year (MC-XI, Buenos Aires), it is of critical importance for members to follow up on the recommendations made at MC-X, and to review the negotiating approaches as mandated in paragraph 30 of the Ministerial Declaration.

In principle, the MC-X Declaration provides the main elements on the way forward, although it does not do so in an unambiguous manner. The wording is based on a 'constructive ambiguity', which means that the text is drafted in such a way that all members believe it reflects their views, leaving various options open and making it subject to further clarifications. The Declaration states a divergence of views between the members on the way DDA objectives are to be pursued, with those lending continued support to the DDA per se and those who believe the DDA has come to an end.

The analysis conducted in this thesis shows that it would be unrealistic to think that the DDA can still be concluded as was envisaged at its launch, namely as a single undertaking. Too much time has lapsed without substantial progress being made, the economic and political realities have changed, and various partial and stand-alone agreements have been negotiated in specific fields. Furthermore without the support of the key players in trade, including the US, the EU, Japan and others, it is most unlikely if not unthinkable that DDA negotiations will be pursued as they were initially conceived. One could query whether a mega round covering as many diverse issues will ever be launched again. This seems increasingly unlikely, given recent experience and the growing complexity of conducting such rounds. There is an explicit commitment by the members in the Ministerial Declaration to advance the negotiations on the remaining Doha issues, which suggests a willingness to pursue the discussions on the DDA issues, albeit in a different manner. ${ }^{37}$ Alternative routes need to be explored.

\section{Cottier and Elsig observe that}

It has become evident that while the present round will be completed (or abandoned) on the basis of the current procedures, future tasks can no longer be addressed without institutional reform. Beyond classical trade issues, the future challenges include additional liberalization of behind-the-border measures, complex negotiations on trade policy responses to climate change mitigation and adaptation, and finding regulatory answers to long term effects of financial and fiscal crises, including the absence of sufficient financial regulation in international law. ${ }^{38}$

As I have argued in the thesis, it is essential to further reflect on how the Secretariat can best perform its negotiating function as mandated by Ministers at Nairobi, and address the

$37 \quad$ Nairobi Ministerial Declaration, para. 31.

38 T. Cottier and M. Elsig (eds.) 'Governing the World Trade Organization, Past, present and beyond Doha', (Cambridge Press, 2011), p. 3. 
issue of how to best achieve wider, more profound trade liberalization in economically meaningful ways. The perspective of concluding the DDA as agreed at the time of its launch is increasingly unlikely, but the need to pursue its key objectives, including further trade liberalization, is as important now as it was before. The stakes are high both for developed and developing countries. There is a need to recognize the changes in world trade and adapt the policies to the new challenges accordingly and these are the key issues to be addressed in the final and concluding chapter. 


\section{CHAPTER 7: KEY FINDINGS, SUMMARY AND CONCLUSIONS}

It is evidenced that the multilateral trading system is very complex and faces challenges and opportunities that are determined by many factors, some of which the members can control and others which are external and beyond their control. The challenges can be better understood through an analogy with a team of rowers that is preparing for a race. The team needs to set realistic targets for the expected outcome of the race. Various factors will determine its outcome, including the choice of the boat, the conditions of the water plan (lake, river, sea) and most importantly the composition and preparation of the team. The boat can contain the latest technology and be fast on smooth water, or be better suited for heavy weather conditions, waves, rain, wind and storm and be slower but steady. The rowers in the boat can be big and strong, or light and small and have different levels of physical condition and preparation.

Having a good boat and a strong team is insufficient. The team needs to fit together and be coherent, which requires a good preparation and training by each team member before getting on the boat. Equally, the team needs to develop a common vision and strategy to achieve its objective. The boat needs to possess the appropriate equipment. The members need to agree on their seat in the boat, who sits in the front, in the middle and who is in the back. The position of the rowers is largely determined by the technical and physical skills of each crew member, their height and weight, experience and leadership capacity. The rower in the first position (stroke) sets the pace, but each crew member plays its part in the collective efforts and needs to fully understand its contribution in that position. It is the responsibility of each crew member to adjust their seat, check the oars and the riggers and adjust the foot position to his or her conditions. The outcome of the race will largely be determined by the good preparation of each and every crew member and yet this is not enough as the total sum is more than the sum of the parts. The team is interdependent as it needs to move together like clockwork and be in full harmony and coherence.

The boat can have a cox, who gives the commands and directions and keeps the team together. His role is important in larger boats, e.g. in the eight, where the technical conditions are much harder than in the smaller boats ( 2 or 4 ). The overall responsibility of coherence nevertheless rests with the team members themselves, which is easier to achieve in a smaller boat with fewer rowers.

The team will need to develop a steady speed, with accelerations to be performed in coordinated ways in order to keep the boat stable and achieve the best performance. If one crew member is out of tune or lacks the technical skills, the boat destabilizes, loses speed and can even turn over. Pulling too hard on the oars will slow down the boat. The speed is mostly dictated by the technical skills of the team and their coordinated motion. Slowing down the pace is much more effective for regaining stability, harmony, coherence and control over the boat than pulling harder. 
The factors that the team cannot master are the weather conditions, the current, the waves, the rain, the wind and the technological evolutions and innovations which will significantly influence the pace and the outcome of the race.

In WTO terms, the analogy means that the members need to be fully prepared for all the challenges that they are presently facing. Members need to conduct research and analysis, develop policy options and determine how to achieve the best collective outcome, taking into account their own levels of development, economic and policy goals. Such analysis needs to be done by each member prior to the start of the negotiations and before developing a common approach and strategy for the race. They need to ensure that the right material and the appropriate equipment are used to meet the changing conditions. This means that the members need to ensure that the agreements contain those elements, including rights and obligations that are of direct interest to them and that they can handle. The boat needs to fit all members of diverse physical size and fitness, meaning that the provisions need to be designed in ways that they can be implemented by all members at different levels of development. The members need to be technically and physically fully prepared, meaning that they need to have the knowledge and capacity to make substantive and technical inputs in the negotiations and shape the contents of the agreements. The members need to understand the specific contribution that they are expected to make in the negotiations, as the agreements reflect the interests of a wide range of members. Negotiations include a give and take, which requires a clear understanding of the concessions that one can make in order to ensure the best collective outcome. They need to establish a common vision and understanding of the key objectives and expected outcomes of the negotiations, meaning that the members need to establish clarity on the directions to be taken. The vision and objectives may require adjustments when the conditions change. This requires flexibility and a capacity to adjust. There needs to be coherence in the approaches, trust and teamwork, as the boat will not advance if members pull in different directions. The members need to think through and agree who sits in the front, in the middle and in the back in order to achieve their negotiating objectives. Some members are better placed to take a leadership role, guide and direct the others and provide advice, but each member has a specific contribution to make. All these elements are very much interdependent and will collectively determine the outcome.

In concluding the thesis, this final chapter thus summarizes the main findings contained in each chapter and offers some policy recommendations.

\subsection{From the GATT to the WTO: a stronger multilateral trading system}

Following an introduction to the structure of the thesis in chapter 1, the second chapter provides explanations as to how and why it became apparent in the 1980s that it was time, and even indispensable, to establish a new and solid institutional basis to conduct international trade. While the GATT had functioned very well for almost half a century, a period in which the rules had been updated several times, it did not have a permanent legal and solid institutional basis. Given the increasing importance of international trade and the 
volume of transactions, it was important to have a body similar to the other Bretton Woods institutions to govern international trade. After all, the creation of such an international trade body had already been part of the initial thinking after WWII, at the same time that the Bretton Woods institutions emerged, but it had not materialized at that time. In a way, the GATT was an abbreviated version of initial aims. It focused on a part of trade - mainly on tariffs, and non-tariff barriers to some extent and mostly for industrial goods.

With the creation of the WTO, the idea of the initial architects of the multilateral trading system materialized at last. Instead of calling it an International Trade Organization (ITO), the WTO was created, correcting what Jackson referred to as a 'birth defect' of the GATT. ${ }^{1}$ It is argued that while this new international organization continued to perform some of the key, traditional functions of the GATT, including facilitating the implementation of the trade agreements and conducting trade negotiations, it was given a much broader mandate, with additional functions, objectives and instruments. With the creation of the WTO a new and permanent institutional framework to govern trade and rule-making was established. This included new rules for decision-making, providing a solid institutional set-up to discuss trade matters, with a Ministerial Conference standing at the apex. The Marrakesh Agreement that led to the creation of the WTO recognized the importance of having a new multilateral trading system to deal with the key challenges, and prepare the future of trade. These changes and additions went a long way towards addressing the challenges that had emerged for the trading system prior to the creation of the WTO.

It is explained how the WTO differed from the GATT, which had not regarded some important new features of international trade, including trade in services and the protection of intellectual property rights. It mainly dealt with the more traditional trade issues in the goods area but even there the rules were increasingly inadequate. One of the main weaknesses of the GATT is that the rules for agricultural trade were ineffective, although the tensions in that sector mounted very high in the GATT days due to the subsidies mostly granted by the large industrial nations, which seriously distorted world markets. This weakness became even more significant as the dispute settlement system of the GATT had become ineffective at addressing and settling trade disputes. The GATT had a weak enforcement mechanism, with legal rulings being increasingly ignored by the parties. This undermined the system per se, as there was less of an incentive for countries to stick to the rules and resort to the legal system in case of a breach of the rules. The GATT was gradually losing its credibility, its raison d'être put into question. Measures were increasingly taken outside the legal framework of the WTO through both voluntary and perhaps less voluntary trade measures, including voluntary export restraints (VERs) and orderly market arrangements (OMAs). These measures included quantitative restrictions, which effectively limited trade and prevented trade patterns and flows from occurring according to the principle of comparative advantage. Not only were these measures economically quite inefficient and costly, but they also contributed fundamentally to eroding the multilateral trading system per se.

1 Cf. Chapter 2, Jackson, 'Restructuring the GATT System'. 
It had thus become apparent that in terms of institutional set-up, rules and coverage for the GATT had reached its limits, no longer fit to address the challenges of the multilateral trading system. The rules were increasingly ignored. It was thus of the essence to reconsider the rules and fix the problems - which is indeed what happened with the creation of the WTO. The rules were extended to cover trade in services, agriculture and the protection of intellectual property rights, and many of the agreements were revisited and updated. One of the main revisions undertaken concerned the way the dispute settlement procedures were designed. These were fundamentally changed, further strengthened and made binding for the members. The revamped Dispute Settlement Understanding (DSU) provisions have considerably strengthened the WTO multilateral trading system. Their implementation has contributed to rebuilding trust and confidence in the system. Members are making frequent use of the DSU, which confirms not only the relevance of the rules, but also the willingness of the members to abide by the rules.

With the patterns of trade gradually becoming more complex and services increasingly becoming an integral part of trade in goods as well as a trade in their own right, there was a need for coverage of it in the new multilateral trading system. This thesis explains that trade in services was a relatively new phenomenon at that time, with the GATT having no experience of it. Much research and analysis had been conducted by international organizations such as the OECD to understand the way business transactions for services are conducted and how best to capture them in terms of rules. The rules of the GATT needed revision in order to cover trade in services. One of the challenges in addressing services is related to the features of services, which, contrary to goods, are intangible and governed by regulations, making them thus harder to capture in terms of trade rules. While goods are mostly governed by tariffs and non-tariff measures, trade in services required a new approach. As services are often covered by domestic regulations, trade rules gradually entered into domestic policy spheres. The question was how to liberalize and regulate trade services? It is also argued that services was one of the areas where the least progress was made in the negotiations, which in part explained efforts made by a select group of countries to advance liberalization in services outside the WTO framework. The outcome of the discussions risk being confined only to the parties of the agreement that may result from the discussions, thus undermining the MFN principle.

It has been shown that the complexity of the ways trade evolved and the closer interconnection between various policy spheres required a closer cooperation between the main international institutions, including the World Bank and the IMF, which resulted in the policy coherence mandate of the WTO. Policy coordination between the G-7 (at first) and the G-20 has been enhanced with time, becoming a main feature of international diplomacy. The WTO actively participates in the debates, which was not previously the case. This was not foreseen in the GATT, but had become a necessity in order to avoid conflicts in policy recommendations. The coherence function becomes of critical importance with markets for both goods and services becoming increasingly interconnected and intertwined. There was 
also a growing and more explicit recognition that trade has become a central point in economic policy-making and is now systematically referred to in the G-20 Declarations. This is particularly important in an environment where the role and contribution of trade to enhancing overall levels of welfare is, again, increasingly misunderstood, resulting in a growing resistance against globalization.

Another consequence of the increased complexity of trade was the need to enhance transparency. Here again the WTO differs significantly from the GATT: the transparency in trade policy-making was significantly improved and strengthened in the WTO. This began in the GATT period with the creation of the Trade Policy Review Mechanism (TPRM), a function which predates the WTO. In more recent years the main achievements in enhancing transparency were accomplished under the umbrella of the WTO. The TPRM has been further strengthened and was complemented by many other transparency mechanisms. This is clearly an important feature of the new multilateral trading system and a significant addition compared to the GATT, which did not provide for similar structures to ensure transparency.

It has been argued how an expanded WTO membership has radically transformed policy debates. The WTO has a much wider and active membership than the GATT, thanks to several factors and developments which have occurred in parallel. As a result of historical developments in the late 1980s, a range of newly independent states emerged, all committed to embracing market-based principles and moving away from their economic systems, which were largely based on central planning. Their objectives were largely pursued through WTO membership. This considerably strengthened the WTO, as the Article XII members who joined the WTO brought it ever closer to universality. Separately, it has been explained how the interest in trade as a policy instrument for economic development has been increasingly recognized by developing countries, who saw trade as an opportunity for a better and fuller integration into the multilateral trading system. This has triggered stronger interest than ever before in the trade rules and the desire for countries to actively participate in the negotiations.

The extended membership has had implications for the ways negotiations are conducted in the WTO as compared to the GATT. Decisions are taken by consensus, which evidently becomes more of a challenge with a larger membership. How can consensus be reached between 164 countries? It has been explained that coalitions emerged in ways that were unknown at the time of the GATT. This again is a distinctive feature of the WTO and one of the main differences with the GATT. In the GATT negotiating positions were mostly articulated and defended by individual countries, with relatively few coalitions. In the WTO negotiating positions are increasingly taken by coalitions of like-minded countries, developed and developing alike, in addition to which countries take national positions. This means that there is far more consultation between members in the preparatory phase of the negotiations, and subsequently more analysis, interaction, brainstorming, debates and reasoning before positions are taken. Much of the analysis is provided by think tanks, 
independent consultants and other international organizations, often providing for a solid basis on which the positions are based.

It was then argued that the way coalitions function, increasingly aligning positions of developing and developed countries alike on topics of common interest, meant that the classical divide between developed and developing countries was eroding, a point that was further developed in Chapter 5. Countries align themselves based on economic and policy interests rather than on standard and/or dogmatic approaches and views. This is yet again a significant development and marked difference between the GATT and the WTO. As many different positions and views need to be reconciled in order to reach consensus, coalitions can perform a useful function: much of the groundwork is undertaken at the level of the coalition, which to a large extent eases the discussions. In many instances the coalition even has a designated spokesperson actively promoting and defending the ideas and interests of the coalition. The coalitions are dynamic rather than static, and their composition changes frequently depending on the topics handled and the evolving nature of the negotiations.

One of the main challenges of the WTO is related to its function to conduct trade negotiations. This has turned out to be the WTO's Achilles heel - it has had a poor track record in this respect for its entire existence. The DDA is the only round of multilateral trade negotiations initiated in the life span of the WTO, has lasted over 15 years and produced one multilateral trade agreement, which entered into force in February 2017. The continuation of DDA negotiations has been put into question at various points in time. The future of the DDA is again uncertain in the wake of the last Ministerial Conference (MC-X, Nairobi), where it became clear that there are different views between the members on the direction of the multilateral trading system. One view is that what had been started in the DDA should be finished before considering other issues. Another is that sufficient efforts have been devoted to finish the DDA with little prospect of an outcome, which led some countries to believe that it is now high time to move on and broaden the agenda - to include newer trade issues that are more directly relevant for current trade patterns. The WTO is at a crossroads and needs to figure out which direction it wants to go in. The decisions that need to be taken in that regard are of critical importance to the future of the world trading system, and of world trade per se. The analysis in the second chapter leads to the conclusion that there is a need to reconsider the ways in which negotiations are conducted in the WTO. It is a key function, fundamental to the very existence of the WTO.

Chapter 2 also explains how the Marrakesh Agreement opened the door for the WTO to address new and emerging trade issues, taking the first Ministerial Conference (MC-I, Singapore) as the main starting point. It provides insights into the state of play of each of these initiatives, establishing that only a few initiatives have resulted in specific and significant outcomes, including the Trade Facilitation Agreement (TFA) and the Information Technology Agreement (ITA). Separately, negotiations resulted in the expanded Government Procurement Agreement (GPA), progress in the discussions on trade and environment, and in the transparency provisions governing regional trade integration. In 
other areas such as trade and labour standards, trade and investment, trade and competition policy, and electronic commerce, there has been hardly any progress until now. Discussions had to be abandoned shortly after the MC-IV (Cancún), when members decided to eliminate trade and investment and trade and competition policy from the agenda. The pressure to revisit the rules, operation and functioning of the system, and to reopen the debates on some of these issues, has been mounting steadily in more recent times. MC-X has again created new opportunities, but the question is how some of the issues can be brought back to life, given that the Ministerial Declaration clearly states that such a decision would have to be taken by consensus.

The analysis in his chapter suggests that the WTO as an institution and its rules need to have more flexibility to accommodate the challenges that have resulted from a rapidly evolving trading environment, its enlarged membership and the growing number of issues on the trade agenda. The growing interdependency between the economies is unprecedented with the result that policy decisions can no longer be taken autonomously by individual members without taking into account the policy and economic implications for other members. Globalization is both a driver and a result of the increased interdependency. The members have not fully come to grips with the implications of globalization for the rules. In addition, the membership of the WTO has drastically expanded, making the organization nearly universal with the evident difficulties that this implies for decision making, based on consensus. The members are increasingly diverse, have a different economic size and development, with each having their own priorities, objectives and vision of how the trading system should function and how it should evolve. While the trade opportunities have expanded, one of the main challenges for the WTO is to align the various positions, reach consensus in decisions, maintain coherence between the members and develop a common vision and understanding of the key objectives, including those of the new members.

\subsection{Globalization, changing patterns of trade and the rise of Asia}

Based on the economic literature, the third chapter provides insights into how globalization has evolved and affected trade and trade policies, requiring another fresh look at some of the rules in the WTO. It is argued that globalization is driven by but also drives the rapid expansion and evolution of patterns of trade and investment witnessed over the last two to three decades. More recently, the focus of attention is moving to GVCs, which provide a new dimension to globalization and in a way is an extension of it. It explains how production processes have become more geographically dispersed than ever before, resulting in new patterns of trade, specialization and competitive forces. Trade has become highly dynamic and the comparative advantage a country may have at one point in time is changing rapidly. Trade is increasingly influenced and determined by technological developments and changes, research and development, the increased availability of skilled labour due to training and education, improvements in infrastructures, better access to finance and capital, the lowering of transaction and shipping costs, increased market information, and a closer integration of markets. Goods and services are increasingly 
interconnected and less and less dissociable. The services component in goods is steadily growing. The way companies operate in international markets is changing again, as they are increasingly building regional hubs and production networks to cater for local markets, taking into account local specificities and thus differentiating between consumer demands. The role of FDI has been of critical importance in building, conquering and penetrating markets for goods and services alike, in ways never seen before. Trade and investment are no longer substitutes, as was characteristic for much of the period of the GATT, but are closely interconnected in order to be closer to the consumer, provide an after sales service and ensure a market presence. The lifespan of products is shortening due to rapid technological changes, requiring business to adapt itself rapidly and to be flexible.

It is argued that in view of the rapid evolution of trade and the trading system, one of the main challenges that countries face is how to remain connected to international markets through the GVCs. The question then is raised as to what policies can be conducive to facilitating a profitable place in global supply chains, adding value and moving away from simple operations. Why do some countries manage to put the right conditions in place while others do not? How can WTO rules contribute to these objectives? The answers point to the need for countries to diversify exports in order to create new opportunities, to upgrade products and to eliminate any obstacles to trade, including tariffs and non-tariff measures. In this sense the WTO initiatives liberalize markets and further reduce transaction costs, which are core elements to stimulate specialization.

It is also argued that new trade patterns have contributed to the emergence of different world economic powers - more specifically China, and to a lesser extent, India. Some countries like China, that were initially used as production sites with simple production and assembly operations and typically cheap labour costs, are gradually growing to become mature markets, developing R\&D capabilities and creating products for world markets. The same countries started outsourcing parts of their production processes to neighbouring countries, thus breaking up the production chain further and spreading the benefits from trade more widely. This is a clear articulation of the ways in which GVCs work and illustrates how countries can benefit from the process of deeper specialization and trade. As a result of these processes trade patterns have changed significantly since the creation of the WTO. The top positions of the nations which are the most important in international trade have changed drastically both in terms of exports and imports and for goods and services. The global landscape has thus fundamentally changed over a very short period of time. Developing countries are collectively taking a growing share in world trade, especially Asia, and in particular South East Asia. Africa, while growing fast, is still lagging behind.

It has been shown that, as a result of the dynamics of trade (the forces at play in combination with new economic activities which emerged in Asia over the past several decades), the economic balance is gradually moving from the West to the East. One of the main driving factors is growing consumer demand in the East, which is stagnating in the West. The middle-classes generate the demand and possess much of the economic wealth. 
The chapter looks at the following questions: Does this shift in balance matter? What are the potential policy implications? A related question is how the WTO could or should respond to these developments. It is argued that there is an increased responsibility for world leaders to assume their role in international trade, to continue working towards more openness of markets, a further reduction of transaction costs for goods and services, and to facilitate trade. The analysis confirms that the balance of powers and decision-making in the WTO has gradually shifted, with a broader range of countries deciding on the trade agenda, a task no longer predominantly performed by the main Western powers, including the United States, the European Union and a few other main traders. This was witnessed in the latest Ministerial Conferences of the WTO, including at MC-IX (Bali) and MC-X (Nairobi), with several Asian countries taking the lead in some of the debates and decisions.

The question is raised as to how the policy responses to the globalization of trade have evolved with time. An important evolution has emerged, it has been observed, as the initial reactions and policy responses to globalization were defensive. The general fear of the negative consequences of globalization for jobs and economic growth in the West triggered a trend towards protectionist measures in the 1980s and early 1990s, with the aim of defending national markets and economic interests. A range of defensive policies were applied, some of which were borderline consistent with trade rules or even being directly in breach of them. Other such reactions included targeting policies and subsidy programmes, with a view to giving domestic industries a competitive edge. Here again many of the policy approaches were questionable in terms of compatibility with the rules of the WTO.

The policy responses were largely counterproductive and costly, without even yielding the intended effects. This confirms the point that protectionism is not part of the solution, but part of the problem. It is therefore not surprising that in more recent years and specifically following the creation of the WTO, a clear shift in the mind set and policies of Western leaders can be observed. A more positive stance in support of globalization can be perceived, driven by a growing awareness that globalization provides new economic opportunities and should be embraced in light of the close interconnectedness of markets. These developments also explain the initiatives taken in the WTO towards more open trade policies, structural reforms, facilitating trade, reducing transaction costs and giving more room for market forces to play out. It has also been shown that the recent calls against the negative impact of globalization are again on the rise. The risk this implies yet again is to provide the wrong policy responses, for example to protect domestic economies with import restrictions and import substitution policies, which have mostly proven not to work and to be costly. This is to be resisted as such policies would increase the cost of trade and affect overall levels of welfare. The main question perhaps, and the biggest challenge for policymakers, is to ensure that the benefits emanating from globalization can be equally spread. There should be sufficient social safety networks to take care of those who suffer from the implications of globalization. Policymakers have the important task of better explaining how the benefits of globalization materialize, and how those who risk being affected by globalization can be protected. 
The question is then raised as to what policy space there is for governments in conducting national policies in a globalizing world, given that all policies are increasingly interdependent. Can countries still pursue their national objectives in a globalizing world economy? One related question is whether the 'nationality' of a product or an industry still matters. It has been evidenced that it has become increasingly hard to put a label of 'nationality' on products, given the ways in which business is organized. This also explains the oft heard view that what really matters is the contribution that the production makes to the national economy. The country of origin of the product and ownership of the business would thus matter less, as long as the economic activities generate investment, technology transfer, jobs, incomes and government revenue. The role of the government is to create an enabling environment, provide for a set of conditions that make it attractive for FDI, and to be host to economic activities. It is argued that for the very same reasons, governments continue to strengthen their efforts to coordinate their policies in order to ensure policy coherence. What matters is creating a level-playing field with all nations abiding by the same rules and principles. The role of the WTO is to support this process, both by liberalizing trade and by providing legally enforceable multilateral rules for trade in goods and services, as well as openness, transparency, stability, predictability and security in the multilateral trading system. In addition, the WTO continues to monitor developments in international trade with the aim of resisting the introduction of new forms of trade restrictive measures, and the creeping in of protectionism.

What can be drawn from this chapter is that the changes in the eco-system are not yet fully understood, often resulting in different and sometimes conflicting policy responses by members. There are those who believe that globalization offers new opportunities and there are those that view globalization as a threat. While the arguments made in the thesis strongly support the former views, as trade and globalization create opportunities, it is argued that policy makers have not paid sufficient attention to the counter arguments. The concerns of those that suffer from the negative implications of globalization have not been sufficiently addressed. Better explanations need to be provided to the public at large on the mechanisms that generate the welfare effects resulting from globalization. Equally, adjustment mechanisms and safety nets need to be built for those who are affected by the negative consequences of globalization and more specifically the losses of jobs that result from delocalization of enterprises and de-industrialization. In terms of policy approaches, it is also suggested to pay more attention in the negotiations to the contribution that GVCs can play as a means to generate value addition in the production process.

The analysis shows that the economic balance is shifting from the West to the East, mainly South East Asia and more specifically China. More power comes with higher responsibilities and the expectation that China takes a stronger leadership role in advancing the multilateral trade negotiations conducted under the umbrella of DDA, commensurate with its growing share in international trade. Interestingly, President $\mathrm{Xi}$ in the beginning of the year spoke out strongly in favour of globalization, open markets and further trade 
liberalization, whereas President Trump was calling for new measures at the border in order to protect the domestic market. There is a need for those who benefit the most from trade and the trading system to take collective leadership.

\subsection{Market access in the GATT and the WTO}

Having provided a clearer picture of how the global economic landscape has evolved and changed over the last two to three decades, Chapter 4 addresses some of the more technical aspects and analyses the efforts in enhancing market access in the GATT and in the WTO. It is argued that there is a marked difference between the GATT and the WTO, as the approaches have evolved considerably with time, which can largely be explained by a change in the trading environment. The world of trade was a relatively simple one at the time of the creation of the GATT and became much more complex in the 1980s and 1990s, thus requiring different approaches and negotiating techniques. The questions raised are what negotiating approaches were applied and how they compare? The first part of Chapter 4 analyses how the market access issues were addressed in the GATT, and the second part scrutinizes the same question from the WTO perspective.

The focus of negotiations in the GATT was initially on tariff reduction, followed by a reduction of non-tariff barriers. The negotiating techniques for reducing tariffs varied and evolved. They included a formula approach to ensure higher cuts on high tariffs and tariff peaks, and gradually moved towards a harmonization of tariffs. Over the lifespan of the GATT, tariffs on industrial goods were reduced to historically low levels on average, but wide disparities remained in tariff commitments between countries and sectors. It is noted that agriculture had mostly been exempt from tariff reductions. This sector had been mostly characterized by the application of non-tariff restrictions, including quotas and other, often less visible measures. Some countries had bound most of their duties for goods, whereas others had few bindings. Separately, many developing countries benefited from preferences granted through the Enabling Clause in order to provide them with better market access opportunities. The balance in rights and obligations thus remained quite distorted and called for continued efforts to increase the share of bindings and to reduce tariffs. This explains why tariff negotiations were again a central part of the DDA negotiations, with particular emphasis on high tariffs and tariff escalation. It is argued that the efforts to reduce tariffs further have largely stalled as a result of the methodologies applied to achieving the initial goals, which have become far too complex and challenging. The efforts by the membership to take all of the different positions, circumstances and conditions into account, loading the draft agreement with exceptions, are seriously undermining the transparency and goals of the draft agreement.

Two examples were provided to explain the importance of tariffs and non-tariff measures in sectors that are of considerable economic importance to developing countries, namely textiles and clothing and leather and leather products. The elimination of all quantitative restrictions in textiles and clothing in the GATT was meant to allow market mechanisms to function, reducing distortions in international trade and enhancing 
developing countries' market access opportunities. It is argued that economically and politically it was a very significant achievement to eliminate all quantitative restrictions for trade in textiles and clothing products over a transition period of 10 years. It is also argued that the efforts to reduce tariff escalation for leather and leather products and eliminating tariff peaks should provide new incentives to producers of the lower end products to upgrade their production process. Various suggestions were made on how this could be achieved, including through regional and sub-regional collaborative efforts and a better connection to GVCs.

The second part of Chapter 4 then analyses how market access efforts are pursued in the WTO and more specifically through the DDA. The negotiations are conducted through two separate tracks, focusing on agriculture and on Non-Agricultural Market Access (NAMA). The main difference between the two sectors is that efforts had never before been made to open the agricultural sector up to competition. A three track approach was established: reducing tariffs in order to enhance market access, addressing domestic support issues and eliminating export subsidies. With regard to NAMA, negotiators were mostly guided by the approaches adopted in previous rounds of tariff negotiations conducted under the GATT. The negotiations for agriculture and NAMA were closely interlinked and pursued in parallel. However, neither of the two tracks was successfully concluded and no tariff reductions could be agreed. Partial outcomes were achieved in agriculture, including on national food security issues and on the elimination of export support (subsidies). It was argued that both are economically vital and the outcomes are significant, but the equally important aspects of tariff reductions and domestic support issues remain unresolved.

Regarding the reasons for the difficulties encountered in negotiating outcomes in both areas, it is argued that the agriculture negotiations have become far too complex, with different formulae proposed for groups of countries depending on their levels of economic development. The different formulae reflected the underlying economic realities in each of the member countries and the challenges they face in meeting the requirements. In addition the draft texts were riddled with exceptions for various situations, thus undermining transparency and clarity as to the economic value of the negotiated outcomes for the members. Some members also claim that as over 15 years have passed since the launch of the DDA negotiations, the figures and data on which the proposals were based are outdated and thus inadequate as a basis for negotiations. In similar ways, there was little agreement in the NAMA field, with differences in views on the formulae and more specifically on coefficients for reductions to be applied. Despite the long history for tariff negotiations, no suitable approach could be agreed by the members, which is a good reason to reconsider and review the approaches in order to ensure workable outcomes.

It was then argued that the lack of progress in these two areas has not prevented members of the WTO from making progress in liberalizing trade in one area that is significant for the world economy: information technology goods, which resulted in the ITA. The initiative for the ITA goes back 20 years and produced significant results. The 
agreement was negotiated by the main countries who were already the producers of technology goods in 1996. A main extension to the ITA was concluded in 2015 and put into effect in 2016. Equally interesting is that the outcome has multilateral application, by virtue of the MFN principle, which fits perfectly into the spirit in which negotiations in the GATT were conducted, and are now in the WTO. While negotiations were undertaken between subsets of countries and include bilateral negotiations, the multilateral application of the outcome shows how a critical mass approach can effectively be applied in multilateral trade negotiations.

A second example shows how a group of countries gathered to launch negotiations in services trade to establishing a Trade in Services Agreement (TISA). These negotiations were conducted outside the framework of the WTO and in spite of the fact that the GATS explicitly foresee that the members pursue negotiations as part of the 'built-in' agenda. It would seem that this initiative is mostly driven by the lack of progress in discussions within the WTO framework. The question is raised if and whether the eventual outcome may have multilateral application. There is no indication at present that the benefits will be extended by virtue of the MFN principle, given that domestic regulations remain a sensitive area for governments.

The take away from this chapter is that, while members got stuck in the discussions on some of the more technical aspects in the negotiations and more specifically with regard to goods and agriculture, and they cannot agree on a tariff formula and domestic support, this has not prevented members advancing the trade liberalization agenda in specific areas. While underscoring the primacy of the multilateral trading system, it is argued that members should pursue efforts to further the negotiations in different formats, the results of which should be shared with and extended to the entire membership. Given the enlarged membership, different levels of development and their different objectives and levels of ambition, one can no longer expect that the negotiations always include all members, as not all members share the same interests. The ITA shows that the benefits of the outcome of the negotiations conducted between a critical mass of members can accrue to the entire membership by virtue of the MFN principle. More flexibility should be applied and room created for similar initiatives with a potentially significant economic impact. In doing so, more attention needs to be paid to the contribution that GVCs can make in the process of value addition generated through sectorial trade liberalization.

\subsection{The fuller integration of developing countries in the multilateral trading system}

Chapter 5 provides explanations of how the position of developing countries in the multilateral trading system has evolved with the creation of the WTO. It addresses the following questions: What development strategies were pursued by developing countries and what was the role of trade and trade policy in support of these strategies? It then looks at the contribution of the various trade capacity building efforts that have been pursued in the WTO with a view to assisting developing countries to integrate more fully into the 
multilateral trading system. How was the assistance provided and did it lead to any tangible outcomes?

It is argued that a major shift in mind-set had been witnessed in developing countries since the late 1980s, with a fuller recognition of the fact that trade can be used as a very powerful tool for generating growth, welfare, income and employment. As a result, developing countries have increasingly moved away from counterproductive inward-looking policies, generating inefficiencies in the allocation of resources and thus making room for more open and liberal trade policies, which are more conducive to attracting FDI, a transfer of technology and generating economic growth. This has often been accompanied by major domestic structural adjustments aligning policies with international rules and disciplines and with a view to facilitating trade. The WTO has been used as one of the main platforms for conducting reforms and introducing more liberal policies to enhance economic growth. These efforts paid off for many, and expectations materialized with several developing countries experiencing high growth rates and taking a large share in world trade. Even Africa, a continent mostly associated with poverty given the large number of LDCs it hosts, has experienced higher growth rates compared to other continents. The fastest economic growth is taking place in Asia.

In parallel to these developments, there has been a growing membership of developing countries in the WTO as well as a more active engagement than ever before in the discussions and negotiations. The nature of the discussions between the WTO members has changed compared to the discussions in the GATT. It could be said that the GATT was largely characterized by a polarization between the members, particularly between the North and the South, or developed and developing countries. The underlying notion was that their economic and policy interests differed and perhaps even conflicted. This led in many cases to special rules for developing countries, including the granting of preferences, which often significantly deviated from the multilateral trade rules. It is argued and demonstrated that there is less polarization in the WTO. Developed and developing countries increasingly align their positions based on common policy objectives and economic interests. The discussions are centred on the issues and the economic stakes that need to be defended, and can very much differ per topic and per country. The approaches taken to recognize the differences in needs and requirements of developing countries in assuming new obligations has significantly evolved. In addition, it is argued that positions taken by developing countries are increasingly based on scientific findings, on research and analysis, thus providing a solid basis for policies to be pursued and serving the best interests of the country. As a result, developing countries are now better associated with the decisionmaking process, which is often viewed as a significant change compared to the GATT era.

Quantitative and qualitative evidence was presented confirming the more active engagement by developing countries in the WTO debates and negotiations. On the quantitative side, it has been shown how the shares of developing countries in world trade have steadily grown and how new trade patterns have evolved. Spectacular growth can be 
witnessed in Asia, but other continents are also growing rapidly, including Africa, despite at an overall slower pace. In addition, the South-South trade has grown steadily, with more goods and services being exchanged between developing countries, thus diminishing their dependency on the traditional markets in the North. From a qualitative perspective, different indicators suggest that developing countries are gradually and steadily integrating more fully into the multilateral trading system. Developing countries have strengthened their physical presence in Geneva by increasing their local representations at the WTO and augmenting staff numbers. They have proven to be in an increasingly better position to articulate their positions and operate either individually or by creating alliances where those best serve their interests. The alliances are often based on economic interests, namely on substance, concepts and approaches. As argued earlier, they vary per topic and include developed and developing countries alike. It is explained how the WTO Chairs Programme, which specifically aims at building and strengthening academic capacities at universities, has helped some developing countries, including LDCs, to scientifically underpin policy decisions and positions. Evidence shows that efforts pursued through this programme are paying off, with a steady improvement in the academic quality of the research undertaken and a better linking of the research and policy worlds.

It has been explained how the combined trade capacity building efforts pursued by the WTO and other agencies, much of which is part of the Aid for Trade initiative, have played a significant role in allowing beneficiary countries to benefit from trade. The WTO disposes of a broad arsenal of tools and approaches that facilitate the incremental generation of human and institutional knowledge. Those tools go far beyond theoretical approaches and largely consist of hands-on training, exposing policy officials to real life situations by making them directly part of the negotiations themselves. The training programmes are very much conducted in partnerships with other international organizations, regional bodies and think tanks, thus adding value and quality to the programmes themselves.

It is argued that the approaches adopted in the WTO are significantly different from the GATT. Following the creation of the WTO, there had only been some rudimentary thinking of trade capacity building, of providing beneficiaries with the required tools and support to integrate more fully into the multilateral trading system. The GATT had a fairly small budget line, as part of the regular budget, providing for the funding of Geneva-based trade policy courses. This was drastically changed in the WTO, especially with the launching of the DDA. In addition to the regular budget for Geneva-based courses, a sizeable budget for field-based trade capacity building activities was secured through extra-budgetary funding. The WTO moved to a more structured way of giving support to developing countries. It is also argued that the considerable under-utilization of the funds, resulting in lower contributions by the donors, is an issue of concern for the longer term sustainability of the support programmes, and needs to be addressed.

A case study was presented with regard to trade capacity building in the newly established TFA. Members adopted an innovative approach in that regard. The incontestable 
economic benefits that the TFA is likely to generate for developing countries are empirically evidenced in the literature. Moreover, the TFA includes legally binding provisions for human, institutional and infrastructural support to developing countries. In other words, rather than having best endeavour provisions, the TFA includes firm commitments between donors and beneficiaries in terms of support to be provided. The TFA entered into force in February 2017 and members are now initiating the necessary preparations for the assistance to be provided. The question is raised whether this new approach created a precedent and could serve as a model for trade capacity building efforts in other areas. The TFA confirms a desire to more fundamentally include trade capacity building provisions in binding manners. This stands in strong contrast to the GATT, where technical assistance was provided on a more voluntary (best endeavour) and ad hoc basis. Given the economic and trade potential of the TFA, such capacity building efforts will be to the advantage of both beneficiaries and donor countries. Donors will find new markets of supply for their goods and services and lower transaction costs, while recipient countries should gain opportunities to link to GVCs and thus to unlock new trade opportunities that will eventually add value in the production process and generate higher revenues.

The key point made in this chapter is that one of the changes in the WTO is the growing role of developing countries in international trade. Their relative shares in international trade have rapidly grown and the patterns of trade are changing with an increased portion consisting of south-south trade. Trade is increasingly recognized and embraced by developing countries as an engine of growth, which explains their efforts to achieve a fuller integration in the multilateral trading system. It was argued that the capacities of developing countries to understand and apply the rules have been strengthened through training and technical assistance. They are better equipped than ever before to actively engage in the debates, take positions on increasingly complex issues and become more influential in the negotiations. A key challenge that remains for many developing countries is the question what policies to apply for a better participation in the GVCs and to generate higher value added in the production process. Finally, the binding obligations that are contained in the TFA, which includes technical assistance and other forms of implementation support to be provided to developing and least-developed countries is a novelty that should be replicated in other agreements.

\subsection{The future of the WTO multilateral trading system}

Based on the analysis conducted in the PHD thesis, chapter 6 addresses the main challenges that the WTO members are currently facing in the multilateral trading system, and includes specific suggestions on the ways forward. It calls for a fresh look at the negotiating approaches in the DDA, as mandated by Minister at the last Ministerial Conference, given that the efforts undertaken by members in negotiating agreements in agriculture and NAMA have become too complex, lack transparency and are unlikely to produce the desired results. Alternative approaches include the offer-request procedure, as well as the conduct of negotiations in specific sectors and/or areas, where there is a common interest and desire by members to liberalize. These areas should be economically meaningful 
and offer real market access perspectives. The approach could be horizontal as well as vertical, so as to cover various stages of the GVCs. It is also suggested that while the multilateral approach to trade negotiations remains the best option, more flexibility should be provided for members to conclude negotiations in different formats, based on the concept of variable geometry, and through plurilateral agreements. Specific suggestions are made with regard to broadening the agenda in order to address the link between trade and investment and trade and competition policy. The Secretariat should be provided with a broader mandate to undertake the necessary research and analysis prior to engaging in a negotiating process on these issues and in order to better appreciate the elements and factors that should be considered in the discussions. A further suggestion is to conduct further research and deepen the understanding on the relationship between regional trade liberalization and multilateralism, as both approaches can be mutually reinforcing, thus advancing trade liberalization more broadly.

One of the main conclusions is that developments in international trade since the creation of the WTO and more specifically the ways in which globalization has evolved require a further review of the rules of the multilateral trading system. There is a growing sense among WTO members that the rules do not pay enough attention to the 'newer' trade issues relevant for the changing patterns in international trade and continue to give undue priority to the traditional trade issues. This became particularly clear during the discussions at MC-X (Nairobi) in December 2015. Trade is more integrated and interconnected with other policy spheres, including investment and competition policy, but that development is not duly recognized in the debate. In addition, efforts to liberalize in the traditional areas have not yielded expected results. While 'older' trade policy issues, including tariffs, continue to be of critical importance in international trade, especially to developing countries, they should not stand in the way of progress, and of addressing issues that are typical and/or characteristic for 21 st century trade. The debates need to also better reflect the growing antiglobalization sentiments and which risk posing a major challenge to the WTO multilateral trading system.

The take away from this chapter is that there is considerable room for progress in the negotiations, provided that members are willing to be flexible, make compromises and respect the different views and levels of ambition of other members. It is unrealistic to expect the DDA to be concluded as it was designed, given the lack of support by several key players. The world has rapidly changed and so have trade and the negotiating environment.

\subsection{Final conclusions and recommendations}

Globalization has fundamentally changed the ways trade is conducted between the world's trading nations and is likely to continue doing so. Globalization is not new per se, but the processes and forces of globalization are very dynamic and evolving rapidly due to technological developments, innovation and a closer interlinkage and dependency between economies. Globalization is there to stay. The main question is how to cope with globalization and what policy responses can be provided? 
The analysis has shown that globalization creates new opportunities for growth and economic development and contributes to enhancing overall levels of global economic welfare. While some countries have been able to adjust to the forces of globalization, benefited from it and grown into mature and effective competitors in the world markets, others find it more difficult to seize the opportunities that globalization can offer and integrate into the world economy. Hence, while there is a general agreement between academics and many policy makers that globalization creates opportunities the analysis has also shown that one of the main challenges for policy makers consists of ensuring that globalization creates inclusive growth to the benefit of all. The recognition of this need is perhaps more important today than ever before, given the growing anti-globalization backlash.

Indeed, as the world economy has stagnated since the economic crisis in 2008, the perception is increasingly gaining ground that globalization is responsible for job losses in the West, as well as for a re-location of economic activities to other parts in the world and much to the detriment of economic growth in many developed countries. The antiglobalization sentiments have grown stronger in recent times and leading to calls for the wrong policy prescriptions, including protectionist border measures. Such policies have proven to be costly in the past and hence need to be resisted. The WTO can make a critical contribution to resist protectionism intensifying its efforts in pursuit of trade liberalization and a further strengthening and updating of the rules of the multilateral trading system per se. The rules need to better reflect the ways in which trade is evolving, with a view of levelling the playing field, creating new economic opportunities for all members, thus ensuring a path towards inclusive growth. Policy makers should also take into account the negative effects that globalization can have for some and create the necessary safety nets.

With regard to the DDA negotiations, the analysis in the thesis shows that the members have difficulties coming to terms with the changes in the eco-system and understanding the implications of globalization for the multilateral trading system. This is directly affecting the DDA negotiations and hampering an outcome. There is a fundamental lack of agreement between the members on the approaches to be adopted in advancing the multilateral trade negotiations. The common vision that was developed at the start of the DDA is no longer shared and there is no agreement on many of the technical aspects in the negotiations. The DDA is in a deadlock with no common understanding between the members on the ways forward. Advancing the trade agenda with a view to liberalizing trade, eliminating trade distortions and improving the rules is important for the credibility of the multilateral trading system as well as for enhancing the overall levels of welfare for consumers and producers alike. The introduction of protectionist measures needs to be avoided and resisted as they increase the costs of goods and services for consumers and producers and undermines growth and development. 
Given the growing interdependency between countries and their economies, all policy decisions require more coherence between the members than ever before. In order to move the trade agenda forward, members need to double their efforts re-establishing trust and developing a common vision for the future. The thesis offers specific suggestions on how to achieve further trade liberalization and which are listed below. The forthcoming WTO Ministerial Conference (MC-XI, Buenos Aires) provides for another opportunity to not only take stock of past achievements, but draw the road map for the future.

The recommendations for the policy makers that emerge from the analysis are to:

- Implement the mandate provided by Ministers at MC-X (Nairobi) to review the negotiating approaches in order to bring the main elements of the DDA work programme to a conclusion.

- Simplify the negotiation approaches: instead of having complex formulas for tariff reductions, riddled with exceptions which undermine the transparency of what has been achieved, apply the offer-request procedure in conjunction with liberalization at the sectorial level.

- Pursue liberalization of trade not only horizontally, i.e. across the board, but also 'vertically', i.e. in specific sectors of economic interest to members and where the greatest benefits can be obtained in terms of value addition, thus taking into account the increased relevance of GVCs and globalization.

- Follow an incremental and step-by-step approach and adopt agreements in areas when and where they are ready (early harvest concept).

- Abandon the single undertaking approach, which in any case has lost most of its significance. Not only were specific results harvested in various areas and in deviation of the single undertaking approach, no efforts were undertaken by members to exchange trade-offs between sectors or areas under negotiation. Moreover, progress in some areas has been held off, given the lack of progress made in the negotiations in other areas.

- Address the 'behind the border' policies, including domestic regulations in services trade, given their increased significance in international trade following the reduction of trade barriers at the border.

- Pursue negotiations at the multilateral level, which is the preferred option, but also plurilaterally, provided there is a critical mass of WTO members willing to sign off on the agreements. The plurilateral and critical mass approaches have proven to work and yield economically meaningful results, as was the case for the TFA and ITA.

- Mandate the Secretariat to undertake research and analysis with regard to the relation between trade and investment and trade and competition policy, two areas that are increasingly intertwined with trade, and are significant for the new ways in which trade is performed.

- Intensify work with regard to a further strengthening and deepening of policy coherence between the WTO members, as the closer interdependency between nations has further reduced the member's space for independent domestic and 
autonomous policy making. Trade policy measures taken by one member are most likely to affect the policies of another member.

- Strengthen further the Secretariat's efforts to build sustainable trade capacity in developing countries; make resources available in predictable ways; ensure a continued relevance of the programmes geared towards the needs of the beneficiaries in order to assist them integrating more fully in the multilateral trading system.

- Apply the model approach of the TFA with regard to trade capacity building, which contains binding obligations on the sides of developed and developing countries, thus moving further away from the best endeavours efforts towards binding commitments.

- Ensure that regional integration and multilateral trade liberalization are mutually reenforcing instead of offering alternative solutions, thus strengthening the multilateral trading system of the WTO rather than undermining it.

- Enhance the Secretariat's efforts to explain the benefits that are derived from trade liberalization and to fend off the growing resistance against globalization. The WTO has much to show for in terms of economically meaningful achievements, whereas public attention is mostly on what is increasingly perceived to be its Achilles heel (the lack of progress in multilateral trade negotiations).

- Ensure that globalization is inclusive with tangible benefits for all and build social safety nets for those that risk being left out.

- Shed more light on achievements and accomplishments, which are well documented and would present a far more positive image and picture of the WTO than the present public (mis-)perception.

- Resist protectionist pressures.

- Build a roadmap for the future.

To conclude in reference to a Chinese proverb, 'the journey is the reward'. The analysis conducted in this thesis and the suggestions for the future direction of the WTO may hopefully contribute to the journey, leading to a strengthened multilateral trading system of the WTO, which is capable of addressing both present and future challenges in international trade, enhanced levels of economic welfare, leading to inclusive growth for all. 


\section{BIBLIOGRAPHY}

Abbott, R., 'GATT and the Trade Policy Review Mechanism', 27 Journal of World Trade (1993), p. 117-119.

Abu-Ghazaleh, T., 'WTO at Cross Roads: A Report on the Imperative of a WTO Reform Agenda', informal discussion paper, WTO, January 2013.

Acharya, R. (ed.), Regional Trade Agreements and the Multilateral Trading System (Cambridge University Press, 2016).

Action Plan on the Belt and Road Initiative, issued by the National Development and Reform Commission, Ministry of Foreign Affairs, and Ministry of Commerce of the People's Republic of China, March 28, 2015. Information found on English.gov.cn, the State Council, The People's Republic of China, 1 July 2016.

Adamantopoulos, K. and Price D.M., 'Towards a Multilateral Investment Regime: Results in the Uruguay Round and Prospects in the OECD', International Banking and Financial Law Supplement: Trade and Investment (March, 1995).

Africa Economic Outlook 2014; the African Development Bank (AFDB), the Organization for Economic Cooperation and Development (OECD) and the United Nations Development Programme (UNDP).

Anderson R. and Muller, A. 'Competition Law/Policy and the Multilateral Trading System: A Possible Agenda for the Future', E15 Expert Group on Competition Policy and the Trade System, ICTSD, World Economic Forum, Geneva, September 2015.

Anderson, K. and Martin, W. (eds.), Agriculture Trade Reform and the Doha Development Agenda, (Palgrave-Macmillian, 2006).

Anderson, K. and Martin, W., 'Agriculture Reform and the Doha Development Agenda' (World Bank, 2005).

Anderson, K., Martin, W. and Valenzuela, E., 'The Relative Importance of Global Agricultural Subsidies and Market Access', 5 World Trade Review (2006).

Anderson, K. and Strutt, A., 'Asia's Changing Role in World Trade: Prospects for SouthSouth Growth to 2030', ADB Working Paper 264, Asian Development Bank, Manilla, 2011.

Anderson, K. and Valenzuela, E., 'The WTO Cotton Initiative: a Tale of Two issues', 30 The World Economy (2007), p. 1281-1304.

Anderson, R. and Arrowsmith, S. (eds.), The WTO Regime on Government Procurement: Challenge and Reform (Cambridge University Press, 2011).

Anderson, R. and Evenett, S. 'Incorporating Competition Elements into Regional Trade Agreements, Characterization and Empirical Analysis', Working Paper (2006), available at http:/www.evenett.com/research/workingpapers/ComprincInRTAs.pdf.

Anderson, R. and Muller, A., 'Competition Policy and the Multilateral Trading System: Three Propositions, an Observation and some Questions for Reflection', Draft Paper, 6 December 2013. 
Anderson, R. and Muller, A., 'Competition Policy and Poverty Reduction: A Holistic Approach', Staff Working Paper, Economic Research and Statistics Division (ERSD 2913-02), February 2013.

Arveladze, G. and Smeets, M., 'Georgia's Post-Accession Structural Reform Challenges', WTO Working Paper Series, ERSD-2017-10, June 2017.

Aslund, A., 'The World needs a Multilateral Investment Agreement', Peterson Institute for International Economics, Policy Brief (January, 2013).

Auboin, M., 'Fullfilling the Marrakesh Mandate on Coherence: Ten Years of Cooperation Between the WTO, IMF and World Bank', WTO Discussion Paper No. 13 (2007).

Audet, D., 'Structural Adjustment in Textiles and Clothing in the Post-ATC Trading Environment', OECD Trade Policy Working Paper No.4, OECD (2004).

Bacchetta, M. and Bora, B., 'Industrial Tariff Liberalization and the Doha Development Agenda', WTO (2003)

Bacchetta, M. and Jansen, M. (eds.), Making Globalization Socially Sustainable (ILO and WTO, Geneva, 2011).

Bacchetta, M. and Janssen, M., 'Adjusting to Trade Liberalization: The Role of Policy,

Baldwin, R., The Great Convergence, Information Technology and the New Globalization (Harvard University Press, 2016).

Baldwin, R., 'Restoring WTO Centrality to a Multi-Tiered Global Trading System', in 'The High and Low Politics of Trade: Can the World Trade Organization's Centrality Be Restored in a New Multi-Tiered Global Trading System?', World Economic Forum, Geneva, August 2015.

Baldwin, R. 'Trade and Industrialization After Globalisation's 2nd Unbundling: How Building and Joining a Supply Chain Are Different and Why It Matters?' Working paper 17716, National Bureau of Economic Research (2011).

Baldwin, R., ' $21^{\text {st }}$ Century Regionalism: Filling the Gap Between $21^{\text {st }}$ Century Trade and $20^{\text {th }}$ Century Trade Rules', CEPR Policy Insight 56, Centre for Economic Research (2011).

Baldwin, R. and Freund, C, 'Preferential Trade Agreements and Multilateral Trade Liberalization', in Chauffour, J.P. and Maur, J.C., Preferential Trade Agreement Policies for Development: A Handbook (World Bank, June 2011).Barton, J.H., Goldstein, J.L., Josling T.E., Steinberg R. H. (eds.), The Evolution of the Trade Regime; politics, law, and economics of the GATT and the WTO (Princeton University Press, 2006).

Berry, S., Levinsohn, J. and Pakes, A., 'Voluntary Export Restraints on Automobiles: Evaluating a Trade Policy’, 89 American Economic Review (1999).

Besson, S. and Aspremont, J. (eds.), Oxford Handbook on the Sources of International Law (Oxford University Press, 2016).

Beverelli, C., Neumuller, S. and Teh, R. 'Export Diversification Effects of the WTO Trade Facilitation Agreement', Working Paper No. 137, FIW Vienna (January, 2015).

Bhagwati, J., Trace Liberalization and "Fair Trade" Demands: Addressing the Environmental and Labour Standards Issues', 18 World Economy (1995), p. 745-759.

Bhagwati, J., Protectionism (MIT Press, 1988). 
Bhala R., 'National Security and International Trade Law: What the GATT Says, and What the United States Does', 19 Journal of International Economic Law (1998).

Blackhurst, R., 'The WTO and the Global Economy', 20 The World (1997).

Blumberg, H. and French, C. (eds.), Lessons from the Gulf War: Social Science Findings (University Press of America, Lanham, MD, 1994).

Bohne, E., The World Trade Organization (International Institute of Administrative Sciences, 2010).

Boulanger, P. and Philippidis, G., 'The EU Battle: Assessing the Trade and Welfare Impacts of CAP Budgetary Reform', 51 Food Policy (2015).

Bown, C.P. and Crowley, M.A., 'Emerging Economies, Trade Policy, and Macroeconomic Shocks' 111 Journal of Development Economics (2014).

Brauner, K., WTO news item, 9 December 2015.

Brewer T.L. and Young, S. "The Multilateral Agenda for Foreign Direct Investment, Problems, Principles and Priorities for Negotiations at the OECD and WTO', 18 World Competition (1995).

Brittan, L., 'Investment Liberalization: The Next Great Boost to the World Economy', 4 Transnational Corporations (1995).

Broadman, H.G., 'From Disintegration to Reintegration, Eastern Europe and the Former Soviet Union in International Trade', World Bank (2005).

Brown, D., International Trade and Core Labour Standards: A Survey of the Recent Literature', OECD Labour Market and Social Policy Occasional Papers (No. 43, 2000).

Buelens, C., 'Trade Adjustments Following the Removal of Textiles and Clothing Quotas', CEPS Working Document No.222 (May, 2005).

Buelens, F. (ed.), Globalization and the Nation State (Edward Elgar, 1990).

Cantwell, J., Technological Innovation and Multinational Corporations (Basil Blackwell, Oxford, 1989).

Capitalism Have Been Re-written to Justify Neo-Liberal Capitalism (Cambridge University Press, 2002).

Carter, E. and Farha, R., 'Overview and Operation of US Financial Sanctions, including the Example of Iran', 44 Georgetown Journal of International Law (2013).

Cattaneo, O., Gereffi, G. and Staritz, C. (eds.), Global Value Chains in a Postcrisis World: A Development Perspective (World Bank, Washington DC, 2010).

Chaisse, J. and Chakraborty, D., 'Implementing WTO Rules Through Negotiations and Sanction: The Role of Trade Policy Review Mechanism and Dispute Settlement System', 28 University of Pennsylvania Journal of International Economic Law (2007), p. 153-187.

Chang, H.J., Kicking Away the Ladder: How the Economic and Intellectual Histories of

Capitalism Have Been Re-written to Justify Neo-Liberal Capitalism (Cambridge University Press, 2002).

Chang, H.J, Soludo, C. and Ogbu, O. (eds.), The Politics of Trade and Industrial Policy in Africa, Forced Consensus, (International Development Research Centre, Trenton, NJ, 2004).

Chauffour, J.P. and Maur, J.C., Preferential Trade Agreement Policies for Development: A Handbook (World Bank, June 2011). 
Cline, W.R. The Future of World Trade in Textiles and Apparel, (2 ${ }^{\text {nd }}$ edition, Institute for International Economics, 1990).

Commonwealth Trade Policy Discussion Papers, 'Trade- Led Regional Value Chains in SubSaharan Africa (SSA): Case Study on the Leather Sector' (2015).

Conzelmann, T., 'Beyond the Carrot and the Stick: How Effective Are State Reporting Procedures in the WTO and OECD?', paper presented at the International Studies Association meeting, Chicago, IL, 28 February-4 March 2007.

Conzelmann, T., 'Beyond the Carrot and the Stick: (How) Do State Reporting Procedures Matter?', paper for presentation at ECPR Uppsala Joint Sessions, 13-18 April 2004.

Cottier, T. and Elsig, M. (eds.), 'Governing the World Trade Organization, past, present and beyond Doha', (Cambridge Press, 2011)

Cottier, T., 'Preparing for Structural Reform in the WTO', 10 Journal of International Economic Law (2007), p. 497-508.

Croome, J. Reshaping the World Trading System (WTO, 1995).

Dadush, U., Osakwe, C., 'WTO accessions and Multilateralism: Case Studies and Lessons Learned' (WTO, Geneva, October 2015).

Daudin G., Riffart, C. and Schweisguth, D., 'Who Produces for Whom in the World Economy?', Document de travail de l?OFCE No. 2009-18, Observatoire Français des Conjonctures Economiques (OFCE), Paris (2009).

Daudin, G., Riffart, C. and Schweisguth, D., 'le commerce Extérieur en Valeur Ajouté', 98 revue de l'OFCE: Observatoire et diagnostiques économiques (2006).

de la Torre, A. and Lederman, D., 'Latin America and the Rise of the South at a Crossroads', World Bank Group, presentation made at WTO workshop on '20 Years of Trade Growth - an in Depth Look at Latin America and the Rising South in the Board context of Global Trade Growth', WTO, 21 June 2016, Power Point Presentation.

de la Torre, A., Didier, T., Ize, A., Lederman, D. and Schmuckler, S., Latin America and the Rising South, Changing World, Changing Priorities (World Bank Group, Washington DC, 2015).

Deardorff, A., Readings, the New World Trading System (OECD, Paris, 1994).

Dedrick, J., 'Who Profits from Innovation in Global Value Chains? iPhones and Windmills', School of Information Studies, Syracuse University (2012) https//www.usitc.gov/research 2012.

Dedrick, J., Kraemer, K., Linden, G., 'Who Profits from Innovation in Global Value Chains? A Study of the iPod and Notebook PCs', Alfred P. Sloan Foundation, Annual Conference, May 1-2, 2008, Boston, MA.

Dehejia, V. and Samy, Y., 'Trade and Labour Standards: A Review of the Theory and New Empirical Evidence', International Policy Center Working Paper (No. 49, 2007).

Dizaji, S. F. and van Bergeijk, P., 'Potential Early Phase Success and Ultimate Failure of Economic Sanctions: A VAR Approach with an Application to Iran', 50 Journal of Peace Research (2013).

Dunkel, A., Trade Policies for a Better Future: The Leutwiler Report, the GATT, and the Uruguay Round (Kluwer Academic Publishers, 1987). 
Dunning, J.H., 'The Competitive Advantage of Countries and the Activities of Transnational Corporations', 1 Transnational Corporations (1992).

EC Commission, 'International Economic Interdependence', discussion paper, (May, 1993). Brussels.

Eckhardt, J. and Poletti, A., 'The Politics of Global Value Chains: Import-dependent Firms and the Signing of EU-Asia Trade Agreement', Journal of European Public Policy, (August, 2015).

Economic Cooperation and Development (OECD) and the United Nations Development Ehlermann, C.-D., 'Six Years on the Bench of the World Trade Court: Some personal Experiences as Member of the Appellate Body of the World Trade Organization', 36 Journal of World Trade(2002).

Elms, D.K. and Low, P. (eds.), Global Value Chains in a Changing World(WTO, 2013).

Erjavec, K., Erjavec, E., 'Greening the CAP - Just a Fashionable Justification? A Discourse Analysis of the 2014-2020 CAP Reforms', 51 Food Policy (2015).

Escaith, H., 'Measuring Trade in Goods and Services', 1 International Trade Forum (2013).

Escaith, H., 'Measuring Trade in Value Added in the New Industrial Economy: Statistical Implications', MPRA Paper No. 14454, Munich Personal RePEc Archive (2008).

Escaith, H. and Gaudin, H., 'Clustering Value-Added Trade Profiles: Structural and Policy Dimensions', WTO Working Paper (2014).

Estevadeordal, A., Suominen, K. and Teh, R., Regional Rules in the Global Trading System, (Cambridge University Press, 2009).

Evenett, E. J. and Hoekman B. M., Economic Development and Multilateral Trade Cooperation (World Bank, Washington, DC, 2005).

Evenett, S. and Jara, A. (eds.) Building on Bali, A Work Programme for the WTO (VoxEU.org eBook, Centre for Economic Policy Research (CEPR), London, 2013).

Financial Times, 'The Tide of Globalization is Turning', 7 September 2016.

Finger, J. M. and Olechovski, A., 'The Multilateral Trade Negotiations', World Bank (1987).

Finger, J.M. and Olechovski, A. (eds.), The Uruguay Round, A Handbook on the Multilateral Trade Negotiations (World Bank, 1987).

Food and Agriculture Organization, United Nations, World Statistical Compendium for Raw Hides and Skins, Leather and Leather Footwear 1993-2012' (2013).

Francois, F., Martin, W., 'Formula Approaches for Market Access Negotiations' 26 The World Economy (2003).

Francois, J., 'Trade Policy Transparency and Investor Confidence: Some Implications for an Effective Trade Policy Review Mechanism', 9 Review of International Economics (2001), p. 303-316.

Francois, J., 'Maximizing the Benefits of the Trade Policy Review Mechanism for Developing Countries', Tinbergen Institute and CEPR (February, 1999).

Frey, B., International Political Economics (Basil Blackwell, Oxford, 1984).

Friedman, Thomas L., The World is Flat, A Brief History of the Twenty-first Century (Farrar, Strauss and Giroux, New York, 2005).

Friedman, Thomas L., The Lexus and the Olive Tree: Understanding Globalisation (2nd edition, First Anchor Books, 2000). 
G-20 Leaders' Communiqué, Shanghai, 8-9 July 2016.

G-20 Leaders' Communiqué, Antalya Summit, 15-16 November 2015.

G-20 Report on Trade and Investment Measures (Mid-May to Mid-October 2015), OECD, WTO, UNCTAD, 30 October 2015.

Gatdula, J., 'Trade Tripper: WTO’s Doha Round: Dead or Alive?' Business World, 8 January 2016.

GATT, International Trade (Geneva, 1994).

GATT, The Results of the Uruguay Round of Multilateral Trade Negotiations, Geneva, (November 1994).

GATT, Ministerial Declaration of the Uruguay Round, Punta Del Este (September 1986).

General Council, Doha Work Programme Decision, adopted 1 August 2004 (2004) WT/L/579.

Gereffi, G., Fernandez-Stark, K., 'Global Value Chain Analysis: A Primer', Centre on Globalization, Governance \& Competitiveness, Duke University, Durham, NC (2011).

Gereffi, G., Humphrey, J. and Sturgeon, T., 'The Governance of Global Value Chains', 12 Review of International Political Economy (2005).

Gereffi, G. and Korzeniewicz, M. (eds.), Commodity Chains and Global Capitalism (Praeger, Westport, CT, 1994).

Graham, E. M., Fighting the Wrong Enemy, Anti Global Activists and Multinational Enterprises, (The Institute for International Economics, Washington DC, 2000).

Graham, E.M. and Krugman, P.R., Foreign Direct Investment in the US (Institute for International Economics, Washington DC, 1994).

Greenaway, D. and Milner, C., The Economics of Intra-firm Trade (Basil Blackwell, Oxford, 1986).

Grubel, H.G. and Johnson H.G., 'Effective Tariff Protection', GATT (1971).

Hamilton, C. (ed.), Textiles Trade and Developing Countries: Eliminating the Multi-Fibre Arrangement in the 1990 (World Bank, 1990).

Hamilton, C., 'An Assessment of Voluntary Restraints on Hong Kong's Exports to Europe and the United States', 53 Economica, (1986).

Harris, R., 'Why Voluntary Export Restraints are "Voluntary”, 18 The Canadian Journal of Economics (1985).

Hecksher, E.F., 'The Effects of Trade on the Distribution of Income', Economic Tidskrift (1919).

Heydon, K. and Woolcock, S. (eds.), The Ashgate Research Companion to International Trade Policy (Ashgate Publishing, 2012).

Hoda, A., Tariff Negotiations and Renegotiations under the GATT and the WTO, Procedures and Practices (Cambridge University Press, 2001).

Hoda, A., Readings, the New World Trading System (OECD, Paris 1994).

Hoekman, B. and Kostecki, M., The Political Economy of the World Trading System: The WTO and Beyond (2 $2^{\text {nd }}$ edition, Oxford University Press, 2001). 
Hoekman, B. and Mavroidis, P., 'WTO “à la carte' ou menu du jour?”: Assessing the Case for More Plurilateral Agreement', 26 The European Journal of International Law (2015), p. 319-343.

Hoekman, B., Ng F. and Olarreaga, M. ‘Agriculture Tariffs versus Subsidies: What's More Important for Developing Countries?' 18 World Bank Economic Review (2004).

Hopewell, K., 'Different Paths to Power: The Rise of Brazil, India and China at the World Trade Organization', 22 Review of International Political Economy (2015), p. 311-338.

Howart J. Y. and Verdier, L., Economic Globalisation, Origin and Consequences (OECD, Paris, 2013).

Hudec, R., Developing Countries in the GATT Legal System ( $3^{\text {rd }}$ edition, Cambridge University Press, 2010).

Hudec, R., Developing Countries in the GATT Legal System (2 ${ }^{\text {nd }}$ edition, Cambridge University Press, 2009).

Hudec, R. Dispute Settlement, in The New World Trading System (OECD, Paris, 1994).

Hudec, R., Developing Countries in the GATT Legal System (Trade Policy Research Centre, London, 1987).

Hufbauer, G., 'FDI Facts and Figures', World Economic Forum 2012: Global Agenda Council for Trade.

Hufbauer, G., Jung, E., Miner, S., Moran, T. and Schott, J., 'From Drift to Deals: Advancing the WTO Agenda', Peterson Institute for International Economics, Commissioned by the ICC World Trade Agenda (2015).

Hufbauer, G. and Schott, J., 'Payoff from the World Trade Agenda 2013', Report to the ICC Research Foundation, Washington DC (2013).

Hummels, D.L., Ishii, J., and Yi, K.-M., (2001), 'The Nature and Growth of Vertical Specialization in International Trade', 54 Journal of International Economics (2001).

Huwart, J.Y. and L. Verdier, 'Economic Globalisation, Origin and Consequences', OECD Paris, 2013.

Hymer, S.T., The International Operations of National Firms: A Study of Foreign Direct Investment (MIT Press, 1976).

Inside U.S. Trade, Vol.33, No. 50, 25 December 2015.

International Labour Office and World Trade Organization, Globalization and Informal Jobs in Developing Countries (ILO and WTO, Geneva, 2009).

International Labour Office and World Trade Organization, Trade and Employment, Challenges for Policy Research (ILO and WTO, Geneva, 2007).

International Labour Office, A Fair Globalization: Creating Opportunities for All (The World Commission on the Social Dimension of Globalization, 2004).

Jackson, J., The World Trading System, Law and Policy of International Economic Relations (MIT Press, Cambridge MA, 1999).

Jackson, J., 'Global Economics and International Economic Law', 1 Journal of International Economic Law (1998).

Jackson, J., 'Dispute Settlement Procedures', in The New World Trading System (OECD, Paris, 1994). 
Jackson, J., 'Restructuring the GATT System', Chatham House Papers (Council on Foreign Relations, 1990).

Janssen, M., Sadni Jallab, M. and Smeets, M. (eds.), Connecting to Global Markets, Challenges and Opportunities: Case Studies Presented by WTO Chair-holders(WTO, 2014).

Jepma C.J. and Rhoen A. (eds), International Trade: A Business Perspective (Open University, Netherlands, 1996).

Jones, K., 'The Political Economy of Voluntary Export Restraints Agreements', 37 Kyklos (1984).

Julius, D., Foreign Direct Investment: The Neglected Twin of Trade (Group of Thirty, Washington DC, 1991).

Julius, D., Global Companies and Public Policy, the Growing Challenge of Foreign Direct Investment (Royal Institute for International Affairs, Pinter Publishers Ltd, 1990).

Kahler, M., 'Rising Powers and Global Governance: Negotiating Change in a Resilient Status Quo', 89 International Affairs (2013) p. 711-729.

Katz, S., 'Senior Advisor: Perspectives of Key WTO Ambassadors on Current Challenges in Global Trade Talks, Centre for the Study of the Presidency and Congress(Spring, 2015).

Kemp, M.C., The Pure Theory of International Trade (Prentice Hall, New Jersey, 1964).

Kennedy, P., The Rise and Fall of the Great Powers (Random House, New York, 1987).

Khandelwal, A.K., Schott, P.K. and Wei, S-J., 'Trade Liberalization and Embedded Institutional Reform: Evidence from Chinese Exporters', 103 American Economic Review (2013).

Kharabi, J., 'Asia's Rising Middle Class', Asia: Weekly insight and Features from Asia (2011), http://asiafoundation.org/2011/01/26/asias-rising-middle-class/?.

Kharas, H., 'The Emerging Middle Class in Developing Countries, Working Paper No 285, OECD Development Centre (2010).

Kirmani, N., Molajani, P. and Mayer, T., 'Effects of Increased Market Access on Exports of Developing Countries', IMF Staff Paper, Washington D.C. (1984).

Kline, J.M., 'International Regulation of Transnational Business: Providing the Missing Leg of Global Investment Standards', Transnational Corporations (February, 1993).

Koopman, R. and Piermartini, R., '20 Years of Trade Growth - An In-Depth Look at Latin America and the Rising South in the Broad Context of Global Trade Growth', Workshop held at the WTO, 21 June 2016.

Koopman, R., Powers, W., Wang, Z., and Wei, S-J., 'Give Credit Where Credit is Due: Tracing Value Added in Global Production Chains', Working Paper No. 16428, National Bureau of Economic Research (NBER) (2010).

Koopman, R., Wang, Z. and Wei, S-J., 'How Much of Chinese Exports Is Really Made in China? Assessing Domestic Value-Added when Processing Trade is Pervasive, NBER Working Paper Series: Working Paper 14109(2008).

Kostecki, M., 'Export-restraint Arrangements and Trade Liberalization', 10 The World Economy (1987), p. 425. 
Kramer, K., Linden, G., Dedrick, J., 'Capturing Value in Global Networks: Apple’s iPad and iPhone', University of California, Irvine, University of California, Berkeley and Syracuse University (2011)

http://citeseerx.ist.psu.edu/viewdoc/download?doi=10.1.1.466.3897\&rep=rep1\&type $=$ pdf.

Krugman, P., 'Is Free Trade Passé?’, 1 Journal of Economic Perspectives (1987).

Krugman, P., Strategic Trade Policy and the New International Economics (MIT Press, 1990).

Laborde, D. and Martin, W., 'Formulas for Failure? Were the Doha Tariff Formulas Too Ambitious for Success?' World Bank Group Policy Research Working Paper (No. 7303, 2015).

Laborde, D., Martin, W., 'Agriculture Trade, What Matters in the Doha Round', IFPRI Discussion Paper (No. 01251, 2013).

Laird, S., 'The WTO's Trade Policy Review Mechanism - From Through the Looking Glass', 22 The World Economy (1999).

Laker, J.A., African Participation at the World Trade Organization, Legal and Institutional Aspects, 1995-2010 (Martinus Nijhoff Publishers, Leiden, 2014).

Lamy, P., Speech delivered at the WTO-MOFCOM-OECD-UNCTAD Seminar on Global Value Chains in Bejing, 19 September 2012, entitled 'Global Value Chains are Binding Us Together'.

Laub, Z., 'International Sanctions on Iran', Council on Foreign Relations, July 2015.

Lawrence, R., 'Rulemaking amidst growing diversity: a club-of-clubs approach to WTO reform and new issue selection', Journal of International Economic Law (2006).

Lawrence, R. and Draper, P., 'Is an Inclusive Trading System Possible? Mega-regional and Beyond', in 'The High and Low Politics of Trade: Can the World Trade Organization's Centrality Be Restored in a New Multi-Tiered Global Trading System?', World Economic Forum, Geneva, August 2015.

Low, P., Gallagher, P. and Stoler, A. (eds.), Managing the Challenges of WTO Participation: 45 Case Studies (Cambridge University Press, 2005).

Low, P. and Santana, R., 'Trade Liberalization in Manufactures: What is left after the Doha Round?', 3 Journal of International Trade and Diplomacy, (2009).

Marchetti, J.A. and Petros C.M., 'The Genesis of the GATS', 22 European Journal of International Law (2011).

Marchetti, J.A. and Petros C.M., 'What are the Main Challenges for the GATS Framework? Don't Talk About Revolution', 5 European Business Organization Law Review (2004), p. 511-572.

Marchetti, J.A. and Roy, M., 'The TISA Initiative: An Overview of Market Access Issues', 48 Journal of World Trade (2014).

Mashayekhi, M., (ed.), 'Services, Development and Trade: The regulatory and institutional dimension of infrastructure services', Volumes I and II, United Nations, New York and Geneva, 2012.

Mashayekhi, M., Olarreaga, M. and Porto, G. (eds.), 'Services, Trade and Development', United Nations, New York and Geneva, 2012. 
Mattoo, A., Stern, R. and Zanini, G. (eds.), A Handbook of International Trade in Services (Oxford University Press, 2007).

Michalopoulos, C., 'The Developing countries in the WTO', 22 The World Economy (1999).

Michalski, W., 'Support Policies for Strategic Industries: An Introduction to the Main issues' in Strategic Industries in A Global Economy: Policy Issues for the 1990s (OECD International Futures Programme, Paris, 1991).

Mohamed, A., 'Nairobi Trade Talks Made History', All Africa, WTO press release, 8 January 2016.

Moise, E. and Sorescu, S., 'Trade Facilitation Indicators: The Potential Impact of Trade Facilitation on Developing Countries', OECD Trade Policy Papers (No. 144, 2013).

Morris, I., Why the West Rules for Now? (Farrar, Strauss and Giroux, 2010).

Narlikar, A., International Trade and Developing Countries: Bargaining Coalitions in the GATT \& WTO (Routledge, 2003).

Narlikar, A., Daunton, M. and Stern, R. (eds.), The Oxford Handbook on the World Trade Organization (Oxford University Press, Oxford, 2012).

Narlikar, A. and Tussie, D., 'The G-20 at the Cancún Ministerial: Developing Countries and Their Evolving Coalitions in the WTO', 27 The World Economy (2004), p. 947-966.

Neilson, J., Pritchard, B. and Wai-Chung Yeung, H., 'Global Value Chains and Global Production Networks in the Changing International Political Economy: An Introduction, 21 Review of International Political Economy (2014).

Nelson, R., 'US Sanctions on Russia: Economic Implications', Congressional Research Service 7-5700, February 2015, https://www.fas.org/sgp/crs/row/R43895.pdf.

Neufeld, N., 'The Long Winding Road: How Members Finally Reached a Trade Facilitation Agreement', Staff Working Paper ERSD-2014-06, WTO (2014).

Nordas, H.K., 'The Global Textile and Clothing Industry Post the Agreement on Textiles and Clothing', Discussion Paper No 5, WTO (2004).

OECD, OECD Economic Outlook (Issue 2, OECD Publishing, 2015).

OECD, Perspectives on Global Development 2014: Boosting Productivity to meet the Middleincome Challenge, (OECD Publishing, 2014).

OECD, Perspectives on Global Development 2012: Social Cohesion in a Shifting World (OECD Publishing, 2012.

OECD, Perspectives du Développement Mondial 2010; le basculement de la richesse (OECD Publishing, 2010).

OECD, 'The Cost and Benefits of Trade Facilitation', Policy Brief (2005).

OECD, A New World Map in Textiles and Clothing: Adjusting to Change (OECD Publishing, 2004).

OECD, Post Uruguay Round Tariff Regimes, Achievements and Outlook (1999).

OECD, Open Markets Matter: The Benefits of Trade and Investment (1998).

OECD, The World in 2020; Towards a New Global Age (1997).

OECD, OECD Instruments for Promoting the Liberalization of Foreign Direct Investment (1995).

OECD, Strategic Industries in a Global Economy (1994). 
OECD, The Impact of Foreign Direct Investment on Domestic Economies of OECD Countries (1994).

OECD, The New World Trading System, (OECD Publishing, 1994).OECD, 'The Uruguay Round and the Future Multilateral Trading System', Working Party of the Trade Committee (1994) TD/TC/WP(94)61/REV1.

OECD, 'Globalisation of Industrial Activities: Sector Case Study of Globalisation in the Automobile Industry (1993) Com/DSTI/IND/TD(93)55.

OECD, 'Sector Case Study of Globalisation in the Pharmaceutical Industry', Working Party of the Trade Committee (1993) TD/TC/WP(93)23.

OECD, Globalization of Industrial Activities (1992).

OECD, International Direct Investment, Policies and Trends in the 1980s(1992).

OECD, Technology and the Economy, the Key Relationships (1992).

OECD, 'Changing Realities for World Trade and Consequences for Trade Policy' (1991) $\mathrm{TD} / \mathrm{TC} / \mathrm{WP}(91) 38$.

Ohlin, B., 'The Reparation Problem: A Discussion', 39 Economic Journal (1929).

Ohmae, K., The End of the Nation-State: The Rise of Regional Economies (Simon and Schuster, 1995).

Orefice, G., Rocha, N., 'Deep Integration and Production Networks: An Empirical Analysis', 37 The World Economy (2014), p. 106-136.

Ostry, S., Governments and Corporations in a Shrinking World (Council on Foreign Economic Relations, 1990).

Pearce, R., The Internationalization of R\&D by Multilateral Enterprises (Macmillan, 1989).

Porter, M., The Competitive Advantage of Nations (Free Press, 1990).

Porter, M., Competition in Global Industries (Harvard Business School Press, 1986).

Porter, R., 'International Trade and Investment Sanctions: Potential Impact on the South African Economy', 23 Journal of Conflict Resolution (1979).

Porter, R. and Sauvé, P. (eds.), The WTO and the Future of the Multilateral Trading System (Harvard University Press, 2000).

President's Xi's speech to Davos, https://www.weforum.org/agenda/2017/01/full-text-of-xijinping-keynote-at-the-world-economic-forum

Primo Braga, C.A., 'World Trade: Have We Reached Peak Globalization?' IMD (Lausanne, Summer 2015 Programme).

Qureshi, H., 'Some Reflections on the GATT TPRM, in the Light of the Trade Policy Review of the European Communities - A Legal Perspective', 26 Journal of World Trade (1992), p. 103-120.

Qureshi, H., 'The New GATT Trade Policy Review Mechanism: An Exercise in Transparency or “Enforcement”", 24 Journal of World Trade (1990), p. 147-160.

Raby, G. (ed.), The New World Trading System: Readings (OECD Publishing, 1994).

Reich, R., 'Who is Us?' 38 Harvard Business Review (1990).

Reinalda, B. (ed.), The Ashgate Research Companion to Non-State Actors (Radboud University Nijmegen, 2011).

Ricardo, D., On the Principles of Political Economy and Taxation (G. Bell and Sons, London, 1817). 
Robb, A., Statement made at MC-X, Nairobi, Kenya, 14 December 2015.

Rodrick, D., The Globalization Paradox (W.W. Norton \& Co., 2011).

Rodrick, D., Unconventional Thoughts on Economic Development and Globalization (weblog), 'August 2, 2007: Does Import Substitution Deserve Its Unsavoury Reputation?', http://rodrick.typepad.com/dani_rodrick_weblog/2007/08.

Rodrick D., 'Has Globalisation Gone Too Far?', Institute for International Economics (1997).

Rolland, S., 'Developing Country Coalitions at the WTO: In Search of Legal Support', 48 Harvard International Law Journal (2007), p. 483-552.

Rugman, A.M. (ed.), New Theories of the Multinational Enterprise(St. Martin's Press, 1982).

Rugman, A.M. and Verbeke, A., Global Corporate Strategy and Trade Policy (Routledge, 1990).

SAANA Consulting, 'WTO Trade-Related Technical Assistance External Evaluation', Final Report, 31 October 2016.

Saito, M, Ruta, M., Turunen, J., 'Trade Interconnectedness: The World with Global Value Chains', International Monetary Fund (2013).

Sapir, A., 'The Interaction Between Labour Standards and International Trade Policy', 18 World Economy (1995), p. 791-803.

Sauvé, P., 'A First Look at Investment in the Final Act of the Uruguay Round', 28 Journal of World Trade (1994).

Schott, J., The Uruguay Round, An Assessment (Institute for International Economics, Washington DC, 1994).

Servan Schreiber, J.J., Le Défi Américan(Denoel 1968).

Shaffer, G., 'Can WTO Technical Assistance and Capacity Building Serve Developing Countries?', 23 Wisconsin International Law Journal (2005), p. 651.

Shaffer, G., Elsig, M. and Puig, S., 'The Law and Politics of WTO Dispute Settlement', University of California Legal Studies Research Paper (Series No. 2016-10).

Shapiro, D. T., 'Be Careful What You Wish For: U.S. Politics and the Future of the National Security Exception to the GATT', 31 The George Washington Journal of International Law and Economics (1997).

Siebert, H. (ed.) Globalisation and Labour (J.C.B Mohr for Kiel Institute of World Economics, Tubingen, 1999).

Smeets, M., 'Changing Patterns in International Trade', 5 Journal of WTO and China (2015).

Smeets, M., 'Is the Economic Balance Shifting from the West to the East?', Conference Paper published by St Petersburg, State University, Department of World Economy, October 2015.

Smeets, M., 'The Agreements Reached at Bali, a Turning Point for the WTO', 68 Internationale Spectator (2014).

Smeets, M., 'Global Governance and Main Challenges', in Economic Theory and Business Performance, Global Challenges, (Department of World Economy, St Petersburg State University, 2013).

Smeets, M., 'Recent Developments in International Trade' in International Economic Relations, Theoretical and Practical Issues(Skifia Print, St Petersburg, 2013). 
Smeets, M., 'Trade Capacity Building in the WTO: Main Achievements since Doha and Key Challenges', 47 Journal of World Trade (2013), p. 1047-90.

Smeets, M., 'Les Défis des Pays Occidentaux dans le Commerce Mondial', Société de Lecture, Geneva, 15 February 2011.

Smeets, M., 'Conflicting Goals: Economic Sanctions and the WTO', 2 Global Policy Dialogue (2000).

Smeets, M., 'Main Features of the Uruguay Round Agreement on Textiles and Clothing and Implications for the Trading System', 29 Journal of World Trade(1995), p. 97-109.

Smeets, M., 'Tariff Issues in the Uruguay Round, Features and Remaining Issues', 29 Journal of World Trade (1995), p. 91-105.

Smeets, M., 'The Impact of the Uruguay Round Agreements on the Countries in the Middle East and North Africa', Editorial Article, Economic Research Forum Newsletter (1995).

Smeets, M., 'Grey Area Measures: Automobiles and Semi-conductors', 6 International Economic Law Society (1993).

Smeets, M., 'Trade Policy Aspects of Globalisation in the Automobile Industry', OECD Observer (1993).

Smeets, M., 'Globalisation, Free Trade and Regional Integration', 77 Economische Statistische Berichten (1992).

Smeets, M., 'The Success of the Economic Dragons', 76 Economische Statistische Berichten (1991), p. 764-767.

Smeets, M., 'Globalisation and the Trade Policy Response', 24 Journal of World Trade (1990).

Smeets, M., 'Non-Tariff Barriers (NTBs) in the Tokyo Round, with Specific Reference to Subsidies and Countervailing Duties', Diplôme, Graduate Institute for International Studies (1981).

Smeets, M., and Fournier, C., 'Trade and Tariffs in Leather and Leather Products', Special Studies, WTO (1998).

Solignac Lecomte, H., 'Building Capacity to Trade: A Road Map for Development Partners: Insights from Africa and the Caribbean', European Centre for Development Policy Management Discussion Paper (No. 33, 2001).

Spero, J., The Politics of International Economic Relations(St. Martin's Press, New York, 1990).

Srinivasan, T.N., Developing Countries in the Multilateral Trading System (Westview, Boulder, CO, 1998).

Steenkamp, E., Grater, S. and Viviers, W., 'Streamlining South Africa's Export Development Efforts in Sub-Saharan Africa: A Decision Support Model Approach', in R. Teh, M. Smeets, M. Sadni Jallab and F. Chaudri (eds.), Reducing Trade Costs for Inclusive Sustainable Growth (Forthcoming, WTO, 2016).

Steger, D., 'The Culture of the WTO: Why It Needs to Change?', 10 Journal of International Economic Law (2007), p. 483-495.

Stern, R., 'Evaluating Alternative Formulae for Reducing Industrial Tariffs', 10 Journal of World Trade Law (1976).

Stewart, T.P., 'The GATT Uruguay Round, a Negotiating History (1986-1992)', Kluwer Law International, Vol. 1 (1993).

Stiglitz, J.E., Making Globalisation Work(W.W. Norton and Co., 2006). 
Stiglitz, J.E., Globalisation and its Discontents (W.W. Norton and Co., 2000).

Sturgeon, T., van Biesebroeck, J.H., and Gereffi, G., 'Value Chains, Networks and Clusters: Reframing the Global Automotive Industry', 8 Journal of Economic Geography (2008).

Sutherland, P., 'Beyond the Market, A Different Kind of Equity', International Herald Tribune, 20 February 1997.

Tangermann, S., 'Agriculture: Food Security and Trade Liberalization', paper prepared for Conference on 'Challenges Facing the World Trading System', Columbia University and John Hopkins University, 29 September-2 October 2014.

Taubman, A., Wager, H. and Watal, J., A Handbook on the WTO TRIPS Agreement (Cambridge University Press, 2012).

Teh, R., Smeets, M., Sadni Jallab, M. and Chaudri, F. (eds.), Trade Costs and Inclusive Growth, Case studies presented by WTO chair-holders (WTO, 2016).

The Economist, 'Briefing: Business in China and the West', 1 January 2011.

The Economist, 'Where are the Profits?' and 'Three Way Split', 11 December 2010.

The Economist, 'Briefing: Chinese Takeovers, Being Eaten by the Dragon' and 'China Buys up the World', 13 November 2010.

The Economist, 'How to Stop a Currency War?', 16 October 2010.

The Economist, 'Import Substitution: Do Not Resuscitate', 7 August 2007.

Toohey, L., Picker, C. and Greenacre, J. (eds.), China in the International Economic Order: New Directions and Changing Paradigms (Cambridge University Press, 2015).

Trade Tripper, Business World, 'WTO’s Doha Round: Dead or Alive?’ 8 January 2016.

UNCTAD, ‘World Investment Report: Investor Nationality: Policy Challenges' (2016).

UNCTAD, 'World Investment Report: Reforming International Investment Governance' (2015).

UNCTAD, 'World Investment Report: Investing in SDGs' (2014).

UNCTAD, 'The Outcome of the Uruguay Round: An Initial Assessment, Supporting Papers to the Trade and Development Report' (1994).

UNCTAD, Protectionism and Structural Adjustment (New York, 1986).

United Nations Conference on Trade and Development, IIA Issues (No 1, 2015).

United Nations, The Determinants of Foreign Direct Investment, A Survey of the Evidence (New York, 1992).

USITC, 'The Economic Effects of Significant U.S. Import Restraints Phase I: Manufacturing', Publication 2222 (1993).

van den Bossche, P. and W. Zdouc, The Law and Policy of the WTO ( $3^{\text {rd }}$ edition, Cambridge University Press, 2013).

VanGrasstek, C., The History and Future of the World Trade Organization(WTO, 2013).

Vernon, R., 'International Investment and International Trade in the Product Cycle', Quarterly Journal of Economics (May, 1966).

Walker, J., 'Strategic Trade Policy, Competition and Welfare: The Case of Voluntary Export restraints between Britain and Japan (1971-2002)', Discussion Paper (IBH-2015-01), Henley Business School, University of Reading (2015).

Whalley, J., 'The Agreement on Textiles and Clothing', in OECD, The New World Trading System (Paris, 1994). 
Whalley, J., 'The Multifibre Arrangement and China's Growth Prospects', in K. Anderson (ed.), New Silk Roads (Cambridge University Press, 1992).

Whalley, J., 'The North-South Debate and the Terms of Trade: An Applied General Equilibrium Approach', Centre for the Studies of International Economic Relations Working Paper, University of Western Ontario (No. 8205C, 1982).

Whalley, J. and Yao, D., 'Assessing the Effects of the MFA/ATC From US and World Trade Data After its Removal', National Bureau of Economic Research (NBER) Working Paper 21299 (2015).

Williams, P.J., A Handbook on Accessions to the WTO (Cambridge University Press, 2008).

Winters, L.A., 'The WTO and Regional Trading Agreements: Is it All Over for Multilateralism?' University of Sussex Working Paper (No. 82-2015).

Winters, L.A., 'Coherence with No "Here": WTO Cooperation with the World Bank and the IMF', Centre for Economic Policy Research, London School of Economics (November, 2001).

Witherell, W.H., 'The OECD Multilateral Agreement on Investment' 4 Transnational Corporations (1995).

Wolfe, R., 'First Diagnosis, Then Treat: What Ails the Doha Round?', European University Institute Working Papers (RSCAS 2013/85).

Wolfe, R., 'The Special Safeguard Fiasco in the WTO: The Perils of Inadequate Analysis and Negotiation', 8 World Trade Review (2009), p. 517-44.

World Bank, Shifting Focus in Trade Agreements - From Market Access to Value Chain Barriers (Washington DC, 2013).

World Bank, From Disintegration to Reintegration: Eastern Europe and the Former Soviet Union in International Trade (Washington DC, 2005).

World Economic Forum, The High and Low Politics of Trade: Can the World Trade Organization's Centrality Be Restored in A New Multi-Tiered Global Trading System?, World Economic Forum, Geneva, August 2015.

World Trade Organization website, http://intranet/en/about_wto/divisions/orgchart.htm, last viewed 1 December 2016.

World Trade Organization website,

https://www.wto.org/english/thewto_e/whatis_e/tif_e/org2_e.htm, last viewed 1 December 2016.

World Trade Organization website,

https://www.wto.org/english/thewto_e/secre_e/current_chairs_e.htm, last viewed 1 December 2016.

World Trade Organization website,

https://www.wto.org/english/tratop_e/dda_e/negotiating_groups_e.htm, last viewed 1 December 2016.

World Trade Organization, Trade Policy Review Mechanism, Report of The Trade Policy Review Body for 2016, 7 November 2016 (2016) WT/TPR/387.

World Trade Organization, Secretariat Report, 15 June 2016 (2016) WT/TPR/S/342

World Trade Organization, press release, 'WTO Report: G20 Trade Restrictions Reach Highest Monthly Level Since Crisis’, 21 June 2016. 
World Trade Organization, Trade Policy Review, Government Report, 15 June 2016 (2016) WT/TPR/G/342.

World Trade Organization, news item, 18 April 2016, https://www.wto.org/english/news_e/news16_e/

World Trade Organization, WTO Accession 2016: Annual Report by the Director-General December 2016, WT/ACC/28.

World Trade Organization, Trade News, 20 December 2015.

World Trade Organization, Nairobi Ministerial Declaration, adopted on 19 December 2015 (2015) WT/MIN(15)/DEC.

World Trade Organization, Work Programme on Electronic Commerce, Ministerial Decision of 19 December 2015, WT/MIN(15)/42, WT/L/977.

World Trade Organization, WT/MIN(15)45-WT/L/979 Export Competition, Ministerial Decision of 19 December 2015.

World Trade Organization, WT/MIN(15)45-WT/L/980 Public Stockholding for Food Security Purposes, Ministerial Decision of 19 December 2015.

World Trade Organization, WT/MIN(15)45-WT/L/978 Special Safeguard Mechanism for Developing Country Members, Ministerial Decision of 19 December 2015.

World Trade Organization, Ministerial Declaration on the Expansion of Trade in Information Technology Products, 16 December 2015, MC-X (Nairobi).

World Trade Organization, Overview of Development in the International Trading Environment: Annual Report by the Director General (Mid-October 2014 to MidOctober 2015), 17 November 2015, WT/TPR/OV/18.

World Trade Organization, Work Program on Small Economies, compilation paper prepared by the Secretariat, 16 October 2015, WT/COMTD/SE/W/22/Rev.7.

World Trade Organization, 'Market Access for Products and Services of Export Interest to Least-Developed Countries', 5 October 2015, WT/COMTD/LDC/W/60.

World Trade Organization, WTO and Least Developed Countries: Twenty Years of Support towards a Better Integration into the Multilateral Trading System, 30 September 2015, WT/COMTD/LDC/W/61.

World Trade Organization, Challenges and Opportunities Experienced by Small Economies when Linking into Global Value Chains in Trade and Commercial Services, WTO, 1 May 2015, WT/COMTD/SE/W/31.

World Trade Organization, Government Procurement: Opening Markets and Promoting Good Governance (2015).

World Trade Organization, Ministerial Declaration on the Expansion of Trade in Information Technology Products, Nairobi (2015) WT/MIN(15)/25.

World Trade Organization, Participation of Developing Economies in the Global Trading System' (2015) WT/COMTD/W/212.

World Trade Organization, WTO at Twenty: Challenges and Achievements, WTO (2015).

World Trade Organization, WTO, Biennial Technical Assistance and Training Plan 20152016 (2015) (WT/COMTD/W/200).

World Trade Organization, World Trade Report 2015: Speeding Up Trade: Benefits and Challenges of Implementing the WTO Trade Facilitation Agreement (2015). 
World Trade Organization and World Bank, Role of Trade in Ending Poverty (WTO, 2015).

World Trade Organization, Press release of 7 April 2014.

World Trade Organization, Trade Policy Review: Government Report 27 May 2014 (2014) WT/TPR/G/300.

World Trade Organization, Trade Policy Review: Secretariat Report (2014) WT/TPR/S/300.

World Trade Organization, World Trade Report 2014: Trade and Development: Recent Trends and the Role of the WTO (2014).

World Trade Organization, Bali Ministerial Declaration, 11 December 2013, WT/MIN(13)/DEC.

World Trade Organization, Trade Facilitation Agreement, 11 December 2013, WT/MIN(13)/36 WT/L/911.

World Trade Organization, Duty Free and Quota Free Market Access for LDCs, 7 December 2013, WT/L/919.

World Trade Organization, Monitoring Mechanism on Special and Differential Treatment, Ministerial Decision of 7 December 2013, WT/MIN(13)/45, WT/L/920.

World Trade Organization, Operationalization of The Waiver Concerning Preferential

Treatment to Services and Service Suppliers Of LDCS, 7 December 2013, WT/L/918.

World Trade Organization, 'Market Access for Products and Services of Export Interest to

Least-Developed Countries', 10 September 2013, WT/COMTD/LDC/W/58.

World Trade Organization, WT/TPR/OV/W/7, 17 June 2013.

World Trade Organization, Decision of the Council for TRIPS, 11 June 2013, IP/C/64.

World Trade Organization, Biennial Technical Assistance and Training Plan 2014-2015 (2013) WT/COMTD/W/200.

World Trade Organization, Overview of Developments in the International Trading System (WTO, 2013).

World Trade Organization, 'Participation of Developing Economies in the Global Trading System' (2013) WT/COMTD/W/201.

World Trade Organization, Report on G-20 Trade Measures (2013) WTOOECD_UNCTAD.

World Trade Organization, Trade Policy Review Mechanism: Fifth Appraisal of the Trade Policy Review Mechanism (2013) WT/MIN(13)/5.

World Trade Organization, Work Programme on Small Economies (2013) WT/L/908.

World Trade Organization, Accessions of LDCs, 25 July 2012, WT/L/508/add.1.

World Trade Organization, Annual Report on Technical Assistance and Training (1 January to 31 December 2011), 25 June 2012, WT/COMTD/W/186).

World Trade Organization, Progressive Learning Strategy (PLS) For Trade-Related Capacity Building in 2012 (2012) JOB/TC/3.

World Trade Organization, World Trade Report 2012: A Closer Look at Non-Tariff Measures (2012).

World Trade Organization, 'ITTC Case Story on Trade Capacity Building in the WTO', 22 June 2011, WT/COMTD/AFT/W/27. 
World Trade Organization, WTO, Annual Report on Technical Assistance and Training (1 January to 31 December 2010) (WT/COMTD/W/178) 15 June 2011, WTO, Geneva.

World Trade Organization, '15 Years of the Information Technology Agreement, Trade Production and Global Production Networks', WTO report prepared for the $15^{\text {th }}$ anniversary of the ITA (2011).

World Trade Organization, Biennial Technical Assistance and Training Plan 2012-2013 (2011) WT/COMTD/W/180.

World Trade Organization, Trade Policy Review Mechanism: Fourth Appraisal of the Trade Policy Review Mechanism (2011) WT/MIN(11)/6.

World Trade Organization, Work Programme on Small Economies (2011) WT/L/844.

World Trade Organization, World Trade Report 2011: The WTO and Preferential Trade Agreements: From Co-Existence to Coherence (2011).

World Trade Organization, 'Ex-post Evaluation of the WTO Trainee and Internship Program 2005-2009', Technical Cooperation Audit Unit, 9 April 2010.

World Trade Organization, World Trade Report 2010: Trade in Natural Resources (2010).

World Trade Organization, Biennial Technical Assistance and Training Plan 2010-2011 (2009) WT/COMTD/W/179/Rev.1.

World Trade Organization, 'Revised Draft Modalities for Agriculture' (2008) TN/AG/W/4/Rev.4.

World Trade Organization, World Trade Report 2008: Globalisation and Trade (2008).

World Trade Organization, Biennial Technical Assistance and Training Plan 2008-2009 (2007) WT/COMTD/W/160.

World Trade Organization, World Trade Report 2007: Six decades of multilateral trade cooperation: What have we learnt? (2007).

World Trade Organization, Recommendations of the Task Force on Aid for Trade' (2006) WT/AFT/1.

World Trade Organization, Transparency Mechanism for Regional Trade Agreements, Decision of 14 December 2006, WT/L/671.

World Trade Organization, WTO Work Programme for the LDCS (WT/COMTD/LDC/11/Rev.1) 11 June 2006.

World Trade Organization, Hong Kong Ministerial Declaration, 18 December 2005, WT/MIN(05)/DEC.

World Trade Organization, A Handbook on the GATS Agreement (Cambridge University Press, 2005). World Trade Organization, Agreement on Agriculture, 1 January 2005, 1867 UNTS 410.

World Trade Organization, The Future of the WTO, Addressing Institutional Challenges in The New Millennium', report by the consultative board to the Director General Supachai Panitchpakdi, WTO, 2004.

World Trade Organization, Report by the Director General: Paragraph 41 of the Doha Ministerial Declaration, 14 August 2003 (WT/MIN(03)/3).

World Trade Organization, Coordinated WTO Secretariat Annual Technical Assistance Plan 2002, dated 8 March 2002, WT/COMTD/W/95/Rev.3. 
World Trade Organization, WTO Ministerial Declaration, Doha, 9-14 November 2001, WT/MIN(01)/DEC/1, 20 Nov.2001.

World Trade Organization, Decision on Implementation Related Issues and Concerns, WTO, 14 November 2001.

World Trade Organization, 'A New Strategy for the WTO Technical Cooperation: Technical Cooperation for Capacity Building, Growth and Integration', 21 September 2001, WT/COMTD/W/90.

World Trade Organization, 'Comprehensive Report of the Textiles Monitoring Body to the Council of Trade in Goods on the Implementation of the Agreement on Textiles and Clothing during the Second Stage of the Integration Process', G/L/459, 31 July 2001.

World Trade Organization, Trade Policy Review of China (2001) WT/TPR/S/230/Rev.1.

World Trade Organization, WTO Secretariat, Special Studies 6: Market Access, Unfinished Business Post Uruguay Round Inventory and Issues, WTO, (2001).

World Trade Organization, WTO Secretariat: WTO Guide to the Uruguay Round Agreements (Kluwer Law International, 1999).

World Trade Organization, Ministerial Conference, Second Session, Ministerial Declaration, 25 May 1998, WT/MIN(98)/DEC/1.

World Trade Organization, Annual Report 1998: Special Topic Globalization and Trade (1998).

World Trade Organization, Ministerial Declaration adopted on 13 December 1996 at the Ministerial Conference, 18 December 1996, WT/MIN(96)/DEC.

World Trade Organization, Telecommunications Services Reference Paper, 24 April 1996.

World Trade Organization, 'Guide to GATT Law and Practice (Analytical Index)' (Volumes 1 and 2, Geneva, 1995).

World Trade Organization, 'The Results of the Uruguay Round of Multilateral Trade Negotiation', GATT Secretariat, WTO, June 1994.

World Trade Organization, Marrakesh Agreement Establishing the World Trade Organization, 15 April 1994, 33 ILM 1125 (1994).

World Trade Organization, WT/MIN(13)/37-WT/L/912 (General Services).

World Trade Organization, WT/MIN(13)/38-WT/L913 (Public Stockholding).

World Trade Organization, WT/MIN(13)/39-WT//L914 (TRQA).

World Trade Organization, WT/MIN(13)/40-WT/L915 (Export Competition).

World Trade Organization, WT/MIN(13)/44, WT/L/919, Duty Free and Quota Free (DFGF) Market Access for Least Developed Countries.

Zahrnt, V., 'The WTO's Trade Policy Review Mechanism: How to Create Political Will for Liberalization?', European Centre for International Political Economy Working Paper (No. 11/2009). 


\title{
Valorization Addendum
}

\section{The WTO Multilateral Trading System in a Globalizing World: Challenges and Opportunities}

\author{
Maarten Smeets
}

\section{What is the societal and or economic relevance of the research results, in addition to the scientific relevance?}

This thesis contributes to a better understanding of the complexities of the trade issues in a context of an increasingly globalizing world. The analysis goes beyond providing explanations on the forces that drive globalization, but offers solutions for the ways forward. It contains specific suggestions on how to unlock the multilateral trade negotiations presently conducted under the umbrella of the Doha Development Agenda and which are in an impasse. These negotiations were launched at Doha in 2001 and are yet to be concluded. The results of the negotiations are expected to generate significant positive welfare effects to the benefit of the society as a whole.

The fact that trade liberalization generates economic benefits and enhances overall levels of welfare has been scientifically proven, but the process of how these benefits are generated and who benefits from trade liberalization are not always well understood. Yet the overall economic benefits that can be obtained from trade liberalization are the very reason why many developing and least developed countries have joined the WTO in recent years. This has also motivated the formerly centrally planned economies that in the last 25 years moved to market based principles, thus underscoring the merits of the WTO's multilateral trading system. While the benefits are undeniable, the anti-trade sentiments are growing again, thus defying the economic rationale. The thesis sheds light on the key functions of the WTO and how the mechanisms of trade liberalization translate into economic gains for the society as a whole. This is perhaps even more significant today than any time before, given the recent calls by some world leaders for introducing policies geared towards providing national preferences over imports. While for some years the anti-globalization sentiments were put to rest, the populist views in society are again on the rise. The growing backlash against globalization, which is often equated with trade liberalization, loss of jobs in the West, deindustrialization and stagnating economic growth, kicked in again rather unexpectedly and needs to be countered. The arguments against globalization are mostly based on a lack understanding of how the benefits of trade liberalization are transmitted to the consumers and how they generate economic welfare. The society stands to gain from better explanations on how globalization has triggered the overall higher levels of economic welfare and to which this thesis makes a contribution. This is not to diminish the arguments made against globalization, as it is recognized that globalization and trade liberalization can have negative effects and those need to be addressed by policy makers. Protectionism as 
advocated by some policy makers, however, is not part of the solution, but part of the problem and needs to be resisted.

\section{Target groups: to whom are the research results of interest and why?}

The target groups that are addressed in the study include all stakeholders in international trade. This includes first of all the members of the WTO, and more specifically the consumers, producers, governments, policy-makers, negotiators, businessmen, parliamentarians, civil society and academics. The target group also includes the WTO Secretariat which provides the technical support to the members in the negotiations, even though the staff is aware of the challenges. One cannot single out or exclude any individual and/or interest group, as the ways trade have evolved imply that hardly anyone escapes from the effects of international trade and the multilateral trade rules, explicitly or implicitly and knowingly or without being aware of it. Trade rules increasingly address all aspect of citizen's daily lives, including through tariffs at the border, which imply a tax to consumers and non-tariff measures within the national economies, standards and technical regulations, safety measures, agricultural or industrial subsidies and any other kind of income support, patents, access to medicine, domestic regulations, including in the area of services, foreign direct investment, preferential trade schemes, access to markets and all other measures that affect competitive conditions in the market place.

All these factors combined determine the consumers' choice, their levels of income, the quality and price of goods, the health and safety of citizens as well as more broadly their living conditions. All stakeholders thus share a common interest, which consists of ensuring that the multilateral trade negotiations advance in ways that all stakes and interest are fully captured in the negotiations and reflected in the rules that emerge from those negotiations. The outcome of the negotiations should produce win-win solutions and mitigate the negative repercussions trade may have on any of the stakeholders.

Developing countries are a specific target group in this thesis, as trade and the new opportunities created for developing countries in terms of market access and their fuller integration into international trade and the multilateral trading system generate economic development perspectives and will contribute to lifting more people out of poverty. In addition, providing for a level playing field through the elimination of distortions in trade, including subsidies granted by developed countries against which developing countries cannot compete opens new economic perspectives. It should also contribute to providing new opportunities for developing countries in their efforts connecting to markets. In order to achieve these objectives, many countries need assistance through trade capacity building, which is provided for by the WTO and discussed in this thesis. 


\section{Into which concrete activities, products, services and processes and/or commercial activities will your results be translated and shaped?}

The thesis provides for a range of specific concrete activities, products and processes. The most important one is the contribution it can make to advance the multilateral trade negotiations that are conducted under the umbrella of the DDA. The negotiations have mostly been blocked for nearly nine years. Ministers have reiterated at nearly all Ministerial Conferences that their top priority was to conclude the DDA, but to no avail. This position has gradually changed with an increasing number of countries no longer fully subscribing to the initial objectives of the DDA. At the last Ministerial Conference (MC-X), the language adopted in the Ministerial Declaration with regard to the future of the DDA was modified significantly, compared to the earlier declarations. The text clearly confirms a growing divergence in views as to whether and/or how the DDA would need to be concluded. Nevertheless, and despite the lack in progress in the DDA negotiations per se and the divergence in views, Members remain unanimous in their determination to advancing trade liberalization. Based on this commitment, the thesis offers an analysis how some specific and economically meaningful results were achieved at MC-IX (Bali) and MC-X (Nairobi) and how the process can be moved forward in the key areas.

A fundamental disagreement between the WTO members exists on the question how to proceed in the negotiations in the three key areas, i.e. agriculture, non-agricultural market access (NAMA) and services. Some members argue that the initial goals established at the start of the negotiations in 2001 and for various reasons that are discussed and analysed in the thesis are no longer realistic. Nevertheless there is a consensus that the constituent parts in the negotiations can and still need to be concluded. How to do so remains unclear as the approaches differ. The thesis contains specific suggestions how to move forward in agriculture and NAMA. The broad all-encompassing formula approach has proven not to work and should be abandoned. It is proposed to replace the highly complex tariff formula methods for both Agriculture and NAMA with a simple offer-request procedure. An important element that needs to be taken into account in that regard is role of the GVCs: members need to address areas where the trade liberalization can offer real and meaningful market access opportunities to the members and generate value added. New and concrete alternative approaches are thus offered in the thesis, geared towards simplifying the process and thus opening the way to concrete results.

It is also proposed to abandon the 'Single Undertaking' approach, which provided the guiding principle in the DDA and instead follow an incremental and critical mass approach in the negotiations, harvesting agreements when they are ready. When agreement is within reach, members should close the deal and move on, instead of waiting for agreement to be reached in other areas under negotiation. This has already held up the DDA for too long and delayed concrete outcomes. This approach has already proven to work in various areas. One example is TFA, ratified earlier this year and now put into effect, thus unlocking significant economic gains and saving billions of dollars in transaction costs. Another example relates to 
the ITA, and which significantly slashes tariffs on high technology goods to the benefit of the society as a whole.

Other suggestions and proposals made in the thesis include new approaches with regard to the trade capacity building in support of developing and least developed countries. It is suggested to replicate the approach adopted in the TFA, which includes binding commitments between donors and beneficiaries in terms of support to be provided, thus holding the potential to generate direct, tangible and measurable benefits for developing countries.

Finally, the thesis will be turned into a book and made available to the public at large, thus spreading and disseminating the information to a broader audience. It will lead to articles, publications, material for lectures, courses, op-eds and policy papers for the members with both academic and policy relevance.

\section{To what degree can your results be called innovative in respect to the existing range of products, services, processes, activities and commercial activities?}

The thesis is innovative as there is a wealth of literature on the GATT and the WTO, but there are fewer publications that compare the WTO system with the GATT from the angle chosen in this thesis, i.e. how globalization and the recent evolutions in international trade affect the negotiations and the multilateral trading system. Most of the literature focuses on specific elements covered in the thesis. The thesis looks at the implications of trade patterns moving from the West to the East, the enlarged and more diverse membership, the complexity of the topics and how they are addressed. The thesis specifically addresses the question how globalization has affected trade rules and vice versa, what have the trade rules meant for globalization? It goes beyond raising the question, but on the basis of the analysis it offers specific policy recommendations on the ways forward. Finally, it is innovative in the sense that the analysis combines theory and practice, given the author's long standing practical and hands-on experience with trade issues in the real world. The thesis is very timely, as the backlash against globalization has been growing during the time of writing the thesis, thus adding to the relevance of the analysis and the policy recommendations.

\section{How will this/these plan(s) for valorization be shaped?}

The research results will be disseminated to the largest extent possible in this form as a thesis as well as in the form of a book, as suggested by my supervisors and members of the assessment committee and which will be published after defending the thesis.

The research results will be shared with the WTO's senior management and could serve as one of the elements in the preparatory process for the next Ministerial Conference to be held at Buenos Aires (Argentina) in December 2017.

The research results will equally be shared with the members of the WTO, including 
policy makers from developed and developing countries that are actively engaged in the negotiations. They may find merit and value in the arguments presented in the thesis, thus facilitating the process of the negotiations and working towards concrete results. It may also contribute to enhancing countries' understanding of the issues that are addressed in the WTO and the DDA negotiations.

The research is likely to be of interest to the public at large, which will hopefully appreciate better the elements that shape globalization, how it impacts on the citizen's daily lives and how it affects the rules of the WTO multilateral trading system. It should contribute to a better communication between the different stakeholders and interest groups, who share a common interest, i.e. to improve the lives and welfare of all citizens. This is what is meant by inclusive growth, thus ensuring that all get a fair piece of the cake and minimizing the negative repercussions of trade liberalization.

The research is expected to also contribute to the academic debates by providing new insights into the todays' trade issues by a practitioner, who not only analyses the issues from a theoretical and academic perspective, but takes into account a long experience with trade issues. The work will be shared with the Universities that are part of the WTO Chairs Program and the Advisory Board members of the WCP.

The research will be of use to countries that are presently contemplating accession to the WTO or are in the process of accession and who need to be more fully informed of the challenges and opportunities that WTO's membership brings.

The research results will be used during the many conferences, courses and lectures that I give at Universities and academic institutions around the world. It will be used for my University lecture at UIBE, China, in July as well as for the two-week summer course that I will be conducting at UIBE. It will hopefully trigger the curiosity of the students to better understand the trade issues and direct their studies and analysis to those areas. They may then become future trade negotiators and base their country's positions on a more solid analysis and grounds.

Finally, the thesis will provide the basis for further research and analysis and will lead to stand-alone publications in academic and peer reviewed journals. One such publication is on Georgia's post accession challenges, and which was accepted for publication by the WTO. It will also be submitted to a peer reviewed journal. Another publication will address the use of economic sanctions in international trade, which I had initially intended to include as a chapter in the thesis but will become a stand-alone publication. Other studies will focus on the bilateralism and regional and regional trade agreements in relation to GVCs. 


\section{Curriculum Vitae}

Maarten Smeets was born on 10 January 1956 in Den Haag (Netherlands). He holds a masters' degree from Tilburg University (1980) in economics with majors in international trade, finance and banking. He was a teaching assistant in international trade. He holds a post-graduate degree from the Graduate Institute of International and Development Studies in Geneva (1981). From 1987 to 1989, he attended the Ecole Nationale d'Administration (ENA, Paris).

$\mathrm{He}$ is a senior international trade economist and head of section at the Institute for Training and Technical Co-operation (ITTC) of the World Trade Organization (WTO). He designs, coordinates and delivers trade capacity building programs of the WTO. He has a shared responsibility for the WTO Chairs Program, which consists of building relations with universities in developing countries around the world. In close consultation with the WTO, the Chairs pursue research in the field of trade and trade policy, undertake curriculum development and conduct outreach activities with civil society and the private sector. $\mathrm{He}$ manages WTO's flagship intern programs, which bring annually some 40 mid- and high level government officials for 10 months to the WTO for hands-on training. He represents the WTO on the board of the Joint Vienna Institute (JVI), an IMF led body.

He is a senior visiting fellow at Clingendael Institute (Den Haag, Netherlands), where he organizes and delivers courses on international trade. He regularly teaches at Universities in the Netherlands, China and Russia as well as at training institutes in Europe and the United States. He has published in various international and peer reviewed journals, contributed to books on international trade and (co-) edited two books. He is an alumnus and fellow of Salzburg seminar (Austria). He is a member of various societies and boards.

Prior to the WTO, he worked from 1989 to 1995 in the Trade Directorate of the OECD (Paris), where he conducted analytical studies in the field of international trade, globalization and trade agreements including the outcome of the Uruguay Round negotiations and which resulted in several publications. He also monitored developments in international trade and the trading system.

He started his career at the Ministry of Economic Affairs, Den Haag, Netherlands, as a trade economist, designing and coordinating trade policy (1981-1987). He represented his country at international meetings in Brussels (EU), Paris (OECD) and Geneva (GATT). He also worked on financial regulations at the French Ministry of Finance. 
Colophon

The WTO multilateral trading system in a globalizing world: challenges and opportunities

Maarten Smeets

ISBN: 9789462404212

This book is produced by:

ฟolf Legal Publishers (WLP)

P.O. Box 313

5060 AH Oisterwijk

The Netherlands

www.wolfpublishers.com

E-Mail:info@wolfpublishers.nl 